

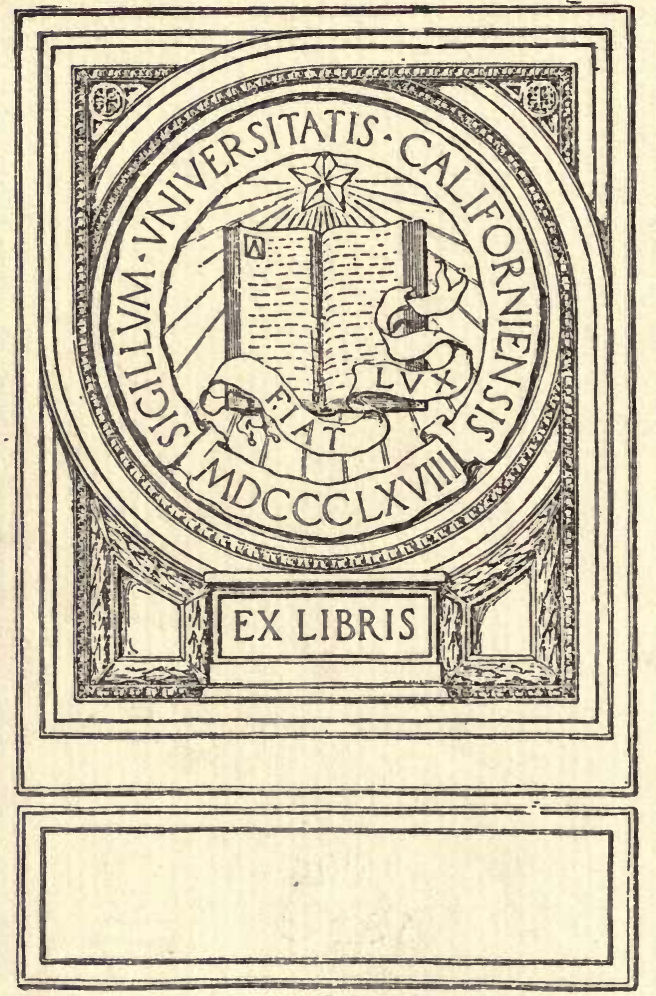




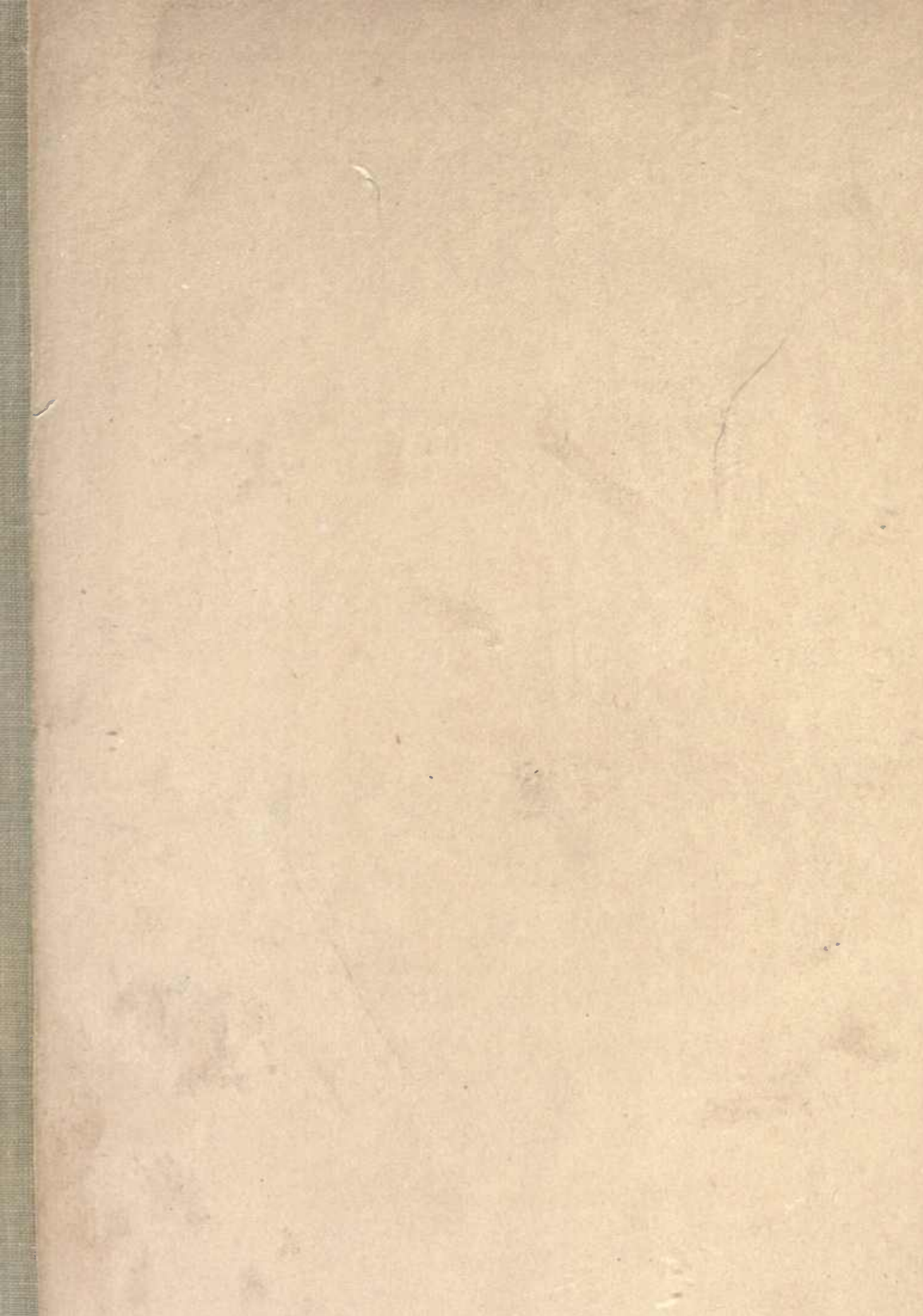




\section{-}




\section{THE MICROANALYSIS \\ . OF \\ POWDERED VEGETABLE DRUGS \\ SCHNEIDER}




\section{BY THE SAME AUTHOR}

Pharmaceutical Bacteriology. Second Revised Edition. 97 Illustrations. Octavo. $\mathrm{x}+44 \mathrm{I}$ pages. Cloth, \$4.00.

Bacteriological Methods in Food and Drug Lab- . oratories. 93 Illustrations. Octavo. $29 \mathrm{r}$ pages. Cloth, $\$ 3.00$.

The Microbiology and Microanalysis of Foods. I3 I lllustrations. Octavo. Cloth, $\$ 3.50$.

\section{P. BLAKISTON'S SON \& CO. PHILADELPHIA}




\title{
THE MICROANALYSIS
}

OF

\section{Powdered Vegetable Drugs}

BY

ALBERT SCHNEIDER, M.D., Ph.D.

(Columbia University)

PROFESSOR OF PHARMACOGNOSY IN THE COLLEGE OF PHARMACY, AND

PROFESSOR OF PHARMACOLOGY IN THE COLLEGE OF MEDICINE,

UNIVERSITY OF NEBRASKA, LINCOLN

SECOND EDITION

WITH 237 ILLUSTRATIONS

\author{
PHILADELPHIA \\ P. BLAKISTON'S SON \& CO.




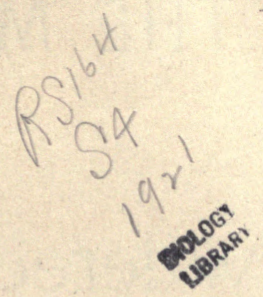

Copyright, i92I, By P. Blakiston's Son \& Co.

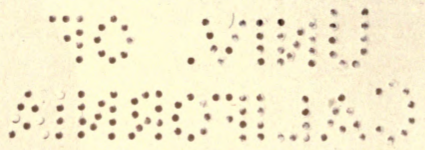




\section{PREFACE TO THE SECOND EDITION}

The first edition has been exhausted for some time, but a series of circumstances, in part incident upon the World War, made it impossible to prepare the second edition at any earlier period. The book has been almost entirely rewritten and includes much new subjectmatter. The drawings used with the first edition have been gone over carefully, making desirable changes and additions. Many new illustrations have been added. The drug descriptions have been largely rewritten, making them more complete. There is now included a statement of the ash content and the more common adulterants of each drug. The keys to the identification of the simple vegetable powders have been carefully revised and many additions made thereto. Keys to the identification of the compound powders of the United States Pharmacopœia (U. S. P.) IX and the National Formulary (N. F.) IV, have been added, also a chápter on quantitative microscopic determinations.

The book is believed to be complete and up to date. It is intended to serve three distinctive though closely correlated purposes, as follows:

1. As a laboratory guide and text-book for students of pharmacognosy in all colleges of pharmacy.

2. As a companion book to that part of the U.S.P. dealing with the microscopic descriptions of vegetable drugs.

3. As a practical reference manual for the practising pharmacist, in determining the quality and purity of the vegetable drugs used by him.

A. S.

Lincoln, Nebraska.

December, 1920.

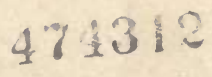





\title{
TABLE OF CONTENTS
}

\author{
PART I \\ GENERAL CONSIDERATIONS
}

PAGE

Chapter I.-The Microscope in Modern Pharmact . . . . . . . 1

Chapter II.-General Suggestions on the Examination of Vegetable

Powders ......................... 10

1. Description of Colors and Color Standards . . . . . . . . 10

2. Tactile Sensations . . . . . . . . . . . . 11

3. Odor and Odor Standards . . . . . . . . . . . 12

4. Taste and Standards of Taste . . . . . . . . . . 20

Chapter III.-The Quality and Purity of Vegetable Drugs from the

Standpoint of the Pure Drugs ACt . . . . . . . . 27

1. The Pure Drug Laws . . . . . . . . . . . . . . . . 27

2. U. S. P. Standards and Definitions of Standards . . . . . . 40

Chapter IV.-Causes Modifying the Characteristics of Vegetable

Powders ................ . . 45 45

1. Normal Variations .............. . . 45

2. Parasites. . . . . . . . . . . . . . . 46

Chapter V.-Powdering Vegetable Drugs ........... 53

Chapter VI.-Adulteration or Sophistication of Vegetable Drugs . 60

1. Adulteration as to Intent .............. 61

(a) Unintentional or Accidental Adulteration . . . . . . . 61

(b) Intentional or Criminal Adulteration . . . . . . . . 62

2. Manner of Adulteration . . . . . . . . . . . . 63

3. Substances Employed in Adulteration . . . . . . . . . . 64

4. The Detection of Adulterations . . . . . . . . . 69

Chapter ViI. - The Microscopical Examination of Powdered Vegetable

Drugs . . . . . . . . . . . . 70 70

1. Equipment and Methods. . . . . . . . . . . . . 70

2. Tissue Terminology and Identification of Tissues . . . . . . . 78

3. Occurrence and Distribution of Tissue Elements in Plant Organs ... 83

(a) Leaves . . . . . . . . . . . . . . . 83

(b) Flowers . . . . . . . . . . . . . 86

(c) Fruits and Seeds ............. . . . 87

(d) Barks . . . . . . . . . . . . . . . . . . 89

(e) Roots and Rhizomes .............. . . 90

(f) Stems .................... . . . . . 92

(g) Woods . . . . . . . . . . . . . . 9 93

(h) Other Plant Parts . . . . . . . . . . . . . 93

4. Tabulation of Tissues and Tissue Elements . . . . . . . . 93

5. Illustrations, with Descriptions, of Plant Tissues . . . . . 101 vii 
Chapter ViII. - Keys to the Study and Identification of Simple Powdered Vegetable Drugs. . . . . . . . . . . 115

1. Key Based Upon the Organoleptic Tests. Macroanalytical Key. . . 115

2. Key Based Upon Microscopic Structure. Microanalytical Key. . . 123

Chapter IX.-Keys to the Stody and Identification of the U. S. P. and

N. F. CoMpound Powders . . . . . . . . . . . . . 132

1. Key Based Upon the Organoleptic Tests . . . . . . . . . . . 133

2. Key Based Upon Microscopic Characteristics . . . . . . . . . . . 134

Chapter X.-Microanalytical Study of Crystals . . . . . . . . . 136

Chapter XI.-Quantitative Microscopic Determinations . . . . 141

\section{PART II}

\section{DRUGS DESCRIBED AND FIGURED}

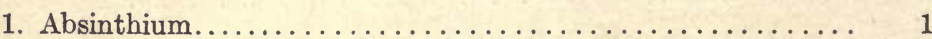

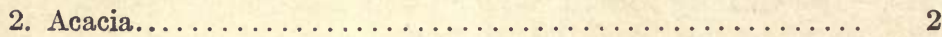

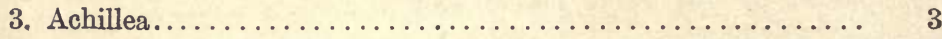

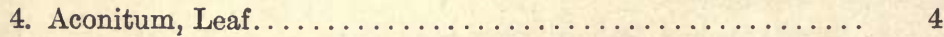

5. Aconitum, Root..................... 5 and 6

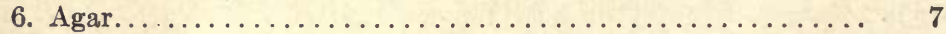

7. Aloes................................. 8

8. Althaea.............................. 9

9. Amygdala.............................. 10

10. Amylum

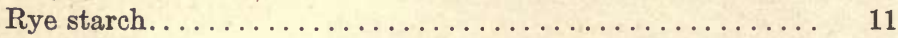

Wheat Starch........................ 12

Corroded Wheat Starch........................ 13

Barley Starch.............................. 14

Corn Starch............................. 15

Sorghum Seed Starch...................... 16

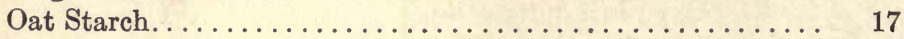

Rice $\operatorname{Starch} . \ldots \ldots \ldots \ldots \ldots \ldots \ldots \ldots \ldots \ldots \ldots \ldots \ldots \ldots \ldots$

Bean Starch............................. 19

Bean Starch (Polarized)...................... 20

Pea Starch............................... 21

Lentil Starch.......................... 22

Potato Starch.............................. 23

Potato Starch (Polarized)..................... 24

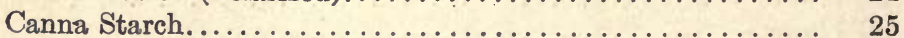

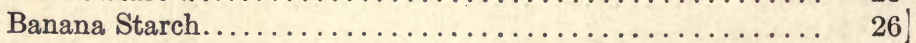

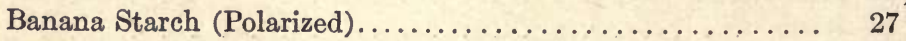

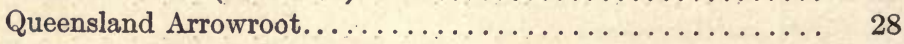

Queensland Starch (Polarized)................... 29

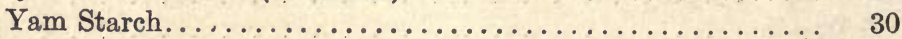

Sago Starch. . . . . . . . . . . . . . . . . . . . . 31

Sago Starch (Polarized)....................... 32

11. Angustura 


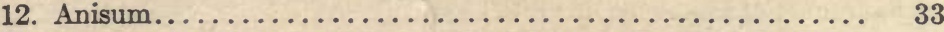

13. Anthemis

14. Apocynum cannabinum....................... 34

15. Apocynum androsæmifolium .................. 35

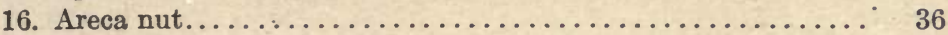

17. Armoracia

18. Arnica Flowers.......................... 37

19. Arnica Roots............................. 38

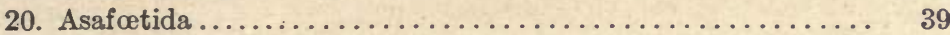

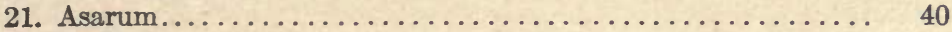

22. Asclepias............................ 41

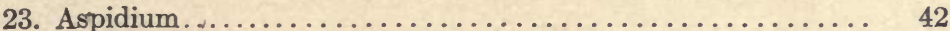

24. Aspidosperma........................... 43

25. Aurantium............................... 44

26. Belladonna Leaves............................ 45

27. Belladonna Roots.......................... 46

28. Benzoin.............................. 47

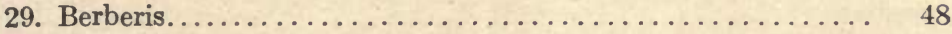

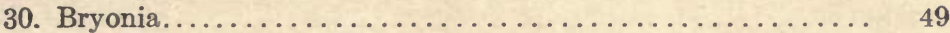

31. Buchu............................... 50

32. Caffea................................ 51

33. Calamus.................................... 52

34. Calendula................................ 53

35. Calumba................................ 54

36. Cambogia........................................ 55

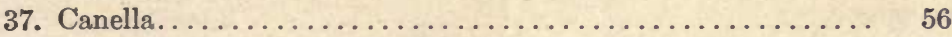

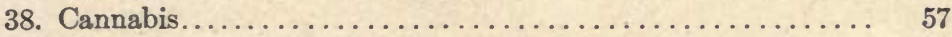

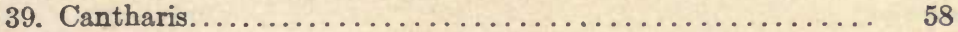

40. Capsicum.............................. 59

41. Carbo animalis

42. Carbo ligni

43. Cardamom

44. Carum

45. Carthamus

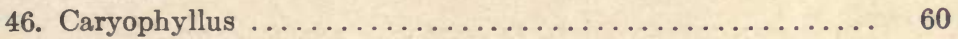

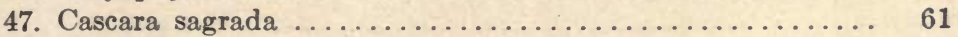

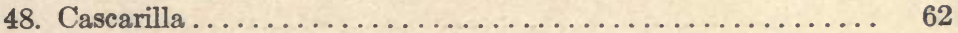

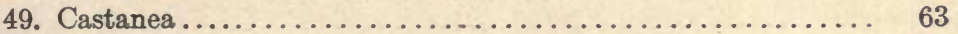

50. Caulophyllum ............................. 64

51. Cetraria

52. Chamælirium............................... 65

53. Chelidonium

54. Chenopodium

55. Chicle.............................. 66

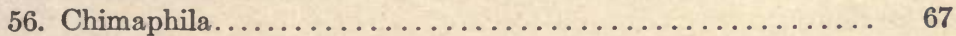

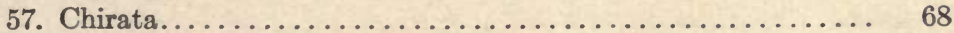

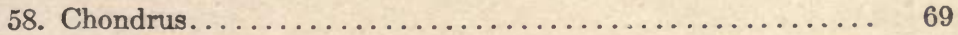

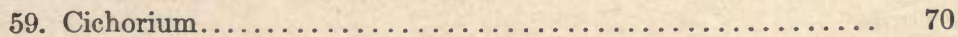

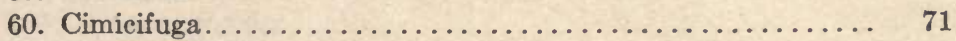

61. Cinchona................................. 72 


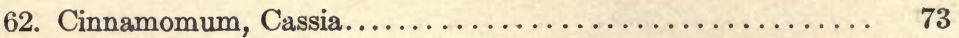

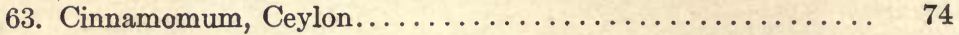

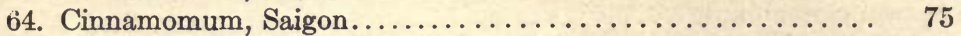

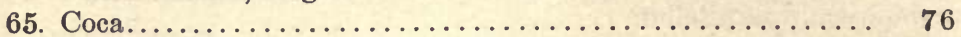

66. Cocculus

67. Colchicum Corm....................... 77

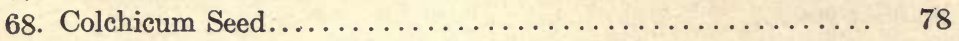

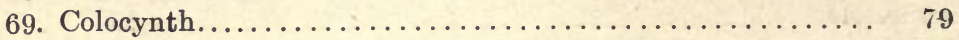

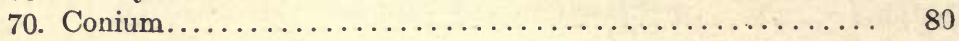

71. Convallaria......................... 81

72. Coriainder

73. Cornus............................... 82

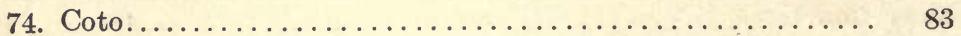

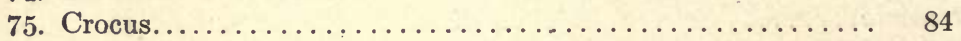

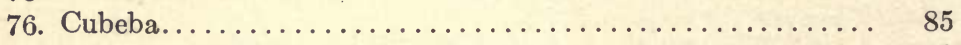

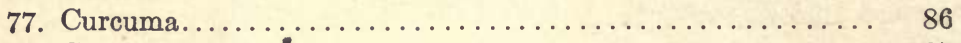

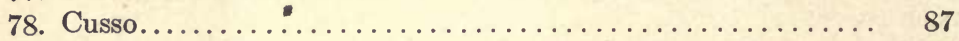

79. Cypripedium............................ 88

80. Dephinium

81. Dextrin

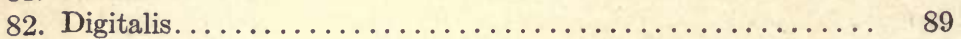

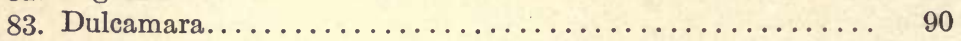

84. Ergota

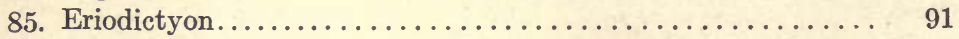

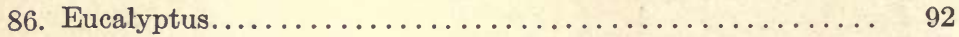

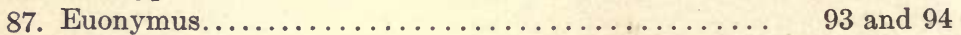

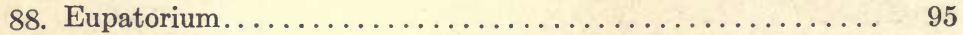

89. Fœniculum............................ 96

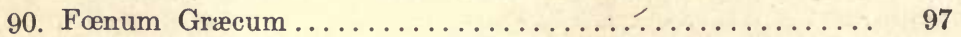

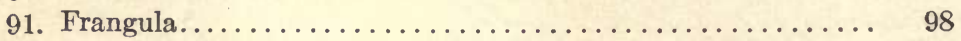

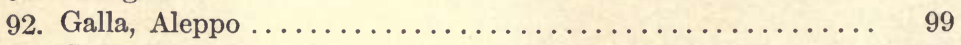

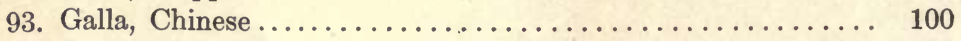

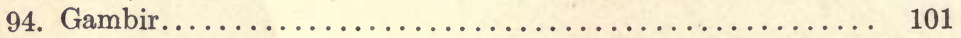

95. Gaultheria

96. Gelsemium ................................... 102

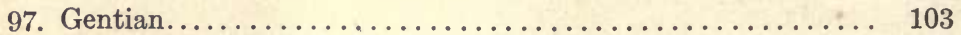

98. Geranium .............................. 104

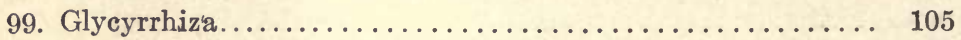

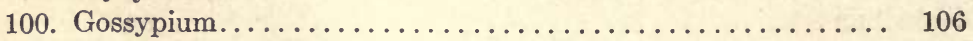

101. Granatum, Stem bark................... 107

102. Granatum, Root bark

103. Grindelia............................. 108

104. Guaiacum

105. Guarana................................ 109

106. Hæmatoxylon

107. Hamamelis............................ 110

108. Hedeoma

109. Helleborus

110. Humulus........................... 111

111. Hydrangea......................... 112 


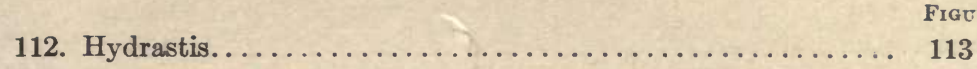

113. Hyoscyamus Leaf. . . . . . . . . . . . . . . . . . . . 114

114. Hyoseyamus Seed......................... 115

115. Ignatia.............................. 116

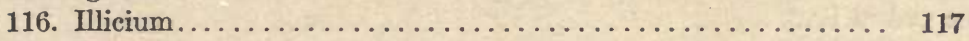

117. Inula.............................. 118

118. Ipecac. . . . . . . . . . . . . . . . . . . . . . . . 119

119. Iris Florentina. . . . . . . . . . . . . . . . . . . 120

120. Iris versicolor. ........................... 121

121. Jalapa.............................. 122

122. Juglans. . . . . . . . . . . . . . . . . . . . . . . 123

123. Kamala............................... 124

124. Krameria, Peruvian....................... 125

125. Krameria, Savanilla....................... 126

126. Lappa............................... 127

127. Leptandra............................. 128

128. Linum

129. Lobelia............................... 129

130. Lupulin............................... 111a

131. Lycopodium............................... 130

132. Mace, true and false................. 131 and 132

133. Manna ..................................... 133

134. Matico................................. 134

135. Matricaria

136. Mel................................. 135

137. Menispermum............................ 136

138. Mentha piperita.......................... 137

139. Mentha viridis

140. Methysticum............................. 138

141. Mezereum.................................... 139

142. Myrica................................ 140

143. Myristica................................. 141

144. Nux vomica............................. 142

145. Opium.................................. 143

146. Paracoto................................ 144

147. Pareira...................................... 145

148. Physostigma............................... 146

149. Phytolacea Fruit.............................. 147

150. Phytolacea Root............................. 148

151. Pilocarpus.................................... 149

152 Pimenta................................. 150

153. Piper, black................................ 151

154. Piper, white........................... 151

155. Podophyllum............................... 152

156. Populus................................. 153

157. Prinos................................... 154

158. Prunus serotina..................... 155 and 156

159. Pulsatilla

160. Pyrethrum Flowers......................... 157

161. Pyrethrum Roots.......................... 158 
162. Quassia............................ 159

163. Quercus

164. Quillaja .......................... 160

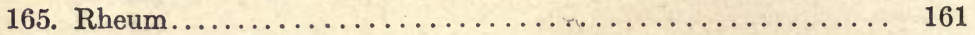

166. Rhus glabra Bark ...................... 162

167. Rhus glabra Fruit...................... 163

168. Rosa gallica

169. Rubus............................. 164

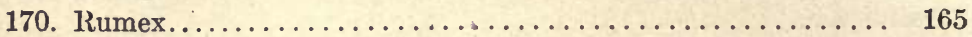

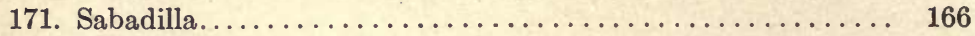

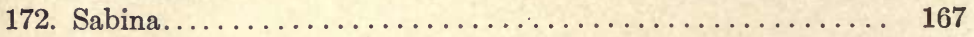

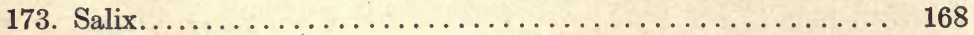

174. Sambucus

175. Sanguinaria........................... 169

176. Santonica

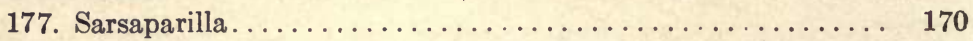

178. Sassafras............................ 171

179. Scilla

180. Scoparius.......................... 172

181. Scopola............................. 173

182. Scutellaria............................ 174

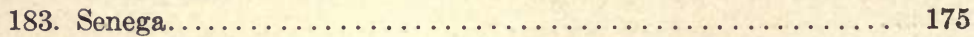

184. Senna............................. 176

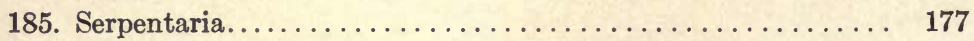

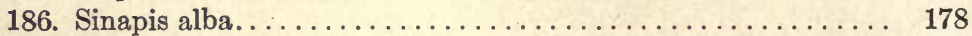

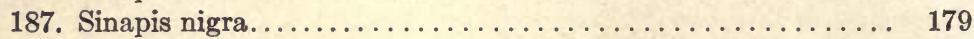

188. Spigelia.......................... 180 and 181

189. Staphisagria......................... 182

190. Stillingia.............................. 183

191. Stramonium Leaf......................... 184

192. Stramonium Seed

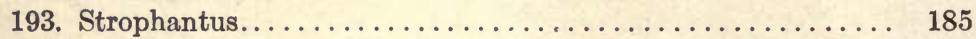

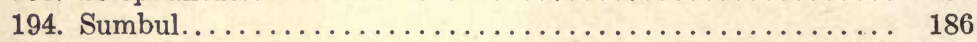

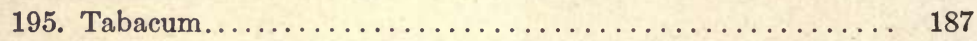

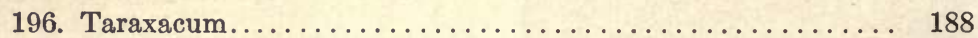

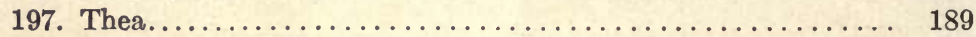

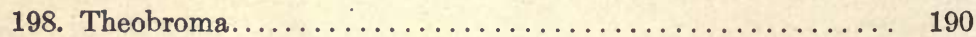

199. Tragacanth.............................. 191

200. Turnera............................... 192

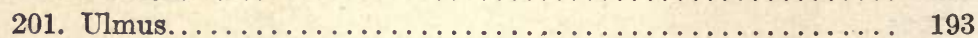

202. Uva Ursi.................................. 194

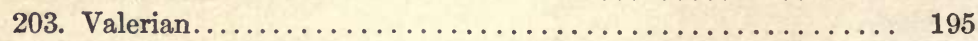

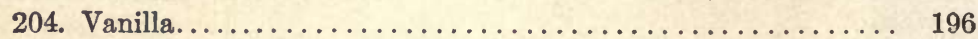

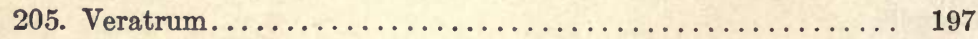

206. Viburnum opulus........................ 198

207. Viburnum prunifolium...................... 199

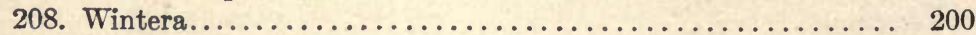

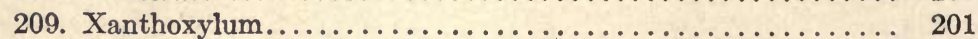

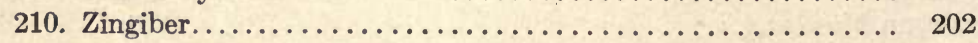




\title{
PART I \\ GENERAL CONSIDERATIONS
}

\author{
CHAPTER I
}

\section{THE MICROSCOPE IN MODERN PHARMACY}

The Federal Pure Food and Drugs Act went into effect June 30, 1906. The act is enforced by the Bureau of Chemistry of the U. S. Department of Agriculture. The Bureau has adopted the U. S. P. (United States Pharmacopœia) and the N. F. (National Formulary) as the legal standards of the quality and purity of drugs. The U.S.P. IX contains the microscopic descriptions of the crude as well as of the powdered vegetable drugs and no pharmacist can use the legal drug standard intelligently unless he has had a thorough course in drug microanalysis in a well equipped laboratory.

The language and terminology descriptive of the drugs and remedial agents mentioned in the U.S. P. and the N. F., constitute the "purity rubric." It soon developed that the legal descriptions and definitions were defective in many ways, as will be more fully set forth in Chapter III of Part I. Controversies have arisen as to the interpretations to be put upon some of the drug descriptions and as to what constitutes wholly negligible and unimportant accidental additions and admixtures. The introduction into the U. S. P. of the microscopic descriptions of vegetables has had the effect of greatly increasing the legal value of the drug descriptions. A very brief introduction into the history of the use of the compound microscope in pharmaceutical practice is not out of place.

The progress in histological investigation, animal as well as vegetable, has kept pace with the progress in the manufacture of lenses for simple and compound microscopes. In other words, histology had its birth with the discovery of the microscope and has become perfected in direct ratio with the improvements in the artificial aids to vision.

The microscope in its earliest and simplest form consisted of a convex lens of some transparent substance. Magnifying lenses were known long before the discovery of glass. The wise Seneca (first century), who was apparently well versed in the properties of lenses, states that the ancients noticed that writing viewed through glass 
globes filled with water appeared magnified, but this phenomenon was attributed to the water, which leads to the conclusion that glass lenses were unknown even after glass was in use.

The first simple microscope of which there is any authentic record was made about 1300 and was known as vitrum pulicarium (flea glass). It consisted of a short cylindrical tube, at the upper end of which the lens was placed. The lower end carried two pieces of glass, just in focus, between which the object was held. The object to be inspected or marveled at was usually a flea, hence the name. The so-called

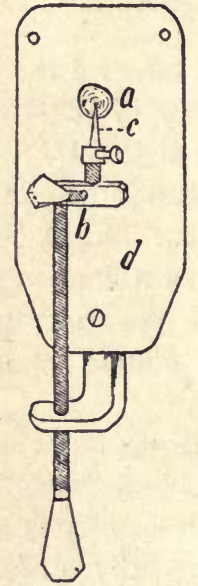

FIG. 1.-Leeuwenhoek's simple microscope (1670).

$a$, lens; $b$, adjustment; $c$, object-holder; $d$, metal plate.

"seed microscope" was similarly constructed. The sides of the tube were open for the admission of light and the two glass plates at the lower end contained small seeds. These first simple microscopes were mere toys and no scientific use was made of them.

It was not until about the year 1650 that scientists began to make use of the simple microscope. Their possible value in scientific investigations being recognized, special efforts were made to increase the magnifying power of the instruments as well as their definition.

Peré della Torre, of Naples (1776), and Lebaillif made excellent glass globules with very high magnifying power. Ch. Chevalier in his treatise on the microscope describes the conditions and requirements for making good magnifying globules. He stated that the globules must have a perfectly spherical form, that the glass must be pure and entirely free from air bubbles.

The Dutch scientist, Anton van Leeuwenhoek, used highly perfected lenses with mechanical conveniences for focussing the object under examination. In 1677 he discovered a large number of fresh water animalculæ as rotifers, vorticellæ, etc. In 1673 he discovered the red blood corpuscles, which, he said, measured 1/1940 of an inch. The diameter, as determined by the most perfect modern instruments, is $1 / 3200$ of an inch; the difference being due to the spherical aberration of these early magnifiers - a source of error then not fully understood. Stellati, the Italian scientist, employed excellent lenses in his study of the anatomy of the bee (1685).

In 1740 Wilson improved the effectiveness and convenience of the simple microscope by supplying a stationary stand with foot and an adjustable mirror for illuminating by transmitted light. 
About the year 1800 the number of forms of simple microscopes was multitudinous. Spherical and chromatic aberrations were in a large measure corrected by employing combinations of lenses, as in modern simple microscopes. Cuff made a simple microscope which was capable of being converted into a compound microscope.

The First Compound Microscope was made in 1590 by Z. Janssen, a spectacle maker of Middleburg, Holland. The exact construction of this instrument is apparently not known. It is said to have been an imposing affair, consisting of a copper tube, 6 feet long, with three lenses mounted upon brass dolphins. Janssen made several instruments, one of which is still preserved at Middleburg and of which Fig. 3 is a diagram. These microscopes were of no practical value, because the image was greatly distorted and discolored. They were looked upon as curiosities rather than instruments of scientific precision.

Even as late as 1821 such eminent authorities as M. Biot, of France, and Dr. Wollaston, of England, declared that "the compound microscope will never excel the simple one."

According to Van Heurck, the oldest compound microscope of which there is any figure is that of $\mathrm{R}$. Hooke (1665). It is evident that the size of the microscopes was greatly reduced FIG. 2.-Wilson's simple microscope about this time, the tube in the Hooke instrument being only about 18 centimetres ( 7 inches) in length; there were, however, four tubes sliding into each

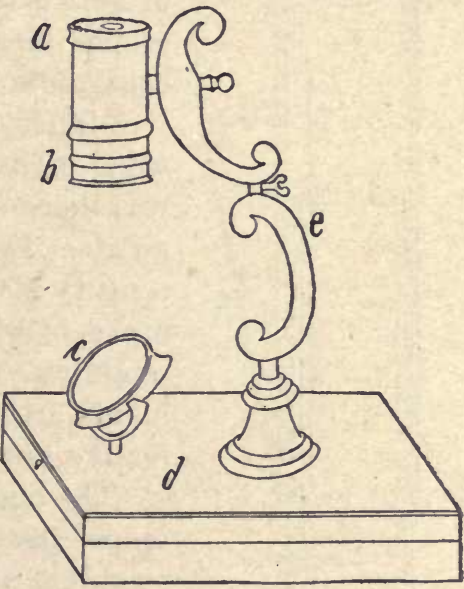
other capable of being drawn out to increase magnification. The field lens (middle lens) was removable. Illumination was vertical by means of a lamp, spherical and bull's-eye condensers. In spite of its complex mechanism it was far from being a satisfactory instrument.

Grindelin (1687) made a compound microscope which showed considerable improvement. Chromatic and spherical aberration were in part corrected by the use of combinations of lenses. The field lenses were more generally used. While the arrangement of lenses in this instrument indicates considerable progress, the mechanical parts were defective. There were neither condensers nor adjustable mirror. Cuff's microscope, which was patented in 1714 , was provided with a 
movable stage capable of receiving various attachments, a mirror capable of being set in any direction, and a bull's-eye condenser. Dellabarre's microscope was, doubtless, superior to the preceding and

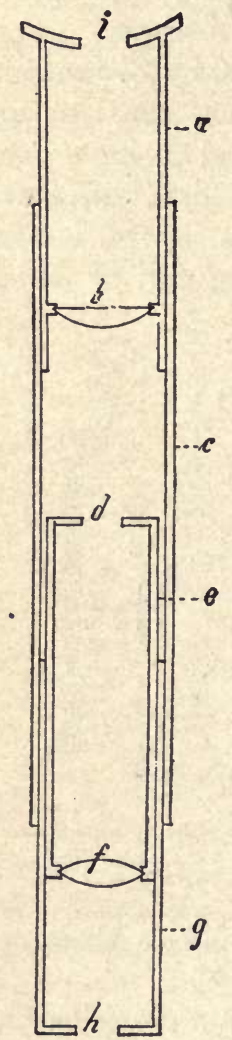

Frg. 3.-Janssen's compound microscope (1590).

$a$, ocular tube; $b$, ocular lens; $c$, outer tube; $d$, diaphragm; $e$, middle sliding tube; $f$, objective lens; $g$, lower sliding tube; $h$, diaphragm; $i$, eye diaphragm. more complete in its construction. The ocular was composed of six lenses, the objective of three lenses, a plano-concave adjustable mirror and a substage condenser. Dellabarre claimed a chromatism for his microscopes, but that was, perhaps, only partially true. Later he reduced the number of lenses employed. Fig. 5 shows the mechanical parts, excepting the foot or base. A point worthy of note is that as the simple and compound microscopes increased in scientific value plainness of construction superceded the evidences of decorative fancies. Scrolls, conventional designs, etc., were omitted, and the mechanical construction was more effectually suited to the optical requirements. During the last half of the eighteenth century some very ornamental instruments were made, of which Martin's (1780) compound microscope was a good example; but in spite of their highly artistic finish they were, as a rule, very defective optically.

The highest magnification of the simple microscope possible with a maximum correction of spherical and chromatic aberration was not sufficient to enable scientists to carry on efficient histological investigations. Most of the compound microscopes in use up to 1800 or perhaps 1825 , were in reality inferior to many of the simple microscopes. It is true they gave a higher amplification, but this apparent gain was more than neutralized by the increase in distortion and a decrease in clearness of image due to chromatic and spherical aberration.

Good compound microscopes have been in use for nearly seventy-five years, but they have not been extensively employed by students of pharmacy for more than about thirty years. The reason why they were not used earlier is, doubtless, to be found in the fact that pharmacy as an independent science is of comparatively recent origin. In the United States it is only within a few years that 
the courses of instruction in colleges of pharmacy have been based upon scientific principles, especially in the department of botany, with its various subdivisions, as vegetable materia medica, vegetable pharmacography and powdered vegetable drugs.

In the United States, Dr. Frederick Hoffmann was, perhaps, among the very first to advocate the use of the compound microscope in the examination of vegetable drugs and their adulterants. ${ }^{1}$ Other authorities have risen sporadically to recommend the use of this instrument. The important American work in the study of vegetable
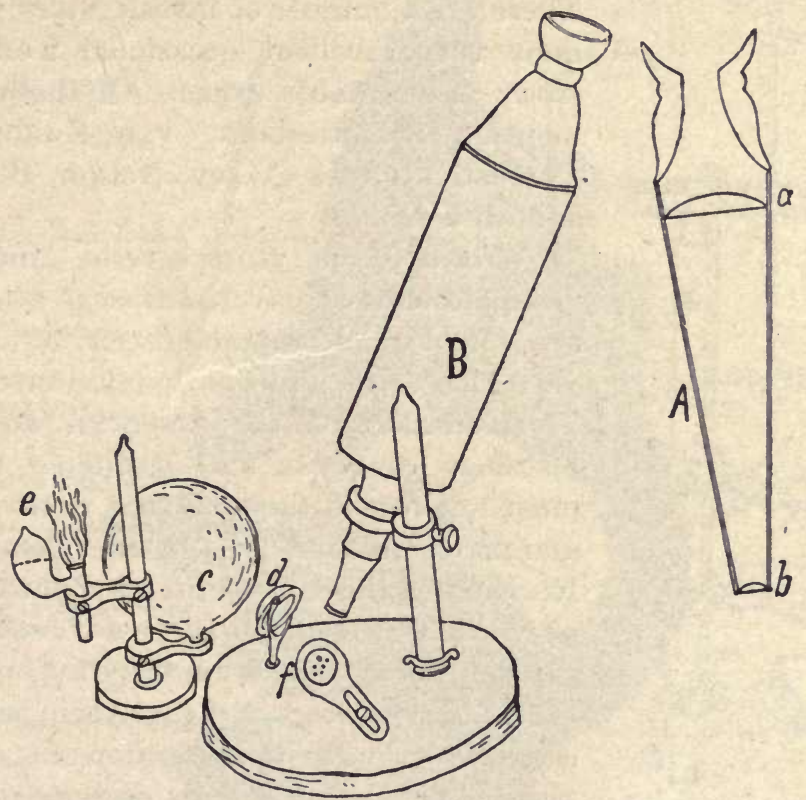

Fig. 4.-Hooke's compound microscope (1665).

$A$, diaphragm of tube, showing eye-lens at $a$ and objective lens at $b ; B$, body or tube of instrument; $c$, spherical condenser; $d$, bull's-eye condenser; $e$, lamp; $f$, stage.

drugs did not, however begin until many years after the work was begun in Germany and France. Berg's excellent Atlas illustrating the histology of drugs was published in 1865 , and even at the present time no English or American author has produced anything equal to it in importance.

Dr. Edson Bastin was among the first Americans to place pharmaceutical botany upon a more scientific basis, and he did much in a quiet way to encourage work in the histological study of vegetable drugs. He was a very thorough and conscientious worker.

1 "American Journal of Pharmacy," 25; 45, 1853. 
Since 1880 a number of American investigators, have been doing energetic work in the critical study of vegetable drugs. Of these we will mention only a few. Sayre and Dohme have made investigations on the histology of vegetable drugs, and the results have been published in the "Druggists' Circular" and the "American Journal of Pharmacy" and other publications. Most of the papers are accom-

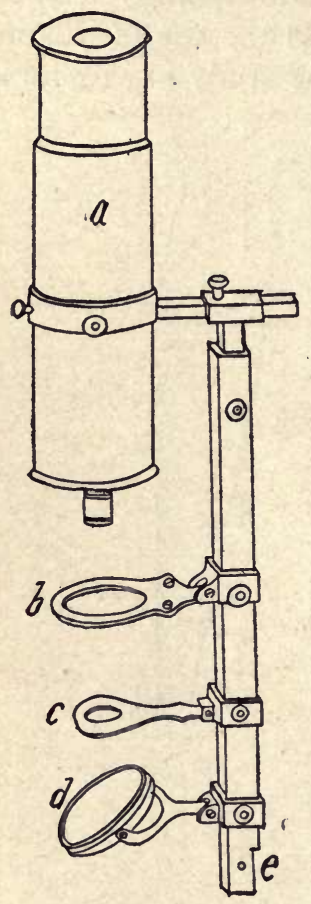

Fig. 5.-Dellabarre's co mpound microscope (1778).

$a$, body or tube; $b$ stage, adjustable; $c$, substage condenser; $d$, mirror; $e$, attachment to base or tripod. panied by illustrations from pen and ink drawings, which are as a rule poor and not in full harmony with the merits of the work done. There are a number of investigators who have done very excellent occasional work in the study of vegetable drugs. Of these we may mention Schlotterbeck, van Zwaluwenberg, -Denniston, Grace Cooley, Nelson, Breithaupt, and others.

Within recent years several American investigators have devoted special attention to the histological characteristies of powdered vegetable drugs and their adulterants.

In speaking of the American work on the histology of crude and powdered drugs we must not forget the influence exerted by Research Committee "C" of the Committee of Revision of the United States Pharmacopœia, of which Dr. H. H: Rusby, of New York, was the chairman. This committee selected a number of investigators and gave them some financial support in the investigation of specially assigned histological studies of vegetable drugs. Much of the best work of recent years has been done under the auspices of this committee. It has accomplished some very important results with reference to the special histology of drugs and the detection of adulterants, and also has proven a very important educational factor.

Let us consider very briefly the general results which have followed the use of the microscope in pharmacy. First of all it has caused a very marked reduction in the adulteration of vegetable drugs, of powdered drugs in particular. A properly trained and equipped modern pharmacist can readily detect the sophistication of powdered drugs, of ground spices and of crude drugs. Sophisticators have gradually 
been forced to admit this fact, and, as a result, they have in many instances ceased their nefarious business, and in other instances they have met the trained scientist with almost equal shrewdness. The customary procedure of the former unscrupulous collectors, dealers, etc., was to adulterate crude drugs and powdered drugs with substances which were common, easily obtained, and which did not materially

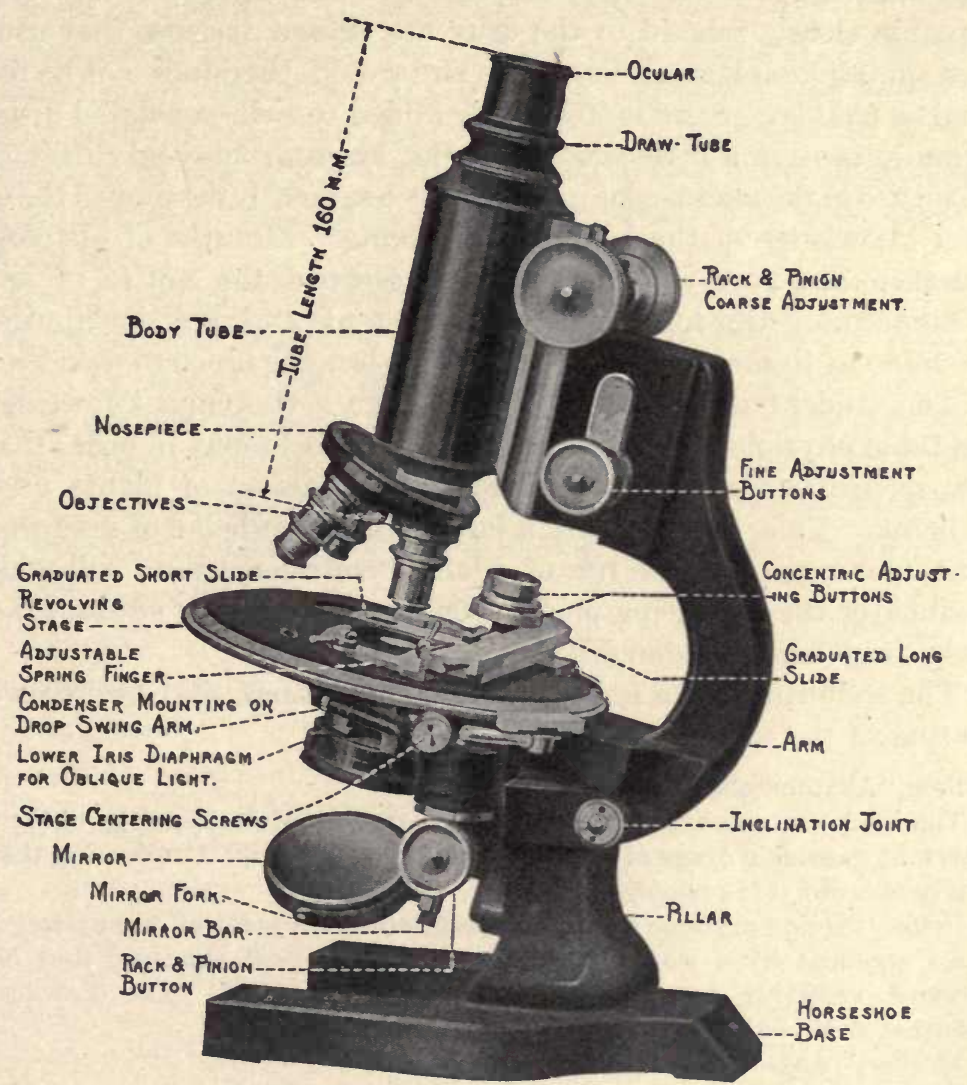

Fig. 6.-A modern compound microscope.

modify the gross characters of the drug. These substances were often added in large quantities and yet may have borne no histological resemblance to the drug itself. All kinds of vegetable tissues, starch and flour in particular, were used, also sand and clay, often colored artifically so as not to modify the normal color of the drug. History records the preparation of wooden nutmegs, clay coffee beans, cloves of pressed starch, etc. The wise modern sophisticator discards such 
crude methods; he rejects the once popular use of starches, corn meal flour and wheat flour because these substances are very readily detected microscopically. If any of the starchy substances are employed, rice starch is chosen, because the granules are small and are not readily distinguished from the smaller granules of the drug itself. He is also careful not to add starch to a powdered drug which is normally free from starch. If a vegetable substance is added, tissues and organs of plants closely related to the drug are chosen, because they usually have similar histological characters and would, therefore, not be recognized so readily. Sand is frequently added to such powdered drugs as normally contain a little sand, as barks, leaves, roots and rhizomes.

The use of the microscope in pharmacy has greatly developed the more exact knowledge of the histology of plants. Minutiæ of histological structure are now recognized which escaped the notice of earlier investigators. Our knowledge of cell contents and their distribution in the different tissues and plant organs has become much more accurate.

The student of pharmacy should have a thorough knowledge of vegetable physiology, gross morphology and histology in order that he may recognize the normal histological characters of plants used in medicine. This, coupled with a fairly good knowledge of microscopy, micro-technique and the use of micro-chemical reagents will make it possible for the practicing pharmacist to recognize the adulteration of crude drugs and powdered drugs.

The following are a few of the classic German and French works treating of the microscopy of vegetable drugs.

Berg,"Anatomischer Atlas," 1865.

This book contains excellent full-page illustrations of the histology of the more important vegetable drugs of the German Pharmacopœia. Considering the date of its production it is a remarkable work.

Collin, "Guide pratique pour la determination des poudres officinales." 1893.

An excellent little work illustrating the histological characteristics of the powdered vegetable drugs of the French Pharmacopœia. The drawings are somewhat crude but quite accurate.

Moeller," Anatomischer Atlas," 1892.

A large royal octavo volume with full-page illustrations of the histological characteristics of the more important powdered vegetable drugs of the German Pharmacopœia. 1896.

Planchon et Collin, "Traite des drogues simples d'origine vegetales" ( 2 vols.),

Two large octavo volumes treating of the histology and commerce of vegetable drugs and related plants. The most complete work of its kind and profusely illustrated.

Tschirch und Oesterle, "Anatomischer Atlas der Pharmakognosie und Nahrungsmittelkunde." 1893.

This work treats of the complete histology of vegetable drugs and related 
substances. The illustrations are excellent and the subjects are comprehensively treated.

Vogl, "Pharmakognosie," 1892.

This work describes the histology of the vegetable drugs used in Austria. The histological descriptions are very accurate and complete. Only a comparatively small number of the drugs are illustrated.

Of the American text books on vegetable pharmacognosy only a few deserve mention. Of the earlier American writers of texts on pharmacognosy that of Maisch contains illustrations of the histology of many of the vegetable drugs, but they are mostly diagrams of low magnification ( 2 to 15 diameters) and, hence, of little value in the study of tissue elements. This author also introduced micro-photographic reproductions of sections of vegetable.drugs, but these proved a total failure.

Several recent American text-books touch on the microscopical characteristics of vegetable drugs, notably that by Sayre, and also the one by Wall. Prof. W. Mansfield of New York has done good work in the microscopical study of vegetable drugs. Dr. Kraemer of the University of Michigan has perhaps done more along this line than any other investigator. It was largely through his untiring efforts that the microscopical descriptions of vegetable drugs were introduced into the U. S., P. IX. 


\section{CHAPTER II}

\section{GENERAL SUGGESTIONS ON THE EXAMINATION OF VEGETABLE POWDERS}

\section{Description of Colors and Color Standards}

The subject of the color of powdered drugs, as well as of other substances, is rather confused for several reasons. First, because there are no reliable standards of color, and second, because of the variable naming of colors. The artificial color standards used by teachers of the primary grades, artists, cloth manufacturers, furniture and house painters, etc., are very far from being accurate or uniform. No matter from what material the color scale is made, or how carefully it is prepared, it is subject to variation in intensity and quality. It is practically impossible to print color scales which are uniform throughout and which will not fade. It has been suggested that certain substances having well recognized and comparatively permanent colors be used as standards of comparison, as the chocolate brown of chocolate, the brown of cassia cinnamon and the yellow of a standard solution of Spanish saffron. Colors are simply the recognizable and distinguishable tints and shades of the primary colors red, green and blue, and the recognizable and distinguishable admixtures of these primary colors. Thus red and yellow makes orange; yellow and blue makes green; blue and red makes purple; etc. It would be possible to prepare a natural scale of colors by projecting the prismatic colors of direct sunlight upon a uniform screen. It would be necessary to adopt prisms of standard size and made of a uniform quality of glass. Any desired tint or shade could be produced by interposing varying thicknesses of milk glass and of smoked glass. By means of suitable and properly placed screens and shutters, comparisons could be made with any one of the primary colors, or any combination of the primary colors or their admixtures.

Perhaps the greatest obstacle to the recognition and comparison of colors is the confused naming of colors, or rather the use of terms which can only be comprehended by those who are familiar with the colors referred to. For instance such names as purple, royal purple, scarlet, indigo, violet, crimson, magenta, ecru, mauve, cerise, heliotrope, 
lavender, marine blue, terra cotta, Pompeian red, canary red, Chinese yellow, etc., are devoid of meaning to the uninitiated.

Form and texture greatly modify the color. This is true of drugs as well as of other substances. The same color on a rough and a smooth surface will present a markedly different tone, the rough surface producing a shade effect, hence the color will appear darker. In the case of powdered drugs it will be noticed that fineness greatly modifies the color, the finer powders producing tint effects as a rule. In some instances a difference in fineness may even modify the quality of the color entirely (licorice root).

We need scarcely urge the necessity of good illumination in the inspection of powders. The color of the powder should be carefully compared with the description given in some standard text-book. In nearly every instance the student will find some slight deviations in the color and consistency observed as compared with that given in the book. An effort should be made to account for these differences.

The student should make careful drawings of the microscopic structure of the powder. The value of this cannot be overestimated. In order to make a correct drawing it is absolutely necessary to study the powder carefully; furthermore, the act of making the drawing, as well as the visualization of the drawing itself, will impress the structural characters more firmly upon the mind.

\section{Tactile Sensations}

The sense of touch is the oldest of the senses in the order of evolution, and the other sense, as taste, smell, sight and hearing, are but modifications or specializations of this primary sense. Touch, as it applies to the examination of drugs, is a tactile sensation appreciated by the hand and fingers, the tongue and mouth, rarely also the larynx. The touch of fingers and hands conveys to the mind conceptions of coarseness or fineness, fatty, oily or unctuous condition, crispness, of moisture, dryness, mucilaginous condition, tendency to lumpiness, etc. In many instances the sense of touch is merely an aid to the sense of sight-that is, touch verifies or assists the visual judgment.

The tactile sense of the fingers may be greatly increased in delicacy by education and practice and by proper care. The most sensitive parts of the fingers are the tips; this sensitiveness is greatly enhanced by cleanliness of hands and nails. The nails should be carefully and evenly trimmed, but never very short, as that reduces sensitiveness. The clean, trimmed, free portion of the nail amplifies or magnifies the tactile sense by pressing upon the opposing delicate dermis when 
the finger is brought in contact with an object. Cold reduces sensitiveness very rapidly; washing in warm water restores the normal activity promptly.

Moisture greatly modifies the consistency or feel of powders. For instance, a powder which appears quite crisp or brittle when dry may become quite soft and somewhat fibrous in moist weather, indicating the presence of bast or perhaps elongated parenchyma cells (many barks).

Tactile sensations usually designated as tastes and odors will be explained later. We would advise students to depend largely upon the tactile sense of the hand and fingers, though lips, tongue and mouth are more sensitive. Frequent and promiscuous tasting and chewing of drugs is pernicious for several reasons.

\section{Odor AND Odor Standards}

The olfactory apparatus is undoubtedly the least reliable of all the sense organs. There is no standard of odors, nor do we have any means of measuring adors. A number of individuals may smell the same odor, but they have no means of comparing either the quality or the quantity of the odor. This being the case, it naturally follows that there is no reliable odor nomenclature. Odors are variously classified as agreeable or pleasant, indifferent, strong, faint, fragrant, aromatic, heavy, acid, pungent, sweet, etc., words which are variable in interpretation and in application. An odor is said to be strong or faint according to individual judgment. An odor may be "overpowering" to one person, while another will pronounce it moderately strong.

A substance capable of stimulating the olfactory apparatus to functional activity must be in a gaseous state. The odoriferous gas or vapor must enter the anterior nares in a large and continuous current. If the nostrils are held shut, though the passages are filled with the odoriferous gas, no odor can be detected. Filling the nostrils with liquids holding odoriferous gases in solution will not produce any effect upon the olfactory nerves. It is also interesting to note that odors entering the nostrils by way of the posterior nares cannot be smelled.

The olfactory nerves become fatigued very quickly, as is evidenced by the readiness with which one becomes "accustomed" to an odor. Tenants of ill-ventilated rooms, in which the stench is often overpowering, do not complain of any bad odor. Those addicted to the use of tobacco are unconscious of the strong odor which not only permeates the entire clothing, but also the entire system of 
the users of tobacco and the atmosphere about them. Consumers of alcoholic drinks are not aware of their alcoholic breath. Those who eat onions and garlic are not conscious of the sulphurous odor which is so annoying to others. Those affected with ozœna or bad breath, due to nasal catarrh, a disordered stomach or bad teeth, are not conscious of the odor.

The condition of the olfactory organs greatly modifies the appreciation of odors. If the nasal passages are more or less occluded through catarrhal inflammations, pathological growths as polypoids, etc., the sense of smell may be very much reduced or practically zero. Those affected with chronic nasal catarrh have a weak and otherwise abnormal sense of smell. The sense of smell in different persons differs, not only by inheritance, but also by education. Savage races and many of the higher herbivora and carnivora have an exceedingly acute sense of smell for certain odors, while for other odors this sense is quite dull. Man is capable of educating this sense to a very high degree, as in "wine-tasters," and tea examiners, who are capable of detecting differences in aroma which wholly escape the inexperienced.

In order that the sense of smell may be fairly delicate, the nasal passages should be unobstructed, the nasal membrane entirely free from inflammation and other abnormal conditions. The membrane should be quite moist with the natural secretion of the mucus cells, rather than comparatively dry. The nasal passages are also well supplied with nerve endings of common sensation, which will explain why many tactile sensations are mistaken for odors, as, for.example, the so-called pungent odors. In contradistinction to the other senses, electrical, thermal and mechanical stimuli do not cause sensations of odor.

The intensity of the odor is directly proportional to the concentration and volume of the odoriferous gas and the rate with which it passes through the nostrils. The olfactory apparatus is extremely sensitive when in a perfectly normal state. According to some authorities, the odor of mercaptan is still quite marked when diluted 300,000 ,000 times, and becomes inappreciable only when diluted 500,000,000 times. The odor of chlorphenol is still noticeable when diluted $1,000,000,000$ times. Certain drugs and chemicals will modify the sense of smell. Anodynes and soporifics will reduce it in activity while strychnin and some other substances will increase its activity,

As regards the estimates of the quality of odors, there is even greater uncertainty than there is concerning the quantity. In a general way odors are designated as agreeable or pleasant, indifferent, and disagreeable; but it becomes evident that such a classification is very unsatis- 
factory, owing to differences of judgment and of experience. If we go back to some of the lower organisms, we will find that certain odors are agreeable because they emanate from desirable substances. The carrion beetle undoubtedly finds the odor of decaying animal matter highly attractive. Certain insects are attracted to flowers having the odor of carrion. In fact all substances, though they may give rise to the most disagreeable odors, according to man's judgment, are eagerly sought after by a host of lower organisms. Even such highly organized animals as buzzards, vultures and hyenas are attracted to decaying animal matter. Many insects are, however, attracted by pleasant odors, as is indicated by their preference for the flowers of certain plants and for which reason they are designated as entomophilous flowers.

There are some remarkable instances of differences of judgment to be noted. Many physicians find the odor of phenol pleasant, while most other persons find it decidedly disagreeable. Some pharmacists maintain that dried taraxacum roots are odorless, while others note a very decided disagreeable odor. The farmer, on entering the crowded habitations of a large city, will note disagreeable odors which escape the notice of the inhabitants entirely. On the other hand, the city dweller, on visiting the farm, will note the disagreeable odors about stables and cattle-pens which the farmer ignores or speaks of as being rather agreeable. Every farmer enjoys the "fresh smell of the soil," which is a faint musty odor of decaying organic particles, associated with the cool vapors arising from the damp, upturned earth.

In man the utility of odors is no longer of prime importance. In some instances, however, they no doubt still serve such a purpose. For instance, we are attracted by the odors of most ripening fruits, as apples, oranges and berries; while we find the odor of poisonous plants, as stramonium, belladonna, tobacco, indian hemp, etc., decidedly disagreeable. There are, however, some fruits and other substances which have pleasant odors which are nevertheless inedible to man.

There are certain suggestions which the student will find useful in testing the odors of vegetable drugs. It is always advisable to leave the examination of drugs with strong odors until the last, in order to avoid confusion when testing drugs having weaker odors. Furthermore, if the fingers and hands are brought in contact with a very odoriferous substance, it is no easy matter to remove it preparatory to examining another drug. For instance, if garlic is rubbed on the hands, repeated washings will not remove the odor; in fact, it will often be appreciable for several days. The odor of star anise (Illicium) is also very persistent. All medical students know how difficult it is to 
remove the dissecting-room odor from hands; repeated washings with soap and hot water and dusting with charcoal is necessary.

To test the powder for odor, place a goodly pinch in the palm of one hand and rub it with the thumb and finger tips of the other hand, closing the palm as much as possible. The rubbing should be done briskly and with considerable force. Now bring the hand near the nose and open the palm somewhat. The warmth and moisture of the hand causes the odoriferous substance to rise and enter the nostrils. The odor is accentuated by sniffing - that is, by a series of sharp and rapid inhalations, causing the air charged with the odor to enter the nostrils in larger volumes. The hands and fingers should not be wet, as excessive moisture absorbs some of the odoriferous gas and reduces the intensity of the odor. If one powder has been rubbed or crushed in one palm, the second should be placed in the other palm; this will tend to guard against the mixing and confusing of odors in instances where hurried examination of several powders is necessary and when no opportunity presents itself for removing the first odor from palm and fingers.

Since there are neither qualitative nor quantitative odor standards, it is difficult to make comparisons, and the information gained from the comparisons is unreliable. Many of the vegetable drugs, however, have very decided odors, so that it is possible to identify them by this characteristic alone. On making a comparison of the different drugs we find that those having odors may be grouped according to a similarity of odors peculiar to certain types. This grouping would be an easy matter if the odors were simple, but unfortunately the odors of most drugs are mixed. For instance, chenopodium has a rather faint camphoraceous odor, but in addition it has a very disagreeable odor. Spearmint has a fragrant odor in addition to the aromatic minty odor. Roman pellitory has a faintly aromatic odor in addition to a somewhat disagreeable odor resembling that of taraxacum. The odor of calamus is spicy and camphoraceous, etc. Since there is no odor standard, there is also no satisfactory odor nomenclature. Authors speak of sour odor, sweet odor and pungent odor, terms which are wholly unscientific and inapplicable. The so-called sour odor is an odor which we have learned to associate with sour taste; the sweet odor is so called because of an odor associated with a sweet taste. Some speak of fragrant odors as sweet, which is simply a misuse of the term sweet. As already indicated, pungent odors are tactile sensations.

The following is an arbitrary classification of the odors which may be detected in the more common vegetable drugs. Certain drugs are chosen as types or provisional standards. 


\section{Odors of Vegetable Powders}

A. AGREEABLE ODORS.

I. Aromatic or Spicy.

1. Anise Type (spicy and fragrant)-Anise, fennel, star anise, sassafras bark.

2. Chocolate or Cacao Bean Type (faintly aromatic)-Cacao beans, butter and hulls, quarana (faint), coffee (very faint).

3. Cinnamon Type (very spicy or aromatic, related to clove type)-Cinnamons, canella, cinnamodendron, cascarilla, coto bark, paracoto, wintera.

4. Clove Type (very aromatic)-Cloves, Asarum, ginger, Pimenta, Cubeb, Calamus, pepper (not marked), Cardamom, Coriander, Carum, Myrica leaves.

5. Fænugreek Type (faintly aromatic, somewhat fragrant, characteristic)-Fœnugreek, Iris vers., Elm bark.

6. Mint Type (very aromatic)-Peppermint, spearmint (aromatic and fragrant), horsemint, penny royal, buchu.

7. Nutmeg Type (very aromatic)-Nutmeg, mace, cola nut (faint).

II. Fragrant, Frequently Designated as Sweet.

1. Honey Type (faintly fragrant, related to flower type)Honey, manna, myrrh, benzoin, storax, Quaiacum (very faint).

2. Fruit or Apple Type (very fragrant, related to flower type) -Figs, apples, raisins, prunes, purging cassia, many so-called berries as strawberry, raspberry, etc.

3. Lemon Peel Type (fragrant and aromatic)-Bitter orange peel, sweet orange peel, citron peel, lemon peel, Melissa when fresh.

4. Matricaria or Chamomille Type (fragrant, related to tea type, characteristic)-Matricaria, Chamomille, Brayera, Anthemis, Matico, Lavendula, Achillea.

5. Orange Blossom, Rose or Flower Type (very fragrant, related to honey type)-Orange blossoms, apple blossoms, rose, Iris flor. (faint), Hæmatoxylon (very faint), Sambucus flowers, Senna, Scutellaria, Marrubium, Vanilla, Spigelia, Castanea, Carthamus, benzoin (Siam), storax (faint).

6. Wintergreen Type (very fragrant, related to flower type)Gaultheria, birch, Marrubium. 
7. Tea or Hay Type (somewhat fragrant, characteristic)Tea, Hamamelis, Eupatorium, Lavendula, Matico, Senna, Brayera, Eriodictyon, Erythroxylon, Matico, Pilocarpus and other leaves, Pyrethrum flowers, Pulsatilla, Uva ursi.

8. Chicory Type (fragrant and somewhat aromatic)-Roasted chicory, phytolacca fruit.

B. INDIFFERENT ODORS.

1. Bitter Almond Type (aromatic, somewhat pleasant)Bitter almond, wild cherry bark, apple seeds, quince seeds and other seeds containing hydrocyanic acid.

2. Caraway Type (aromatic, pleasant to many)-Caraway, coriander, fennel.

3. Camphor Type (characteristic, usually considered disagreeable; terebinthine odor)-Calamus, Chenopodium, camphor, Grindelia, Eucalyptus, Juniperus, rosemary, Sabina, Salvia, Santonica, Serpentaria, Tanacetum, Thuja.

4. Bean Type (bland, not pleasant)-Castor beans and croton beans when fresh, calabar beans, beans, peas, unroasted peauuts.

5. Seaweed Type (briny odor, not agreeable)-Characteristic of all seaweeds, as Irish moss.

6. Soil Type (faintly musty odor)-Very marked in Sarsaparilla, noticeable in nearly all roots, rhizomes, tubers and most barks, especially when moist. Due to soil present.

7. Sumbul Type (musk-like, heavy, disagreeable to many)Sumbul, Santalum album (faint).

8. Jalapa Type (smoky or creosote odor, due to smoke in drying)-Jalapa and other drugs dried over a flame and over open fireplaces, as Russian rhubarb.

9. Tannin Type (a faint odor resembling the jalapa type, noticeable in substances rich in tannin) Podophyllum, Rheum, Rumex, Rhatany, Galla, Lappa, Chirata, Hydrastis, Frasera.

C. DISAGREEABLE ODORS.

1. Cannabis Indica Type (variously designated as heavy, nauseous, stupefying and suffocating; increased by moisture)-Absinthium, Apocynum, Asclepias, Aspidium (when old), Belladonna leaves, Calendula, Chelidon- 
ium, Cimicifuga when moist, Cypripedium, Digitalis leaves, Dulcamara, ergot (when old), Gelsemium, hellebore, Hyoscyamus, Indian hemp, ipecac, Lactucarium Lobelia, opium, Sabadilla, Scoparius, Senega (when old), Stilliniga, Stramonium leaves and seeds, Strophantus, tobacco.

2. Rancid odor (due to the decomposition of fats and oils) Castor beans and croton beans (when old), Cocculus Indicus, Delphinium, Staphisagria, ergot and Senega (when old).

3. Garlic or Alliaceous Type (sulphurous odor)-Asafœtida, garlic, onions, Galbanum, mustard (when moist).

4. Conium Type (mouse odor)-Conium when moistened with potassium hydrate or other alkaline solution.

5. Melissa Type (ant odor)-Dried Melissa, when briskly crushed.

6. Valerian Type (very characteristic, develops with age)valerian, Viburnum prunifolium, lupulin, Humulus.

7. Taraxacum Type (cow odor, characteristic)-Calumba, Phytolacca root, Taraxacum, Pyrethrum root, Inula, Althæa, aconite, Symphytum, Bryonia.

The following is an alphabetical list of vegetable drugs which are practically odorless. Few substances are entirely odorless, but in the drugs enumerated the odors are not sufficiently marked to be diagnostic. It will also be noted that the drugs which are practically odorless exceed those which are tasteless, due to the fact that taste-sensations are more delicate and hence more readily detected and compared.

\section{Odorless or Nearly Odorless Drugs}

1. Areca (odor faintly fragrant).

2. Aconite root (faintly horseradish-like when fresh or moistened).

3. Aspidosperma (faintly aromatic).

4. Belladonna root.

5. Berberis.

6. Bryonia (resembling Taraxacum).

7. Calumba (resembling Taraxacum).
8. Carbo animalis.

9. Carbo vegetabilis.

10. Caulophyllum.

11. Cetraria.

12. Chamælirium.

13. Chimaphila.

14. Chirata.

15. Cichorium (not roasted).

16. Cinchona (faintly aromatic).

17. Colchicum (seed and corm).

19. Convallaria. 
20. Cornus.

21. Dextrin.

22. Frangula.

23. Geranium.

24. Glycyrrhiza (faint peculiar odor).

25. Gossypium.

26. Granatum bark.

27. Hydrangea (resembling Jaraxacum.

28. Hyoscyamus seeds.

29. Ignatia beans.

30. Kamala.

31. Leptandra.

32. Linum.

33. Lycopodium.

34. Magnolia.

35. Menispermum.

36. Mezereum.

37. Nux vomica.

38. Pareira.

39. Physostigma (bean-like).

40. Phytolacca root (like Taraxacum).
41. Populus.

42. Prinos.

43. Quassia.

44. Quercus.

45. Quillaja (causes sneezing).

46. Rhamnus purshiana.

47. Rhus glabra fruit.

48. Rhus toxicodendron.

49. Rubus.

50. Salix.

51. Sanguinaria.

52. Santalum rubrum.

53. Sarsaparilla (soil odor marked).

54. Sassafras pith.

55. Scilla.

56. Sinapis (when dry; alliaceous when moist).

57. Triticum repens.

58. Veratrum viride.

59. Viburnum opulus.

60. Xanthoxylum.

The student will find that many odors are very difficult of classification. The separation into aromatic and fragrant will depend largely upon judgment; likewise the separation into agreeable, indifferent and disagreeable. It must, however, be remembered that there are a great variety of factors which will modify the odor of drugs, as has already been indicated, and as will be explained more fully in subsequent chapters.

The odor of the whole drug may differ qualitatively as well as quantitatively from that of the crushed, bruised or powdered drug. The whole drug may have a characteristic odor, which may be masked or obscured, due to other odors liberated by the crushing process. For example, well-dried, uncrushed or only slightly bruised melissa has a fragrant, lemon-like odor; when thoroughly crushed, the fragrancy is almost entirely obscured by a very decided disagreeable odor recalling crushed ants. Uncrushed Mentha viridis has a very fragrant odor, resembling that of the leaves of garden sweet Mary; upon crushing there is developed an odor resembling catmint. Crude 
sabina has the terebinthine odor characteristic of conifers; upon thoroughly crushing there is liberated a peculiar and very disagreeable odor. The same is true of worm seed (Santonica) and some other drugs. In consideration of these facts it is advisable to test the odor of the drug before it is crushed or powdered as well as afterward. The odor of powdered drugs weakens very rapidly. The great surface area exposed permits the volatile odoriferous substances to escape very quickly. Very fine comparatively fresh powders of drugs which have well marked odors in the crude state, have only a faint or barely appreciable odor. In the case of coarse and medium powders the odor may readily be accentuated by crushing a pinch of the powder in the palm of the hand or in a small mortar, as already indicated.

Since the olfactory apparatus is easily fatigued, it is not advisable to test the odor of many drugs in rapid succession. Thoroughly testing from four to eight drugs in the course of one hour will be sufficient. The intervals should be long enough to enable the olfactory nerves to recover entirely from each functional depression.

\section{Taste and Standards of Taste}

A substance to be tasted must be in solution and must come in contact with the gustatory nerve endings. We are capable of recognizing four basic tastes, namely-sweet, acid, salt and bitter. The nerve endings which give rise to these different tastes differ structurally and occupy different positions in tongue and oral cavity. Bitter substances produce the most marked effect when placed on the base of the tongue; acids when placed at the lateral edges of the tongue. Any part of the tongue will, however, appreciate any sapid substance. The intensity of the taste is proportional to the strength of the solution and to the gustatory surface acted upon. The sensation requires some time to develop and endures as long as any of the sapid substance is present. Various stimuli will cause sensations of so-called taste, as electrical currents and contact stimuli. Temperature greatly modifies this sense. Very hot or very cold substances cannot be tasted; a temperature of about $40^{\circ} \mathrm{C}$. is the most favorable. Pungent substances, as pepper, alcohol, etc., greatly obscure any gustatory sensations.

The gustatory nerves are not quickly fatigued, nor is their sensitiveness readily impaired or obscured. It is difficult to cover one taste by another, as is well known by those who are in search for vehicles or menstrua for disguising the taste of disagreeable medicines. Quinine is persistently bitter, no matter what is added to it. Salt is appreciated as long and as often as it may be applied to the tongue. 
Upon applying salt and sugar at the same time, both tastes are recognized. A very marked taste may, however, entirely obscure another faint taste.

There are a number of sensations usually recognized and designated as tastes which are purely tactile and are not due to the stimulation of the gustatory nerves. The most important of these are the so-called pungent, hot or burning tastes of the spices and the astringent taste of tannin-bearing drugs. Some authors also speak of mucilaginous, gritty, sandy and cooling tastes. These are merely tactile sensations of the tongue and mouth. Pepper, cinnamon, allspice, alcohol, garlic, onions, horseradish, are tasteless as far as the pungency is concerned.

Aromatic taste is also a misnomer. By this term is meant an odor associated with a taste or tactile sensation. For instance, in eating an apple we appreciate a sweet taste, an acid taste and an odor. This explains why fruit generally has an insipid taste to those afflicted with catarrh or bad colds. In the case of cinnamon there is a pungent tactile sensation, a sweetish taste and an aromatic odor. In the case of wine and many other alcoholic drinks there is a pungent tactile sensation, a sweet taste, an acid taste and an odor. It is evident, therefore, that aromatic tastes may be divided into true aromatic, having a true taste combined with an odor; pseudo-aromatic, having a tactile sensation usually recognized as a taste, combined with an odor; and mixed aromatic, having a tactile sensation and a taste combined with an odor. It is generally understood that the odors associated with aromatic tastes are pleasant. Such terms as aroma, flavor and bouquet, are employed in speaking of the aromatic tastes of wines and other drinks, soups, spiced foods, etc. Many of the finer aromas of wines, brandy, whisky and other substances are little understood; some are the products of distillation and others are doubtless due to subtile fermentative and chemical changes.

Many of the true taste sensations and the commonly associated tactile sensations (pungency and acridity in particular), do not develop promptly. In the case of some drugs considerable time elapses before the sensation is well developed. In a few instances the student. will conclude that the drug is tasteless, but after a time a taste or tactile sensation will develop, which becomes more and more pronounced, as, for example, the pungency of croton seed, of sanguinaria, of aconite, etc. This is doubtless due to the slow solubility of the sapid or pungent substance. In some drugs the taste is obscured by a benumbing effect, as in aconite.

In testing the taste of drugs it is advised not to use more material than is necessary. This precaution against large doses and swallowing 
will serve as a safeguard against annoying or even dangerous if not fatal symptoms from an overdose of very powerful drugs, as aconite, hyoscyamus, belladonna, strophantus, and others. The promiscuous tasting and swallowing of drug particles, though they are comparatively harmless, will often develop annoying dyspeptic symptoms. It should also be remembered that some individuals are very sensitive to the effects of certain drugs. Minute doses of nutmeg, mace and aconite have been known to produce alarming nervous symptoms.

If the drug is comparatively harmless, there should be no hesitancy about tasting a larger quantity if necessary to develop a decided sensation. From one to three grains is an average dose of the powerful drugs, as aconite, Belladonna, Digitalis, Hyoscyamus, Nux vomica, tobacco, Strophantus and others; if this is kept in mind, there need be no danger of an overdose, especially if little or none of it is swallowed.

As soon as the taste is fully developed the mouth should be well rinsed with pure water in order to remove powder particles and the taste, preparatory to testing the next drug. Some taste sensations (bitter), tactile sensations (pungency) and benumbing effects are quite persistent and not easily removed; but several rinsings with lukewarm water will usually be sufficient.

While tasting a powder the student should also note concomitant effccts, as coloration of saliva, frothiness of saliva, benumbing effects upon tongue and pharynx, mucilaginous condition, grittiness, etc.

The following classification of true tastes, so-called aromatic tastes and tactile sensations which are generally or occasionally designated as taste sensations, will serve as a review of the subject.

\section{Tastes of Vegetable Drugs}

A. PURE TASTE SENSATIONS.

I. Pleasant or agreeable.

1. Sweet (pleasant in all degrees of concentration)-Sugar.

2. Salty, Saline (agreeable in weak solutions; disagreeable in strong solutions) - Salt.

3. Acid, Acidulous, Sour (agreeable in weak solutions; very disagreeable in strong solutions) - Vinegar.

II. Disagreeable.

1. Bitter (disagreeable in all degrees of solution)-Quinine.

B. AROMATIC TASTE SENSATIONS (ASSOCIATIONS OF TRUE TASTES AND TACTILE SENSATIONS WITH PLEASANT ODORS).

I. True Aromatic Sensations (a true taste sensation, usually acid or sweet, associated with an agrecable odor)-Many fruits, candies. 
II. Pseudo-Aromatic Sensations (tactile sensation associated with an agreeable odor)-Cloves.

III. Mixed Aromatic Sensations (true taste sensations and tactile sensations associated with agreeable odors)-Some fruits, cinnamon.

C. TACTHE SENSATIONS DESIGNATED AS TASTE SENSATIONS.

I. Pungent, Acrid, Hot, Sharp, Biting, Burning (quite generally designated as taste sensations; found with many drugs and all of the spices)-Pepper.

II. Astringent, "Puckery" (usually designated as tastes, and observed in many drugs, usually due to tannin; often associated with a bitter or acrid taste)-Alum, green persimmons, nut galls, some barks, etc.

III. Mucilaginous (quite generally designated as a taste sensation)Slippery elm bark.

IV. Cooling refreshing (more generally spoken of as "sensations;" often associated with acid tastes and pungently aromatic drugs, as the mints)-Cool ærated water, menthol.

V. Sticky, Gummy (quite génerally designated as "feels")-Due to the presence of gums, resins and wax.

VI. Sandy, Gritty (generally designated as feels)-Due to the presence of sand particles, stone cells (the rind of the pear) and other minute hard particles.

Some taste sensations are not primarily due to sapid substances. For example, the slightly sweet taste of drugs and other substances rich in starch is due to the action of ptyalin (the ferment of saliva), which has the power of converting starch into sugar. As with odor, it is not advisable to taste many drugs in rapid succession; not that the gustatory nerves are easily fatigued, but because one taste sensation should be entirely removed before the second drug is tasted. The socalled pungent tastes are especially difficult to get rid of and slow to disappear, as, for instance, those of croton seeds, sabadilla and mezereum. Some sapid substances require time to enter into solution; hence in hasty work two or three drugs might be tested as to taste before the sensation of the first drug has had time to develop. With some persons reflex dyspeptic symptoms develop after tasting five or six drugs in comparatively rapid succession. More or less painful irritation of lips, mouth and tongue may also follow from the repeated tasting of drugs.

The following is a grouping of the more common vegetable drugs according to taste. The student must keep clearly in mind that the 
taste of drugs varies quantitatively and qualitatively with the change in the chemical constitency of the sapid substances.

In this classification, astringency and pungency are treated as taste sensation, though, as already stated, they are tactile sensations. Odors should be kept distinct from tastes; hence aromatic tastes is a misnomer which should be avoided. Mucilaginous state, grittiness, cooling sensations, etc., must be considered as pure tactile sensations. Many of the mixed tastes cannot be definitely described.

The following is a tabulation of the simple tastes (inclusive of astringency and pungency) and mixed tastes as they occur in the more common dried vegetable drugs:

I. Simple tastes.

1. Sweet.

2. Saline.

3. Acid.

Primary taste sensations.

4. Bitter.

5. Astringent. Tactile sensations

6. Pungent. $\}$ generally described as tastes.

II. Mixed Tastes.

1. Sweet-acid.

2. Sweet-bitter.

3. Sweet-acid-pungent.

4. Sweet-bitter-pungent.

5. Sweet-pungent-astringent.

6. Sweet-bitter-astringent.

7. Sweet-bitter-astringent-pungent.

8. Sweet-pungent.

9. Saline-bitter.

10. Bitter-pungent.

11. Bitter-astringent.

12. Bitter-pungent-astringent.

13. Pungent-astringent.

\section{Drugs with Simple Tastes}

I. Sweet-Althæa, Cassia fistula (pulp), cereal coffee, dextrin, Taraxacum (very faint), Triticum repens, starches.

II. Saline-Chondrus crispus. A pure saline taste is rare. Even in Chondrus the saline taste is associated with a bitter taste. Many leaves and flowers have a more or less decided saline taste.

III. Acid-Rhus glabra, vanilla. 
IV. Bitter-Absinthium, Angustura, Anthemis, Apocynum, Aspidosperma, Aurantium flor. (slightly pungent), Berberis, Bryonia, Carthamus (saliva yellow), Cetraria, Chamælirium, Chirata, Cichorium, Cocculus, Colocynth, Conium, Crocus (saliva yellow), Digitalis, Erythroxylon, Gelsemium, Hydrastis, Ignatia, Lactuca, Lavendula, Lupulin, Matricaria, Marrubium (also saline), Menispernum, Nux vomica, Pareira, Populus, Quassia, Rhamnus purshiana, Scoparius, Staphisagria, Stramonium leaves and seeds, Strophantus, Sumbul, Thuja, valerian.

V. Astringent-Areca, Castanea, Galla, Gaultheria, Geranium Krameria, Santalum rubrum.

VI. Pungent-Cantharides (animal drug), Capsicum, Cardamom, Caryophyllus, coriander, coto bark (somewhat bitter), croton seeds, Gubeba, Hedeoma, Lobelia, mace, Mentha, Methysticum, Mezerion, Myrica, Pimenta, Piper, Sinapis, Zingiber.

\section{Drugs with Mixed Tastes}

I. Sweet-Acid-Vanilla.

II. Sweet-Bitter-Amygdala, Dulcamara, Frasera, Frangula, gentian, Lappa, Scutellaria, Spigelia, Taraxacum(?).

III. Sweet-Acid-Pungent-Illicium.

IV. Sweet-Bitter-Pungent-Belladonna root, Caulophyllum, Colchicum corm, Convallaria, Cypripedium, Euonymus, juniper berries, hellebore, Podophyllum.

V. Sweet-Bitter-Astringent-Cichorium (roasted), Rosa centifolia.

VI. Sweet-Bitter-Pungent-Astringent-Aspidium.

VII. Sweet-Pungent-Aconite, Anisum, Carum, cinnamon, Fœniculum, Glycyrrhiza, Hydrangea, 'Jalapa, Phytolacea fruit and root, senega.

VIII. Sweet-Pungent-Astringent-Cinnamon (Saigon), sassafras bark.

IX. Saline-Bitter-Marrubium and some other leaves and flowers.

X. Bitter-Pungent-Arnica, Asarum, Asclepias, Aurantium flowers and peel, Belladonna leaves, Brayera, Calamus, Canella, Cascarilla, Chenopodium, Colchicum seed, coto bark, Curcuma-Delphinium, Eucalyptus, Grindelia, Hyoscyamus leaves and seeds, Iris flor., Juglans, Leptandra, Matico, Pilocarpus, Piscidia, Pyrethrum flowers and root, rosemary, Sabadilla, Sanguinaria, Santonica, Scilla, Serpentaria, Stillingia, tobacco, Tanacetum, Veratrum viride, Xanthoxylum. 
XI. Bitter-Pungent-Astringent-Eucalyptus, Myrica, Myristica, Tanacetum.

XII. Bitter-Astringent-Caffea, Chimaphila, Cinchona, Cornus, Eupatorium, Granatum bark, Guarana, Humulus, Melissa, Prinos, Prunus virg., Quercus, Rheum, Rubus, Rumex, Salix, Thea, Theobroma, Viburnum op. and prun.

XIII. Pungent-Astringent-Gossypium, Quillaia, Rhus toxicodendron.

The following drugs are practically tasteless when thoroughly dried:

1. Carbo animalis (entirely tasteless).

2. Carbo ligni (entirely tasteless).

3. Cetraria (slightly bitter).

4. Cydonium (sweetish and very mucilaginous).

5. Erythroxylon (somewhat pungent and benumbing).

6. Guaiacum (somewhat pungent).

7. Kamala (entirely tasteless).

8. Linum (bitterish and mucilaginous).

9. Lycopodium (entirely tasteless).

10. Physostigma (entirely tasteless).

11. Santalum rub. (entirely tasteless).

12. Sassafras pith (mucilaginous).

13. Taraxacum (practically tasteless when old). 


\section{THE QUALITY AND PURITY OF VEGETABLE DRUGS FROM THE STANDPOINT OF THE PURE DRUGS ACT}

\section{The Pure Drugs Laws}

Through the efforts of a few public-spirited men backed by the American public we now have a national pure food and drugs law. This law went into effect June 30,1906 . There is no single legislative act of recent times which equals this in importance. With this law as a guide the several states have enacted similar laws. In addition to this we have city ordinances which likewise have more or less supervision as regards the quality and purity of foods and drugs. If the letter of the law or laws were followed we should have nothing but foods and drugs of absolute purity and of the highest quality but in spite of all legal restrictions, adulteration continues to be practiced. In fact as the prohibitory measures become more and more stringent the methods of those who sophisticate and misrepresent become more and more subtle. The chief benefit of the law is that it makes it possible to punish offenders. Mere legislative enactment will not stamp out the pernicious methods of the sophisticators; for the lawbreakers existed before the law and it is they who made it necessary to formulate a law to hold them in chreck.

Under the pure food and drug laws, federal and state laboratories have been established in which much good work has been done. Offenders have been fined and otherwise punished as provided by the law. But after all, the chief work thus far has been of an educational nature. Rulings and decisions by the Department of Agriculture have been issued from time to time which serve as guides of conduct and give information of the highest importance. Numerous papers of instruction and lay constructions of the law have been published in the pharmaceutical journals. Findings and notices of judgment have been reported, etc., all of which is intended to teach and advise those concerned in such a way as to make it easier for them to conform to the requirements of the law. Many technical offenders have been let off with a warning when it became evident that the offense was due to ignorance of the law rather than criminal intent. 
Until the advent of the pure drug laws, adulteration and substitution of crude and powdered drugs was sufficiently common to make the expected physiological or therapeutic effect of drugs most uncertain and to create doubt in the mind of the physician. This lead physicians away from the use of drug store preparations and induced them to use the preparations of the large manufacturing houses, the proprietaries and even patent remedies. Large manufacturing houses have the necessary equipment to assay, test and standardize the drugs and preparations manufactured. Many of the proprietaries are carefully tested physiologically and thereapeutically before being placed on the market. It is, therefore, not surprising that the physician should prefer these preparations of guaranteed origin and composition and activity to the preparations put up by a druggist who has perhaps never studied the science of pharmacy and who is wholly incapable of testing the drugs which he handles. When competent pharmacists shall have gained the confidence of physicians then the business and profession of pharmacy will receive better recognition.

With the progress in science, the former crude methods of sophistication have been largely abandoned. Wooden nutmegs, coffee beans of pressed clay and starch, imitation eggs, cabbage leaf and corn silk tobaccos, etc., are things of the past. Spices appear to be most peculiarly suited to the work of the sophisticators. Black pepper, capsicum and mustard are very frequently adulterated. Wheat flour with curcuma is a most common adulterant of mustard. Wheat flour and cornmeal are added to capsicum. Ground cinnamon, nutmeg, pepper, allspice, and other spices are often of very inferior quality though no foreign substances are added. Teas and ground coffee are likely to be adulterated. The former may have exhausted tea leaves, the leaves of old plants, the leaves of Japanese tea (Thea japonicum), foreign leaves, etc., the latter may contain chicory and other roots, coffee shells, nut shells, figs, prunes, cereals, etc.

The sweepings, trimmings and refuse of vegetable drugs are mixed with powdered drugs where these additions are less likely to be detected. Other forms of adulteration will be described in another chapter. Under the law any importer may bring into the United States such articles as Bombay mace, clove stems, pyrethrum stems, olive pits, cocoanut shells, peanut shells, senna siftings, senna with stems, buchu with stems, cubeb with stems, mallow leaves, licorice trimmings, inferior gum tragacanth, all manner of substandard and adulterated and wholly inferior drugs labeled "for technical use only," etc., etc. If these articles are correctly declared at the port they cannot be refused entry, no matter how certain it may be that said articles will 
subsequently appear in interstate and intrastate commerce as adulterants, even bearing the U. S. P. or other high standard label. These articles above named have been found on the Pacific Coast, distributed as follows: Bombay mace, sold as true mace or mixed with true mace; clove stems as a common adulterant of cloves; powdered pyrethrum stems sold as high grade Dalmation and Persian insect powder; ground olive pits and cocoa shells as the adulterants of black pepper, of nut galls, of cloves, of allspice, etc., ground peanut shells in spices, senna siftings, senna with stems, buchu with stems and cubeb with stems, etc., bearing the U. S. P. label. Mallow leaves are added to Origanum and other leaf spices and to the herbaceous drugs. To such an extent is marjoram adulterated that some spice dealers have decided to take this article off the market rather than take the risk of marketing an adulterated article.

Sections 6,7 and 8 of the federal food and drugs act reads as follows:

SEc. 6. - That the term "drug" as used in this Act, shall include all medicines and preparations recognized in the United States Pharmacopcia or National Formulary for internal or external use, and any substance or mixture of substances intended to be used for the cure, mitigation, or prevention of disease of either man or other animals.

SEC. 7.-That for the purpose of this Act an article shall be deemed adulterated:

In the case of drugs:

First. If, when a drug is sold under or by a name recognized in the United States Pharmacopœia or National Formulary, it differs from the standard of strength, quality, or purity, as determined by the test laid down in the United States Pharmacopœia or National Formulary official at the time of investigation: Provided, That no drug defined in the United States Pharmacopœia or National Formulary shall be deemed to be adulterated under this provision if the standard of strength, quality, or purity be plainly stated upon the bottle, box, or other container thereof although the standard may differ from that determined by the test laid down in the United States Pharmacopœia or National Formulary.

Second. If its strength or purity fall below the professed standard or quality under which it is sold.

SEc. 8. - That the term "misbranded," as used herein, shall apply to all drugs, or articles of food, or articles which enter into the composition of food, the package or label of which shall bear any statement, design, or device regarding such article, or the ingredients or substances contained therein which shall be false or misleading in any particular, and to any food or drug product which is falsely branded as to the State, Territory, or country in which it is manufactured or produced.

That for the purposes of this Act an article shall also be deemed to be misbranded:

In case of drugs:

First. If it be an imitation of or offered for sale under the name of another article.

Second. If the contents of the package as originally put up shall have been removed, in whole or in part, and other contents shall have been placed in such 
package, or if the package fail to bear a statement on the label of the quantity or proportion of any alcohol, morphine, opium, cocaine, heroin, alpha or beta eucaine, chloroform, cannabis indica, chloral hydrate, or acetanilide, or any derivative or preparation of any such substances contained therein.

In August, 1912, Congress adopted a measure which is a most important addition to the act of June 30,1906 , and which reads as follows:

"An article shall be deemed misbranded if its package or label shall bear or contain any statement, design or device regarding the curative or therapeutic effects of such article or any of the ingredients therein, which is false and fraudulent."

This law is especially directed against proprietary remedies and socalled patent remedies. In addition to the Service and Regulatory Announcements of the Bureau, the Department of Agriculture has from time to time issued rulings and interpretations of the food and drugs act which should be consulted by those interested. The Department has also issued legal definitions or standardized descriptions of food articles, drugs and spices, which have been quite generally adopted as standards by the several states in the administration of the state food and drugs laws.

The Federal Pure Food and Drugs act is administered by the Bureau of Chemistry of the Department of Agriculture, Washington, D. C Appointment to any position in the Bureau is under the United States civil service rules and regulations; and the educational and special training requirements for this department of the government service are unusually high. Those in the laboratory division must, as a rule, hold university degrees, or the educational equivalent thereof, must have done graduate work, and must have specialized along the lines of the work to be done. Examinations for vacancies to be filled, are held from time to time, throughout the United States, and to which all citizens are eligible, provided they can meet the educational and other requirements.

The United States Treasury Department coöperates with the Department of Agriculture in the enforcement of the pure food and drugs act, but this coöperation is rather loose. The treasury department is primarily interested in the proper fixing of the tariff and revenue schedules, and the work done in the analytical laboratories of this department pertains to questions of tariff rates, rather than purity and quality.

There is also a certain coöperation between the Bureau of Chemistry and the Bureau of Animal Industry, the latter giving the major attention to animal food products, meat inspection, etc. Even here the coöperation is not as close nor as harmonious as it should be. 
Since the adoption of the federal pure food and drugs act, every state in the union has adopted a similar act, usually a close copy of the federal act, and administered by some state commission, bureau, or department. The state administration is not uniform. In one state the law is administered by the Board of Health, in another by the Dairying Commission, in another by the Veterinary Commission, in another the work is divided, the pure food law under the Board of Health, while the drugs law is under the Board of Pharmacy. Some states administer the law excellently, while others administer it very laxly or indifferently. Some states have an equipment which cannot be excelled, while in other states the equipment is wholly inadequate.

The coöperation between state and federal authorities is, as a rule, quite close.

The following is an outline of the Bureau of Chemistry machinery which is operative in enforcing the Pure Food and Drugs Act of June 30, 1906, and all amendments thereto.

Chief and Assistant Chief of the Bureau, at Washington.

Two Chief Chemists, one for foods and one for drugs, at Washington.

Chief of the Micro-Chemical Laboratory, at Washington.

Chief Chemist in charge of the Main or Check Laboratory, at Washington, with a corps of assistants.

Analytical Laboratories, at the larger ports and commercial centers in the United States. Each laboratory has a chief of the laboratory or station chief.

Analysts, mostly chemists, with an occasional microanalyst and bacteriologist.

Chief Inspector, at Washington.

Corps of Inspectors. These are assigned to the various laboratories and their work was formerly directed by the chief of inspectors in Washington.

United States District Attorneys and assistants, in different judicial districts, who direct the court proceeding against violators of the law.

Pharmacognosists and other Specialists, usually attached to one of the sub-laboratories or station laboratories.

The inspectors are empowered to secure samples of drugs and medicamenta presented for entry at any port or such as are intended for interstate commerce. Federal inspectors have no jurisdiction over articles intended for intrastate commerce only. Three samples of each article are taken, all duly sealed, numbered (Inspector's serial number-I. S. No.) and recorded. One sample is left with the firm 
from whom the samples were secured, another sample is taken to the station laboratory, and the third sample is shipped to the Washington check laboratory. The firm may have the sample which was left with them analyzed by an analyst of their own choice. If the findings of the station laboratory analysts show that the article was adulterated, this information is forwarded to Washington. If the check analysis carried on in the Washington laboratory confirms the findings of the sub-laboratory, then the firm or dealer is given a preliminary hearing at the station laboratory, before the chief of said laboratory. If the firm or dealer cannot explain satisfactorily why an adulterated article should have been in their possession, said firm is fined, or if the charge is contested, the firm must stand trial before a judge or jury, as defendant may elect. If the firm loses the case, said firm must, as a rule, pay a fine and the cost of the trial. The chief of the laboratory at which the sample was analyzed, the analyst or analysts who examined the sample, and the inspector who took the sample, are usually required to appear as witnesses, in behalf of the government.

The fact that the work of the inspectors was directed from the Washington office proved unsatisfactory. The clerical and administrative work at the Washington office soon became heavily burdened by the many station laboratories, who were not allowed to act without authorization and direction from Washington.

With the object of harmonizing and unifying the work of the inspectors and the several station laboratories, the United States has been since (1914) divided into three inspection districts, the Eastern, the Central and the Western district, each in charge of a district chief who has immediate supervision of the work of the laboratories, as well as that of the inspectors, in his district. Under this plan, the inspectors and laboratories of each district are independent of the other districts and are directly responsible to the central office at Washington. The district chiefs conduct preliminary hearings and carry on much of the business which was formerly assigned to the central office. However, all of the work done by a district chief is subject to review in Washington; nor can a district chief institute a prosecution, nor order a seizure, without authorization from the central office.

The district boundaries are as follows. Eastern District.-All U. S. territory east of a boundary line extending along the western boundary of Pennsylvania, of Virginia, the westerly boundary projection of West Virginia, of North Carolina, of Georgia, and including all of Florida in the eastern district. Western District.-All territory (inclusive of the Philippine Islands) lying west of a boundary line 
extending along the castern boundaries of Montana, Wyoming, Colorado and New Mexico, leaving all of Texas in the Central district. Central District.-All of the territory lying between the two boundary lines given.

The western district laboratories are located at San Francisco, Denver, Seattle and Honolulu, the main district laboratory being at San Frăncisco. The central district laboratories at Chicago, St. Paul, St. Louis, Cincinnati and at New Orleans, the main laboratory being at Chicago. The eastern district laboratories are at New York, Boston, Buffalo, Philadelphia, Savannah and San Juan, the main laboratory being at New York.

The following tabulation and chart indicates the location of the laboratories.

\section{Location of Laboratories}

1. Main, control or check laboratories at Washington, D. C.Bureau headquarters.

2. District Laboratories.

A. Eastern district.

(a) New York City-District headquarters.

(b) Boston.

(c) Buffalo.

(d) Philadelphia.

(e) Savannah.

$B$. Central district.

(a) Chicago-District headquarters.

(b) St. Paul.

(c) St. Louis.

(d) Cincinnati.

(e) New Orleans.

C. Western district.

(a) San Francisco-District headquarters.

(b) Seattle.

(c) Denver.

(d) Honolulu.

Insecticides and related products are looked after by the Federal Insecticide Board, a body created by special appointment, as is also the U. S. Tea Commission which controls the tea imports, and under whose jurisdiction the tea inspections are made by expert tea tasters or testers. Under Roosevelt's administration the Food and Drug Referee Board was created, to which a number of the leading American 
chemists were appointed. It was the duty of this Board to settle certain disputed points regarding the chemical and biological principles

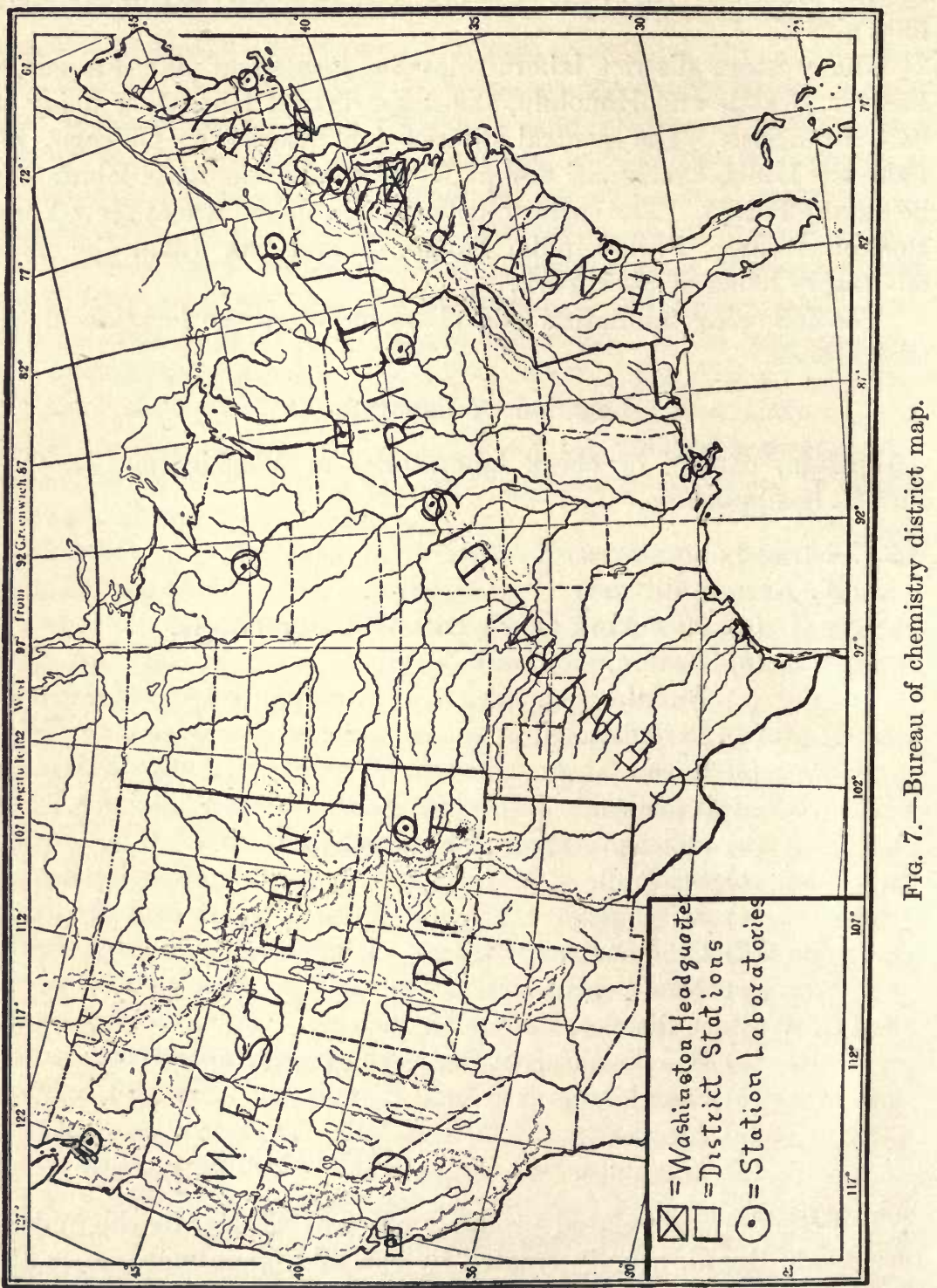

involved in the federal act. This Board gave much attention to the use of food preservatives, notably sodium benzoate. The board was discontinued on February 1, 1914, and its work assigned to the 
chief of the Bureau and to specialists to be appointed by the Bureau from time to time.

Among the specially appointed experts giving attention to crude drugs were the pharmacognosists, whose duty it was to look after the drugs presented for entry at the main ports (New York, Detroit, San Francisco). These were appointed on the per diem basis, being paid for actual time devoted to drug examination, and were attached to sub-laboratories at port cities. The work done by these experts proved quite unsatisfactory for several reasons. The pay offered was insufficient, and being on a per diem basis they could not always be on hand when important work was to be done, nor were they supplied with the equipment to do efficient work. The entire work gradually dwindled and was finally abandoned by resignation of the experts, and such work as is still carried on is now being done by a special pharmacologist or pharmacognosist, attached to the Washington laboratory.

In addition to laws governing the quality and purity of foods and drugs, copied after the federal act, many of the states have additional laws, such as cold storage acts, food sanitation acts, etc., all directed toward a better safeguarding of the public health.

Thus far the Bureau of Chemistry has centered the attention upon food products, and the various state activities authorized to administer the state food and drugs laws have likewise given the major attention to foods. There are several reasons for this. Those who are appointed to direct the work, laboratory, inspectorial and administrative, are, as a rule, comparatively unfamiliar with drugs and medicamenta, and therefore have some hesitation in entering upon the consideration of a. subject with which they have little familiarity in the comparative sense. There are indeed inspectors who have much special knowledge of drugs, and also laboratory analysts and other specialists who have. special knowledge of methods to be employed in the examination of medicamenta of all kinds, of drug commerce, of drug plant culture, of drug preparation, etc., but these specialists are rarely in a position to direct any of the administrative proceedings in the Bureau. Furthermore, foods are undoubtedly of greater importance than drugs and should receive correspondingly more attention and consideration. In some of the states practically no attention is given to drugs, beyond the occasional alcohol percentage determination in a tincture or extract. Very rarely is a drug tested or assayed chemically, and there is no equipment for making physiological assays. Patent and fake remedies are, as a rule, unmolested in every way. For a time the Washington laboratory gave considerable attention to so-called patent and the more important fake remedies. 
In mentioning the activities working in behalf of better drugs, we must not forget to mention the Council of Pharmacy and Chemistry of the American Medical Association, with offices and laboratories at Chicago. The council has adopted certain rules and regulations governing the admission of proprietary articles manufactured by reliable manufacturing houses into the annual publication of the council, "New and Nonofficial Remedies." The council also tests and exposes fake remedies and the results of such investigations are published in the Journal of the American Medical Association.

There should be a well-defined coöperation between Federal and State laboratories. Federal inspectors should play directly into the hands of the state inspectors and vice versa. In this way it would be possible to trace all suspicious importations to their final destiny. This is especially important because of the double or sub-standard clause in the law. Under the law there is no restriction on the importation of clove stems (even though declared to be for the sole purpose of adding to cloves to the extent of 5 per cent., which the law allows), of ground olive pits when declared to be intended as a base for chicken feed, or for some other legitimate purpose; of inferior belladonna leaf and stems (when low quality is correctly declared), etc., etc. The final destiny of such importations should be ascertained by the state inspectors after being released by the customs officials and out of the jurisdiction of the Federal authorities, in order that it may be ascertained what use is made of them. The chances are that the clove stems and the ground olive pits finally serve as adulterants of spices and drugs, and the inferior belladonna, cinchona, aconite and other drugs finally reach the retail drug store labeled "superior quality drugs," even bearing a false high-standard assay label under a guarantee.

The sub-standard clause should either be stricken out or it might be changed to read as follows: "However, no drug defined in the United States Pharmacopœia or the National Formulary shall be deemed adulterated under this provision if the standard of strength or quality be plainly stated upon the package thereof, although the standard or quality may differ from that determined by the tests laid down in the United States Pharmacopœia or National Formulary provided, that such deviation from the official standard is not due to foreign admixtures of any kind, and provided the label bear a statement of compensatory correction for making official preparations therefrom." As the law now reads there is nothing to prevent mixing a standard or super-standard drug with some foreign material, thus increasing the bulk very materially and yet conforming to the required 
legal assay standard. Again, the micro-analyst may find the drug mixed with 30 per cent. flour and yet it cannot be declared adulterated, because the added material is harmless and because the assay determination will show it to be up to the declared and required standard. In other words, the law permits adulteration, provided the label so states. That is, it is perfectly legitimate to add sand, flour, starch, nut shells and other harmless or inert substances to such drugs as aconite, belladonna, hydrastis, strophantus, etc., provided it is so stated on the label. There is no doubt that a sub-standard quality clause is necessary, but it should, by all means, be so changed as not to permit or encourage adulterations, even if of a harmless nature. There are certain drugs which (unless sophisticated as above) cannot have sub-standards, as chemicals generally, oils, alcohol, etc. But drugs of vegetable origin may be wholly free from foreign admixture and yet fall below the United States Pharmacopœial standard as determined by chemical assay and other methods of testing, and it would no doubt work unnecessary hardships to exclude these.

The guaranty clause under the Federal law has often been wrongly comprehended. To federal and state officials it signifies absolutely nothing as far as such guarantee might be a guide or indication of the purity or quality of the articles so guaranteed. Legally, in the enforcement of the pure drugs law, the guaranty has been of importance. Without it the responsibility would in all instances have to be fixed upon those in whose possession the adulterated articles were found, whether or not the possessors of such articles were in any wise blamable. The retail dealer who does not test his drugs as to purity or who does not make sure that he is dealing with reliable wholesale houses, should be punished if inferior or adulterated drugs are found in his possession. The wholesale dealer and manufacturer who fails to supply pure articles to the retail dealers should be doubly punished.

According to a decision signed by the secretaries of the Department of Agriculture, of the Treasury Department and of Commerce, the guaranty statement under the federal law was abandoned May 1st, 1916. The reasons for this decision are perhaps apparent without any explanation. It is generally known that the guaranty statement was misused by the unscrupulous and generally misunderstood by the laity. Most of the laity were of the opinion that the guaranty statement was an actual guarantee that the articles bearing such labels were pure and wholesome. Others believed that the Department of Agriculture had examined such articles and stood sponsor for their quality and purity. This decision greatly simplifies the enforcement of the federal pure food and drug act. 
Most of the vegetable drugs used in the United States enter via the port of New York. It is, reasonable to suppose that the importer would strive to please the customers nearer the port of entry and the center of business; thus, as a perfectly natural consequence, the articles of more or less inferior quality or those of second choice, fall to the more remote customers. Most dealers deny that they handle a first and a second quality article, but such is nevertheless the case.

The Department of Agriculture has appointed special drug examiners, who are stationed at the several ports of the United States with instructions to carefully examine all drugs appearing at the ports of entry. This is being done, and yet a goodly percentage of drugs now found in the United States are adulterated. This can be explained in several ways. It may be that a consignment which was found to be adulterated and which was rejected by the special examiner was simply reimported at some other point and thus entered into the trade. It is also probable that in some instances hasty floor inspection without careful micro-analytical verification, is responsible for the admission of some adulterated vegetable drugs. This is especially likely with such drugs as belladonna, scopola, hyoscyamus, stramonium and certain of the barks, as coto, cinchonas, cascaras and a few others. In the case of these and of other drugs having no marked distinguishing macroscopic characteristics, the microscopic verification should never be omitted. Of course, in the case of all broken, ground, powdered and otherwise reduced or fragmentary drugs, the microscopic examination is all important.

A drug may be of prime quality and reach the retailer in excellent condition, and yet be entirely worthless by the time it reaches the consumer (the patient). This worthlessness may be due to prolonged though normal ageing, or the deteriorating process may have been hastened by climatic conditions, inadequate packing and storing and by attacking insect parasites and mold. Containers have been found in retail stores which had not been opened for five years or more. Again, the contents of some containers resembled a fertilizer, having been completely decomposed by bacteria and higher fungi. In other instances the entire storeroom was overrun by insect parasites which had honeycombed the crude drugs and rendered them unfit for use. The following are a few suggestions on how to remedy certain defects quite commonly met with in retail drug stores and how to meet the requirements of the pure drugs enactment, state as well as federal.

1. Moldy Drugs. - The prevalence of moldiness in powdered drugs is due in part to the moist atmosphere and partly due to the fact that, as a rule, there is no suitable arrangement to warm and dry out the 
drug stores. Stoves, hot air furnaces, steam and hot water plants will serve the purpose. A dwarfed wood stove back of the prescription counter, in which an occasional paper box, newspaper, wrapping paper or small pieces of pine boxes are burnt, will not answer the purpose. The store needs a heating device which is kept in operation every day not only during the winter months but also during moist and rainy weather throughout the year. Keep the drug store dry and the mold will not appear. Moldy drugs are unfit for use.

2. Insect Parasites. - The persistent and general presence of insect pests (weevils) simply indicates that things are not just right. The building may be old and rotten or the containers may be old. Anyway, the containers need cleaning, scalding, drying out, etc. Not only must the weevils and their larvæ be destroyed, but their eggs as well. There should be no cracks in floor, in walls, partitions. Perhaps the walls need a coat of calsomine or new paper and the woodwork a new coat of paint or varnish. Never place a drug in any container until there is absolute certainty that all insect pests, including larvæ and eggs, which may be present, are destroyed. To place a fresh drug in a container which held an infested drug, without first cleaning it as suggested, simply results in the immediate infection and destruction of the new supply.

3. Old Drugs.-The rate of deterioration of crude and powdered vegetable drugs varies but it may be stated as a general rule that crude and powdered vegetable drugs, as well as all preparations made therefrom, are wholly unfit for use at the end of three years. Old materials of this kind should be destroyed, even though they may have been of prime quality originally. Retailers should not secure more drugs and make more preparations than they can use within a reasonable time, say on an average in one year. Many substances used medicinally will of course keep for a much longer period, as chemicals generally; but no means have yet been found to prevent the neverceasing gradual deterioration of vegetable drugs and their preparations. Never purchase an old store stock, no matter how low the price asked. Secure a fresh stock and start in right.

4. Guaranties.-As already stated the federal guarantee statements were discontinued May 1, 1916. It is, however, likely that manufacturers, importers and dealers will continue to furnish their own guarantees. A wise rule for the retail pharmacist to follow is not to accept any guarantees on faith; for, guaranties are not necessarily evidence that the articles are pure or up to standard, but every retail dealer should see to it that every guaranteeable article which he purchases is guaranteed, as this shifts the legal responsibility 
from him to the one giving the guarantee. The pharmacist should be prepared to test all of the drugs which he handles as to their quality and purity.

\section{U. S. P. Standards and Definitions of Standards}

There has been considerable confusion regarding the names of drugs and the U. S. P. standards of quality and purity. It would be highly desirable to formulate suitable legal definitions which would serve as standards under the pure drugs laws, national and state.

The present U. S. P. and N. F. definitions are in many instances unsatisfactory as a guide for those who are called upon to enforce the law. The chief source of the confusion and misunderstanding is due to the fact that it is difficult to harmonize the archaic legal phraseology with modern scientific terminology.

The Bureau of Chemistry has from time to time formulated standard definitions, largely of spices and food products concerning which dispute has arisen in court proceedings, which definitions are published in the Service and Regulatory Announcements. So far the Bureau has not seen fit to change the U. S. P. and N. F. definitions (purity rubric), but attempts have been made, through inquiry among specialists in pharmacy and pharmacognosy, to arrive at better definitions regarding some of the drugs of vegetable origin. The federal Insecticide Board has given a standard definition for insect powder and for other products over which this board has jurisdiction. The federal Tea Commission fixes the tea standards and the Bureau of Animal Industry looks after animal food standards.

The following definitions are believed to harmonize with the U.S.P. and N. F. purity rubrics and the legal interpretations put thereon by the Bureau of Chemistry.

1. U.S.P.Drug Defined.-Any drug bearing the name of the United States Pharmacopoia, whether it is the true Latin or common name, the latinized U. S. P. name, the common U. S. P. name, the technical U. S. P. name, or any non-pharmacopœial name in common use and commonly applied to the U. S. P. drug, must comply with the U.S. P. requirement as to quality and purity. Unless such article bear some other truthful qualifying label, indicating its deviation from the U. S. P. standard or quality, it is legally and actually presumed to be a U.S. P. article. To illustrate: the words senna, senna leaflets, Cassia acutifolia, African senna, senna leaves, Alexandrian senna, are all lawfully and properly applicable to the U. S. P. senna obtained from Africa. These terms refer to the leaflets (exclusive of stems, pods, seeds and 
other foreign material) obtained from a plant botanically known as Cassia acutifolia.

The state of comminution of the drug has in no wise any bearing whatsoever upon the U.S. P. requirement of quality and purity of said drug. To illustrate: whole senna leaf, three-quarter senna, half senna, broken senna, sifted senna, blown senna, hand-picked senna, powdered senna, senna for percolation, senna for manufacturing purpose, etc., is presumed to be U. S. P. senna. Senna with stems, senna with sand and pebbles, Aden senna, American senna, senna siftings, senna stems, senna dust, senna refuse, senna dirt, senna pods, senna with pods and seeds, are not senna U. S. P. and anyone selling these articles for senna or for senna U.S.P. is guilty of a misdemeanor. The U. S. P. declarations of the identity, quality and purity of drugs are very clear and very simple and the U. S. Department of Agriculture has been very liberal in the interpretation of the U. S. P. purity rubric.

2. U. S. P. Label.-Adding the label U. S. P. to any drug of the U. S. P., shall be construed as meaning that the drug to which said letters are applied, does comply with the purity and quality requirement (purity rubric) of the U.S. P., irrespeetive of the state or degree of comminution of said drug and also irrespective of the methods or processes of collecting, garbling or drying which may have been employed to prepare such drug for the market.

3. Omission of U. S. P. Label.-Omitting the U. S. P. label from any drug of the U.S.P., without any specific declarations to the contrary, shall in no wise release such drug from the U. S. P. purity rubric requirements, no matter by what name such drug may be designated (as scientific name, technical names, trade names, common names of any language whatsoever, etc., etc.).

4. Non-pharmacopæial Drugs.-All drugs not defined or described in the U. S. P., designated by any recognizable and defining name whatsoever, shall conform to the standard of quality and purity established by usage or as determined by competent authorities; unless the label bear some additional distinctive statement of quality and purity, in which case the article must conform to the qualifying specifications added to the name.

5. Quantitative Limits of Harmless Adulterants.-Any and all substances, whether of vegetable, animal or mineral origin, even though such substances are not harmful to man or to other animals, which are. not a part of the drugs as defined in the U. S. P., shall be considered as adulterants, no matter whether accidentally present in excessive amounts, or added in any quantities whatsoever, with the intent to deceive. 
6. Quantitative Limits of Harmful Adulterants.-Any U. S. P. drug or N. F. preparation containing any foreign substance or substances, which in themselves have toxic or harmful effects, or effects different from that of the official drug or preparation, if present in appreciable amounts (as determined by chemical, or microscopical, or bacteriological tests), said drug or preparation shall be deemed adulterated, no matter whether such substances are accidentally or intentionally added or whether they have developed within or upon the drug (as bacteria, yeast cells, mold, mites and other parasites).

7. Tests for Determining the Quality and Purity of Drugs.- The test methods of the U. S. P., or desirable modifications thereof, shall be used, with such other methods (chemical, macroscopical, microscopical, and bacteriological) as may become necessary or desirable.

8. Fineness of Vegetable Drugs for Percolation.-The U. S. P. specifies the exact fineness of the vegetable powders intended for percolation. However, based upon the examination of numerous samples of vegetable drugs it is evident that many, in fact most of the commercial powders, are so variable in the degree of fineness that it is impossible to obtain uniform products from percolation. In many of the samples examined the fineness varied (in the same sample) from a very fine meal to particles from $1 / 4$ to $1 / 2$-inch in diameter or length. The U. S. P. specifies the exact fineness of leaf, root, stem, wood, flower, fruit, seed, etc., intended for percolation in the preparation of tinctures and fluid extracts, and pharmacists should comply with such requirements. The U.S.P. should specify the exact diameter of mesh and diameter of the wire, hair or other material used in sieve construction. This is a matter of great importance and should receive the prompt attention of the U. S. P. Revision Committee.

Retail pharmacists are supposed to reduce the commercial vegetable powders to the required uniform fineness, but unfortunately this is generally not done. Wholesale drug dealers could prepare the powders more readily but these also fail to do so.

To label a powder "for percolation" whether or not the fineness required by the U.S. P. is given in terms of the sieve mesh, is unlawful unless such powder is of the fineness specified by the U. S. P. for making the percolation.

9. Compensating for Loss in Drug Action.-As is generally known, drugs of all kinds lose in physiological activity and therapeutic value with age. Some tests have been made indicating the rate of such loss with regard to some of the more important crude drugs and the preparations made therefrom. Some pharmacopœias specify the time when certain drugs are to be discarded because of age. The U. S. P. 
should specify a uniform method of powdering, packing and storing vegetable drugs. Every package of a vegetable powder should have upon it a statement of the age of the crude drug from which said powder was made, date of powdering, fineness of powder, assay strength, and a scale of compensation for assay variation and for age deterioration. To illustrate: a glass stoppered glass container of one pound of belladonna root might have the following data upon a suitable label:

Roots from the crop of 1919.

Powdered November 16, 1919.

Fineness No. 60 (Standard mesh sieve).

Assay, $0.53 \%$ of mydriatic alkáloids.

Assay compensation, -17.77 per cent.

Age compensation:

End of six months, 5 per cent.

End of one year, 12 per cent.

End of two years, 20 per cent.

End of three years, 35 per cent.

End of fourth year, 50 per cent.

(Not to be used after the fourth year).

Should the drug assay less or more than the pharmacopœial standard, suitable quantity compensations should be made. All assayable drugs intended for the retail drug trade, should be assayed. This should be made a legal requirement and every package of such assayable drug should bear the correct assay statement. If the retail pharmacist were in position to use drugs standardized as above suggested, physicians could reasonably hope for better results from medication. Wholesale pharmaceutical manufactures usually assay the crude drugs which they employ, but their guarantees are based upon the proper standardization of the manufactured product itself.

10. Ash Determination of Vegetable Drugs.-By determining the ash content of vegetable drugs, particularly those in the powdered state, it is frequently possible to get valuable and useful data regarding the quality and purity of the article thus tested. An unusually high percentage of ash indicates excess of sand, clay, dirt and other inorganic impurities. The acid insoluble ash should be determined in most instances. In the great majority of drugs most of the ash is soluble in hydrochloric acid and the per cent. of acid insoluble ash is practically the per cent. of silica present (of sand, sand particles of clay and of dirt, etc.).

Thus far there has been no uniformly applied method for determining the ash percentage of organic drugs. The pharmacopœias of the different countries report the ash content of drugs in a desultory and 
erratic fashion and without specifying the methods followed. The absolute or natural ash content of a drug is obtained when the sample is free of all foreign matter, hence a thoroughly washed average sample must be used. The cleaning and washing must, however, be carefully done in order that none of the tissue may be removed and that none of the salts of the drug may be leached out or washed away and that no foreign salts may be added. A rapid rinsing and washing in distilled water (using a wicker wire holder or container) would serve the purpose. The cleaned sample must then be dried to constant weight at a temperature of $100^{\circ} \mathrm{C}$. Ashing this cleaned and dried sample gives the absolute ash percentage. This method will yield results as uniform as they can be made, taking into consideration the natural variation in different samples of the same drug. The ash percentage thus obtained would merely serve as a comparative guide to the amount of sand, dirt, clay and other inorganic impurities that may be present in the unwashed commercial sample of the same drug, making reasonable allowance for the natural, incidental and unavoidable impurities present. We will suppose that the absolute ash of an average sample of colchicum corm is 2.0 per cent. and that of the commercial sample under examination yields 5.0 per cent. with 3.0 per cent. of acid insoluble ash. It would be safe to conclude from these data that the drug was very carelessly gathered. Or it might be that the excess of ash was due to the addition of some foreign vegetable substance having a higher ash content than colchicum. The micro-analysis supplemented perhaps by chemical tests would determine the quality and purity of the drug. The ash test is in nearly all cases subsidiary and supplementary to the microscopical examination and to the chemical assay. In many instances the ashing can be omitted.

For practical purposes it is not necessary to determine the absolute ash content. Determining the ash content of the well-cleaned and garbled drug will answer all practical check purposes. The U.S.P. should state the average ash yield for each vegetable drug, giving the approximate maximum limit with the commercially unavoidable inclusions of clay, dirt and sand. 


\section{CHAPTER IV}

\section{CAUSES MODIFYING THE CHARACTERISTICS OF VEGETABLE POWDERS}

Different drug samples of the same kind vary greatly as to the gross characteristics. In many instances the deviations from the normal or type specimen are so great that the identity of the drug is not readily recognized. It is, therefore, of prime importance to be cognizant of the possible variations in the gross characters which a drug may undergo. It is necessary to enter into a consideration of those factors or influences which are capable of modifying vegetable drugs, as time and manner of collecting, curing, packing, shipping and storing; the influences of climatic conditions, of cultivation, the presence of parasites, etc. If these factors are kept in mind, the student will have little difficulty in determining whether or not a given drug is of fair quality.

A thorough knowledge of the normal drug is necessary in order to recognize the deviations from the normal. A thorough knowledge of the normal histology of a drug is necessary to a recognition of the presence of attacking hyphal fungi, additions of foreign tissues and tissue elements, etc. Naturally the factors which modify the characteristics of crude vegetable drugs also effect the powders made therefrom.

\section{Normal Variations}

By normal variation is meant such differences in different samples or specimens of the same vegetable drug as are the result of normal, necessary or unavoidable influences due to time, place and environment. Variations in size and form of crude drugs are generally not noticeable when such drugs are reduced to powder, and if the quality is unaltered, there is no reason why small, broken and otherwise altered crude drugs should not be used in the powdered form.

There is, also, considerable variation in the color of different specimens. Younger or comparatively immature plant parts are likely to assume a darker color and to shrink considerably upon drying. There are unavoidable variations in the manner of curing, packing and storing which will cause slight differences in the color and other characteristics of the drug. It would be an endless task to enumerate all of the pos- 
sible normal variations in form, size, color, odor and taste. We can only call the student's attention to their existence, and urge upon him the necessity of a careful study of the drug in order that he may recognize these slight normal variations and distinguish them from those of a more objectionable character.

The student must also keep in mind the manner in which the drug is prepared for the market. Some roots and rhizomes, as sarsaparilla, curcuma, jalapa, are exposed to high temperatures, which converts some of the starch into paste and causes the drug to become glossy, brittle and darker in color. The smoky (creosote) odor of jalapa is due to the fact that the tubers are dried over an open fire. Some rhizomes, roots and barks are partially or wholly peeled. All of these differences in crude drugs modify more or less the appearance of the powder, and this should be kept in mind in examining powders macroscopically as well as microscopically.

\section{Parasites}

One of the troubles of the practicing pharmacist is caused by the various vegetable and animal pests which infest vegetable drugs. Some of these parasites attack the drug yielding plants themselves (aphis), but the majority of them work their destructive influences after the drug has been gathered, dried and stored. Their presence greatly modifies the appearance and value of drugs; and it is, therefore, of great importance to be able to recognize the parasites or the effects which they produce. Suggestions on the methods employed to destroy them or to prevent their occurrence will be valuable.

Strictly speaking, "parasites" is a misnomer, since the pests referred to attack dead tissues, and are, hence, saprophytic in their habits instead of parasitic; but since they are quite universally designated as parasites we shall retain that term in its older, though more inaccurate application.

\section{THE VEGETABLE PARASITES}

The vegetable parasites which are found in and upon the various vegetable drugs belong to the lower forms of plant life, as bacteria, hyphal fungi and lichens. Some are present before the drug is collected, as the lichens, less rarely also the hyphal fungi, but by far the more objectionable species develop in and upon the drug after it is ready for the market. All external plant parts or tissues are exposed to the presence of a multitude of lower organisms, both plant and animal, and many of these are normally present. For instance, a 
close microscopical examination of the outer layers of barks, the epidermis of flowers, leaves, roots and rhizomes, will reveal the presence of bacteria, insect remnants, low forms of algæ, besides other foreign substances which are carried to the plants by air and water currents, and are, therefore, normally and unavoidably present and are not an indication of a poor quality or an adulteration of the drug.

\section{a. Bacteria.}

Bacteria are practically omnipresent. Owing to their minuteness they are transported from place to place by the slightest air currents. They are circulated in the soil by the currents caused by rains and the evaporation of moisture. They cling to all exposed plant parts. In spite of their omnipresence they probably do not develop in or upon dry drugs in sufficient numbers to produce any material change.

Bacteria are normally present in large numbers in some vegetable substances, as the seeds of Abrus precatorius, the leaves of Drosera and Nepenthus and the root tubercles of leguminous plants. They are abnormally present in many drugs. For instance, gum opium is mixed with bacteria of the air, dust and dirt and from the often dirty hands and instruments of the collectors. Manna, aloes, gums, solid extracts and gelatine, are among the substances which usually contain bacteria in large numbers. Some of the very important fermentative changes which take place in drugs during the various stages of curing are, in all probability, induced by bacteria. German investigators have shown that the flavor of tobacco is dependent upon the species of bacterium which causes the fermentative changes during the "sweating process." Future investigations may go to prove that the variable deterioration of stored drugs is due to the presence of bacteria which decompose the alkaloids and other active constituents.

Bacteria and higher fungi frequently cause disease, death and decay of plants and fresh vegetable substances, as, for instance, pear blight, apple blight, carnation blight, rotting of fleshy fruits, of tubers, bulbs and fleshy roots; but since only few drugs are used in the fresh state, these destructive organisms concern the pharmacist but little. One of the highly important pharmaceutical researches will be along the line of microbial decomposition changes in pharmaceuticals of all kinds and of soda fountain syrups and extracts. Thus far no one has seriously considered these vital problems.

\section{b. Hyphal Fungi.}

Hyphal fungi are higher in the scale of evolution than bacteria, and are designated hyphal because they consist of a more or less densely interwoven network of usually branching elongated (filamen- 
tous) cells known as hyphæ. There are a great many species, differing widely as to gross characteristics.

A few drugs are derived from this group of plants, of which by far the most important are Claviceps pupurea (ergot) and Ustilago maydis (corn smut). Ergot is a fungus which attacks the undeveloped seeds of rye, wheat and other cereals, the fungus displacing the grain substance entirely, developing into a structure which gradually takes on the form of a distorted and enlarged cereal grain, as of rye, wheat, barley, grass, etc. Corn smut attacks the developing seeds of Indian corn. Polyporus fomentarius (Zunder, Feuerschwamm) was formerly employed for checking hemorrhage. Impregnated with a solution of saltpeter it is still extensively employed in the outlying rural districts of certain lands for lighting fires and pipes, with the aid of flint and steel. Lycoperdon giganteum (Surgeon's fungus) is still a popular remedy in certain countries for checking hemorrhage.

In looking over a collection of leaves and herbs there will be found leaves and herbaceous stems with circumscribed areas of a dark or brown color, indicating the presence of a blight fungus which attacked the plant before the drug was collected. A careful inspection of the unpeeled tree barks may reveal the presence of black spots about the size of a pin-head; these are the apothecia of spot fungi, or perhaps of lichens, to be mentioned later. Since these spot fungi do not occur upon root barks, their absence or presence is of some diagnostic value. Since parasitic fungi are so widely distributed, one may expect to find them normally present in many drugs. The drug, however, decreases in value with the increase in the areas infected. The fungi modify or destroy the active constituents of the drug by decomposing them chemically. This applies especially to leaves and herbs; fungi rarely infest the living tree barks in sufficient numbers to seriously lessen the medicinal value.

Drugs which are slowly or incompletely dried, or which are stored in damp rooms or containers, are almost invariably attacked by hyphal fungi as well as bacteria. The hyphal fungi belong to a group commonly known as molds. They grow very rapidly; a day often being sufficient for the fungus to spread through a large collection, the hyphæ growing over the surface, into crevices and intercellular spaces, into broken cells, along the path of vascular tissue, finally spreading through the entire supply. In the case of leaves the hyphæ gain entrance into the spongy tissue and palisade tissue by way of stomata and broken epidermis. In the actively growing stage the hyphæ are white, presenting a wooly appearance. This whitish growth can readily be seen as it spreads over the drugs. There is also the very marked and 
characteristic moldy or musty odor. If left to itself the fungus finally ceases growing, due to lack of nourishment. The white color due to the presence of the living hyphæ then disappears and the attacked portions of the drug gradually assume a darker coloration. Drugs thus attacked are worthless because of the decomposition of most of the active constituents. Leaves and herbs are especially liable to be attacked by molds; to a somewhat lesser degree, also larger roots and rhizomes. Not only are crude drugs attacked by these fungi, but powdered drugs as well, also extracts, tinctures and more especially the syrups. The spores of the molds are to be found everywhere, and are carried about by air currents; hence it would be impossible to exclude or destroy the spores. It is, therefore, necessary to prevent their germination, and, very fortunately, this can be done quite readily in the case of vegetable drugs, whether crude or powdered. The greatest foes to the development of fungi, molds and baeteria in particular, are dryness, cold and sunlight. Therefore, carefully drying all vegeteble drugs and storing them in dry containers in a dry, cool and well-ventilated store-room, will prevent the development of fungi, even though the spores may be present. It is, however, not advisable to keep drugs exposed to sunlight, as that hastens the destructive changes of the active constituents:

Microscopically, the presence of a fungus, whether spot fungus or mold, is readily detected by the presence of the characteristic hyphæ, which are not readily mistaken for anything else.

\section{c. Lichens.}

Lichens are a very interesting group of plants, resulting from the symbiotic association of a fungus and an alga. They, therefore, present the histological characteristics of certain hyphal fungi and some of the lower usually single-celled algæ.

These plants never develop upon the drug itself. When present it may be known that they developed upon the drug-yielding plant before the drug was collected. They are found upon the exterior surface of some unpeeled tree barks. Lichens never develop under ground, hence they are not found upon root barks or other subterranean plant organs. Their presence is, therefore, diagnostic of stem barks, though it must not be supposed that they are found on all stem barks. They appear most commonly as circumscribed patches, varying in size and color (crustose lichens). The predominating colors being ash gray, with perhaps a greenish tinge, some are reddish yellow or orange. The apothecia may resemble those of spot fungi or they may be linear (Graphis). Sometimes remnants of foliose lichens 
(Parmelia, Physcia) are present; more rarely also remnants of fruticose forms (Usnea). The cinchona barks are especially rich in lichens, presenting a mottled appearance, due to the presence of the crustose thalli, through which the apothecia are distributed. Some of the smaller more rudimentary lichens closely resemble some of the spot fungi.

The presence of lichens is not indicative of a poor quality of the drug. If present in considerable numbers there is no doubt that a portion of the active constituents of the drug are destroyed, due to the life activities of the lichens. Since lichens are less parasitic (saprophytic) in their mode of living than fungi, they do abstract correspondingly less of the assimilation products of the host plant. The host plant serves principally as a physical support rather than a source of food, though there is little doubt that some food is supplied to the lichen by the host plant in addition to the assimilation products prepared and supplied by the symbiotic algæ (gonidia). In any case, lichens occur only sparingly upon a comparatively few stem barks and need cause no concern to the pharmacist as regards the value of drugs. They are principally of botanical interest, and, as already indicated, they are of occasional diagnostic value.

\section{ANIMAL PARASITES}

The most destructive pests to vegetable drugs are certain animals which feed upon the drugs in containers and store-rooms. Some drugs are more readily attacked than others. Those rich in starch, sugar and inulin, are especially liable to attack, no matter how poisonous they may be, as strophantus, belladonna root and aconite root.

These parasites belong principally to the insecta and aracbnida. Of the insecta the most common is Sitodrepa panicea. This is a small beetle about one-fourth inch in length, of a dull brown color. The insect passes its entire existence among the drugs. The larva hatched from the egg is a light colored grub, which feeds very voraciously upon the drug for several weeks, then pupates (resting stage), and finally develops into the sexually mature insect (imago), which also feeds upon the drug and lays the eggs from which a new generation springs. Sometimes almost the entire drug is destroyed, leaving only a thin outer shell, which crumbles to pieces under the slightest touch.

There are a number of other insect parasites which may be found among drugs. Lasioderma serricorne resembles Sitodrepa in form and habits. Ptinus brunneus is somewhat larger with long antennæ; it is similar in habits, but seems to show some preference for leaves and leafy herbs and powders. Other comparatively rare insect para- 
sites, which occasionally attack drugs, are Bostrichus dactilliperda and Anthrenus scrophulariaceae, which are more common upon furs and skins; Anthrenus varius generally attacks dried animal substances, particularly furs. Tenebrio obscurus, Calandra oryza, Tinea penionella (the ordinary cloth moth), and number of other insects may on occasion be found feeding upon drugs.

Of the arachnida, there are certain mites which occasionally attack drugs, especially powdered drugs, and such substances as sugar, starch, flour and bran. These animals are very small and closely rlated to the familiar cheese mites, sugar mites, meal mites, itch mites, etc. As a rule, they are nearly colorless, and this, eombined with their minuteness, makes it difficult to detect them in the early stages of infection. They occur less frequently than insects and cause serious trouble in isolated instances only.

A knowledge of the exact species of the parasites which may attack vegetable drugs is of secondary or minor importance. The point of real interest is that drugs, both crude and powdered, may be attacked by various animal parasites; that these parasites are often very destructive and constitute a nuisance sometimes not readily combated. If one keeps in mind that some drugs are more readily attacked than others, it will simplify the matter of watching the stock on hand for incipient evidences of the presence of parasites. If mature insects are present it indicates that the drug is infested. Looking over the infected roots and rhizomes one may readily observe small circular openings which the larva make in eating their way in or out of the drug. By means of the powerful jaws the insect converts the drug into a powder, some of which may be found at the bottom of the container or scattered through it. The grub literally destroys the entire interior of the drug, leaving only a thin outer shell which serves as a protection to the insect or larva.

The following drugs are most liable to be attacked by animal parasites: aconite root, angelicum, apocynum, asclepias, belladonna root, calamus, colchicum corm, ergot, ginger, inula, iris, jalapa, pellitory, rheum, taraxacum, squill, most of the leaves and herbs. These drugs, whether in the crude state or powdered form, should be inspected frequently and if the parasites are present, as evidenced by the presence of the insects themselves, their larvæ or the powder-like particles of the drug, the container should be emptied, the larvæ, insects and attacked specimens should be removed, drugs and container thoroughly cleaned, dried and then replaced. These watchful measures are usually all that is required, but to make sure that all of the parasites are rendered inactive, the drug should be exposed to some 
insecticide which does not destroy or modify the active constituents of the drug nor poison it. Bisulphide of carbon is perhaps the most effective insecticide. It kills the larvæ and mature insects, but does not destroy the eggs; hence several inspections are necessary after the insecticide has been used, as the eggs may be present from which new larvæ develop.

The bisulphide of carbon may be used as follows: Place the cleaned drug loosely in the container or in a roomy, dry, clean box with tight cover or lid. Pour some of the bisulphide of carbon in a flat vessel and place it in the box containing the drug, close the box and leave the drug exposed to the vapor of the insecticide for several hours or more, the time of exposure depending upon the quantity of the drug.

Pieces of gum camphor placed with the drug are said to drive away insects; it does, however, not kill them. Boxes and containers in which insect parasites have existed should be thoroughly washed and scalded in boiling water to kill the eggs that may be present and then thoroughly dried, before the drugs are replaced.

Powdered drugs may be treated like crude drugs. Larvæ and insects may, however, be more readily removed by sifting; the eggs will, of course, pass through the sieve with the powder; hence repeated inspection and perhaps repeated sifting may be necessary. The mature insects of powdered drugs usually work their way to the sides of the glass bottles and other transparent containers where they can be readily detected. The larvæ remain in the interior of the powder.

Chloroform and ether may be used like bisulphide of carbon, or it may be sprinkled over the drug directly and the container closed. These insecticides must, however, not be used too frequently or too profusely, as they undoubtedly destroy some of the active constituents.

In the majority of cases it is best to discard infested drugs, especially powders, as it is not possible to remove the insects completely without much care and trouble. Furthermore, the presence of parasites in considerable numbers is an indication that the store-room, as well as drug stock and containers, need a thorough overhauling and cleaning, in order to make it suitable for the purpose of storing crude and powdered drugs. It is difficult and practically impossible to prevent the invasion of parasites in dirty, littered store rooms having bad floors, walls and ceilings with large cracks, nail holes, nooks and corners which are never cleaned, and where the atmosphere is moist and where fresh air does not circulate, and to which sunlight has no access. The opinion that "any old corner" will do as a store-room for drugs is all too prevalent. The store-room should be dry, cool, well lighted and well aerated and spacious. 


\section{CHAPTER V}

\section{POWDERING VEGETABLE DRUGS}

As a rule it is necessary to reduce vegetable drugs to powders for purposes of extraction and for internal administration. Formerly it was quite the rule for the retail pharmacist to grind his own drugs but at the present time this work is generally done for him by the wholesale dealers in drugs. Thus the retailer is quite dependent upon the wholesaler for the quality and purity of this class of drugs. The fact that powdered drugs and spices are frequently sold at a lower figure than the whole or crude article has often raised comment. Certain inferior spices are commercially known as "grinding spices," because their inferiority (defective, small, shrivelled, worm eaten, discolored, moldy, undeveloped, etc.) is such that it would be difficult if not wholly impossible to market them in the whole state. Reducing them to a powder, or grinding them, covers these defects. Again, trimmings, broken bits, sweepings, screenings, tailings, winnowings, etc., are frequently added to the drug or spice, in the process of grinding or powdering. Adulterants are sometimes added to the milling article. These are some of the conditions which make it possible for the unscrupulous miller to sell a powdered article at a lower figure than is asked for the crude article.

1. Selection of Drugs for Powdering. - Vegetable drugs to be powdered should be of good quality, well garbled and free from dirt, dust, lime, sand and other undesirable substances. In other words, the quality and purity of powdered vegetable drugs should be equal to that of the corresponding crude drugs.

2. Preparing Drugs for Powdering.-Before crude vegetable drugs are powdered they are again dried to remove hygroscopic moisture; that is, for the purpose of rendering the process of powdering easier, as the tenaciousness of vegetable tissues increases with the amount of moisture present. It should also be kept in mind that low temperatures increase the brittleness of vegetable tissues. It might, therefore, prove advantageous to powder the drugs during very cold weather or in an artificially reduced temperature.

Since uniformity of the strength of the percolate depends largely upon the uniformity in the fineness of the powder, it is evident that 
conditions for powdering crude drugs should be as uniform as possible, especially as to manner of grinding, of sifting, as to temperature and dryness during grinding. Drying should be done at a constant moderate temperature (60 degrees C.) in order to prevent the loss of active constituents by heat. Gas ovens with thermo-regulators are most suitable.

3. Powdering. - For purposes of reducing vegetable drugs, various drug mills are used, in some instances a mortar and pestle are sufficient. Whatever the apparatus employed, it should have the desired operative effectiveness, irrespective of size and working capacity. The larger, more carefully constructed mills, however, yield the most uniform powders. It is practically impossible to prepare a uniform powder by means of pestle and mortar, although this apparatus is highly recommended by some authorities. It is a tedious process, and the more delicate tissues are reduced to a fine powder long before the more fibrous portions begin to be broken up; it is very difficult to reduce bast, tracheids, vessels and similar tissues to anything like a uniformly fine powder. Some authorities suggest that this difficulty may be overcome by separating powders thus prepared into three grades as to fineness, and in percolating to place the finest powder at the bottom of the percolator. This suggestion is, however, not practicable.

4. Sifting.-The fineness is determined and measured by passing the powders through a sieve with meshes of known dimensions. These meshes should be uniform and square and their dimensions should indicate the size of the opening, irrespective of the diameter of the wire, silk, hair or other substance employed in sieve construction. Here, again, it is found that the larger machine-operated sieves are more satisfactory than the smaller hand-sieves. Sifting should be done carefully. It is necessary to clean the sieves frequently, as very fine particles cling to the wire, silk or hair, especially at the angles, thus allowing only particles to pass through which are considerably smaller than the free mesh.

The fineness of powders is indicated by the diameter of the meshes given in the metric system or English system, representing a definite number of meshes to the centimeter or to the inch.

The homogeneity and fineness of the powder is greatly modified by the force with which the sieve is operated. Sifting lightly allows only the finer particles to pass through; upon shaking the sieve with greater force coarser particles pass through also. Sieves should be

${ }_{1}^{1}$ For description of apparatus and methods for powdering, sifting, etc., of vegetable drugs, consult a standard American work on the Practice of Pharmacy. 
kept closed so as to prevent loss of powder and also to prevent inhalation of poisonous and irritating drugs. ${ }^{1}$

5. Uniform Powdering.-All parts of the drug should be reduced to the same degree of fineness. Typical starch-bearing parenchyma is reduced to the desired degree of fineness before the more tenacious tissues, as bast, tracheids, vessels, etc., begin to be finely crushed. As the less resisting tissues become reduced sufficiently they should be removed by means of a sieve of the desired mesh, and the remaining fibrous tissues should be reduced until all will pass through the sieve. With some drugs it is possible to separate the parenchymatous, medicinally active tissues, from the fibrous and comparatively inactive tissues, as with ipecac. Some pharmacopœias recommend that this be done. It is, however, a process not readily put into practice, and hence is not generally carried out, even with the few drugs where such a process would be practically possible.

6. Mixing of Powders.-After grinding and sifting, the powder should be thoroughly mixed, in order that the comparatively active and inactive particles may be uniformly distributed; otherwise one portion of the powder might be more active than another portion. Upon standing for some time and during shipment, the heavier particles become more or less separated from the lighter particles. It is, therefore, necessary to thoroughly mix the powder again just before a portion or all of it is to be used.

7. Fineness of Powders.-The fineness of the powder will depend upon its intended use. Theoretically it may be stated that the finer the powder the more rapid and complete will be the extraction of active constituents, no matter whether the powder is intended for internal use, for alcoholic extraction, or for aqueous extraction. The active constituents occur in the cell-lumen and in the cell-walls; the individual cell should, therefore, be broken that the extractive substance, whether it be the saliva, gastric juice, alcohol, water or other menstrua, may permeate the cell-wall and occupy the cell-lumen and take up (by solution and osmosis) the medicinal principles. Theoretically, therefore, all cells, whether long, tabular or isodiametric, should be separated from each other and each cell should be broken in two. This would imply that the various drugs should be reduced to very fine powders. Such a condition exists practically in so-called meals, as flour, almond meal, insect powder and most powders intended for internal use. Upon making a microscopic examination of 'powders designated as No. 80 and No. 100, it will be found that cell groups still

${ }^{1}$ In powdering as well as sifting irritating and poisonous drugs, eyes, nose and mouth should be protected by means of a cloth or sponge. 
remain. It must also be kept in mind that the cells of different drugs vary considerably in size. Drugs from aquatic plants, semi-aquatic plants and plants growing in marshy soil, have larger cells than drugs from plants growing in dry soil; hence the powders of the former drugs need not be so finely reduced as those of the latter.

While vegetable powders cannot be too fine, from a theoretical standpoint, it is found that for practical purposes of extraction (percolation) the very fine powders or meals are not suitable as they will not allow the menstruum to pass through. The small particles pack together so closely as to check or prevent percolation. The fineness of powders must not only be adapted to the methods and agents employed in percolation, but also to the extractive it is desired to obtain.

Powders intended for internal use cannot be too fine. As regards the fineness of powders for the preparation of infusions, extracts and tinctures, it may be stated that for alcoholic extraction the fineness must be greater than for aqueous extraction, since alcohol does not penetrate and permeate cell-walls so readily as does water.

Some drugs cannot readily be reduced to a fine powder directly, as, for instance seeds rich in oil; as nutmeg, croton beans, castor beans, almonds, cardamom and other aromatic seeds. . The oil is first removed and the powdering done subsequently, or some inert substance is added, as sand, sugar, starch, or dry woody substance, which serves as a comminuting menstruum. Orange peel, lemon peel, slippery elm, mezerion, etc., are first chopped into small bits, dried and then powdered in the usual way.

The use of Lloyd's reagent (prepared kaolin) for purposes of alkaloidal extraction will have a very important bearing upon the future therapeutic use of alkaloids. This new method will no doubt also necessitate some suitable modification of powdering and otherwise preparing the drug for extraction with this reagent.

In the United States the size of the meshes of the sieves or the fineness of the powders is indicated in the English system. ${ }^{1}$ Very fine powders, exceeding 100 meshes to the linear inch, are usually

1 The U. S. P. specifies the size of the sieve mesh in terms of the linear inch but does not indicate the particular gauge wire to be used. In the construction of standard screen scale sieves, the U. S. Bureau of Standards specifies that the openings shall increase in the ratio of $\sqrt{2}$ or 1.414, the starting point being a screen having an opening of 0.0029 -inch which is the opening in a 200-mesh 0.0021 wire sieve, thence increasing the opening by $\times 1.414$ until the 1.050 -inch 0.149 wire sieve is reached. For purposes of closer grading or sizing of powders, the size of openings increase in the ratio of $\sqrt[4]{2}$ or 1.189. Such close sizing is of course wholly unnecessary for grading powdered vegetable drugs. The W. S. Tyler Company of Cleveland, Ohio, manufacture standard screen scale testing sieves. 
designated as dusted powders or meals, and are intended for internal use or other special use. Nos. 80-100 are also largely intended for internal use, but may also be employed for alcoholic percolation. Nos. 50 and 60 are more generally better suited for percolation. For aqueous extraction coarser powders are suitable, as Nos. 20-40. For decoctions, broken drugs or even entire drugs, as leaves, leaflets and some herbs, may be employed,

In Europe the number of meshes are given in the metric system. In Germany, for instance, 5 to 15 meshes to the centimeter indicate coarse powders; 20 to 25 meshes, medium; and 30 to 50 meshes, fine powders. Sieves for fine powders are usually made of silk thread, horse hair for medium powder and wire for coarse powders. For very fine meals bolting cloth is used in sifting. Powders containing acid are not passed through metal sieves, as the wire would be corroded. The fineness of the material used in sieve construction should harmonize more or less with the fineness of the powder. The hygroscopic moisture of the powder and that of the sieve threads interferes very materially with uniform sifting; hence the necessity of keeping powder and sieve dry and cleaning the sieve repeatedly. Frequent cleaning is especially required when sifting oily powders.

8. Preservation of Powders.-As elsewhere stated, powdered drugs deteriorate much more rapidly than do crude drugs; it is, therefore, urged not to powder drugs until required for use, and never to powder more than can be used within a comparatively short period of time. Some powders deteriorate more rapidly than others, just as some crude drugs deteriorate more rapidly than others. After grinding the powder should again be carefully and thoroughly dried at a moderate temperature and immediately placed in perfectly dry, wellstoppered bottles or other suitable containers. Each package or bottle of the vegetable powder should have upon it a statement of the age of the drug from which the powder was made, date of powdering and when it should be renewed and some effective method of compensating for loss of active constituents should also be adopted as has already been suggested.

9. The Characteristics of Vegetable Powders.-Since vegetable powders are readily subject to deterioration and adulteration, it is quite important that the pharmacist should be able to recognize the characteristics of pure powders. While the odor and taste are the same in quality as that of the crude drug, it should be kept in mind that these properties are less marked quantitatively. The odor in particular dissipates very rapidly. Attention should be given to fineness, consistency and weight. If powders of oily drugs are dry 
and mealy, it indicates that the oil was removed previous to powdering. If the powder is deficient in weight as compared with bulk or volume, it indicates that winnowings or a poor grade of drug were used.

The color of the powder is, of course, uniform and harmonizes more or less with the predominating color of the crude drug, but it must be remembered that the color varies greatly. For instance, exposure to light deadens the color quite rapidly, the tendency being toward grayish shades and tints. Exposure to moisture and the presence of vegetable parasites, produces shade effects. The fineness of the powders, also, greatly modifies the color, increased fineness producing tint effects. In some instances the quality of the color is even changed; for instance, powdered licorice of medium fineness is yellow, while the licorice meal is much lighter, with a decided lemon tint. Roasting produces dark to nearly black colorations. Powders made from plant parts rich in oil and fat, as cloves, almonds, larkspur, stavesacre, etc., darken rapidly, and become rancid, due to the decomposition of the fats into fatty acids and glycerin.

Powdered vegetable drugs may be grouped according to the following colors:

I. Very Light. Mostly seeds and roots.

1. White, as starches and cereal flour.

2. Very light, tinged with yellow, red or some dark substance; as althæa, orris root, colocynth, etc.

II. Yellow. Mostly roots and rhizomes. A few flowers and barks.

1. Pale yellow and straw yellow.

2. Orange yellow and lemon.

3. Brownish yellow and yellowish brown.

III. Green. Mostly leaves and herbs.

1. Grayish green.

2. Brownish green.

IV. Gray. Mostly roots.

1. Ash gray.

2. Brownish gray and dark gray.

V. Brown. Mostly barks.

1. Reddish brown.

2. Dark brown.

VI. Very dark. A few barks, as juglans. Roasted drugs.

1. Very dark, tinged with red or yellow.

2. Black, as charcoal.

Since the gross characters of powdered vegetable drugs are variable and otherwise inconstant and unreliable, the pharmacist must look to 
other and more dependable characters for purposes of study and identification. The histological elements of drugs are not materially changed, no matter what the changes in color, odor, taste and weight may be. A careful microscopical examination is the only reliable means of determining the identity of a powder, but here also difficulties are met with, as will be explained in the following chapters.

The methods of microscopic examination should be uniform for the different powders, and great care is necessary to avoid confusion. The examiner will not be able to obtain reliable results unless he is familiar with the histology of plants and has the ability to recognize different cell-forms in whatever position they may be found. For microscopic examination the most suitable fineness is No. 40 to 60 for low powers and about No. 80 for high power work. Very fine powders, as No. 100 and finer, are rarely desirable for microscopic work. 


\section{CHAPTER VI}

\section{ADULTERATION OR SOPHISTICATION OF VEGETABLE DRUGS}

It is not necessary to enter into a discussion of the various motives which lead to the practice of sophistication in pharmacy; suffice it to know that crude as well as powdered vegetable drugs are frequently placed upon the market variously adulterated. In some instances adulteration is the rule rather than the exception, as in the case of powdered cloves, mace and of other spices, powdered sarsaparilla, spigelia and aconite, etc. In recognition of such facts it becomes highly important that the practicing pharmacist should have the training requisite to detect such fraudulent work.

Naturally, those who market adulterated drugs make special efforts to conceal the fraud, and in this the misplaced ability of the unscrupulous is pitted against the intelligence of the trained pharmacist, whose duty it is to detect and expose such fraudulent practices. The uneducated and inadequately qualified pharmacist is wholly defenseless against the criminal practices of the unprincipled collector, dealer and jobber, and such unqualified pharmacists cannot guarantee pure drugs to the physician and in turn the physician is unable to give his patients the proper treatment, because, as a rule, the physician is not qualified to judge the purity and quality of the medicamenta prepared by the druggist. The sick are thus absolutely helpless in the matter.

It is evident that with the progress in pharmaceutical education adulteration decreases and the methods of adulteration become altered in accordance with such progress. Because of the closer study of crude drugs and of powdered drugs resulting from the operation of the pure drugs laws, the former crude methods of adulteration have been abandoned because of the ease with which they were detected. Some of the modern methods of adulteration, however, incite the admiration of the skilled analyst. Some clever deceptions are now being practiced. Many of the present forms of adulteration are indeed crude enough as to materials used but the actual operation of the fraud is often a skillful evasion and perversion of the law by lawyer as well as judge, against which the testimony of skilled analyst is often ineffective. 


\section{Adulteration as to Intent}

Not by any means all of the drug adulterations are premeditated and deliberately carried out with criminal intent. Ignorance plays a very important part in unintentional sophistication, and this indicates very clearly the necessity of employing technical skill for the purpose of examining all medicinal substances intended for the relief and cure of disease.

\section{Unintentional or Accidental Adulteration.}

This form of adulteration is by no means uncommon, and is due to ignorance and carelessness. In some instances the perpetrators of this form of adulteration are apparently free from blame, but in other instances the ignorance displayed is so marked and the carelessness so evident as to deserve as much condemnation as intentional deception. The following are the principal causes of this form of sophistication:

1. Ignoranice on the part of collectors who gather the wrong plant or mix the genuine drug with worthless material. This particular form of sophistication is not very common, as collectors, natives and others, usually select the right drug instinctively. Such errors are generally made by new and inexperienced collectors, but these soon learn to avoid such mistakes; furthermore, they are quite generally properly instructed by the experienced collectors.

A much more fruitful source of sophistication is carelessness on the part of collectors. Roots and rhizomes are hurriedly and carelessly gathered, an excessive amount of soil is left clinging to them, along with undesirable plant parts, and the roots, leaves, branches, etc., of smaller foreign plants. This applies particularly to the roots and rhizomes collected in America, which are, as a rule, also carelessly dried. Again, collectors are not adequately instructed as to how and when to collect. Drugs collected out of season or carelessly dried are more or less worthless.

2. Insufficient information on the part of botanists who fail to distinguish between related species and varieties. Drugs from two wholly distinct species or varieties, one of which is more or less worthless, are supposed to be identical, and are placed upon the market variously intermixed. Thus the bark of Rhamnus purshiana and of $R$. Californica has been indiscriminately gathered and marketed, aslo the barks of different species and varieties of cinchona, some of which are comparatively inert. Again, in a number of instances the botanical origin of the drug-yielding plant is unknown, as with some sarsaparillas, coto bark and some cinnamons. This form of sophistication was more common in the past. There is also great lack of reliable 
information regarding the exact influence of climatic conditions, cultivation, etc.

3. Ignorance on the part of the practicing pharmacist. The pharmacist who does not have an adequate pharmaceutical training is wholly at the mercy of unscrupulous jobbers, who will sell him their worthless material, reserving the first quality drugs for the intelligent pharmacists who cannot be duped so readily. The ignorant pharmacist will frequently purchase a cheap drug, especially powdered drugs and spices, under the impression that he is getting a first-class article at a bargain. The ignorant pharmacist is also liable to use and sell material which has become worthless through age, exposure to moisture, contamination with bacteria, hyphal fungi and other parasites.

4. Exaggeration and untrustworthy work of analytical chemists who claim to have discovered medicinal substances which do not exist at all, or only in small quantities. This is usually the case when some new remedy is vaunted. This form of sophistication is often unintentional and is primarily due to inherent human enthusiasm which naturally leads to more or less exaggeration. Opposed to the inherent tendency to make more or less exaggerated claims for new remedies is the equally inherent skepticism towards the new. The enthusiast as well as the skeptic are often in the wrong and they act as checks upon each other. In this connection it is well to mention the work of the Council on Pharmacy and Chemistry of the American Medical Association. This council has a most wholesome checking influence upon the manufacture of fraudulent remedies.

\section{Intentional or Criminal Adulteration.}

This form of adulteration is due to an utter lack of conscience. Foreign substances are added to the drugs with a view to deriving a pecuniary profit above that which comes from dealing in the pure article. Every housewife knows that powdered spices, as pepper, cinnamon, allspice and cloves, are subject to adulteration. This is of such common occurrence that it is advisable to purchase the whole spice and grind it at home. The pharmacist should apply this suggestion to vegetable drugs, in so far as that is possible. The following are the common methods and sources of criminal adulteration:

1. Intentional adulteration by collectors. The prime motive may spring from a scarcity of the drug; an effort is, therefore, made to bring the quantitative supply to the normal by adding worthless material or inferior grades. Again, the quantitative supply may not be deficient, but inordinate greed on the part of the collector leads to the addition of some adulterant for the purpose of increasing the bulk. 
2. Intentional adulteration and misbranding by dealers and jobbers. (a) Dealers may purchase inferior drugs from collectors and sell them as first-class articles. This is very common practice. Foreign material is added to the drug and sold at a price below that of the honest dealers; or (c) The dealer may maintain the price while furnishing additional bulk to be sold over and above the amount that can be sold by honest competitors.

3. Intentional adulteration by practicing pharmacists. This is of comparatively rare occurrence, as far as crude and powdered vegetable drugs are concerned. The pharmacists' chief guilt and participation in adulteration lies in the purchase and use of inferior, substandard, adulterated, and otherwise objectionable and worthless drugs.

4. Fraudulent testimony by scientists (botanists and chemists), who for financial gain, prepare fraudulent reports as to the value of new drugs and medicines or who stand sponsor for the fraudulent claims of crooked manufacturers. These so-called scientists are doubly guilty. In the first place as to their claims as authoritative scientists and investigators and secondly as to the fraudulent report of the remedy itself. Scientific men of unquestioned high standing, do not lend themselves to such practices.

In the criminal practices above outlined it is the middleman, dealer or jobber, who is most likely to prove the guilty party. The grower or collector is as a rule closely. supervised by the dealer, who will generally insist upon a genuine article at the lowest possible figure but who will not hesitate to accept low grade and adulterated drugs at a very low price and selling them to the unwary and ignorant as articles of first quality and at a first quality price. It is, after all, the intelligent practicing pharmacist who must assume the responsibility of purifying the drug trade.

\section{Manner of Adulteration}

The adulterants added to vegetable drugs vary greatly as to kind and quantity. In some instances the foreign substance is added in comparatively small quantities, so as to prevent ready detection; in other instances large quantities are added, and again there maybe complete substitution. We may, therefore, recognize partial substitution and complete substitution.

\section{Partial Substitution.}

This form of sophistication is most commonly practiced, the intention being to retain the apparently normal identity of the drug. The adulterant must, therefore, not be added in large quantities, other- 
wise the fraud is too readily detected. The amount added will depend somewhat upon the judgment and intelligence of the sophisticator. If he fears the detective powers of the pharmacist he will add only small quantities (one to five per cent., or somewhat more). In other instances he will not hesitate to add as much as fifty per cent., or even more. It is generally quite difficult to estimate the amount of the adulterant added. In the case of crude drugs it would be necessary to go through the entire collection and carefully winnow out the foreign substance or substances. This is a tedious task, but the results are quite accurate. In the case of powdered drugs the matter becomes still more difficult, as will be more fully explained in Chapter VI.

\section{Complete Substitution.}

This form of sophistication is not commonly practiced with vegetable drugs, tbough it is not at all unusual in other departments of pharmacy. It is recorded that nutmegs have been made of wood, imitation coffee beans have been made of pressed clay, cloves of roasted and pressed starch. For years Ruellia ciliosa has been largely substituted for Spigelia. Poke root is a very common adulterant of belladonna root. A mixture of tartar emetic and some inert vegetable powder has been substituted for powdered ipecac, etc. But such crude substitution is not commonly practiced. It is more usual to substitute a closely related plant or plant part for the drug itself, whether in the crude or powdered state. For instance, the western senega is substituted for the southern variety; one variety of cinchona for another; etc.

\section{Substances Employed in Adulteration}

The materials more usually employed in the adulteration of vegetable drugs may be divided into two groups; those added to crude drugs and powdered drugs and those which may be added to powders only. The material employed does not necessarily give any indication whether or not the sophistication was accidental or intentional, though in many instances it does give such evidence. For instance, if willow leaves and poplar leaves are found with tea we may safely conclude that the sophistication was criminal, as even the most ignorant collector can distinguish between tea leaves and willow leaves. If starch or flour is found in a powder normally free from starch, we may again safely conclude that the sophistication was criminal. The presence of the first year leaves of digitalis among the second year leaves may be unintentional. 
A. Organic Substances.

1. Closely Related Plants and their Varieties.-This is the more usual material employed, as in many instances the physiological action, the gross characters and histological characters are closely similar. In some instances, however, the gross characters may be similar while the histological characters are different, and vice versa. For example, we find that A pocynum cannabinum and A. androsaemifolium; Surinam quassia and Jamaica quassia; resemble each other as to gross appearances, but the histological characters are quite different.

2. Remote Plants and their Varieties.-Not infrequently plants and plant parts having no close botanical relationship to the drug-yielding plant, are used as sophisticants, whether for crude drugs or powders. Sawdust is added to powdered vegetable drugs to increase the bulk. Remote plants and plant organs may be substituted for the drug itself because of a similarity in physiological action. Such adulterations are, as a rule, quite readily detected.

3. Refuse and Winnowings.-These are usually powdered and added to the pure article or sold separately. The refuse and winnowings of spices, pepper in particular, are quite generally used as indicated. This will explain why it is possible for some dealers to sell ground spices and other vegetable powders at a price much below that of the market value of the genuine crude drug itself. The fraud is not by any means easily detected by the novice because the histological characters of the refuse and winnowings are the same or similar to those of the pure article. Giving careful attention to weight, color, odor and taste (organoleptic tests), will generally disclose the fraud, especially when combined with a careful microscopical examination.

4. Exhausted Drugs.-Exhausted drugs, whether crude or powdered, are not infrequently redried and again placed upon the market, generally after being mixed with the pure article. This applies, for instance, to tea, ground coffee, expressed cloves and other powdered spices, drugs and other medicinal substances. In some hotels and tea-houses where tea is used in large quantities, the exhausted leaves are collected, dried and rolled with good tea and placed upon the market. Coffee grounds are collected, dried and mixed with good ground coffee. Exhausted powders are taken from the percolators, dried and mixed with pure powders.

5. Inferior Drugs.-Drugs having become more or less worthless through infection with vegetable and animal parasites, through age, exposure to moisture and sunlight, etc., are sold as genuine or mixed with the genuine. Drugs more or less worthless because collected out of season, improperly dried, etc., are also placed upon the market. 
Such drugs are generally sold in the powdered state, as that renders detection of fraud more difficult. In the case of crude inferior drugs careful attention should be given to color, odor and taste, as compared with the pure drug. Such drugs should he tested chemically in order to determine the per cent. of active constituents, provided they are assayable.

6. Starches and Meals.-These substances are added to powdered drugs only. Starch and flour have ever been extensively employed in drug adulteration. They are cheap, plentiful everywhere, easily obtained and perfectly harmless. If starch is added to a drug which is normally free from starch, the fraud is readily detected. Various cereal meals are generally employed, as wheat flour, corn meal, oat meal, etc. Occasionally the flour or starch is partially roasted in order to develop the desired change in color. Meals free from starch are occasionally employed in the adulteration of vegetable powders, especially almond meal.

Some powdered drugs are so commonly adulterated that dealers boldly assert that a pure article does not exist. Kamala is quite generally adulterated with colored starch and sand. Such substances as powdered pepper, cayenne pepper and mustard, are quite frequently adulterated with considerable quantities of flour, corn meal and other cereals.

7. Insects and Insect Remnants.- These are never added intentionally. They are quite frequently accidentally present in some drugs, as leaves, flowers and barks. The insects cling to or are retained by the various plant parts, where they die and are collected with the drug. Aphidæ (plant lice) are very plentifully found with the strobiles of humulus, also in some leaves and herbs. In all such instances the organisms are dead and are rarely present in suff.cient numbers to lessen the value of the drug. The presence of living insects and other animals is evidence that the drug is being attacked by a destructive parasite.

\section{B. Inorganic Substances.}

1. Sand.-This substance is added to powdered drugs, and it is surprising to find how extensively it is used. It must, however, be kept in mind that a small amoun of sand is normally present in many drugs. Air currents carry dust and sand particles to all exposed parts of plants; it accumulates in crevices of barks and other irregularities of plant surfaces; it is read ly reta ned by waxy and resinous excretions of leaves, flowers and fruits; it is retained by trichomes, etc. Soil, which is simply a mixture of sand particles and decayed 
organic matter, clings to all subterranean plant organs. This makes it evident that some sand will be found upon many crude drugs and mixed with the powders made from them, as there is no means of removing it entirely, even with the most careful washing and winnowing. We would naturally expect to find more sand with the powders of roots, rhizomes and tubers; less with barks, and still less with most herbs, flowers and fruits. It should be wanting in powders of peeled barks, of woods, of peeled roots, rhizomes, tubers and seeds.

2. Dirt, Clay, Lime.-Not infrequently collectors leave enough dirt attached to subterraneán plant organs as to amount to adulteration, as, for instance, Mexican sarsaparilla and many of the roots and rhizomes collected in the United States. Clay is sometimes added to powders (goa powder). Valerian is very likely to contain an excess of clay. Lime is not intentionally added, but it will be found in powders made from limed crude drugs, as iris, ginger and nutmeg.

3. Substances Much Used for Purposes of Adulteration.

To enumerate all of the substances which may be used for the purpose of adulterating powdered spices and vegetable drugs is impossible. There are, however, certain substances which are used more than others and these should receive especial consideration and study. Based upon many years of experience in the microscopical examination of the class of substances named, the following materials are given as being most commonly employed for the purpose of adulteration.

1. Ground olive pits and nut shells.

2. Ground coco nut shells.

3. Clove stems and allspice stems.

4. Peanut shells.

5. Cereals (roasted, ground and broken), wheat flour, rye flour, barley flour.

6. Corn meal, corn starch, corn cobs.

7. Sand. Small pebbles.

8. Dirt, clay.

9. Mallow leaves. Willow leaves.

10. Beans and peas.

11. Curcuma.

12. Milling refuse and screenings.

13. Trimmings, fragments, etc.

Microscopically these substances are quite readily recognizable and the student is advised to secure samples of the materials listed and to make a careful microscopical examination of them. It may be stated 
that these common adulterating substances are more likely to be found in spices than in vegetable drugs.

The substances and combinations of substances which are occasionally used for purposes of adulteration is legion. Rocks, shot, pieces of lead and iron, pressed and baked clay, saw dust, colored starches, colored and loaded plant tissues, spurious roots, barks, woods, leaves, fruits and flowers have been used. The analyst must not be surprised at anything, because the unexpected is constantly revealed. Special forms or kinds of adulterations are constantly changing. Old familiar methods disappear and new methods appear. The additions of some coloring agents, as Prussian blue, indigo, is falling into disuse. Elm bark is now rarely adulterated. Hydrastis, despite the high price, is rarely adulterated. False crocus is not often found. Imitation coffee beans and nutmegs are becoming extremely scarce. Practices of adulteration vary and shift geographically with changes in the thoroughness or laxness with which the pure food and drug laws are enforced.

4. Commonly Adulterated Powdered Vegetable Drugs.-The following powdered vegetable drugs and spices are very frequently adulterated:

Aconite-Stems and foreign species.

Asafoetida-Vegetable tissue, starch, mineral matter, etc.

Belladonna L-Foreign leaves.

Belladonna R-Phytolacca root.

Benzoin-Bark impurities.

Cloves-Clove stems. Exhausted.

Colocynth-Rind and seed.

Coto Bark-Spurious barks.

Ergot-Mold, mites, worthless.

Galla-Oak bark, nut shells, olive pits.

Henbane - Dirt, stems, sand.

Ipecac-Stems, foreign roots.

Mace-False mace, cereal.

Marjoram-Leaves of related plants, mallow leaves, etc.

Mustard-Cereal and curcuma.

Pepper (black)—Refuse, nut shells.

Pepper (white) - Cereal, bleached.

Pilocarpus-Spurious leaves.

Pyrethrum (insect powder)-Entire herb used. Related species used. Stems used.

Sage-Foreign leaves and herbs. Dirt.

Sarsaparilla-Crowns, stems. 
Spigelia-Ruellia ciliosa.

Valerian-Dirt and clay.

5. Pebbles, Lead, etc.-Such substances are not commonly employed, and are nearly always added to crude drugs. Pebbles are often added to coffee beans and to senna. Shot, pebbles, lead foil, etc., have been found in the interior of lumps of gum opium. Stones have been found in the interior of bundles of sarsaparilla and other bundled crude drugs.

6. Coloring Substances. - The desire to place an attractive article upon the market has led to the pernicious habit of coloring certain drugs. We have already referred to the habit of liming, which does serve some useful purpose besides giving a white color. In certain parts of China tea is quite generally colored with indigo and Prussian blue. Coffee beans are similarly colored. Adulterants are often colored before adding them to the drug in order to simulate the normal color.

Bleaching, liming and otherwise changing the color of drugs, crude or powdered, in order to hide inferiority, is contrary to the law and cannot be too strongly condemned.

\section{The Detection of Adulterations}

The practicing pharmacist should not take the purity of an article for granted, but should satisfy himself to that effect personally. Every drug as soon as received should be inspected carefully to determine whether or not it is the drug intended, as some mistake may have been made in the order, in the packing, labeling or shipping. The drug should then be carefully examined to determine its purity and quality, and in order to do this the pharmacist must be thoroughly familiar with the characters of the normal drug. If the drug is not of standard quality it should be returned to the shipper.

In the case of powdered drugs the matter becomes more difficult. The intelligent use of a good compound microscope is absolutely necessary. The student must have a thorough knowledge of vegetable histology. He must know the normal tissue elements in order that he may recognize the presence of foreign elements. The recognition of the adulterant is of prime importance; its identity is of lesser importance as a rule. In many cases it will be found very difficult, if not impossible, to determine the identity of the sophisticant. The quantitative determination of the sophisticant is also quite difficult. 


\section{CHAPTER VII}

\section{THE MICROSCOPICAL EXAMINATION OF POWDERED VEGETABLE DRUGS}

\section{Equipment and Method}

The ability to identify powdered vegetable drugs and their adulterants will depend largely upon the intelligent use of a good compound microscope and the necessary accessories and reagents. It is further evident that the study of the histology of crude drugs is a necessary preparation to the study of these drugs in the powdered state. In the powders the cells and cell-contents appear broken and intermingled. This fragmentary state of tissue elements renders their identification more difficult as compared with these elements as they appear in carefully prepared sections of crude drugs.

As already indicated, the fineness of the powders varies greatly. For examination under a compound microscope Nos. 60 to 100 are most suitable. No. 80 is, perhaps, the fineness best suited in the great majority of cases. A No. 100 is generally too fine and a No. 60 is somewhat coarse. Very coarse powders must be further reduced by means of a pestle and mortar. For low powder examinations powders from 40 to 60 fineness are very suitable.

The equipment and apparatus required by the micro-analyst is comparatively inexpensive, yet it is very earnestly advised to secure only those appliances which are useful or essential for the work in hand. The following list is submitted without entering into detail, as it may be assumed that the microscopist does not require detailed explanations:

1. Simple lens.

2. Compound microscope.

(a) Ocular with micrometer scale.

(b) Oculars, Nos. 2 and 4.

(c) Objectives, Nos. 3, 5 and 7 .

3. Slides and covers.

4. Section knife or razor, and strop. Safety razor blades may be used.

5. Polarizer, for the study of starches, crystals and other substances. Should be convenient to use. The selenite plates are useful.

6. Accurate metal or hard rubber millimeter ruler for measuring crude drugs, fruits, seeds, etc. 
7. The required glassware and adjunct apparatus.

8. The required reagents.

9. Equipment for making moisture determinations.

10. Equipment for making ash determinations.

The laboratory in which the work is done must be roomy, welllighted, provided with the necessary shelves, apparatus and supply cases, reference books, etc. The analyst must see to it that the necessary things are provided. A skillful worker should have the tools of his choice.

It is impracticable to enter into a full discussion of the technique and methods to be employed by the micro-analyst. The following suggestions will serve as a guide to methods of procedure.

For microscopic examination a pinch of the powder is mounted in some clearing fluid. Heat may be employed to remove air bubbles and to increase the translucency. The student is at first greatly confused by the optical picture which presents itself. Cell-fragments and cell-contents are variously intermingled with various cell-groups, but this confusion vanishes with experience and with the knowledge of the histologic structure of plants. With the exception of very fine meals, it will be found that cells occur in groups, the number of cells in each group depending upon the fineness of the powder and the size of the cells. Bast cells, trichomes, tracheids, wood cells, ducts and other elongated elements appear in longitudinal view. Tabular elements, as epidermal cells, appear in surface view. The more delicate elements, as meristem cells, leaf parenchyma, pith cells, ordinary isodiametric parenchyma, are usually pretty well broken. Sclerenchyma cells are rarely broken and belong to the strikingly characteristic elements noticeable in powders; the same may be said of the short thick bast cells found in cinchona, cinnamon and some other drugs. Hair cells, epidermal cells and pollen grains are quite diagnostic. Glandular structures are of little significance in the examination of powders, as they are usualy too much broken. Cell-contents are very important, especially the starches and the crystals of calcium oxalate. Starch granules usually appear entire, likewise the crystals of calcium oxalate, excepitng the large crystals, as they occur in scilla, rhubarb, soap bark, orris root and in a few other drugs, which are more or less broken in the powdering.

It is rarely desirable or necessary to use many micro-chemical reagents in the study of vegetable powders. An intelligent use of a suitable clearing fluid, ${ }^{1}$ a solution of chloriodide of zinc and a $1 / 50$ normal iodine solution is about all that will be required. To hasten

${ }^{1}$ A mixture of equal parts of glycerin and water will be found most useful. 
the clearing up process and to remove air bubbles from the tissues heat should be applied, but the student must bear in mind the changes that heat produces in cell-contents, as starch granules, fats, inulin coloring substances and some other contents. Fortunately, the crystals of calcium oxalate remain unaltered. A concentrated solution of potassium hydrate and of sulphuric acid may prove useful as some drugs give characteristic color reactions with these reagents. Fehling's solution may be found useful in developing the sugar reaction.

The following is a tabulation of the color reactions of the different vegetable elements with chloriodide of zinc. A drop of the reagent is to be added to the section or pinch of powder and the slide mount examined immediately in order that all of the color changes may be noted.

I. Cell-walls.

1. Cork.-No reaction.

2. Epidermis, not suberized or lignified.-Reaction as for parenchyma.

3. Parenchyma. - A gradual change from reddish brown to deep violet. Reaction may require several hours to develop fully. Reaction due to cellulose.

4. Bast.-As for parenchyma. Reaction more rapid.

5. Collenchyma.-As for bast.

6. Sieve tissue or phlom.-As for bast. Reaction more rapid.

7. Lignified cells (tracheids, vessels or ducts, wood cells, some bast, sclerenchyma and other lignified elements).Reddish brown reaction, which gradually deepens. Reaction due to lignin.

II. Cell-contents.

1. Starch.-As for parenchyma. The reaction is, however, so rapid that the reddish brown coloration is rarely noticeable.

2. Protoplasm and proteids.-Reddish brown.

3. Tannin globules.-Reddish brown.

4. Laticiferous fluid.-Wine red.

5. Amylodextrin granules.-Reddish brown.

6. Crystals.-No reaction.

7. Oils and fats.-No reaction.

8. Resin and waxes.-No reaction.

9. Mucilage and gums.-No reaction.

10. Sugar and inulin.-No reaction.

We shall give a few tests which have proven useful in the examina- 
tion of powdered vegetable drugs. Some of the test results are largely approximate, and are primarily intended to serve as aids or checks to the chemical examination.

\section{METHODS USEFUL IN THE EXAMINATION OF VEGETABLE DRUGS, SPICES AND SOME FOOD PRODUCTS}

1. Mace Test.-To a pinch of the powdered mace add 10 per cent. sodium hydroxide solution. Banda or true mace changes color only slightly, whereas wild or Bombay mace turns a deep orange color.

2. Conium Test.-To the substance to be tested for the presence of conium fruits (as anise, caraway or other umbelliferous fruits), add 25 per cent. sodium or potassium hydroxide solution. In the presence of one per cent. or more of conium fruits a distinct mouse odor is developed in time (10 minutes to one-half hour). This test is not reliable with old umbelliferous fruits, as many of them develop a more or less marked mouse odor with alkalies.

3. Lignin Test.-The classic phloroglucin-hydrochloric acid test is useful in making estimates of the amount of lignified tissue present, as in old belladonna root, aconite roots and stems, lobelia herb, fruit products, spices, etc.

4. Grahe's Cinchona Test.-Drive the moisture from the inner surface of a small test-tube by holding it over a Bunsen burner. Into this dried test-tube place a pinch of finely powdered cinchona bark (No. s0) and heat rather carefully over an alcohol lamp or Bunsen burner. When the bark begins to char, red fumes begin to fill the tube and condense on the side of the tube as a reddish purplish liquid. The intensity of the reaction is approximately proportional (direct proportion) to the percentage of alkaloids present. Some skill and experience is necessary to perform this test well. The tube must not be heated too quickly or too much, and the powder should be uniformly fine.

5. Beaker Sand Test.-Pour a definite amount of the powdered spice or vegetable drug into a beaker, add water, stir until the sand is washed away from the vegetable particles and settles to the bottom of the beaker. Let a stream of water run into beaker so as to wash out the vegetable matter. The final washing and decanting must be done carefully so as not to lose the sand. Salt brine may be used instead of water, should the vegetable matter have a comparatively high specific gravity. Dry sand and weigh to obtain the percentage of sand present.

6. Ash Determinaiion.-According to the regulation method. The percentage of the acid-insoluble residue should also be determined. It should be borne in mind that the ash determination gives only approximate results as far as the presence of clay and dirt is concerned, since the organic matter of dirt is combustible. The ash percentage varies extremely in vegetable drugs, especially in herbs and leaves. The sand percentage is comparatively high in those herbs and leaves having abundant trichomes, especially if the drug plants (or herbaceous spices) bearing such trichomes are grown in dry sandy soil. Dirt (and sand) percentage is apt to be high in roots and rhizomes, particularly when rootlets are abundant and when the gathering is carelessly done.

7. Sublimation Test for Benzoic Acid.-Place a drop or two of the suspected liquid or semi-liquid food substance into a deep watch crystal of one inch diameter. Place over it a clean dry slide. Now hold the watch crystal over a flame (alcohol lamp) until the substance (as wine, vinegar, catsup, jam, jelly, etc.), comes to an 
active boil. The steam vapor, carrying with it the benzoic acid, is condensed on the slide. Remove the slide and set it aside until the condensed moisture has evaporated; very moderate heat may be used to hasten evaporation. Examine under the microscope, whereupon the benzoic acid crystals may be seen, provided any were present. The test is delicate, very reliable and very few substances interfere with it. It is very pronounced in the presence of .001 per cent. of benzoic acid or of sodium benzoate.

8. Salicylic Acid T est.-Made like the benzoic acid test. The crystal formation (plates) is very pronounced in dilutious of $1: 10,000$. After having examined the crystals under the microscope, add a drop of weak solution of ferric chloride to the crystals upon the slide, whereupon a blue coloration develops. Boric acid is likewise deposited by sublimation, but the test is not as satisfactory as that for benzoic acid and for salicylic acid.

9. Curcuma Thread Test for Boric Acid.-Boil 5 grams of powdered curcuma in $10 \mathrm{cc}$. of alcohol. To the evaporated alcoholic extract add a little soda and several cc. of 50 per cent. alcohol. In this place paper (bast fiber), cotton or linen threads and bring to a brisk boil for a few moments. Remove threads and dry between blotting paper, lay them in a very weak solution of sulphuric acid and rinse in water. When dry the threads should be a golden yellow.

The test for the presence of boric acid (also for borax) is made as follows: Dip the end of a prepared thread in a 10 per cent. solution of hydrochloric acid and allow to dry. Lay the thread on a slide, cover with cover glass and examine. It should be of a reddish brown color. To the edge of cover glass apply a droplet of a 10 to 13 per cent. solution of sodium carbonate, followed by a droplet of the suspected solution. In the presence of boric acid, the thread is colored blue, which coloration remains for a longer or shorter period and then changes to gray and violet. The test is a very delicate one and is not hindered by the presence of sodium chloride, magnesium sulphate and aluminum sulphate. Strong solutions of phosphoric acid, silicic acid, calcium chlorite and magnesium chlorite, interfere with the reaction more or less.

10. Formaldehyde Test.-Concentrated hydrochloric acid added to weak solutions of formaldehyde $(1: 5000)$ or substances containing formaldehyde, forms stellate clusters having a somewhat crystalline appearance. The formaldehyde can be deposited on a slide by sublimation (as for benzoic acid) and the acid added. The stellate clusters appear upon evaporation of the hydrochloric acid.

11. Sulphurous Acid Test.-Moisten starch paper with a very dilute solution of potassium-iodide iodine solution which colors it blue. In the presence of the merest trace of sulphurous acid the paper is decolorized. Do not use heat in this test.

12. Iodine Reaction.-The color reaction of starch with $\mathrm{N} / 50$ iodine solution is of great importance in the examination of vegetable drugs, spices and fruit products, such as jams, jellies, catsups, etc., as it will give some indication of the amount of starch present and in the case of fruit products it will show whether or not ripe or green fruits and juices of unripe fruit were used, and whether or not starch paste may have been added as a filler or thickening agent. As is known, green fruits generally, contain more or less starch, whereas ripe fruits are quite free from starch. The reaction may be observed only in the fruit pulp cells, indicating the presence of unripe fruit, or it may be limited to the non-cellular portions of such substances as jams and jellies, indicating the use of fruit juices obtained from unripe fruits.

13. Hand Giluten Test.-Moisten wheat flour with water making a dough. Knead constantly and carefully under a slow stream of hydrant water, washing out 
all of the starch and most of the wheat tissue. The gluten separates out as a tenaceous gummy mass. With care fairly accurate quantitative results may be obtained. Weigh the dried flour and compare with the dried gluten mass obtained from it. With cereal flours other than wheat, the entire dough mass is gradually washed away, leaving no gluten.

14. Micro-Gluten Test.-Mount a small pinch of the flour in water on a slide, being careful not to use too much water. Cover with cover glass and gently move cover glass to and fro and rotate at the same time. The gluten separates out into stringy fragments which may readily be seen under the low power. Very small quantities of wheat flour added to other cereal flours can be detected by this method. The gluten fragments can be made to appear more distinctly by adding a droplet of very weak solution of saffranin or fuchsin, after the rotation of the cover glass.

There are a number of chemical tests giving color reactions which can be done conveniently by the micro-analyst, as the boric acid reaction with curcuma, the $\mathrm{H}_{2} \mathrm{SO}_{4}$ color reaction with some barks, capsicum, guaiac, resin, cubeb, etc.; the $\mathrm{H}_{2} \mathrm{SO}_{4}$ plus formaldehyde color reaction with morphine; the ferric chloride color reaction with salicylic acid; etc. These tests should be used when, in the judgment of the analyst, they may serve to give better information regarding the identity, purity and quality of the drug.

The organoleptic tests (i.e.-color, feel, taste, odor) are valuable adjuncts to the microscopical work. There is, however, some variation of opinion regarding the interpretation and valuation which is to be placed on comparisons of color, odor and taste, even among those having had considerable experience and endowed with a fairly normal special sense development. Our color terminology is in great confusion, and so far as the olfactory sense is concerned, there are only comparatively few odors or flavors which admit of ready comparison such as tea flavor, coffee odor, vanilla odor, raspberry flavor, loganberry flavor, and the odor of such drugs as valerian, cubeb, fenugreek, asafetjda, aloes, turpentine, camphor, calamus, etc., and the odor of the spices. Our comparative judgment of tastes is more reliable. Much experience is necessary to form fairly reliable estimates of flavors (associations of tastes and odors), though pure fruit flavors are, as a rule, readily distinguishable, as that of apples, dried apples, peach, dried peach, quince and strawberry. Manufactured fruit preparations generally lose much of their flavor due to many causes, as cooking, steaming, fermentative changes, presence of decayed (moldy) fruits, mixing of several kinds of fruits or fruit juices, etc., to say nothing of the wholly artificial or imitation fruit flavors and so-called fruit products which have little or no fruit in their composition.

While it is not practicable to examine all powdered drugs according to a definitely fixed outline, yet for the sake of uniformity in laboratory 
methods some system should be observed in the procedure. It is suggested that the following report card be used in the microscopical examination of powdered drugs and spices.

\section{REPORT BLANK}

No.

Label

Sample received.

Sample examined

Condition of wrappings and seals

Organoleptic Tests.

Consistency or Feel

Color

Odor. .

Taste.

Adjunct Tests

Ash.

per cent.

Acid-insoluble ash

per cent.

Sand (beaker test) per cent.

Special tests

Microscopical findings

Conclusions.

Analyst.

The following is a report of analysis filled out according to the report card:

No.: 5432.

Label: Broken Senna, U. S. P., John Smith \& Co., Kalamazoo, Michigan.

Sample received: Aug. 15, 1912. Sample examined, Aug. 20, 1912. Conditions of wrappings and seals: Good.

Organoleptic tests

Consistency or Feel: Dry, gritty, sandy, dirty.

Color: Not abnormal.

Odor: Senna-like.

Taste: Sandy, gritty.

Adjunct tests

Ash: 19.6 per cent.

Acid-insoluble: 9.4 per cent.

Sand (beaker test): sand and small pebbles 9 per cent. 
Special tests: Pebbles picked out by hand, about 4 per cent. Senna seeds, pod fragments and stems present.

Microscopical findings: The histological characters of African senna.

Stem tissue excessive. Sand and dirt excessive. Senna seeds and pods present in considerable quantity.

Conclusions: Adulterated with sand, pebbles, senna seeds, senna pods and stems, 25 per cent. Misbranded because labeled U.S. P., whereas it is below the U. S. P. standard. Corresponds with what is known in commerce as Senna siftings or Senna refuse.

Richard Roe, Analyst.

The skilled micro-analyst has little difficulty in determining the purity and comparative quality of the simple spices, as pepper, allspice, cloves, cinnamon and ginger. However, matters are not so easy or simple when it comes to the examination of powdered vegetable drugs, compound vegetable powders and vegetable products of unknown composition. A thorough knowledge of and wide familiarity with cell-forms, tissue elements and formed cell-contents is an absolute essential in order that accurately reliable and conclusive results may be obtained and serious confusion may be avoided. Marked differences in the reports of findings by micro-analysts are in part due to the personal equation, in part due to variations in methods and also to differences in judgment in estimating the quantity of tissue elements present and in part due to a lack of extensive and intensive experience.

The true worth of the work of the micro-analyst has thus far not been properly valued. The doubt in the minds of the critics is due, very largely, to the unsatisfactory results traceable to the efforts of those who are not sufficiently qualified. Even the most skillful analysts admit numerous defects and shortcomings in methods and in results. For example, the quantitative estimates based upon optical judgment are approximate only, and with most workers there is a very marked tendency to make these estimates volumetric rather than gravimetric. This can in a measure be corrected by bringing into play the judgment of the relative weights of the several substances under comparison. For example, the amount of -sand present in powdered belladonna root may be volumetrically estimated at 20 per cent. In this case the acid insoluble ash residue may show 35 to 40 per cent. of silica. An example like this also indicates why the micro-analyst should make the sand and ash determinations. The percentage estimates based upon microscopical examination may vary within 25 to 50 per cent. when small amounts of admixtures are considered. For example, the actual amount of arrow-root starch 
in the so-called arrow-root biscuit is 2.5 per cent. The micro-analyst's estimates may range from a trace or small amount to 5 per cent. When the quantities of admixtures are large, from 30 to 90 per cent., the estimations may approximate within 10 or 15 per cent. of the actual amount present. These estimates can no doubt be made much more accurate by uniform methods of technique, aided by certain mechanical devices. For example, in the examination of vegetable powders, spices, meals, flours and similar substances, the samples should be thoroughly mixed, and slide mounts should be of standard and uniform thickness and the relative amounts of the ingredients should be estimated by means of microscope slides having uniform ruled squares of definite measuring value in microns. These and other details in the methods should be more fully worked out.

Several micro-analysts have declared themselves as opposed to giving percentage estimates of the several ingredients of a compound. However, not to give the approximate percentages will cause great confusion and very materially lessen the value of the work done. For example, to report a pancake flour as composed of "buckwheat and wheat flour, the former predominating," instead of "buckwheat 75 per cent. and wheat 25 per cent.," would certainly be unsatisfactory.

Recently some dispute has arisen as to the relative value or importance of the microscopical and chemical analysis of foods and drugs. With certain substances the microscopical analysis is of first importance, while with others the chemical analysis is of the greater value. The following examples will serve to explain the relative value of the chemical and microscopical analyses. Suppose the substance to be examined is a baby food. The microscope may reveal approximate percentages of oil globules, steam dextrinized wheat starch, unchanged wheat and arrowroot starch, wheat tissue and milk sugar. The chemical analysis will show a definite percentage of sugar, soluble starch, insoluble starch, fat, vegetable fiber and ash. This is a good example of a case where the two methods of analysis are of equal importance; one without the other would be unsatisfactory, incomplete and inconclusive. Again, the chemical assay may show that a sample of powdered or crude belladonna leaf contains 0.35 per cent. of mydriatic alkaloids, and yet the microscopical examinations may prove the presence of from 20 to 30 per cent. of some foreign leaf.

\section{Tissue Terminology and Identification of Tissues}

A uniform tissue terminology is essential to a comparison of results in the critical examination of vegetable drugs and spices. That is the names of tissues, tissue elements and of cell-contents, should be 
uniformly applied and interpreted by all analysts. This does not appear to be the case as may be ascertained from a comparison of the terms used by the several authors on plant histology and pharmacognosy. It is suggested that the student give special attention to the study of fully formed or matured tissues and tissue elements according to the following tabulated outline. This work may be taken up as a preliminary preparation to the micro-analytical examination of vegetable drugs and spices, crude as well as powdered. The terminology as it applies to cell-contents such as starches, proteids, oils, fats, crystals, etc., is but little confused.

\section{Tabulation of the Principal Vegetable Tissues}

Trichomes or Hair Cells.-(These belong to the epidermal tissue). The following are the principal kinds:

Simple: Single-celled; varying from very short to very long, walls thick or thin, smooth or rough, warty, etc., as cotton, in tea leaves, sage, wheat, rye, apricot, quince, peach, strawberry, raspberry, loganberry, etc.

Many-celled: (usually two to five-celled); varying from short to very long; cellwalls usually quite thin; smooth, roughened, warty, etc., as in digitalis, aconite, mints, tobacco, belladonna, and in many other vegetable substances.

Aggregate or Stellate: As in mallows, castanea, hamamelis.

Branching: Typically developed in mullein.

Glandular: Trichomes with secreting end cells. End cells vary in number from one, two and more, commonly five to ten as in the mints, tobacco, hyoscymus, nettle, etc. The number of secreting cells is occasionally diagnostic. The multicellular structures of kamala and lupulin are usually designated as glands.

Multicellular: More than one row or layer of cells, as in cocoa, Indian hemp (multicellular glandular trichomes), rhus glabra fruits, etc. Not common nor widely distributed in the plant kingdom.

True Multicellular Trichomes: As in rhus glabra.

False Multicellular Trichomes or emergencies; as in Indian hemp. Pappus, prickles, warty excrescences and similar structures should be included here.

Unusual Trichomatic Structures: T-shaped as in Pyrethrum flowers; shield-form as in the olive leaf, etc. Naturally such unusual structures are highly diagnostic. None of the U. S. P. drugs contain any of the very unusual trichomatic structures.

EPIDERMis.- In plants, a single layer of cells, bearing the above mentioned trichomes. Including also the outer layer of the seed coat 
or testa in which the cells often show remarkable structural variations. The cells differ greatly as to size and form, thickness and structure of cell-walls, as to cell-contents, etc. Note especially epidermal cells of leaves; of fleshy fruits (of tomato, window cells of apple and quince); the papillose cells of coca leaves and rose petal; of young stems, etc.

Cuticle: The outer or external cell-wall, with various markings and projections. Extremely variable as to thickness. The inner wall of epidermal cells (the wall parallel to the cuticle or outer wall) never presents any diagnostic characters and need not be further mentioned.

Vertical Cell-Walls: These may be wavy (sinuous), or straight; thin, much thickened, warty, porous.

Stomata: Somewhat variable as to size of guard cells but the structural differences are not sufficiently marked to be of any special diagnostic value. The relative occurrence and distribution of stomata on upper and lower surfaces of bifacial (dorsiventral) leaves will occasionally prove diagnostic.

Nebenzellen (Neighboring Cells) : May be of great diagnostic value, indicated by number of cells, size and form of the cells and nature of cell-contents.

HyPODERM.-One or more layers of cells immediately underneath the epidermis, as in buchu, mace, fig. The cells are usually much larger than those of the epidermis but quite generally without diagnostic structural characters or contents (cystoliths in fig leaf). Cell-walls may be mucilaginous as in buchu. Not common.

Collenchyma.-Characterized by cell-walls thickened at the angles.

Parenchymatous: Cells nearly isodiametric or slightly elongated, as in gentian root.

Bast-like: Cells much elongated, the usual or typical form, as in labiate stems. The characteristic thickenings at the angles of the cells are seen in transverse section.

Palisade Tissue or Cells.-Elongated cells usually placed endwise, vertically to surface; as the palisade tissue of the leaves, of the seed coat (testa of many seeds, bean, pea, apple seed, quince seeds, etc.). Generally of great diagnostic value, excepting in case of leaf palisade which is only exceptionally diagnostic.

Bast Cells or Bast Fibers.-Elongated cells. Cell-walls with or with out lignin; comparatively non-porous; ends tapering pointed.

Typical: Greatly elongated cells; extremely flexible; colorless; usually non-lignified but much thickened walls. Typically devel- 
oped in willow bark, in cotton root bark, mezereum, etc. .Widely distributed in barks, stems and roots.

Sclerenchymatous: Short cells with greatly thickened and usually porous, lignified walls. Typically developed in cinchona barks, cinnamon barks, sassafras bark, etc.

Branching: Cells usually elongated and more or less branching at the ends, as in wild cherry bark, soap bark, etc. Not very common.

Sclerenchyma Cells or Stone Cells.-Cells generally not greatly elongated; thickened, porous and lignified walls; often of brownish color; ends not tapering pointed.

Typical: Cells approximately isodiametric; walls may be greatly thickened, comparatively thin-walled or unevenly thickened. Very widely distributed in the plant kingdom; found in barks (especially the outer bark), roots, fruits (principally in the pericarp), in the pear, quince, etc.

Elongated or Bast-Like: Resemble short bast cells but ends are truncate instead of tapering pointed. Found in some barks (coto), in star anise, some roots, coffee hulls, currants, etc.

Branching: Never greatly elongated. Typically developed in tea leaves, in some nut shells (peanut pericarp), seed pits (endocarp), some barks, etc.

Wood Fibers or Wood Cells.-Differ from bast in that the fibers are more firmly bound together, more porous, always lignified, much more uniform in transverse diameter though walls vary considerably in thickness. Ends usually very blunt, or truncate, or diagonally cut.

TracheIDs.--Resemble wood fibers very closely, cell-walls more porous as a rule, ends tapering pointed, walls usually lignified. Typical bast, wood fibers and tracheids are similar as to the measurements of the transverse diameter. The following are the principal kinds.

Typical: Walls always lignified, very porous, forming the woody tissue.

Tracheids with Bordered Pits: Typically developed in the pines, forming the woody structure. Rare in other plant groups.

Bast-Like Tracheids : Soft, flexible, generally non-lignified elements; ends tapering pointed. Not a diagnostic tissue in any of the important drug plants. In roots, some young barks, etc.

DUCT OR Vessels. - The water conducting tubes of vascular bundles and of other conducting tissues. Always lignified. The following are the principal types: 
Porous: Very variable in transverse diameter. The pores vary in form and size, gradually merging into the reticulate type. Pores slit-like (transverse and diagonal); cats-eye (slits with borders), circular, oval, etc. Very widely distributed among herbs, shrubs, trees (conducting tubes of woody tissues).

Scalariform: Typically developed in the fern group. Less commonly present in other plant groups.

Reticulate: A modification of the porous type. Very common in dicotyledonous herbs. Very variable in transverse diameter. Gradually merging into the spiral type.

Spiral: Typically developed in monocotyledonous plants, though also common in dicotyledons. Gradually merging into the annular type.

Annular: Typically developed in the grass family; less common in other plant groups.

Parenchymatous Tissue.-A term applied to the predominating tissue in plants or in plant parts. We thus speak of wood parenchyma, bark parenchyma, leaf parenchyma, seed parenchyma, fruit parenchyma, etc., etc. The following types are recognized, in a more limited sense.

Parenchyma Proper: The cells are practically isodiametric, thinwalled, walls only slightly porous and never lignified. There are, as a rule, intercellular spaces due to the fact that the cells are loosely united. Widely distributed in the plant kingdom, occurs in roots, stems, fleshy fruits, tubers, rhizomes, bulbs and corns.

Pith: The central tissue of stems, rhizomes and roots. A typical parenchyma.

Bark Parenchyma : Cell-walls may be suberized (cork-tissue), often not suberized (inner bark parenchyma).

Endosperm Tissue: The parenchyma of seeds. Cells extremely variable as to the thickness of walls, porosity of walls, contents. Often a highly diagnostic tissue.

Fruit Pulp (of false as well as true fruits): A typical parenchyma. Pericarp Parenchyma: Generally a typical parenchyma.

Leaf Parenchyma or Spongy Tissue : Composed of from one to three rows of palisade cells (upper, sometimes also a lower, as in Eucalyptus), and the aerating, pneumatic or spongy tissue proper. Very rarely diagnostic. Cell-contents sometimes diagnostic (crystals, resin, coloring substances, etc.).

Sieve Tubes.-Associated with vascular bundles, typically developed in cucurbitaceous plants, of no special diagnostic value. 
Elongated, narrow conducting cells usually accompany the sieve tubes. These are rarely of diagnostic value.

Crystal Bearing Fibers.-Rectangular cells united end to end forming elongated threads, each cell bearing a prismatic crystal of calcium oxalate. Usually associated with bast tissue. Typically developed in cascara bark and other barks, licorice root, etc.

LACTICIFERous Ducts. - Typically developed in the fig and dandelion. Also found in other plants. Highly diagnostic of the fig.

Resin Ducts.-Typically developed in the bark and wood of the coniferæ.

Glands.-As in leaves (buchu, eucalyptus, pilocarpus, bay, etc.), in some barks, fruits, seeds, etc.

Glandular Cells.-As in mace, elm bark, canella bark, allspice, ginger, etc. Usually contain mucilage, resin, oleo-resin and oil. Size of cells, relative number of cells and character of cell-contents often very diagnostic.

Atypical Cells and Tissues.-Essentially fomative or immature and of very little diagnostic value. Includes the so-called phloem tissue, cambium, cork cambium, phellogen, so-called conducting cells of the phloem portion of vascular bundles, apical cells, and immature cells generally.

\section{Occurrence and Distribution of Tissue Elements in Plant}

Organs

The following suggestions are to be considered carefully, as a rather full knowledge of those tissue elements and cell-contents which are most likely to retain their individuality after powdering, or which will prove diagnostic, will simplify the work of studying and identifying vegetable powders.

\section{LEAVES}

Under this head are included leaves, leaflets, herbs, and flowering tops in which leaves predominate. The predominating color of leaves when powdered is green, due to the presence of chlorophyll. In some instances the color merges into brown or yellowish-brown, as in coca and pilocarpus.

1. Epidermal Elements.-By far the most important diagnostic elements of the leaf are the epidermal, inclusive of trichomes, stomata and Nebenzellen (neighboring cells). The epidermal elements being the more resisting parts of the leaf are not so readily reduced in powdering and appear in cell-aggregates of tabular form, presenting mostly a vertical view; rarely one may also find fragments showing 
the epidermal cells in profile view. Trichomes usually appear more or less broken;

2. Upper Epidermis.-Carefully note the general form of the cells as determined from an examination of transverse and tangential (surafce) sections. Make careful measurements of normal or typical cells, remembering that epidermal cells lying over vascular bundles (of veins and midril) are considerably elongated. The outer walls of the cells or cuticle. should be examined in transverse view to note thickness and special modifications, resinous or waxy deposits, etc., also in vertical view to note presence or absence of warty, linear or other cuticular markings, which may prove diagnostic. The vertical walls may be straight and distinct, somewhat variable in thickness; more rarely porous and nodular, as in buchu. In many leaves the vertical walls are wavy instead of straight, and these differences are occasionally diagnostic. As a rule, epidermal cells have few important or diagnostic contents. Occasionally crystals of calcium oxalate are found; also a few chlorophyll granules. They may contain resin (pilocarpus), inulin and hesperidin (buchu), also a small amount of starch, tannin and coloring matter. In brief, note carefully form and size of the cells; thickness of cuticle, cuticular markings; and occasional possible diagnostic cell-contents.

3. Trichomes or Hair-Cells.-Trichomes or hair-cells are very important and diagnostic. These, more than any other elements, are the means of identifying the substance having such structures. The non-glandular trichomes are especially diagnostic. The glandular hairs are, as a rule, small and delicate, and their identity is often lost in the powdering. The non-glandular hairs are divided into single celled, many celled, stellate or aggregate and branching. Study these carefully as to length, diameter, form (curved, inclined, erect), thickness of walls and cuticular markings, rarely also color and contents (Cannabis Indica). Length is very variable in different plants-for example, single-celled trichomes vary from mere wart-like outward projections of the outer walls of epidermal cells, as in coca leaves and anise fruit, to the long ( 1 to 3 inches) fibres of the cotton seed. The many-celled simple trichomes (usually 3 to 5-celled) also differ in length, but vary more diagnostically in width. Occasionally the number of trichomes is more or less diagnostic (Alexandria and India senna). Aggregate and branching hairs are very striking in appearance and hence highly diagnostic.

Each hair-cell, which is simply a modified epidermal cell, is surrounded by epidermal cells (neighboring cells) which generally differ somewhat from other or normal epidermal cells. As a rule, they are 
somewhat elongated in a direction radial from the base of the haircells. The number and form of these neighboring cells may occasionally prove diagnostic.

In the case of glandular hairs, the size and number of end cells or secreting cells may be diagnostic. Under this group must also be included those structures more specifically designated as glands (kamala, lupulin, Grindelia robusta), and emergencies.

4. Stomata.-The stomata themselves are of no practical diagnostic significance. In the case of typically dorsiventral leaves they are wanting in the upper epidermis. In the more or less isolateral leaves there are stomata on both surfaces. In some instances it is possible to distinguish between upper and lower epidermis by the number of stomata. The size and form of the guard-cells is quite uniform in the different species of plants. In leaves having an excessively thickened cuticle, as eucalyptus, ficus and others, the guard-cells are not readily observed. Rarely do these cells have any diagnostic or characteristic contents; generally they contain chlorophyll and occasionally some resin.

5. Neighboring Cells.-While. the stomata themselves present little that is significant in the identification of drugs, the neighboring cells (Nebenzellen) present some very striking diagnostic features, and they should, therefore, be studied with great care. The number to each stoma varies from two to five or six. In India senna, for example, there are, as a rule, two cells, one much larger than the other. The cells may contain resin, crystals and other substances not found in the guard-cells or normal epidermal cells. The cuticular markings may be different. The form of the outer wall may be different. In coca leaves they do not have the wart-like projections so characteristic of the normal epidermal cells.

6. Air Chamber.-The air chambers of the stomata are of no significance. As a rule, the cells bounding the space contain crystals of calcium oxalate, usually of the aggregate form.

7. Hypoderm.-Usually a hypoderm is wanting, and, when present, is rarely of importance in powders. As a rule, the cells are colorless, empty and well broken in the powdering. In ficus and other plants, a few of the cells contain cystoliths. In buchu the cell-walls are mucilaginous. They may contain crystals. The cells of the lower hypoderm are usually smaller than those of the upper. Again, the lower. hypoderm may be entirely wanting, as in buchu.

8. Palisade Tissue.-This tissue is rarely of any significance in powders, as the cell-walls are delicate and well broken. They all resemble each other in containing an abundance of chlorophyll. They vary considerably in length and in transverse diameter. 
9. Spongy Tissue.-The cells of this tissue are also delicate and readily crushed. They vary in form and size. Frequently they contain chlorophyll and aggregate and prismatic crystals of calcium oxalate. They may contain coloring matter, resin and wax.

10. Stone-Cells.-Typical or well-defined sclerenchyma cells in the leaf parenchyma are rare, but very characteristic when present, as, for example, the large branching stone-cells of tea and hamamelis. There are other mechanical elements associated with the leaf blade, but they are rarely of any diagnostic value in powders. Among these may be mentioned the mechanical pillars in eriodictyon, the lateral lines or ridges of coca, and the mechanical cells of the olive leaf, etc.

11. Vascular Tissue. - This is abundant in all leaves, but presents no diagnostic features. It consists of ducts (porous reticulate, spiral and annular), bast and tracheids.

12. Glands.-Though common and often containing important constituents (eucalyptus, buchu, pilocarpus, etc.), they are of very little value in the identification of powdered vegetable drugs. They vary in size, number, position and abundance; consistency and color of contents. The contents may prove of diagnostic value.

13. Petiole or Leaf Stalk. - The petiole rarely presents any characteristic elements. It is, histologically, similar to the stem or branches, but, as a rule, less distinctively defined. The parenchyma cells usually contain some starch, resin, crystals, coloring matter and other contents common to stems of the same plant. Stone-cells or sclerenchyma-like tracheids may prove diagnostic. There may be cork tissue present. The vascular tissue is similar to that of the leaf blade.

14. Lower Epidermis.-Compare carefully with upper epidermis. When stomata are wanting, it indicates the upper epidermis.

\section{FLOWERS}

Flowers, or parts of flowers, reduced to powder, are quite readily recognized or identified, since, in addition to certain characteristic histological elements (as epidermal cells, trichomes and pollen grains), there is, as a rule, a distinctive color, the predominating colors being brown, yellow or yellowish, blue and red.

1. Staminate Elements. - The vegetable tissue of stamens is not characteristic or diagnostic and need not be described more fully. The important elements are the pollen grains. Carefully note form, size and external markings (exine). They may vary greatly in size, but the difference in form is usually more diagnostic. They may be triangular, spherical or oval. Note carefully the markings of the exine. The predominating color (exine) is brown to yellowish brown. 
The pollen grains of different flowers from the same family or order usually resemble each other quite closely. Pollen grains may cling to any part of the flower, and are even found with pistillate flowers (Cannabis Indica, brayera). The number of pollen grains is rarely diagnostic. If considerable pollen is found with what are supposed to be pistillate flowers, as Indian hemp, brayera and crocus, it may indicate adulteration. Occasionally the number of pollen grains is indicative of the quality and purity of the article, as in insect powder (Pyrethrum).

2. Pistillate Elements.-These are not characteristic or diagnostic. The cells are usually parenchymatous, small and thin-walled.

3. Petals. - Note the epidermal elements and compare with those of the leaf. Stomata are usually fewer in number and less distinct and the epidermal cells are less characteristic. Trichomes are less common, but very diagnostic. The epidermal cells may contain diagnostic coloring matter. Parenchyma and vascular tissue usually deficient and not important.

4. Sepals.-The tissue elements and cell-contents of sepals are in all respects similar to those of the leaf.

5. Pappus. - These structures are present in many flowers (Compositæ) and quite important, though closely similar in different species.

6. Stone-Cells or Sclerenchyma.-These elements are often found. They may be derived from the torus (receptacle), or, in the case of highly matured flowers, from the seeds, and are generally highly diagnostic.

To sum up briefly, the important diagnostic elements of flowers are pollen grains, trichomatic structures, cell-contents and occasionally stone-cells. Vascular elements are not very abundant nor especially characteristic. Parenchymatous tissue is quite typical and quite free from starch and other storage substances. Resin and other secondary products may be present. The student should keep in mind whether a part (as petals, carolla without calyx, etc.) or the entire flower is used.

\section{FRUITS AND SEEDS}

Fruits and seeds are placed in one group. The terms fruit and seed are very loosely applied; in one instance it refers to a fruit (fennel, caraway, coriander, etc.), again to the flower (Artemisia); in other instances the term fruit or seed is applied, not to the whole organ, but to a part, as in peeled colocynth, decorticated pepper, etc.

1. Epidermal Elements.-Those of the pericarp are, in many instances, similar to those of leaf or stem, and such a comparison should be kept in mind. Trichomes are usually non-glandular and diagnostic. 
In the case of seeds the epidermal cells undergo remarkable and varied modifications. They may be trichomatic, filamentous, as in strophantus, nux vomica, cotton seed; gelatinized and palisade-like, as in cydonia; sclerenchymatous, as in almond seeds, besides other peculiar modifications. Owing to the predominance of endosperm tissue epidermal elements are sparingly distributed through the powder, and for this reason a very careful study is necessary to find the sparingly present, but perhaps very diagnostic elements.

2. Stone-Cells.-These are often abundantly present. In form they vary from typical to elongated bast-like, as in the pericarp of Cassia fistula and the seed of Caffea. In color they vary from deep reddish-brown to nearly colorless. Usually they occur in groups, sometimes singly (almond, pepo), and in some instances they are very sparingly present. The thickness and porosity of cell-walls is quite variable and should be considered. In some instances the wall of one side of the cell is thinner than that of the others.

3. Special Tissues of Testa.-Most of these special tissues have a purely mechanical function. Some are sclerenchymatous (Cydonia); some carry prismatic crystals of calcium oxalate (bean). Other tissues consist of thin-walled cells and are much broken in the powders. The cells may vary in form; they may be tabular, elongated, cubical or hour-glass form. They are rarely diagnostic.

4. Endosperm Tissue.-This is essentially parenchymatous and constitutes the predominating tissue of seeds. The cells vary in thickness of the walls; also in porosity and in the character of localized thickenings. As to form the cells of the endosperm tissue are mostly typical of parenchyma; they may be rectangular, elongated. While the variation in size may be considerable, it will be found that this difference proves to be only of occasional diagnostic value. The peripheral cells are, as a rule, smaller than the more internal ones.

The cell-contents should be studied with great care. Note especially the absence or presence of starch. Be careful not to confuse proteid granules with starch granules. (almond, croton and castor beans). Look for resin-bearing cells. Oils and fats are generally present. Occasionally crystals may be found. Vascular tissue is quite deficient in seeds and rarely, if ever, diagnostic.

Oil cells and resin-bearing cells may occur in the endosperm, in the pericarp and in other seed and fruit parts. These are, as a rule, very diagnostic, and should be studied carefully as to number, size, form and color of contents.

5. Parenchyma of Pericarp.-This is generally a typical parenchyma. Compare with parenchyma of roots and rhizomes. Usually 
the cells are quite free of stored food substances or formed organic contents as starch, proteid granules, etc. They may contain resin. Resin glands are common in the pericarp of many fruits, as in the umbelliferæ. The cells are generally quite large, thin-walled porous and loosely united. The parenchyma cells of fleshy fruits especially are very thin-walled and filled with cell-sap.

\section{BARKS}

The medicinal barks present many striking and diagnostic histological characteristics, principally due to the relationship and variation in the two predominating tissues associated with the cork tissue (outer bark) and bark parenchyma, namely, bast and sclerenchyma. There are also some striking cell-contents. The predominating color of the powdered bark is reddish-brown. Some are very light, as Ulmus and Quillaja. A few are very dark, as Juglans.

There is no reliable means of distinguishing between root barks and stem barks, either macroscopically or microscopically, especially when the outer bark has been removed, as is often the case. As a rule root barks contain considerable starch and the color of powders made therefrom is grayish in tone. Lichen elements and hyphal tissue of higher fungi are wanting.

1. Outer Bark Parenchyma.-This tissue usually consists of typical cork cells and it displaces the epidermis. The cells may be diagnostic in form and size. They may contain proteid granules, tannin granules and reddish-brown coloring matter. Also crystals of calcium oxalate (aggregate and prismatic). This tissue is removed in peeled barks, as Ulmus, Quillaja, cinnamons and others.

2. Lenticels. - These never present diagnostic characters in powders. The cells are suberized and usually empty.

3. Inner Bark Parenchyma.-This differs from the outer parenchyma, in that the cells are less typically suberized and are more characteristic as to form and contents. The cells are usually loosely united, oval to somewhat elongated; walls colorless and of some thickness. Note cell-contents carefully. Starch, which is present in variable quantity, is rarely diagnostic. Crystals (mostly calcium oxalate) are quite important. The acicular, prismatic and aggregate forms predominate. Minute crystals (crypto-crystalline) occur in cinchona and cinnamons. Resinous and waxy contents may prove of diagnostic value, also coloring matter, mucilage, etc. Occasionally the outer cell layers of this tissue become more or less collenchymatous.

4. Ducts and Glands.-These are generally of no great diagnostic value in powders. The contents are of some diagnostic value. 
Glandular parenchyma cells as of rhizomes, barks, pericarp, seed tissue, etc., are very frequently of great diagnostic value.

5. Bast.-This is very important. Carefully note the length and diameter of cells and whether they occur singly or in groups. Note porosity and thickness of cell walls. In some instances (cinchona, cinnamons and others) the bast cells are short and thick, approaching the character of sclerenchyma. Again, the cells may be branching, as in Prunus and Viburnum. Contents of bast cells are rarely diagnostic.

6. Crystal-Bearing Fibers.-These accompany the bast fibers. They consist of rectangular, thin-walled cells united end to end, each cell bearing a prismatic crystal of calcium oxalate. Their function is in all probability mechanical, giving additional support to the bast fibers. These fibers may prove of great diagnostic value, as in Quebracho.

7. Sclerenchyma.-Sclerenchyma cells are even more diagnostic than bast. They vary in form, size and thickness of walls. They may occur singly or in groups. They are mostly typical - that is, approximately isodiametric, thick-walled and porous. Again, they may be rectangular, elongated or branching. Rarely is the color and lamellation (Coto) characteristic. In some instances (cinnamon) the walls are not uniformly thickened. Contents of sclerenchyma cells are rarely diagnostic. Note number, size and branching of pores.

8. Medullary Rays. - This tissue is very prominent in some barks. Note number of cell rows and size of cells, porosity of walls; and cellcontents, as starch, resin, crystals.

9. Epidermal Tissue.-This is, of course, wholly wanting in the older barks, having been displaced and pushed off by the deeper tissue. The same may be said of the chlorophyll-bearing parenchyma which in the younger branches occurs beneath the epidermis.

\section{ROOTS AND RHIZOMES}

Roots and rhizomes are closely similar in histological structure. In the powdered state there is no reliable means of distinguishing between them, either microscopically or macroscopically. The color of the powder is rather variable. The predominating color is light brown, often tinged with ash-gray, but there are exceptions, as the deep reddish-brown of rhatany and the yellow of licorice, hydrastis and curcuma. Some are very light, as Iris florentina, Colchicum corm and Althæa. Any of the typical tissues may be present, excepting epidermal tissues and trichomes, which are very sparingly present if at all. 
1. Epidermal Elements.-These are usually indistinct or wanting; when present compare with those of the leaf and stems, which see. Trichome are quite universally absent. Terminal rootlets are quite generally lost in collecting; hence, hair-cells are not found. Epidermal cells, when present, do not present any. special diagnostic features; they are usually suberized.

2. Cork.-Suberized tissue is quite generally present and displaces the epidermal tissue. As a rule, it presents no strikingly diagnostic features in the form and number of cells, or in cell-contents. The cell-walls are quite uniform in thickness and coloration.

3. Parenchyma.-This tissue is, as a rule, quite typical and abundant. The cells do not vary greatly in size and thickness of walls. In monocotyledonous roots and rhizomes they are, as a rule, considerably elongated in the long axis of growth. The peripheral cells are tangentially flattened and smaller than the more centrally located cells.

The cell-contents are highly important and diagnostic; above all the starch granules. It must, however, be kept clearly in mind that the pasty starch of certain drugs, as sarsaparilla, curcuma and others, is not a natural product, but artificially producd by heat. Such starch usually occurs in lumps of the dimensions of the cell-lumen (Curcuma), the individual granules having lost their structural characteristics almost entirely.

Unmodified granules should be critically studied and compared as to size, form, position and size of hilum, distinctness of lamellation, etc. Are they simple or compound? Are the granules free or do they form aggregates? If compound, do the granules occur in twos, threes or fours? The careful study of starch granules cannot be too strongly emphasized, as it will not only be the key to the identification of the powders, but will also be of inestimable value in the recognition of starchy or starch bearing substances which are quite frequently employed as adulterants.

Parenchyma cells frequently contain crystals, usually of calcium oxalate. These may occur as fine granules (belladonna), prismatic, aggregate and acicular crystals. The aggregate and acicular forms vary most in size. The form and size of the crystals is of great diagnostic value.

Resin and mucilage bearing cells are often diagnostic. Note the size of the resin-bearing cells and the color of the resin. Wax-like and other cell-contents may occasionally prove diagnostic.

Inulin is very abundant in certain plants taking the place of starch, and will, therefore, prove very diagnostic in comparison with starchbearing plants. 
4. Vascular Tissue.-The endoderm cells may prove diagnostic (varieties of sarsaparilla). They should be carefully examined as to the size and form of the cells, thickness and uniformity of thickness of the cell-walls, porosity and color of cell-walls and nature of cellcontents. The ducts will frequently prove diagnostic. Study them as to size (diameter), form of thickenings (porous, scalariform, recticulate, spiral, annular). The bast and wood elements accompanying the vascular bundles vary in quantity. Sieve tissue, conducting cells, and meristematic tissues are rarely diagnostic. The parenchyma of the vascular bundle is, in most respects, similar to other parenchyma. Tracheids may prove diagnostic. Study them carefully as to size, number and form of pores, etc. In some instances the abundance of tracheids and wood elements will prove diagnostic. Note carefully the form, grouping and contents of the cells of the medullary rays.

5. Laticiferous Ducts. - These occur in a number of vegetable drugs and will be of considerable diagnostic value to the careful observer.

6. Pith.-This is usually deficient and of little diagnostic value. The cells are usually thin-walled, typically parenchymatous and pretty well broken in powders. Note porosity of walls and absence or presence of crystals and resin.

\section{STEMS}

There are only comparatively few medicinal stems. They are mostly quite woody, and some, as coniferous stems, have the leaves included.

1. Epidermal Elements.-Usually present, and should be carefully compared with those of leaves. As a rule, they are less abundant and less characteristic.

2. Hypoderm.-Usually of no significance (see Leaf). .

3. Chlorophyll-bearing Parenchyma.-This may be present, but is rarely diagnostic.

4. Collenchyma.-When quite abundant and typically developed it will prove quite diagnostic, but it is only the transverse view of long cells which will present the characteristic appearance of these elements.

5. Bast.-See "Roots and Rhizomes."

6. Parenchyma.-Cell-contents less abundant and usually less characteristic or diagnostic (see Roots and Rhizomes).

7. Woody Tissue.-This is usually very abundant and diagnostic. Note length, diameter and porosity of elements. Note medullary rays and cell-contents.

8. Sćlerenchyma.-Not generally present (see Barks). 
9. Pith.-Usually present, but not specially diagnostic. Note cell aggregations (rosettes) and cell-contents, as resin, mucilage, crystals and starch.

10. Vascular Elements.--See "Roots and Rhizomes."

\section{WOODS}

There are only a few employed, and are quite characteristic in color, as the straw-yellow quassia, olive-green guaiac, red sandalwood, purplish hæmatoxylon and reddish-brown sassafras.

1. Wood Cells.-Note diameter, thickness of walls, and contents as starch, resin and crystals.

2. Ducts. - Note presence or absence, diameter, porosity and other markings. Often diagnostic.

3. Medullary Rays. - Important and often diagnostic. Note number of cell-rows, porosity of cell-walls, and cell-contents.

\section{OTHER PLANT PARTS}

Under this head are included ergot and corn smut (fungi); dextrin (modified starch); Kamala (trichomes and glands); Lycopodium (spores of club-moss); Iceland moss (lichen); Irish moss (marine alga); starches, cereal flour, resin, waxes, gums, etc., etc. These must be studied with great care as to minute details of structure.

\section{Tabulation of Tissues and Tissue Elements}

The following summarizing of plant organs with their characteristic tissues and tissue elements will be found useful and suggestive in the critical histologic examination and study of crude drugs and powdered drugs.

\section{Leaves.}

$1^{1}$ Epidermal elements.-By far the most important diagnostic elements of the leaf.

$1^{2}$ Upper epidermis.

$1^{3}$ General outline of cells as determined from an examination of transverse and surface sections.

$2^{3}$ Measurements. Size of cells sometimes diagnostic.

$3^{3}$ Cuticle.

$1^{4}$ Thickness. Very variable.

$2^{4}$ Surface markings. Linear, warty, none.

$3^{4}$ Surface deposits. Resinous, waxy, none. 
$4^{3}$ Vertical walls. In vertical view.

$1^{4}$ Thickness. Not excessively variable or characteristic.

$2^{4}$ Form. Wavy or straight; often a diagnostic comparative feature.

$3^{4}$ Porosity of walls.

$4^{4}$ Nodular thickenings. Characteristic when present.

$5^{3}$ Cell-contents. Not commonly present or plentiful.

$1^{4}$ Chlorophyll. Usually wanting, not characteristic.

$2^{4}$ Starch. Very rarely present.

$3^{4}$ Crystals. Not common, diagnostic on occasion.

$4^{4}$ Inulin and hesperidin. Plentiful and diagnostic in a few instances (Buchu).

$5^{4}$ Coloring matter, resin, wax.

$6^{4}$ Tannin, etc.

$6^{3}$ Hair cells (trichomes). Very important and diagnostic.

$1^{4}$ Nonglandular.

$1^{5}$ Simple.

$1^{6}$ Single-celled.

1? Size. Rather variable.

$2^{7}$ Form. Sometimes diagnostic.

$3^{7}$ Thickness of walls and exterior markings.

$2^{6}$ Many-celled.

$1^{7}$ Number of cells.

$2^{7}$ Size, form, etc., as above.

$2^{5}$ Aggregate or stellate. Quite characteristic and diagnostic.

$1^{6}$ Number of cells.

$2^{6}$ Form and relative position of cells.

$3^{5}$ Branching. Quite characteristic.

$1^{6}$ Number of cells.

$2^{6}$ Size and form of cells.

$3^{6}$ Number of branching cells.

$2^{4}$ Glandular. Usually few, small and quite indistinct. Sometimes diagnostic.

$1^{5}$ Neck or basal cells; size and number.

$2^{5}$ End or secreting cells; size and number.

$3^{4}$ Neighboring cells.

$1^{5}$ Number. Sometimes diagnostic.

$2^{5}$ Size and form. Radially elongated.

$4^{4}$ Contents. Usually none in nonglandular hair-cells; when present, quite diagnostic. (Cannabis Indica). 
$5^{4}$ Color and external markings.

$7^{3}$ Stomata. Often wanting. For characteristics see lower epidermis.

$2^{2}$ Lower epidermis. Make careful comparisons with upper epidermis.

$1^{3}$ General outline of cells.

$2^{3}$ Measurements. Transverse diameter usually somewhat more than that of upper epidermis. Vertical diameter usually less.

$3^{3}$ Cuticle. Usually thinner than upper. Characteristic thickenings.

$4^{3}$ Outer wall. Sometimes with diagnostic modifications. (Coca leaves.)

$5^{3}$ Vertical walls. More generally wavy in outline than those of upper epidermis.

$6^{3}$ Hair cells. Usually much more numerous than upper epidermis. (See upper epidermis.)

$7^{3}$ Stomata. ${ }^{1}$ Nearly always present. Vertical or surface view to show the striking structural characteristics.

$1^{4}$ Number. Variable, but not diagnostic, excepting when comparing upper and lower epidermis.

$2^{4}$ Size (of guard cells). Somewhat variable, but rarely diagnostic.

$3^{4}$ Guard cells. Difficult to see in leaves with thick cuticle, as in eucalyptus.

$1^{5}$ Form. Constant in vertical view; variable in profile view. Not diagnostic.

$2^{5}$ Contents. Chlorophyll and occasionally coloring matter. $4^{4}$ Nebenzellen. $^{2}$ Sometimes quite characteristic. Compare carefully with normal epidermal cells.

$1^{5}$ Number to each stoma. From two to five or six. Number sometimes diagnestic.

$2^{5}$ Variations in size. Somctimes diagnostic (senna).

$3^{5}$ Markings (cuticular). Sometimes quite different from those of normal epidermal cells.

$4^{5}$ Outer wall of cells. Sometimes quite different in form from normal cells (coca).

${ }_{1}$ When stomata are wanting in an epidermal fragment, it indicates that said fragment belongs to the lower epidermis. When stomata are present on both sides it will be found that they are quite generally more numerous in the lower epidermis.

${ }^{2}$ The English equivalent for this German term is neighboring cells. 
$5^{5}$ Contents. Sometimes diagnostic (some species of jaborandi).

$5^{4}$ Air chamber. Never diagnostic. Crystals of calcium oxalate usually more numerous in the spogny tissue cells bounding the air chamber.

$2^{1}$ Hypodermal elements. Usually wanting and rarely of any significance, especially in powders.

$1^{2}$ Upper hypoderm.

$1^{3}$ Size and form of cells. Larger than those of lower hypoderm.

$2^{3}$ Number of cell layers. Usually two.

$3^{3}$ Cell walls. Colorless and comparatively thin. Mucilaginous in buchu.

$4^{3}$ Contents. Usually empty.

$1^{4}$ Cystoliths in large cells (Ficus).

$2^{4}$ Mucilage.

$3^{4}$ Crystals of calcium oxalate.

$2^{2}$ Lower hypoderm. Compare with the upper.

$3^{1}$ Palisade tissue. Never characteristic in powders.

$1^{2}$ Size and length of cells.

$2^{2}$ Rows of cells. One to three.

$3^{2}$ Contents.

$1^{3}$ Chlorophyll.

$2^{3}$ Crystals. Not usual.

$4^{1}$ Spongy tissue. Rarely characteristic.

$1^{2}$ Form of cells.

$1^{3}$ Oval and elongated.

$2^{3}$ Branching.

$2^{2}$ Contents.

$1^{3}$ Coloring matter. Not usual.

$2^{3}$ Crystals. Prismatic and aggregate.

$3^{3}$ Resin, wax, inulin, tannin.

$4^{3}$ Chlorophyll.

$5^{1}$ Stone cells in leaf parenchyma. Rare but diagnostic (tea).

$6^{1}$ Mechanical cells. Usually not diagnostic. (Eriodictyon, lateral lines of coca).

$7^{1}$ Glands. Not characteristic in powder.

$1^{2}$ Form.

$2^{2}$ Contents. Resin, wax, coloring matter.

$3^{2}$ Number.

$4^{2}$ Position in leaf parenchyma.

$8^{1}$ Leaf stalk (petiole). Structure usually not characteristic, - similar to that of stem. 
$1^{2}$ Epidermis. See above.

$2^{2}$ Cork cells.

$3^{2}$ Parenchyma with cell-contents, as starch, crystals, resin, coloring matter, etc.

$4^{2}$ Stone cells (sclerenchyma). Sometimes diagnostic.

$5^{2}$ Vascular tissue.

$1^{3}$ Bast.

$2^{3}$ Tracheids.

$3^{3}$ Vessels. Occasionally characteristic.

II. Flowers.

$1^{1}$ Staminate structures.

$1^{2}$ Vegetative tissue elements. Not characteristic, diagnostic or distinct.

$2^{2}$ Pollen grains. Very important and diagnostic.

$1^{3}$ Size. Not very variable.

$2^{3}$ Form. Quite variable and characteristic.

$3^{3}$ Color. Mostly yellowish brown.

$4^{3}$ Markings of exine. Characteristic and diagnostic.

$2^{1}$ Pistillate structures. Not diagnostic.

$3^{1}$ Petals.

$1^{2}$ Epidermal elements. Compare with leaf.

$1^{3}$ Structure and form. Hair cells.

$2^{3}$ Contents. Coloring matter.

$2^{2}$ Parenchyma. Deficient and not important.

$3^{2}$ Vascular tissue. Deficient and not diagnostic. (See leaf.) $4^{1}$ Sepals. Compare with leaf. Quite important.

$5^{1}$ Pappus. Often diagnostic.

$6^{1}$ Stone cells. Usually from torus. Quite important and characteristic.

III. Fruits ANd Seeds.

$1^{1}$ Epidermal elements. Special modifications of cells, often very characteristic and diagnostic. Compare with leaf.

$1^{2}$ Hair cells. Usually nonglandular and characteristic.

$2^{2}$ Stomata. Rare and not important.

$2^{1}$ Stone cells. Usually present. Often diagnostic.

$1^{2}$ Form and size. Variable.

$2^{2}$ Color. Reddish brown to nearly colorless.

$3^{2}$ Cell-walls.

$1^{3}$ Porosity.

$2^{3}$ Thickness. 
$1^{4}$ Uniform.

$2^{4}$ Thicker on one side.

$3^{1}$ Special cells of testa.

$1^{2}$ Size and form. Often very characteristic

$2^{2}$ Color.

$4^{1}$ Endosperm (parenchyma) cells.

$1^{2}$ Form and size.

$2^{2}$ Cell-walls.

- $1^{3}$ Thickness. Quite variable.

$2^{3}$ Porosity.

$3^{3}$ Form. Usually quite regular; wavy, irregular.

$3^{2}$ Contents. Usually not diagnostic.

$1^{3}$ Starch. Absent or present. See starch under roots and rhizomes.

$2^{3}$ Proteid granules.

$3^{3}$ Amylodextrin granules.

$4^{3}$ Oils and fats.

$5^{3}$ Crystals.

$6^{3}$ Resin, wax, etc.

$5^{1}$ Vascular tissue. Not specially characteristic. Plentiful in pericarp. Deficient in seeds.

IV. BARKS.

$1^{1}$ Suberized tissue or true cork.

$1^{2}$ Size and form of cells.

$2^{2}$ Contents.

$1^{3}$ Granular contents. Tannin.

$2^{3}$ Red or reddish brown coloring matter.

$2^{1}$ Lenticular structures. Like those of other plant organs. Not characteristic.

$3^{1}$ Bark parenchyma. Not diagnostic.

$1^{2}$ Size and form of cells. Usually loosely united. Sometimes much elongated.

$2^{2}$ Contents.

$1^{3}$ Crystals. Prismatic and aggregate.

$2^{3}$ Starch. Not plentiful or diagnostic.

$3^{3}$ Mucilage, resin, coloring matter, etc.

$4^{1}$ Collenchymatous parenchyma. Not common or very characteristic.

$5^{1}$ Ducts and glandular structures. Not important.

$6^{1}$ Bast fibres. Very important and diagnostic.

$1^{2}$ Occurrence.

$1^{3}$ Singly. 
$2^{3}$ In groups.

$3^{3}$ Continuous concentric layers.

$2^{2}$ Size and form. Porosity of walls.

$1^{3}$ Typical.

$2^{3}$ Very large and short (Cinchona).

$3^{3}$ Branching cells.

$3^{2}$ Contents. Some starch.

$7^{1}$ Crystal-bearing fibres accompanying bast and stone cells. Quite

$8^{1}$ Sclerenchymatous tissue. important and diagnostic.

$1^{2}$ Occurrence.

$1^{3}$ Singly.

$2^{3}$ In groups.

$3^{3}$ Continuous concentric layers.

$2^{2}$ Size and form.

$3^{2}$ Cell-walls.

$1^{3}$ Porosity.

- $2^{3}$ Thickness.

$1^{4}$ Uniform.

$2^{4}$ Thicker on one side (cinnamon).

$3^{3}$ Color.

$9^{1}$ Medullary ray tissue. Radially curved.

$1^{2}$ Cell-forms. Porosity of walls.

$2^{2}$ Cell-contents. Starch and crystals.

$3^{2}$ Number of cell rows.

$10^{1}$ Epidermal. Quite generally wanting.

$11^{1}$ Chlorophyll-bearing parenchyma. Usually wanting in the older barks.

V. Roots ANd Rhizomes.

$1^{1}$ Epidermal elements. Usually not distinct or wanting.

$2^{1}$ Cork. Usually typical when present.

$3^{1}$ Parenchyma. Typical and well developed.

$1^{2}$ Form of cells.

$1^{3}$ Outer parenchyma tangentially flattened.

$2^{3}$ Inner parenchyma isodiametric.

$2^{2}$ Cell-contents. Very important.

$1^{3}$ Starch granules.

$1^{4}$ Simple.

$1^{5}$ Form and size.

$2^{5}$ Lamellation.

$3^{5}$ Position of hilum. 
$1^{6}$ Centric.

$2^{6}$ Excentric.

$2^{4}$ Compound. In twos, threes and fours.

$3^{4}$ Aggregate, as in oats and rice.

$2^{3}$ Crystals of calcium oxalate.

$1^{4}$ Crystal dust or powder. Rare.

$2^{4}$ Prismatic. Comparatively rare.

$3^{4}$ Acicular. Raphides. Larger and smaller.

$3^{3}$ Cystoliths. Rare.

$4^{3}$ Mucilage cells.

$5^{3}$ Resin.

$6^{3}$ Coloring matter.

$4^{1}$ Vascular tissue.

$1^{2}$ Endoderm. Cells sometimes diagnostic.

$1^{3}$ Size and form of cells.

$2^{3}$ Thickness of cell-walls.

$3^{3}$ Contents.

$2^{2}$ Ducts. All possible forms.

$3^{2}$ Phloem.

$1^{3}$ Sieve tissue with contents.

$2^{3}$ Conducting cells.

$4^{2}$ Parenchyma.

$5^{2}$ Bast.

$6^{2}$ Tracheids. Often important.

$\mathbf{1}^{3}$ Size and form.

$2^{3}$ Size, number and form of pores.

$5^{1}$ Woody tissue. Variable in amount.

$1^{2}$ Wood fibers.

$2^{2}$ Tracheids.

$3^{2}$ Ducts. Note form, size and markings.

$4^{3}$ Medullary rays.

$1^{4}$ Size and form of cells.

$2^{4}$ Number of layers.

$3^{4}$ Cell-contents.

$5^{3}$ Cell-contents. Crystals, some starch, etc.

$6^{1}$ Pith tissue. Usually deficient.

VI. Stems.

$1^{1}$ Epidermis. Usually present. See leaf.

$2^{1}$ Hypoderm. Not generally present. See leaf.

$3^{1}$ Chlorophyll-bearing parenchyma.

$4^{1}$ Collenchyma. Usually typical. In interrupted patches. 
$5^{1}$ Bast.

$6^{1}$ Parenchyma. See roots and rhizomes. Contents less plentiful and less characteristic.

$7^{1}$ Woody tissue.

$1^{2}$ Wood cells and tracheids.

$2^{2}$ Medullary rays.

$8^{1}$ Vascular tissue. See roots and rhizomes.

$9^{1}$ Sclerenchyma. See barks.

$10^{1}$ Pith. Usually present. Variable in amount.

$1^{2}$ Size and form of cells. Rosettes.

$2^{2}$ Cell contents. Mucilage, resin, starch.

VII. Woods. SeE WOody tissue of stems.

$1^{1}$ Wood cells.

$2^{1}$ Ducts.

$1^{2}$ Size.

$2^{2}$ Number and size of pores.

$3^{1}$ Medullary rays. Important and often diagnostic. Study transverse, tangential and radial sections carefully.

VIII. Pith. See stems.

V. Illustrations with Descriptions of the More Common Plant Tissues

From the foregoing it will be seen that the fully formed and matured tissues and tissue elements and formed cell-contents, which occur in drugs of vegetable origin and which are recognizable under the compound microscope, are comparatively few in number and may be classified as follows:

\section{Tissues}

1. Epidermal and endodermal.

2. Hypodermal.

3. Parenchymatous tissues.

4. Tracheids and wood fiber.

5. Ducts of vascular tissue (bundles).

6. Cork tissues of all kinds.

7. Bast tissues.

8. Sclerenchymatons cells and tissues.

9. Medullary ray tissues.

10. Secretory and excretory glands and ducts.

11. Pollen grains and spores. 


\section{Cell-Contents}

1. Starch granules.

2. Crystals of calcium oxalate.

3. Resins and resinoid substances.

4. Mucilages and gums.
5. Inulin, sugars, tannin.

6. Protein granules.

7. Fats and oils.

8. Coloring matter.

Formative tissues, cambial tissues, apical area tissues, phellogenic tissues, plasmic elements, and phloem tissues generally, are of little interest to the student of pharmacognosy and are of no practical significance in the microscopical examination of powdered vegetable drugs. The following illustrations, with descriptions, will serve as a guide to the study of tissues, tissue elements and of cell contents.

\section{DESCRIPTION OF PLATE I}

Fig. 8.-Types of Pollen Grains.-1. Saffron flower. 2. Flax. 3. Pink. 4. Pumpkin and squash. 5. Cloves. Mature pollen grain. 6. Cloves. Immature pollen grain. 7. Onagraceæ. Circea lutitiana (Enchanter's Nightshade). 8. Scutellaria. 9. Mallow. Distended by moisture. 10. Mallow. Nermal form. 11. Albuco. 12. Lobelia inflata. 13. Compositæ, showing one mature and two immature pollen grains. 14. Hibiscus. 15. Pine pollen. 16. Santonica. 17. Mentha species. 18. Hyoscyamus niger.

FIG. 9.-Potato Starch.-The granules are large and the markings (hili, lamellations) are distinct. The cross bands under the polarizer are very distinct. Potato starch, mounted in water, makes a good test object for judging the resolving power of objectives. Dried and ground potatoes and potato parings are sometimes used for adulterating purposes.

FIG. 10.-Starches.-1. Sago starch from Cycas revoluta (Cycadaceæ). The commercial article known as sago is usually in the form of small granules (pearl sago). There are many false sagos made from other than Cycad or Palm starch. Much of this false sago is made from corn starch.

2. Canna starch from several species of Canna. The markings are very distinct, the hili being at the larger end as a rule. Also called arrowroot (tous le mois arrowroot).

3. Cassava or tapioca starch from the tuberous roots of Manihot utillissima and other species of Manihot. Simple and compound granules; the granules are largely separated in the processing, thus giving the appearance of simple granules. Their compound origin is, however, recognizable by the contact facets.

4. Maranta starch (Arrowroot starch) from Maranta arundinacere (Marantaceæ). The granules have many of the structural characteristics of potato starch.

5. Yam starch from several species of Dioscorea (Dioscoreaceæ).

FIG. 11.-Dextrinized Starch.-The process of baking and cooking causes the starch granules to undergo marked structural changes. They become much enlarged, the outline becomes quite indistinct and the hili and lamellations are distorted and correspondingly indistinct. 1. Normal wheat starch granules. 2. Normal rye starch granules. 3. Dextrinized wheat and rye granules. 4. Normal and dextrinized corn starch. 5. Normal and dextrinized bean starch. 6. Normal and dextrinized ginger starch. 
MICROSCOPICAL EXAMINATION OF POWDERED VEGETABLE DRUGS 103

PLATE I

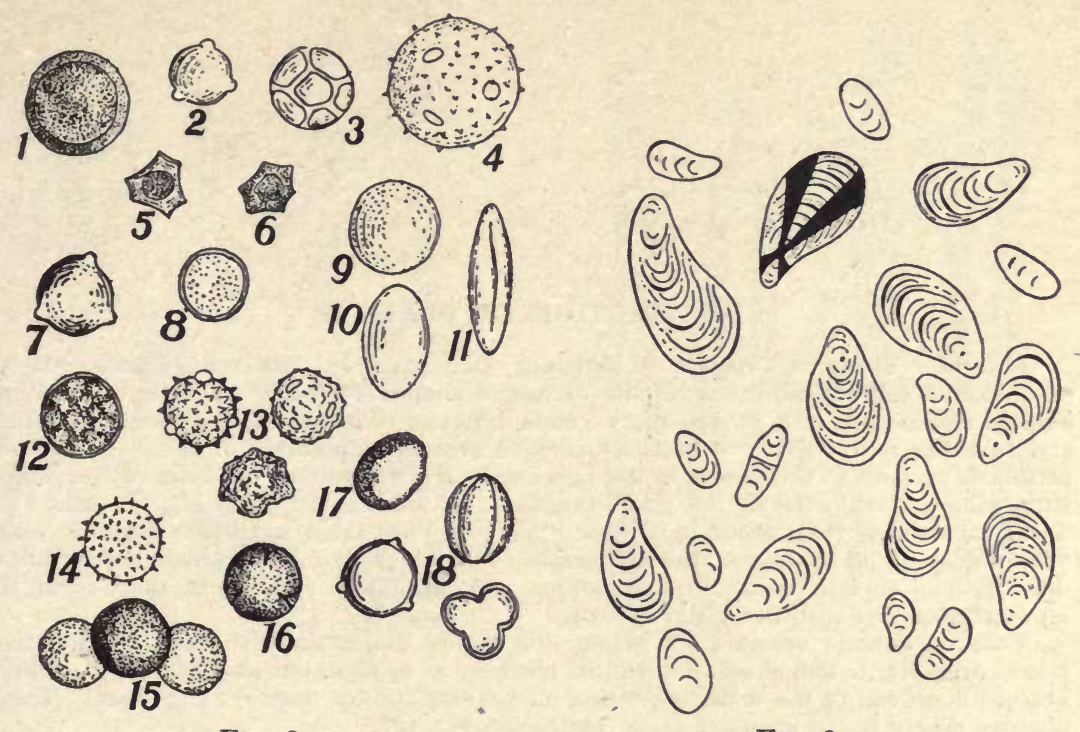

FIg. 8.

Fra. 9.

(寀)

(9)

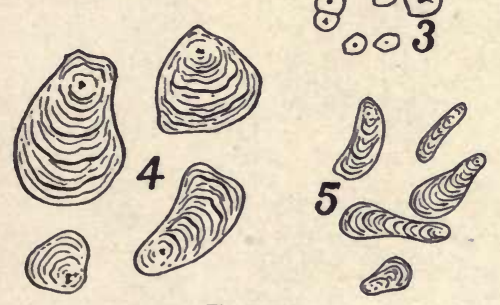

Fig. 10.

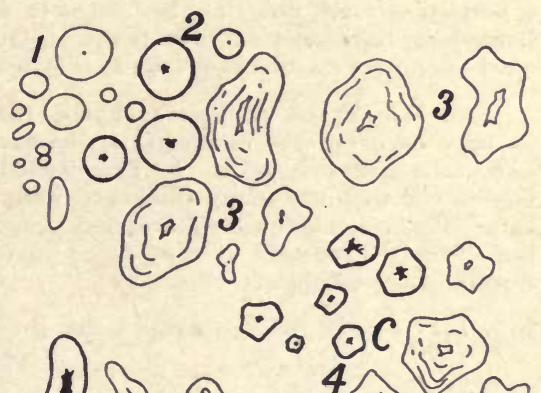

(1) (3) (1) : 0

FIG. 11. 


\section{DESCRIPTION OF PLATE II}

FIG. 12.-Types of Crystals of Calcium Occurring in Different Plants.-1. A parenchyma cell containing a bundle of needle shaped (acicular) crystals of calcium oxalate (raphide). 2, 3, 4, Acicular crystals differing in length, as they occur in Scilla and in other representatives of the liliaceous groups of plants. 5. Much elongated prismatic crystals as they occur in Quillaja and in Iris florentina. 6. Prismatic crystals very widely distributed in the plant kingdom. 7. Elongated prismatic crystals. 8. Twin crystals as they occur in Ulmus bark. 9. Very large aggregate crystals very widely distributed in the vegetable kingdom. 12, 13. Very minute prismatic (pyramidal) crystals as they occur in Belladonna. 14. Prismatic crystals as they occur in Hyoscyamus and in other plant groups.

Calcium oxalate crystals are among the highly diagnostic structural characteristics of drug plants and should be studied not only as to form but also as to size. They are not dissolved in the usual mounting media and are not destroyed by heat. They dissolve slowly in the stronger acids (hydrochloric acid).

Fig. 13.-Types of Bast Cells as They Occur in Barks and in Other Plant Parts. 1. Shorter bast cell as they occur in the cinnamon barks. 2. Typical bast cell (showing a portion of a cell only) as they occur in willow bark, in Ulmus, in Mezereon, etc. 3. Branching bast cells as they occur in Quillaja in Prunus bark. 4. Greatly thickened sclerenchymatous bast cells as they occur in the Cinchonas.

FIG. 14.-Types of Sclerenchyma (Stone) Cells.-1. Typical sclerenchyma cells as they occur in the endocarp of drupaceous fruits and nuts. 2. Elongated bastlike sclerenchyma cells. 3. Thin-walled typical sclerenchyma cell. 4. Sclerenchyma cell with unequally thickened walls as they occur in the cinnamons. 5. Large thin-walled sclerenchyma cells as they occur in the seed coat of Amygdala. 6. Branching sclerenchyma cells as they occur in tea leaves and in peanut exocarp. $7,8,9$, Forms of sclerenchyma cells.

Fig. 15. - Typical Sclerenchyma Cells (in groups) as they occur in the pulp of the pear. 
PLATE II

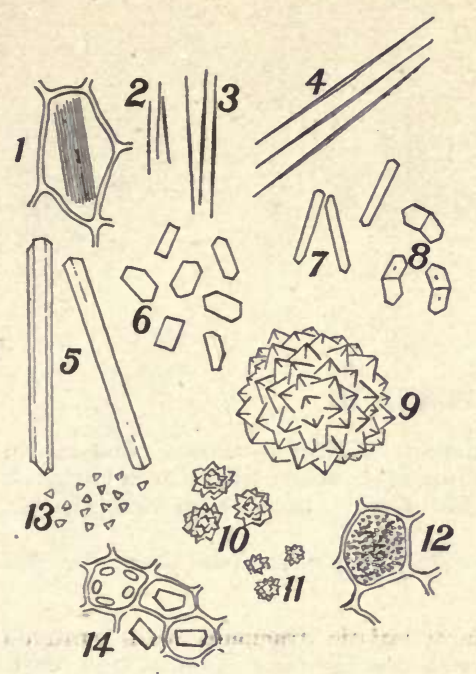

Fig. 12.

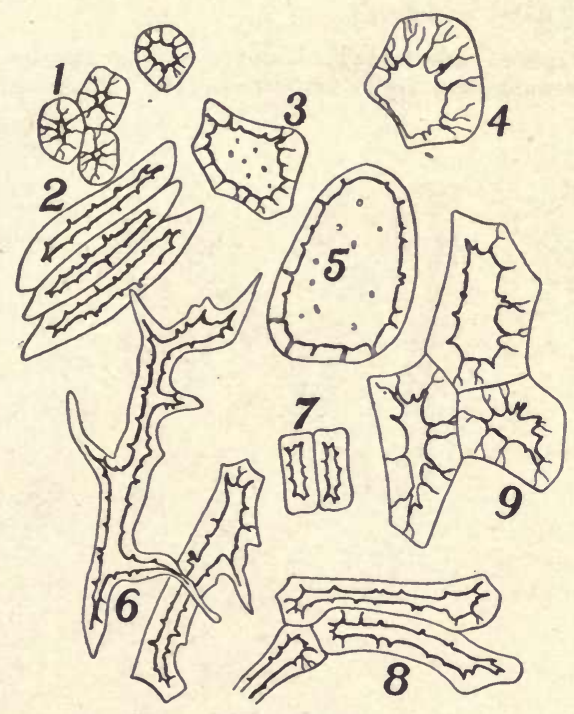

FIg. 14.

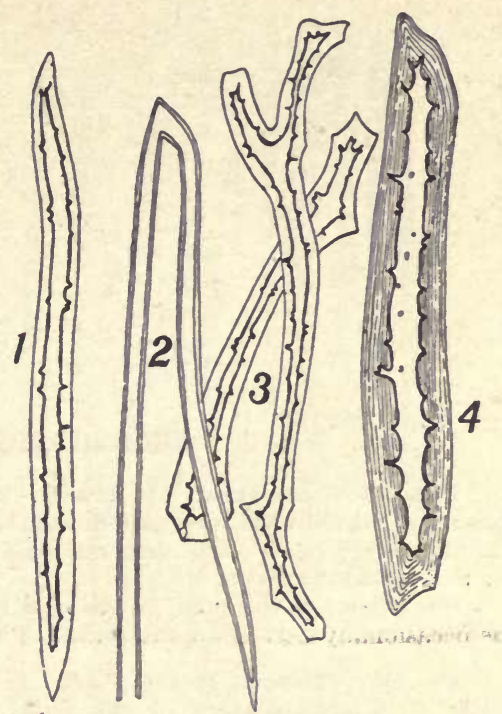

FIG. 13.

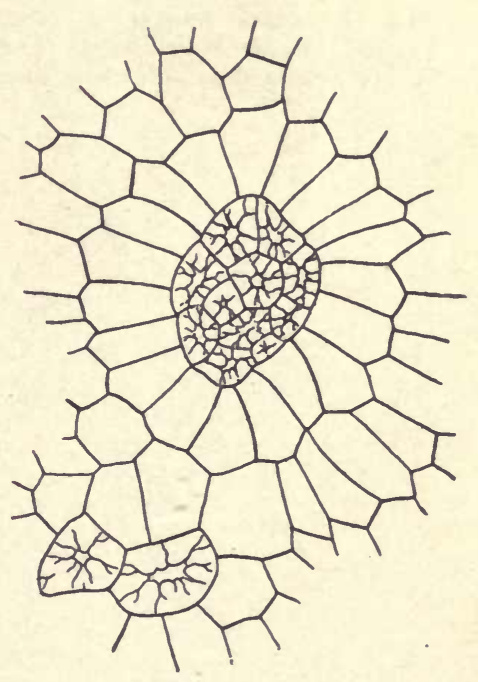

FIG. 15. 


\section{DESCRIPTION OF PLATE III}

Fig. 16.-Buckwheat.-1. Proteid-bearing tissue. 2. Starch-bearing endosperm tissue. Cell walls are very thin and the entire cell lumen is packed with starch granules. 3. Starch granules. The granules resemble those of corn, being somewhat smaller. 4. Sclerenchymatous fibers.

Buckwheat is the predominating ingredient of the buckwheat pancake flours and is occasionally used as an adulterant of spices.

Frg. 17.-Tissues of the Pine.-1. The characteristic tracheids with bordered pits. 2. Bast-like fibers of the bark. 3. Crystal-bearing bark parenchyma cells. 4. Tracheids in radial view. 5. Medullary ray cells in radial view. Pine wood (pulp) is much used in making paper.

Frg. 18.-Sclerenchyma Cells of Olive Pits.-Ground olive pits were, until recently, extensively employed as an adulterant of spices and drugs.

Fig. 19.-Clove Stems.-A very common adulterant of cloves and of allspice. 1. Typical sclerenchyma cells. 2. Sclerenchyma cells with unequally thickened walls. 3. Sclerenchymatous bast fibers. 
MICROSCOPICAL EXAMINATION OF POWDERED VEGETABLE DRUGS 107

PLATE III

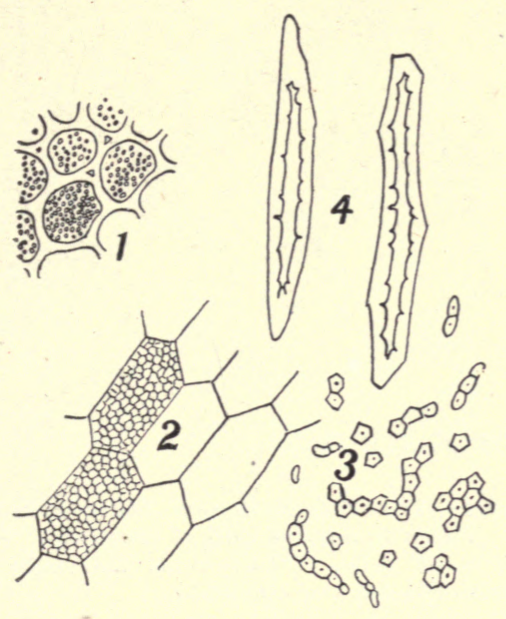

FIG. 16.

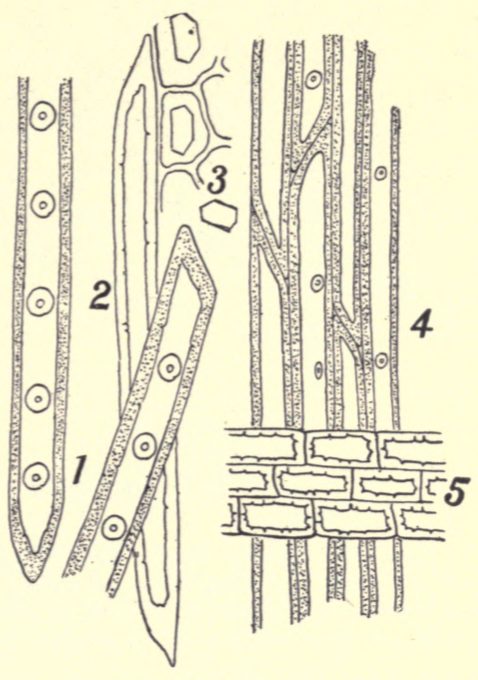

FIg. 17.

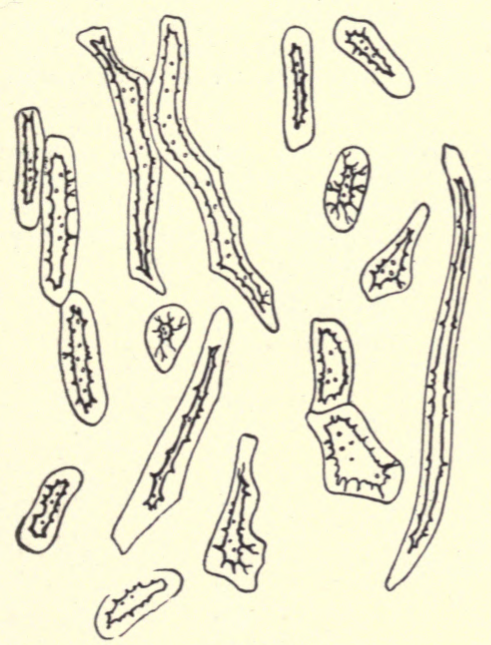

FIG. 18.

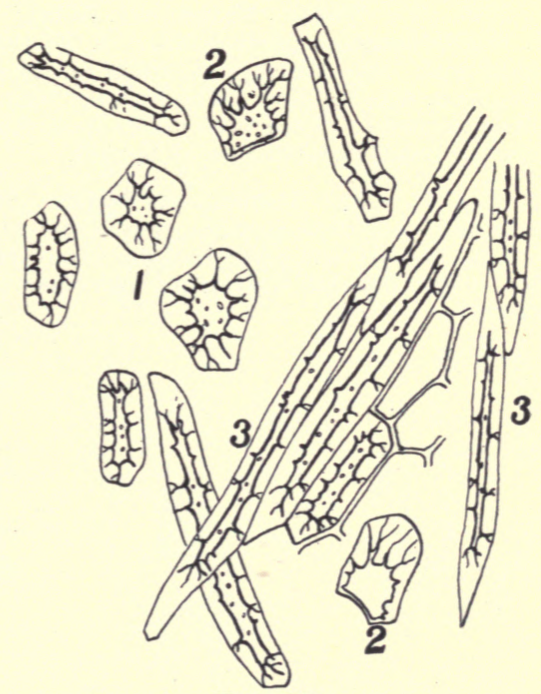

FIG. 19. 


\section{DESCRIPTION OF PLATE IV}

Fig. 20.-Cassia Buds and Cassia Stems.-1. Sclerenchymatous fibers of the cassia stems. 2. Bast fibers of cassia stems. Parenchymatous cells of the buds. 4. Trichomes of budds. 5. Thick-walled parenchyma cells. Cassia buds and cassia stems are frequently used in adulterating cloves, allspice and cinnamon.

Fig. 21.-Coffee Adulterants.-1. Sclerenchyma cells of date pits. 2. Sclerenchyma cells of the walnut shell. 3, 4, 5. Tracheids and inulin-bearing parenchyma cells of chicory. Figs and prunes are also much used as coffee adulterants, also cereals, fleshy roots, acorns, etc.

FIG. 22.-Wheat Tissues.-1. Wheat starch. 2. Trichomes from the bran. 3. Starch-bearing parenchyma. 4. Epicarp cells. 5. Proteid-bearing cells from middlings. Rye histology is similar to that of wheat. Wheat flour is used in macaroni, spaghetti, noodles, etc. Wheat flour, bran and middlings are much used for adulterating purposes. Rye starch differs from that of wheat in the larger size of the granules and the greater prominence of the hili.

FIG. 23.-Rice Tissues.-1. Starch. Single granules and aggregates. These aggregates are characteristic of rice and of oats. 2. Starch-bearing endosperm cells. $3,4,5$. Epicarp and pericarp cells. In form the starch granules of rice, oat, corn, darnel, millet, fox-tail, buckwheat and chess resemble each other. The size varies very much. 
PLATE IV

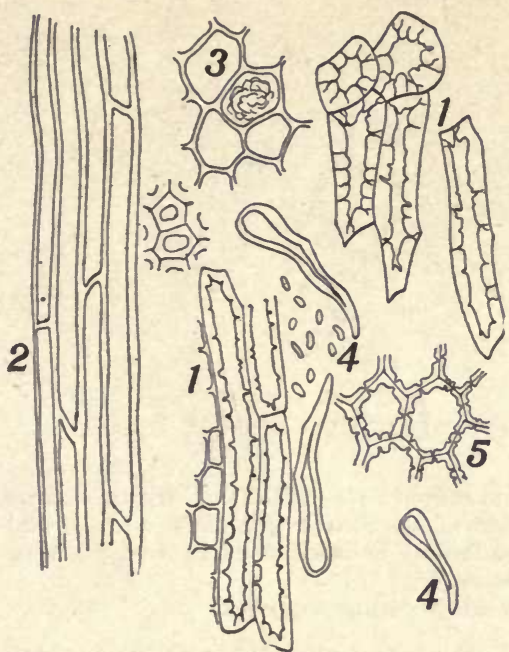

FIG. 20.

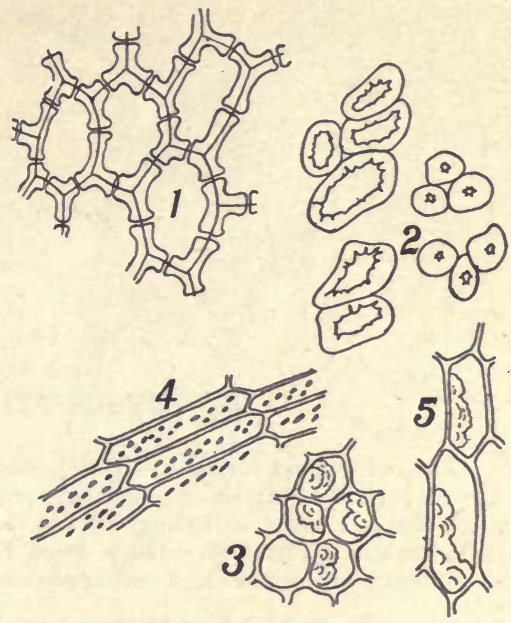

FIG. 21.

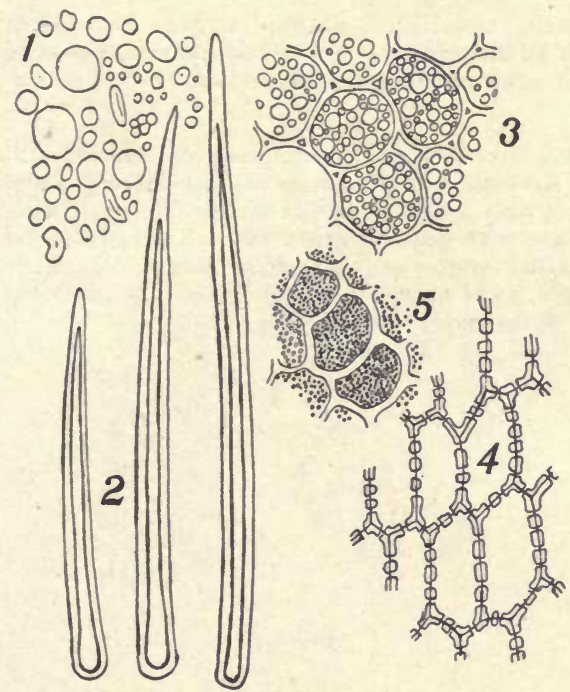

FIG. 22.

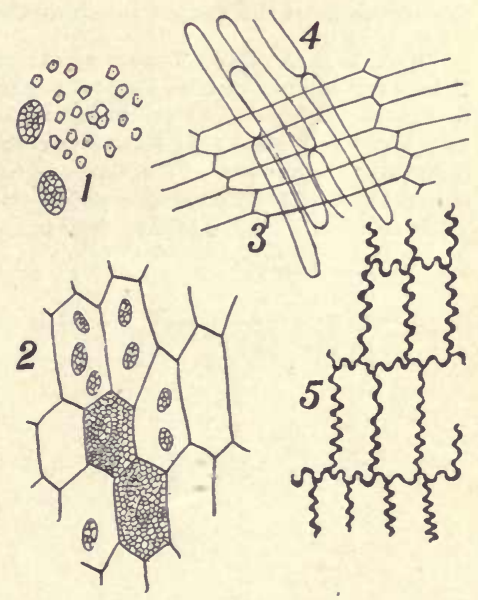

Fig. 23. 


\section{DESCRIPTION OF PLATE V}

FIg. 24.-Bean Tissues.-1. Epidermal palisade tissue with the crystal-bearing hypoderm. 2. Starch-bearing endosperm tissue. 3. Starch granules with prominent fissured hili. 4. Spongy tissue. 5. Epidermal palisade cells in vertical view. 6. Prismatic crystals of calcium from hypoderm.

Ground beans, peas and lentils are used for adulterating purposes.

FIG. 25.-Histology of Mallow Leaf.-1. Transverse section of leaf showing stellate trichome, epidermal, palisade and spongy tissue cells. Aggregate crystals of calcium oxalate are present. 2. Stellate or aggregate trichomes. 3. Epidermal cells (lower) showing stomata. Mallow leaves are extensively employed for adulterating leafy spices and drugs.

Fig. 26.-Histology of Corn.-1. Corn starch. 2. Starch-bearing endosperm of corn kernel. 3. Trichomes of the chaff of the corn cob. 4. Sclerenchymatous cells of the corn cob. Ground cobs are used for adulterating purposes and also in the manufacture of artificial maple syrup flavor.

Frg. 27.-A Few Types of Trichomes.-1. Branching trichome of mullein. 2. Many-celled simple trichome of henbane showing wart-like marking on outer surface. 3. Simple single-celled trichome as of rye and wheat. 4. Glandular trichome with two secreting cells. 5. Glandular trichome with one secreting cell. 6. Many-celled glandular trichome. 7. Simple, single-celled trichome of Indian hemp. 8. Much elongated and twisted single-celled trichome, as of sage. 9. Sessile glandular trichom $\theta$ (Eriodictyon). 10. Indian hemp. 11. Pyrethrum. 12. Simple trichome. 
PLATE V

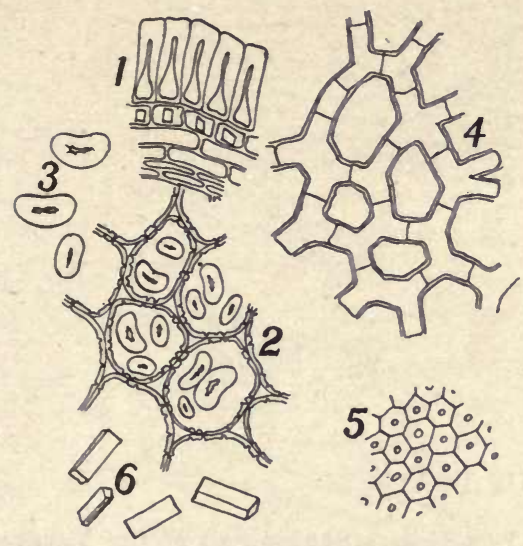

FIG. 24.

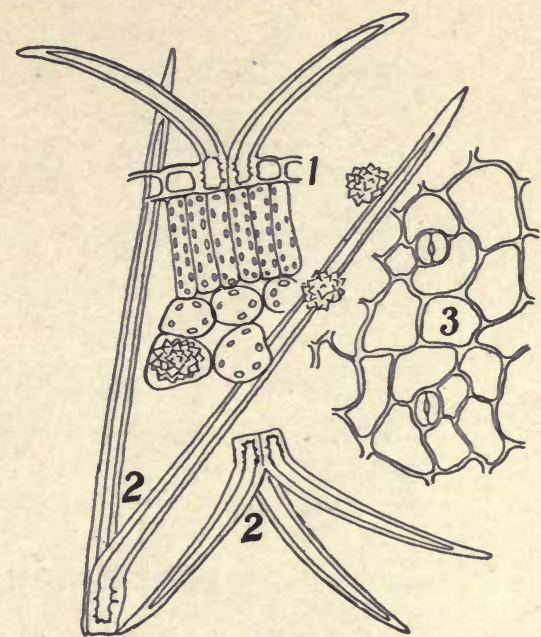

FIG. 25.

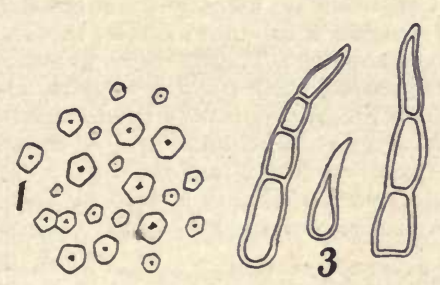

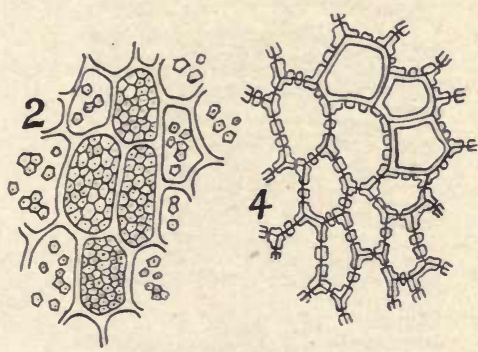

FIG. 26.

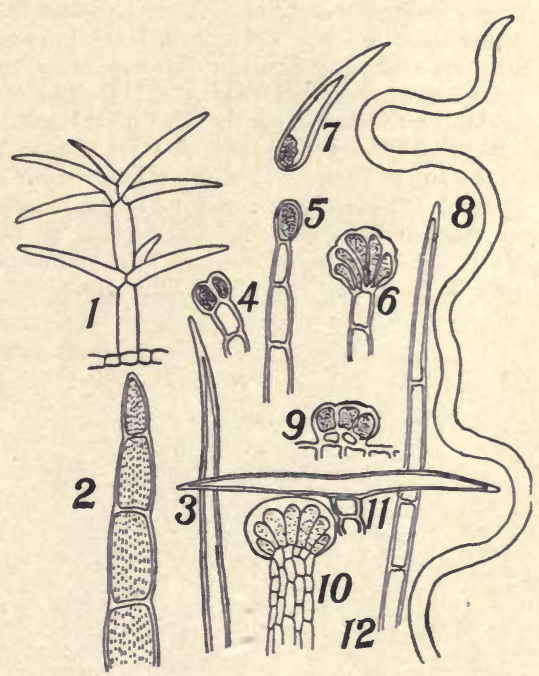

FIG. 27. 


\section{DESCRIPTION OF PLATE VI}

Frg. 28.-Illustrating the Histology of a Typical Bark Showing all of the Tissues Which May be Found in a Bark. - A, Longitudinal section in the radial direction but not showing the medullary rays. B, Transverse section. 1. Outer bark. The demarkation between outer and inner bark is not always distinct. 2. Inner bark. 3. Beginning of wood tissue. a, Epidermis. Always wanting in tree trunks and older branches. $b$, Cork tissue. $c$, Bark parenchyma. Cell-walls are usually not suberized and the cells may contain various inclusions such as crystals of calcium oxalate, tannin, starch granules and resin. $d$, Groups of sclerenchyma cells. These, when present, normally predominate in the outer bark. $e$, Crystal-bearing fibers which usually accompany the bast fibers. $f$, Bast fibers. These, when present, normally predominate in the inner bark. The fibers may occur singly or in groups. $g$, Cambium. $h$, Wood fibers. $i$, Ducts. Usually of the typically porous type. $k$, Medullary rays.

An excellent typical bark having all of the histological elements indicated in Plate VI is Rhamnus purshiana. The demarkation between outer bark and inner bark is well defined in Ulmus and Quillaja. 


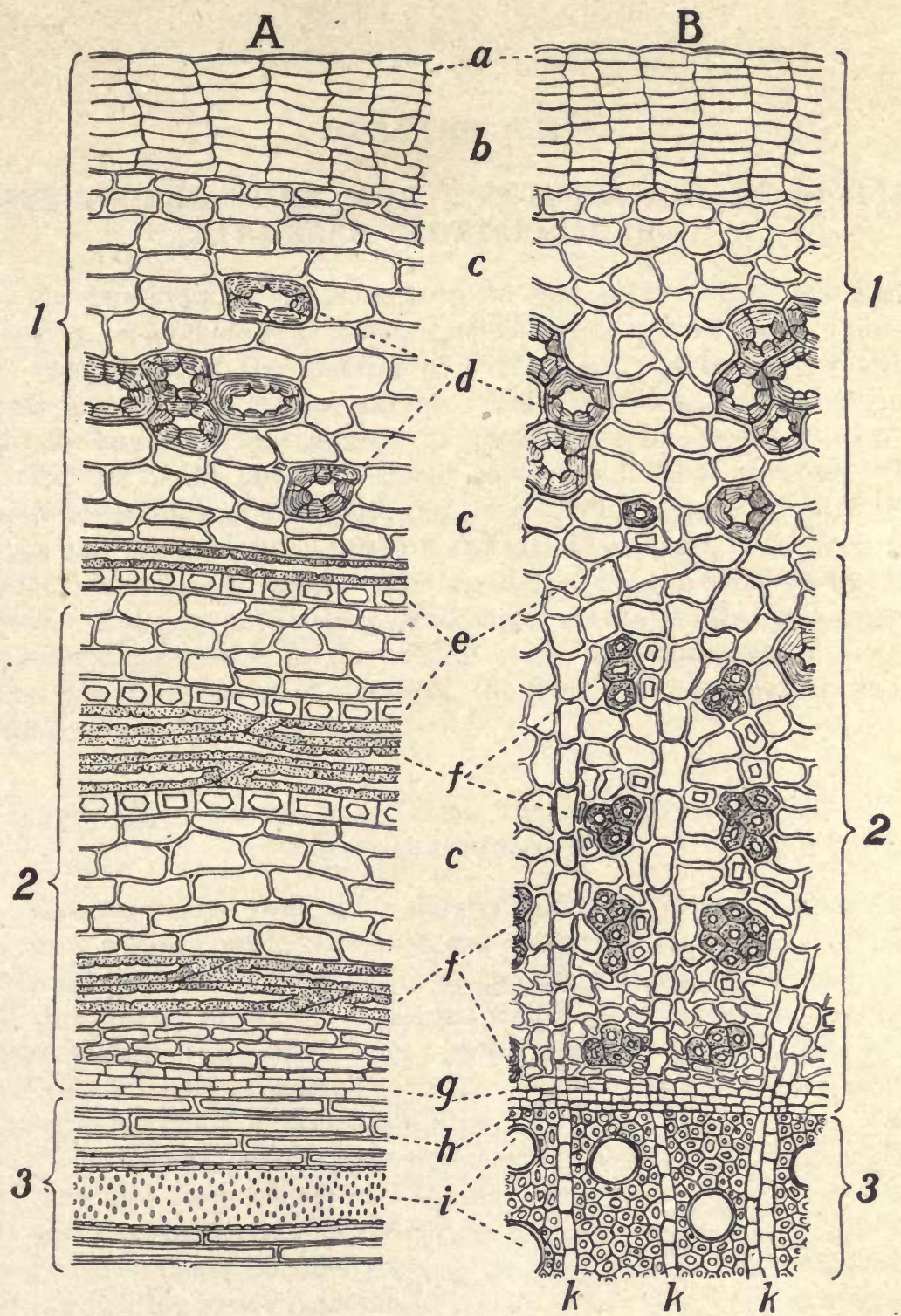

FIG. 28. 



\section{CHAPTER VIII}

\section{KEYS TO THE STUDY AND IDENTIFICATION OF SIMPLE POWDERED VEGETABLE DRUGS}

The two keys are supplementary to each other. Each key may, however, be used alone as it is independently complete in itself. Since the recognition of the identity of a vegetable powder is primarily dependent upon a careful microscopical examination, it is evident that the key based on the gross characteristics is of secondary value.

The use of the keys will serve two very important purposes. It compels careful macroscopical and microscopical examination of the drugs and it establishes a uniform and logical sequence in the method and manner of examination. The use of the keys as a means of identjfication of the drugs is largely incidental. As the student gains more and more experience in the critical study and examination of the vegetable drugs listed in the keys, the keys lose more and more in primary value and significance.

\section{Key Based Upon the Organoleptic Tests. Macroanalytical Key}

This key will prove an aid to the study and identification of powders by those who are not in possession of a compound microseope. It will be noted that the major divisions or groupings are based on color and for that reason the key is somewhat defective or confusing, because of the variation in colors, as has been explained elsewhere, and also because the powders fade quite rapidly, even if kept well in the dark. Basing the primary or major grouping on color differences is, however, wholly consistent because this character is, as a rule, striking and is the very first to be observed. It should also be borne in mind that the odors and tastes cited refer to crude drugs. The process of powdering does not change the taste and odor qualitatively, but quantitatively these properties lessen considerably with time. The following suggestions may prove useful. If the odor is very weak, it may be concluded that the powder is old, or that it may be adulterated with some odorless substance. If the taste is abnormally weak, the addition of some tasteless substance may be suspected. In comparatively rare in- 
stances adulteration is indicated by qualitative differences in odor as well as in taste.

\section{MACROANALYTICAL KEY}

Very Light to White

.. Odorless or odor slight

.... Sweetish

......Pure white or nearly pure white

....... Crisp; crackling sound on touch ${ }^{1} \ldots \ldots \ldots \ldots \ldots$. . . . . . .

........ Mealy. Not crisp to touch........................ Flours

......... Gluten test positive..................... Wheat flour

......... Gluten test negative.................. Other cereal flours

...... Brownish. Very mobile.......................... Dextrins

....Mucilaginous or gelatinous

......Brownish

....... Bitter, pungent. Does not dissolve....................... Scilla

....... Tasteless. Gelatinizes. Odorless ................... Tragacanth

....... Saline. Seaweed odor when moist................. Chondrus

...... Nearly snow-white. Tasteless

....... Dissolves readily. Sticky...............................

....... Does not dissolve. Gelatinizes. Not sticky............... Agar

....Very bitter

. Somewhat pungent. Grayish color..............(corm) Colchicum

....... Not pungent. Yellowish....................... Colocynth

....Pungent, astringent. Causes sneezing................ Quillaja

..With odor

.... Faintly fragrant

Althrea

...... Sweetish, mucilaginous

......Bitterish, somewhat pungent................. Iris florentina

....Fenugreek odor. Very mucilaginous................... Ulmus

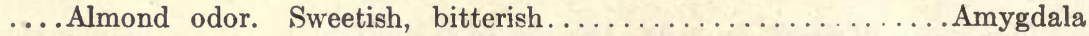

....Aromatic. Very pungent. Yellowish................. (white) Piper

Yellow or Distinctly Yellowish

..Odorless or odor faint and not characteristic

....Tasteless. Very mobile............................Lycopodium

....With taste

.......Bitter

....... Saliva colored yellow

........ Sweetish ................................ Frangula

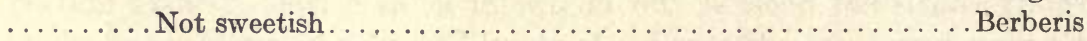

....... Saliva not colored

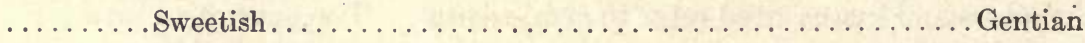

......... Not sweetish

.......... Dull yellow. Not exceedingly bitter

$\ldots \ldots \ldots \ldots$. Somewhat fibrous. Not granular...................... Palumba

.......... Bright yellow. Very bitter.

${ }^{1}$ Dried casein, dextrin and dried milk have a similar crisp crackling feel but these substances are not odorless and are yellowish to brownish in color. 
Lemon yellow......................... Hydrastis

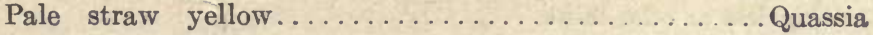

Very sweet. Pale yellow......................... Glycyrrhiza

Astringent

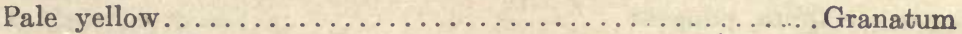

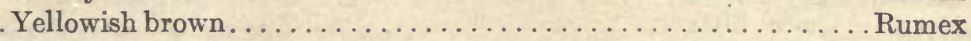

.... Pungent (very characteristic odor when moist)...... Brassica and Sinapis With odor

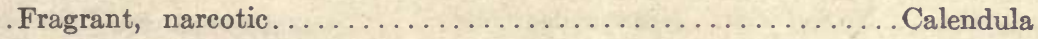

Hop odor. Bitter............................... Lupulin

Aromatic .

Bitter

.. Somewhat pungent

Pale yellow........................... (flowers) Pyrethrum

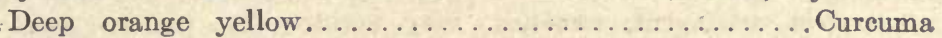

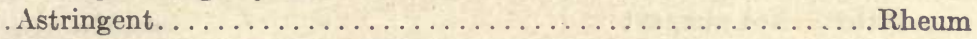

Aromatic. Ginger odor....................... Zingiber

Aromatic. Pepper odor..................... (white) Pepper

Very sweet; odor faint....................... Glycyrrhiza

RED or DISTINCTLY REDDISH

..Odorless

....Tasteless

......Wood fibers present.................... Santalum rubrum

No fibrous tissue. Sandy or gritty ................. Kamala

With taste

Very pungent; persistently acrid.................. Sanguinaria

Very astringent.......................................

With odor

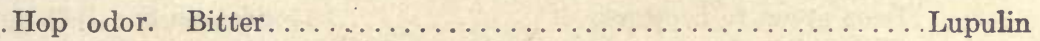

Characteristic odor, recalling iodoform............... Crocus

Faintly aromatic

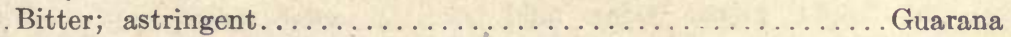

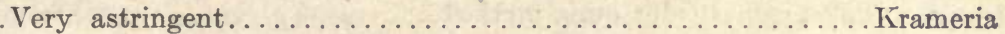

Slightly sweetish and astringent. Saliva red........... Hæmatoxylon

Very pungent. Odor characteristic...........................

Very Dark to Black

. Odorless

Tasteless. Black

Dull black............................ (vegetable) Charcoal

Lustrous black........................... (animal) Charcoal

Bitter, pungent. (Faintly aromatic)................. Juglans

With odor. Not entirely black

Aromatic. Odor characteristic

Very pungent

Mottled dark gray. Pepper odor.................(black) Piper

Very dark brown. Clove odor.................. Caryophyllus

Not pungent. Bitterish, astringent

Sweetish. Characteristic odor.............. (roasted) Cichorium

Not sweetish. Characteristic odor..............(roasted) Caffea 
Gray to Dark Gray, with Brownish Tinge

. Odorless or odor faint

. Pungent and bitter (faint narcotic odor) Ipecac

.Sweetish (faint narcotic odcr) Cimicifuga

Quite pungent. (seed) Colchicum Quite bitter. . Pungency faint

Soil odor. Somewhat mucilaginous............... Sarsaparilla . No soil odor. Not mucilaginous.............. (root) Belladonna

Not sweetish................................ Veratrum

. Very astringent. Galla

Pungent, not bitter

..Astringent. Saliva frothy. Causes sneezing............ Quillaja .. Astringent, sweetish......................... Hydrangea

... Not astringent, sweetish, very acrid.................. Aconitum

Bitter. Not pungent

. Extremely bitter. Granular with fiber............... Nux vomica ...... Moderately bitter. Fibrous, not granular............ Menispermum With odor

. Narcotic odor. Sweetish, pungent. Ergot

Highly aromatic and pungent

...... Dark to dark gray............................ (black) Piper ....... Light gray to yellowish. (white) Piper

Green or Greentsh

.. Deep olive green.

. Not olive green

. Odor heavy, narcotic, nauseous

.Somewhat pungent

Deep green to brownish.

Scopola and Belladonna

Brownish pale green.

Hyoscyamus

Not pungent

Bright green. Odor mild.

Digitalis

Pale green. Odor quite marked

Stramonium

Brownish green. Odor very strong........... Cannabis Indica

..Quite pungent. Deep green to brownish................Lobelia

Odor agreeable, fragrant, aromatic

. Pungent and more or less bitter

... Faintly fragrant.

(leaves) Aconitum

Mint odor very marked. Cooling sensation

.Highly aromatic. Mentha Pip

Highly fragrant. Mentha vir.

Sage odor. Grayish green color

. Odor very marked. Bitter.

.Salvia

.. Odor milder.

Marjoram

Bitter or slightly bitter

Astringent

Saline

Tanacetum and Achillea

. Not saline

.Odor characteristic, faint...

. (unroasted) Caffea

.. Odor tea-like. Brownish green 
.Very astringent

Hamamelis

.Slightly astringent.

Eupatorium

Odor tea-like. Dark

Pungent

Greenish brown ................................ (herb) Arnica

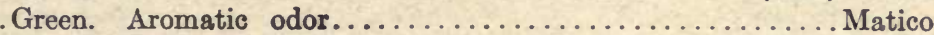

. Not pungent or astringent........................... Melissa

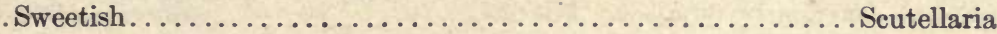

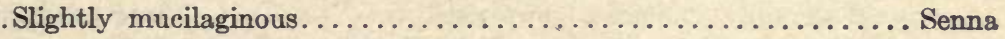

. Very acridly pungent. Sweetish............... (leaves) Aconitum

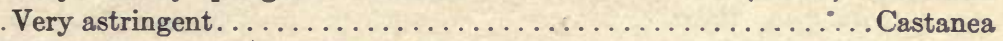

.... Odor camphoraceous, terebinthine

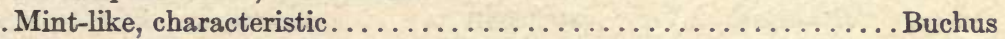
Aromatic, not mint-like. Cat odor................. Eucalyptus . Odor peculiar, ant odor....................... (crushed) Melissa

Nearly odorless

Very astringent, sweetish, bitter, pungent.............. Aspidium

. Not astringent, slightly pungent............................

\section{LIGHT Brown}

..Odorless or odor slight

Tasteless

......Very mobile

Lycopodium

Not mobile

Mucilaginous or gelatinous

Gelatinizes completely..................... Tragacanth

. Mucilaginous, does not gelatinize, sweetish..............Pepo

. Not mucilaginous, sweetish................... Triticum

With taste

.Very sweet.

Manna

Bitter

Extremely bitter

..Very light color.

Colocynth . Pale straw yellow.

Quassia

Moderately bitter Fibrous

Yellowish

Grayish

Populus

Bitter pungent

Chamaelirium

Sweetish. Bitter-pungent taste faint

Mealy. Grayish Taste faint.

(root) Belladonna

. Not mealy. Yellowish.

Convallaria

Sweetish. Bitter taste marked

Very light brown.

Euonymus

Grayish (Somewhat narcotic when moist)......... Podophyllum

Yellow tinge (Soil odor).................... Caulophyllum

Not sweetish

Very mucilaginous.

Scilla

Not mucilaginous

Very pungent.

Xanthoxylum 


\section{Very bitter}

Very light color......................... Asclepias

........... Brownish

Leptandra

Not fibrous, granular.

Colchicum

Pungent

....... Extremely pungent, acrid. Not fibrous.............. Aconitum

....... Extremely pungent. Fibrous.......................ezereum

........Moderately pungent. Sweetish................ (root) Phytolacca

...... Bitter, astringent. Fibrous

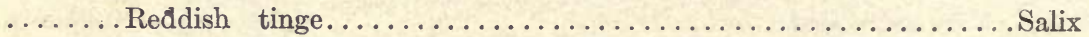

........ Not reddish

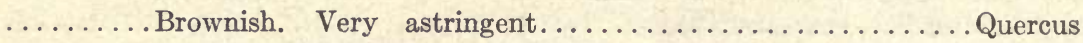

........ Grayish. Moderately astringent............. (bark) Granatum

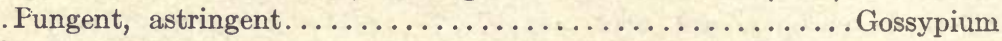

..With odor

....Garlic odor, very marked $\ldots \ldots \ldots \ldots \ldots \ldots \ldots \ldots$. Asafœtida

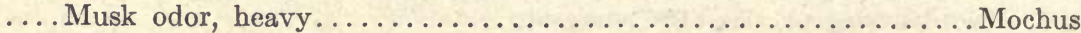

.... Seaweed odor. Mucilaginous, saline ................. Chondrus

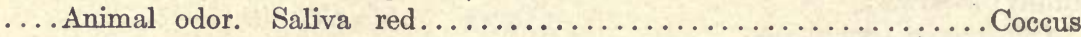

....Aromatic, spicy

...... Sticky on masticating

....... Tasteless

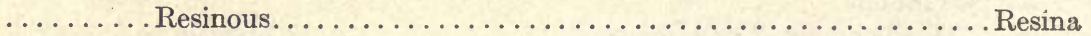

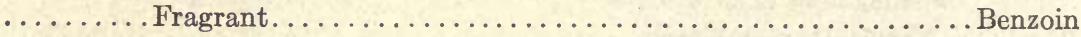

.........Pungent

. Bitter.

Myrrh

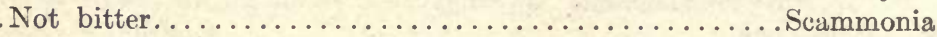

. Not sticky on masticating

Pungent

. Bitter

.............. Light brown

. Not granular. Grayish

Very aromatic.

Limonis

Not very aromatic

Calamus

Culor brown

Odor faint:

.Inula

Odor marked, camphoraceous................. Asarum

Light straw yellow. Very aromatic...............Canella

Not bitter

. Very spicy, characteristic.................... Zingiber

. Not very spicy........................ Pyrethrum

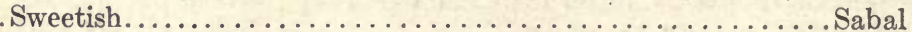

....Hop odor, characteristic

...... Light brown..$\ldots \ldots \ldots \ldots \ldots \ldots \ldots \ldots \ldots \ldots \ldots \ldots$ Humulus

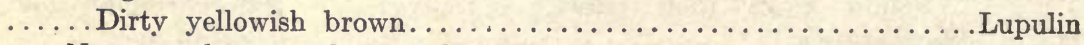

.... Nauseous, heavy or disagreeable odor

...... Bitter

. Sweetish mucilaginous. 
Not sweetish or mucilaginous

Grayish.

Apocynum

Not grayish

Very bitter. Greenish color................ Strophanthus

Moderately bitter. Brownish color............. Gelsemium

Bitter pungent

Sweetish.

Cypripedium

Not sweetish

(herb) Lobelia

Bitter, sweet.

Dulcamara

.... Fragrant, pleasant

Bitterish

Mucilaginous

Sambucus

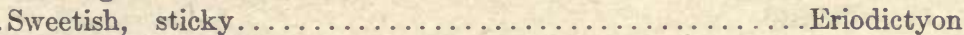

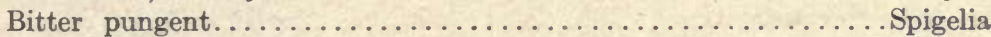

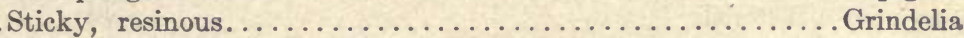

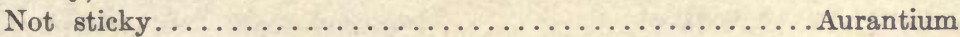

. Odor peculiar, characteristic

.Smoky, creosote odor. Sweetish, pungent.................Jalapa

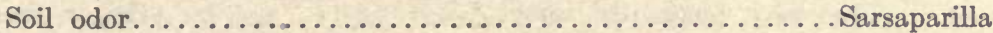

Strong characteristic odor. Bitter, mucilaginous........... Fenugreek

Peculiar odor. Cow odor

Bitter.

Taraxacum

Sweetish bitter.

(unroasted) Cichorium

Brown to REDdish Brown

..Odorless

... Tasteless

...... Light brown.

Triticum

Reddish brown

rubrum

With taste

Astringent. Odor slight $\ldots \ldots \ldots \ldots \ldots \ldots \ldots \ldots \ldots \ldots \ldots \ldots \ldots$ Krameria

Saliva colored red. Sticky......................... Kino

Saliva not colored red. Not sticky

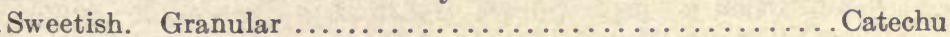

Not sweetish. Fibrous..................... (bark) Hamamelis

Acrid

Cambogia

Bitter

Very bitter

Brown

Chirata

Reddish brown

(red) Cinchona

Yellow brown.

(yellow) Cinchona

Moderately bitter

Saliva yellow

Sweetish.

Frangula

Not sweetish.

Rhamnus purshiana

Saliva not yellow

Light yellowish brown

Pareira

Cinnamon brown

Aspidosperma

Bitter astringent.

Gambir

.Sweetish.

Chimaphila

Not sweetish 


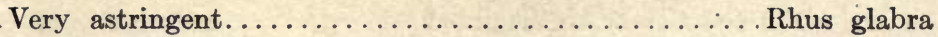

. Moderately astringent........................ Cornus

Astringent

. Somewhat fragrant. Reddish brown.................. Areca

. Not fragrant. Dull brown...................... Geranium

Sweetish. Mobile............................. Dextrine

Very pungent

.Reddish brown .......................... Sanguinaria

Yellow brown........................ Sinapis and Brassica

With odor

.Saffron-like odor. Very bitter............................

.....Aromatic, spicy

.......Pungent

....... Sweetish

. Bitterish

Astringent. . .

Sassafras

Not astringent.

Coto and Paracoto

Not bitter.

Cinnamons

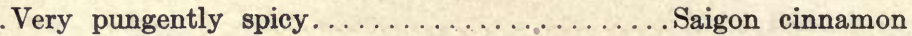

Less pungent...................... Cassia cinnamon

. Characteristic flavor.................. Ceylon cinnamon

Not sweetish

Bitterish

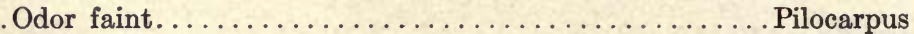

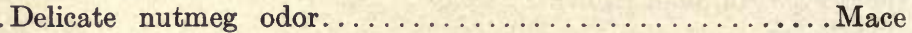

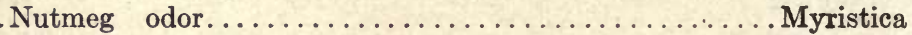

Not bitter. Very dark brown color............. Caryophyllus

. Bitter pungent

Very pungently aromatic...................................

. Bitter almond odor. Very bitter........ Prunus virg. and P. serotina

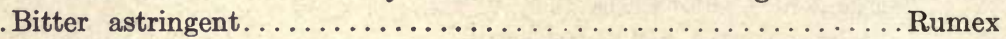

Characteristic odors

Anise odor

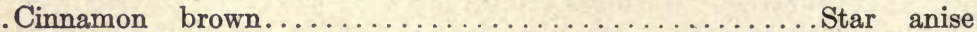

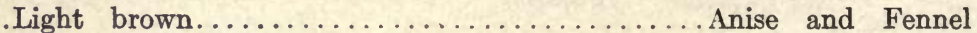

Caraway odor. Dark brown................................

Parsley .odor. Brown color...................... Petroselinum

. Sassafras odor. Pungent........................ Sassafras

Fragrant

Bitter astringent

. Odor marked............................ Theobroma

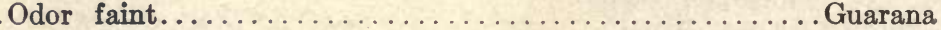

Bitter pungent

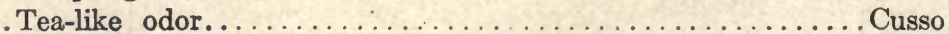

. Odor recalling Gaultheria..................... Arnica flores

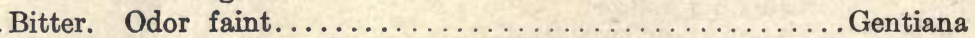

Heavy or disagreeable odor

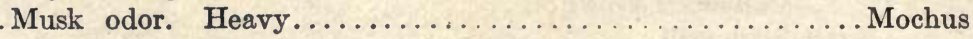

Animal odor. Disagreeable. Acrid taste

.Very dark. Greenish gloss................... Cantharides 
. Brown. No greenish gloss.............................

Narcotic odor. Dark brown. Very bitter. Opium and Lactucarium Valerian odor

Bitter............

Valerian

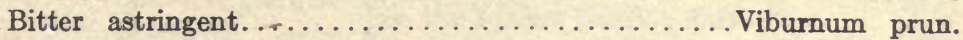

.. Sweetish, bitter, pungent.........................

Peculiar odor

.Very pungent. Reddish to deep red.............. Capsicum

Very bitter

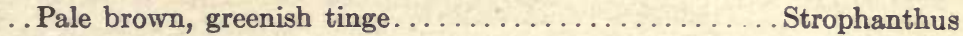

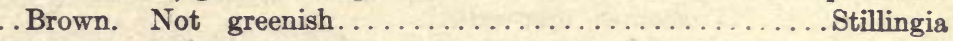

Not pungent or bitter

Fenugreek odor

Reddish brown..................... Iris vérsicolor

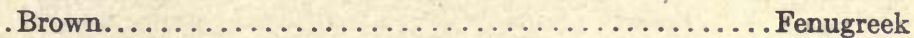

Garlic odor when moistened.............. Sinapis and Brassica

Bitter almond odor

.Fibrous. Deep brown................................

. Not fibrous. Light brown.............. Amygdala amara

\section{Key Based upon Mircoscopic Structure}

\section{Microanalytical KeY}

The use of this key presupposes a knowledge of vegetable tissues, tissue elements and formed cell contents, a knowledge which can be attained only through painstaking work with the compound microscope. The experienced micro-analyst does not require a key to the identity of vegetable products, but he will nevertheless find such an arrangement or tabulation convenient in his routine work. It is not reasonable to suppose that any micro-analyst, no matter how extensive his experience, can retain a complete memory picture of the different histological elements of the numerous vegetable drugs and other substances of vegetable origin. The key is an attempt at a logical summarizing of the more important histological elements which appear in the more important vegetable drugs. The histological characteristics given apply to the pure simple vegetable powders, hence caution must be observed where adulteration is suspected.

\section{MICROANALYTICAL KEY}

Lignified Elements (Vessels, Tracheids, Sclerenchyma, Etc.) Present

..Epidermal elements (trichomes, stomata, etc.) present.

....Pollen grains present

..... Trichomes present

........ Single-celled

........ Tapering pointed toward two ends

......... Fibrous tissue not excessive 
. Sclerenchyma cells present.

. Abundant mature pollen grains. . (expanded) Pyrethrum flores Abundant immature pollen grains (unexpanded) Pyrethrum flores Fibrous tissue excessive, pollen grains few...... (stems) Pyrethrum Tapering pointed toward one end

With glandular trichomes

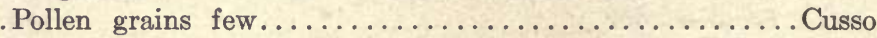
..Pollèn grains abundant. (Papillæ of stigma)....... Matricaria Glandular trichomes wanting

.Trichomes thick-walled.................. Scoparius

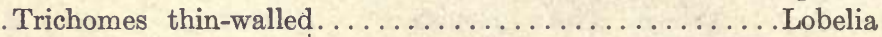

Trichomes simple, 2- to 5-celled

Glandular trichomes present

$\therefore$.... Sessile, many-celled

..............Pollen grains spherical (conical projections)....... Grindelias

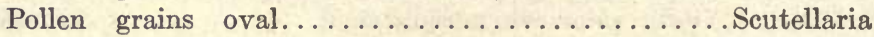

. Sessile, single-celled. . . . . . . . . . . . . . . Eupatorium

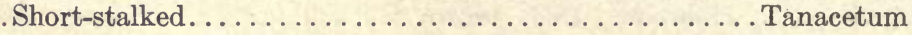

Glandular trichomes wanting

Pollen grains with distinct conical projections

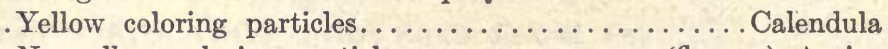

. No yellow coloring particles..............flowers) Arnica

................ Pappus present

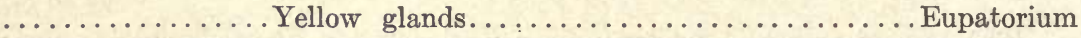

$\ldots \ldots \ldots \ldots \ldots$. No yellow color or glands............ (flowers) Arnica

...... Trichomes wanting

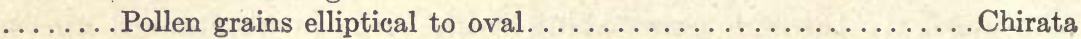

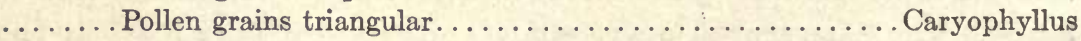

....Pollen grains few or wanting

..... Trichomes wanting or few

........ Sclerenchyma cells present

Stomata present

.. Guard cells indistinct. Cuticle very thick..........Eucalyptus

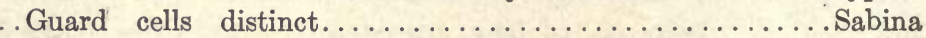

Stomata wanting or very few

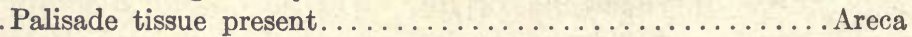

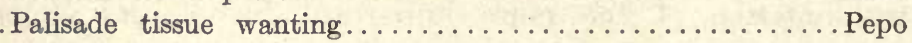

. Sclerenchyma cells wanting

Stomata few or wanting

Hypoderm present. Palisade tissue

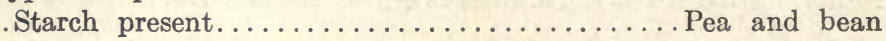

Starch wanting

Palisade tissue with granular contents.......... Fenugreek

Palisade without granular contents

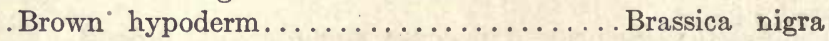

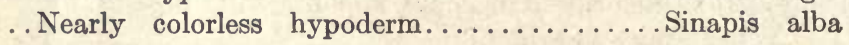

Stomata abundantly present

.Vertical walls of epidermal cells sinuous

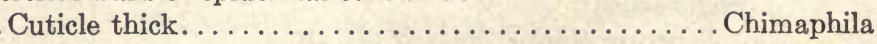

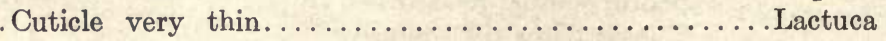


.Vertical walls not distinctly sinuous

Epidermal cells with inulin..................... Buchu

Epidermal cells without inulin

.Lower epidermal cells papillose.

. Coca

.Epidermal cells not papillose............... Uva ursi

Trichomes present

Aggregate (stellate) trichomes

.Glandular trichomes present.

Castanea

Glandular trichomes wanting.

Hamamelis

.Single celled trichomes.

. Sclerenchyma cells present

Few, large, branching...

Not branching, normal. Trichomes few

.Trichomes few, long. Stomata numerous.......... Pilocarpus

Trichomes very short. Stomata few..............Pimenta

Sclerenchyma cells wanting

.Stomata present

Trichomes wavy, long, slender.

Eriodictyon

Trichomes not wavy nor very long

Hair cells with eystoliths.

. Cystoliths wanting

Yellow glands present.

Humulus

Yellow glands wanting

Trichomes medium, few. Cuticular markings

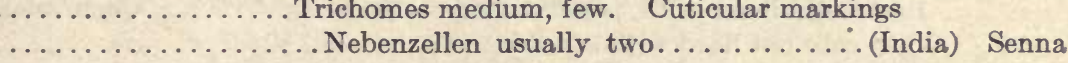

. Nebenzellen usually 4 to $5 \ldots \ldots \ldots$. (African) Senna

Trichomes large. Cuticular markings

.Stomata large.................... (leaf) Aconitum

Stomata medium...................... Lobelia

Trichomes slender, ends thickened............ Turnera

Stomata few or wanting

.Trichomes few. Tracheids numerous............ Dulcamara

Trichomes numerous

Long, slender

... Endosperm cells thick-walled.............. Nux vomica

.Endosperm cells thin-walled..............Strophantus Short

Few, very short......................... Anise

Ends recurved, longer................ Chinese galla

Simple, 2 - to 5-celled trichomes

. Sclerenchyma cells present

.Trichomes bright red.................... Rhus glabra

Trichomes very ferw, not red............................

.Sclerenchyma cells wanting

.Vertical walls of epidermal cells straight, resin present.... Matice

Vertical walls sinuous. Resin wanting........ (flowers) Arnica

Glandular trichomes present

Non-glandular trichomes twisted................. Salvia

Non-glandular trichomes warty

Trichomes large.

Stramonium 
Trichomes shorter.

Marjoram

Non-glandular trichomes not warty

. Micro-crystalline calcium oxalate

. Glandular trichomes long stalked........... Tabacum

. Glandular trichomes short stalked......... Belladonna

Micro-crystalline calcium oxalate wanting

. Trichomes very numerous............... Digitalis

. Trichomes fewer, large................ Hyoscyamus

.. Trichomes long, slender, twisted...........Marrubium

.. Epidermal elements wanting

.Sclerenchyma cells present

. Bast present

With acicular crystals (raphides)

. Compound starch granules.

Sarsaparilla

.......... Simple starch granules

Chamaelirium

Bast fibers medium.

.Hydrangea

Raphides wanting

Bast cells large, comparatively short

.Sclerenchyma cells few.

. Cinchona

. Sclerenchyma cells numerous

..Starch quite abundant............... Cassia cinnamon

... Starch sparingly present............... Ceylon cinnamon

. Bast cells lined with prismatic crystals............. Quebracho

. Bast cells not lined with crystals

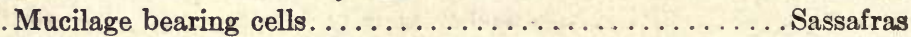

Mucilage bearing cells wanting................. Berberis

. Bast cells not greatly thickened

. Scalariform ducts. Large compound starch........ Methysticum

Ducts wanting

.Sclerenchyma cells unequally thickened.

Cascarilla

.......... Sclerenchyma or bast branching

. Bast plentiful.......... Prunus virginiana and Viburnum op.

. Bast fibers few..Viburnum prunifolium and Prunus serotina

. Sclerenchyma typical

. Crystal bearing fibers abundant

. Sclerenchyma cells in groups

. Collenchymatous parenchyma.

Rhamnus pursh.

No collenchymatous parenchyma

Large wax or resin cells.

Xanthoxylum

No wax or resin cells. (bark) Myrica

Sclerenchyma cells mostly singly

Bast plentiful.

. Bast sparingly present

.Large simple starch granules.

.Populus

Starch wanting.

Menispermum

$\ldots \ldots \ldots \ldots \ldots$ Crystal bearing fibers wanting. (bark). Punica

Bast wanting or sparingly present

........ Starch plentiful

.........Pasty 


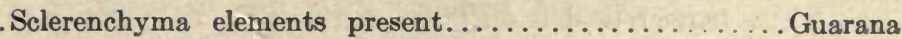

Sclerenchyma elements wanting. Yellow color.

Curcuma

Simple starch granules

. Aggregate crystals present, large.......................

Aggregate crystals wanting

.Starch granules very large, hilum large.

.Starch granules medium.

Calumba

Compound starch granules

.Sclerenchyma cells in groups.

Menispermum

Sclerenchyma sparingly present, single cells

. Raphides present.

Asclepias

Raphides wanting

.Stone cells rectangular, thin-walled.

Veratrum

Starch sparingly present or wanting

Aconitum

Sclerenchyma (or bast fibers) branching

Prunus serotina and Viburnum prunifolium

Sclerenchyma cells not branching

Inulin present.

(root) Pyrethrum

Inulin wanting

. Parenchyma cells large, thin-walled

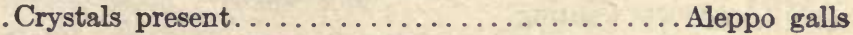

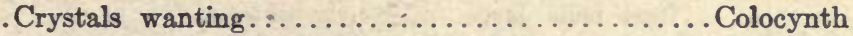

Parenchyma cells medium in size

Walls thin

..Sclerenchyma cells deep red............ (fruit) Phytolacca

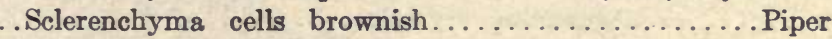

Walls not thin

. Sclerenchyma elongated

Yellowish resin present...........Paracoto and Coto

No resin. Cells bast-like................ Caffea

. Cystoliths present...............Ruellia ciliosa

Sclerenchyma cells not elongated

.Sclerenchyma cells singly.

Amygdala

. Sclerenchyma cells in groups

. Crystals present

Yellowish wax present

Simple starch granules.

Canella

. Compound starch granules......... Rhus glabra

Wax wanting.

Cornus

Crystals wanting

...Sclerenchyma unevenly thick..(seed) Hyoscyamus

.Sclerenchyma typical..........................

Sclerenchyma cells wanting or very sparingly present

Bast present

.Starch plentiful

Acicular crystals (raphides) present

.Small aggregate starch. Spiral ducts........... Cypripedium

.Large simple starch. No spiral ducts........ (root) Phytolacca

Acicular crystals wanting 
Large reticulate ducts

. Numerous prismatic crystals................ Glycyrrhiza

. Numerous aggregate crystals................ Stillingia

No large reticulate ducts

.Starch simple

Large porous ducts.

(bark) Rubus

Ducts medium

. Porous

Euonymus

Reticulate.

Althaea

Yellow tracheids.

Hydrastis

Starch compound

Bast plentiful, typical.

Gossypium

Porous tracheids plentiful.

Krameria

Starch sparingly present or wholly wanting

. Ducts present

. Annular and spiral ducts.

Triticum

Annular ducts wanting

Large reticulate ducts.

Gentiana

Large porous ducts

Abundant wood fibers.

.Quassia

. Some tracheids. Parenchyma.

Gelsemium

Ducts wanting

.. Bast cella large, sclerenchymatous.

Cinchona

$\ldots \ldots \ldots$. . Bast cella large, sc

............. Large elongated prismatic erystal.

Quillaja

$\ldots . \ldots . .$. Medium prismatic crystals................ Viburnum op.

Aggregate crystals..................... Prunus virg.

Bast cells not branching, typical

. Crystal bearing fibers present

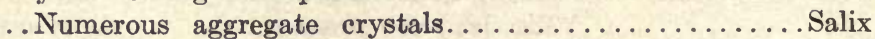

. Aggregate crystals few ................. Frangula

Crystal bearing fibers wanting

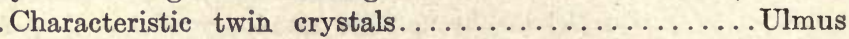

. Crystals few or wanting.........................

. Sclerenchyma cells and bast fibers wanting

Large thin-walled parenchyma. No wood fibers........... Colocynth

Wood fibers and tracheids predominating

Tracheids with bordered pits

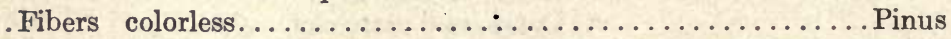

$\ldots \ldots \ldots$ Fibers reddish brown $\ldots \ldots \ldots \ldots \ldots \ldots \ldots \ldots \ldots \ldots$ Santalum rubrum

Simple pores

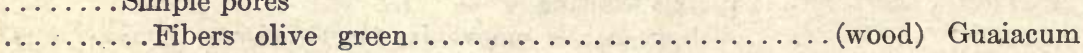

......... Fibers pale yellow, nearly colorless.............. Quassia

.....Wood fibers and tracheids comparatively few

No starch present

Inulin present

.......... Ducts large 
Parenchyma cells much distorted Inula

Parenchyma cells not irregular.

.Lappa

Inulin wanting

Ducts or tracheids quite numerous

..Parenchyma cells large. Ducts reticulate

. Red cell contents.

Iris versicolor

. No red cell contents.

Gentiana

Parenchyma cells medium in size

. Cystoliths present (Sclerenchyma).

Ruellia

... No cystoliths. (No sclerenchyma).............. Spigelia

Ducts or tracheids few

. Numerous prismatic crystals.

Limonis and Citrus

Numerous acicular crystals.

Scilla

. No crystals. Red oil globules.............. Capsicum

Starch present

Simple starch

Crystals present

. Very large crystals, prismatic........... Iris florentina

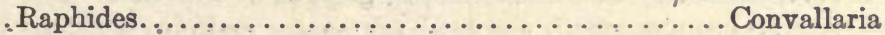

. Aggregate, quite large, numerous............. Geranium

Crystals wanting

.Starch pasty. Yellow color.

Curcuma

Starch not pasty

..Parenchyma cells thick-walled. Oil......(seed) Colchicum

Parenchyma cells not thick-walled

. Ducts scalariform. Yellow resin............Male fern Ducts reticulate

. Starch granules large

Yellow resin. Starch abundant.........Zingiber

.. No yellow resin. Starch sparing............ Sumbul

. Starch granules small to medium

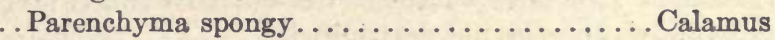

. Parenchyma not spongy. Red color...... Sanguinaria

Ducts porous, or tracheids

.Large porous ducta................................

Ducts or tracheids medium

Parenchyma cells porous............. Serpentaria

Parenchyma cells not porous

. Red cell contents.

Leptandra

. No red cell contents.

Cimicifuga

........ Starch granules compound

. Crystals of calcium oxalate present

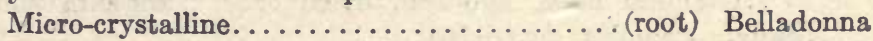

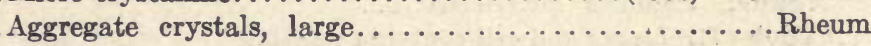

Raphides............................. Ipecac

No crystals present

Ducts very large, reticulatc.

Bryonia

Ducts or tracheids medium, some spiral ducts

Starch plentiful, no aggregates

Resin cells present.

Asarum 


\section{No resin cells}

................ Hili very prominent. Starch abundant. (corm) Colchicum Hili less distinct. Many granules simple....Valerian Starch granules small, many aggregates

.Spiral ducts. Aggregate crystala............Podophyllum . No spiral ducts.................... Caulophyllum

\section{Lignified Tissue Elements Wanting or Sparingly Present}

. . Cellular structures present

... Single-celled trichomes present. Starch granules simple

...... Starch granules polygonal. Numerous aggregates. Oat meal

..... Starch granules mostly spherical

....... Hili distinct in larger granules................... Rye flour ....... Hili indistinct

Trichomes shorter. Granules smaller............ Barley flour ......... Trichomes longer. Granules larger.............. Wheat flour

\section{.... Trichomes wanting}

...... Starch very abundant; simple, polygonal

....... Granules small; elliptical aggregates present.......... Oat and Rice

....... Granules larger. Aggregates wanting.................. Corn

......Starch wanting

....... Cells highly mucilaginous

.Calcareous deposits. Effervesces with $\mathrm{HCl}$............ Chondrus

......... No calcareous deposits. A few diatoms present............. Agar

....... Cells not mucilaginous

......... Epidermal cells (leaf and pericarp) many............. Opium

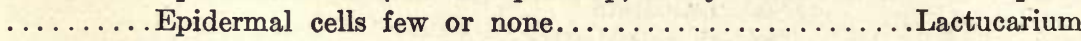

....... Cellular structure glandular, yellow................... Lupulin

....... Cellular structure spore-like, brown................. Lycopodium

........ Pseudo-parenchyma. Trace of rye starch................ Ergot

. . Cellular structures wanting. Cell-contents (starch) only

....Starch granules not dextrinized

..... Granules simple

....... Larger granules spheroidal to discoid

......... Hili of larger granules distinct................. Rye starch .........Hili very indistinct

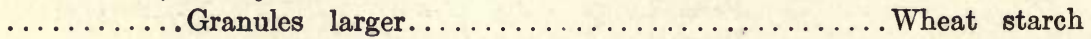

.......... Granules smaller......................... Barley starch

.......Granules polygonal

......... Larger, distinct hili...................... Corn starch

......... Very small granules....................... Rice starch

...... Granules large, elliptical, ovoid........Maranta and potato starch

....Starch granules dextrinized........................ Dextrine

..Cellular structures and cell-contents wanting

.... More or less completely soluble in water

..... Crystals deposited from aqueous solutions

.......Prismatic and acicular crystals...................... Catechu

........Acicular crystals

........ Colorless solution. Manna

......... Colored solution 
Crystals largely in clusters

Aloes

.Crystals generally not in clusters.

Gambir

No crystal formation

Colorless mucilaginous solution.

Acacia

Brownish solution

........Reddish brown solution. Bacteria present. Kino

Dull brown particles present. Musk odor.

Mochus

. Not soluble in water or only slightly so

Does not emulsify in water. Abundant crystals......... Balsam Tolu

Emulsifies in water. No crystals present

White emulsion. Numerous globules and bacteroid granules

. Globules numerous, mostly irregular in form............ Asafœtida

. Globules fewer, mostly regular in form............ Ammoniacum

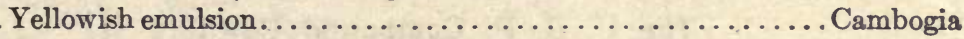

. Brown granular emulsion, no globules...... Opium and Lactucarium

Does not emulsify in water

. Soluble in alcohol

.Powdered fragments showing conchoidal fracture in water mounts .Fragments colorless.................Resina and Dammara . Fragments colored

..Brownish coloration................ (fresh) Guaiac resin . Greenish coloration.................. (old) Guaiac resin

.Fragments granular in water mounts

....... Crystals (benzoic acid) on sublimation............. Benzoin .No crystals on sublimation.......................

Not soluble in water or alcohol

Chitinous spicules present. Animal odor

.Spicules colorless, longer....................... Cantharis

. Spicules black, shorter......................................

. Spicules wanting

. Colors saliva red.

Coccus

Musk odor. 


\section{KEYS TO THE STUDY AND IDENTIFICATION OF THE U. S. P. AND N. F. COMPOUND POWDER}

There are twenty-one compound powders, of which seven are official in the U. S. P. IX and fourteen are official in the N. F. IV.

\section{The U. S. P. Compound Powders}

1. Pulvis Aromaticus.

2. Pulvis Cretæ Compositus.

3. Pulvis Effervescens Compositus.

4. Pulvis Glycyrrhizæ Compositus.

5. Pulvis Ipecacuanhæ et Opii.

6. Pulvis Jalapæ Compositus.

7. Pulvis Rhei Compositus.

\section{The N. F. Compound Powders}

1. Pulvis Acetanilidi Compositus

2. Pulvis Aloes et Canellæ.

3. Pulvis Antimonialis.

4. Pulvis Antisepticus.

5. Pulvis Aromaticus Rubifaciens.

6. Pulvis Cretæ Aromaticus.

7. Pulvis Cretæ et Opii Aromaticus.

8. Pulvis Gambir Compositus.

9. Pulvis Hydrargyri Chloridi Mitis et Jalapæ.

10. Pulvis Kino et Opii Compositus.

11. Pulvis Myricæ Compositus.

12. Pulvis Pancreatini Compositus.

13. Pulvis Rhei et Magnesiæ Anisatus.

14. Pulvis Talci Compositus.

For the exact composition of these powders the student is referred to the U. S. P. IX and N. F. IV respectively. The general introductory remarks to the keys of the simple powders also apply here. As an introduction to the examination of the compound powders the student should make a careful microscopical study of the following substances, mounted in suitable media, as oil, water, alcohol, etc. 
1. Crystals of acetanilid.

2. Crystals of caffeine.

3. Aloes.

4. Powdered antimony oxide.

5. Powdered calcium phosphate, lead acetate.

6. Crystals of salicylic acid by the micro-sublimation test.

7. Crystals of boric acid, of menthol, of phenol, of thymol.

8. Crystals of zinc sulphate, of sodium bicarbonate.

9. Finely powdered chalk.

10. Sugar.

11. Gambir. Kino.

12. Calomel.

13. Pancreatin. Peptone.

14. Heavy magnesium oxide. Zinc oxide.

15. Talcum powder. Calcium oxide.

16. Powdered opium. Morphine.

17. Honey, different varieties.

18. Powdered soap.

19. Gum acacia. Tragacanth.

20. Tartaric acid. Potassium and sodium tartrate.

21. The allotropic forms of sulphur. Washed sulphur.

22. Powdered sugar of milk.

23. U. S. P. gray powder.

24. Vegetable extracts, solid.

25. Mercuric oxides. Turpeth mineral.

26. Pepsin. Ox gall. Papain.

27. Meat extracts.

28. Wool fat. Suet. Lard.

29. Butter. Oleomargarine.

30. Diatomaceous earth.

\section{Key Based upon the Organoleptic Tests}

White to Nearly White

.. Odorless

...Acid taste............ (tartaric acid powder) Pulv. Eff.' Co. (U. S. P.)

…Soda taste............. (sod. and potass. salts) Pulv. Eff. Co. (U. S. P.)

... Somewhat acridly pungent..............Pulv. Acetan. Co. (N. |F.)

...Taste recalling soda....................Pulv. Tale. Co. (N. F.)

.. Sweet taste........................... Pulv. Cret. Co. (U. S. P.)

With odor

... Odor of phenol, pungent..................Pulv. Antisept. (N. F.) Animal odor....................... Pulv. Pancreat. Co. (N. F.) 
Light Brown to Brown

. Odor slight

$\ldots$ Bitter................... Ipulv. et Opii (U. S. P.)

....Acid taste................... Pulv. Jalap. Co. (U. S. P.)

.. Odor distinct

.....Aromatic

..... Sweet, bitter, pungent

....... Nutmeg flavor..................... Culv. Cret. Arom. (N. F.)

........ No nutmeg flavor............. Pulv. Cret. et Opii Arom. (N. F.)

.... Anise odor

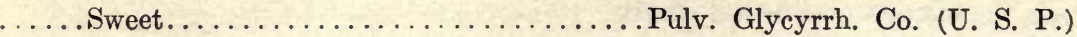

...... Bitter..................... Rulv. Rhei et Mag. Anis. (N. F.)

....Rhubarb odor

.....Pungent....................... Rulv. Rhei Co. (U. S. P.)

......Bitter, anise odor............. Pulv. Rhei et Mag. Anis. (N. F.)

Yellowish, Aromatic, bitter.............. Aulv. Aloes et Canell. (N. F.)

Brown to Redish Brown

...Aromatic

.... Clove odor, very pungent.............. Pulv. Myric. Co. (N. F.)

.... Cinnamon odor

......Very pungent...................... Aulv. Arom. Rubifac. (N. F.)

......Astringent, bitter............... Pulv. Kino et Opii Co. (N. F.)

.... Cinnamon-cardamon odor................ Pulv. Arom. (U. S. P.)

.... Cinnamon-nutmeg odor................ Pulv. Gambir Co. (N. F.)

Very Dark, tasteless, odorless.................... Antimon. (N. F.)

\section{Key Based upon Microscopic Characteristics}

Tissue Elements and Formed Cell Contents (Starch) Present

..Trichomes present..................... Gulveyrrh. Co, (U. S. P.)

..Trichomes wanting

... Bast cells and sclerenchyma cells present

...... Ginger starch present

....... Capsicum present. ............ Pulv. Arom. Rubifac. (N. F.)

....... Capsicum tissue absent.............. Pulv. Arom. (U. S. P.)

..... Ginger starch wanting.

. Glove elements present .............. Pulv. Cret. Arom. (N. F.)

. Gambir crystals present ...............Pulv. Gambir Co, (N. F.)

Sclerenchyma cells present, but no bast

Ginger starch present................... Pulv. Myric, Co. (N. F.)

.......Aloes crystals present ............ Pulv, Aloes et Canell, (N. F.)

....... Capsicum tissue present.............Pulv. Myric, Co, (N, F.)

....Bast and sclerenchyma wanting

......Large aggregate crystals of rhubarb

....... Ginger starch present................ Pulv. Rhei Co. (U, S. P.) . Ginger starch wanting............Pulv. Rhei et Mag. Anis. (N. F.)

. Acicular crystals (Ipecac) present.... Pulv. ipecac. et Opii (U. S. P.)

Acicular crystals (small) wanting

........ Compound starch present 
Aggregate crystals (calomel) present...Pulv. Hydrarg. et Jalap. (N. F.) Prismatic crystals present..........Pulv. Jalap. Co. (U. S. P.)

Tissue Elements and Formed Cell Contents Wanting

..Abundant dark, nearly black particles...........Pulv. Antimon. (N. F.) .. No black particles

....Very minute crystalline particles.

Pulv. Cret. Co. (U. S. P.)

Abundant larger crystals, soluble and insoluble in water

Crystals by the micro-sublimation test

Abundant water insoluble prismatic crystals....Pulv. Talc. Co. (N. F.) .Crystals largely water soluble, angles rounded..Pulv. Antisept. (N. F.) No crystals by sublimation

.Large lined and ridged crystals.........Pulv. Acetan. Co. (N. F.) Crystals largely water soluble.......................

(soda and potass. salts) Pulv. Eff. Co. (U. S. P.)

Crystals soon soluble......... (tartaric acid) Pulv. Eff. Co. (U. S. P.)

Abundant minute granules and larger crystals..Pulv. Pancreat. Co. (N. F.) 


\section{CHAPTER X}

\section{MICROANALYTICAL STUDY OF CRYSTALS}

In addition to the widely distributed (in the plant kingdom) and in many instances highly diagnostic crystalline forms of calcium oxalate; the student of pharmacognosy will frequently meet with other crystalline formations, such as those of fats, of acids, of alkaloids, of alkaloidal salts, etc. He should familiarize himself with the microscopical appearance of the principal form types as such knowledge is frequently of great value in arriving at a better knowledge of the identity and quality of vegetable drugs and of many of the preparations made therefrom. Such a study will also serve as an introduction to the critical microscopical examination of face lotions, so-called vanishing creams, salves, ointments, fats, oils, etc.

The entire field of crystallography is still in great confusion, for which reason it would be unwise to enter into a discussion of polariscopic behavior, extinction angles, axial structure, optical characters, form types, etc. Those especially interested may consult the classic German works on the subject, some of which date back fifty years and more. The Zeitschrift für Krystallographie is devoted entirely to this subject; besides there are a number of recent manographs on physical crystallography, microscopic crystallography, chemical crystallography, etc.

For a practical study of crystals the following solvents are desirable.

1. Distilled water.

2. Alcohol.

3. Ether.

4. Chloroform.

5. Alcohol and chloroform mixed.

6. Acidulated water $\left(\mathrm{HCl}\right.$ and $\left.\mathrm{H}_{2} \mathrm{SO}_{4}\right)$.

Crystals of the more common metallic salts (chlorides, sulphates) may be obtained from solutes in the distilled water. Very dilute solutions should be used in order that single crystals may appear upon the slide. The rate of evaporation, temperature, impurities present, etc., greatly influence the size and form of the crystals. Drawings should be made of the crystals, noting variations in size 
and form, the angles, and the sides. A comparative microscopic and polariscopic study should be made of fine sand and of powdered glass mounted in water. Under the polariscope the sand particles show a characteristic play of colors whereas glass shows none. This simple test proved of great value in the "powdered glass in foods" craze or obsession which pervaded the entire United States while at war with Germany.

The following additional crystals should be studied.

1. Agaricinic Acid.-By the micro-sublimation method using small bits of Agaricus or of Polyporus. Note transition forms of the crystals. Recrystallize in ether, in alcohol, in chloroform.

2. Asparagin.-From expressed juice of asparagus, potato, dahlia, or from the aqueous extracts of the plants named. Recrystallize as for (1).

3. Benzoate (sodium).-By the micro-sublimation method, using a 1-1000 acidulated aqueous solution. (See page 73.)

4. Benzoic acid.-By the sublimation method, from a 1-1000 aqueous solution. (See page 73.)

5. Benzoin.-From benzoin by the sublimation method, in a test tube or on a slide.

6. Berberine.-By the sublimation method from the drug. From aqueous extract. From acidulated water extract.

7. Boric acid.-By the sublimation method. From aqueous solution.

8. Brucine.-From hot water extract. From alcoholic extract. From acidulated water extract. From solution of the sulphate.

9. Caffeine.-From aqueous extract. From gold chloride solution.

10. Cocaine.-From alcoholic (dilute) solution. From mixture of alcohol, ether and chloroform. From a solution of the hydrochloride.

11. Codeine.-From water, from ether, from benzol. From solutions of the sulphate.

12. Cubebin.- Remove oil and extract with hot alcohol.

13. Hydrastin.-From alcoholic solution. From ether. From chloroform.

14. Lichenic acid.-From bits of lichen by the sublimation method. Recrystallize the sublimate in alcohol, in ether, in benzol, in chloroform.

15. Menthol.-By sublimation.

16. Morphine.-As for codeine.

17. Opium.-Meconates in smoking opium and in Persian opium. From acidulated aqueous extracts.

18. Physostigmine.-From chloroform extract; from benzine. 
19. Piperine.-Heat ground white pepper in milk of lime, dry, and extract residue with ether. Recrystallize from hot alcoholic solution.

20. Quinine.-From water. From acidulated water. From solution of the sulphate.

21. Salicylic acid.-By sublimation from 1-1000 aqueous solution.

22. Strychnine.-(See Brucine.)

23. Vanillin.-From ether. From alcohol. From chloroform. From water.

24. Phytosterol.-Pure crystals from plant fats by the method of the Bureau of Animal Industry.

25. Cholesterol.-Pure crystals from animal fats by the method of the Bureau of Animal Industry.

26. Fat crystals.-As they occur in old and rancid vegetable and animal oils and fats.

\section{DESCRIPTION OF .PLATE VII}

The fatty bases employed in pharmaceutical manufacture may undergo molecular disintegration and bacterial decomposition, which decomposition changes became manifest by change in color, rancidity, mustiness and by the formation of fat crystals. The following are the principal types of fat crystals.

Fig. 29.- Phytosterol Crystals. - These are the characteristic crystals derived from vegetable oils and fats, isolated in purity by the method employed by the Bureau of Animal Industry (U. S. Dep't. Agr.), in Circular No. 212, May 10, 1913.

FIG. 30.-Cholesterol Crystals.-Pure crystals derived from animals fats by the method employed by the Bureau of Animal Industry.

Fig. 31-Beef Fat Crystals.-As they appear in beef fat. $a$, A cluster of crystals as they appear under the low power of the compound microscope. $b$, Ends of the crystals as they appear under the high power.

Frg. 32.-Duck Fat Crystals.- $a$, Low power; $b$, high power.

Frg. 33.-Lard Crystals.- $a$, Clusters of crystals as seen under the low power of the compound microscope. b, Crystals more highly magnified. (From rancid lard.)

Fra. 34.-Smoking Opium.-Crystals of the menconates of the alkaloids of opium as they appear in Chinese smoking opium. 


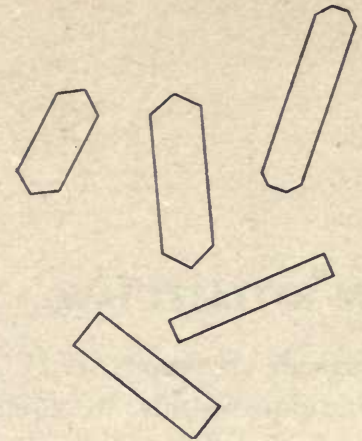

Fig. 29.
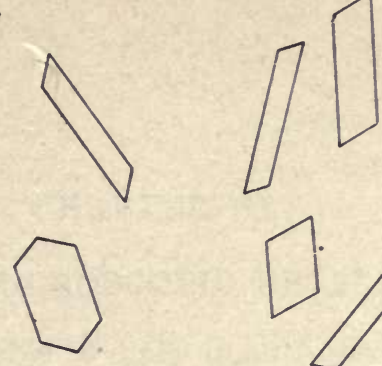

PLATE VII

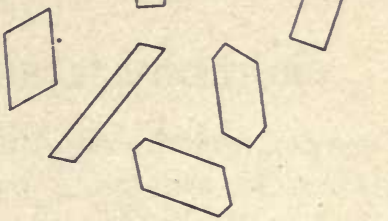

Frg. 30.

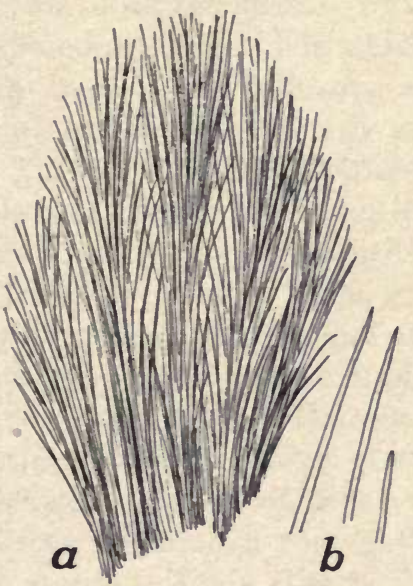

FIG. 31.

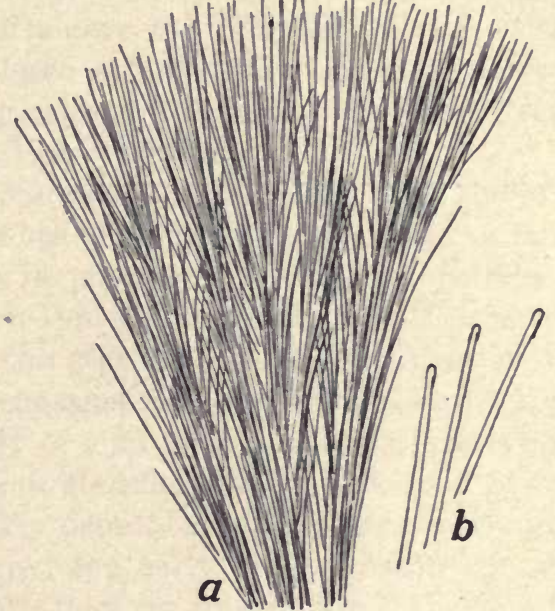

Fig. 32.

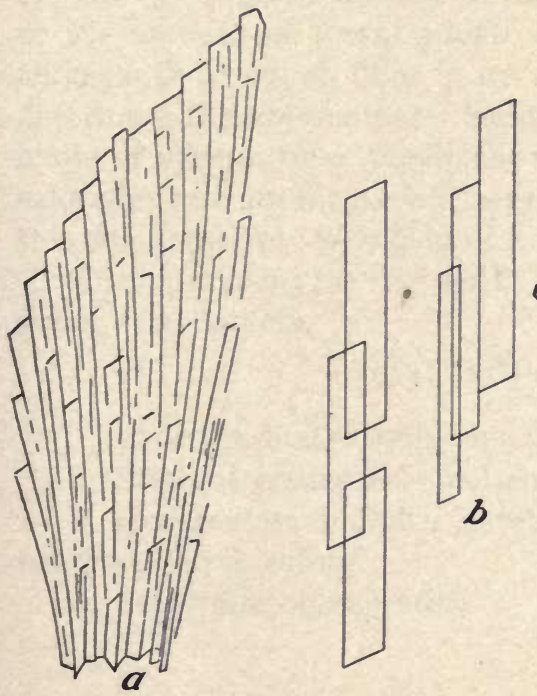

Fig. 33.

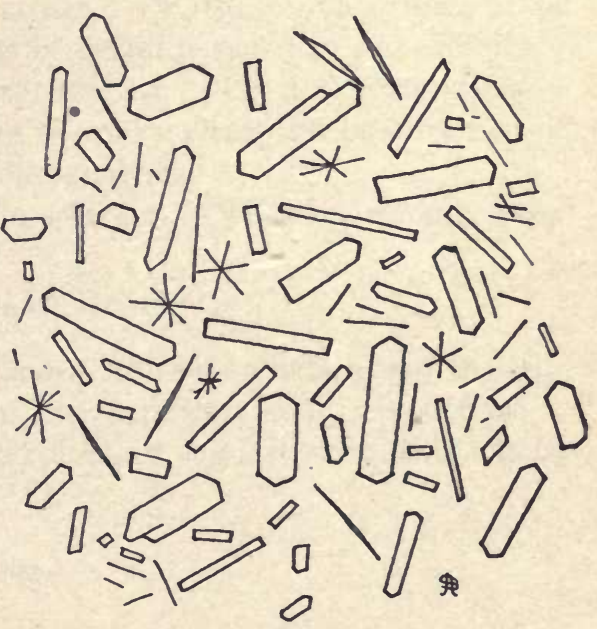

Frg. 34. 



\section{CHAPTER XI}

\section{QUANTITATIVE MICROSCOPIC DETERMINATIONS}

It is frequently desirable to make quantitative determinations by means of the compound microscope, and a number of tentative methods for doing such work have been proposed from time to time by various authors. Thus Meyer (Die Grundlagen und die Methoden für die Mikroscopische Untersuchung von Pflanzenpulvern, 1901) proposed some methods which have served as the basis for others to build upon. The following suggestions will be found comparatively simple and will serve many practical purposes.

The quantitative microscopical methods are based upon the principle that certain cell forms and cell contents generally occur in fairly uniform amounts or quantities in plant parts at certain periods of their development. Thus, green apples bear starch granules numerically inversely proportional to the stage in the development of the apple; that is, the green apple contains starch whereas the ripe apple is free from starch. The quality of gum tragacanth is inversely proportional to the number of starch granules present. A good quality of belladonna root contains a fairly definite amount of starch granules, whereas belladonna root gathered too early in the season contains less starch. Again, the problem may be to determine the relative amounts of wheat flour and of buckwheat flour in a pancake mixture; or the amount of cereal added to sausage meat, or the amount of tragacanth or starch filler in ice cream. Or, the problem may be to determine the approximate degree of decomposition in soda fountain fruits or syrups, or in medicinal syrups, etc. The following selected examples and problems will serve to make clear the possibilities in this comparatively new field of microanalysis.

The equipment for this work, in addition to what has already been given, is as follows.

\section{Apparatus and Reagents}

1. $25 \mathrm{cc}$. graduated cylinders, open. Closed cylinders may be used.

2. Straight graduated pipettes, 1 cc. capacity, with free outflow.

3. Hemacytometer with Turck ruling, or the Levy counting chamber with Turck ruling.

4. Stage micrometer scale. 
5. Counting slides, to be ruled or marked as directed below.

6. Suspending media.

(a) Two to three per cent. solutions of gum Arabic, cherry gum.

(b) Ten to thirty per cent. solutions of glucose, sugar, syrup.

(c) Oils, fats, vaseline, etc.

7. Iodine solution, to be diluted as may be required.

8. Stains.

(a) Loeffler's Methylene Blue--Mix 30 cc. of a saturated alcoholic solution of methylene blue with $100 \mathrm{cc}$. of a 0.1 per cent. aqueous solution of potassium hydrate. Filter.

(b) Ziehl's Carbol Fuchsin.-Mix 10 cc. of a saturated alcoholic solution of fuchsin with 5 grams of phenol crystals and add 100 cc. of distilled water. Filter. This is a diffuse stain and is used in staining acid fast bacteria.

(c) Broca's Differential Stain.-To 80 cc. of the above methylene blue stain add $10 \mathrm{cc}$. of the carbol fuchsin. Mix and let stand for several days and filter. This stain is used to differentiate between dead and living bacteria. In the presence of this stain dead bacteria take on a red coloration while living bacteria (living at the time the stain was applied) are stained blue.

1. Preliminary Micrometric Determinations.-Determine the exact areas of the fields of view under the low, medium and oil immersion powers. This is done by determining the diameters of the respective fields by means of the stage micrometer, employing the formula, radius squared times pi $(3.1416)=$ the area. In this manner determine the areas of the fields of the three magnifying powers, and record these values for future reference and use in making quantitative determinations. The stage micrometer is then no longer required.

2. General Method for Making Bacterial, Yeast and Spore Counts.If it is desired to determine the relative amount of bacterial, yeast or mold decomposition in a drug, food, syrup, tincture, fluidextract, etc., the following methods may be used. Weigh (if solid or semisolid), or measure (if sufficiently liquid to be poured), a definite amount (usually $1 \mathrm{gram}$, or $1 \mathrm{cc}$.) of a well mixed average sample of the substance to be examined; dilute as may be required $(1: 5,1: 10,1: 100)$; mix or shake well and make the counts by means of the hemacytometer. This method will be found very satisfactory with all substances which contain no confusing particles, as liquid substances generally, syrups of all kinds, gelatines, glue, oils, fats, meats and meat products, egg albumin, etc.

A second general method should be used if the substance to be examined for bacteria should contain mineral and organic particles 
which might be confused with bacteria; such as milks, frozen eggs, sausage meats, pastes of all kinds, etc. Proceed as follows: Deliver $1 / 10$ cc. of the properly sampled, mixed, and diluted (if necessary) portion of the substance to be examined upon a well cleaned (by means of alcohol) slide and spread this volume (namely 1/10 cc.) evenly and uniformly over an area of $10 \mathrm{sq} . \mathrm{cm} .(2 \mathrm{~cm}$. by $5 \mathrm{~cm} .=10 \mathrm{sq} . \mathrm{cm}$.), let it air dry upon a leveling table (drying may be hastened somewhat by using moderate heat), add a drop or two of alcohol and again dry; stain for from one to three minutes in a few drops of a 10 per cent. solution of methyl-blue (or Hoffman's violet), wash gently in water, and if desired decolorize somewhat by means of acidulated alcohol, and again wash in water. Set aside until air dry and make the counts by means of the oil immersion objective. The counting should be done carefully, selecting ten fields each from five or more different areas of the mount, and determine the average of the entire count. The computation is simple. We will suppose that the substance under examination was a highly contaminated gelatine. The field of view of the oil immersion was 1/50 sq. mm., the dilution used was 1:100, and the average number of bacteria per field was found to be 30 , then the total number of bacteria per gram of the gelatine would be 1,500,$000,000(50 \times 30 \times 100 \times 1,000 \times 10=1,500,000,000)$. The problem may be stated more in detail as follows: If there are 30 bacteria in $1 / 50$ of $1 \mathrm{sq}$. mm., then there would be 50 times thirty bacteria in 1 sq. mm., or 1,500 bacteria. Since the dilution employed in this case was 1-100, two ciphers must be added, making 150,000 bacteria per $1 \mathrm{sq} . \mathrm{mm}$. of the original substance. In the entire slide mount there are 1,000 sq. mm., hence representing $150,000,000$ bacteria when figured back to the original undiluted state. Since the entire amount of the substance upon the slide was $1 / 10 \mathrm{cc}$. (or $1 / 10 \mathrm{gram}$ ), we must multiply by ten in order to reduce to $1 \mathrm{cc}$. or $1 \mathrm{gram}$. The special advantage of the staining method lies in the fact that bacteria, as a rule, stain differently from other minute organic particles. Small crystals which might be mistaken for bacteria do not take the stain at all. The instructor in charge must assist the student in the use of the hemacytometer.

The area upon which the material is to be spread (on the slide) is indicated as follows: Upon a piece of white card board mark the area above indicated by means of ruler, pen and India ink, and lay the slide over this ruled card when spreading the material.

Substances deficient in albuminous matter for fixing purposes (on the thoroughly cleaned slide) should have added to them a small quantity of egg albumin solution. The pipette should be clean when 
it is about to be used. After the substance has been drawn up into the pipette, and before delivery upon the slide, touch the delivery end of the pipette upon a clean glass surface, and similarly touch the pipette upon the slide after the desired amount (1/10 cc.) shall have been delivered. Spreading must be done carefully. If too much heat is used in drying the material is apt to peel off; especially is this likely to occur if oil or fat is present, as in milk. Excess of fat and oil may be removed from the slide mount after drying and dehydrating with alcohol, by dipping a few times into xylol or benzol, or ether.

In a general way, the Loeffler stain will be found most useful for purposes of differentiating between bacteria and non-bacterial particles. Ziehl's stain will be found especially useful if it is suspected that the substance under. examination contains acid fast bacteria. It is a diffuse stain and demands the careful use of the decolorizing agent (acidulated alcohol). The Broca stain is especially recommended in cases where it is desirable to differentiate between dead and living bacteria (that is dead, or living at the time that the stain was applied). In brief, the Loeffler stain will be employed for routine purposes, and the others for occasional special purposes.

For making the yeast and spore counts, use the $1 / 250 \mathrm{cmm}$. areas of the hemacytometer, sampling, mixing and diluting as for the bacterial count. The staining method is rarely if ever required for making spore or yeast counts, as these structures are not likely to be confused with anything else. The spore count is not a reliable indicator of the amount of mold decomposition. It simply indicates that the mold present had proceeded to the spore forming stage. A vegetable product (as catsup, jam, jelly, preserve, etc.,) may be completely decomposed by mold and yet the spores may not be abundant. On the other hand, abundant spores does indicate a high degree of mold contamination.

If it is desired to determine the relative or comparative degree of bacterial, yeast or mold decomposition, the following procedure is to be followed. After having made the counts as above indicated, place a small amount ( 5 cc. or 5 grams) of the substance under examination in a clean beaker, and set aside in an incubator at a temperature of $37^{\circ} \mathrm{C}$. for a period of five days, by which time complete decomposition (bacterial as well as mold, and perhaps also yeast) will have taken place. Again make the desirable counts and compare the two findings, and from such comparison deduce the percentage of decomposition in the substance at the time the original examination was made. We will suppose that the original examination of a fruit product gave the following results: 


\section{A Soda Fountain Fruit}

Total bacteria $250,000,000$ per ec. Total yeasts. $40,000,000$ per cc.

Fragments of mold hyphæ. 50,000 per cc.

After some of the fruit product had been incubated in a clean sterilized beaker for four days at a temperature of $37^{\circ} \mathrm{C}$. it had undergone total decomposition (100 per cent. decomposition), represented, let us suppose, by the following counts:

\section{Completely Decomposed Product}

Total bacteria $3,000,000,000$ per cc. Total yeasts. $150,000,000$ per cc. Mold hyphæ. $2,000,000,000$ per cc.

Since a substance cannot be decomposed 300 per cent., we must consider each count at 100 per cent., add and divide by three. Considering first the bacterial counts, we find that $25 / 300$ times 100 per cent. equals 8.3 per cent., (that is, $250,000,000:: 3,000,000,000:: x: 100$ per cent.). As to the yeasts we have $4 / 15$ times 100 per cent., or 26.6 per cent. The mold count in the original as compared with the completely decomposed material is negligible, amounting to a very small fraction of 1 per cent., and may be considered as zero. $8.3+26.6$ $+0 \div 3=11.6$ per cent. decomposition of the fruit product, of which yeast decomposition was preponderant. . In another product the several kinds of decomposition may be quite different in kind as well as in degree. These estimates are approximate only, but are entirely practical. The analyst must remember to make the culture of the substance under examination without any additions or modifications of any kind. If the material contains vegetable tissues and cell elements in coarser aggregates, a small well mixed bit of the material to be examined should be rubbed through a wire 100 mesh sieve, and likewise a bit of the completely decomposed material. This must be uniformly done in order that the results of the counts may be uniform.

3. A Microscopical Standard for Pyrethrum Insect Powders.-According to Insecticide Decision No. 1, by the U. S. Department of Agriculture under date of July 15, 1911, the term "insect powder," when used without qualification, means an insecticide made from the powdered flower heads of Chrysanthemum (Pyrethrum) cinerarixefolium (Trev.) Bocc., Chrysanthemum (Pyrethrum) roseum Web. and Mohr, and Chrysanthemum marshalli (Pyrethrum carneum M. B.) Ashers. The terms "Pyrethrum" and "Pyrethrum powder" are, when applied to insecticides, synonymous with "insect powder." In designating a mixture of powdered flowers and stems, the term "insect powder" may be used, provided this is immediately qualified by word or phrase 
so as to indicate clearly the nature of the article. The qualifying word or phrase should appear in type sufficiently clear and in position sufficiently prominent to attract the immediate attention of the purchaser. In a case of this kind, where the constituent substances are named, the predominating substance should be named first in order.

The following is recommended as the official description of insect powder:

Insect Powder. Pyrethrum Insect Powder.

Made from the flower heads of Chrysanthemum cinerariafolium Bocc., C. roseum Web. and Mohr, and C. Marshallii Ashers.

Fine powder, ranging from No. 80 to fine meal.

Rather dull yellowish brown color.

Somewhat aromatic odor, faintly recalling chamomile.

Bitter and somewhat pungent taste.

The histological characteristics (microscopical) of the three official species of Chrysanthemum are closely similar. Vascular and parenchymatous tissues are not characteristic. T-shaped trichomes (the basal cells usually broken and removed, leaving the double tapering pointed, soft, flexible, somewhat bent and twisted, rather thick-walled colorless, end-cell plainly to be seen) are the most characteristic structures. Amount of fibrous tissue (ducts, tracheids, sclerenchymatous elements) is in direct proportion to the amount of stem tissue present. Amount of sclerenchyma cells and clusters (typical cell forms, singly and in groups) is in direct proportion to the amount of matured (old) flower heads present. Pollen grains should be abundant and show the general structural characteristics of the pollen grains of the flowers belonging to the natural order Compositæ, that is, they are spherical with numerous distinct conical projections of the exine, and yellowish brown in color when mature.

Pyrethrum insect powder should contain not less than 2,500,000 pollen grains per gram of the air dry powder; or, should show at least an average of two pollen grains per field of the high power (No. 2 ocular and No. 7 objective), or, 20 grains per field of the low power (No. 2 oc. and No. 3 obj.) of the compound microscope. Lignified (showing red coloration with $\mathrm{HCl}$ and phloroglucin) fibrous elements (in clusters) and sclerenchyma cells (single cells and in clusters) must not exceed 50 per cent. of the entire mass of the powder, as estimated ocularly under the compound microscope. Ash should not exceed 8 per cent.

A high grade insect powder is made from the partially expanded flower heads of the official species of Chrysanthemum, and would show the following microscopical characteristics: 
Immature pollen grains (irregular in outline with conical projections of extine indistinct) abundant, 12,500,000 per gram or even more.

Fibrous tissue should not exceed 25 per cent.

Sclerenchymatous tissue is sparingly present.

Ash should not exceed 5 per cent.

Insect powder is extensively adulterated. The most common adulterants are the stems of the plants (official species of insect flower) from which the flower heads have been removed (fibrous tissue 80 to 90 per cent. with practically no pollen grairs), flower heads of related species of Chrysanthemum and of Pyrethrum, of Calendula, of Chamomile and of other species of plants. Japanese and Chinese insect pow ders made from unknown species of Chrysanthemum and Pyrethrum are used as adulterants (often as substitutes). Mustard hulls, curcuma, flour, corn meal and other inert vegetable substances have been used as adulterants. Fully matured (old) flower heads may be used (sclerenchyma cells very abundant, abundant fibrous tissue with pollen grains comparatively few and fully matured). Note that the decision of the Department of Agriculture does not specify the "unexpanded" or "partially expanded flower heads."

To make the counts of the pollen grains, place 1 gram of the very fine air dry, well mixed sample of the insect powder in a $25 \mathrm{cc}$. graduated cylinder, add $5 \mathrm{cc}$. of water, mix thoroughly, then add 2 per cent. gum arabic solution up to the $10 \mathrm{cc}$. mark, making a dilution of 1-10. Mix thoroughly by shaking for 20 seconds. Make the counts by means of the hemacytometer, using the $1 / 250 \mathrm{cmm}$. areas of the counting chamber.

4. A Microscopical Method for Determining the Percentage of Flours and Starches in Foods and Drugs. - It is frequently necessary to ascertain the proportions of different flours in a mixed meal, as in pancake flours, compounds of flour and corn meal, of flour and buckwheat, etc., and to determine the amount of cereal and starch filler in sausage meats, in ice creams, in mince meats, in pies and pie stocks, in face and dusting powders, in baking powders, in jams, in jellies, in powders, pills and tablets, etc. The chemical methods are not only time consuming but often unsatisfactory and in many instances wholly inapplicable. The following microscopical method is simple, quickly carried out and the results are sufficiently accurate for all practical purposes.

(a) The Mixing or Suspending Solution.-The liquid in which to make the suspensions of substances to be examined shall be a 3 per cent. filtered aqueous solution of pure gum arabic. Boiled distilled water shall be used. A 20 per cent. sterilized stock solution may be kept on hand from which the desirable dilutions can be made. 
The gum arabic solution keeps the starch granules in suspension long enough to permit making the counts. Stronger solutions of the gum are not recommended because they interfere with the ready mixing of the substance to be examined and also because they tend to agglutinate the smaller starch granules and proteid granules, thus interfering with ready counting.

Other pure vegetable gums, or egg albumen, may be used in place of the gum arabic in case the latter is not at hand or is not readily obtainable.

(b) Making the Suspensions.-Into a 100 cc. graduated cylinder pour $10 \mathrm{cc}$. of boiled distilled water, adding thereto 1 gram of the substance to be examined and mix thoroughly by means of a stirring rod and by shaking. The particles clinging to the stirring rod must finally be washed into the suspension. Add 2 per cent. gum arabic solution up to the $100 \mathrm{cc}$. mark and again mix thoroughly by shaking. The required time and severity of the shaking depends upon the character and nature of the substance to be examined.

(c) Adding the Iodine Test Solution.-After mixing the 1 gram of substance in the $10 \mathrm{cc}$. of distilled water, add $10 \mathrm{cc}$. of a 1/10 normal iodine starch test solution and shake thoroughly; then add (to the 100 cc. mark) the gum solution as explained in (b).

The iodine solution is to be used with all substances in which the starch granules may not be very distinct through partial dextrinization or in cases where other particles (fat, oil, proteiad granules, casein, etc.), may interfere with the ready counting of the starch granules. It will be found useful in the examination of cereal flours, dusting powders, pills, tablets, etc.

(d) Making the Starch Count.-Immediately after the final thorough mixing, dip a glass rod into (to a depth to or below the middle of the cylinder) the suspension taking up a droplet which is lightly and quickly touched upon the counting area of the well of a Thoma-Zeiss hemacytometer having the ruling of Fuchs and Rosenthal, or that of Turck, or that of Bürker. Spread and mix the droplet upon the counting chamber by means of a very slender or pointed glass rod (a pin, using either the point or the edge of the head, is very satisfactory) and place the cover glass in position.

Substances containing larger starch granules as rye flour, wheat flour, arrowroot starch, potato starch, etc., require the use of the 1/250 $\mathrm{cmm}$. areas of the hemacytometer, counting the granules in not less than 25 different areas of the dimension indicated. Careful attention must be given to the starch granules which lie upon or across the ruled 
lines, in order that they may all be counted and yet none of them counted twice.

In the ease of substances containing small starch granules as rice, corn, chestnut and buckwheat, the $1 / 4000 \mathrm{cmm}$. areas of the hemacytometer may be found more satisfactory.

The suspension must be shaken thoroughly each time a hemacytometer mount is to be made.

(e) Making the Comparative Starch Count.-Determine the exact number of starch granules in 1 gram of the air dry pure substance according to the method above outlined. This gives the exact number of starch granules representing 1 per cent. of the substance under examination and is the starch granule factor to be used in ascertainigg the percentage of the starch or starch bearing substance present. Such numerical starch granule factors must be very carefully determined. Four or five different hemacytometer mountings should be carefully counted and the average results obtained should be checked by making additional counts of 2, 4 and perhaps 10 and even higher per cent. suspensions of the substance. We will suppose that a pancake flour shows the following starch counts according to the proposed method:

Corn starch, 226,000,000 granules per gram.

Wheat starch, $665,000,000$ per gram.

Let us suppose that corn meal contains $1,305,000,000$ starch granules per gram and wheat flour contains $910,000,000$ starch granules per gram, then we would find from the above figures that the pancake flour under examination was composed of corn meal 25 per cent. and wheat flour 75 per cent.

(f) Estimating the Percentage of Starch in the Dextrinized or Otherwise Modified State.-The method is applicable provided the identity of the starch is still recognizable. The number of modified undissolved dextrin granules still recognizable as starch granules will indicate the percentage of air dry starch which it represents.

(g) Starch Percentage Tables.- It is desirable to prepare accurate tables giving the average number of starch granules in 1 gram of the starch, dextrin, flour or other starch bearing substance, for the convenience of laboratory workers. Such tables must be prepared from counts made of meals, flours, seeds and grains, reduced to a very fine powder (meal).

In making comparative starch determinations as explained under (e), all vegetable substances of a cellular nature must be reduced to a very fine powder in order to make it possible to count all of the starch granules representing 1 gram of the substance under examination.

Until numerical starch percentage tables, as above suggested, are 
available, it will be necessary for each analyst to determine such starch granule factors for himself as he may require. Such factors need be determined once only, provided a permanent record is kept. The following are a few numerical starch granule factors:

Table of Numerical Starch Counts and Starch Percentages*

\begin{tabular}{|c|c|c|c|}
\hline Name & $\begin{array}{l}\text { Starch granules } \\
\text { per gram }\end{array}$ & $\begin{array}{l}\text { Numerical } \\
\text { starch ratio } \\
\text { (corn starch } \\
\text { as } 1 \text { ) }\end{array}$ & $\begin{array}{l}\text { Starch } \\
\text { percent- } \\
\text { age }\end{array}$ \\
\hline 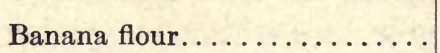 & $281,150,000$ & 0.115 & 22 \\
\hline Barley flour.............. & $3,624,000,000$ & 1.490 & 62 \\
\hline Bean flour.... & $206,650,000$ & 0.084 & 57 \\
\hline \multirow{2}{*}{ Corn $\operatorname{starch} . \ldots \ldots \ldots \ldots \ldots$} & $2,432,000,000$ & 1.00 & \multirow[t]{2}{*}{100} \\
\hline & $1,880,000,000$ & 0.778 & \\
\hline \multirow{2}{*}{ Corn meal................ } & $1,305,000,000$ & $0.703\}$ & \multirow{2}{*}{71} \\
\hline & $520,000,000$ & $0.213\}$ & \\
\hline Ginger (peeled) ........... & $1,919,000,000$ & 0.789 & 20 \\
\hline Ginger starch... & $2,314,000,000$ & 0.951 & 100 \\
\hline 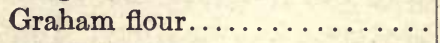 & $309,973,000$ & 0.168 & 75 \\
\hline Maranta starch........... & $465,000,000$ & 0.190 & 100 \\
\hline Oat meal............... & $4,769,000,000$ & 1.960 & 68 \\
\hline 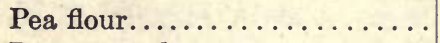 & $182,325,000$ & 0.075 & 55 \\
\hline 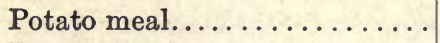 & $131,650,000$ & 0.054 & 80 \\
\hline Potato (raw) .......... & $50,700,000$ & 0.021 & 18 \\
\hline 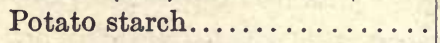 & $147,500,000$ & 0.061 & 100 \\
\hline Rice flour ${ }^{1} \ldots \ldots \ldots \ldots \ldots \ldots$ & $1,660,000,000$ & 0.682 & 79 \\
\hline Rice, ground $^{2} \ldots \ldots \ldots \ldots \ldots$ & $3,280,000,000$ & 1.348 & 79 \\
\hline Rye flour (grain).......... & $2,984,000,000$ & 1.227 & 78 \\
\hline \multirow[t]{2}{*}{ Sago $\left(\right.$ pearl) ${ }^{3} \ldots \ldots \ldots \ldots \ldots$} & $80,975,000$ & 0,004 & \multirow[t]{2}{*}{100} \\
\hline & $910,000,000$ & 0.375 & \\
\hline \multirow[t]{2}{*}{ Wheat flour (white) ${ }^{4}$. } & $1,822,000,000$ & $0.749\}$ & \multirow[t]{2}{*}{75} \\
\hline & $2,400,000,000$ & $0.987)$ & \\
\hline
\end{tabular}

* From a table prepared by Berger at the author's suggestion.

1 The aggregates were counted as one.

2 The aggregates were broken up and the individual granules were counted.

3 Exact count impossible because of agglutination of many granules.

- There is considerable variation in the number of starch granules in the different wheat flours and also in the ratio of larger $(15 \mu$ and over) and smaller (less than $25 \mu)$ starch granules in one and the same variety of wheat flour.

\section{Determining the Starch Granule Size Ratio in Wheat Flours.-} The suspensions of the flour and the starch counts are made as described under method (4) just given. Two separate counts are how- 
ever made, one of the larger starch granules (all granules 15 microns and more in diameter) and one of the smaller starch granules (all granules less than 15 microns in diameter). The ratio between the number of larger and smaller starch granules shall be known as the starch granule ratio and it is recommended that this ratio be used in estimating the quality of wheat flours. It would appear that the quality of wheat flour, from the standpoint of the baker, is in direct ratio to the relative number of larger starch granules present. A starch granule ratio of $1: 3$ to $1: 4$ is high; from $1: 4$ to $1: 6$ is medium, and from 1:6 to $1: 8$ is low, and the quality of the flours made from wheat showing such ratios is correspondingly good or high grade, medium grade and poor or low grade. It would also appear that flour made from wheat grown in the eastern United States gives the higher starch granule ratios $(1: 3$ to $1: 6)$, while flour made from wheat grown in the far West (California, for example) shows the lower ratios ( $1: 6$ to $1: 8$ ). It would appear, based upon the examination of many samples, that the starch granule ratio for flours made from wheat grown in the middle West (Kansas, Iowa, Illinois, Nebraska) is approximately $1: 5$. It must be kept in mind, however, that the different processes employed by millers (sterilized, bleached, patent flours, etc.) also modify the ratio. The starch granule ratio has no bearing on the differences in gluten and proteid granule content of different wheats and of different wheat flours. It would appear that bread made from wheat flour in which the relative number of larger granules is high (ratio of $1: 3$ ) is lighter and softer, hence more palatable and no doubt also easier of digestion, than bread made from flour with a low starch granule ratio.

It may be stated that there are very marked local geographic variations in the starch granule ratios. Also, the ratio varies with different varieties of wheat.

6. Microscopical Examination of Smoking Opium.-Place a small bit of the material on a slide, cover with No. 2 cover glass, applying enough pressure to spread the mass. Examine first under the low power of the compound microscope. Smoking opium shows numerous colorless prismatic crystals in the dark brown matrix. These crystals are large enough to be seen distinctly under the low power of the compound microscope and resemble somewhat the phytosterol crystals of vegetable oils and fats and are probably crystals of meconates of the opium alkaloids. The number of crystals is in direct proportion to the total alkaloids present, hence the relative number of crystals seen under the microscope indicates the quality of the smoking opium.

Smoking opium is no longer allowed entry into the United States. 
Imitation smoking opiums composed of syrups, vegetable jams and jellies, etc., are offered for sale by opium smugglers. This double crime and deception is readily detected by means of the compound microscope.

7. Determining the Fat Content of Milk and Cream by Means of the Compound Microscope.-By means of a pipette graduated into tenths of 1 cc., run $0.5 \mathrm{cc}$. of the thoroughly mixed sample of milk into a 100 cc. graduated cylinder and add warm (not hot) distilled water up to the $100 \mathrm{cc}$. mark making a dilution of 1-200. Mix thoroughly by shaking vigorously for 20 seconds. Warm the mixture in the sun or in the incubator (at $37^{\circ} \mathrm{C}$.) for a few minutes and again shake.

By means of a rather slender glass rod dipped well into the cylinder, take up a droplet of the diluted well mixed milk suspension and place on the counting chamber of the Thoma-Zeiss hemacytometer, cover with cover glass, and make the counts of the butter fat globules, following the suggestions already given under examination of starch and flour suspensions. The $1 / 4000 \mathrm{cmm}$. areas are to be used in making the counts and the average of not less than fifty areas counted (from not less than two different hemacytometer mounts) is to be used as the factor for estimating the fat content of the milk under examination. $578,100,000$ butter fat globules per cc. of milk corresponds to 1 per cent. of butter fat. Dividing the number of globules found in the sample under examination by $578,100,000$ will give the percentage of butter fat present.

Caution must be observed in making fat counts of pasteurized and boiled milks as many of the globules are more or less agglutinated. The method is not recommended for evaporated and condensed milks (sweetened and unsweetened), although the tests thus far made would indicate that the results are fairly reliable. For making fat counts of cream use dilutions of $1-800$ to $1-1000$.

8. Agar in Jams, Jellies and Similar Fruit Products.-The usual method is to ash a sample of the jam or jelly at as low a temperature as possible, and to add weak hydrochloric acid for the purpose of decomposing the carbonates, etc. In the presence of agar, the siliceous skeletons of marine diatoms will appear in the ash residue when examined under the compound microscope. The following substitute method is recommended:

Dissolve as completely as possible (with heat) 5 cc. or 5 grams of the substance in $100 \mathrm{cc}$. of distilled water and centrifugalize for 30 minutes while still hot. Decant off all of the liquid (with suspended insoluble matter) excepting about 2 or 3 ec. of bottom sediments and examine this residue under the compound microscope. In the presence of agar 
there will be found undissolved agar cell fragments and remnants of undissolved parasitic algal forms which are quite constantly found upon agar, and the characteristic agar diatoms (mostly the comparatively large discoid Arachnodiscus Ehrenbergii Baillon).

Finding one or more marine diatoms or algal remnants (of agar or of agar parasite), in one slide mount or in 5 to 50 fields of view of one or more slide mounts, is evidence that agar is present, but it is not possible to state with any degree of accuracy how much agar was added.

The preceding examples will serve as a beginning in this phase of micro-analytical work. Many other problems will suggest themselves. The following cases are suggested for solution, by the student, with the guidance of the instructor in charge.

1. What is the percentage of senna in compound licorice powder based upon the number of senna trichomes present?

2. What is the percentage of ginger in the several U.S.P. and N.F. compound powders containing this substance?

3. What is the percentage of cinnamon in the compound powders containing this substance, based upon the number of bast cells present?

4. What is the percentage of corn starch in the baking powders of the market?

5. Obtain face powders in the open market and examine for corn starch. What is the percentage of corn starch present?

6. Determine the number of starch granules per gram in the following vegetable drugs:

(a) Belladonna root.

(b) Aconite root.

(c) Colchicum corm.

(d) Phytolacca root.

(e) Ipecac.

(f) Nutmeg.

(g) Cocoa.

(h) Iris florentina.

7. Determine the number of bast cells per gram of the following barks:

(a) Cinchona bark.

(b) Wild cherry bark.

(c) Cascara bark.

(d) Aspidosperma bark.

(e) Cinnamon barks.

(f) Sassafras bark.

(g) Krameria bark.

(h) Canella bark. 


\section{A GENERAL METHOD FOR MAKING QUANTITATIVE MICRO- ANALYSES OF VEGETABLE DRUGS AND RELATED SUBSTANCES}

Several special microanalytical methods (qualitative as well as quantitative) have already been given. Attemps have been made from time to time to develop quantitative micro-analytical methods which might be generally applicable, notably by Chamot, Meyer, Hanausek, Weinzierl, König, Vogel and others. These quantitative methods are largely based upon the fact that certain tissues and tissue elements are quantitatively fairly constant in plant organs and plant parts and in the various manufactured plant products found upon the market. For example, mature ginger contains a fairly definite percentage of starch. Green apples contain considerable starch whereas ripe apples contain only a trace of starch. Belladonna roots gathered too early in the season are deficient in starch. Old thick cinnamon bark is deficient in bast. Cloves contain no sclerenchyma cells whereas clove stems are rich in this tissue. The chief difficulty in the way of formulating definite working methods is the lack of available data upon which to base such methods. For example, if we had a record of the starch content of ginger, of the apple, of belladonna root, of aconite root, of colchicum corm, etc., for each month of the growing season, then we could readily use the starch factor in determining the percentage of the articles gathered green or too early in the season. If we had a complete morphologically descriptive record of the development of the pollen grains in the insect flowers, we would then be in a position to determine quantitatively the amount of overripe flowers used in a given insect powder. In other instances it is possible to work out on the spot the necessary data for each quantitative analysis; as, for example, in the estimation of the percentage of stems in cloves, the percentage of black pepper refuse in black pepper, the percentage of stems in senna leaves, etc. Patience and a willingness to work are the essentials to success in the working out of such methods. As the details for the quantitative microanalysis of any one vegetable substance are fully and accurately worked out, the figures obtained should be carefully and permanently recorded for the benefit of those who follow after.

The chief source of error in making quantitative microanalytical determinations, of the kind here described, is the fact that while the different tissue elements and cell contents are fairly constant in tissues of the same kind (in the same relative position and of the same age and seasonal growth), we have no usable records of the quantitative tissue 
variations in plants, more especially in the perennials. For example, how does the bast, sclerenchyma and bark parenchyma in the bark of the white oak vary from year to year, not only in the trunk of the tree but also in the branches? Such a study would be of great value in the practical application of the method in the examination of cinnamon barks, sassafras bark, wild cherry bark, cascara bark and barks in general. What is the annual increase in fibrous tissue in belladonna roots? What is the relative amount of fibrous tissues in the wild growing and in the cultivated chicory? What is the relative amount of fibrous tissues in trimmed licorice roots and in the licorice trimmings? What is the exact quantitative relationship of like tissues in the inner and outer barks of the same species of trees? Since such data are not available, they must be carefully ascertained for each individual case or problem and the figures obtained carefully recorded.

At best any quantitative microanalytical methods which may be worked out will give approximate results only; however, these approximate results are sufficiently accurate for all practical purposes. The chief factors in the variation of results are dependent upon the fact that the tissue elements and cell constituents vary (in different vegetable substances of the same kind gathered at the same time) in proportion to the size of the plant part or plant organ. This difference amounts to but very little in average commercial articles of the same kind and may in fact be wholly ignored. The chief reason why the microanalytical methods should be developed is because this is frequently the only method which will give the information desired, the chemical methods being wholly inapplicable.

The following general method is given with the hope that it will serve as a basis for a further development of this most important addition to the analytical methods employed in food and drug laboratories.

1. Selecting the Sample.-Secure an average commercial sample of the crude drug or spice, free from impurities. Great care must be observed in selecting and preparing an average sample. It should be a true average sample of the commercial article of recognized standard quality or grade, as defined by the Department of Agriculture, Bureau of Chemistry, or in case the article is not defined or described by the Bureau of Chemistry, it must be of the quality and grade generally recognized in commerce, or as described or defined in recognizedly authoritative works of reference. Foreign inclusions, as vegetable tissues, dirt, clay, sand, pebbles, etc., must be removed by any suitable method, provided that none of the substance of the article itself is thereby removed or destroyed or rendered unrecognizable. Enough of the material must be taken to assure an average sample for analytical purposes. 
In order to be able to select an average or representative sample of the commercial article, considerable experience is necessary. Spice dealers are, as a rule, excellent judges of the quality of the products to which they have given years of close observation. The wholesale drug dealers are thoroughly familiar with the appearance of the crude drugs as they are offered on the market. Grain merchants can, at a glance, determine the grades of the various cereals. Tea experts will recognize aromas and flavors entirely lost to the inexperienced observer. Fortunately, it is not expert ability which is required to select a. representative sample, but rather a familiarity with a fair quality or grade of the articles to be examined. If, for example, it is desired to examine ground black pepper as to the approximate percentage of pepper hulls present, the comparison is to be made with a fair quality of whole black pepper, not with so-called "grinding peppers," or peppers otherwise defective, or with some special commercial variety or blend of black pepper. Before grinding, all sand, dirt, pepper stems, and markedly defective fruits must be removed. Considerable care must be observed in selecting an average sample of a root drug or of a drug composed of roots and rhizomes, or of leaves and stems. It is necessary to have on hand carefully selected average samples of drugs, spices, cereals, coffees, teas, cocoas, etc., inclusive of the various refuse tissues and the various milling by-products, as well as articles commonly employed as adulterants, such as nut shells, olive pits, tea dust, coconut shells, screenings and tailings, refuse and trimmings, colocynth seeds and rind, corn cobs, corn silk, bran and millings, cereal chaff, wild mace, wild nutmeg, chicory, male fern chaff, tobacco stems, senna stems, senna siftings, roots of Ruellia ciliosa, false senega, pokeroot, etc., etc.

2. Grinding or Powdering the Sample.-After the average sample has been garbled, cleaned and thoroughly dried, it is reduced to a No. 80 powder, inclusive of all tissues which may be present.

In some instances it will be found necessary to reduce the material to be examined and compared to a much greater fineness, in a special mill or a mortar. In order to make accurate starch counting possible the starch bearing tissue must be made sufficiently fine to pass through a 200 mesh sieve or through bolting cloth. In other instances certain tissues may be removed and separated in comparative purity by means of very coarse mesh sieves (Nos. 8, 20,40). In this manner such substances as bran, crude fiber, coarser meals, shells, etc., may be separated from the finer elements and their percentage values determined separately, as will be explained.

3. Mixing the Powdered Sample.-After the grinding, the entire amount must be thoroughly mixed by means of a spatula. Shaking 
in a container is not satisfactory. If the amount of the material is considerable, (20 grams and more), divide the thoroughly mixed material (spread out in a circular layer) into quadrants, remove one quadrant and again mix this thoroughly by means of a suitable spatula. A second division may be made if necessary. The final sample should be not less than 5 grams.

4. Making the Diluted Suspension.-Dry the thoroughly mixed sample for one hour at a temperature of $80^{\circ} \mathrm{C}$. Weigh out 5 grams
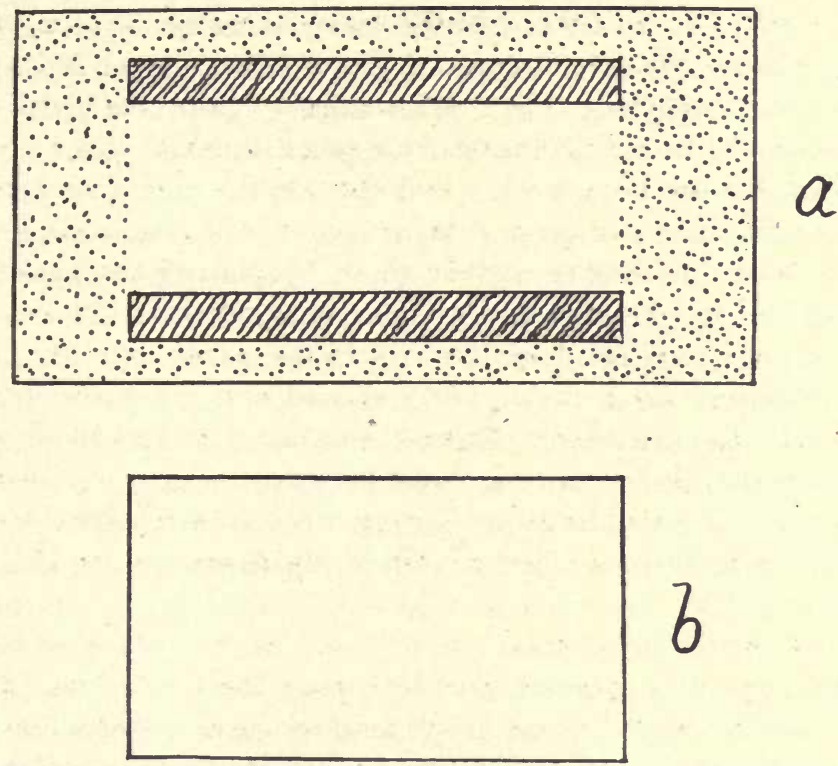

Frg. 35.-Special counting chamber for making quantitative microanalyses of foods, spices and drugs. The two glass slips upon the extra size slide are exactly $0.2 \mathrm{~mm}$. thick and the area bounded on two sides by the two slips is 10 sq. $\mathrm{cm}$. $(1,000 \mathrm{sq}$. $\mathrm{mm}$.). $0.2 \mathrm{cc}$. suspensions of this material to be examined is spread in this area and covered with the rectangular cover glass (b). Full size. (Made by the Bausch and Lomb Optical Company.)

of the sample and place it in a 25 cc. graduated cylinder, add $10 \mathrm{cc}$. of distilled water (or $10 \mathrm{cc}$. of a mixture of equal parts of distilled water and glycerin) and mix thoroughly by means of a glass rod. Fill up to the 25 cc. mark with a 5 per cent. gum acacia solution and again thoroughly mix. The gum solution will hold the tissues in suspension until the microscopic examination is made. The above makes a dilution of 1-5, which will be found satisfactory in most cases. Higher dilutions, as 1-10, 1-25, 1-100, may be used if desired or if necessary for accurate results, as in starch counting.

Other suspending media may be used, as glycerin, oils, a thin syrup, 
solution of cherry gum, solution of gum mastic, gelatin solution, India gum solution, plain vaseline, etc. It is advised to stir the material in a little water first, as stated above, for if the gum solution should be added at once, considerable difficulty may be encountered in getting minute particles, starch granules in particular, evenly distributed. It is of course necessary to stir and mix the suspension thoroughly each time a new mount is to be made.

5. Making the Counts. - The mounts must be made without a time lapse in the entire procedure. Immediately after the thorough mixing, take up from $0.5 \mathrm{cc}$. to $1.00 \mathrm{cc}$. of the material by means of a graduated straight cylinder pipette, having a free outflow ( 1 cc. or 2 cc. pipettes graduated into tenths), reject 0.1 to $0.2 \mathrm{cc}$. and then deliver just 0.2 cc. upon the counting chamber or counting slide and at once mix and spread this out between the two slips on the slide (use a platinum loop or needle, or any blunt needle, or a very thin glass rod), and cover with the special rectangular cover glass, by placing the proximal end of the cover at the distal ends of the two slips, pushing it forward upon the two slips, lying flat upon them. If the exact amount indicated (namely, 0.2 cc.) has been properly spread and the cover glass carefully placed, the entire space between the two slips and the cover glass will be occupied by the material without any excess or overflow. The mount should be set aside on a leveling table for a few minutes, otherwise starch granules may become unevenly deposited by the force of gravity.

If the powders to be examined are very fine, as starches and some meals, face powders, dusting powders, etc., the counts may be made by means of the hemacytometer, instead of the above special counting chamber. A number 80 powder does not permit the use of the hemacytometer for counting. It is perhaps self-evident that actual numerical determinations per cc. or per gram may be made by means of the method just outlined, since definite quantities and definite counting areas are used.

The following is the manner in which the individual field counts are to be made. In the case of rather coarse particles, such as the larger bast cells, groups of sclerenchymatous tissue cells, fragments of fibrous tissue, fragments of vascular tissue, etc., for which the low power is usually employed, count all of the recognizable structures which lie within the circular area of the field of view, including all of the counting groups lying across the margin of the field, provided, the groups or the cells extend far enough into the field of view to be distinctly recognizable. Next shift the mount so that the new field of view does not reveal any of the counting elements of the preceding field. Unless this rule is closely observed there is likelihood of counting one cell group twice. 
This must be avoided. On the other hand, it is advisable not to shift the mount more than may be necessary to obtain an entirely new field as above explained. The counts should be made in groups of ten selected from five nearly equidistant areas of the mount, avoiding the extreme margins of the area of the mount, and the average of the fifty counts is taken. If the group counts (of ten each) show wide numerical variation, it indicates that the material was not uniformly distributed on the counting chamber. The dilutions from which the counts are to be made should be such that not more than five to ten counting elements will appear in one field of view.

In making numerical counts of minute particles, such as starch granules, trichomes, epidermal cells, sparingly present and rather small sclerenchyma cells or short bast cells, for which purpose the high power is usually employed, it is advisable to make the dilutions such, that not more than from ten to twenty-five of the counting particles will appear in one field of view. In such cases it is the rule to count one half of the particles which lie across the margin of the field of view. - If the tissue elements upon which the percentage count is to be based are very sparingly present, from one to two to even less than one per field of view, it is necessary to take the average of many counts, 100 fields or more, in order that an average may be obtained which will yield a reliable percentage determination. In some cases coloring agents such as phloroglucin and hydrochloric acid (lignin test), iodine test solution (for starch), chloriodide of zinc, and others, will prove useful:

If it is desired to make careful starch counts of drugs and spices, it is necessary to use a higher degree of fineness. The particles must be small enough to pass through a 200 mesh sieve or through bolting cloth. In the case of vegetable substances having starch aggregates, it is advised to count the aggregates as one, rather than to attempt to give the number of individual granules in each aggregate, as, for example, in making starch counts of oat, rice, aconite and buckwheat, but care must be observed not to omit to state this in the recorded results.

In the above method it is not necessary to give any attention to differences in specific gravity of the different tissue elements and cell contents. Should it be desired to give the percentage of sand present (by weight) in a given vegetable powder, it would be necessary to ascertain by the trial method that mixture of the substance and sand which would give the same counts as the article under examination. Let us assume that by the trial method we found that the addition of 5 grams of sand to 5 grams of the powder we obtained the same sand 
count as in the substance under examination, then we would know that the sand adulteration amounted to 50 per cent. However, in the case of sand adulteration, the simpler and almost equally accurate beaker or test tube sand test will be employed, rather than the microscope.

The depth of the mount, namely $0.2 \mathrm{~mm}$., requires good working distance of the compound microscope in order that the entire depth may be brought into view. The cover glass used must be thin, not to exceed the thickness of the ordinary No. 2 covers. The usual lense combination (qcular and objective) giving a magnification of about 350 to 500 diameters may be used. A good observer who is entirely familiar with tissues and tissue elements could use a lower magnification with better effect, such as a well corrected combination giving a magnification of about 180 diameters.

The procedure is as follows: Carefully examine each and every separate and distinct field, counting all of the characteristic tissue elements, and record the findings numerically. The mechanical stage will be of advantage in shifting the counting chamber. It will be found that from thirty to fifty distinct fields can be counted in one mount. The averages of not less than fifty counts should be taken upon which to base the percentage estimates of quality or adulteration.

Before beginning the counts, it is advisable to look the mount over under the low power (about 90 diameters) for the purpose of ascertaining whether or not the material is uniformly distributed. If it is unevenly spread, a new mount should be made. In fact, the low power alone is used in examining some substances, as for example Cinchona bark, the identity and purity determinations of which are based upon the counting of the characteristic large bast elements. Difficulty may be encountered in getting the total counts of aggregates of cells, as bast and sclerenchyma. As a rule, however, in a number 80 powder, aggregates which are so large as to make counting difficult are rare. Some investigators have suggested that the quantitative estimates should be based upon the actual measurements of cells and cell contents. This is not necessary, as the average of the numerical count is fully as accurate as the average based upon measurement. However, as already indicated, where identity depends upon differences in size, then measurements (linear) must be made.

It is necessary that the same microscope and the same objectives and ocular be used at all times, in order that the results may be relatively uniform. For instance, should a partial count be made with one instrument, and completed with another instrument, even if 
approximately of the magnifying power, the results would be inaccurate. In order that the work of different analysts may be unified, it is necessary to adopt standard methods. The surface area of the field of view of each microscope used must be accurately determined by means of the stage micrometer. The Bureau of Chemistry method for the examination of tomato products directs that the field of view be unified by means of the draw tube, so that each field shall equal $1.50 \mathrm{sq} . \mathrm{mm}$. (diameter of field of view equals $1.382 \mathrm{~mm}$., therefore, area of field equals $1.50 \mathrm{sq}$. $\mathrm{mm}$.). This method is faulty because no allowance is made for the differences in magnification of the microscopes used. Proper adjustment of this kind should be made by means of the ocular diaphragm, after having reduced the microscopes to the same magnification by means of the draw tube. Accurate comparative results may be obtained by any number of analysts provided a counting chamber of definite area be used. The special counting chamber recommended has a depth of $0.2 \mathrm{~mm}$., the total contents of the entire area being 0.2 cc.

6. Making the Comparisons. - In the identical manner as above set forth ( 1 to 5 inclusive) prepare and examine the article to be compared and of which the quality or purity is to be determined. From a comparison of the two averages of counts thus obtained, it is possible to determine the approximate percentage of admixture and adulteration. Let us suppose that the article in question was Cassia cinnamon and the average counts were as follows.

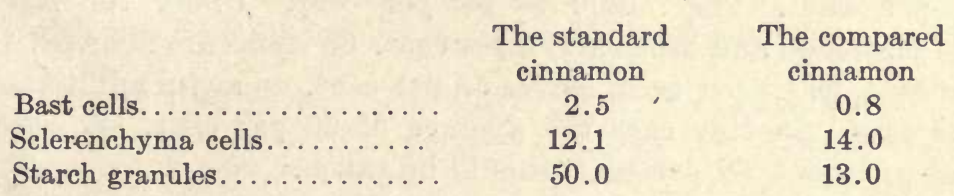

The most diagnostic tissue of cinnamon is the bast and if we use this count alone (2.5:0.8:: 100 per cent. : $x$ per cent.) the conclusion would be drawn that the article in question was 32 per cent. adulterated or 32 per cent. below a good or standard quality of cassia cinnamon. The other counts (sclerenchyma and starch) are corroborative. The bark parenchyma count is not given because the microscopic appearance of this tissue is non-characteristic, the cells being much broken up making counting difficult if not impossible.

The odor of the compared article was musty and the taste quite feeble. The conclusion based upon the organolectic tests alone is that the article in question is of very inferior quality made from old bark and that adulteration amounts to over 30 per cent. 


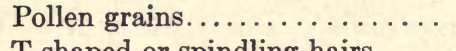

Standard insect powder

Compared insect

5.4

powder

T-shaped or spindling hairs....

Sclerenchyma cells...........

Fibrous tissue...............

$\begin{array}{rr}5.4 & 0.2 \\ 2.0 & 2.1 \\ 10.0 & 0.6 \\ 8.0 & 60.0\end{array}$

The findings would indicate that the article in question was 100 per cent. adulterated and that the adulterant was Pyrethrum stems. The small amount of pollen found in the compared article may be wholly ignored as that amount of pollen is normally present in and upon leaf and stem tissue, even though no flowers are present. A so-called insect powder may show abundant pollen grains and yet be 100 per cent. adulterated, as when foreign flowers are used, hence the analyst must be able to recognize different pollens.

$\begin{array}{lcc} & \begin{array}{c}\text { Sample powdered } \\ \text { cloves }\end{array} & \text { Clove stems } \\ \text { Bast cells of clove stems....... } & 6.0 & 10.0 \\ \text { Sclerenchyma cells.......... } & 12.0 & 21.0\end{array}$

In the above example the comparison is made with pure clove stems, which article is the most common adulterant of powdered cloves and in this case the two tissues, namely bast and sclerenchyma, are present in fairly constant ratio, hence both counts may be used and should check each other, if carefully made. The double proportion would be $10: 6$ :: $21: 12:: 100$ per cent. : $x$ per cent. $10 x=600=$ 60 per cent. $21 x: 1200=58$ per cent. Under the law (federal pure food and drugs act) 5 per cent. of stems are allowed. Sixty per cent. less 5 per cent. leaves 55 per cent. unlawful adulteration in this case. In this case the average of 60 per cent. and of 58 per cent., namely, 59 per cent. should be taken.

\begin{tabular}{|c|c|c|}
\hline & Sample cocoa & Cocoa shells \\
\hline & 3.8 & 13.9 \\
\hline lerenchyma cells. . & 2.6 & 10.0 \\
\hline
\end{tabular}

The spiral ducts are most readily recognized and are fully as diagnostic as the sclerenchyma cells. Both tissue elements should be included in the counts and the average of the two percentages obtained should be used. Thus, $13.9: 3.8:: 10.0: 2.6:: 100$ per cent.: $x$ per cent. $13.9 x=380=20.1$ per cent., and $10 x=260=26$ per cent. $20.1+26 \div 2=23.05$ per cent. of shells in the cocoa under examination. Under the law 3.50 per cent. of shells (called "crude fiber") is allowed, hence in the above case we have $23.05-3.50=$ 19.55 per cent. of excess of shells or crude fiber. The starch count is of 
little value because this substance is present in small amounts and is furthermore quite variable in amount in the different varieties of cocoa. The endosperm cell count is impracticable because the cells are very much broken up. The amount of vascular elements (represented by spiral ducts) and of sclerenchyma cells is negligible in absolutely pure (wholly freed from shells by hand) cocoa and chocolate.

In the case of aconite root, belladonna root, colchicum corm, ginger, and other plant structures rich. in starch, a careful starch count would indicate whether or not the article was gathered out of season or before maturity. In the case of leaves and herbs which contain distinctive trichomes, as senna, digitalis, artemisia, etc., these structures would serve as the basis for percentage determinations. In other cases measurements (relative size of starches in Rio and Carthagena ipecacs, relative lengths of trichomes in India and African senna) must be resorted to in order to determine percentage admixtures.

- In many instances it may not be necessary or even desirable to reduee the substance to uniform fineness. In a compound, as cattle, chicken or condition powder, one or more of the components (as bran, crude fiber, sulphur, charcoal, meals) may be separated in comparative purity by means of the nest of sieves; the several coarse and comparatively pure components are weighed and their percentage values finally computed. The finer components are mixed and reduced to the desired fineness for making the microscopic counts as already explained, and the results added to those obtained by the sifting process. The following will serve as an illustration of the method of procedure.

A Condition Powder, using ten grams of a well mixed sample.

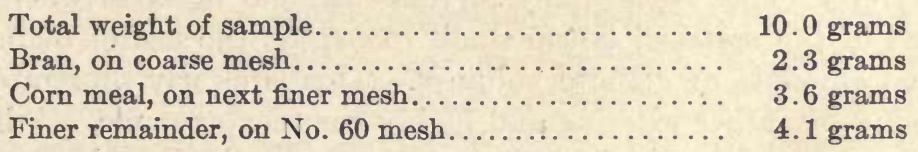

The finer remainder reduced to a No. 200 mesh powder and examined microscopically gave the following counts (one gram of the powder suspended in 99 cc. of the gum solution).
Corn starch.
$51,000,000$ per gram
Wheat starch
$8,000,000$ per gram
Sulphur particles. .
$13,000,000$ per gram
Charcoal particles.....................
Wheat tissue elements. $32,000,000$ per gram 800,000 per gram

In the above counts the corn starch count is to be interpreted in terms of corn meal, as no corn starch was added as such. The wheat starch count and crude fiber of wheat is to be interpreted as wheat 
middlings. The percentages of sulphuir and of charcoal are determined by the actual trial method. The following is the reconstructed formula of the condition powder, based upon the above data.

Condition Powder

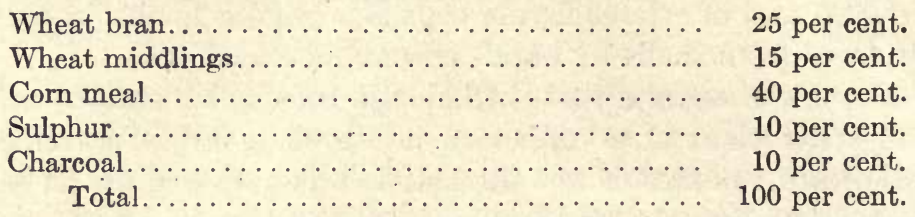

Corn meal reduced to a fineness so as to make a count of the total starch granules possible, gives 1,305,000,000 granules per gram. The starch content of wheat, middlings varies considerably, but an average article will give a starch count of 200,000,000 granules per gram. One gram of sulphur will show about 140,000,000 particles per gram. The number of charcoal particles per gram will depend upon the degree of fineness. In the above about $350,000,000$ per gram. From these figures it is simple to deduce the formula given.

The experienced microanalyst can estimate percentages with some degree of accuracy by optical judgment, but such estimates will not be acceptable in court proceedings. Thus, based upon the inspection of an ordinary slide mount, certain face powders are declared to contain about 3 per cent. of rice starch or corn starch; so-called arrowroot biscuits show about 2 to $2 \frac{1}{2}$ per cent. of arrowroot starch; a pancake flour is estimated to contain 25 per cent. buckwheat and 75 per cent. wheat flour; a baking powder is estimated to contain 25 per cent. corn starch; etc. This is the only method possible in cases where the amount of the material is too small to permit the use of definitely weighed amounts or definite volumes. This is clearly illustrated in the following rather extreme and highly complex example. A bit of vomit smear on a small piece of newspaper was submitted by a physician with the explanation that it represented a medicinal substance of which he desired to know the composition. A careful microscopical examination of the smear revealed the following ingredients.

1. Starch granules and the bast cells derived from the peeled roots of Althcea officinalis.

2. Papillose epidermal cells with red coloring matter of the petals of the red rose.

3. Abundant globules of metallic mercury.

4. Numerous chalk particles.

5. A few pollen grains.

6. Crystals of calomel. 
7. Abundant crystals of basic mercuric sulphate (turpeth mineral).

8. The starch granules, yellow lignified fibers and the crystal bearing fibers of Glycyrrhiza glabra.

As has been stated in Part $I$, one of the most important requirements or qualifications on the part of the microanalyst, is the ability to interpret the finding intelligently and correctly. The above findings are not numerous nor were they difficult to recognize. The interpretation proved very interesting, as follows:

(a) Confection of Rose, U.S. P. indicated by (2) and (5). Turning to the Pharmacopoia, the formula for confection of rose was copied.

Red rose petals (No. 60 powder)

.80 grams

Sugar............................. 640 grams

Clarified honey........................ 120 grams

Stronger rose water. $160 \mathrm{cc}$.

(b) Blue Mass U. S. P., indicated by (1), (3) and (8).

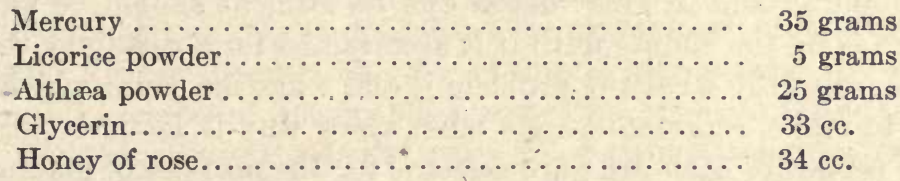

(c) Gray Powder U. S. P. indicated by (3), (4) and (5).

Mercury

38 grams

Clarified honey

10 grams

Prepared chalk.

57 grams

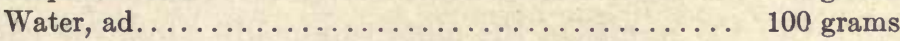

(d) Calomel.

(e) Turpeth mineral.

Based upon the optical appearance of the several ingredients of the smear as seen under the microscope, assisted by a number of trial combinations which were compared with the smear (microscopically), the following was given as the formula of the medicinal substance represented by the material upon the bit of newspaper.

Reconstructed Formula based upon the above.

Confection of rose, U. S. P. . 8 parts

Blue mass, U. S. P. 12 parts

Gray powder, U. S. P. 35 parts

Calomel.

15 parts

Turpeth mineral.

30 parts

Naturally, problems of the kind just illustrated require much time and careful study, and as already indicated, much experience in the practical use of the compound microscope.

The following quantitative microanalytical determinations should 
be made by the student under the direction and guidance of the instructor. Each problem will require at least one full laboratory period. The exercises are graded, beginning with a few simple percentage determinations of simple powders, the microscopical characteristics of which are easily recognized, and ending with the percentage determination of a compound powder. By the time the student has worked out the ten problems very carefully, he will be in position to solve any ordinary problem in vegetable drug adulteration.

The work done by the members of the class should be compared and discussed and the differences in results should be accounted for by the instructor in charge. If the work of the students has been carefully done the percentage differences based upon the counting methods should not exceed 5 . If the percentage differences exceed 5 the exercise should be repeated. The personal factor must be carefully considered. The instructor in charge must explain each problem very carefully and in great detail and no student should be allowed to begin upon the counts until it is ascertained for a certainty that he understands fully what the problem is and what the count which he is about to make, represents. He must know why it is that only one or two tissues of each drug are selected for the purpose of making the percentage counts. The various quantitative microanalytical methods which have been proposed should be explained and discussed and the advantages and disadvantages of the several methods explained. The results of the microanalytical method herein recommended should be compared with the results of the more commonly employed chemical methods. Such a comparison will demonstrate that the percentage results by the microanalytical methods are fully as accurate as the percentage results by the usual chemical tests and analyses, as carried out by analysts of about equal qualifications and experience.

1. Cinchona Bark.-Reduce an absolutely pure average sample of Cinchona Ledgeriana and of $C$. succirubra to a No. 80 powder. Make 1-5 suspensions in the manner already explained and by means of the special counting chamber determine the average number of bast cells per field. Take the average of not less than fifty counts of not less than two mounts. The average of the counts thus obtained represents the number of bast cells in a pure 100 per cent. cinchona bark. The individual bast cells should be counted. Thus a group of three bast cells should be counted as three. No attention is given to the bark parenchyma cells nor to the sparingly present sclerenchyma cells. In this particular exercise the percentage difference of the counts by the students should not exceed 1 per cent.

Make percentage mixtures of cinchona bark, using absolutely pure 
Rhamnus purshiana bark as the admixture. The rhamnus bark must be reduced to the same fineness as the cinchona bark and the mixing must be thorough. Make three admixtures. One of fifty parts of cinchona bark and fifty parts of rhamnus bark; the second mixture of seventy-five parts cinchona and twenty-five parts rhamnus; the third mixture of ninety parts cinchona and ten parts rhamnus. The usual suspensions of those several mixtures are made and the counts made as for part one of this exercise. The results should be compared and discussed. Keep the admixtures for problem two.

2. Rhamnus Purshiana Bark.-Prepare an absolutely pure average sample of Rhamnus purshiana bark as for cinchona and make a count of the bast tissue, counting each group of bast cells as one. The sclerenchyma cells (individuals and groups) are not counted as they are rather difficult to recognize and the counts based thereon would only cause confusion and would give widely varying results.

Use the mixtures prepared for the cinchona counts and from the counts obtained therefrom determine the percentages of rhamnus bark present. Do not ascertain the rhamnus percentages by merely utilizing the counts of the cinchona bast cells as obtained from problem one. Compare the errors in the two problems from the same admixtures and it will be found that the variation in results will be somewhat greater for problem two, although the error should not exceed 3 per cent., even for beginners in this kind of work.

3. Senna Leaflets.-Prepare two samples. One of pure whole or broken leaflets of Cassia angustifolia and one of pure whole or broken leaflets of Cassia acutifolia. Make the 1-5 suspensions and determine the number and the length of the simple single-celled trichomes present. In the $C$. angustifolia the trichomes are fewer and longer as compared with those of $C$. acutifolia. Also search for epidermal tissue fragments and note the number and size of the neighboring cells of the stomata in the two varieties of sennas.

Make a fifty to fifty admixture of the two sennas and determine the amount of each kind of senna based upon the count of the trichomes, utilizing the following suggestion. The count of those trichomes which exceed in length the longest cells of the $C$. acutifolia represents C. angustifolia (100 per cent.). In this exercise the differences in result will be found to be considerable.

Make admixtures of each of the two samples with wheat flour and determine the amount of such admixture from the trichomatic counts. In this case the difference in the results should be slight. This particular problem will also serve as a preparation for problem ten.

Make admixtures of pure senna leaflets and of senna stems and 
make percentage determinations; likewise of senna pods and of senna leaflets.

4. Insect Powder.-Secure samples of pure flower heads of the three species of pyrethrum (Chrysanthemum roseum, C. Marshalli and $C$. androsamifolium), both the fully expanded flower heads and the partially expanded heads, making six samples. The thoroughly dried flower heads are reduced to a No. 80 powder and the counts are made of the pollen grains (mature and immature) and of the groups of the sclerenchyma cells and also of the groups of fibrous tissue. The trichomes and the somewhat papillose epidermal cells have a diagnostic significance only. The counts thus obtained should be carefully made and the results recorded for future reference and use.

Prepare a powder of the stems of one of the species of insect flower and make a careful count of the groups of the fibrous tissue present. A few pollen grains will also be noted. The count of the groups of fibrous tissue represents a 100 per cent. stem tissue. Now make admixtures of pure insect powder and pure stem tissue, and from a count of pollen as well as of the stem tissue, acertain the amount of the several admixtures. A whole series of problems will suggest themselves and should be tried out as time and opportunity will permit. The sclerenchyma group count and mature pollen grain count will indicate the percentage amount of mature flower. heads used. What is the number of pollen grains per gram in a 100 per cent. insect powder?

5. Digitalis Leaves.-Secure samples of the leaves from the first year plants, and from the second year plants at the time of flowering. Dry, powder and prepare for the count as the above samples. Make counts of the simple trichomes. In the first year plants the leaves will show fewer trichomes. What are the total trichomatic counts for the first year leaf and for the second year leaf? Also make a count of the groups of fibrous tissue in the two samples of leaf.

Prepare samples of digitalis stems and make counts of the trichomes and of the groups of fibrous tissue. Make fifty to fifty admixtures of digitalis leaf and of digitalis stem and redetermine the amount of leaf and of stem respectively, based upon the trichome count and also upon the count of the groups of fibrous tissue.

Digitalis leaf (in the powdered form) is identified by the simple and the glandular trichomes. The cells of the simple trichomes are more or less collapsed, usually one cell is flattened in one plane, the cell following being collapsed in a plane at right angles to that of the other. The glandular trichomes usually bear two terminal secreting cells. In making the counts of the trichomes, all trichomatic frag- 
ments, distinctly recognizable as such are to be counted as one, and it is important that all of the comparative counts be made of powders of the same degree of fineness. The percentage estimates based upon the counts of the first year and the second year leaves will be quite variable and will show wide ranges in results.

6. Glycyrrhiza.-Prepare samples of pure average samples of the peeled and the unpeeled licorice, and of licorice trimmings. Counts are made of the yellowish groups of fibrous tissue, especially of the groups of crystal bearing fibers. The starch count may be ignored, In the case of the unpeeled licorice a count is to be made of the dark brown cork tissue elements. The following counts are to be made of the three samples.

(a) The number of cork tissue elements and groups of such elements in the unpeeled licorice; also a count of the yellow fibrous tissue and crystal bearing tissue groups.

(b) The fibrous and crystal bearing groups in the peeled licorice.

(c) The number of fibrous tissue groups in the licorice trimming.

Make admixtures of the pure licorice and of the licorice trimmings and determine the percentages of the admixtures from the results of the counts. The results of the counts will again be utilized in exercise ten.

7. Sublimed Sulphur.-Examine carefully samples of pure sublimed and of precipitated sulphur and note the microscopic differences. Make careful percentage admixtures of sublimed sulphur in plain vaseline and from such admixtures make the counts of the sulphur particles. A 1, 5 and a 10 per cent. mixture should be counted. If it is found that the sulphur particles are too numerous to permit counting then dilutions must be made and the percentages redetermined from a carefully prepared 1.5 per cent. vaseline suspension. How many particles of the sublimed sulphur in one gram? The results of the counts are to be used in exercise ten.

8. Black Pepper.-Four substances are required; an average commercial sample of pure whole black pepper; an average commercial sample of whole white pepper; a sample of whole pepper known in the trade as "grinding peppers;" and a sample of "black pepper refuse" (consisting of pepper stems, tailings and screenings). These several samples are to be reduced to the same degree of fineness and the following counts made.

(a) Of the black pepper, the dark to nearly black fragments and groups, consisting entirely of the pericarp tissue; and the colorless tissue fragments (starch bearing) consisting wholly of the endosperm tissue elements. The counts represent 100 per cent. black pepper. 
(b) Of the white pepper. The dark fragments derived from the pericarp tissue are identical with those of the black pepper. They are sparingly present; and the colorless tissue fragments (starch bearing) consisting wholly of the endosperm tissue. The two counts together represent 100 per cent. white pepper.

(c) Of the "grinding peppers," make the counts as for black pepper, and compare with the counts for black pepper.

(d) Of the black pepper refuse, make the count of the black tissue groups and the groups of fibrous tissue.

Admixtures of black pepper and of black pepper refuse are to be made and the percentages of the admixtures redetermined from the counts. "Grinding peppers" will show an excess of pericarp tissue. Pepper adulterated with refuse will also show an excess of pericarp tissue, but in addition will show groups of fibrous tissue derived from pepper stems.

Admixtures of pepper and other substances which are frequently employed as adulterants, such as cereal, cornmeal, ground olive pits, etc., may be made and the percentage adulteration redetermined from the counts.

9. Mustard.-Three substances are required. Ground mustard (either white or black) of known purity; ground turmeric of known purity; and wheat flour. No count is to be made of the mustard, as it reveals no structure upon which a percentage count could be based. Make the following counts. A count of the yellow starch clusters of turmeric; and a count of the starch granules and of the starch bearing tissue groups of the wheat flour.

Make admixtures of mustard and of wheat flour, adding from 1 to 5 per cent. of turmeric, and from the counts redetermine the percentages of the admixtures.

The following addition should be made to this problem. Make counts of 100 per cent. ground mustard hulls, and from admixtures of mustard and of mustard hulls, redetermine the percentages of the admixtures.

10. Compound Licorice Powder.-This substance contains powdered sugar the count of which can be made from an alcohol or oil mount; or, the counts of all of the ingredients may be made from a vaseline suspension. Of course it will be necessary to make a separate count of a pure sample of powdered sugar. In so doing it should be kept in mind that most of the powdered sugar of the market contains a small amount of corn starch. The amount of corn starch present should be determined according to the method given elsewhere in this volume. The following counts are to be made. 
(a) A count of the licorice tissue upon which the per cent. of licorice is based. Is the licorice of the peeled or of the unpeeled variety?

(b) A count of the sulphur particles present.

(c) In case anise is used as the flavoring agent, instead of the oil of anise, then a separate count must be made of a pure sample of anise in order that the percentage amount in the compound powder may be ascertained.

(d) A count of the sugar particles present.

The reconstructed formula based upon the results of the several counts should be closely similar to that of the actual pharmacopœial percentages composition.

The microscopes used by the students must be standardized to the same magnification and the same area of the field of view. In each instance it must be stated whether the high or the low power was used in making any given count or set of counts: in most instances the low power will suffice. For making starch counts and counts of similar minute particles, the high power must be used.

The following is a list of vegetable drugs and spices giving the microscopical characteristics of each substance named upon which the percentage counts are to be based. Where more than one histological element is named, the first is the one considered the most important for the purpose of making the counts. The other elements may be used for check purposes. The structural elements proposed for purposes of making the percentage counts, are not necessarily also the more important for purposes of identification, and in many instances that combination of tissues and of tissue elements which will unmistakably identify the drug or spice, is of little value for the purpose of the percentage determination. It will be found that some vegetable drugs reveal no special identifying microscopic structures, as belladonna leaves, stramonium leaves, spigelia roots and rhizomes, cypripedium roots and rhizomes, lappa roots, fennel, caraway, and others. For this very reason added adulterants are all the more readily recognized as these usually reveal some distinctive microscopical characteristic. In such cases the percentage counts are made of the adulterants and the result subtracted from the total amount leaving the percentage of the drug or spice itself. Belladonna, for example, is frequently adulterated with phytolacca, and the adulteration is at once recognized by the very characteristic scattering acicular crystals of phytolacca, but these diagnostic structures are of no value for making percentage determinations. On the other hand, ground olive pits which are so frequently used for the purpose of adulterating spices, nut gall and 
other drugs, is not only readily recognized but it is ideal for the purpose of making exact percentage counts.

\section{LIST OF SUBSTANCES WITH MICROSCOPICAL STRUCTURES UPON WHICH THE PERCENTAGE COUNTS ARE TO BE BASED}

1. Absinthium.-T-shaped trichomes.

2. Aconite leaf.-Trichomes. Sclerenchyma cells.

3. Aconite root.-Sclerenchyma cells. Starch aggregates.

4. Amygdala. - Sclerenchyma cells (for unblanched almonds only).

5. Amylum.-Size, form, markings, position of hilum, etc.

6. Anisum.-Trichomes.

7. Asclepias.-Groups of sclerenchyma cells.

8. Aspidium.-Resin particles. Starch. Scalariform ducts.

9. Aspidosperma bark. - Large sclerenchymatous blast cells.

10. Belladonna leaf.-Trichomes? Cells with microcrystalline calcium oxalate.

11. Belladonna root.-Starch? Cells bearing microcrystalline calcium oxalate? Ducts?

12. Berberis.-Sclerenchymatous bast cells.

13. Caffea.-Sclerenchymatous bast cells. Endosperm cells.

14. Calendula.-Trichomes. Pollen.

15. Calumba. - Sclerenchyma cells. Starch. Ducts.

16. Canella.-Groups of sclerenchyma cells.

17. Cannabis.-Simple trichomes.

18. Capsicum.-Color and characteristic epidermal elements.

19. Carbo.- Size and number of black particles.

20. Caryophyllus.-Bast cells. Color of tissue fragments.

21. Cascarilla.-Bast cells.

22. Chamælirium.-Bast cells.

23. Cinchona. - Large bast cells.

24. Cinnamon.-Bast cells. Sclerenchyma cells.

25. Coca.-Fragments of the lower epidermis.

26. Colchicum corm.-Starch granules. Spiral ducts.

27. Convallaria.-Number of raphides.

28. Cornus.-Groups of sclerenchyma cells.

29. Coto bark.-Bast and sclerenchymatous groups.

30. Crocus.-Pollen grains and colored tissue.

31. Cubeb.-Groups of sclerenchyma cells and of endosperm cells.

32. Curcuma.-Number of yellow particles (agglutinated starch).

33. Cusso.-Pollen. Simple and glandular trichomes.

34. Cypripedium.-Number of raphides.

35. Dextrine.-As for starch. Recognizable starch granules.

36. Digitalis. - Non-glandular trichomes.

37. Eriodictyon.-Non-glandular trichomes.

38. Euonymus stem bark.-Bast cells. Aggregate crystals.

39. Eupatorium.-Trichomes. Pollen grains.

40. Galla (Chinese).-Trichomes.

41. Gentian.-Fragments of large reticulate ducts.

42. Glycyrrhiza. - Groups of yellow tissue with crystal bearing fibers. Cork tissue in unpeeled licorice. Fibrous tissue of trimmings. 
43. Gossypium.-Bast. Fibrous tissue groups.

44. Hæmatoxylon.-Colored tissue. Reaction with copper solution.

45. Hamamelis.-Trichomes. Sclerenchyma cells.

46. Hyoscyamus.-Non-glandular trichomes.

47. Ipecac.-Raphides. Fibrous tissue. Starch.

48. Iris florentina.-Starch. Crystals.

49. Jalap.-Resin bearing cells. Starch.

50. Kamala.-Glands and trichomes.

51. Krameria.-Bast cells and groups of bast.

52. Lobelia.-Trichomes and groups of fibrous tissue.

53. Lupulin.-Number of glandular structures.

54. Lycopodium. - Number of spores.

55. Mezereum.-Number of bast fragments.

56. Nux vomica.-Trichome fragments and groups of endosperm tissue.

57. Paracoto.-As for coto.

58. Physostigma. - Starch granules.

59. Phytolacca.-Number of raphides.

60. Pimenta.-Groups of sclerenchyma cells and trichomes.

61. Piper, black.-Groups of endosperm cells and pericarp tissue.

62. Piper, white.-Groups of endosperm cells.

63. Prunus serotina.-Bast and sclerenchyma.

64. Prunus virginiana.-Bast.

65. Pyrethrum flowers.-Pollen grains. Sclerenchyma. Fibrous tissue.

66. Quillaja.-Bast and crystals.

67. Rhammus purshiana.-Groups of bast and crystal bearing fibers.

68. Rheum.-Aggregate crystals. Ducts. Colored tissue.

69. Sarsaparilla.-Number of raphides. Ducts. Starch.

70. Sassafras.-Bast. Groups of sclerenchyma cells.

71. Scopola.-As for belladonna leaf and root.

72. Senna.-Trichomes. Neighboring cells.

73. Stramonium.-Non-glandular trichomes.

74. Strophantus.-Trichomes.

75. Tabacum.-Glandular and non-glandular trichomes.

76. Thea.-Trichomes and sclerenchyma cells.

77. Viburnums.-Bast, and bast and sclerenchyma cells.

78. Zingiber.-Starch granules. Cork tissue. 

PART II ,

THE MICROSCOPICAL CHARACTERISTICS OF THE VEGETABLE POWDERS 



\section{PART II}

\section{THE MICROSCOPICAL CHARACTERISTICS OF THE VEGETABLE POWDERS}

In order that the student may take up the critical study of powdered vegetable drugs as to quality and purity, he must have the necessary preparation. Such preparation is given in the courses in general botany, in plant morphology and histology, and in pharmacognosy, as presented in the first and second years of the college curriculum.

The significance of the adulteration of drugs has been explained in Part I. Throughout the examination of the powders listed in Part II, the student is urged to search for the foreign inclusions which may be present and to record these descriptively and by means of drawings. The first thing to be accomplished is to acquire the ability to recognize foreign inclusions, after which the special training must be directed along the following lines.

1. To recognize those inclusions which are wholly unavoidable.

2. The wholly negligible inclusions.

3. The usual or more or less normal sophistication and adulteration.

4. Conventional sophistication.

5. Unquestionable sophistication and adulteration.

As to (1), the student will soon learn that all crude as well as powdered vegetable drugs contain some foreign substances, as dirt and sand particles, some bacteria, occasional spores and pollen grains, a trace of foreign vegetable tissue, occasional nematode or insect, remnants, etc. Even the gum tragacanth contains some starch; the highest grade cloves contains a small amount of stem tissue; the best quality black pepper contains some pepper refuse; the best chocolate and cocoa contains some shell tissue; and the purest coffee contains some coffee chaff. These are among the wholly unavoidable inclusions and which may not be considered as adulterants.

As to (2), it is common knowledge among dealers in drugs and those who use drugs for manufacturing purposes, that certain more or less accidental and unavoidable inclusions are always to be found in crude as well as in powdered vegetable drugs, and which inclusions are generally considered so small in amount as to be wholly negligible. 
These inclusions usually consist of dirt, clay, foreign roots, leaves, stems, etc. It is also generally admitted that with greater care on the part of the growers and gatherers of drugs, these inclusions could be removed with the exception of the substances mentioned under (1); but the extra labor entailed and the consequent increase in the price, does not, by general agreement, warrant the removal of the wholly negligible inclusions, which rarely reach 5 per cent.

(2) gradually merges into (3). It is common practice on the part of the careful wholesale pharmaceutical manufacturer, to open up the bales of crude drugs as they are received, spreading them out on a floor and to cull out foreign plants, roots, etc.; or to winnow out dust, dirt, foreign seeds, fruits, chaff, etc.; or to remove, by means of sieves, pebbles, defective or undersized specimens, etc. This more or less common normal or usual sophistication often amounts to 10 per cent. and may reach 20 per cent. in some instances. This type of sophistication or adulteration is generally due to carelessness in gathering and garbling for the market. This form of adulteration usually escapes the vigilance of the U.S. customs and the food and drug inspection, and even when detected the amount of adulteration is usually not considered sufficient to warrant entering upon condemnation procedures, and the dealer is informed that the article contained an excess of foreign matter and is advised to avoid future shipment of such inferior quality.

Among the conventional adulterations may be mentioned the limeing of ginger and nutmeg, the coloring of tea and coffee, adding a trace of Prussian blue to beet sugar to increase its whiteness, adding caramel to bay rum, whiskey, brandy, etc., adding color to butter and cheese, etc. Some of these forms of adulteration are time honored and the reasons for their existence are generally not clearly understood. In some instances it is supposed to please the esthetic sense, but in the majority of instances the custom arose from a desire to hide or mask inferiority or poor quality. The conventional forms of adulteration are gradually being abandoned, or are made unlawful. Thus, it is no longer permissible to color tea or coffee in the United States. Prussian blue may no longer be added to sugar.

The forms of actual and unquestioned adulterations were discussed in Part I. The student should be given adulterated samples and he should be required to determine the percentages of the adulterants according to the methods outlined in Part I. The student should be fully informed as to the importance of experience and good judgment in rendering a decision as to the degree and the kind of adulteration which has been perpetrated, always bearing in mind that the law is for the protection of the consumer but that the dealer also has his 
rights and privileges under the same law. These are matters which must be left to a competent and experienced instructor for fuller explanation and discussion.

In entering upon the special study of powdered vegetable drugs and spices, the student should be supplied with liberal samples of the pure article reduced to suitable fineness, usually No. 80 . The necessary chemicals and reagents must be at hand; also a drug mill and a nest of sieves. The question is frequently asked, how many samples can a student examine in the time usually allotted to the laboratory course in the microanalysis of vegetable powders? The student who has the university entrance requirement (namely, graduation from an accredited high school or its educational equivalent) to the college of pharmacy, and who has had one year of botany in the college of pharmacy, plus the laboratory course in pharmacognosy, can readily examine from four to five powders during a laboratory period of two hours each; or, from fifty to seventy-five powders during the semester. The diligent student can, however, examine a far greater number of powders, though not all of them with the same degree of care or the same detail. He may examine from fifty to seventy-five carefully, including the making of drawings of the more important histological elements, and perhaps an equal additional number merely as to the microscopical characteristics, without making drawings.

The descriptions are given in alphabetical sequence for convenience of study and cross reference. The drugs marked "U. S." are official in the pharmacopoeia of 1910 (made official September 1st, 1916). Upon comparing the U.S. P. IX with earlier editions, it will be found that many comparatively unimportant drugs have been dropped and the weeding out process will no doubt be continued for the good of all concerned.

Most of the drawings were made to scale by means of the Abbe camera lucida. The more characteristic tissue elements are figured but no attempt has been made to indicate the relative abundance of the different tissues or cell contents figured. The following is the plan of the sequence of the special description of each powder; official name, common names, indication whether official or not, usual fineness of the powder, botanical origin and part used, color, odor, taste, histological characteristics, ash content, and more common adulterants. 


\section{1. (Fig. 1.) ABSINTHIUM. Absinthium.}

Fl. ex. 30. Tinct. 30 .

Mugwort, Wormwood, E., Wermuth, Alsei, G., Absinthe commune, Grande absinthe, aluine, Fr.

The leafy tops of Absinthium vulgare Lam., Compositæ.

Grayish green.

Faintly aromatic, disagreeable and narcotic when briskly rubbed.

Very bitter, somewhat saline.

The most distinctive tissue elements are the very abundant $\mathrm{T}$ shaped, rather thin-walled trichomes with three to four basal cells; the rather large, yellowish, sessile, glandular trichomes with several vertical tiers of cells, are also quite diagnostic; some pollen grains presenting the characteristics of the pollen of the order Compositæ will generally be found. The vertical walls of the epidermal cells are wavy or sinuate and the stomata are abundant and fairly large.

Compare with Achillea and insect powder which are similar in certain of the histological characteristics.

Ash should not exceed 13 per cent.

Related species may be used as adulterants or may be substituted for it, although this is of rare occurrence. 


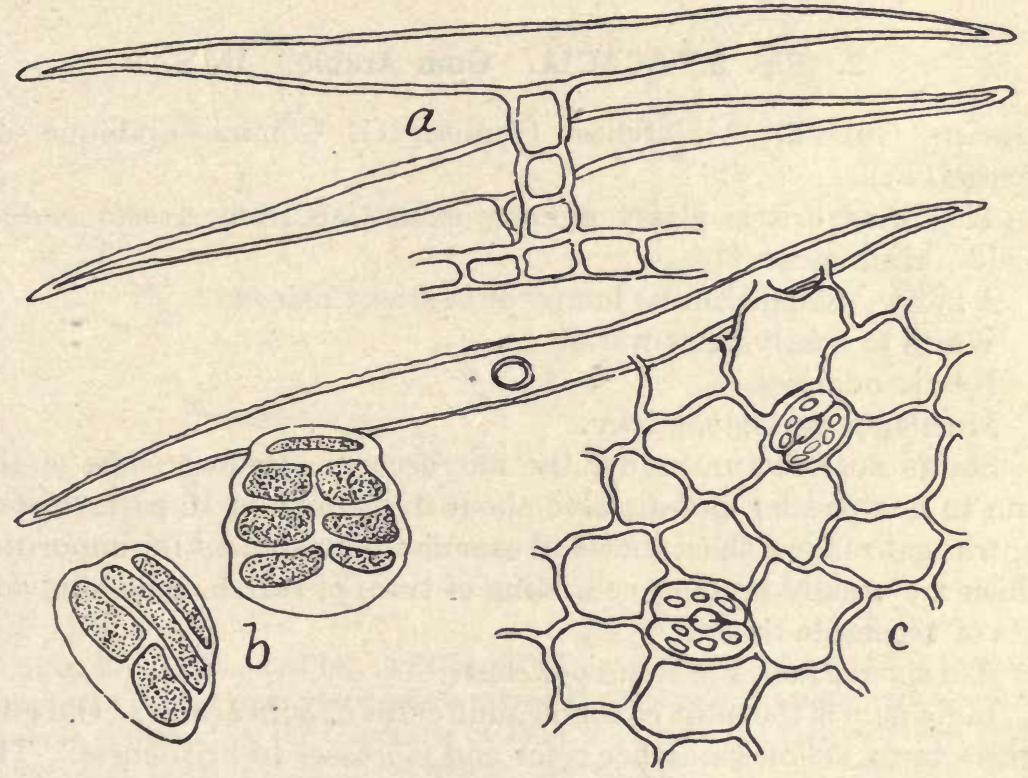

Fig. 1. ABSINTHIUM. $a$; the very abundant and characteristic ' T-shaped trichomes; $b$, glandular sessile trichomes; $c$, epidermal cells with two stomata. 


\section{2. (Fig. 2.) ACACIA. Gum Arabic. U. S.}

Acacien Gummi, Arabisches Gummi, G. Gomme arabique du Sènegèl, Fr.

The dried brittle glassy gummy exudation from Acacia senegal Willd., Mimosaceæ.

A meal. Should not be lumpy or in sticky masses.

White to nearly snow white.

Nearly odorless.

Mucilaginous taste, sticky.

Shows no structure under the microscope. Reduce some of the gum to fine powder and dissolve about five grams in 10 parts water; centrifugalize for a short time and examine the sediment for impurities which are usually present, consisting of trace of starch, some dirt and bits of vegetable tissue.

Ash should not exceed 3.6 per cent.

India gum is the most common adulterant of gum acacia. Old gum acacia turns yellowish amber color and increases in brittleness. The impurities are generally negligible and should not exceed 1 per cent. 

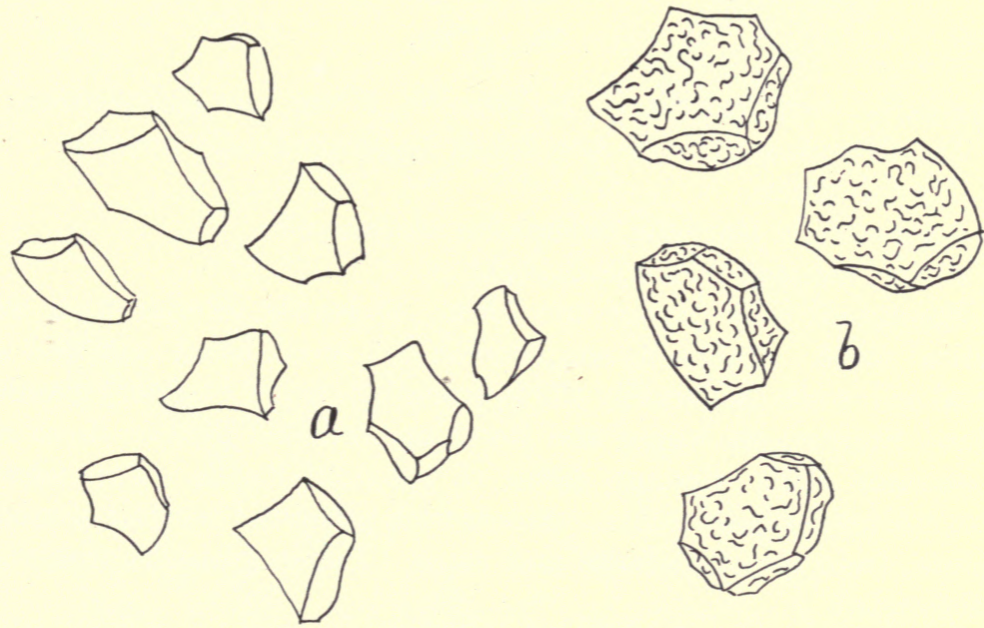

Fig. 2. GUM ACACIA. INDIA GUM. a, a water mount of the powdered fragments of true gum acacia show a typical conchoidal fracture with absolutely smooth surfaces. $b$, the fragments of India gum mounted in water show typical conchoidal fracture but the surfaces are characteristically wrinkled. These observations must be made as soon as the mounts are made as both gums soon dissolve in water. 


\section{3. (Fig. 3.) ACHULLEA. Yarrow, Milfoil.}

Fl. ex. 30 .

Schafgarbe, Schafgrippe, G. Millefeuille, Herbe aux charpentiers, Fr. The flowering parts of Achillea Millefolium L., Compositæ.

Grayish green.

Aromatically fragrant, resembling chamomille.

Bitter, astringent, somewhat saline.

Epidermal cells (upper and lower) of leaves tabular with wavy vertical walls. Hair cells simple with one to six basal cells and long apical cell; walls moderately thick, smooth. A few bladdery glandular hairs. Stomata on upper and lower epidermis. Two or three rows of palisade cells. Spongy tissue of spheroidal cells. Parenchyma, bast, tracheids, spiral ducts. Fibers with prismatic crystals of calcium oxalate, from stems, petioles and veins. Pollen grains characteristic of the order.

Ash should not exceed 12 per cent.

On account of its cheapness and wide distribution this drug is rarely adulterated. The following species indigenous to Europe are sometimes employed: $A$. ptarmica L., $A$. aceratum L., $A$. nobilis L., $A$. moschata L., A. atrata L., A. Nana L. 


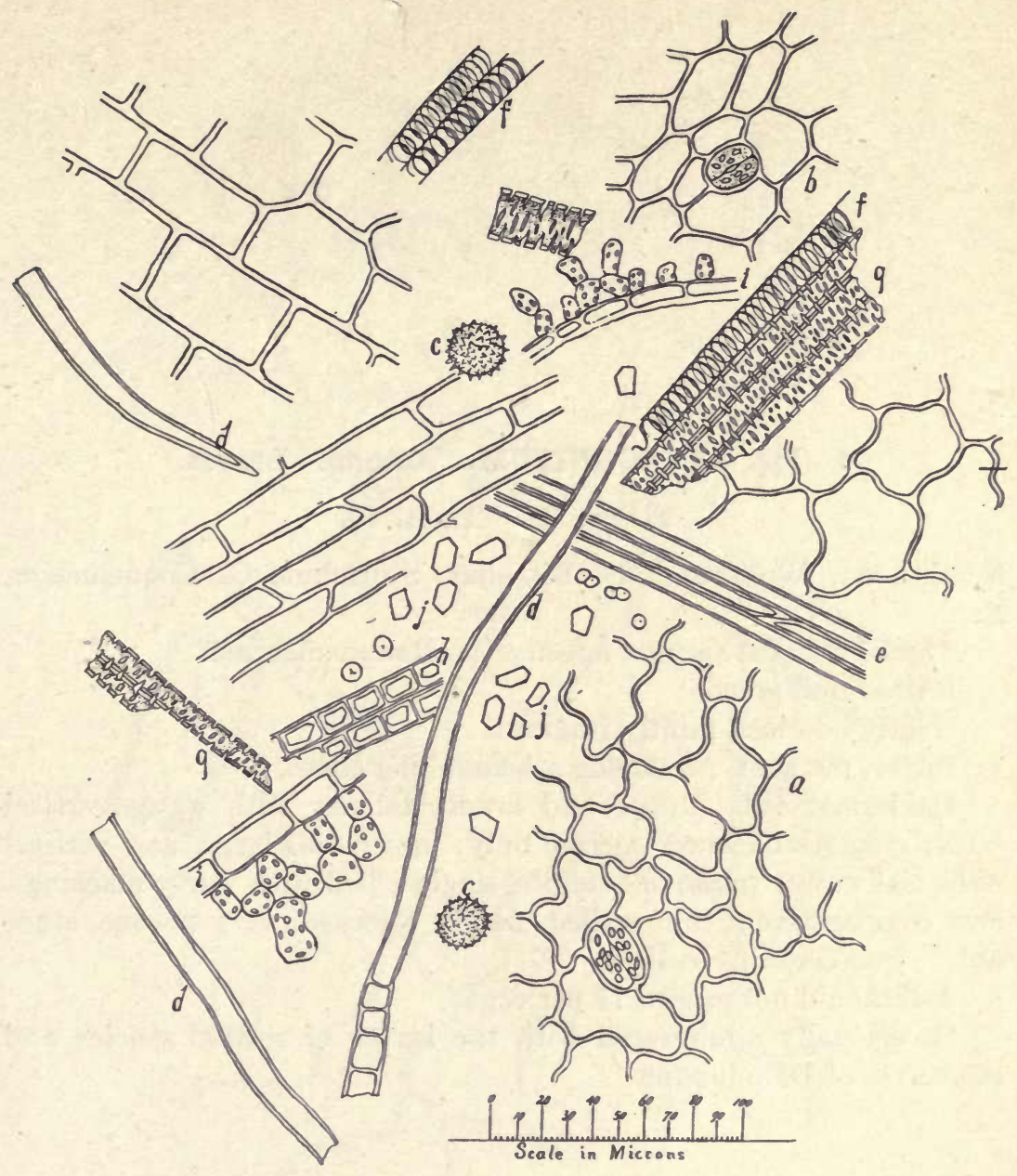

Fig. 3. ACHILLEA.

$a$. Upper and lower epidermis.

$b$. Epidermis of petiole and stems.

c. Pollen grains.

d. Trichomes.

e. Bast of vascular bundles.

$f, g$. Tracheids and ducts of vascular bundles.

$h$. Prismatic crystal bearing fibers.

$i$. Side view of epidermal tissues.

$j$. Prismatic crystals and starch. 


\section{4. (Fig. 4.) ACONITUM. Aconite. Leaves.}

Fl. ex. 30 . Tinct. 40.

Monkshood, Wolfsbane, E. Eisenhut, Sturmhut, G. Coqueluchon, Fr.

The leaves of Aconitum napellus L., Ranunculaceae.

Rather dull green.

Nearly odorless, faintly fragrant.

Bitter, pungent, producing a benumbing effect.

Epidermal cells (upper and lower) tabular with wavy vertical walls; stomata on lower surface only; upper cells larger and vertical walls less wavy; trichomes simple, single celled with warty markings. Few comparatively thin walled, nearly colorless, very porous, stone cells. Pollen grains oval.

Ash should not exceed 17 per cent.

Occasionally adulterated with the leaves of related species, and the leaves of Delphinium. 


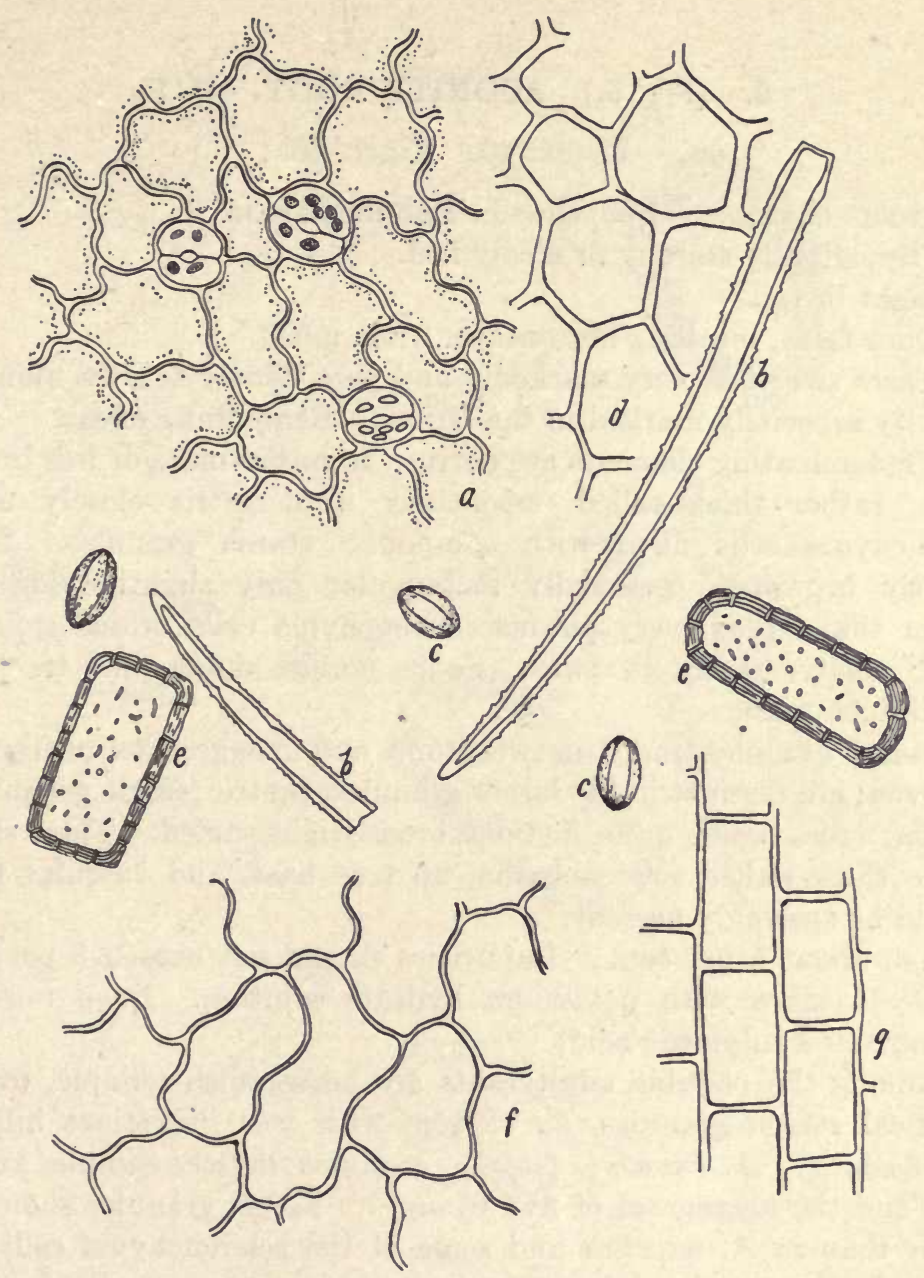

Fig. 4. ACONITUM. Leaf.

a. Lower epidermis.

b. Trichomes.

c. Pollen grains.

d. Parenchyma cells of stem.

e. Sclerenchyma cells.

f. Upper epidermis. 


\section{5. (Fig. 5.) ACONITE ROOT. U. S.}

Fl. ex. 40. Tinct. 60 .

The roots of Aconitum napellus L. Ranunculaceae.

Dry, slightly starchy or mealy feel.

Light brown.

Odor faint, recalling horseradish when moist.

Taste sweetish, very markedly and persistently acridly pungent; acridity especially marked in the fauces. Benumbing effect.

Predominating elements are derived from the more or less broken, large, rather thick-walled, essentially isodiametric closely united parenchyma cells filled with compound starch granules. A few slightly brownish, essentially rectangular only slightly elongated, rather thin-walled, very porous sclerenchyma cells, which generally occur singly, rarely in twos. Some porous ducts and tracheids; spiral ducts rare.

Starch granules singly, in twos, fours and in aggregates of from five to seven; hili distinct in the larger granules, centric; single granules $5 \mu$ to $15 \mu$; cross bands quite distinct, broad, right angled. There should be no thick-walled sclerenchyma, no true bast, and vascular tissue should be sparingly present.

Ash about 5 per cent. Impurities should not exceed 5 per cent.

Deep yellow with potassium hydrate solution. Deep red with concentrated sulphuric acid.

Among the possible adulterants are horseradish (simple, oval to elliptical starch granules, $5 \mu$ to $15 \mu$, with very indistinct hili and lamellations); A. Fischeri, (starch granules mostly simple and in twos and the aggregates of five to nine). Single granules somewhat larger than in A. napellus and some of the sclerenchyma cells considerably elongated; Japanese aconite (sclerenchyma cells wanting). Suspect other species and varieties of aconite, also the use of exhausted powder, crowns and stem parts (fibrous tissue excessive and a few 2- to 5-celled trichomes). Suspect roots from other groups of plants. 


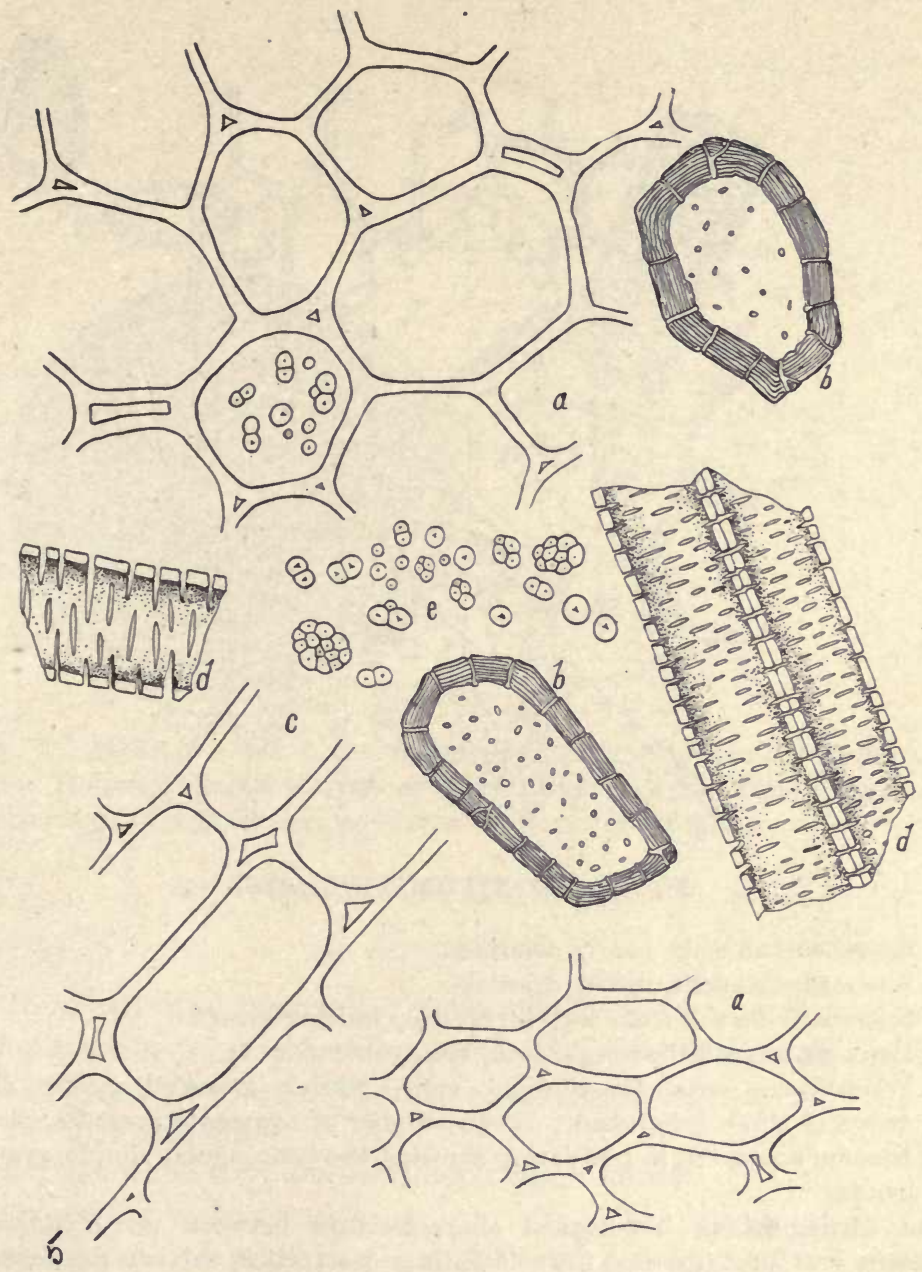

Fig. 5. ACONITUM. Root.

a. Parenchyma cells with starch.

b. Sclerenchymal cells.

c. Parenchyma, longitudinal view.

d. Ducts.

e. Starch granules. 


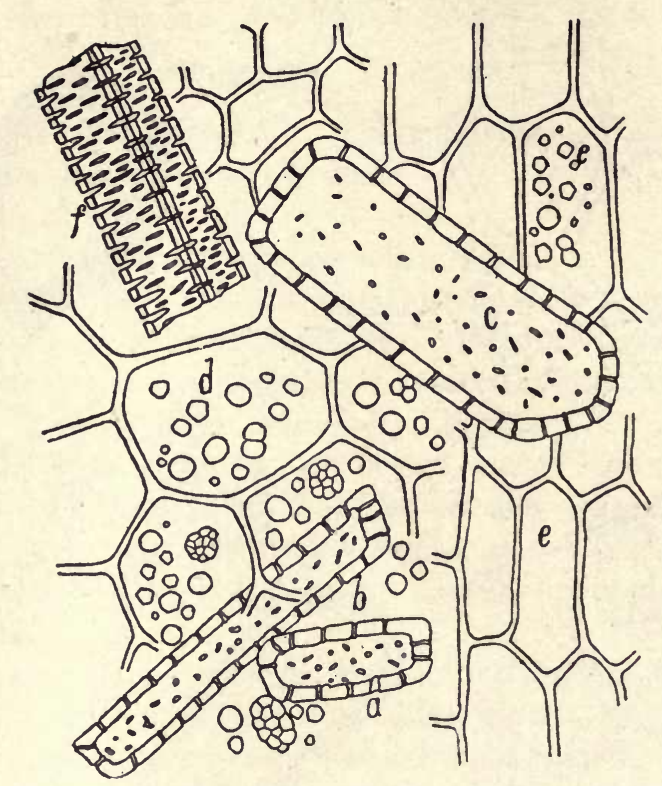

Fig. 6. ACONITUM FISCHERI.

a. Sclerenchyma cells, nearly colorless.

b. Sclerenchyma cells, nearly colorless.

c. Sclerenchyma cell from cork layer, deep reddish brown.

d. Parenchyma cells bearing starch, transverse view.

e. Parenchyma cells, longitudinal view. Starch granules mostly simple, rarely two and three compound. Large number of aggregate granules, many of which become separated in powdering showing the pentangular simple granules.

f. Ducts.

The distinguishing histological characteristics between A. Napellus and A. Fischeri are: In $A$. Fischeri the cell-walls are as a whole thinner, particularly of the parenchyma cells. Sclerenchyma cells are more abundant and more elongated. Starch granules mostly simple with many aggregate granules and polygonal simple granules.

It would be difficult to detect admixtures of the two roots in powdered form. 


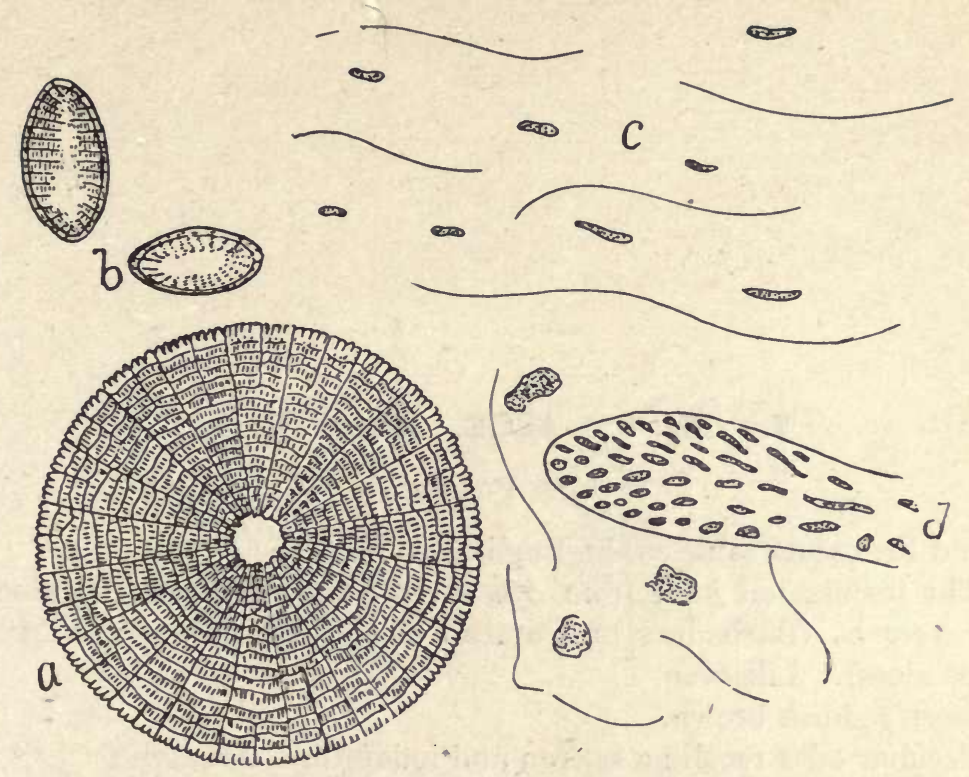

Fig. 7. AGAR. $a$ and $b$, two species of dictams which are constantly present in agar. The larger species is Arachnodiscus Ehrenbergii Bail. c and $d$, mucilaginous tissue elements of agar as they appear in the commercial article.

\section{6. (Fig. 7.) AGAR. Agar. U. S.}

Granulated.

The bleached and specially prepared seaweeds belonging to the Rhodophyceae, represented by species of Gracilaria and Gelidium.

Hard granular when dry; mucilaginous when moist.

Pale brownish color.

Odorless when dry, seaweed odor when moist.

Tasteless, mucilaginous.

The process of preparing the seaweed for the market does not entirely destroy the cell structure, and in even the highest and purest grades of commercial agar cell remnants and the siliceous skeletons of diatoms may be found.

The ash of a good quality of commercial agar should not exceed 4 per cent.

Agar is seldom adulterated. It may be mixed with other seaweeds and it has been mixed with starch and cereal, although this is of rare occurrence. Agar is used as an adulterant, being occasionally added to jellies and as a filler to ice cream. 


\section{7. (Fig. 8.) ALOE. Aloes. U. S.}

Fine Powder.

G. and Fr. names same as the English.

The inspissated juice from Aloe Perryi Baker (Socotrine aloes); Aloe vera L. (Barbadoes or Curacao aloes); and Aloe ferox Miller (Cape aloes). Liliaceae.

Deep reddish brown.

Peculiar odor recalling saffron and iodoform. Aromatic.

Very bitter, somewhat aromatic.

Barbadoes aloes is more granular than Socotrine aloes, and the latter is more shiny. Impurities of dirt and vegetable parenchyma cells may be considerable, particularly in the Barbadoes aloes. Water and alcohol mounts show a fairly characteristic crystalline structure, consisting of fragments, prismatic crystals and stellate clusters which differ in the three principal commercial varieties, namely Barbadoes, Socotrine and Cape aloes as shown in Fig. 8.

Ash of Socotrine aloes should not exceed 2.5 per cent.

Aloes are not often adulterated. Impurities may be excessive. 

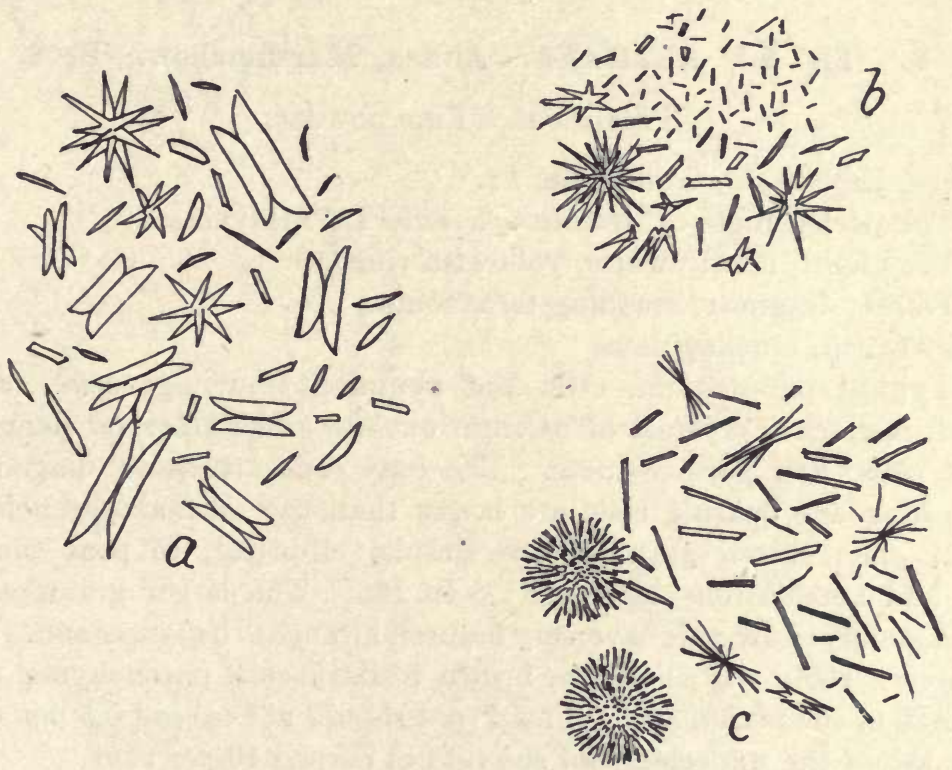

Fig. 8. ALOES.

The characteristic crystals as seen in alcohol mounts. $a$, Cape aloes; $b$, Barbadoes aloes; $c$, Socotrine aloes. 
8. (Fig. 9.) ALTHAEA. Althea, Marshmallow. U. S. Finely cut. Fine powder.

Althee, Eibisch, G. Guimauve, Fr.

The peeled roots of Althaea officinalis L., Malvaceae.

Very light, nearly white, yellowish tinge.

Faintly fragrant; recalling taraxacum.

Sweetish, mucilaginous.

Typical parenchyma cells and abundant mucilage cells, rather small aggregate crystals of calcium oxalate and numerous elongated bast cells; and porous ducts. The bast cells are quite diagnostic. The mucilage bearing cells are larger than the normal parenchyma cells. The starch granules are símple, elliptical, to pear shaped, hili and lamellations indistinct; 5 to $18 \mu$. The larger granules will occasionally show a transversely fissured hilum at the larger end. The unpeeled roots will show the brown to dark cork parenchyma cells.

Ash of the peeled and unlimed root should not exceed 6.5 per cent. The ash of the unpeeled root should not exceed 10 per cent.

Among possible adulterations, suspect flour and other starchy cereal meals. Old material may be used. 


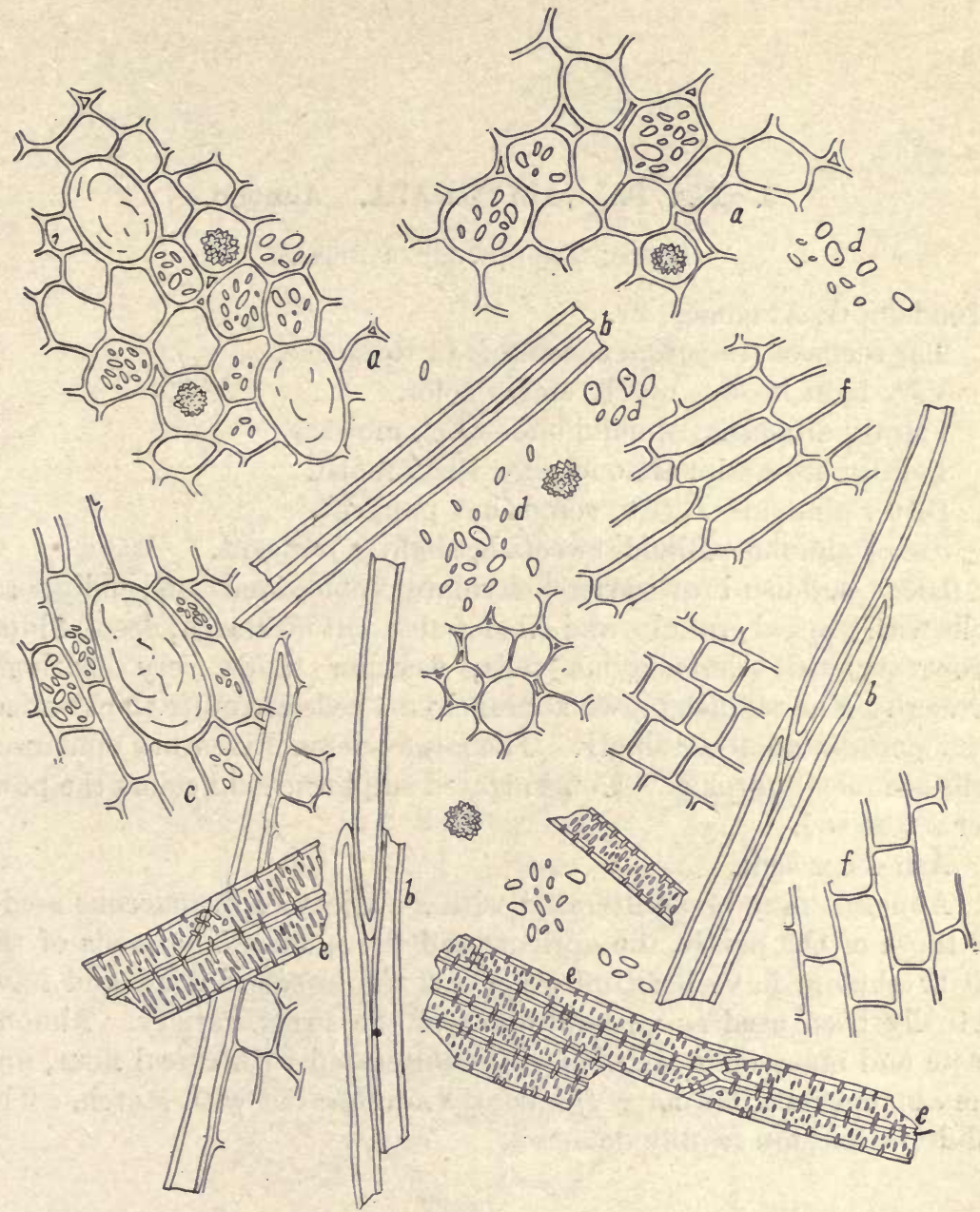

Fig. 9. ALTHAEA.

a. Parenchyma with mucilage cells, starch and aggregate crystals.

b. Bast cells.

c. Parenchyma, longitudinal view.

d. Starch granules and crystals.

$e$. Tracheids.

f. Parenchyma, longitudinal view. 


\section{9. (Fig. 10.) AMYGDALA. Almond.}

Paste; fine powder or meal.

Mandeln, G. Amandes, Fr.

The seeds of Amygdala communis L. Rosaceae.

Very light brown, nearly cream color.

Faintly aromatic; almond odor when moist.

Faintly aromatic; almond odor when moist.

Bitter almond-Bitter, somewhat pungent.

Sweet almond-Bland, sweetish, slightly pungent.

Large, reddish brown sclerenchymatous epidermal cells; endosperm cells with proteid granules and oil globules, but no starch; deep reddish brown typical sclerenchyma cells; vascular tissue very sparingly present. The reddish brown sclerenchyma cells are quite thickwalled, very porous and occur singly. The large sclerenchymatous epidermal cells are mostly broken. Concentrated sulphuric acid colors the powder a rose red.

Ash 4 per cent.

Almonds may be adulterated with a variety of drupaceous seeds, as those of the peach, the apricot, and the plum. The seeds of the bitter almond have been mistaken for the sweet almond and have actually been used as an adulterant of the sweet variety. Almond paste and macaroons are generally adulterated with cereal flour, and the almond face powder is frequently adulterated with starch. The adulterations are readily detected. 


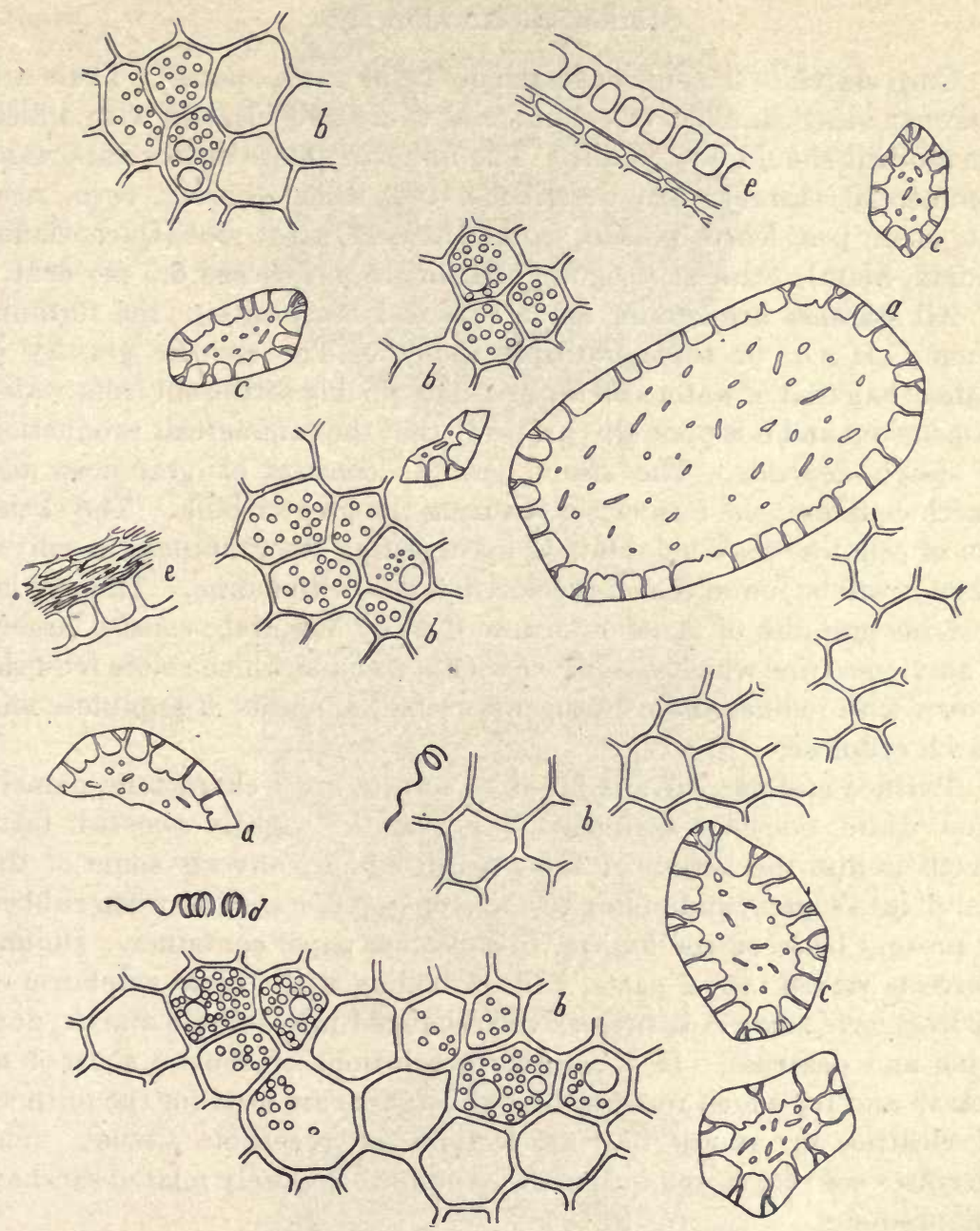

Fig. 10. AMYGDALA.

a. Sclerenchymatous epidermal cells.

b. Endosperm cells with proteid granules and oil globules.

c. Sclerenchyma cells of testa.

d. Spiral duct.

e. Cells from inner coat of testa, lateral view. 


\title{
10. (Figs. 11-32). AMYLUM, Starch. U. S.
}

\author{
Stärke, G. Amidon, Fr.
}

Corn starch is the official starch of the pharmacopoeia. There are however other starches of commercial value and interest with which the student should be familiar. The following more or less important commercial starches are described: Rye, wheat, barley, corn, rice, oat, bean, pea, lentil, potato, canna, banana, arrowroot (Queensland, Indian, Siam), yam, and sago. Ash should not exceed 0.5 per cent.

All starches are similar as to chemical composition, the formula being $\mathrm{C}_{6} \mathrm{H}_{10} \mathrm{O}_{5}$, or some multiple thereof. The specific gravity is higher than that of water and the granules quickly settle out from water suspensions and it is upon this property that the commercial production of starch depends. The starch granule consists of granulose and starch cellulose, the former constituting the greater bulk. The skeleton of cellulose may be obtained by digesting the granulose in saliva, when it will be found that it is colored yellow with iodine. The amylodextrine granules of mace, first described by Tschirch, consist largely of amylodextrine which is isomeric with starch but which colors reddishbrown with iodine, and contains only small amounts of granulose and starch cellulose.

Purified starches are similar as to certain gross characters, namely snow white, odorless, tasteless (excepting the slightly sweetish taste which is due the action of the ptyalin which converts some of the starch into sugar), and giving rise to a crisp crepitant feel when rubbed or pressed between the fingers, in a cloth or paper container. Boiling converts starch into a paste, and on boiling with dilute sulphuric or hydrochloric acids it is successively changed into soluble starch, dextrine and dextrose. It is soluble in solutions of caustic soda or of potash and for which reasons these substances are used for the purpose of clearing up starch bearing sections of vegetable tissues. The diastases convert starch into maltose and other closely related saccharine products.

Although the starches are similar as to chemical composition, they differ considerably as to physical properties (optical, morphological, microscopical appearances) and in digestibility. Starches are not digested at the same rate in the saliva, intestinal tract, or by the plant diastases. Arrowroot starch (Maranta) is preferred for children and invalids, because of its supposedly greater digestibility. It is perhaps self-evident that the rate of digestion of starch also depends upon the size of the granules. Dishes prepared from rice starch are more easily or more quickly digested than are dishes made from potato starch or from corn starch. 


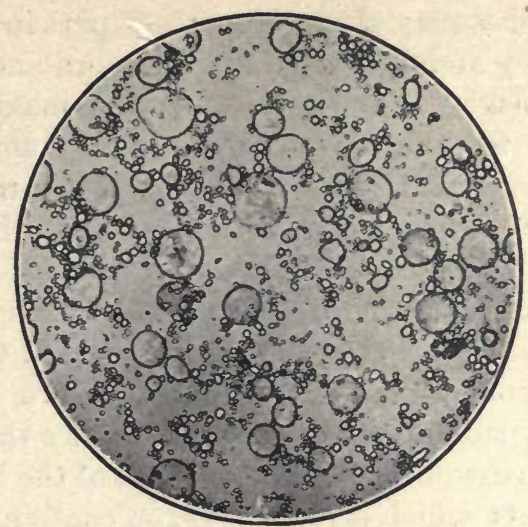

Fig. 11.-Rye Starch.

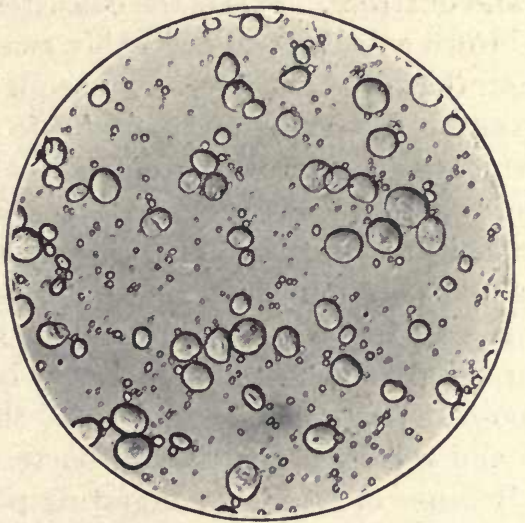

Fra. 12.-Wheat Starch.

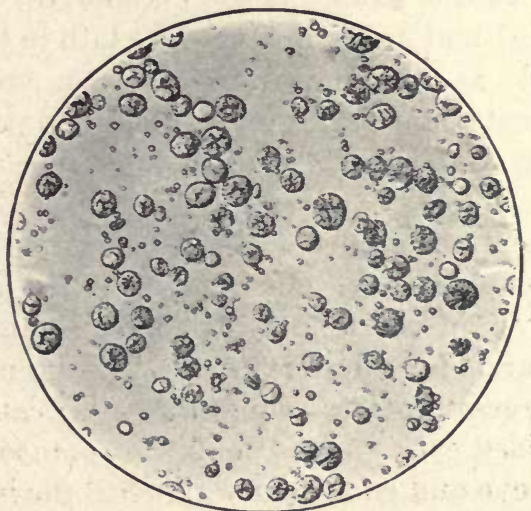

Fig. 13.-Corroded Wheat Starch. 
Vegetable starches play a very important part in human economy. The starch of barley and of other cereals, of corn and of rice, figure in beer making, whiskey making and in saké making, respectively. Library paste, the fixative of court plasters, of stamps, and of labels, and of envelopes, is made from starch. Glucose is made largely from corn starch. The "karo" or "corn syrup" of the market is corn starch glucose to which a small amount of syrup is added to increase the sweetening power, as pure glucose is less sweet than is syrup (sucrose). Glucose has a food value about equal to that of cane sugar or syrup, and is somewhat more readily digested, and is especially indicated in kidney troubles and in dropsy. Since the discontinuation of the brewing industry, in this country, some of the breweries are now making malt extract which is really a syrup containing from 70 to 85 per cent. of total sugars, largely maltose with some sucrose and small amount of dextrin and dextrose. It is of the consistency of thick honey, brown to reddish brown color and an agreeably sweet taste. Its food value is greater than that of sucrose syrup and equal to that of glucose and it furthermore assists in starch digestion, due to the presence of the enzyme maltase which is carried over from the malt in the process of manufacture. Malt syrup is considered an excellent food in wasting diseases as tuberculosis, and for infants. In pharmaceutical practice it is employed as an emulsifying agent and as a basis for cod liver oil. It is sweeter than glucose but less sweet than cane sugar. Its special value as a food for infants lies in the fact that it is less prone to fermentative decomposition in the intestinal tract than is cane sugar, and it also assists and regulates the normal bacterial activity of the intestinal tract. Because of its starch digesting power it is an ideal sweetening agent to be used with starchy foods, as pancakes, hot rolls, bread, etc. Starch is used in the manufacture of dextrin (white and brown dextrin) and as a stiffening for cloth in the laundry. It is also much used as an adultrant in ice cream, confections and in sausage meats (starch and cereal fillers), in pastes (vegetable as well as animal), in so-called egg substitutes, in spices, powdered drugs, etc.

The microscopic appearance and the polariscopic behavior of the formed plant starches is most interesting and of the utmost importance to the microanalyst in the identification of vegetable substances as well as in the search for adulterations. The granules vary greatly in size, yet the largest (potato, canna, maranta) can hardly be recognized by the unaided eye. A thin mount of potato starch on a slide held between the eye and good light will reveal the individual granules to one possessed of undiminished normal vision. Under the high 


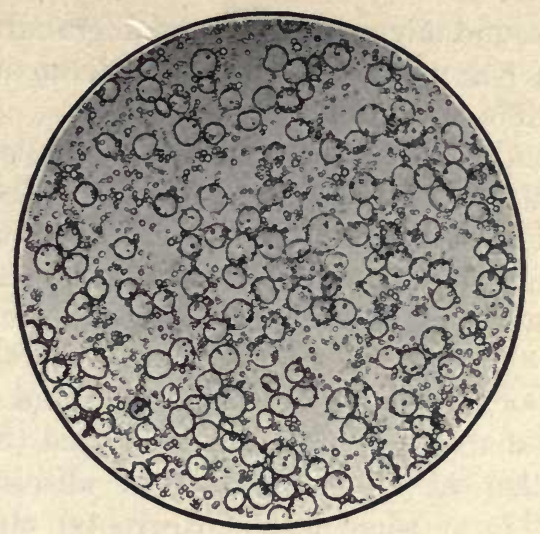

FIG. 14.-Barley Starch.

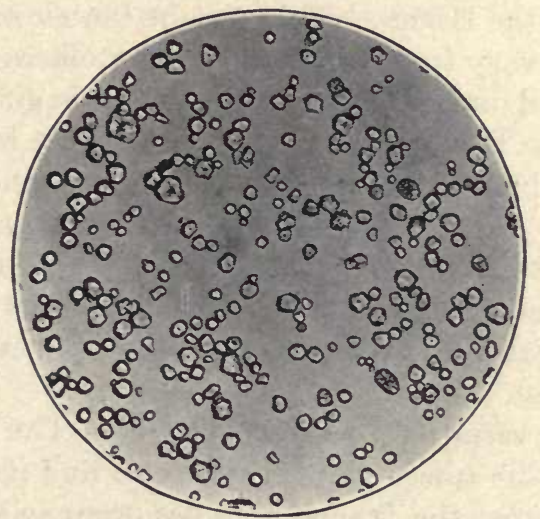

FIG. 15.-Corn Starch.

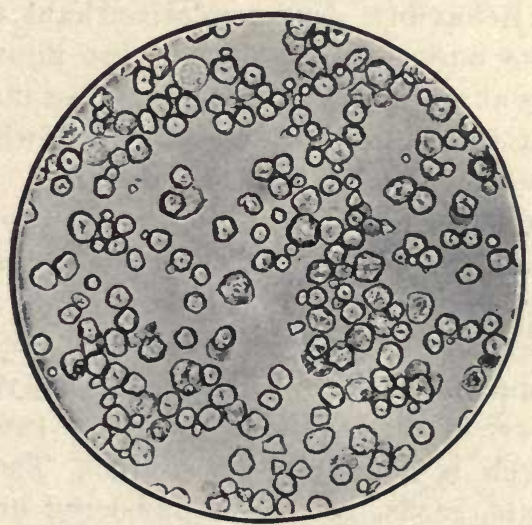

Fig. 16.-Sorghum Seed Starch. 
power of the compound microscope the starch granules stand out most clearly, revealing many highly diagnostic differences in structure. These structural differences are as follows.

1. Arrangement and Grouping.-Starch granules may be simple or compound, or they may occur in aggregates. The corm of Colchicum contains typical compound starch granules. The starch granules of the potato, of the arrowroots, of wheat and of rye, are largely simple. Rice and oats contain aggregates, also found in aconite and in other plants.

2. Form.-They may be polygonal (corn), round or discoid (wheat, rye, barley), pear-shaped (potato), kidney-shaped (bean), bell-shaped (sweet potato), spherical (blood root, pepper, allspice), very irregular (sago), osyter shell form (some of the arrowroots), etc. The ends may be truncately cut (orris root, ginger, curcuma).

3. Position of the Hilum. - This may be centric or excentric. The excentricity may vary from slight (as in Phytolacca and Belladonna) to nearly 1-12, and higher, (as in Curcuma and in ginger).

4. Form of the Hilum. - In many starches the hilum is indistinct (as in wheat and barley), in others it is very prominent (bean, colchicum, orris root). It may be radiately fissured or star-shaped, Xshaped, linear, V-shaped, Y-shaped, or U-shaped. The excentric hili are as a rule not prominent, whereas the centric hili are generally very distinct (bean), although there are many exceptions (wheat, barley, and others).

5. Size.-The variation in size is extreme. The smallest granules occur in some of the spices (pepper, allspice) and in some of the grass family (rice), whereas the largest granules occur in some of the palms and in widely separated plant groups (Liliaceae, Solanaceae).

6. Polariscopic Behavior.-Under polarized light, two wedge-shaped (tapering from the outer surface toward the hilum) bands appear which always cross at the hilum, and the polarizer may be used for the purpose of locating the hilum in those starches in which this structure (or rather the absence of a structure) is indistinct. These bands may be very marked (as in potato, corn, arrowroots) or quite indistinct (wheat, ginger, barley). In isodiametric starch granules with centric hili (corn, rice, pepper, cardamom) the cross bands are at right angles to each other, whereas in elongated granules, bean, pea, and in the starches with excentric hili, the cross bands are not right angled.

The manufacture of commercial starches, or rather the obtaining of commercial starch, is comparatively simple. The starchy material (roots, stems, fruits, seeds, grains) is powdered or pulped, with or without previous soaking in water, and the starch washed out of the 


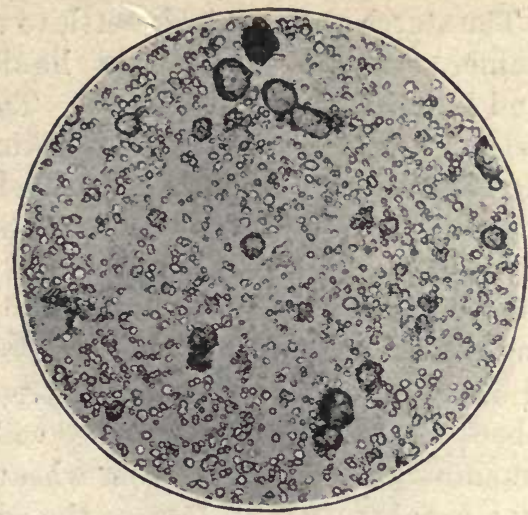

FIG. 17.-Oat Starch.

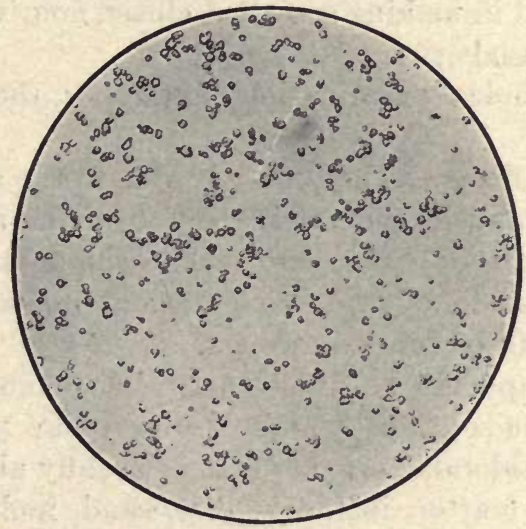

FIG. 18.-Rice Starch.

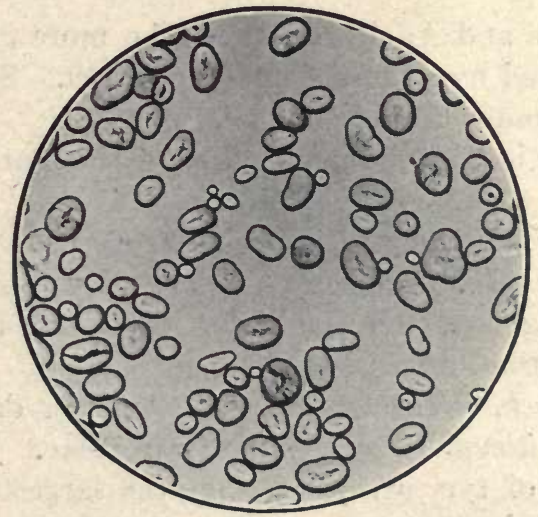

FrG. 19.-Bean Starch. 
tissues on sieves. The starch grains quickly settle to the bottom of the vat or other container, and the supernatant liquid containing the tissue fragments and impurities is decanted off. The starch is again washed and purified and finally dried. Before packing and marketing, the lumps resulting from the drying may be coarsely broken, or the hard masses may be reduced to a fine powder, in which the individual granules become almost wholly separated. One of the methods for purifying starch, is to agitate it in a dilute alkali, which dissolves nitrogenous matter and other impurities. Unless this agent is very carefully used and again quickly and completely removed, the starch granules will also become partially dissolved and will show an alkaline reaction. In the manufacture of starch from wheat, the gluten may first be removed by a fermentation process, or the wheat flour is made into a dough and the starch washed out of the gluten on a sieve. The gluten is then used in making so-called gluten flour which is especially recommended for diabetics.

In the microscopical examination of starches, the following should be looked for.

1. Corrosion Effects.-These may be due to the action of enzymes or due to the prolonged or excessive action of the alkaline purifying agent. If the corrosion effects are due to the action of bacteria (in wheat starch obtained by the fermentation process) or mold, then these organisms will be found in excess.

2. Organic Impurities.- These may be demonstrated by the addition of iodine solution which stains them yellowish brown. Starches with considerable organic matter usually also reveal bacteria and other foreign matter, including dirt, sand, mold, and tissue elements, and such starches are brownish in color, and have more or less odor.

3. Admixtures and Adulterations. - The more expensive starches may be adulterated by adding a cheaper starch. Such practice is at once recognized under the microscope.

The following is the botonical source of the more important commercial starches.

1. Rye starch, Roggenstärke, G. From the grains of Secale cereale L., Gramineae. The granules are very variable in size, the largest measuring $60 \mu$, the smallest 5 to $8 \mu$. Some of the largest granules with distinct fissured hili.

2. Wheat starch, Weizenstärke, G. Amidon de ble, Fr. From the grains of Triticum vulgare Vill., Gramineae. The granules are similar to those of rye, excepting that the largest granules usually do not exceed $50 \mu$ in diameter, and that they lack a distinct hilum. 


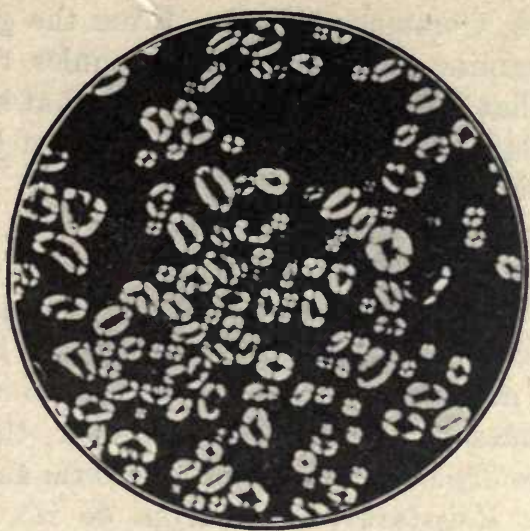

FIG. 20.-Bean Starch (Polarized).

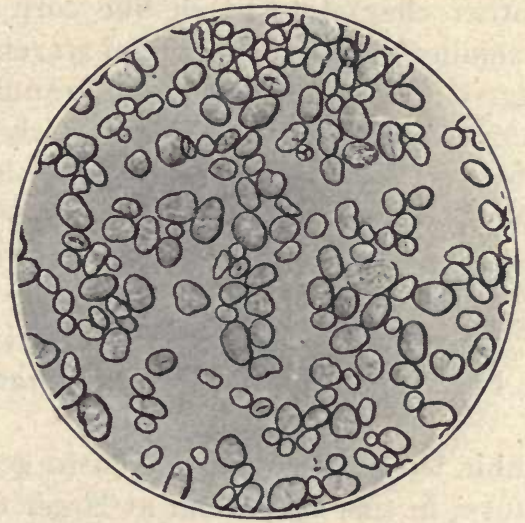

Fig. 21.-Pea Starch.

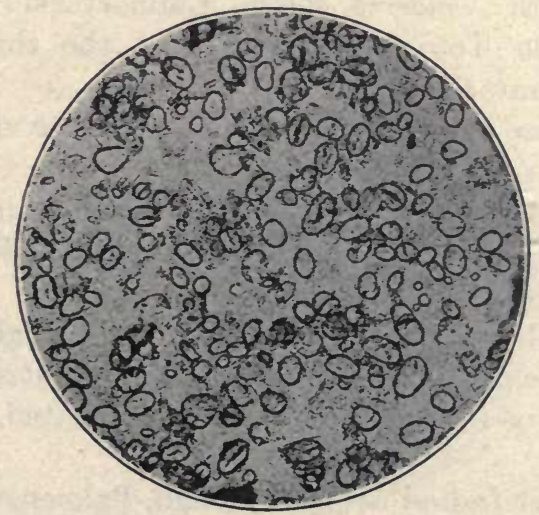

FIG. 22.-Lentil Starch. 
3. Barley starch, Gerstenstärke, G. From the grains of Hordeum sativum Pres., Gramineae. The starch granules resemble those of wheat excepting that they are generally somewhat smaller and somewhat more irregular in outline. An admixture of barley and wheat starch would be difficult to detect.

4. Corn starch, Kornstärke, G. Maisstärke, G. Fecule de mais, Fr. From the kernels of Zea mays L., Gramineae. This is the official starch of the U. S. P. The granules are usually polygonal, though some of them are rounded or spheroidal. The hilum is distinct, fissured, and the polarizing bands are very distinct. The majority of the granules measure about $25 \mu$ in diameter, though some reach a diameter of 30 to $35 \mu$. They are quite uniform as to size and form.

5. Rice starch, Reisstärke, G. Farina de riz, Fr. The starch obtained from the seeds of Oryza sativa, Gramineae.

In form and other characters much like corn starch but much smaller; it is the smallest of the commercial starches; granules quite uniform; many aggregated; a few compound granules. (2 to $8 \mu$.)

6. Potato starch, Kartoffelstärke, G. Fecule de pomme de terre, Fr. From the tubers of Solanum tuberosum L., Solanaceae.

Granules small to large; irregularly oval or pear-shaped; hilum not very conspicuous, excentric, nearer the narrowed end; stratification distinct. (50 to $90 \mu$.)

7. Maranta or Arrowroot starch, Marantastärke, G. Salep des Indes occidentalis, Fr. From the rhizomes of Maranta arundinacea L., Marantaceae.

Granules resemble those of potato starch in general appearance, smaller, more uniform in size and hilum at larger end instead of the narrower end. (30 to $75 \mu$ ).

8 Canna starch, Toulema starch, Cannastärke, G. Amidon de canne, Fecule de Tolomane, Fr. From the rhizomes of Canna edulis Ker., Marantaceae.

In form and size not unlike potato starch, more variable in outline; hilum mostly near the narrower end. (50 to $115 \mu$.)

9. Brazilian arrowroot, tapioca or Cassava starch, Cassavastärke, G. Amidon de Cassava, Fr. From the roots of Manihot utilissima Pohl, Euphorbiaceae.

Granules of about the size of corn starch; single granules spheroidal; hilum quite distinct, somewhat radiate, centric; many granules compound in twos and threes, mostly separated, showing facets. (15 to $30 \mu$.)

10. Sago, East Indian arrowroot, Sago, Palmenstärke, G. Sagou, Fr. From the pith of various palms-Metroxylon Sagu Rottboell, 


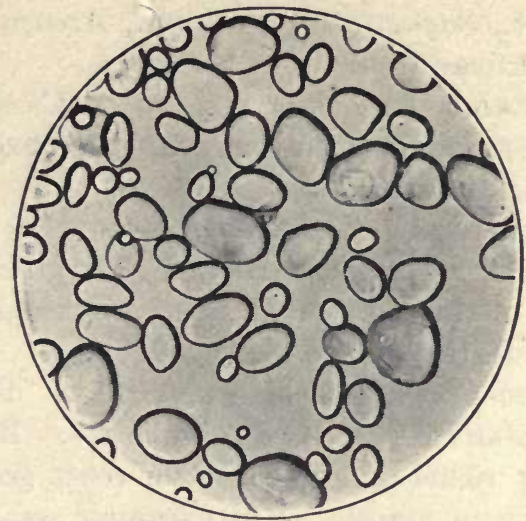

FIG. 23.-Potato Starch.

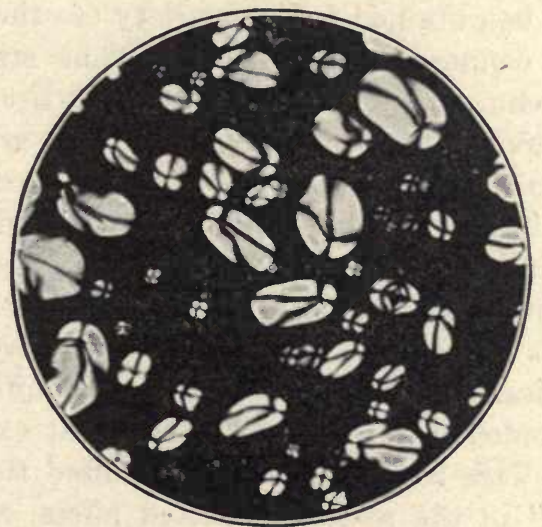

Frg. 24.-Potato Starch (Polarized).

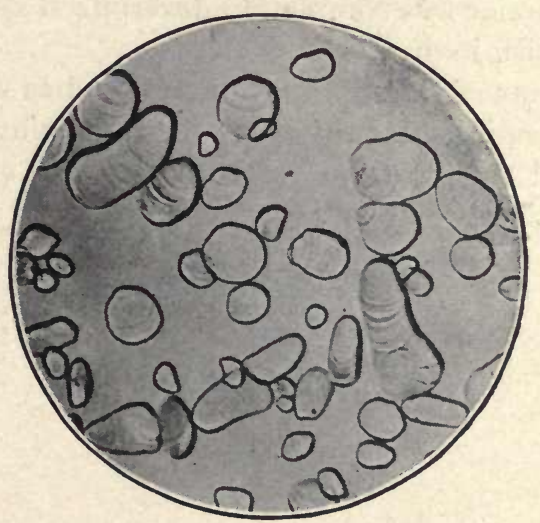

Frg. 25.-Canna Starch. 
M. Rumphii Mart., Sagus farinifera Lam., Arenga sacharifera Lab., Palmae. Also obtained from Cycas roots.

Granules somewhat larger than those of Cassava; irregular in outline; mostly compound as in Cassava, hilum excentric; stratification quite distinct. (30 to $75 \mu$.)

11. Yam starch, Guiana arrowroot. From the tuberous roots of various species of Dioscorea of the tropics. The granules are elongated with the hilum at the extreme smaller end, markings distinct, broader end somewhat truncate. (30 to $50 \mu$.)

12. Sweet potato starch, Brazilian arrowroot. From the tuberous roots of Batatas edulis Chois., Convolvulaceae. Roots from tropics are comparatively richer in sugar, while roots grown in temperate climates are richer in starch. Hili excentric, granules bell-shaped. (10 to $40 \mu$.)

Starches may be obtained from a variety of other plants but only exceptionally in commercial quantities. Thus starch may be obtained from the bean, the pea, the banana, from curcuma, from ginger, from Batatas edulis Chois., from the roots of the arucarias, from the roots of the zamias. Oat starch occasionally is found in the market.

Upon examining the commercial products made from starch or from meals rich in starch, as pearl sago, tapioca, macaroni, spaghetti, etc., it will be found that some or many of the starch granules are more or less heat dextrinized. Such products may also contain an excess of impurities. In the Chinese and India puffed rice, the starch granules are so much disintegrated by the heat explosions as to be unrecognizable. This is also true of the puffed rice of the market. In "grape nuts," in the so-called malted milks, and in some other manufactured foods in which considerable starch and cereal is used, the starch is more or less completely dextrinized and no longer gives a blue reaction with iodine.

The illustrations of the more common starches will serve to make clear their microscopic characteristics. The following key is based upon the microscopical examination, without the use of the micrometer scale or the polarizer. 


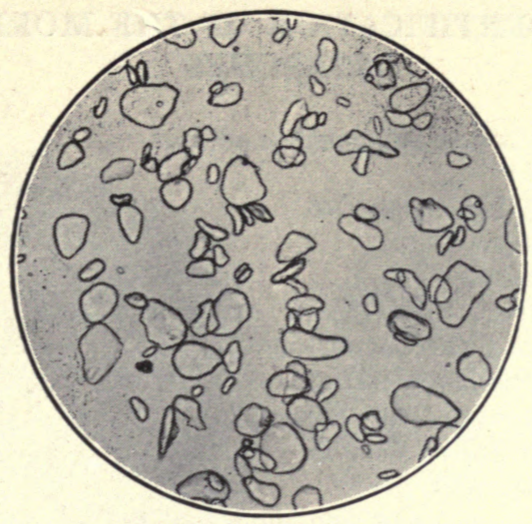

FIg. 26.-Banana Starch.

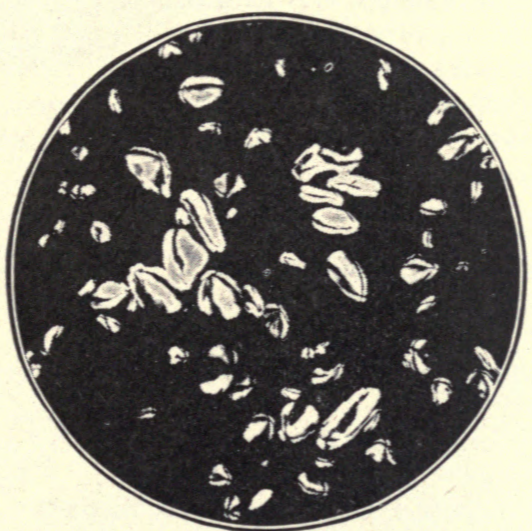

Fig. 27.-Banana Starch (Polarized).

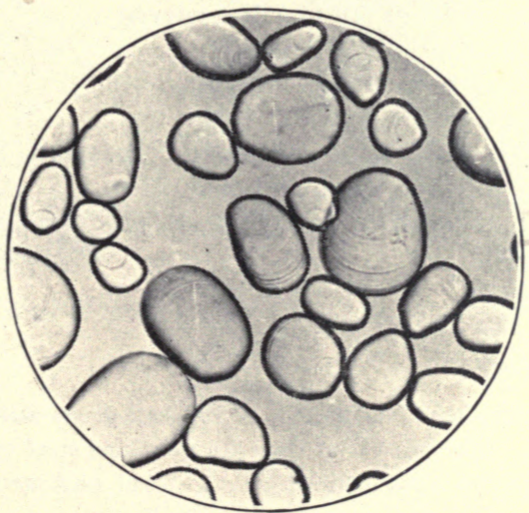

Fig. 28.-Queenland Arrowroot. 


\section{KEY TO THE IDENTIFICATION OF THE MORE IMPORTANT STARCHES}

Hili Centric

.. Individual granules largely polygonal in outline

....Aggregates present

......Aggregates elliptical or rounded

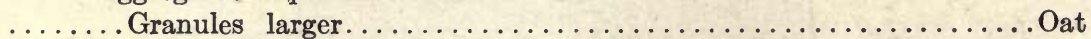

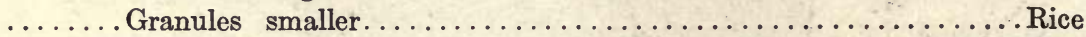

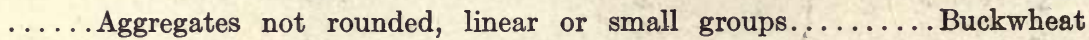

... Aggregates wanting, hili very distinct. . . . . . . . . . . . . . . . ${ }^{1}$

. Granules not polygonal, rounded or more or less irregular

....Granules kidney-shaped, large fissured hili

...... Outline quite regular......................................

...... Outline quite irregular

........Few or no aggregates or compound granules............... Pea

.... Not kidney-shaped, rounded with facets................ Cassava

...... Some compound granules, very irregular...................

. . Granules distinctly round, very variable in size

....Larger granules showing occasional fissured hili................ Rye

.... Hili indistinct, barely perceptible

..... Granules smaller................................. Barley

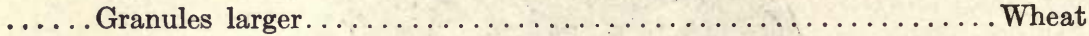

\section{HiLI EXCENTric}

. .Granules ovoid, pear-shaped to elongated

.... One end truncately cut

..... Truncate end abruptly tapering, hili indistinct............. Ginger

..... Truncate end not tapering, large $V$-shaped hili........... Orris root

.... Not truncate

..... Hili usually at larger end, fissures.

Maranta

Hili usually at smaller end, pin point

...... Distinctly pear-shaped, lamellations very distinct

........ One end with distinct projection..................... Canna

......... End projection usually wanting.................. Potato

....... Granules elongated and more or less curved

......... Broad end more or less truncate .................... Yam

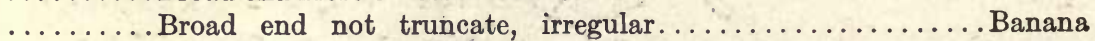

........ Truncate narrower end with blunt tip.............. Curcuma

....... Bell-shape granules; some compound granules....... Sweet potato

.. Granules quite irregular as to shape and outline

.... Hili usually at broader end; many small granules....... Horse chestnut

....Large fissured hili................................ Chestnut

..Granules showing facets

.... Hili transversely fissured

.... Hili radiately fissured........................ Sweet potato

1The starch of broom corn, sorghum, of fox tail grass and of other grasses, is similar to that of corn. The starch of darnel resembles that of rice. In a general way, the starch of related plants is similar as to form and structure. 


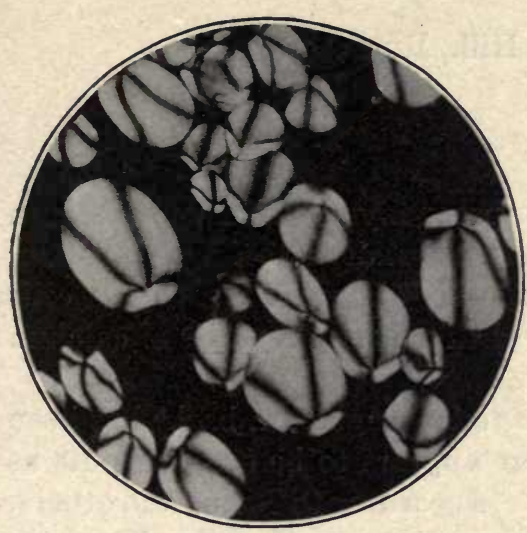

Fig. 29.-Queenland Arrowroot (Polarized).

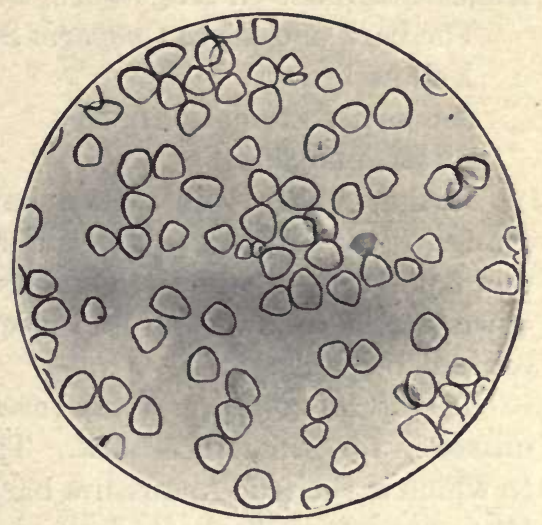

Fig. 30.-Yam Starch.

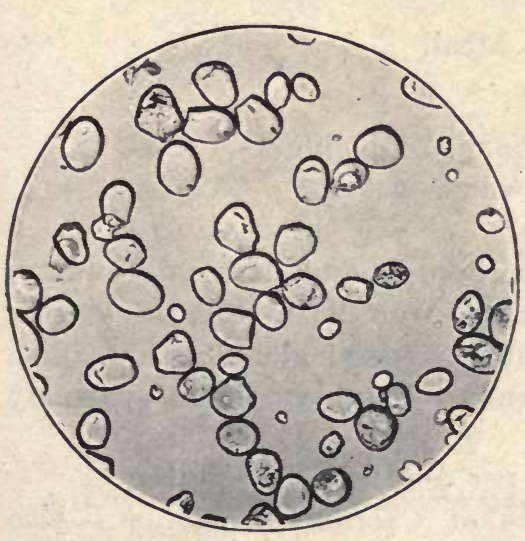

FIG. 31.-Sago Starch.

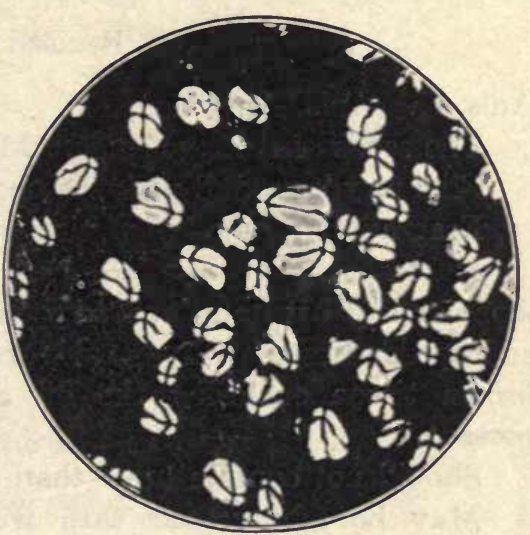

FIG. 32.-Sago Starch (Polarized). 


\section{ANGUSTURA. Angustura. Bark.}

Fl. ex. 60 .

Augusturarinde, G. Angusture, Fr.

The bark of Galipea Cusparia St. Hill., Rutaceae.

Yellow brown

Somewhat aromatic; musty.

Bitter, pungent.

Rather small, thin walled bark parenchyma with small starch granules and aggregate and prismatic crystals of calcium oxalate; numerous typical stone cells; no bast cells. Larger parenchyma cells with golden yellow resin and a few with acicular crystals of calcium oxalate (raphides).

The bark of Strychnos nux vomica (false Angustura bark) has been mistaken for Angustura bark. There appears to be some dispute as to which is the true Angustura bark. According to Zornig and others, true Angustura bark is derived from Galipea officinalis Hancock, which differs from the above bark in that it contains bast fibers and crystal bearing fibers. The bark of Angustura brava or Evodia febrifuga St. Hil. is often mistaken for the true Angustura bark.

\section{2. (Fig. 33.) ANISUM. Anise. U. S.}

Bruised. Meal.

Anis, G. Anis, Anis vert, Fr.

The seeds of Anisum vulgare Moench, Umbelliferae.

Fine powder a dull yellowish brown.

Fragrantly aromatic. Anise odor.

Numerous short single celled trichomes, and externally warty, more or less bent and curved measuring from 25 to $150 \mu$ in length; endosperm tissue with proteid granules and oil globules; a reddish brown tissue enclosing the oil glands. Vascular tissue sparingly present.

Should not contain more than 8 per cent. ash.

May be adulterated with fruits of Conium maculatum. Also adulterated with various inert vegetable substances, fennel and flavored with star anise. If the seeds to which a strong solution of sodic hydrate has been added give off a mouse odor (odor of mouse urine) it indicates the presence of Conium fruits. 

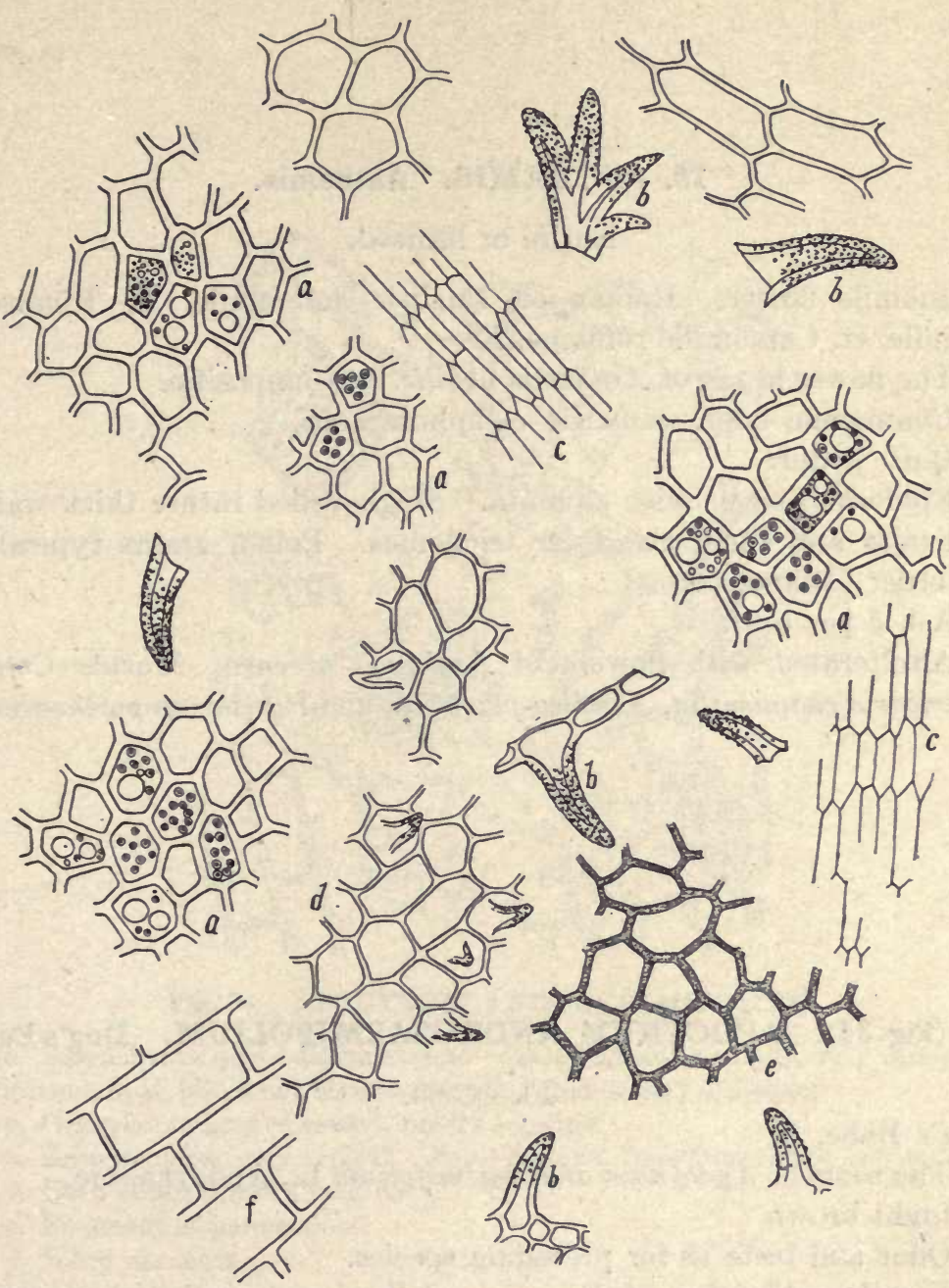

Fig. 33. ANISUM.

a. Endosperm cells with proteid granules and oil globules.

b. Trichomes.

c. Thin-walled parenchyma of testa.

d. Epidermal cells of pericarp with trichomes.

c. Reddish brown cells of pericarp.

f. Parenchyma, longitudinal view. 


\section{ANTHEMIS. Anthemis.}

Entire or bruised.

Chamomile flowers, Roman or English chamomile, E. Römische Kamille, G. Camomille romaine, Fr.

The flower heads of Anthemis nobilis L., Compositæ.

Chamomile odor, somwhat camphoraceous.

Quite bitter.

Epidermal tissue with stomata. Single celled rather thick walled trichomes and some glandular trichomes. Pollen grains typical of the order Compositæ.

Ash 5 per cent.

Adulterated with flowers of Anthemis arvensis, Maruta Cotula, Matricaria chamomilla, Achillea ptarmica, and Pyrethrum parthenium.

14. (Fig. 34). APOCYNUM ANDROSAEMIFOLIUM. Dog's Bane. Fl. ex. 60.

Dog's Bane, E.

The roots of Apocynum androsaemifolium L., Apocynaceae.

Light brown.

Odor and taste as for preceding species.

Histology like that of the species following excepting that numerous typical yellowish sclerenchyma cells are present. Compare also the resin bearing cells.

Ash 12 per cent. 


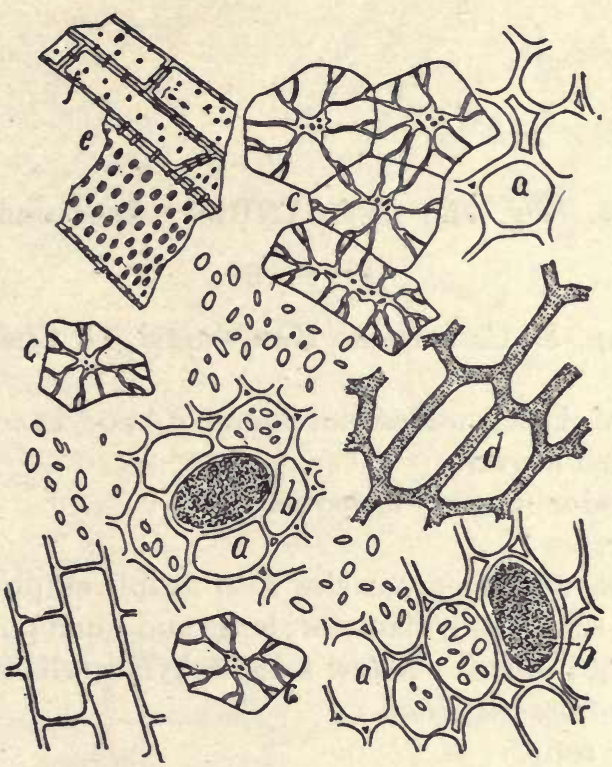

Fig. 34. APOCYNUM ANDROSAEMIFOLIUM.

a. Parenchyma cells bearing starch. Starch granules simple, very rarely two compound, oval, hilum and stratification wanting or very indistinct.

b. Granular substance (resin), nearly colorless.

c. Sclerenchyma, very typical. Pores distinct, branching; color yellow.

d. Deep reddish brown cork cells.

$e$. Fragment of porous duct.

f. Wood elements. 


\section{5. (Fig. 35.) APOCYNUM. Apocynum.}

Fl. ex. 60 .

Canadian hemp, E. Canadische Hanfwurzel, G. Chanvre du Canada, Fr.

The roots of A pocynum cannabinum L., Apocynaceae.

Light grayish brown.

Faint soil odor (musty) narcotic.

Very bitter.

Parenchyma cells medium size with simple elliptical starch granules from 3 to $12 \mu$ in long diameter; large and small porous ducts; cork tissue sparingly present. A few sclerenchyma cells are present, like those of $A$. Androsaemifolium.

Ash 11 per cent.

Canadian hemp and dog's bane are variously substituted for each other. Not generally adulterated. 


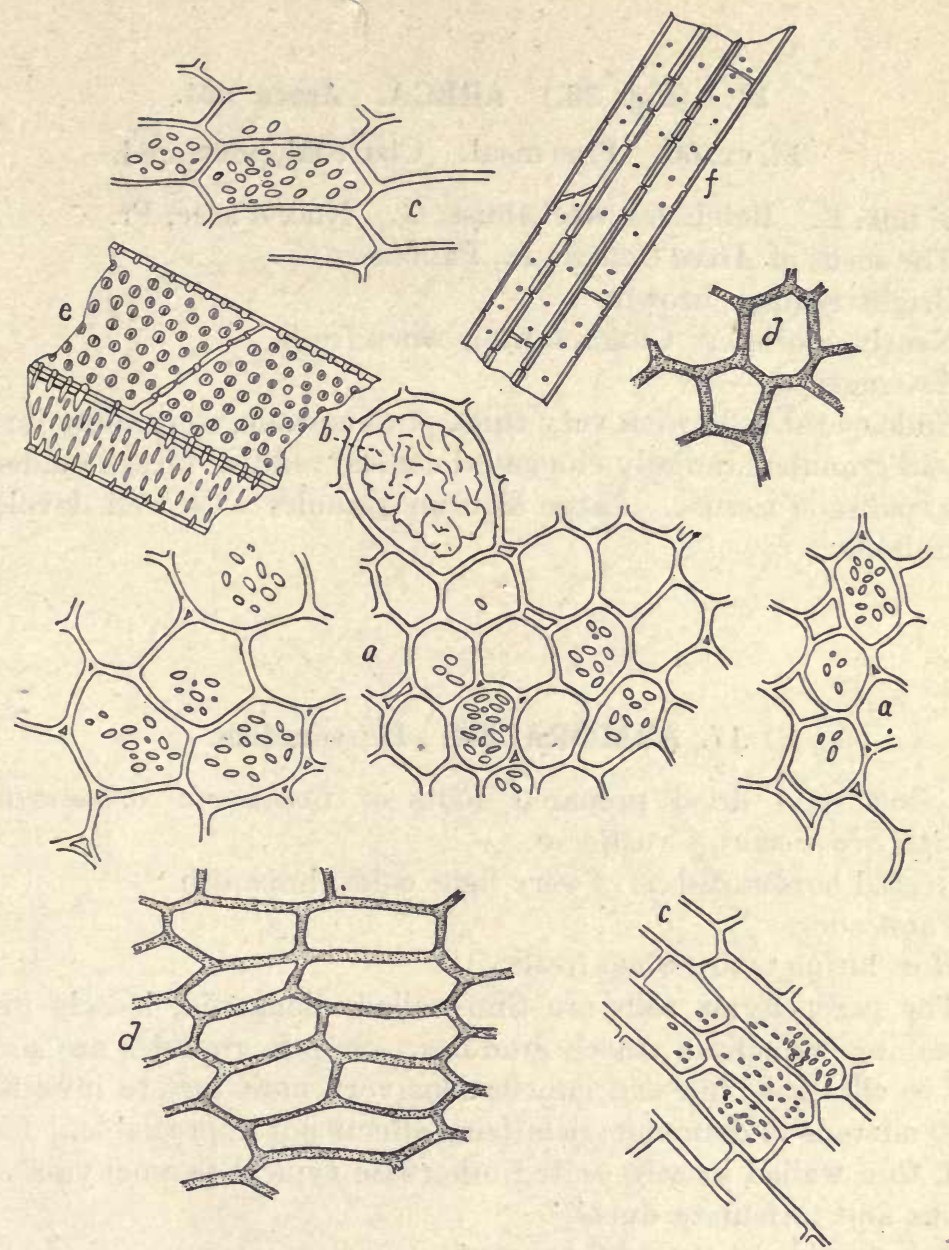

Fig. 35. APOCYNUM CANNABINUM.

a. Parenchyma bearing starch. Granules similar to those of A. Androsaemifolium.

b. Resin bearing cell, resin colorless and crystalline. These resin bearing cells are quite large, the one figured is one of medium size.

c. Parenchyma, longitudinal view.

d. Deep reddish brown cork cells.

e. Porous duct.

$f$. Wood elements. 


\section{6. (Fig. 36.) ARECA. Areca nut.}

Fl. ex. 60. Fine meal. Charcoal, powdered.

Betel nut, E. Betelnuss, Arekanuss, G. Noix d'arec, Fr.

The seeds of Areca Catechu L., Palmae.

Bright reddish brown.

Nearly odorless. Characteristic when fresh.

Astringent.

Endosperm cells with very thick porous walls, containing fat and proteid granules; radially elongated conical reddish brown epidermal cells (palisade tissue). Large aleuron granules with well developed crystalloids.

\section{ARMORACEA. Horseradish.}

The fresh and dried prepared roots of Cochlearia armoracia L., (Roripa armoracia), Cruciferae.

Grated horseradish is of very light color, brownish.

Faint odor.

Hot, biting taste, when fresh.

The parenchyma cells are thin-walled, elongated, loosely united containing numerous starch granules. Starch granules are simple, oval to elliptical; hili and lamellations very indistinct to invisible; 5 to 10 microns in diameter; polarizing effects not appreciable. Elongated, thin walled loosely united otherwise typical parenchyma cells; porous and reticulate ducts.

Ash should not exceed 6 per cent.

Horseradish has been used as an adulterant of aconite root, and conversely aconite has been accidentally mixed with horseradish roots resulting in fatal poisoning. Horseradish has anti-scrobutic properties. Drying and boiling dissipates the volatile oil to which it owes its pungent properties. 


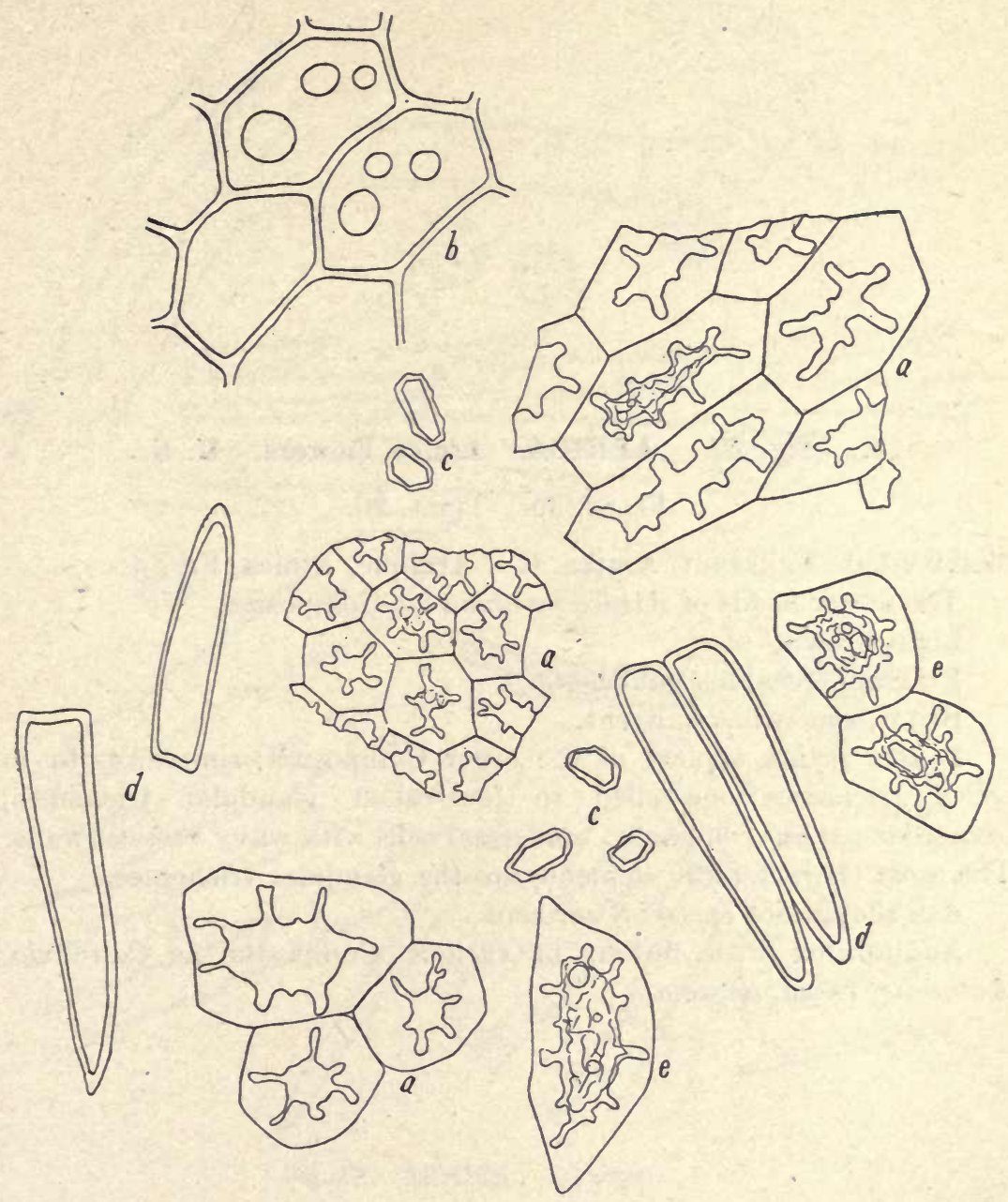

Fig. 36. ARECA NUT.

a. Endosperm cells with fat.

b. Cells with large aleuron granules.

c. Crystalloids, prismatic, enclosed in proteid matter.

$d$. Radially elongated reddish brown epidermal cells. 
18. (Fig. 37.) ARNICA. Arnica Flowers. U. S. Fl. ex. 30. Tinct. 20.

Wohlverleih, Fallkraut, Arnika, G. Arnique, Arnica, Fr.

The flower heads of Arnica montana L., Compositæ.

Light brown.

Fragrant, recalling gaultheria.

Bitter, somewhat pungent.

Pollen grains typical of the order Compositæ; simple, 4- to 6celled trichomes; one-celled to four-celled glandular trichomes; numerous pappus remnants; epidermal cells with wavy vertical walls. The most characteristic elements are the glandular trichomes.

Ash should not exceed 8 per cent.

Adulterated with flowers of various Compositæ as Calendula, Anthemis, Inula, Senecio. 


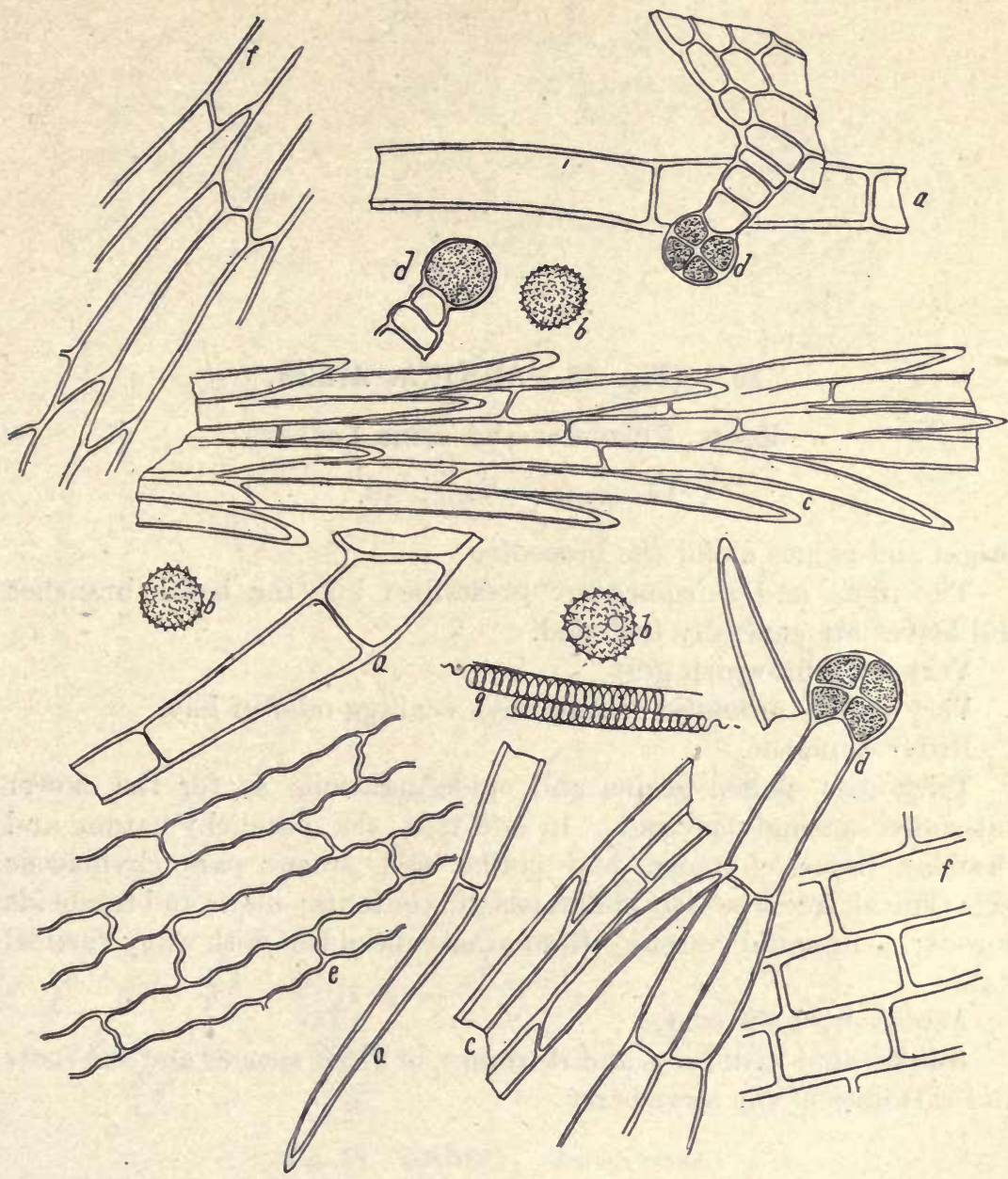

Fig. 37. ARNICA. Flowers.

a. Trichomes.

b. Pollen grains.

c. Pappus.

d. Glandular trichomes.

e. Epidermal cells.

f. Parenchyma, longitudinal view. 
19. (Fig. 38.) ARNICA. Arnica.

\section{Roots, Rhizomes and some Leaves.}

Fl. ex. 60. Tinct. 40 .

Origin and names as for the preceding.

The roots and rhizomes are prescribed but the basal branches and leaves are generally included.

Very dark brownish gray.

Very faintly aromatic or fragrant, recalling odor of hay.

Bitter, pungent.

Trichomes, pollen grains and epidermal cells as for the flower but more sparingly present. In addition, the parenchymatous and vascular tissue of roots, leaf stalks and stems; parenchymatous cells typical, free from any characteristic contents; ducts and tracheids porous; some spiral vessels. Epidermal cells of leaf with wavy vertical walls.

Ash about 9 per cent.

Adulterated with roots and rhizomes, of other species and the roots and rhizomes of the strawberry. 


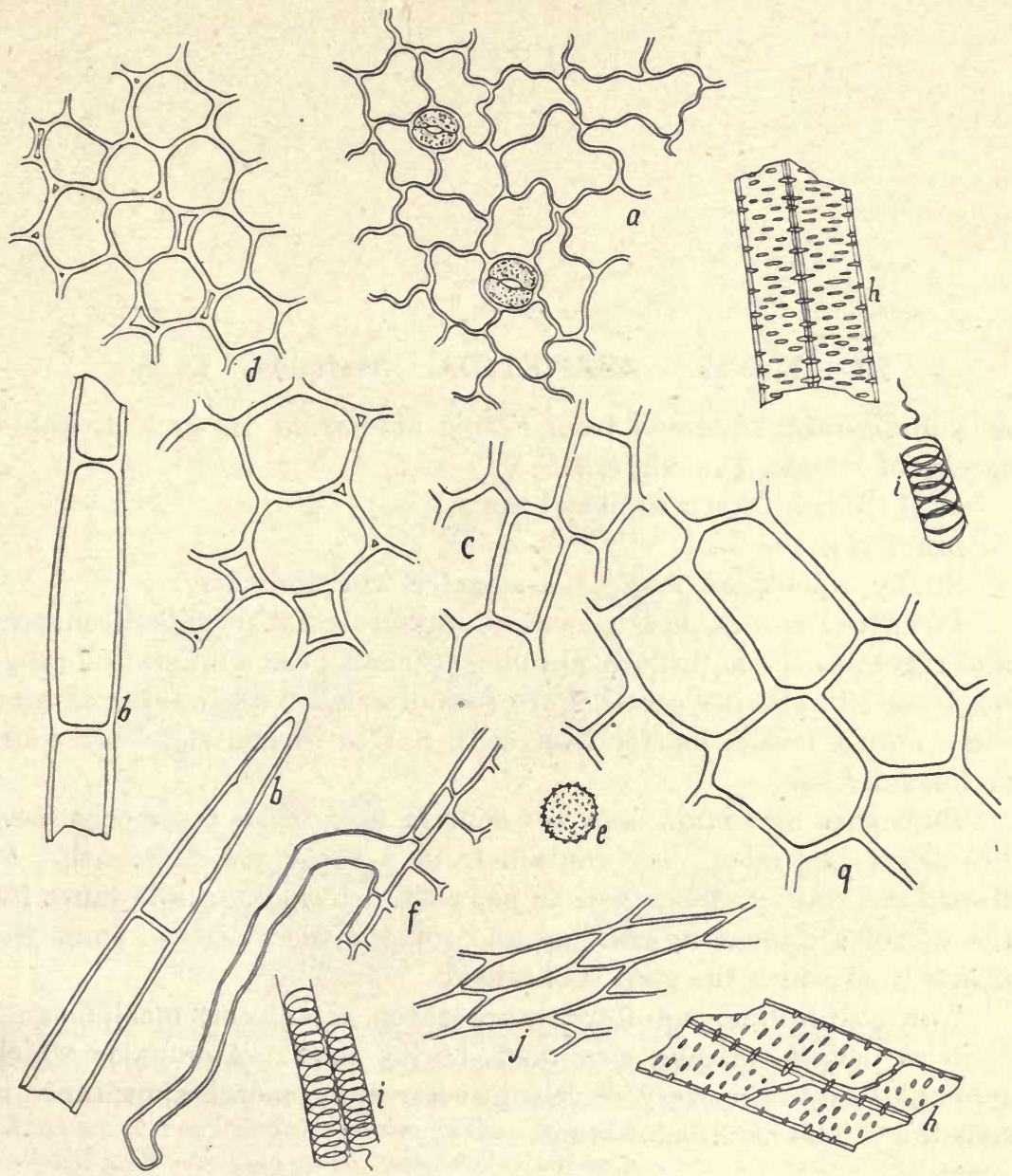

Fig. 38. ARNICA. Entire plant.

a. Epidermal cells of leaf.

b. Trichomes.

c. Parenchyma, longitudinal view.

d. Parenchyma, transverse view.

e. Pollen grain.

f. Trichome and epidermal tissue of root.

$g$. Parenchyma of root.

$h$. Porous ducts.

$i$. Spiral ducts.

j. Parenchyma. 


\section{0. (Fig. 39.) ASAFCETIDA. Asafetida. U. S.}

A gummy-resin obtained from Ferula Asafœtida L. and of other species of Ferula, Umbelliferæ.

Dull reddish brown to light brown.

Marked garlic odor.

Sticky, somewhat pungent, associated with the odor.

Powdered asafœtida is generally adulterated with mineral matter and vegetable tissue (usually gramineous chaff), the adulteration ranging from 10 to 90 per cent. Pure (commercially) asafœtida contains some Ferula tissue, mostly bast cells, not to exceed eight per cent. and usually less:

Pure gum asafœtida does not contain more than 4 per cent. ash. Powdered asafœetida may contain from 8 to 50 per cent. ash. It should not contain more than 10 per cent. ash, making allowance for the use of a diluent in grinding and for additions derived from the plants from which the gum is obtained.

The most common adulterants are starch, cereal, corn meal, magnesium carbonate, talcum, rice chaff, barley chaff. Ammoniac which resembles asafœtida very closely in color and general appearance is sometimes used as an adulterant. 


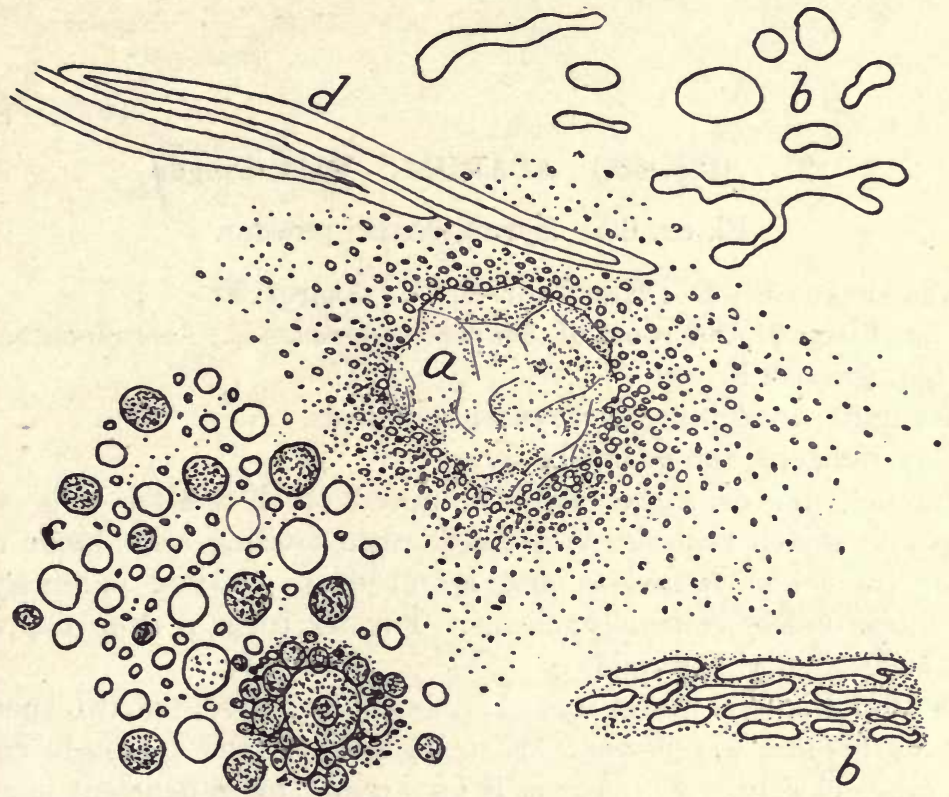

Fig. 39. Asafœtida. Characteristic appearance of water mounts. $a$, a bit of the gum from which numerous minute globules are thrown off into the surrounding water, showing very active Brownian movement; $b$, irregular globules of the gum; $c$, globules of the gum as they appear in a heated mount. The larger globules gradually take up (by positive surface tension and adsorption) the smaller particles. Some remain clear by virtue of not taking up particles. Gradually the globules become agglutinated and massed; $d$, bast cells, the most constantly present impurity in even the best quality. 


\section{1. (Fig. 40.) ASARUM. Wild Ginger.}

Fl. ex. 60. Syrup, coarse powder.

Canada snakeroot, E. Hazelwurzel, G. Asaret, Fr.

The rhizomes and roots of Asarum canadense L., Aristolochioceae. Light grayish brown.

Aromatic, recalling ginger; camphoraceous.

Very pungent, somewhat bitter.

Parenchyma of rather loosely united thick walled cells with compound starch granules and larger resin bearing cells; some cork tissue; tracheids; reticulate and spiral ducts. Outer parenchyma cells more or less collenchymatous. Powder turns a deep red with concentrated sulphuric acid.

In 1897 Bicknell found that $A$. canadense represented two species, $A$. canadense and $A$. reflexum. Histologically the two species resemble each other closely. A. reflexum is apparently more deficient in resin and starch, parenchyma cells have thinner walls. Vascular tissue more deficient." Reaction with sulphuric acid less marked. 

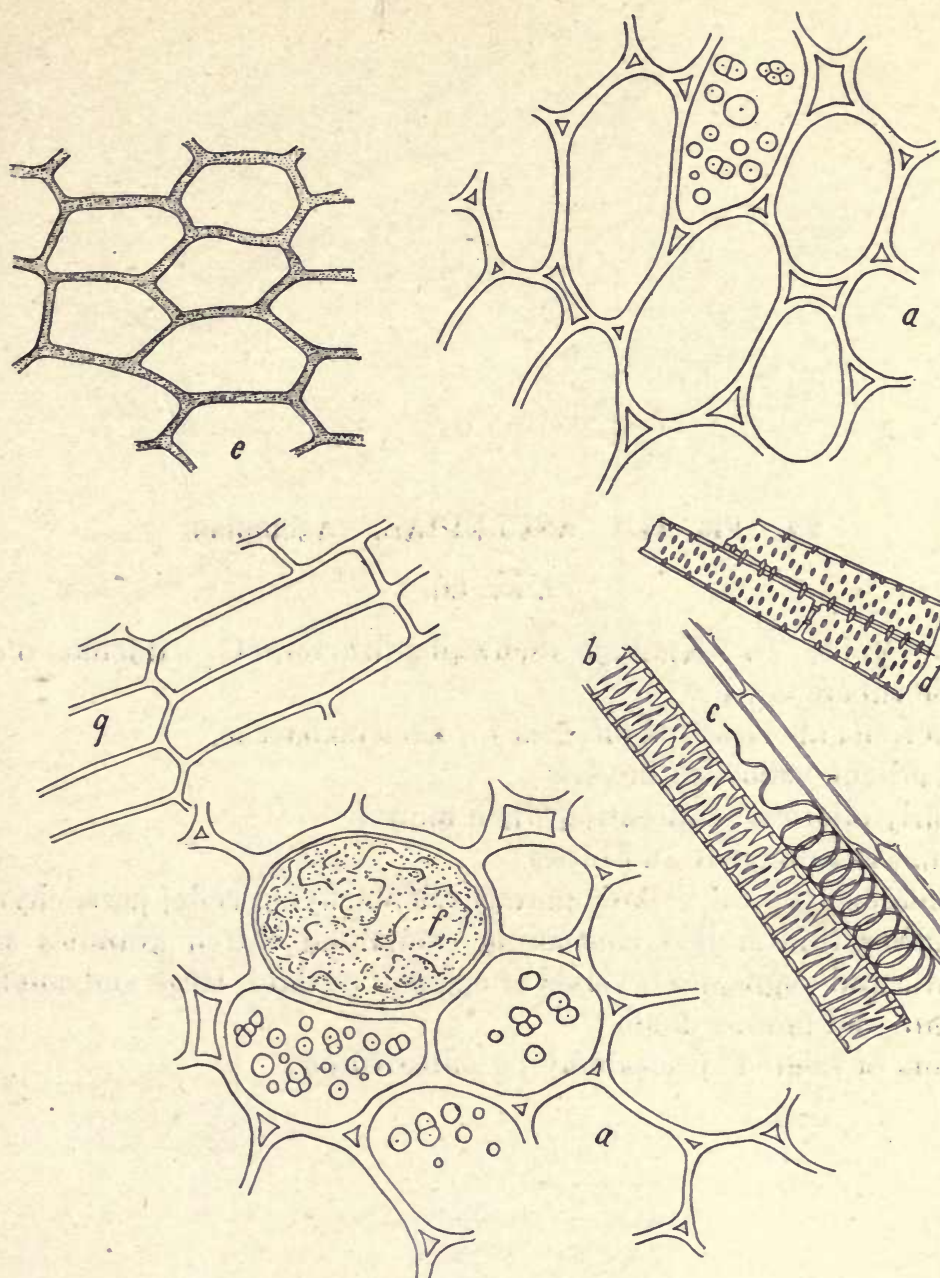

Fig. 40. ASARUM.

a. Parenchyma with starch.

b. Reticulate duct.

c. Spiral duct.

$d$. Porous ducts.

e. Cork tissue.

$f$. Resin cell.

g. Parenchyma, longitudinal view. 
22. (Fig. 41.) ASCLEPIAS. Asclepias.

Fl. ex. 60 .

Pleurisy root, E. Knollige Schwalbenwurzel, G. Racine d'asclepiade tubereuse, Fr.

The roots of Asclepias tuberosa L., Asclepiadaceae.

Very light yellowish brown.

Nearly odorless; nauseating when moist.

Somewhat pungent and bitter.

Numerous typical yellow, porous sclerenchyma cells; parenchyma cells rather thin walled containing compound starch granules and prismatic and aggregate crystals of calcium oxalate; large and smaller reticulate and porous ducts.

Roots of related species may be substituted. 


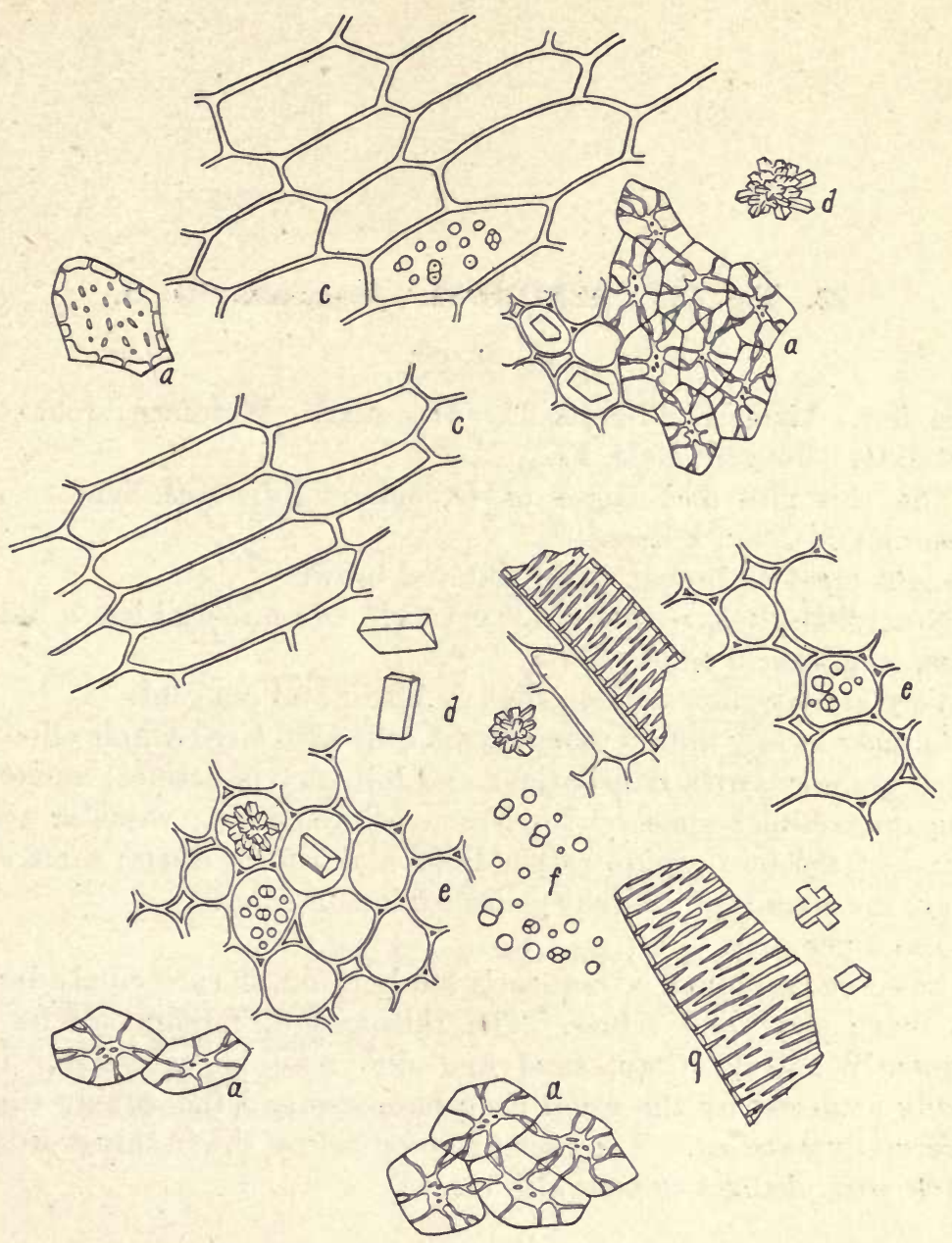

Fig. 41. ASCLEPIAS TUBEROSA.

a. Sclerenchyma cells.

c. Parenchyma, longitudinal view.

$d$. Prismatic and aggregate crystals.

e. Parenchyma with starch and crystals.

$f$. Starch granules.

g. Reticulate ducts. 


\section{3. (Fig. 42.) ASPIDIUM. Aspidium. U. S.}

Fl. ex. 60 .

Male fern, Male shield fern, E. Wurmfarn, Waldfarn, Johanneswurzel, G. Fougére malé, Fr.

The rhizomes and stipes of Dryopteris Filix-mas Schott, and D. marginale Gray, Filices.

Light greenish brown. Old material brown.

Nearly odorless, recalling taraxacum. Old material has a heavy, nauseating, rancid odor.

Very astringent, sweetish, slightly bitter and pungent.

Largely loosely united parenchyma cells with large simple elliptical starch granules, with lamellations and hili very indistinct; numerous large intercellular spaces with lemon colored resin; vascular tissue typical of the fern group, rather large scalariform ducts; some cork tissue; the resin is of a bright yellowish lemon color.

Ash 3 per cent.

Powdered aspidium is frequently adulterated, the principal adulterant being chaff and refuse. The rhizomes of foreign species are frequently added. Clay, sand and dirt may be excessive. It is readily attacked by the usual drug parasites and the supply should be carefully watched. The greenish coloration of the freshly powdered article soon changes to yellowish brown. 


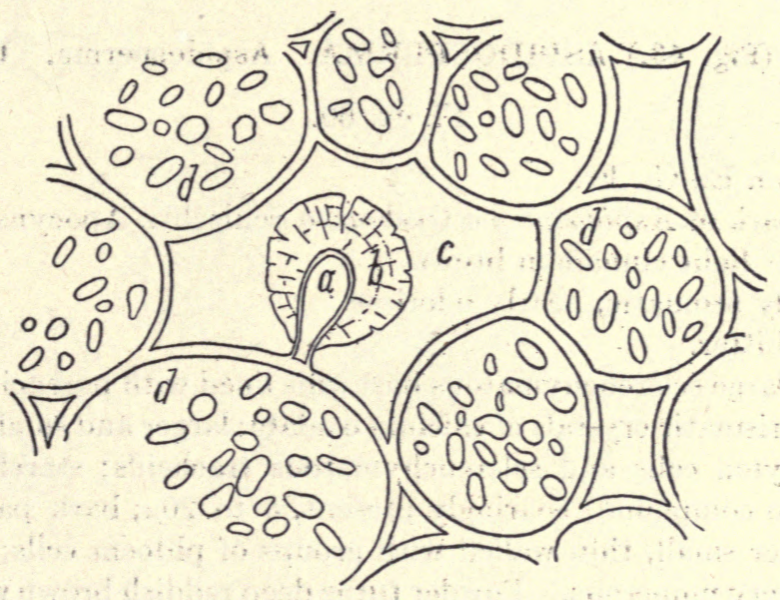

Fig. 42. ASPIDIUM.
a. Intercellular resin gland.
$b$. Resin of golden yellow cólor.
c. Intercellular space.
d. Starch bearing parenchyma cells. 
24. (Fig. 43.) ASPIDOSPERMA. Aspidosperma. U. S.

Fl. ex. 60 .

Quebracho. E., G., Fr.

The bark of Aspidosperma Quebracho Schlecht., Apocynaceae.

Rather light cinnamon brown.

Faintly aromatic, nearly odorless.

Very bitter.

Very large sclerenchymatous bast cells lined with parenchyma cells bearing prismatic crystals of calcium oxalate; larger and smaller typical sclerenchyma cells and sclerenchymatous tracheids; starch granules (simple to compound) sparingly present, 5 to $20 \mu$; bark parenchyma cells rather small, thin walled with groups of phloem cells; prismatic crystals very numerous. Powder turns deep reddish brown with potassium hydrate solution.

May be adulterated with the barks of related species; the wood tissue may be excessive; old and worthless bark may be used. 


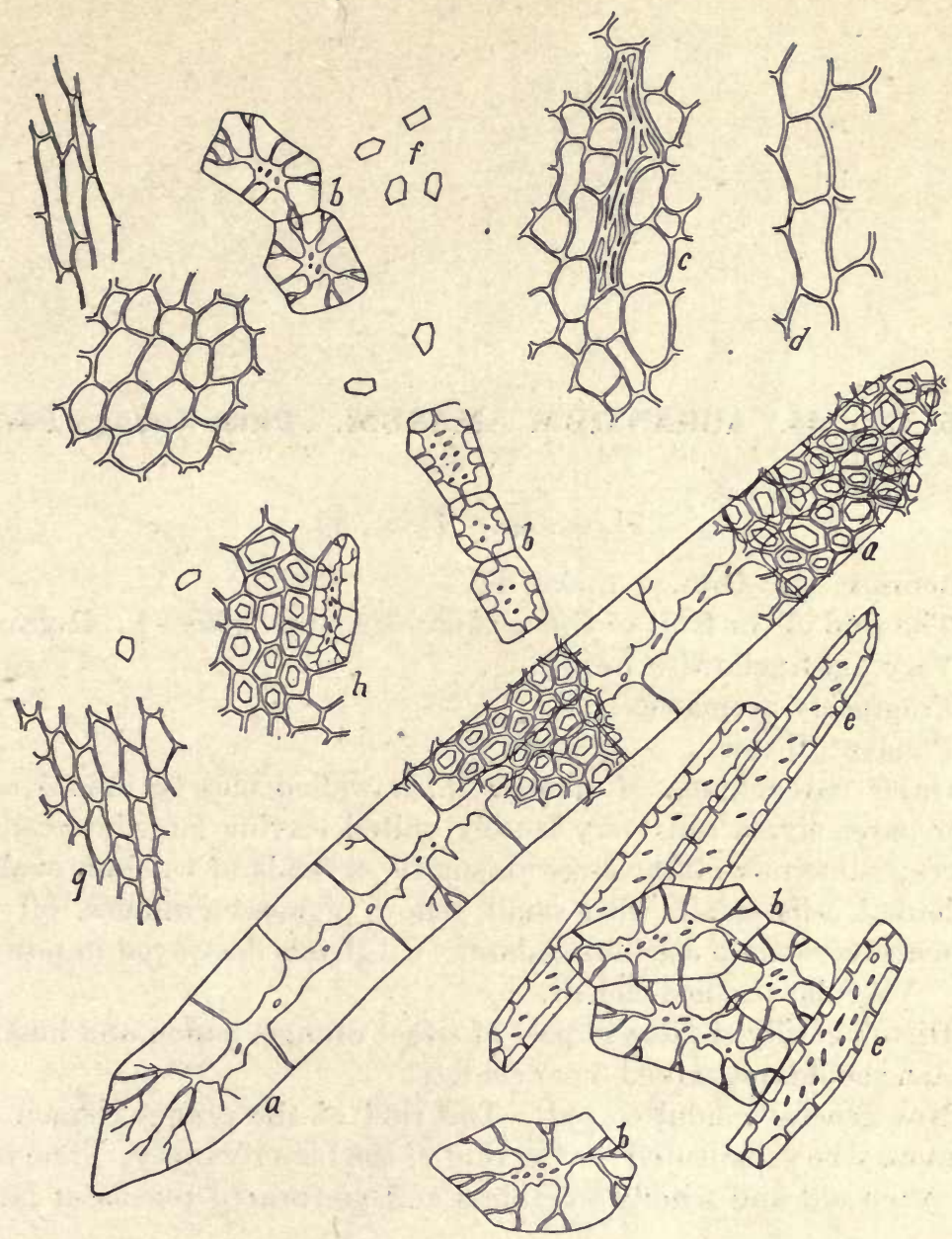

Fig. 43. ASPIDOSPERMA.

a. Very large bast cell, all lined with crystal bearing cells.

$b$. Sclerenchyma cells.

c. Parenchyma with phloem group.

d. Parenchyma.

$e$. Sclerenchymatous tracheids.

f. Prismatic crystals.

g. Small celled parenchyma.

$h$. Crystal bearing parenchyma and stone cell. 


\section{5. (Fig. 44.) AURANTIUM AMARUM. Bitter Orange Peel.} U. S.

Fl. ex. 40. Tinct. 30 .

Pomeranze, G. Orange amére, Fr.

The rind of the fruit of Citrus Aurantium var. amara L., Rutaceae.

Very light yellowish brown.

Fragrantly aromatic.

Pungent, bitter.

Outer parenchyma of smaller thick walled closely united cells; inner parenchyma cells very loosely united leaving large intercellular spaces; numerous rather large prismatic crystals of calcium oxalate; epidermal cells small, with small yellow pigment granules, oil and prismatic crystals of calcium oxalate. Oil glands destroyed in powdering. Vascular tissue deficient.

Histologically similar to peel of sweet orange, lemon and lime.

Ash should not exceed 6 per cent.

Not generally adulterated. The rind of the orange, lemon and limes may be substituted for the rind of the bitter variety. The rinds are often old and wholly worthless and perforated by insect larvæ. 


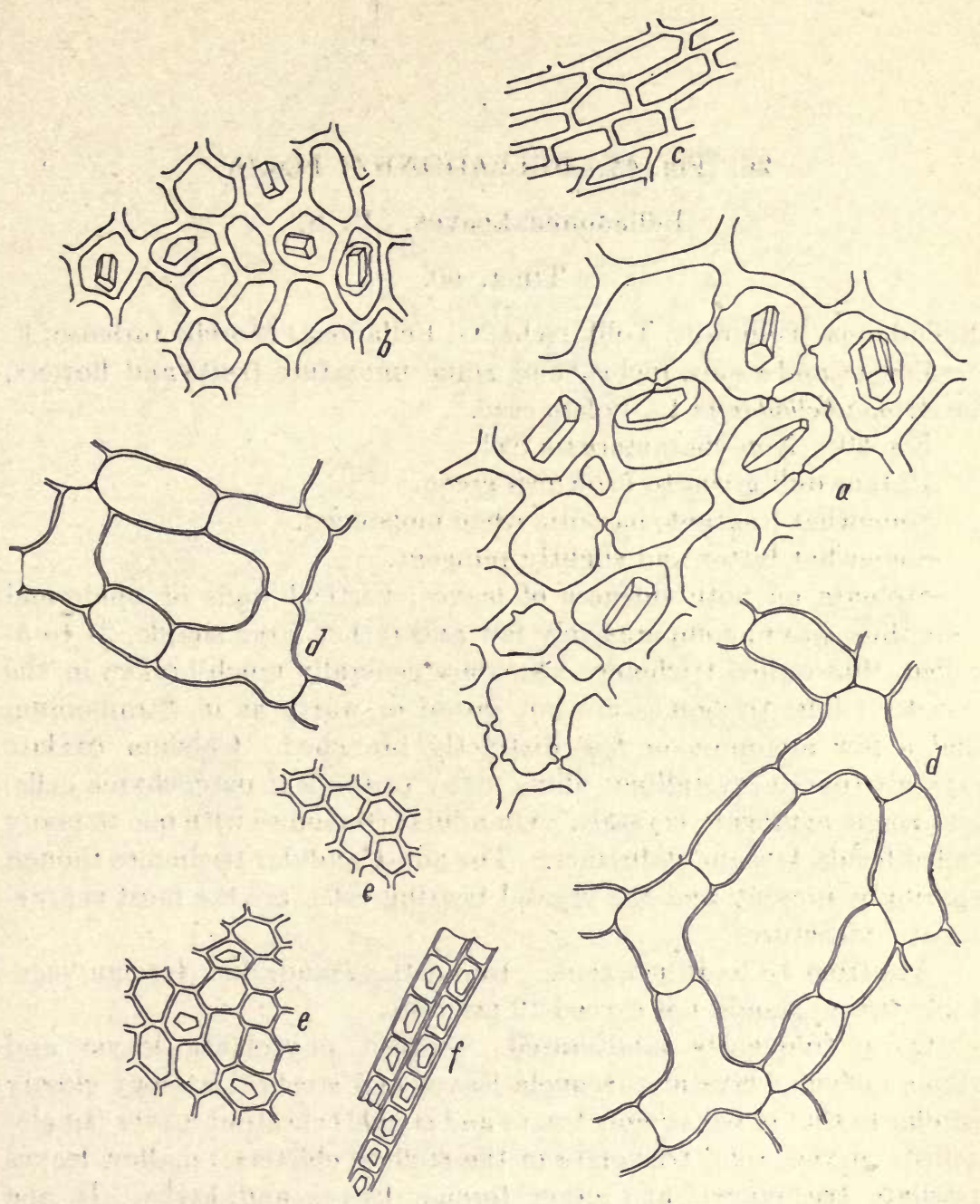

Fig. 44. AURANTIUM AMARUM.

$a, b$. Outer parenchyma with crystals.

c. Parenchyma, longitudinal view.

d. Inner spongy parenchyma.

e. Epidermis, vertical view.

$f$. Crystal bearing fibers. 


\section{6. (Fig. 45.) BELLADONNA FOLIA.}

\section{Belladonna Leaves, U. S.}

Tinct. 60 .

Belladonna, Tollkraut, Tollkirsche, G. Belladona, Morelle furieuse, F.

Leaves and stems, inclusive of some immature fruits and flowers, of Atropa belladonna L., Solanaceae.

No. 80. Non-characteristic feel.

Rather dull green to brownish green.

Somewhat fragrant; narcotic when moistened.

Somewhat bitter and slightly pungent.

Stomata on both surfaces of leaves; vertical walls of epidermal cells thin, wavy; comparatively few and rather large simple, 2- to 5celled, thin-walled trichomes which are generally much broken in the powder. The trichomes are not pitted or warty as in Stramonium and a few are more or less distinctly branched. Calcium oxalate crystals (micro-crystalline) filling many of the leaf parenchyma cells; and single aggregate crystals. Glandular trichomes with one to many celled heads, few and indistinct. The non-glandular trichomes though sparingly present and the crystal bearing cells, are the most characteristic structures.

Ash from 15 to 18 per cent. Impurities (sand, dirt, foreign vegetable tissue) should not exceed 10 per cent.

Quite frequently adulterated. Suspect phytolacca leaves and stems (acicular crystals); scopola leaves and stems (histology closely similar to that of belladonna leaves and stems); chestnut leaves (singlecelled, curved, rigid trichomes of the stellate clusters); mallow leaves (stellate trichomes), and other foreign leaves and herbs. In the American grown belladonna the stems are included. 


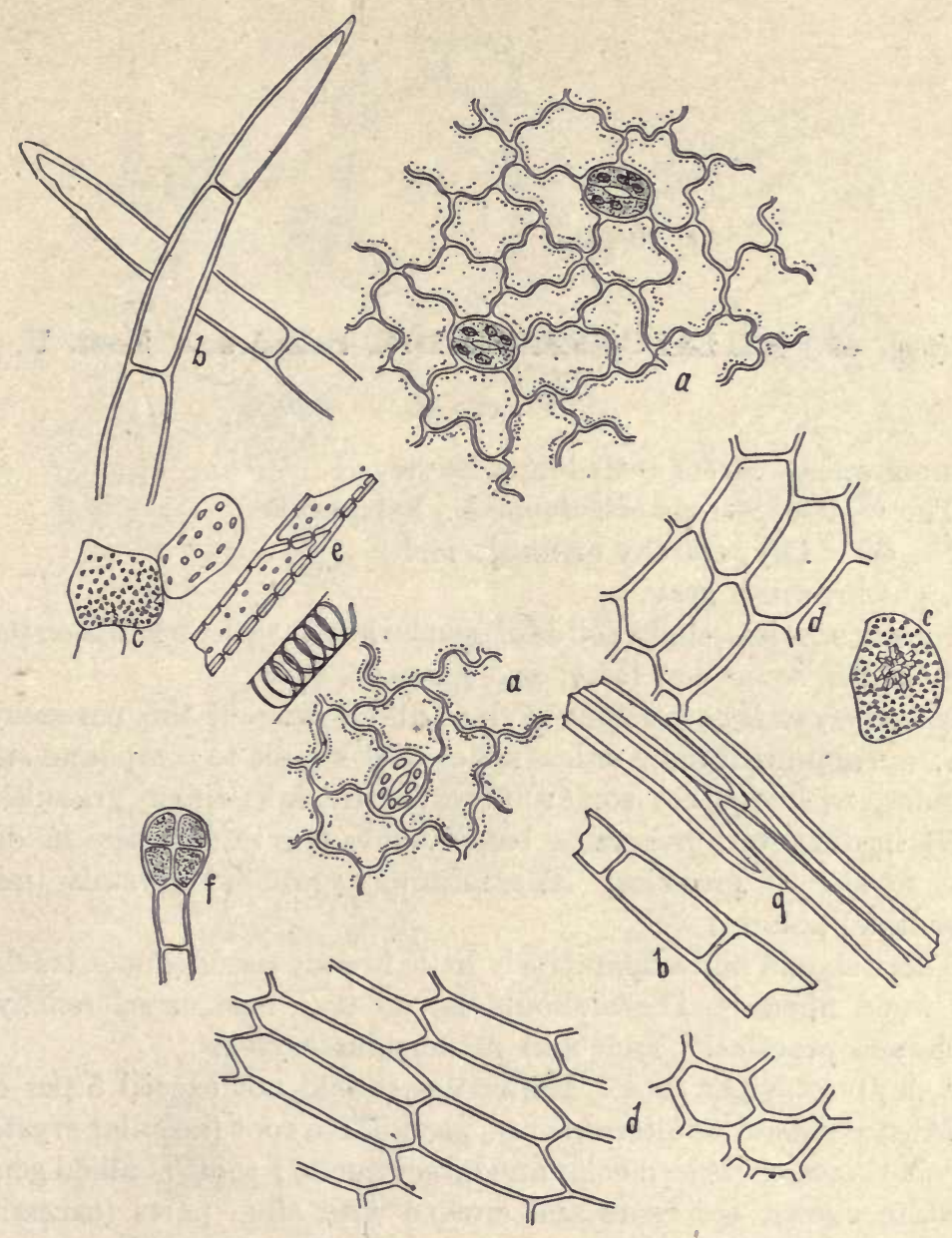

Fig. 45. BELLADONNA. Leaf.

a. Epidermal cells.

b. Trichomes.

c. Leaf parenchyma cells with crystals.

d. Parenchyma.

$e$. Tracheids and spiral duct.

$f$. Glandular trichome.

g. Bast cells. 
27. (Fig. 46.) BELLADONNAE RADIX. Belladonna Root. U. S. Fl. ex. 40.

Common names as for belladonna leaves. .

The roots of Atropa belladonna L., Solanaceae.

No. 60. Dry, starchy or mealy feel.

Light brownish gray.

Nearly odorless, slight soil odor, somewhat narcotic when moistened.

Sweetish, somewhat bitter and pungent.

Micro-crystalline calcium oxalate filling some of the parenchyma cells; and abundant more or less spheroidal, simple to compound starch granules, with distinct somewhat excentric hili; single granules $6 \mu$ to $17 \mu$ in diameter; polarizing bands increasing in clearness in direct ratio to size of granules. The minute pyramidal crystals (microcrystalline) polarize well.

There should be comparatively little fibrous tissue (ducts, tracheids and wood fibers). There should be no true bast or sclerenchyma. Trichomes practically none and no acicular crystals.

Ash about 8 per cent. Impurities should not exceed 5 per cent.

Most common adulterants are, phytolacca root (acicular crystals); scopola rhizomes (brown color and larger ducts); roots of allied genera; of white clover, old roots and crowns with stem parts (excessively fibrous). Roots gathered too early are deficient in starch. 

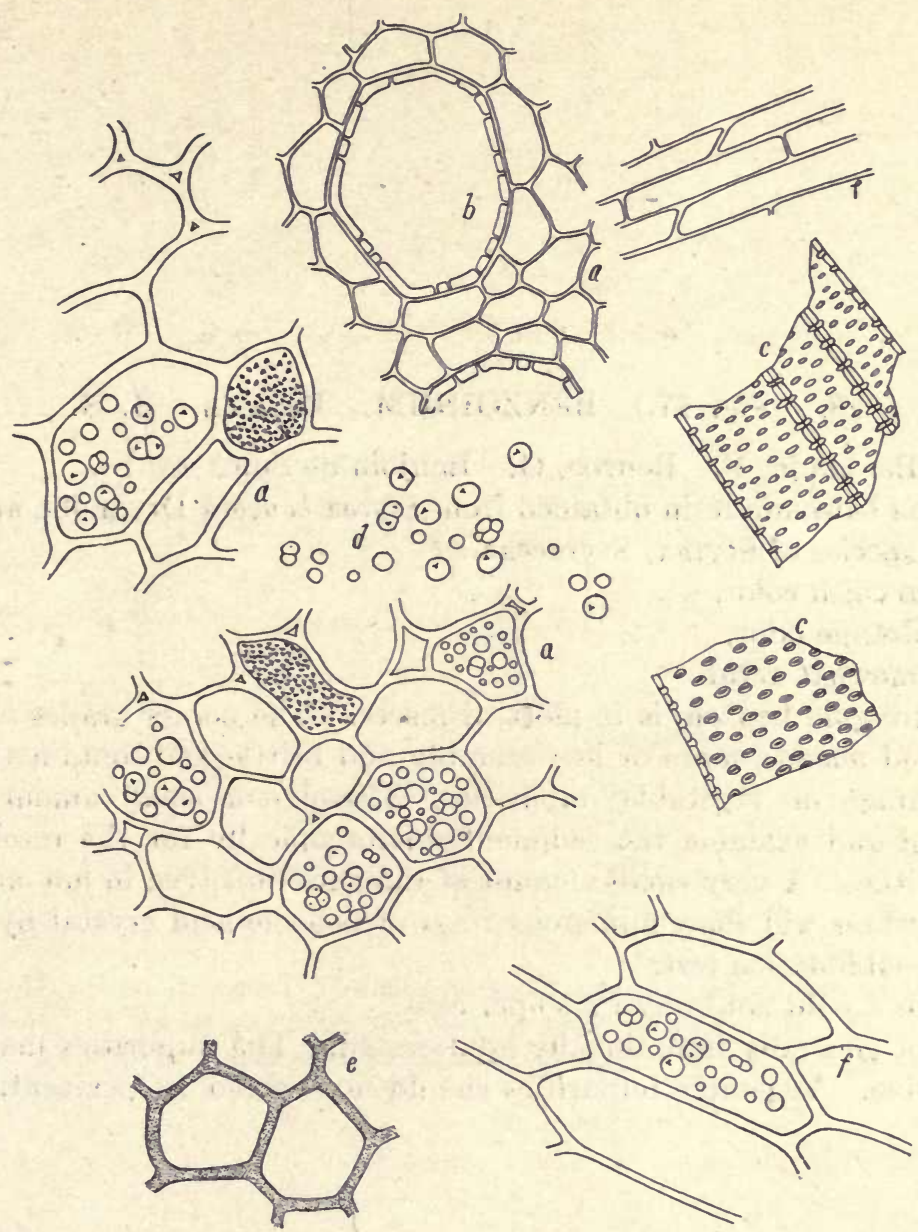

Fig. 46. BELLADONNA. Root.

a. Parenchyma with starch and crystal sand.

b. Duct, end view.

c. Porous ducts.

d. Starch granules.

e. Cork cells.

f. Parenchyma, longitudinal view. 
28. (Fig. 47.) BENZOINUM. Benzoin. U. S.

Gum Benjamin, E. Benzoe, G. Benjoin de Sumatra, Fr.

The balsamic resin obtained from Styrax benzoin Dryander, and of other species of Styrax, Styraceae.

Brownish color.

Balsamic odor.

Somewhat acrid.

Pure gum benzoin is in mottled pieces. The poorer grades are in marbled masses, more or less crumbly and brittle and contain a high percentage of vegetable impurities. Dissolve a small amount in alcohol and examine the sediment microscopically for the insoluble impurities. A very small amount of the gum dissolved in hot acidulated water will show numerous rings of benzoic acid crystal by the micro-sublimation test.

Ash should not exceed 2.50,per cent.

Not generally intentionally adulterated. The impurities may be excessive. Vegetable impurities should not exceed 10 per cent. 


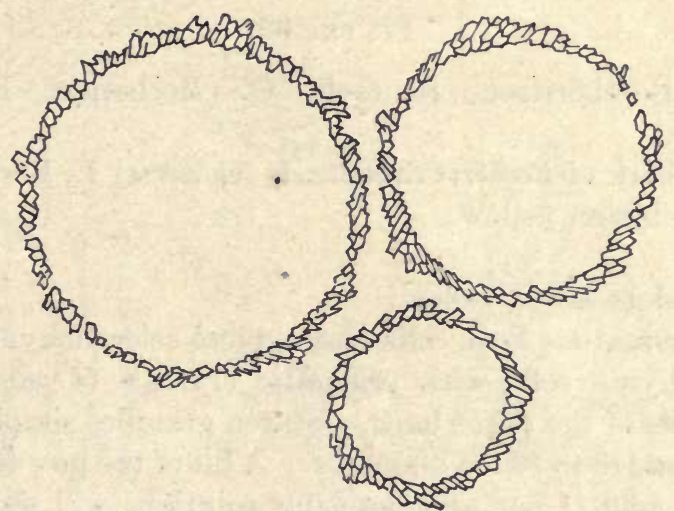

Fig. 47. Gum Benzoin. The characteristic arrangement of the crystals of benzoic acid by the micro-sublimation test, as described in Part I. The crystal rings are never as close together as indicated in the figure. The test is very marked in the presence of $1-1,000$ of the acid. 


\section{9. (Fig. 48.) BERBERIS. Barberry.}

Fl. ex. 60 .

Sauerdorn, Bereberitzen, Saurach, G. Berberide, Epine-vinette, Vinettier, Fr.

The root bark of Berberis canadensis (vulgaris) L, Berberidaceae.

Brownish lemon yellow.

Odorless.

Bitter; colors saliva yellow.

Sclerenchymatous bast cells and typical sclerenchyma; numerous bark parenchyma cells with prismatic crystals of calcium oxalate. Suberized cells of the outer bark. Starch granules simple and two to three compound, 3 to $10 \mu$ in diameter. A bit of the powder mounted in dilute nitric acid ( 1 per cent. aqueous solution) will show clusters of acicular crystals of berberine.

Ash 3 per cent.

Related species of Berberis are substituted for the Canadian barberry. Likely to be attacked by insect parasites and the container should be kept closed with a little chloroform added from time to time. 


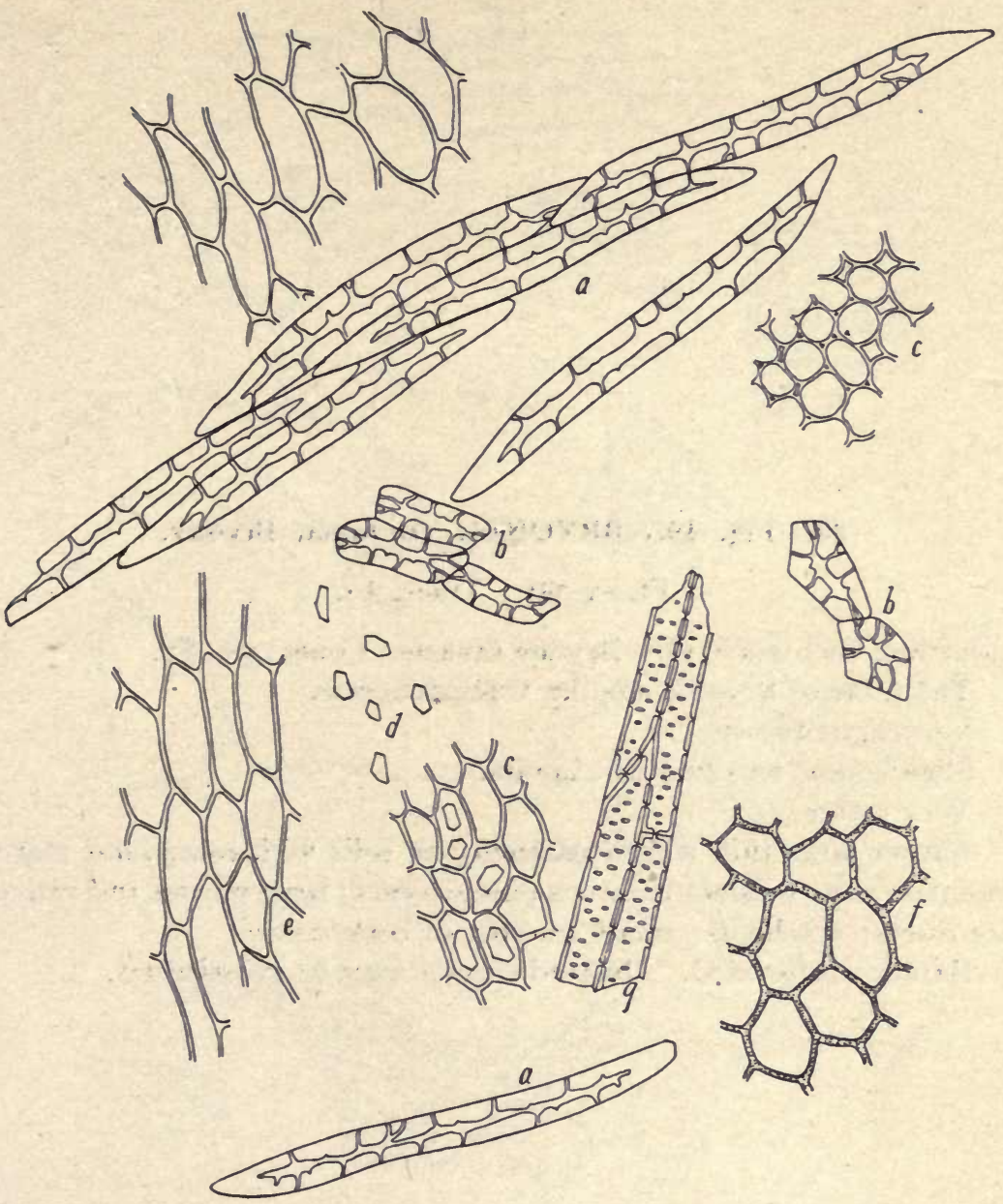

Fig. 48. BERBERIS.

a. Sclerenchymatous bast cells.

b. Sclerenchyma.

c. Parenchyma.

d. Prismatic crystals.

e. Parenchyma, longitudinal view.

$f$. Outer cork cells. 
30. (Fig. 49.) BRYONIA. Bryonia, Bryony.

Fl. ex. 60. Tinct. 40 .

Zaunrübe, Gichtrübe, G. Bryone blanche, Coulevree, Fr.

The roots of Bryonia alba L., Cucurbitaceae.

Very light brown.

Slight odor, recalling taraxacum.

Very bitter.

Rather large thin walled parenchyma cells with compound starch granules; some collenchymatous parenchyma; large porous and reticulate ducts; tracheids; small amount of cork tissue.

Rarely adulterated. Related species may be substituted. 


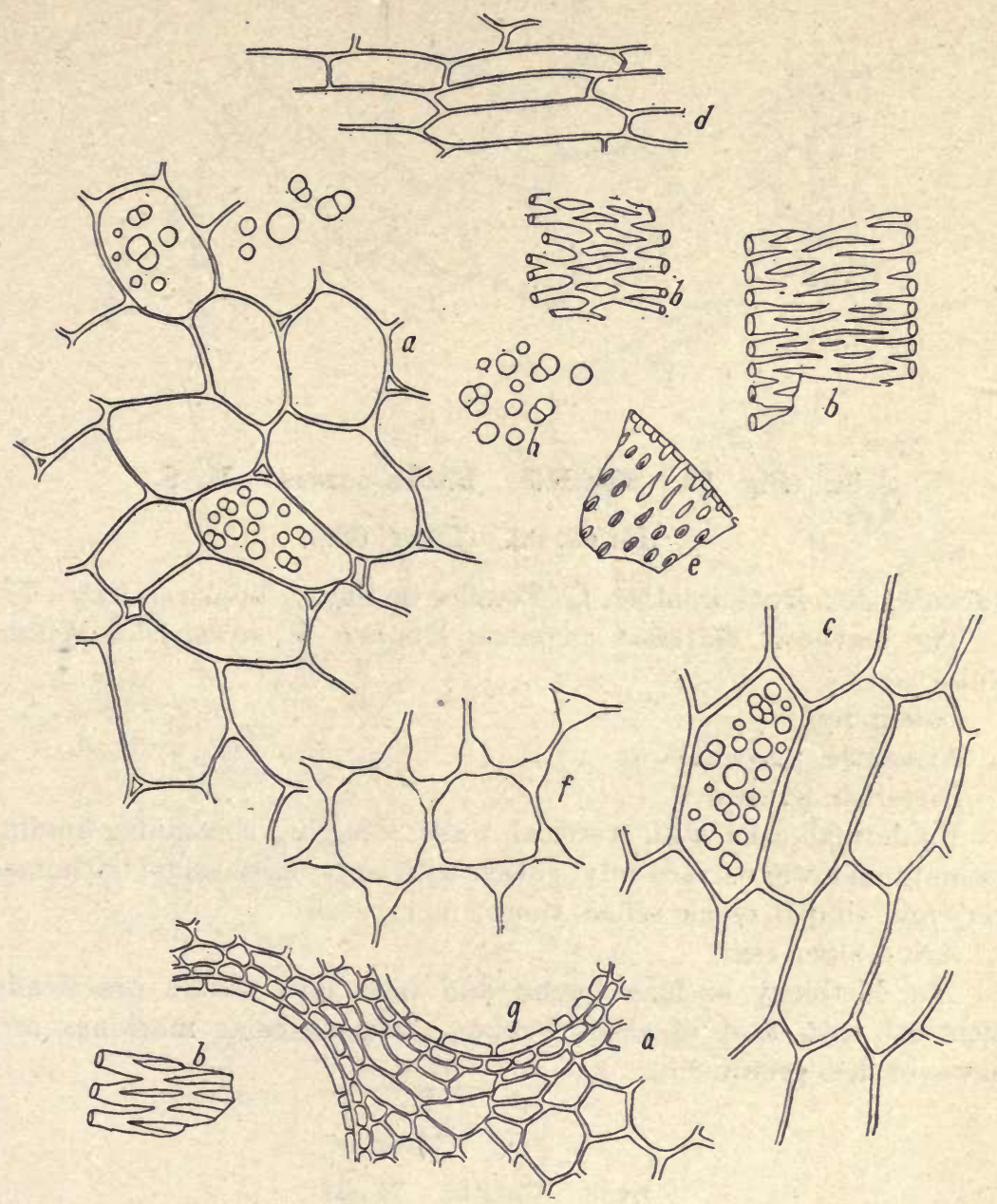

Fig. 49. BRYONIA ALBA.

a. Parenchyma with starch.

b. Reticulate ducts.

c. Parenchyma, longitudinal view.

d. Parenchyma.

e. Porous duct.

$f$. Collenchymatous tissue.

g. Duct, transverse view.

$h$. Starch granules. 
31. (Fig. 50.) BUCHU. Buchu leaves. U. S. Fl. ex. 60 . Tinct. 60 .

Buccoblätter, Buckublätter, G. Feuilles de bucco (booko, buchu), Fr.

The leaves of Barosma crenulata Hooker, B. serratifolia Willd., Rutaceae.

Pale green:

Aromatic, mint-like.

Bitterish, pungent.

Epidermal cells with vertical walls straight, containing inulin; stomata on lower surface only; cuticle with warty elevations; trichomes very few, simple, single celled, short; no crystals.

Ash 4.5 per cent.

The histology of long buchu and false long buchu practically identical with that of short buchu. The cuticular markings are, however, less prominent. 


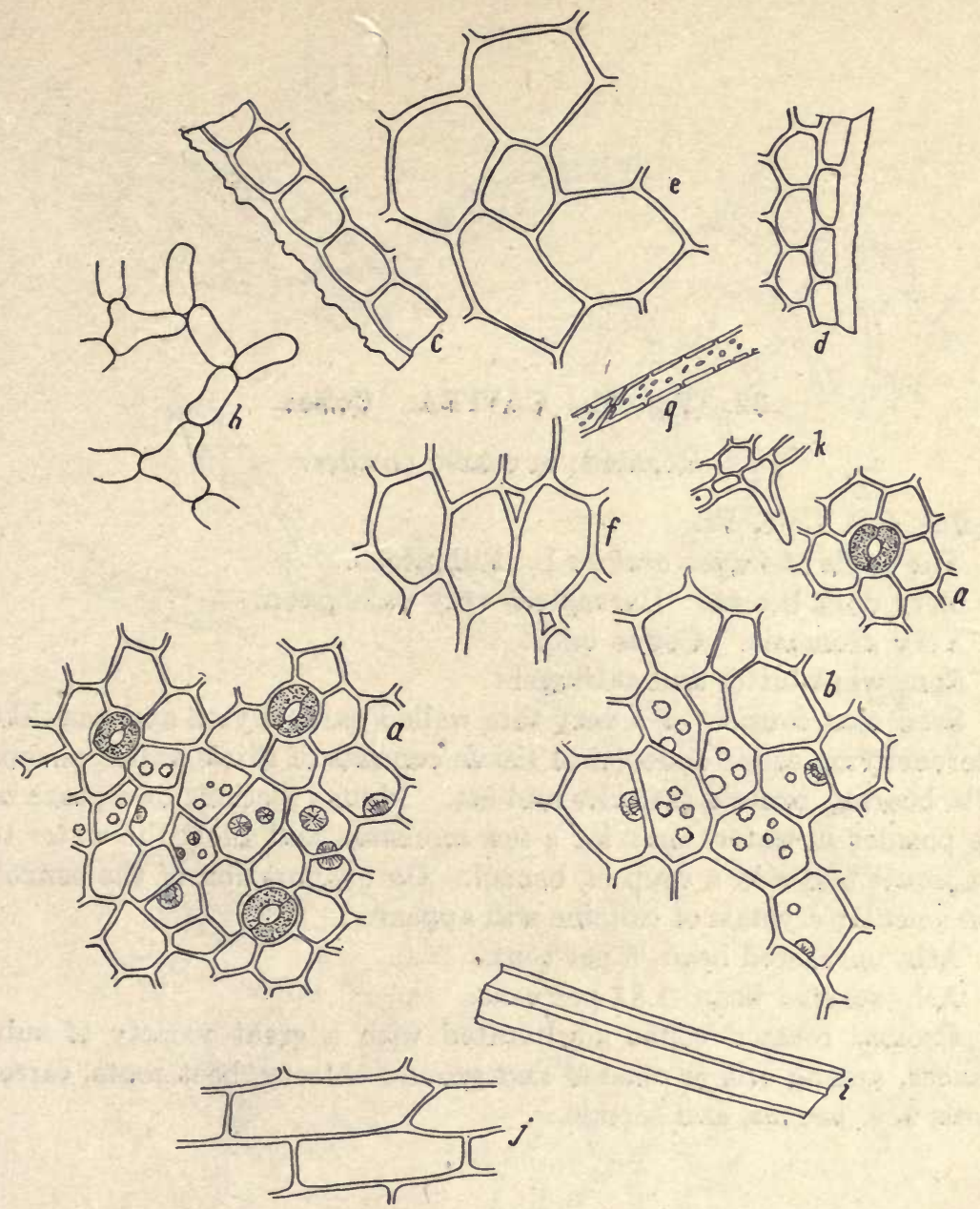

Fig. 50. BUCHU. Short.

a. Lower epidermis.

b. Upper epidermis.

c. Lower epidermis, lateral view.

d. Upper epidermis, lateral view.

$e, f$. Parenchyma.

g. Tracheids.

$h$. Spongy tissue cells.

$i$. Bast cells.

j. Parenchyma, longitudinal view.

$k$. Trichome. 
32. (Fig. 51.) CAFFEA. Coffee.

Roasted; in coarse powder.

Kaffee, G. Café, Fr.

The seeds of Caffea arabica $\mathrm{L}$., Rubiaceae.

Very dark brown. Unroasted, very pale green.

Very aromatic. Coffee odor.

Somewhat bitter and astringent.

Seed coat consists of a very thin walled parenchyma and bast like sclerenchyma cells; endosperm tissue consists of thick walled porous cells bearing proteid granules and fat. Mount sections or a pinch of the powder in water, heat for a few moments and allow the water to evaporate and add a drop of benzol. On evaporation of the benzol, fine acicular crystals of caffeine will appear.

Ash, unroasted bean, 5 per cent.

Ash, roasted bean, 1.81 per cent.

Ground roasted coffee adulterated with a great variety of substances, among others roasted and ground chicory, beet roots, carrot roots, figs, prunes, and cereals. 

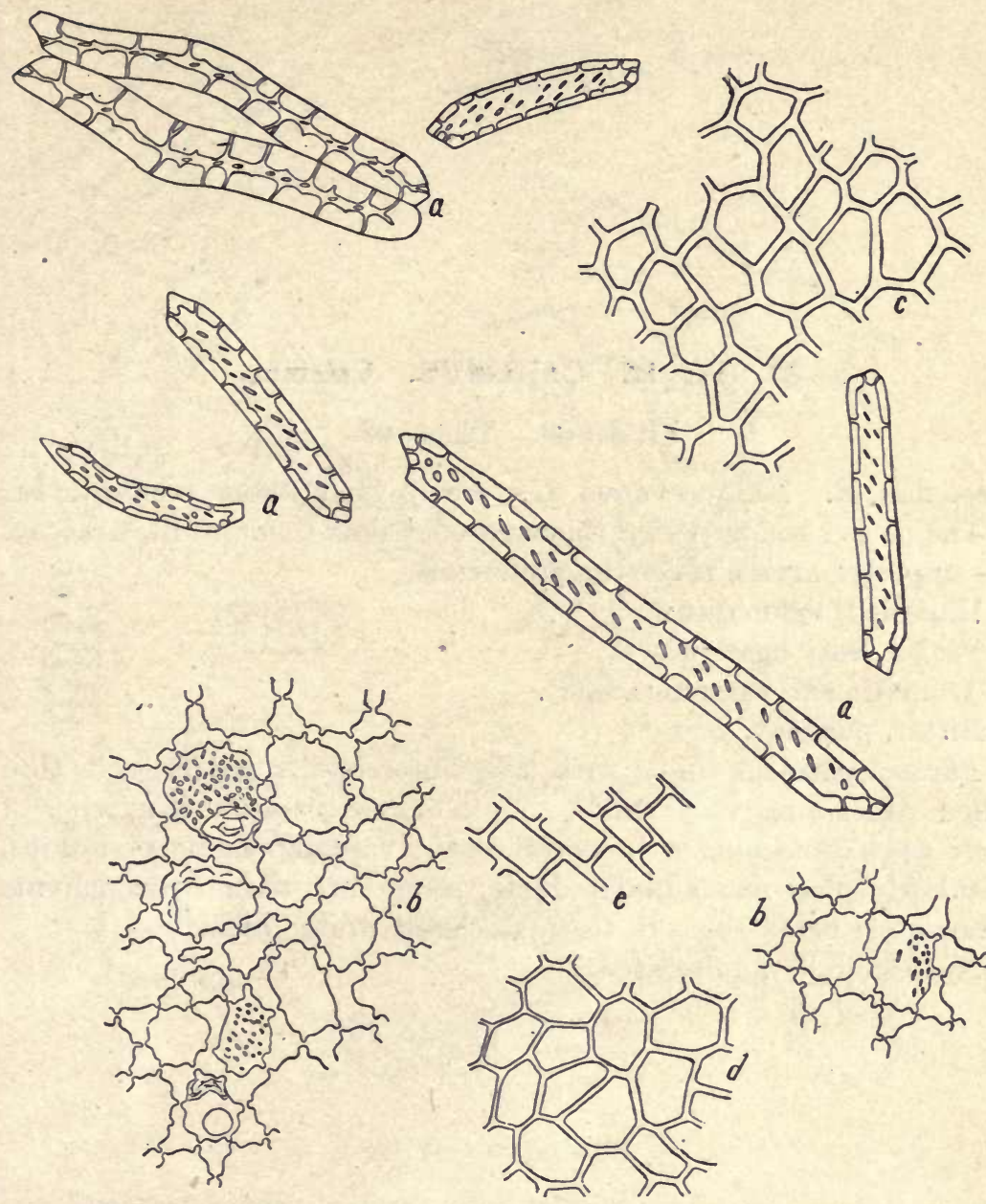

Fig. 51. CAFFEA.

a. Sclerenchyma cells of testa.

$b$. Endosperm cells with fat and minute starch granules.

$c, d, e$. Outer tissue cells. 


\section{3. (Fig. 52.) CALAMUS. Calamus.}

Fl. ex. 60 . Tinct. 60 .

Sweet flag, E. Kalmuswurzel, G. Acore vrai, Acore odorant, Fr. The peeled and unpeeled rhizomes of Acorus Calamus L., Araceae. The unpeeled article takes the preference.

Unpeeled, light brown.

Peeled, very light brown.

Aromatic and camphoraceous.

Bitter, pungent.

Parenchymatous tissue with large intercellular spaces, cells thin walled containing very small, simple starch granules; a number of larger cells containing a brownish resin; vascular tissue of porous, reticulate, spiral and annular ducts; some cork tissue; parenchyma immediately below the cork tissue of closely united cells.

Not generally adulterated. 


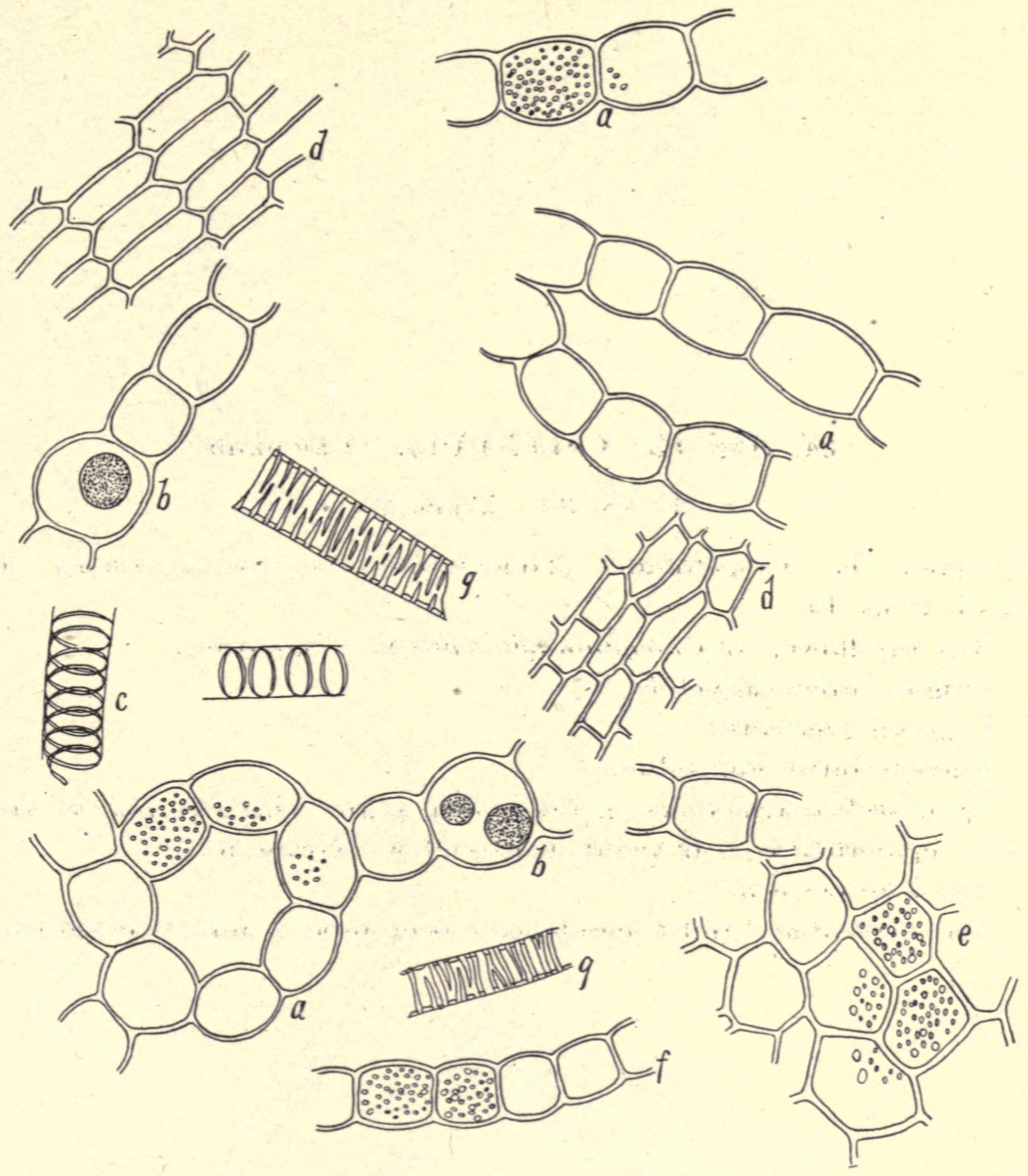

Fig. 52. CALAMUS.

a. Parenchyma with minute starch granules.

$b$. Oil and resin bearing cells.

c. Spiral duct.

d. Outer parenchyma and epidermis.

$e$. Parenchyma from near periphery.

$f$. Parenchyma as $a$.

g. Reticulate ducts. 


\section{4. (Fig. 53.) CALENDULA. Calendula.}

Fl. ex. 30. Tinct. 20 .

Marigold, E. Ringelblume, Todenblume, G. Souci, Fleurs de tous le mois, Fr.

The ray flowers of Calendula officinalis L., Compositæ.

Bright, brownish yellow.

Fragrant; narcotic.

Slightly bitter and saline.

Many-celled trichomes; a few pollen grains characteristic of the order; epidermal cells of petals with yellow coloring matter.

Ash 5.40 per cent.

The colored and rolled petals have been used as imitation saffron. 


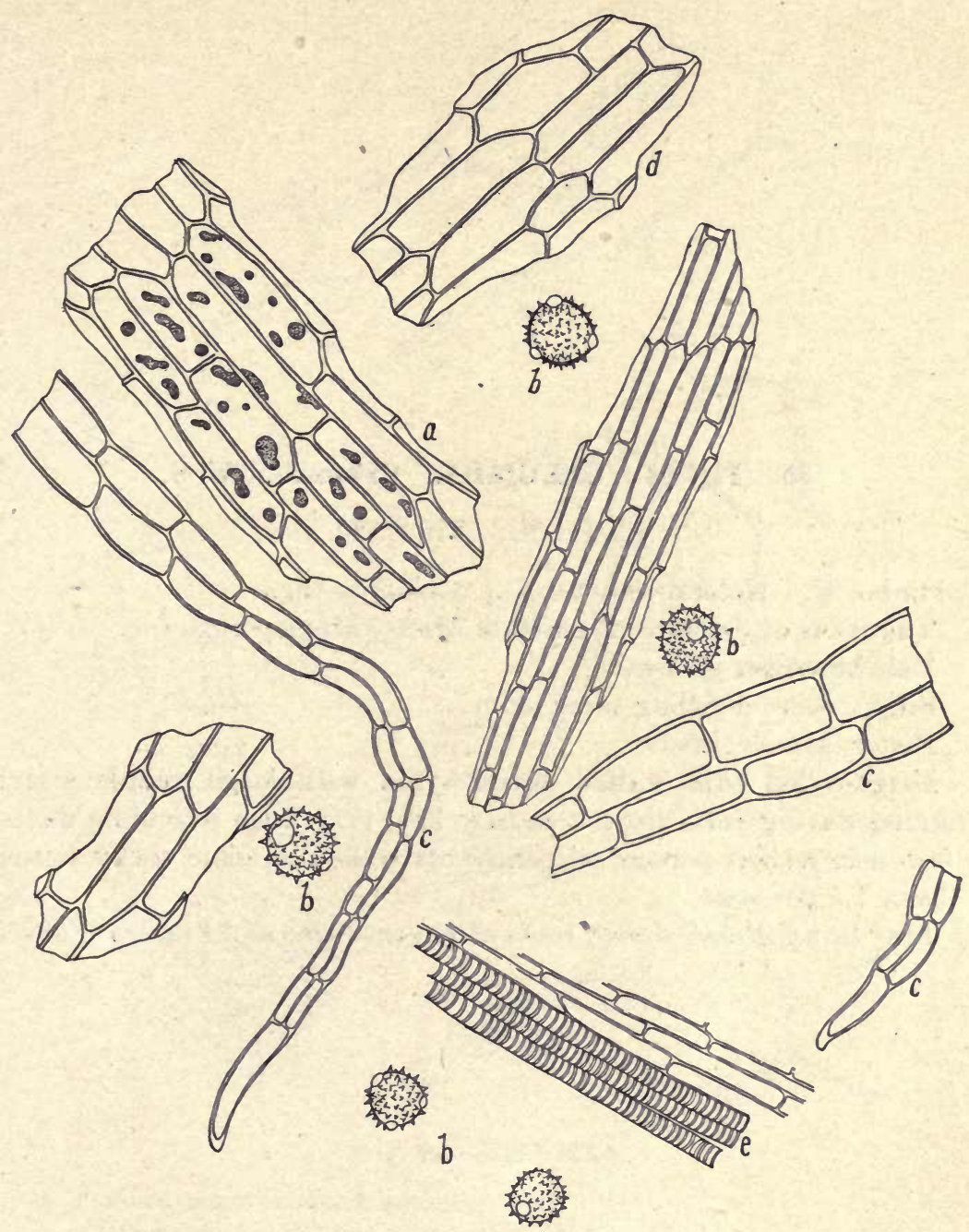

Fig. 53. CALENDULA.

a. Epidermal cells of petal with yellow coloring bodies.

$b$. Pollen grains.

c. Trichomes.

d. Parenchyma.

e. Ducts. 
35. (Fig. 54.) CALUMBA. Calumba. U. S.

Fl. ex. 20. Tinct. 20 .

Columbo, E. Kolombowurzel, G. Colombo, Fr.

The roots of Jateorrhiza palmata Miers, Menispermaceae.

Pale brownish yellow.

Slight odor, recalling taraxacum.

Bitter, mucilaginous.

Large-celled thin walled parenchyma with large simple starch granules having very distinct radiate hili; very large reticulate ducts; a few thin walled porous sclerenchyma cells and some corky tissue. Ash 7.5 per cent.

May be adulterated with roots of Bryonia alba and Frasera Walteri. 


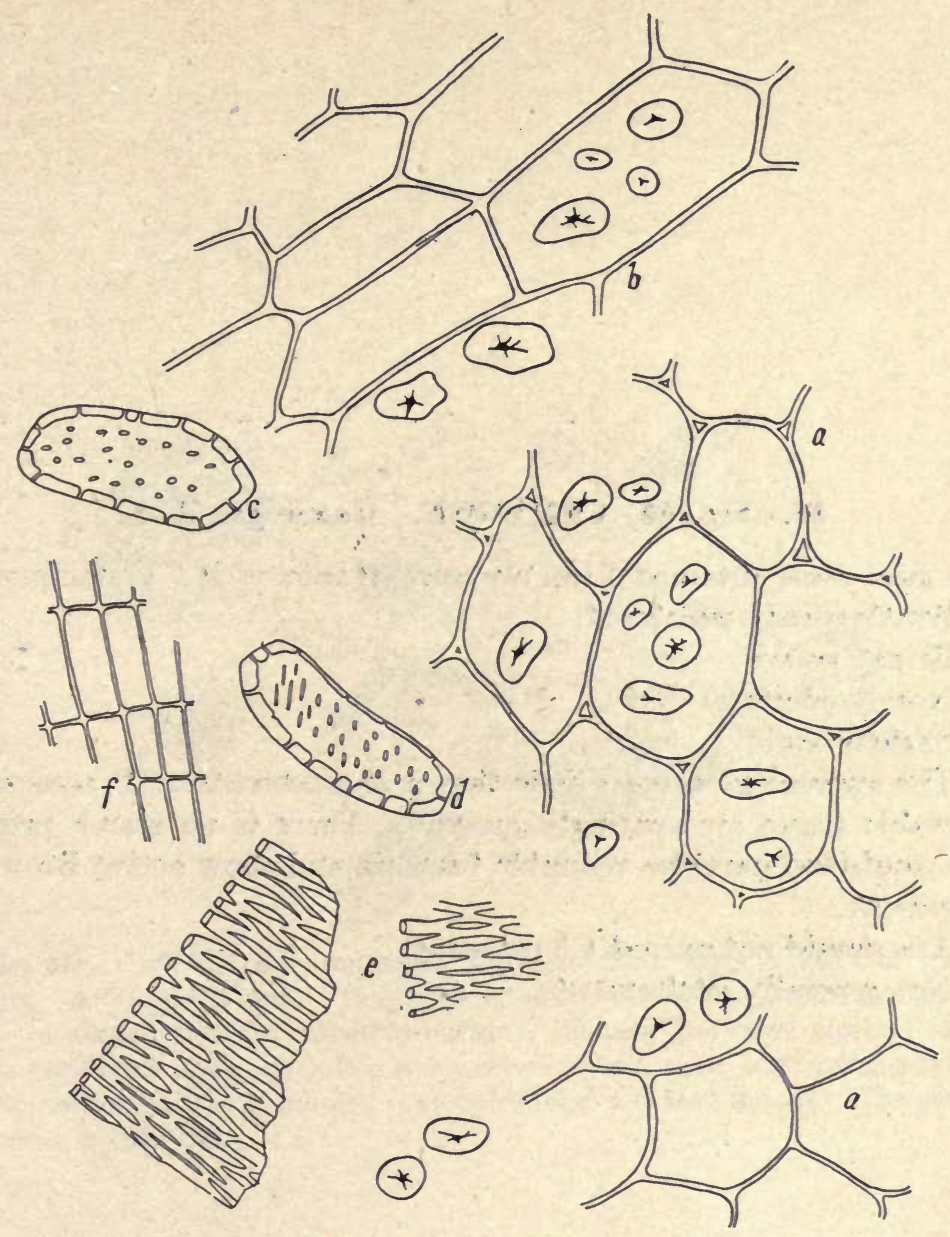

Fig. 54. CALUMBA.

a. Parenchyma with starch granules.

b. Parenchyma, longitudinal view.

$c, d$. Sclerenchyma cells.

$e$. Reticulate ducts.

f. Cork cells, lateral view. 
36. (Fig. 55) CAMBOGE. Gamboge. U. S.

The gum resin obtained from Garcinia Hanburii H., Guttiferae.

Brittle, easily powdered.

Bright yellow.

Nearly odorless.

Slightly acrid.

The microscope reveals little that is characteristic. Fragments of vegetable tissue are sparingly present. There is no starch present. The emulsified particles resemble bacteria and show active Brownian movement.

Ash should not exceed 1.5 per cent.

Not generally adulterated. 


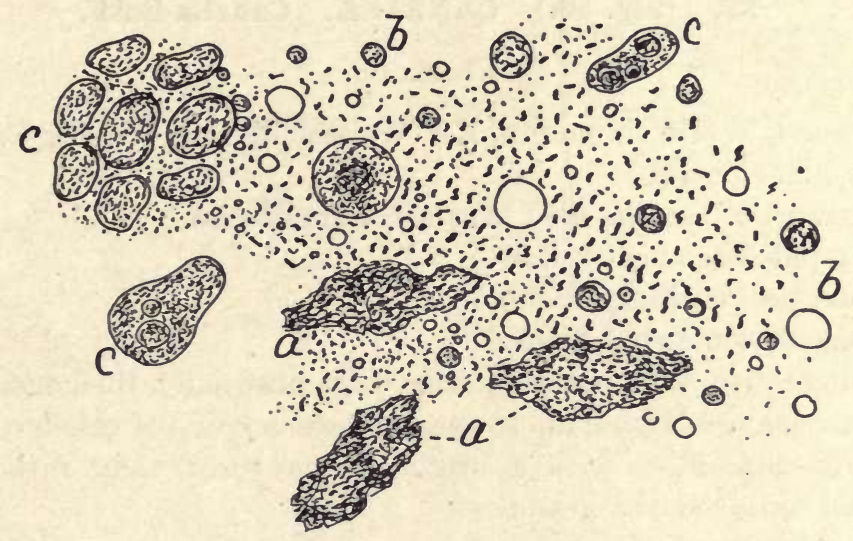

Fig. 55. CAMBOGE. Gamboge. Characteristic appearance of water mounts. $a$, bits of the gum. They appear to be made up of agglutinated bacteria; $b$, the emulsified particles resemble bacteria, showing Brownian motion, among which are found larger globules, some colorless and some containing adsorbed minute particles of the gamboge; $c$, globules from a heated mount. The general color tone is yellowish. 


\section{7. (Fig. 56.) CANELLA. Canella Bark.}

Fl. ex. 60 .

White wood, White cinnamon, E. Weisser Zimmt, Weisser Canel, G. Canelle blanche, Fr.

The bark of Canella alba Murray, Canellaceae.

Very pale brownish yellow.

Aromatic, recalling cinnamon.

Pungent, somewhat bitter.

Isodiametric sclerenchyma cells with unequally thickened walls; bark parenchyma with numerous aggregate crystals of calcium oxalate and large cells filled with a bright yellow resin; some rather small spherical simple starch granules.

Ash 6 per cent.

Not generally adulterated. Winter's bark may be substituted for it. 


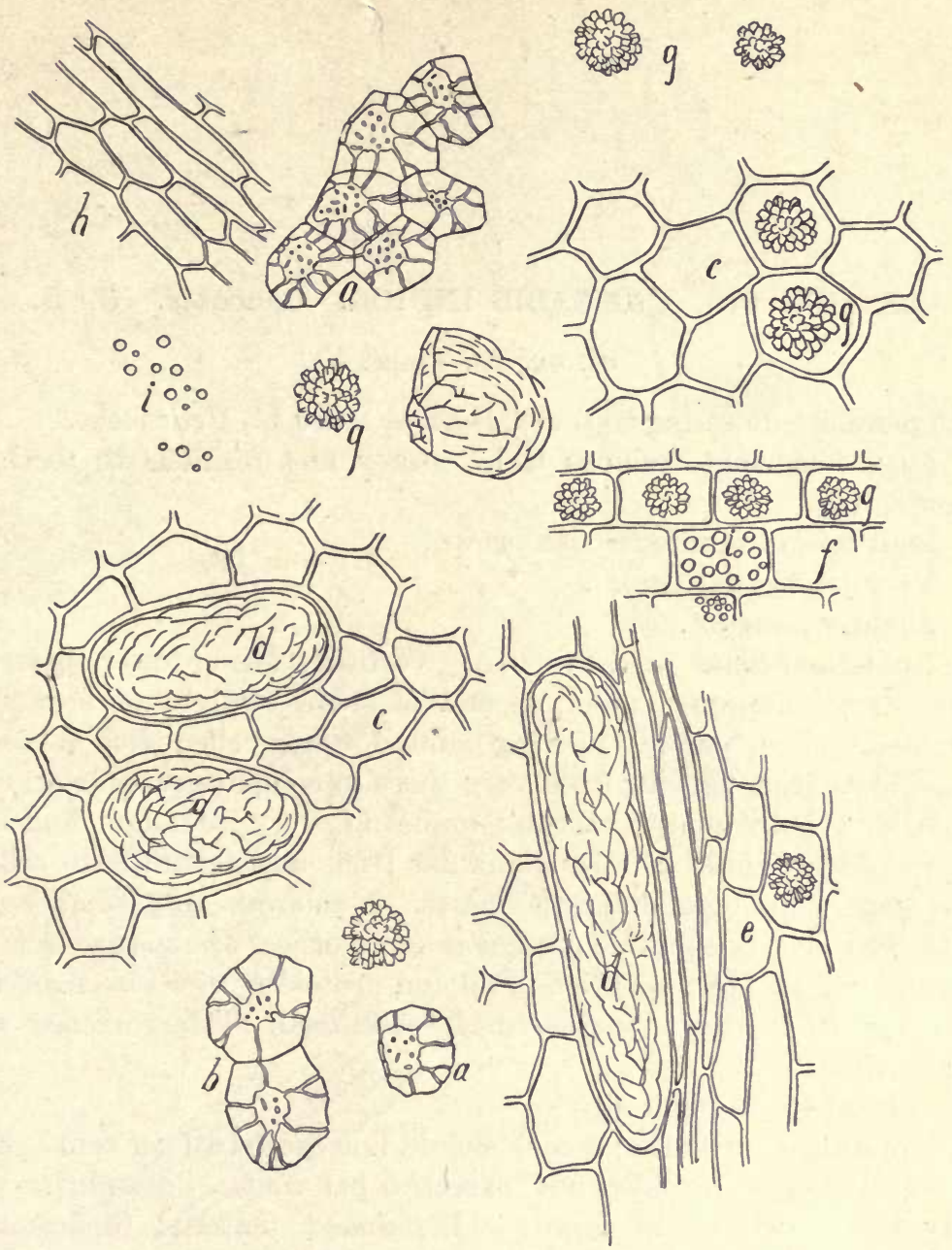

Fig. 56. CANELLA.

$a$. Sclerenchyma cells, walls unequally thickened.

b. Typical sclerenchyma.

c. Parenchyma.

$d$. Resin bearing cells.

e. Parenchyma, longitudinal view.

f. Parenchyma with starch granules and crystals.

g. Aggregate crystals of calcium oxalate.

h. Parenchyma.

i. Starch granules. 


\section{8. (Fig. 57.) CANNABIS INDICA. Cannabis. U. S.}

Fl. ex. 20. Tinct. 40

The pistillate flowering tops of Cannabis sativa L., Urticaceae.

Dry, somewhat resinous feel. Sticky and resinous to teeth on masticating.

Dull green to dull greenish brown.

Very heavy, narcotic.

Slightly pungent.

Epidermal tissue predominates. Vertical walls of lower epidermal cells wavy, of upper epidermis and of stems straight or nearly so; abundant, rigid, curved, tapering pointed, single-celled trichomes with basal cystoliths, varying from very short to comparatively long; resin particles are abundant; vascular tissue not very abundant and noncharacteristic; multi-cellular glandular trichomes (gland 8-16 celled), also some simple glandular trichomes. Numerous very small aggregate crystals. Seed tissue present in more or less abundance (sclerenchyma, endosperm tissue rich in oil and proteid granules). American and Indian hemps are structurally identical. Effervescence with dilute $\mathrm{HCl}$.

Ash 10 to 20 per cent.

Impurities (including seeds) should not exceed 10 per cent. Seed often excessive (should not exceed 5 per cent.). Staminate tops may be added (pollen grains). Exhausted material (deficient in resin, more brown in color) may be used. Excess of stems may be suspected. 


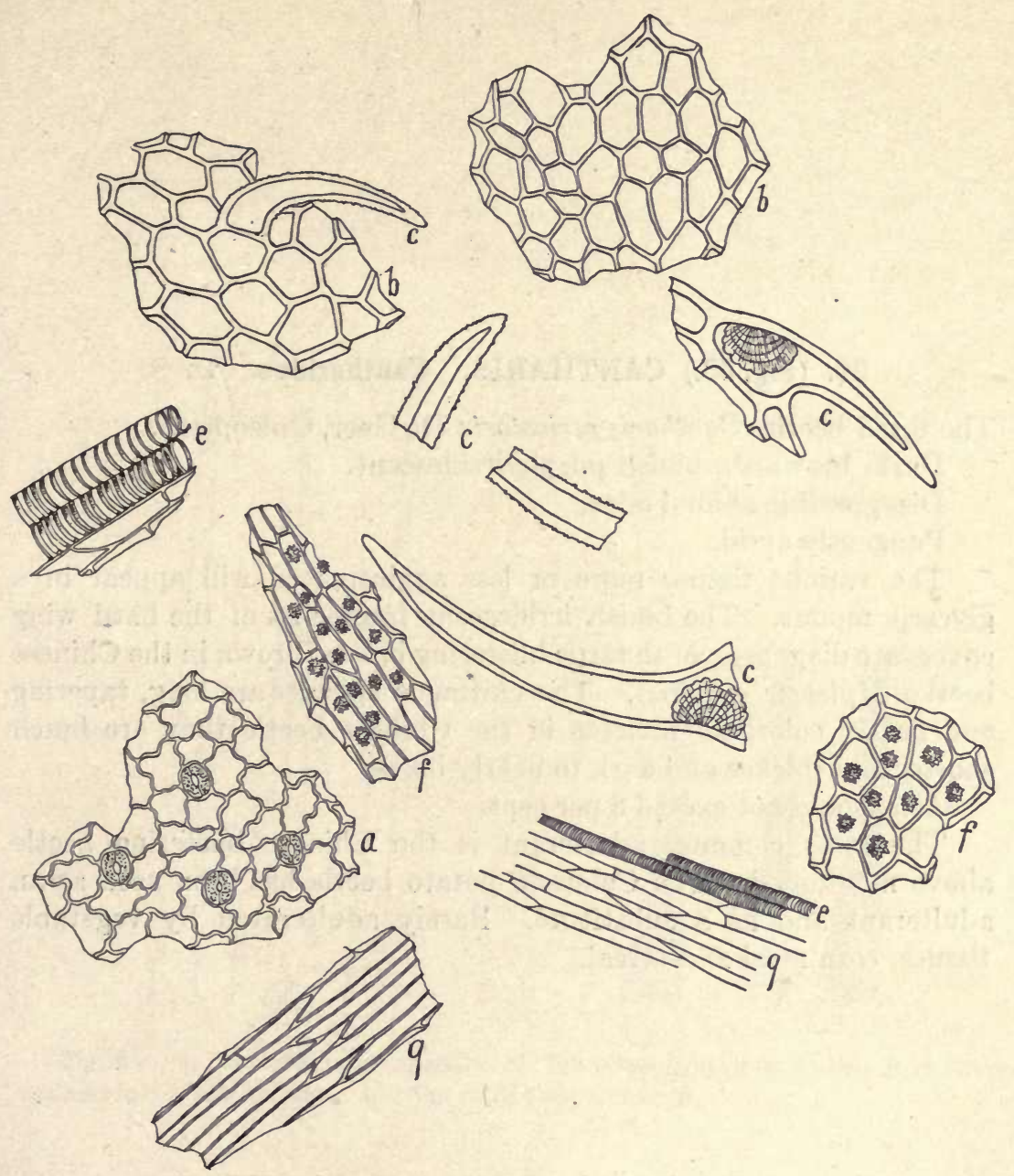

Fig. 57. CANNABIS INDICA.

a. Lower epidermis of leaves.

b. Upper epidermis of leaves.

c. Trichomes with cystoliths.

e. Spiral ducts.

f. Parenchyma with minute aggregate crystals.

g. Phlœm tissue. 
39. (Fig. 58.) CANTHARIS. Cantharides. U. S.

The dried beetles Cantharis vesicatoria De Geer, Goleoptera.

Dark, brownish, bluish purple irridescent.

Disagreeable animal odor.

Pungently acrid.

The various tissues more or less agglutinated will appear in a glycerin mount. The bluish irridescent fragments of the hard wing covers are diagnostic of the true blistering beetle (brown in the Chinese beetle, Mylabris cichorii). The chitinous spicules are long, tapering and nearly colorless, whereas in the Chinese beetle they are much shorter and thicker and dark to nearly black.

Ash should not exceed 8 per cent.

The most common adulterant is the Chinese blistering beetle above mentioned. The Colorado potato beetle has been used as an adulterant and as a substitute. Rarely adulterated by vegetable tissues, corn meal and cereal. 


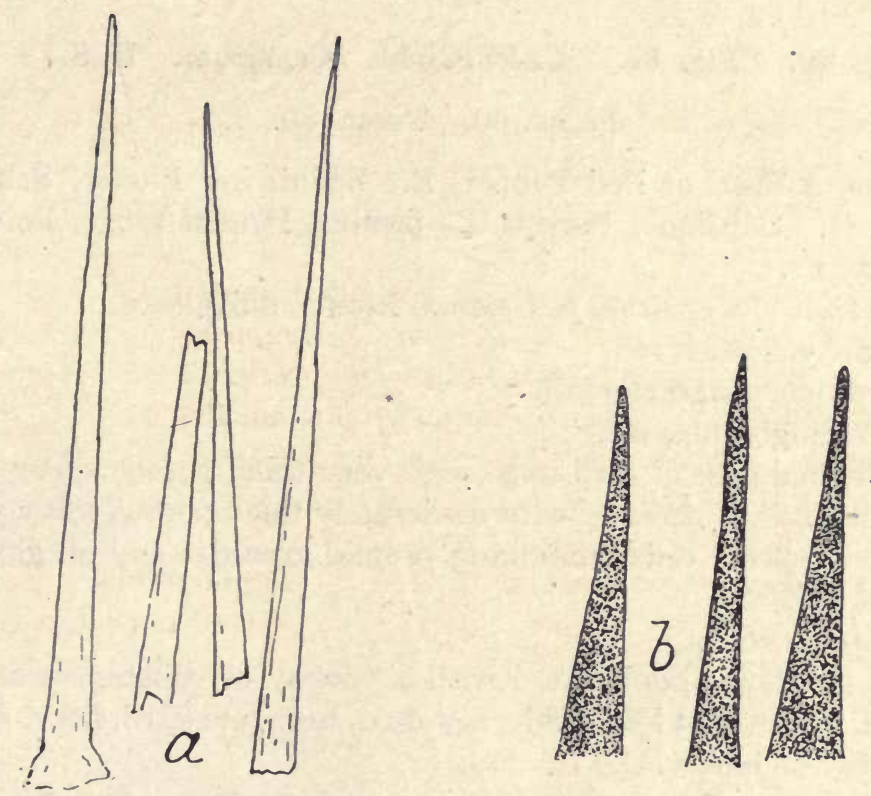

Fig. 58. $a$, the chitinous spicules of the true blistering beetle (Cantharis vesicatoria); $b$, the chitinous spicules of Mylabris cichorii. 
40. (Fig. 59.) CAPSICUM. Capsicum. U.S.

Fl. ex. 60. Tinct. 30 .

Cayenne, African or Pod Pepper, E. Spanischer Pfeffer, Schlotenpfeffer, G. Capsique, Piment des jardins, Piment rouge, Poivre de Cayenne, Fr.

The fruit of Capsicum fastigiatum Blume, Solanaceæ.

Bright yellowish red.

Faint odor, characteristic.

Exceedingly pungent.

Epidermal cells of seed large with very thick porous wavy walls; epidermal cells of pericarp with moderately thick porous wavy yellow walls; endosperm cells containing proteid granules and oil globules, walls porous.

Ash 6 per cent.

The powder is adulterated with a variety of substances as fruit of allied species, red lead oxide, saw dust, bran, mustard, flour, starch, etc. May be moldy. 


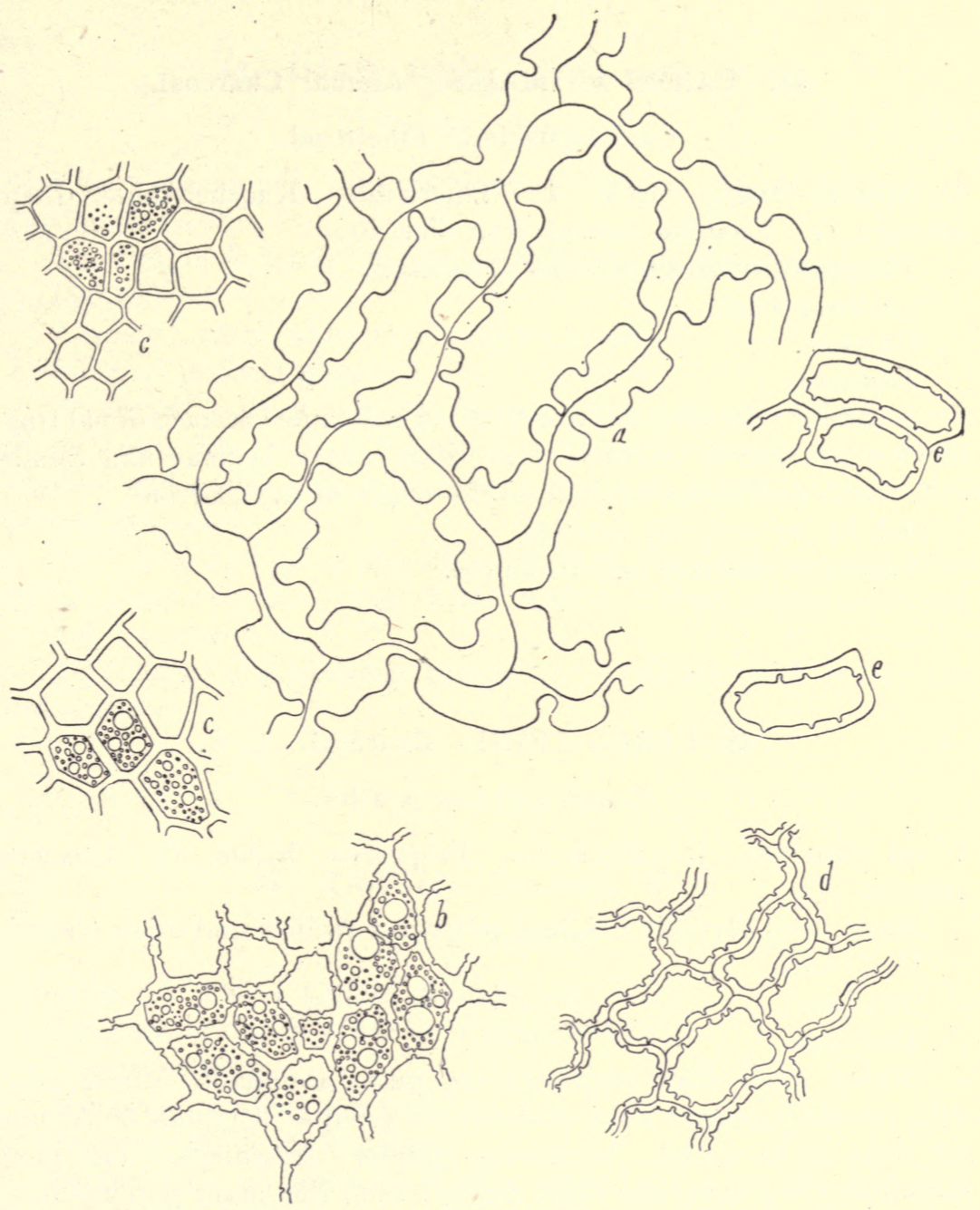

Fig. 59. CAPSICUM.

a. Epidermis of seed.

$b$. Endosperm cells with proteid granules and oil globules.

c. Peripheral endosperm.

d. Epidermal cells of pericarp.

$e$. Isolated epidermal cells. 


\section{CARBO ANIMALIS. Animal Charcoal.}

Coarse powder. Fine meal.

Bòneblack, Ivory black, E. Thierkohle, Knochenkohle, Beinschwarz, G. Charbon animal, Noir d'os, Fr.

The partially oxidized bones of animals.

Lustrous black.

Odorless.

Tasteless.

A careful microscopical examination will reveal an occasional fragment which shows traces of Haversian canals, lacunae and canaliculi, which unmistakably disclose the origin of the charcoal.

Ash 85 per cent., by ignition.

Vegetable charcoal may be added.

\section{CARBO LIGNI. Charcoal. U. S.}

Coarse and fine powder.

Wood charcoal, E. Holzkohle, Präparirte Kohle, G. Charbon végetble, Fr.

Made from partially oxidized soft wood (willow and other plants).

Dull black.

Odorless.

Tasteless.

Brown wood fiber remnants are quite abundant, intermingled with the black coarser more oxidized cell groups. Crystals of calcium are also to be found. Numerous splintery fragments. The most distinctive fragments are those derived from the larger porous ducts.

Ash should not exceed 3 per cent.

Not generally adulterated. It is difficult to determine the source of the wood from which the charcoal is made. 


\section{CARDAMOM. Cardamom. U. S.}

Fl. ex. 60 . Tinct. 30 .

Malabar cardamom, E. Cardamom, Kleine Kardamomen, G. Cardamomes, Fr.

The fruit of Elettaria Cardamomum W. et. M., Scitaminaceae.

Light brown.

Aromatic, spicy, somewhat comphoraceous.

Pungent, cooling sensation.

Epidermal cells of pericarp of polygonal cells; parenchyma cells of pericarp thin walled containing prismatic crystals of calcium oxalate; endosperm cells containing oil, minute starch granules and proteid granules.

Ceylon cardamom is distinguished from the Malabar cardamom by the presence in the former of thick walled, conical, simple trichomes.

Ash 7 per cent.

Adulterated with related species and varieties, with orange and lemon seeds.

\section{CARUM. Caraway. U. S.}

Entire; bruised.

Kümmel, G. Carvi, Cumin des prés, Fr.

The fruit of Carum Carvi L., Umbelliferae.

Greenish brown.

Aromatic, recalling coriander.

Pungent; bitterish, sweetish.

Parenchyma of pericarp of thin walled more or less collapsed yellowish cells. Endosperm cells contain fat and proteid granules; cell walls of endosperm cells are of uniform medium thickness, cells isodiametric, closely united. Vascular tissue very sparingly present. No trichomes or sclerenchyma. Yellowish resin particles or lumps.

Ash 7.5 per cent.

Not generally adulterated. May contain the fruits of other Umbelliferae. Should be free from Conium fruits. 


\section{CARTHAMUS. Safflower.}

Entire.

African, False, American, or Dyer's Saffron, E. Saflor, G. Carthame, Fr.

The florets (removed from receptacle or torus) of Carthamus tinctorius L., Compositæ.

Deep red.

Fragrant; faint odor of cured tobacco.

Somewhat bitter; saliva yellow.

Epidermal cells with red coloring matter soluble in water. Pollen grains quite large, exine with rather blunt conical projections and three very distinct pores.

Ash 5.5 per cent.

Much employed as an adulterant of and substitute for Crocus Sativus. Exhausted safflower may be found occasionally.

\section{6. (Fig. 60.) CARYOPHYLLUS. Cloves. U. S.}

Ground, rather coarse.

Gewürznelken, Nägelein, G. Girofle, Gérofle, Clous aromatiques, Fr.

The unexpanded flowers of Eugenia aromatica K., Myrtaceae.

Deep dark reddish brown.

Very aromatic; clove odor.

Very pungent, benumbing.

Pollen grains triangular mostly immature; very few, rather, short thick walled bast cells; outer parenchyma of closely united cells containing aggregate crystals of calcium oxalate; cuticle enormously thickened; inner parenchyma spongy. Numerous large glands containing oil and resin. No starch present but the parenchyma cells contain oil and small granules of tannin. A concentrated solution of potassium hydrate causes the precipitation of acicular and radiately aggregate crystals (eugenol reaction).

Ash 6.5 per cent.

Quite frequently adulterated; with clove stalks, mother cloves (clove fruit), exhausted cloves, roasted flour, etc. Accurate quantitative determinations (microanalytical) of the clove stem adulteration may be made by the methods given in Part I. This problem should be performed by the entire class. 

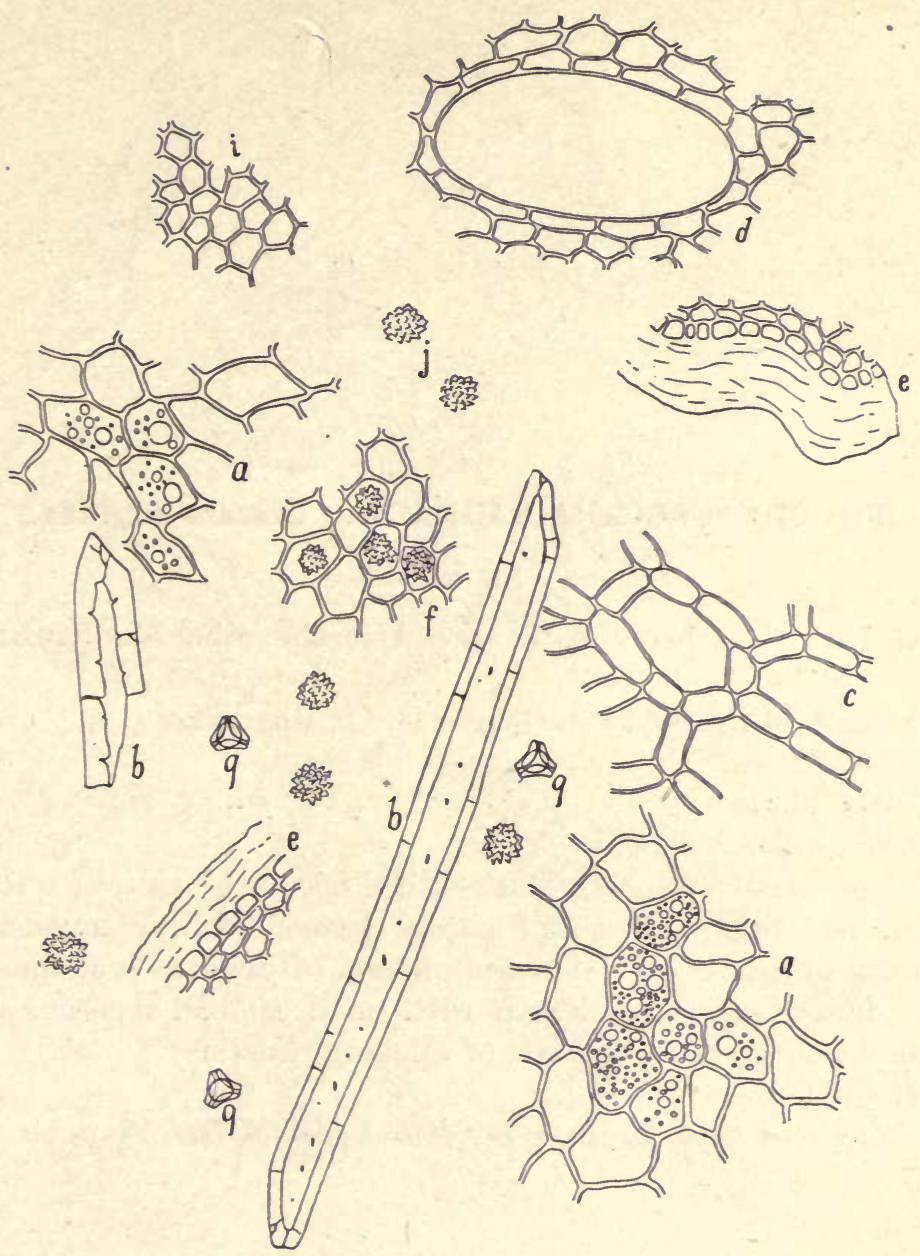

Fig. 60. CARYOPHYLLUS.

a. Parenchyma cells with oil and granules.

b. Bast cells.

"c. Inner spongy parenchyma.

$d$. Oil gland.

$e$. Epidermal tissue, lateral view.

f. Crystal bearing parenchyma.

g. Pollen grains.

$i$. Epidermal cells, vertical view.

$j$. Aggregate crystals of calcium oxalate. 
47. (Fig. 61.) CASCARA SAGRADA. Cascara Sagrada. U.S. Fl. ex. 40 .

Sacred bark, Bearberry bark, E. Amerikanische Faulbaumrinde, G.

The bark of Rhammus Purshiana D. C., Rhamnaceæ.

Yellow brown.

Nearly odorless.

Bitter; saliva yellow.

Numerous porous, mostly thick-walled sclerenchyma cells. Rather slender, but thick-walled and porous bast fibers, accompanied by numerous prismatic crystal-bearing fibers. Brown cells of the outer bark. Inner bark parenchyma, with small, simple, spherical starch granules and aggregate crystals of calcium oxalate.

Ash 5.8 per cent.

Adulterated with the bark of related species (see Frangula). 


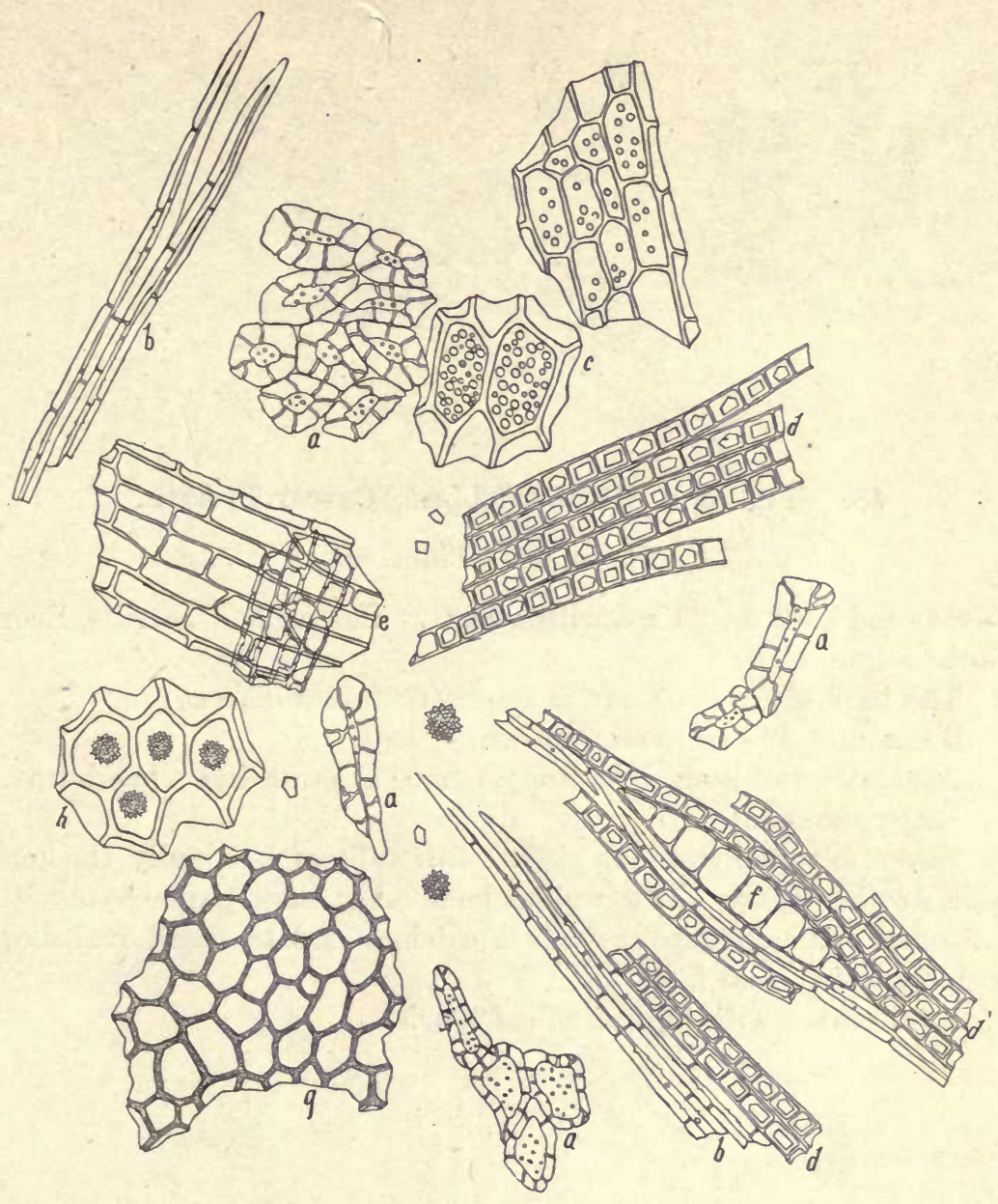

Fig. 61. CASCARA SAGRADA.

a. Sclerenchyma.

b. Bast.

c. Parenchyma with starch.

d. Crystal bearing fibers.

e. Parenchyma and medullary ray.

$f$. Medullary ray, tangential view.

g. Outer cork.

h. Parenchyma with aggregate crystals. 
48. (Fig. 62.) CASCARILLA. Cascarilla Bark.

Fl. ex. 60. Tinct. 60 .

Sweetwood bark, E. Kaskarillrinde, G. Cascarille, Chacrille, Ecorce éluthérienne, Fr.

The bark of Croton Eluteria Bennett, Euphorbiaceae.

Somewhat dull cinnamon brown.

Aromatic, recalling cinnamon; somewhat musk-like when burnt.

Bitter, pungent.

Outer sclerenchymatous tissue with cells of unequally thickened walls; rather short, thick walled bast cells; bark parenchyma with prismatic and aggregate crystals of calcium oxalate, small oval simple starch granules and fat.

Adulterated with bark of allied species. 


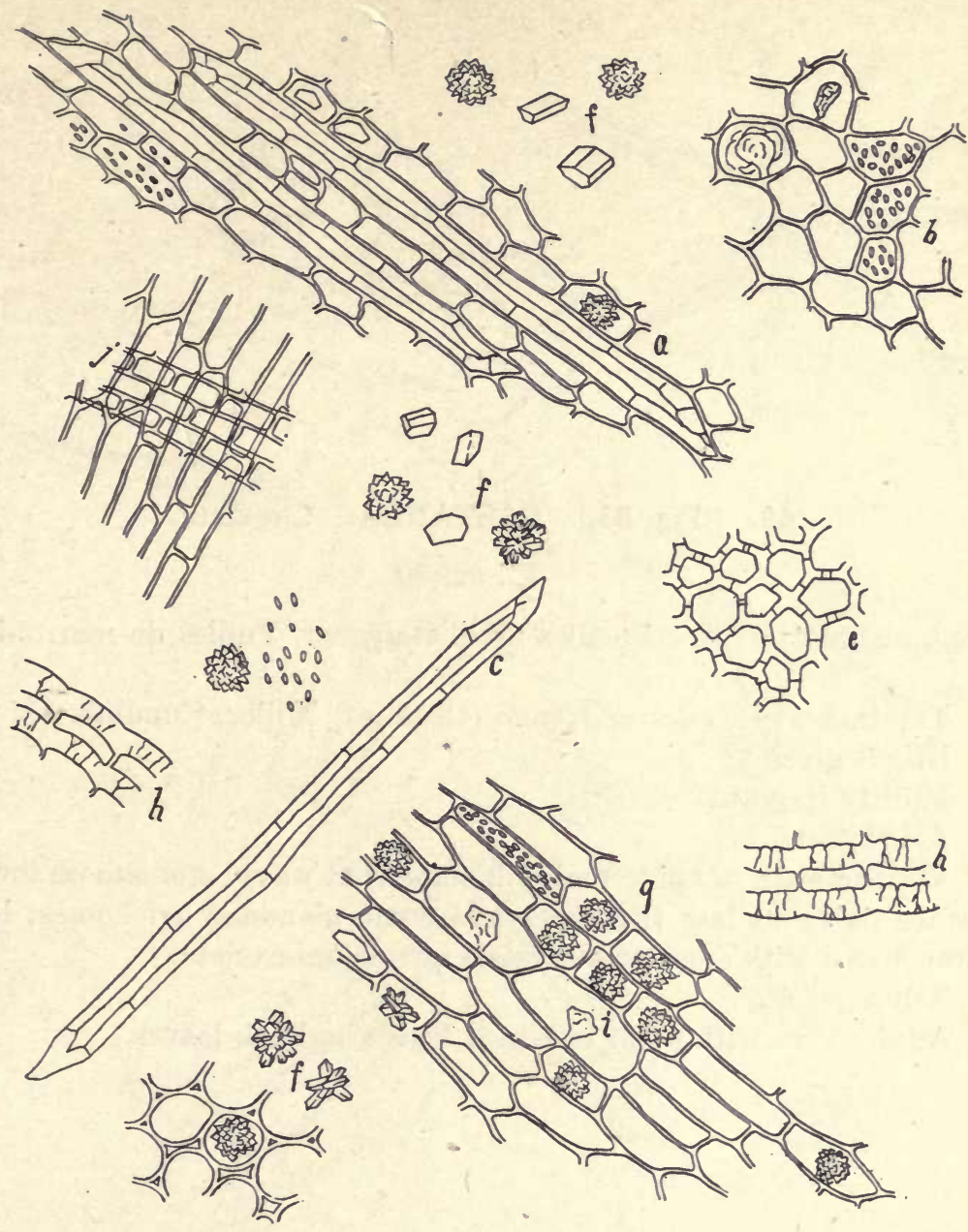

Fig. 62. CASCARILLA.

a. Parenchyma cells, longitudinal view, with crystals and starch. Two bast cells enclosed.

b. Parenchyma with starch and resin.

c. Bast cell.

e. Outer sclerenchyma, vertical view.

f. Prismatic and aggregate crystals of calcium oxalate.

g. Parenchyma.

h. Outer sclerenchyma, lateral view. 
49. (Fig. 63.) CASTANEA. Chestnut.

Fl. ex. 30 .

Kastanienblätter, G. Fueilles de châtaigener, Fuilles de marronier, Fr.

The leaves of Castanea dentata (C. sativa) Miller, Cupuliferæ.

Bright green.

Faintly fragrant.

Astringent.

Vertical walls of epidermal cells somewhat wavy; stomata on lower surface only; stellate trichomes and some glandular trichomes; leaf parenchyma with aggregate crystals of calcium oxalate.

Ash 5 per cent.

Adulterated with other chestnut leaves and oak leaves. 


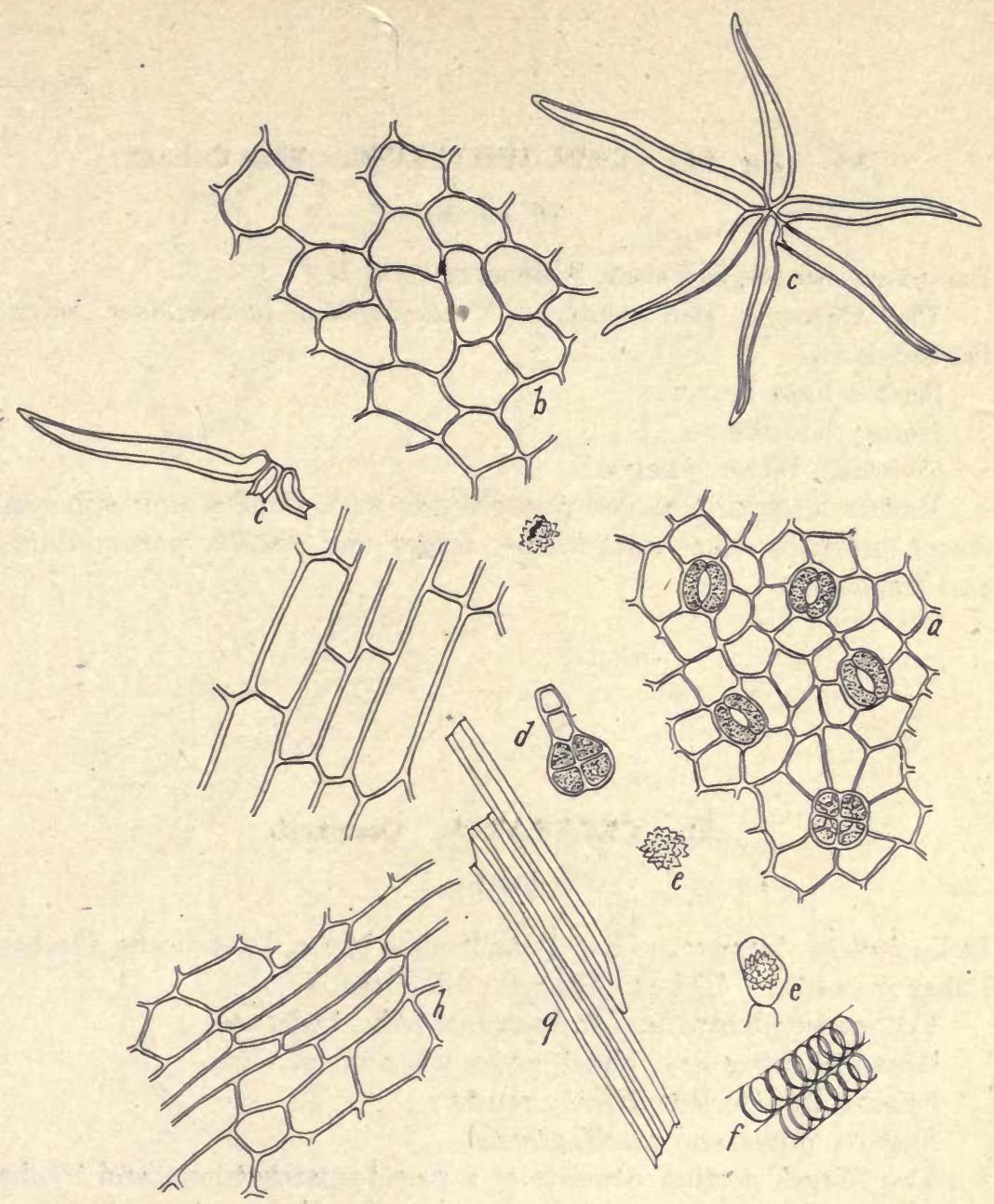

Fig. 63. CASTANEA. Leaf.

a. Lower epidermis.

b. Upper epidermis.

c. Stellate trichomes.

d. Glandular trichome.

e. Aggregate crystals.

f. Spiral ducts.

g. Bast fibers.

h. Parenchyma. 


\section{0. (Fig. 64.) CAULOPHYLLUM. Blue Cohosh.}

Fl. ex. 60 .

Pappoose-root, Squaw-root, Blueberry-root, E.

The rhizomes and roots of Caulophyllum thalictroides Mich., Berberidaceae.

Rather light brown.

Nearly odorless.

Sweetish, bitter, pungent.

Rather large thin walled parenchyma with small simple spherical starch granules; some cork tissue; larger and smaller porous ducts; and tracheids.

\section{CERTRARIA. Certraria.}

Entire.

Iceland moss, Lungwort, E. Isländisches Moos, Isländische Flechte, Lungenmoos, G. Lichen (Mousse) d'Islande, Fr.

The entire plant, Cetraria islandica Ach., Lichenes.

Brownish when dry; bluish green when moist.

Practically odorless; faintly musty.

Slightly bitter and mucilaginous.

The fungal portion consists of a pseudo-parenchyma and hyphal network. The algæ (gonidia) are single-celled, spherical, green. Apothecia and spores are rare.

Ash 7 per cent.

Adulterated with various impurities as pine leaves, mosses and grass leaves. Other species of foliose lichens may be substituted. 


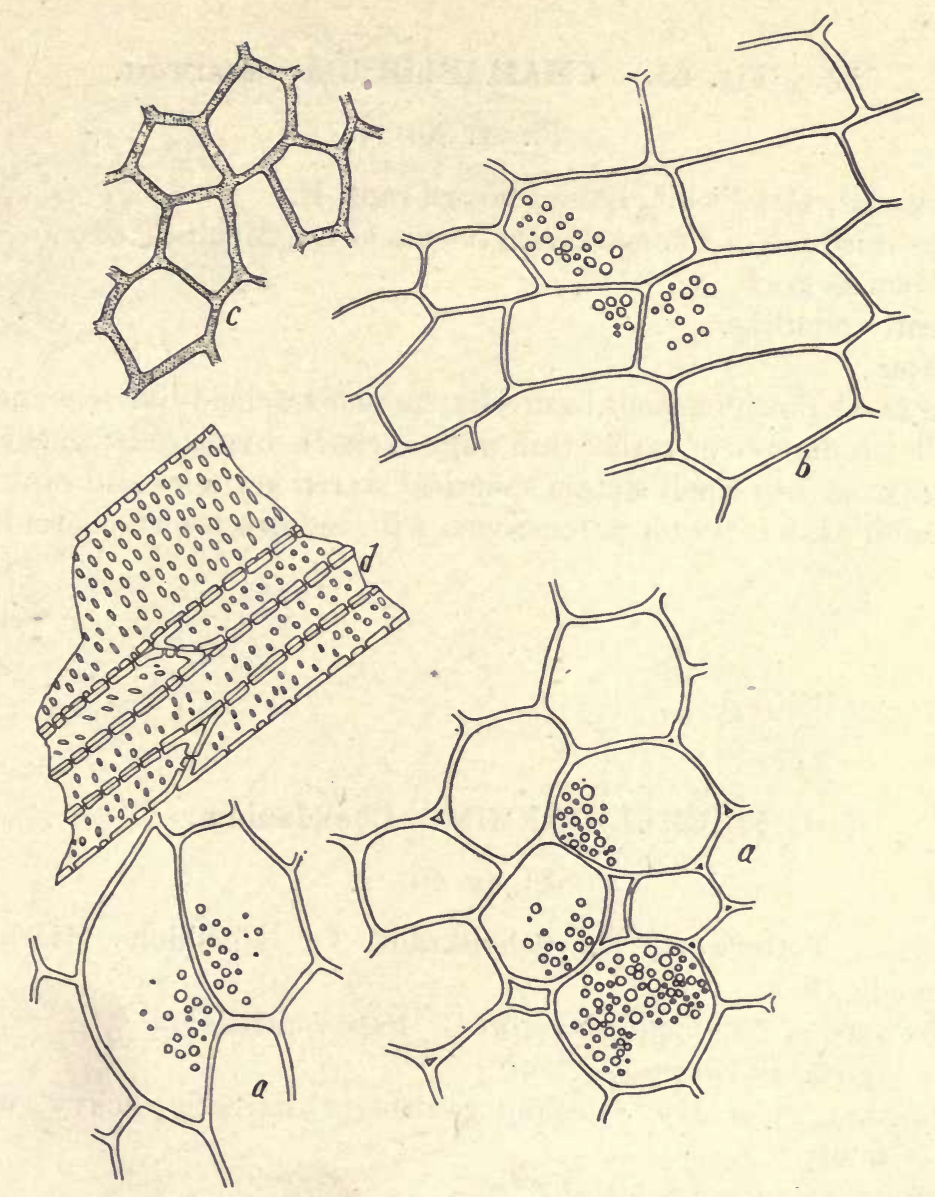

Fig. 64. CAULOPHYLLUM.

a. Parenchyma with starch granules.

b. Parenchyma, longitudinal view.

c. Cork cells.

$d$. Large and smaller porous ducts. 


\section{2. (Fig. 65.) CHAMAELIRIUM. Starwort.}

$$
\text { Fl. ex. } 30 \text {. }
$$

Blazing star, Devil's bit, False unicorn-root, E.

The rhizomes of Chamaelirium luteum Gray, Melanthaceae.

Brownish gray.

Nearly odorless.

Bitter.

Large sclerenchymatous bast cells; smaller tracheid-like sclerenchyma cells; isodiametric, rather thin walled sclerenchyma cells; tracheids; parenchyma with small simple spherical starch granules and raphides of calcium oxalate; outer parenchyma with reddish brown contents.

\section{CHELIDONIUM. Chelidonium.}

Fl. ex. 40 .

Celandine, Tetterwort, E. Schollkraut, G. Chelidone, Herbe à l'hirondelle, Fr.

The herb of Chelidonium majus L., Papaveraceae.

Dark greenish brown.

Fragrant when dry, recalling gaultheria; narcotic, heavy, when fresh or moist.

Somewhat pungent, bitterish.

Vertical walls of upper and lower epidermis wavy; stomata on lower surface only; simply, long, many-celled, smooth and thin walled trichomes above and below.

Glaucium luteum (horn poppy) and G. corniculatum may be substituted for Chelidonium. 


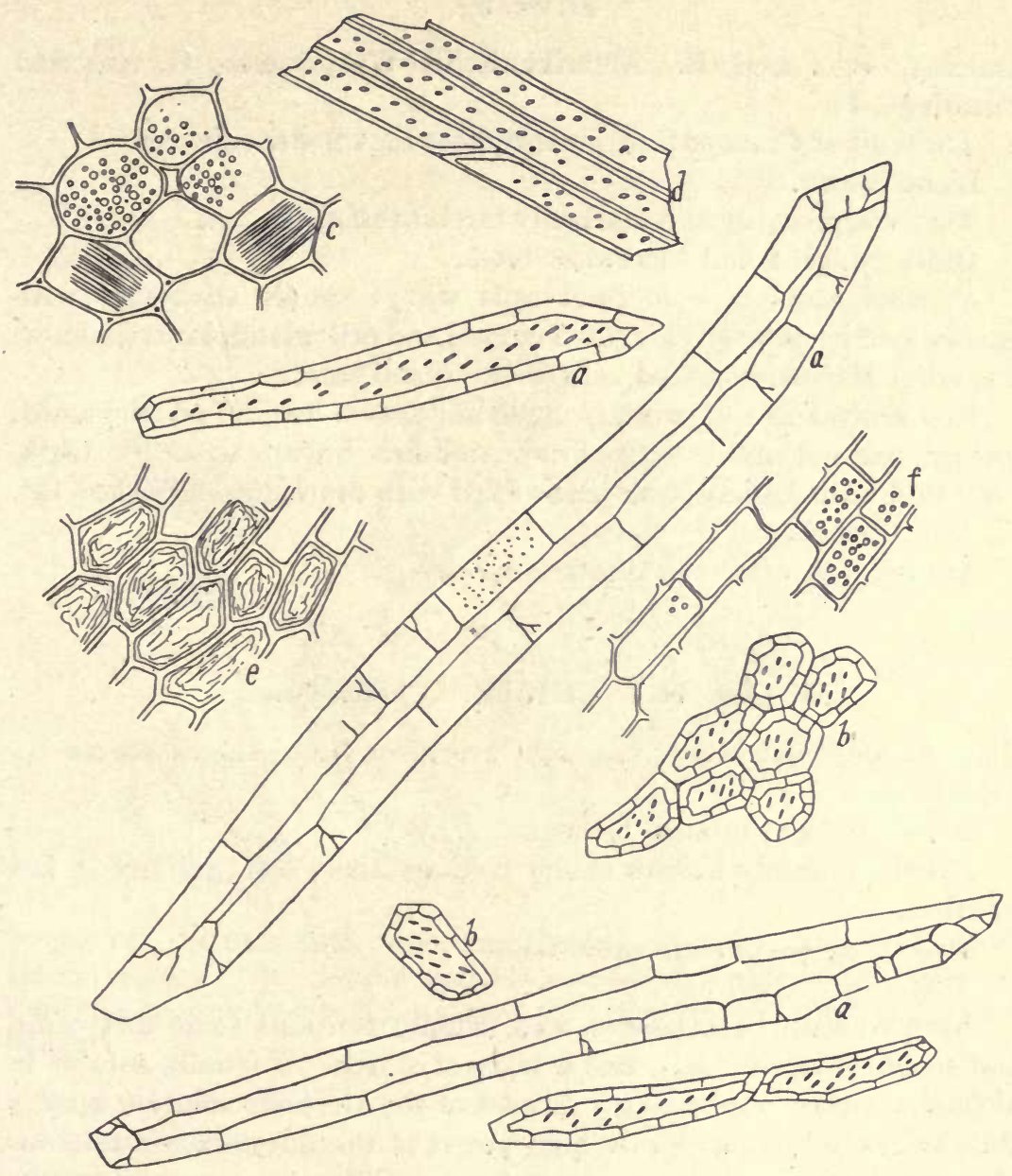

Fig. 65. CHAMAELIRIUM.

$a$. Reddish brown bast cells.

b. Sclerenchyma.

c. Parenchyma with starch and raphides.

d. Tracheids.

$e$. Cells with reddish brown contents. 


\section{CHENOPODIUM. Chenopodium.}

Fl. ex. 60 .

American wormseed, E. Amerikanischer Wurmsamen, G. Anserine vermifuge, Fr.

The fruit of Chenopodium ambrosioides L., Chenopodiaceae.

Light brown.

Very disagreeably and markedly terebinthine.

Quite pungent and somewhat bitter.

Vertical walls of epidermal cells wavy; simple trichomes with usually four basal cells, elongated curved end cell; glandular trichomes; numerous leaf parenchyma cells with crystal sand.

Epidermal tissue of pericarp much like that of leaf but no trichomes; spongy parenchyma. Deep bright reddish brown tissue of testa. Very thin walled endosperm tissue filled with proteid granules and fat.

Ash 7 per cent.

Adulterated with fruit of allied species.

\section{5. (Fig. 66.) CHICLE. Chicle Gum.}

The gummy exudate from the evergreen tree Achras sapota L., Sapotaceae.

Brown to light reddish brown.

Brittle, crumbly masses in dry cold weather; soft, gummy in hot weather.

Faintly aromatic, agreeable odor.

Tasteless. Gum like.

May contain bark tissues, and usually contains some dirt, sand and some tissue elements, and a trace of starch. Partially soluble in alcohol. Upon evaporating a droplet of the alcoholic solution upon a slide and examining under the high power of the microscope numerous globules of uniform size and spherical form will be seen; resembling very closely a smear of a pure culture of some coccus and streptococcus form. Pouring the alcoholic solution into water, a whitish emulsion forms which rises toward the top portion of the water. The cork cells and cork cell fragments which are generally present are deep reddish brown in color with deep reddish brown cell contents.

Ash 4.85 per cent.

May contain an excess of sand, dirt and vegetable tissue. 


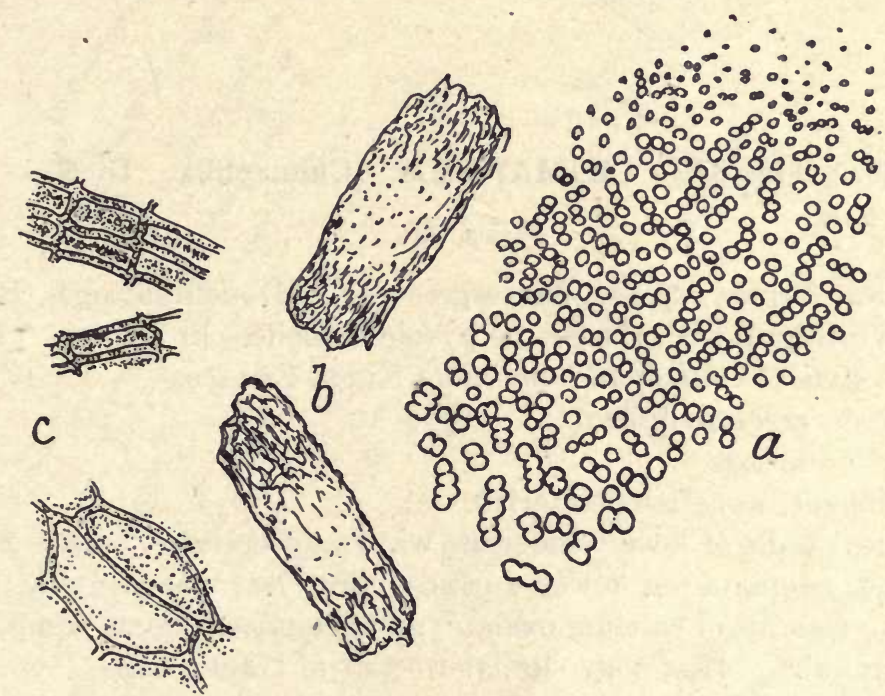

Fig. 66. CHICLE GUM. $a$, globules of gum precipitated upon a slide from an alcohol solution. The globules resemble coccus and streptococcus forms very closely; $b$, undissolved bits of the gum; $c$, cork cells, the most constantly present impurity. 
56. (Fig. 67.) CHIMAPHILA. Chimaphila. U. S. Fl. ex. 30 .

Pipsissewa, Prince's pine, Wintergreen, E. Dodenblüthiges Harnkraut, Wintergrün, G. Herbe de pyrole ombellée, Fr.

The leaves of Chimaphila umbellata Nutt., Ericaceae.

Grayish, greenish brown.

Nearly odorless.

Astringent, sweetish, bitterish.

Vertical walls of lower epidermis wavy and nodular, cuticle much thickened; stomata on lower surface only; leaf parenchyma with aggregate crystals of calcium oxalate; no trichomes. Some compound starch granules. Histology similar to that of Gaultheria. 


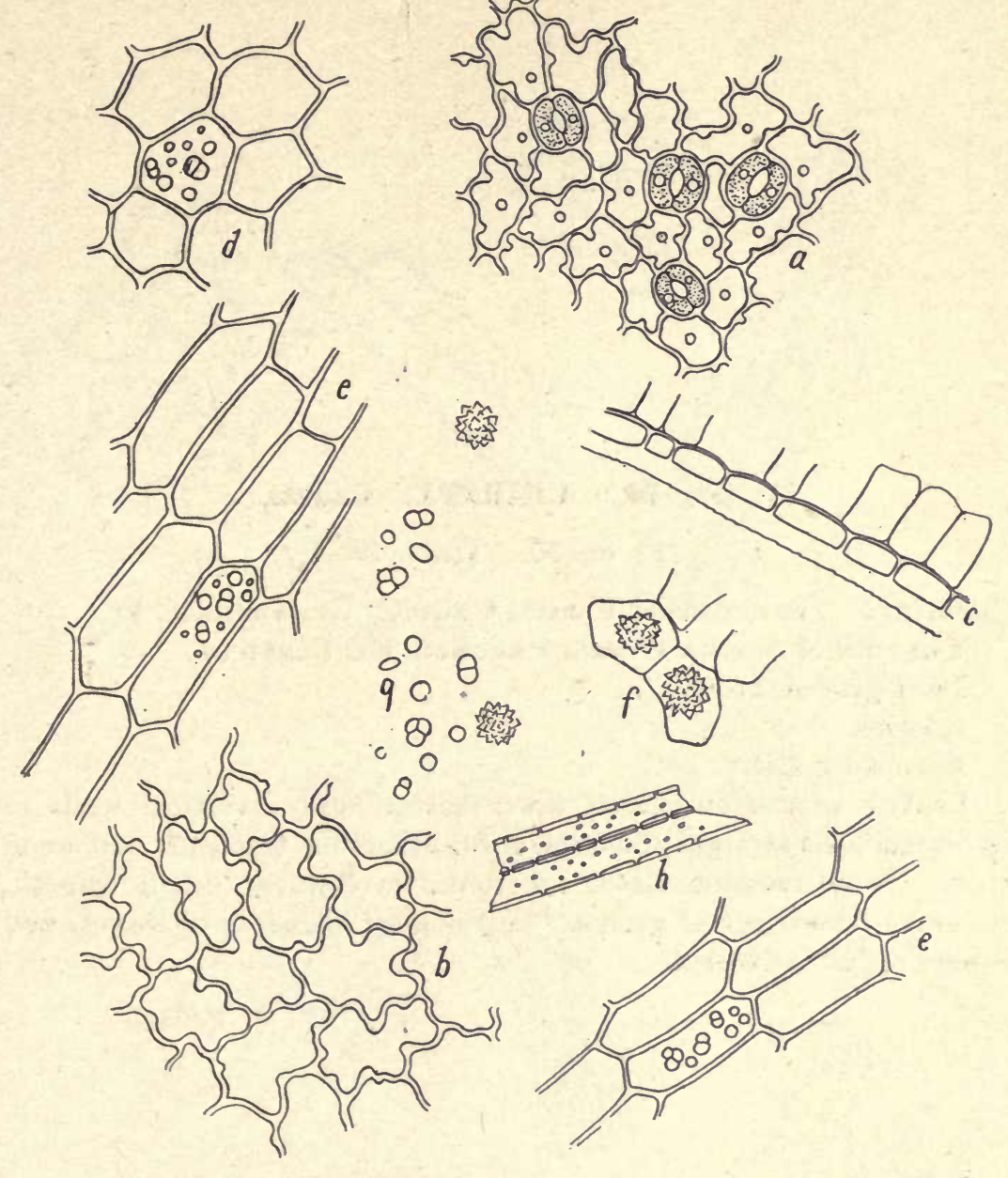

Fig. 67. CHIMAPHILA.

a. Lower epidermis.

b. Upper epidermis.

c. Upper epidermis, lateral view.

d. Parenchyma with starch.

$e$. Parenchyma, longitudinal view.

$f$. Leaf parenchyma cells with crystals.

g. Starch granules.

h. Tracheids. 


\section{7. (Fig. 68.) CHIRATA. Chirata.}

F1. ex. 30 . Tinct. 40 .

Chiretta, E. Ostindischer Enzian, Chiretta, G. Chirette, Fr.

The herb of Swertia Chirata Hamilton, Gentianaceae.

Dark grayish brown.

Odorless.

Extremely bitter.

Leaves with stomata on lower surface only; vertical walls of epidermal cells straight; no trichomes; numerous tracheids and wood fibers. Some medium sized, spheroidal to elliptical, nearly smooth, yellowish brown pollen grains. Histological elements of leaves, and flowers rather indistinct. 


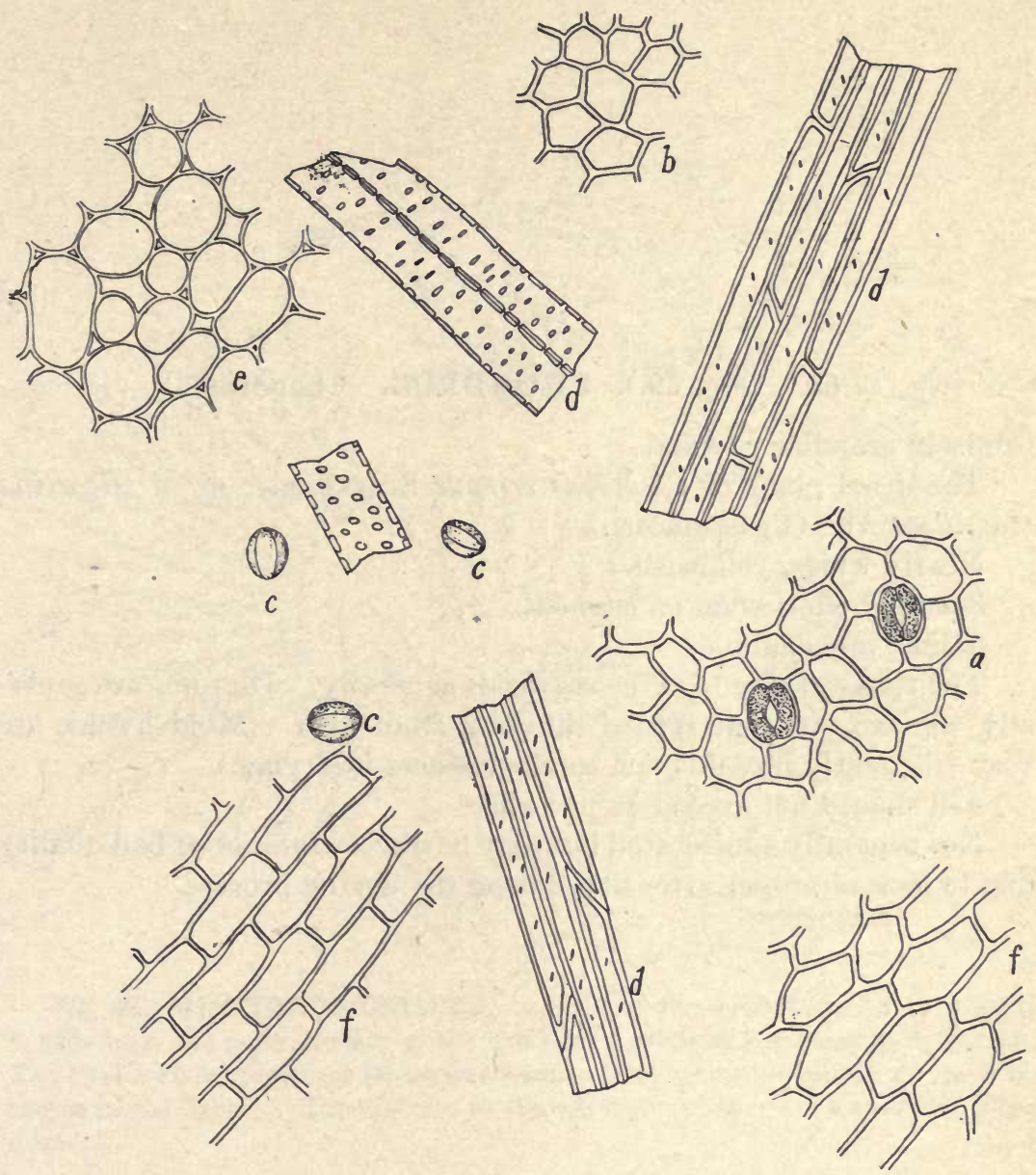

Fig. 68. CHIRATA.

$a, b$. Epidermal tissue.

c. Pollen grains.

d. Tracheids.

$e, f$. Parenchyma. 
58. (Fig. 69.) CHONDRUS. Chondrus.

Coarsely granular powder.

The dried plant of Chondrus crispus Stackhouse, or of Gigartina mamillosa Ag., Gigartinaceæ.

Nearly white, yellowish.

Seaweed odor when moistened.

Saline, mucilaginous.

The tissue elements of the seaweeds generally. Diatoms are generally wanting, in that regard differing from agar. Mold hyphæ are very frequently present, due to carelessness in drying.

Ash should not exceed 15 per cent.

Not generally adulterated but may be of very inferior or bad quality due to lack of proper attention during the drying process. 


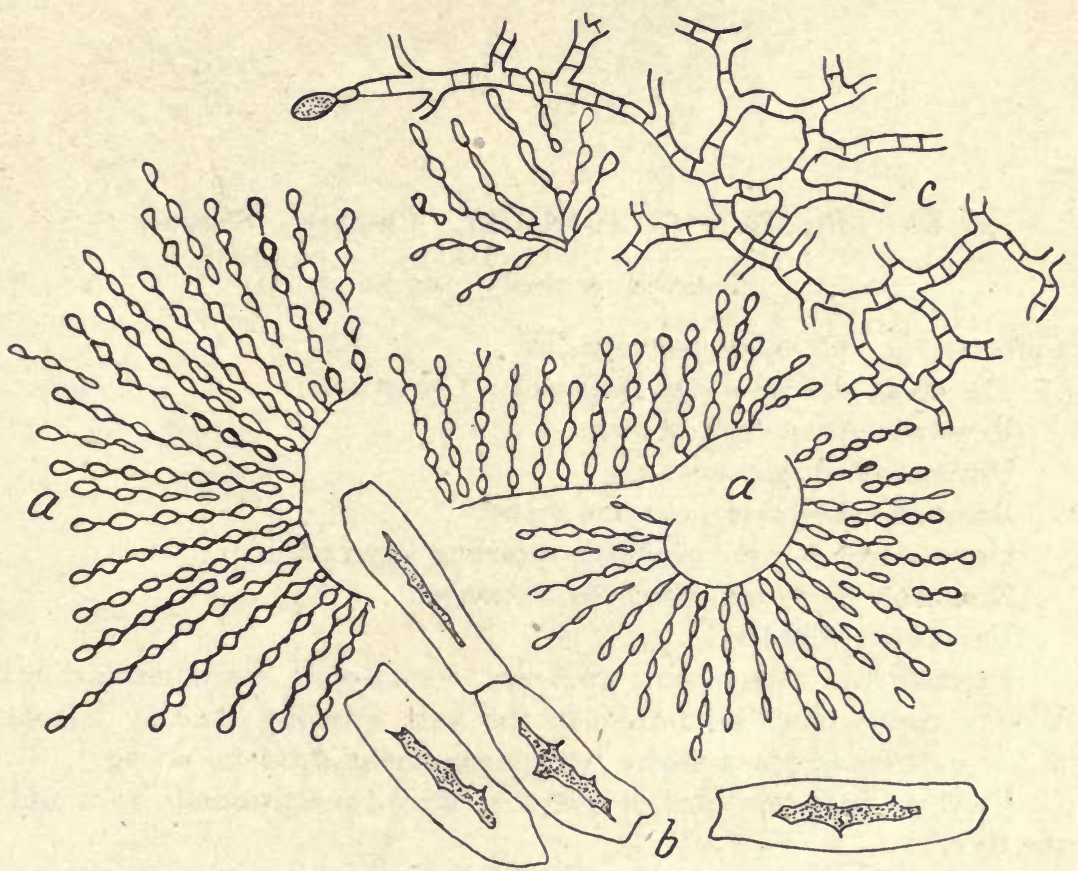

Fig. 69. CHONDRUS CRISPUS. $a$, cells of the outer tissue of the thallus; $b$, cells from the inner portion of the thallus; $c$, a fungus very frequently present. The hyphæ show numerous transverse septæ. The spores are elliptical (one being shown in the figure). The diatoms so characteristic of agar are wanting in Chondrus. 


\section{9. (Fig. 70.) CICHORIUM. Chicory. Succory.}

Roasted, coarsely powdered.

Cichorie, G. Chicoree sauvage, Fr.

The roots of Cichorium Intybus L., Compositæ.

Roasted-Very dark brown.

Unroasted-Light brown.

Roasted-Aromatic, characteristic.

Unroasted-Nearly odorless, recalling taraxacum.

Roasted-Sweetish, bitterish, astringent.

Unroasted-Bitter.

Parenchyma with inulin; tracheids; cork tissue; lacticiferous ducts. Woody tissue more abundant in the wild growing chicory. Roots of the cultivated plant fleshy; the parenchyma predominating.

Used as an adulterant of coffee or added intentionally to modify the flavor. 


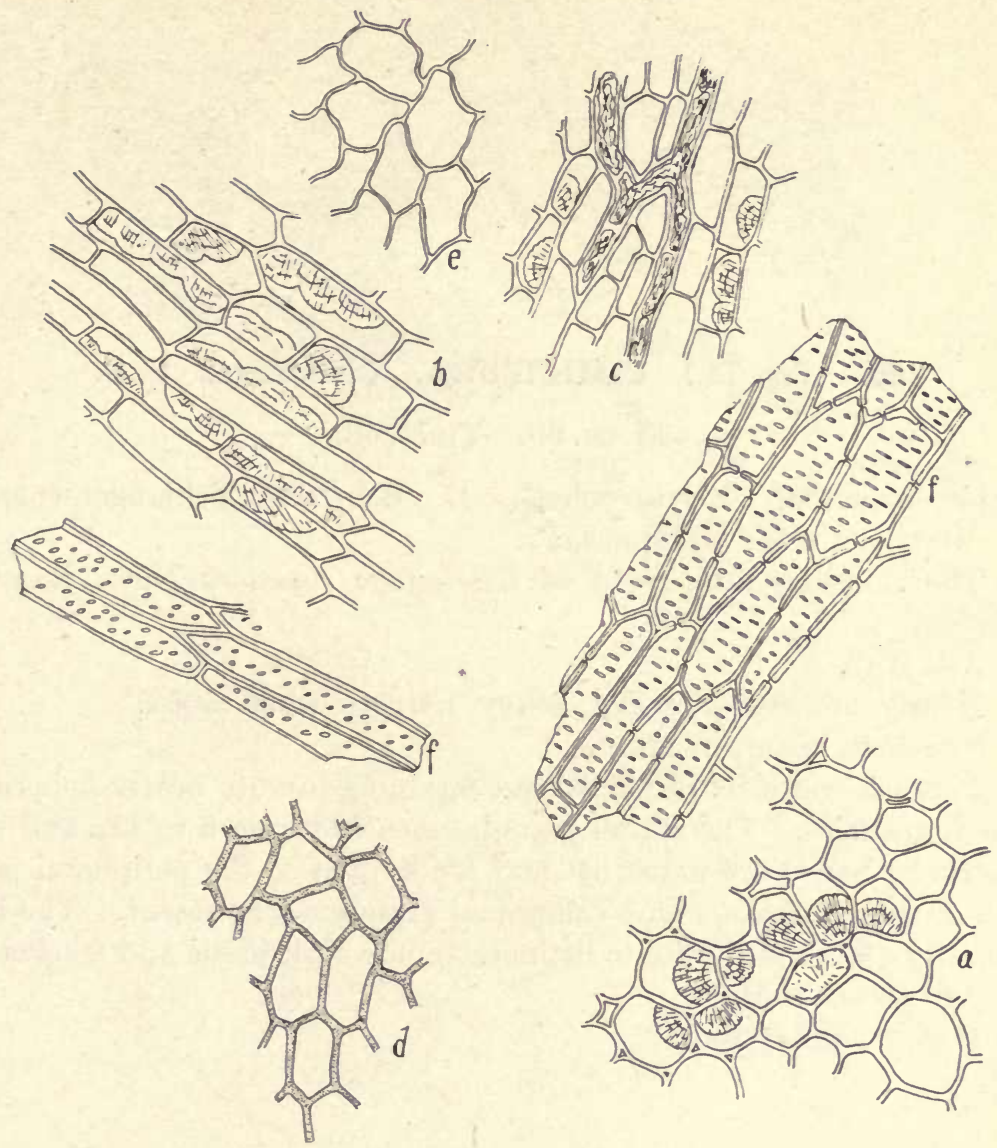

Fig. 70. CICHORIUM.

a. Parenchyma with inulin.

b. Parenchyma, longitudinal view, with inulin.

c. Laticiferous ducts.

d. Cork tissue.

e. Parenchyma.

f. Tracheids. 
60. (Fig. 71.) CIMICIFUGA. Cimicifuga. U. S. Fl. ex. 60 . Tinct. 60 .

Black snakeroot, Black cohosh, E. Schwarze Schlangenwurzel, G. Racine d'actée à grappes, Fr.

The rhizomes and roots of Cimicifuga racemosa Nutt. Ranunculaceæ.

Ash gray.

Nearly odorless when dry; heavy, narcotic when moist.

Sweetish, bitter, pungent.

Parenchyma cells rather large containing minute nearly spherical starch granules. The starch granules measure from 6 to $13 \mu$ and the polarizing bands are indistinct and are limited to the peripheral portion of the granule. Some compound granules are present. The hili are rather large but quite indistinct. Some cork tissue and tracheids.

Ash 10 per cent.

Rarely adulterated. 


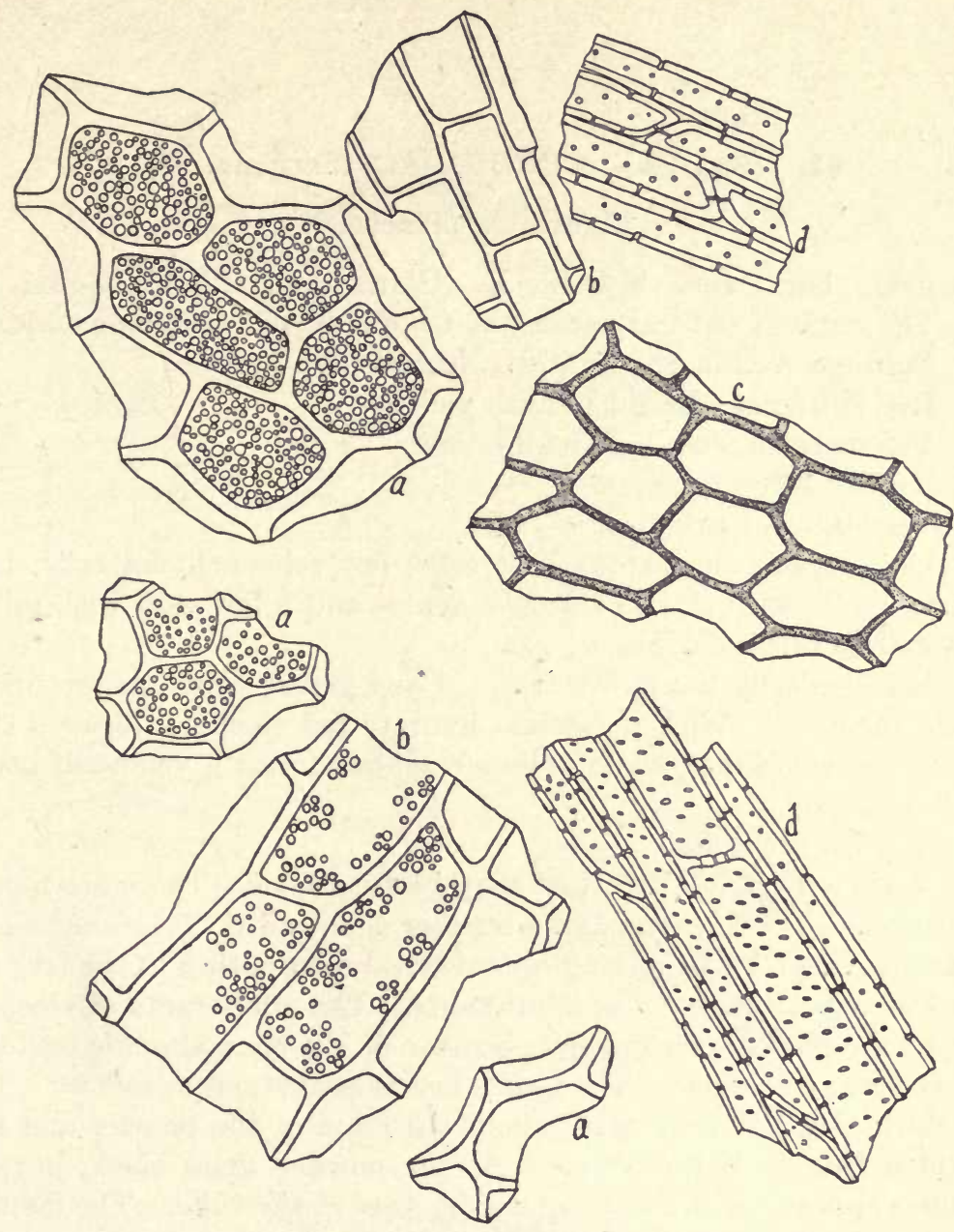

Fig. 71. CIMICIFUGA.

a. Parenchyma cells with starch.

b. Parenchyma, longitudinal view.

c. Cork tissue.

$d$. Tracheids. 


\section{1. (Fig. 72.) CINCHONA. Cinchona. U. S.}

Fl. ex. 60. Tinct. 60 .

Peruvian bark, Jesuit's bark, E. Chinarinde, G. Quinquina, Fr. The bark of several species of Cinchona, (C. Ledgeriana Moens, C. Calisaya Wedd., and hydrids), Rubiaceæ.

Red cinchona-Bright reddish yellow.

Yellow cinchona-Yellowish brown.

Faintly aromatic; musty.

Very bitter, astringent.

Large sclerenchymatous bast cells; few sclerenchyma cells; bark parenchyma with simple starch granules and a few cells with microcrystalline calcium oxalate.

Histologically the powders of red and yellow cinchona are practically identical. With potassium hydrate red cinchona forms a deep blood red coloration, while yellow cinchona forms a yellowish brown coloration.

Ash 7.5 per cent.

Various bark adulterations may be suspected. There are numerous varieties of cinchona and a number of so-called "false cinchonas." Various bitter barks having no botanical relationship to the true cinchonas have been used as adulterants. The adulterants of cinchona barks are readily recognizable, because of the characteristic bast cells of the true cinchonas. The Grahe test is carried out as follows. Into a clean, dry test tube place about 0.5 gram of the powder and heat over a Bunsen burner flame. As the powder chars black, purplish fumes appear which condense on the sides of the tube. The distinctness and volume of the purple fumes are proportionate to the amount of alkaloids present. 


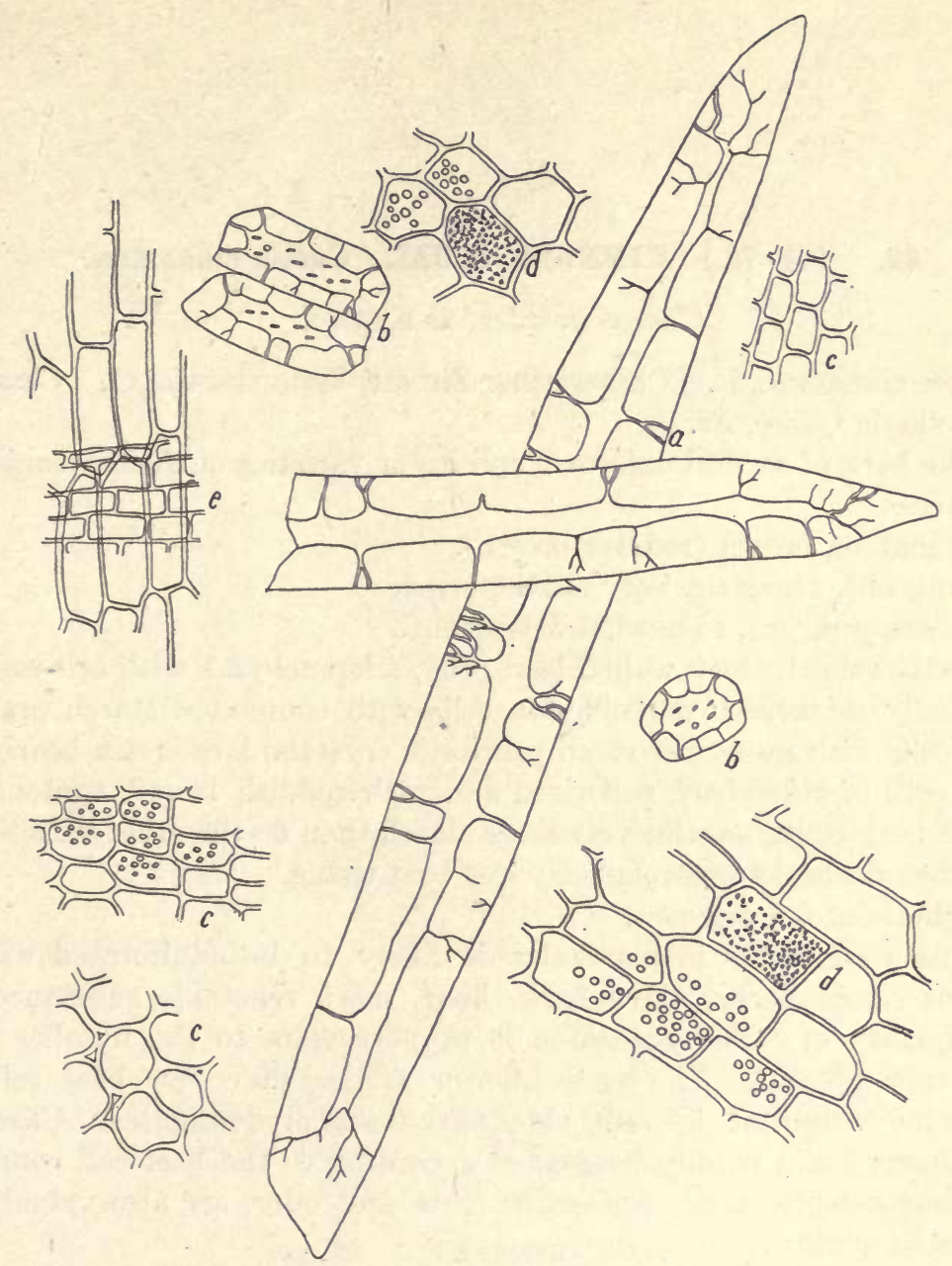

Fig. 72. CINCHONA. Red.

a. Large sclerenchymatous bast cells.

$b$. Sclerenchyma cells.

c. Bark parenchyma.

d. Cells with crystal sand.

e. Medullary ray. 


\section{2. (Fig. 73.) CINNAMOMUM. Cassia cinnamon.}

Coarse powder, as a spice.

Chinese cinnamon, E. Chinesischer Zimmt, Zimmtkassia, G. Casse, Cannelle de Chine, Fr.

The bark of several unknown species or varieties of Cinnamomum, Lauraceæ.

Cinnamon brown (reddish brown).

Fragrant, aromatic, very characteristic.

Sweet, pungent, somewhat astringent.

Rather short, thick walled bast cells; sclerenchyma with cell walls unequally thickened; parenchyma cells with compound starch granules; cells with numerous small prismatic crystals; large resin bearing cells; cells of outer bark suberized and with reddish brown contents. Cassia bark contains relatively more starch than do the other varieties of cinnamon barks and relatively less bast tissue.

Ash about 6.5 per cent.

Cassia cinnamon in particular is likely to be adulterated with inferior cassia barks, clove bark, flour, inert vegetable substances. The quality of cassia cinnamon is proportionate to the number of bast cells present. The very inferior grades show few bast cells, which indicates that the outer older bark tissue predominates. Cassia cinnamons could readily be graded according to the bast cell count. The organoleptic tests, especially taste and odor, are also valuable guides to quality. 


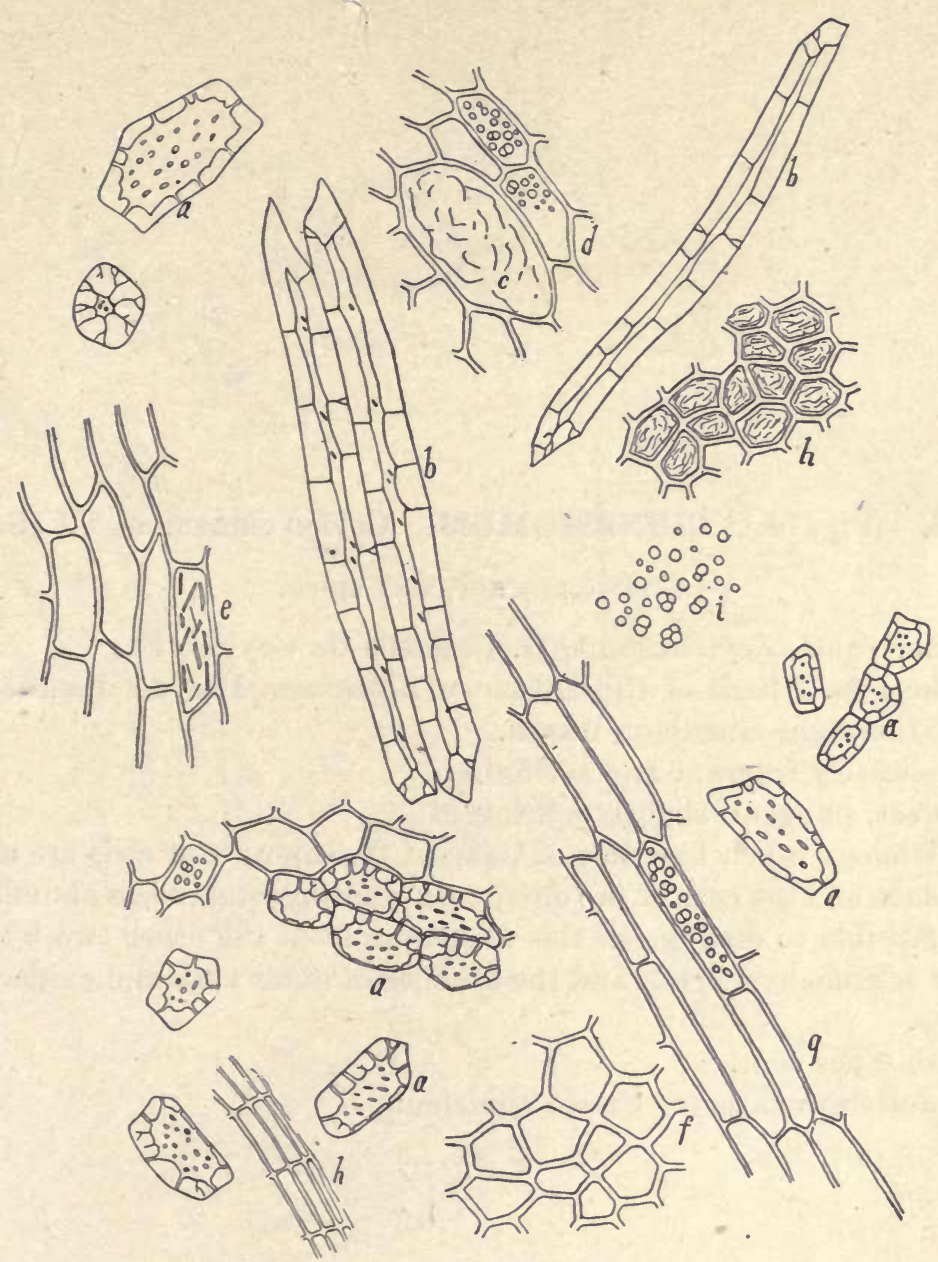

Fig. 73. CINNAMON. Cassia.

a. Sclerenchyma.

b. Bast.

c. Resin cell.

d. Parenchyma cells with starch.

$e$. Crystal bearing cell.

$f$. Outer cork cells.

g. Parenchyma, longitudinal view.

$h$. Cells with reddish brown contents. 


\section{3. (Fig. 74.) CINNAMOMUM. Ceylon cinnamon. U. S.}

Coarse powder, as a spice.

Brauner canel, Zeylonzimmt, G. Cannelle de Ceylon, Fr.

The rossed bark of Cinnamomum Zylanicum Breyne, Lauraceae.

Rather light cinnamon brown.

Delicately fragrant and aromatic.

Sweet, pungent, slightly astringent.

Histology much like that of Cassia Cinnamon; bast cells are more abundant and the cells of the outer cork wanting; starch less abundant. It is possible to distinguish this cinnamon from the other two by the larger sclerenchyma cells and the absence of outer cork and epidermal tissues.

Ash 4 per cent.

Adulterations as for Cassia cinnamon. 


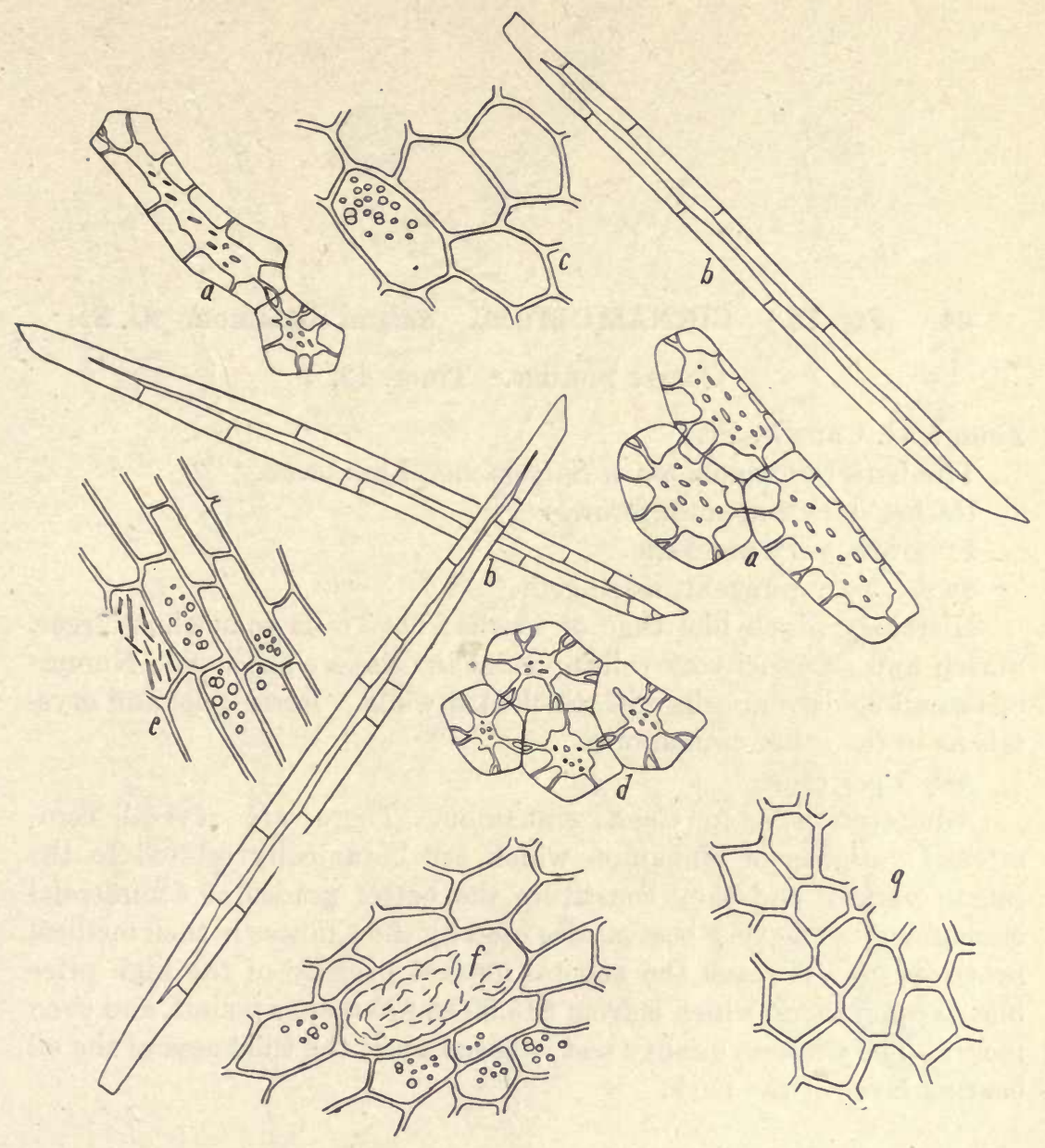

Fig. 74. Cinnamon. Ceylon.

$a$. Sclerenchyma cells with unequally thickened walls.

b. Bast cells.

c. Parenchyma cells with starch.

$d$. Typical thick-walled parenchyma.

$e$. Parenchyma, longitudinal view, with starcb and crystals.

$f$. Resin and oil cell.

$g$. Outer cork cells, sparingly present. 


\section{4. (Fig. 75.) CINNAMOMUM. Saigon cinnamon. U.S.}

Coarse powder. Tinct. 40.

Zimmt. G. Canelle, Fr.

The bark of Cinnamomum Saigonicum, Lauraceae.

Rather dark cinnamon brown.

Fragrant, very aromatic.

Sweet, very pungent, astringent.

Histology much like that of Cassia; bast cells somewhat larger. Starch and sclerenchyma cells much as in Cassia cinnamon. Numerous" small epidermal cells with thickened walls. Resin cells and crystals as in the other cinnamons.

Ash 5 per cent.

Adulterations as for Cassia cinnamon. There are several commercial varieties of cinnamon which are botanically related to the saigon variety and they constitute the better grades of commercial cinnamons. The very best grades used by the Chinese in their medical practices do not reach the general market because of the high price placed upon them, which is from $\$ 15.00$ to $\$ 75.00$ per pound, and even more. The Chinese quality test is based upon the thickness of the oil bearing layer of the bark. 


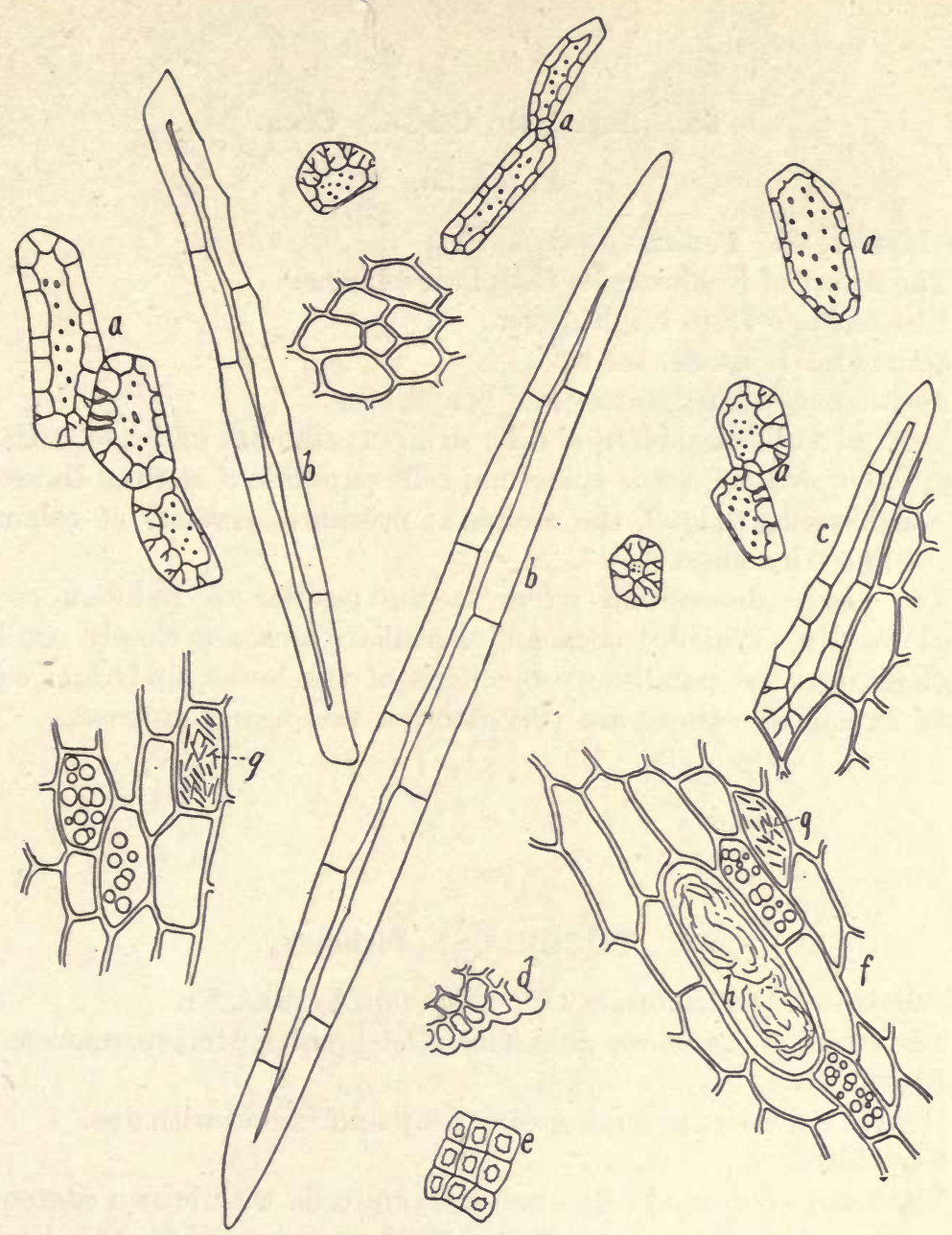

Fig. 75. CINNAMON. Saigon.

a. Sclerenchyma.

$b, c$. Bast.

d. Epidermis, lateral view.

e. Epidermis, vertical view.

$f$. Parenchyma, longitudinal view with crystal bearing cell $(g)$ resin cell $(h)$ and starch. 


\section{5. (Fig. 76.) COCA. Coca.}

Fl. ex. 50.

Cocablätter, G. Feuilles de coca, Fr.

The leaves of Erythroxylon Coca Lam., Lineæ.

Brownish green to bright green.

Somewhat fragrant, tea-like.

Astringent, slightly bitter and benumbing.

Vertical walls of epidermal cells straight; stomata on lower surface only; outer walls of lower epidermal cells papillose excepting those of the neighboring cells of the stomata; prismatic crystals of calcium oxalate; no trichomes.

The above description refers to the powder of Bolivian coca. The Peruvian (Truxillo) coca and Brazilian coca are closely similar histologically; the papillose projections of the lower epidermal cells of the Brazillian variety are very distinct and nearly globose.

\section{COCCULUS. Fishberry.}

Kokkelskörner, Fischkörner, G. Coque du Levant, Fr.

The fruits of Anamirta paniculata Colebrooke, Menispermaceæ.

Brown.

Heavy, narcotic; becoming very fishy and rancid with age.

Very bitter.

Flattened epidermal cells; parenchyma cells with brown contents. Numerous sclerenchymatous, thick walled, porous wood fibers. Endosperm cells thin walled, filled with proteid granules and oil. Acicular and prismatic crystals and crystal aggregates.

Ash 5 per cent.

Rarely adulterated. The endosperm tissue may become rancid. 


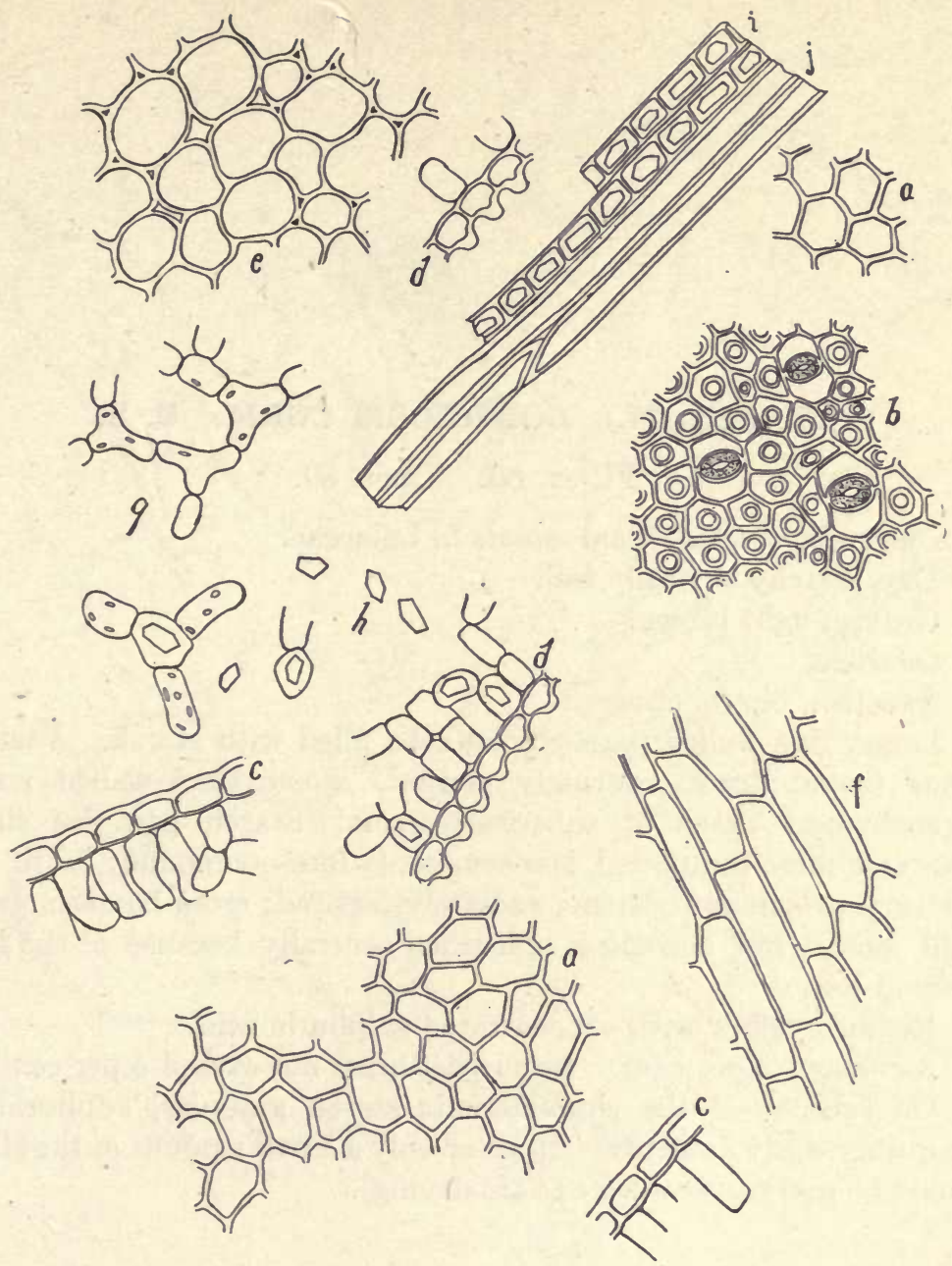

Fig. 76. COCA.

a. Upper epidermis.

b. Lower epidermis.

c. Upper epidermis, lateral view.

$d$. Lower epidermis, lateral view.

e. Parenchyma.

f. Parenchyma, longitudinal view.

g. Spongy tissue of leaf.

$h$. Prismatic crystals.

$i, j$. Bast cells and crystal bearing fibers. 


\title{
67. (Fig. 77.) COLCHICUM CORM. U. S.
}

\author{
Fl. ex. 60. Tinct. 30 .
}

The corms of Colchicum autumnale L. Liliaceae.

Dry, starchy or mealy feel.

Grayish light brown.

Odorless.

Sweetish, bitter, pungent.

Large, thin-walled parenchyma cells filled with starch. $\dot{\text { Vascular }}$ tissue (spiral ducts) sparingly present. Some thick-walled porous parenchyma. Trace of suberized tissue. Starch granules single, two- and three-compound, less commonly four-compound; $7 \mu$ to $21 \mu$; hili very prominent, centric, radiately fissured; cross bands marked, right angled but becoming indistinct centrally because of the large fissured hili.

Reddish yellow with concentrated sulphuric acid.

Ash about 3 per cent. Impurities must not exceed 5 per cent.

On account of the characteristic starch granules, adulterations are quite readily detected. None or only a small amount of the starch should be pasty (use of heat to aid drying). 


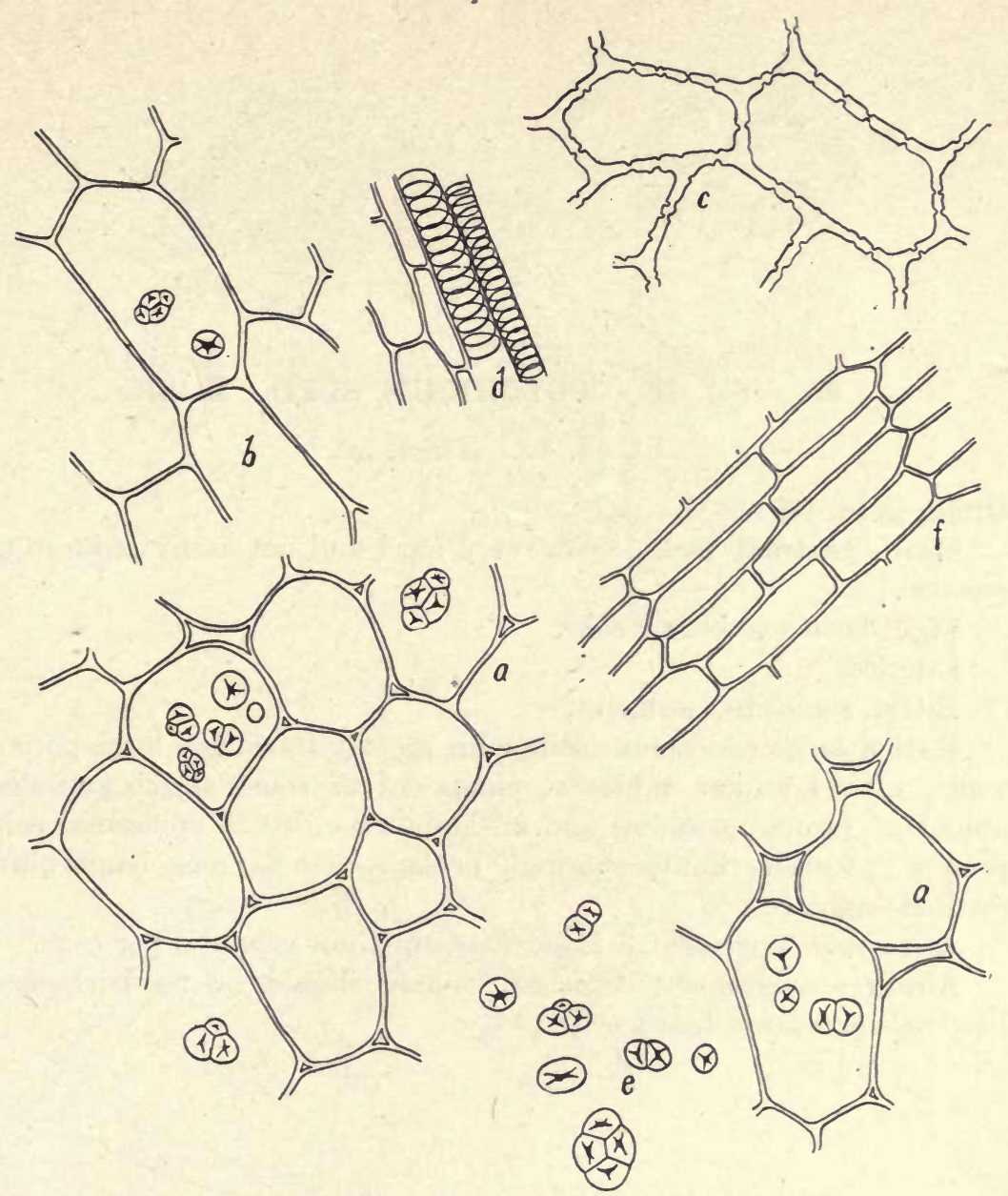

Fig. 77. COLCHICUM. Corm.

a. Parenchyma with starch.

b. Parenchyma, longitudinal view.

c. Thick-walled, porous parenchyma.

d. Spiral ducts.

e. Starch granules.

f. Phloem tissue. 


\title{
68. (Fig. 78.) COLCHICUM SEED. U. S.
}

\author{
Fl. ex. 40. Tinct. 50 .
}

Origin as for (67).

Hard, granular feel. Seeds very hard and not easily reduced to powder.

Light brown to brown color.

Odorless.

Bitter, somewhat pungent.

Rather large endosperm cells with greatly thickened large-porous walls, with granular contents, composed of some starch granules, abundant proteid granules and oil globules. Brown epidermal cells present. Starch granules sparingly present, $2 \mu$ to $6 \mu$; cross bands quite distinct, right angled.

Ash about 3 per cent. Impurities must not exceed 5 per cent.

Adulterations easily detected. There should be no trichomes, bast cells or sclerenchyma cells. 


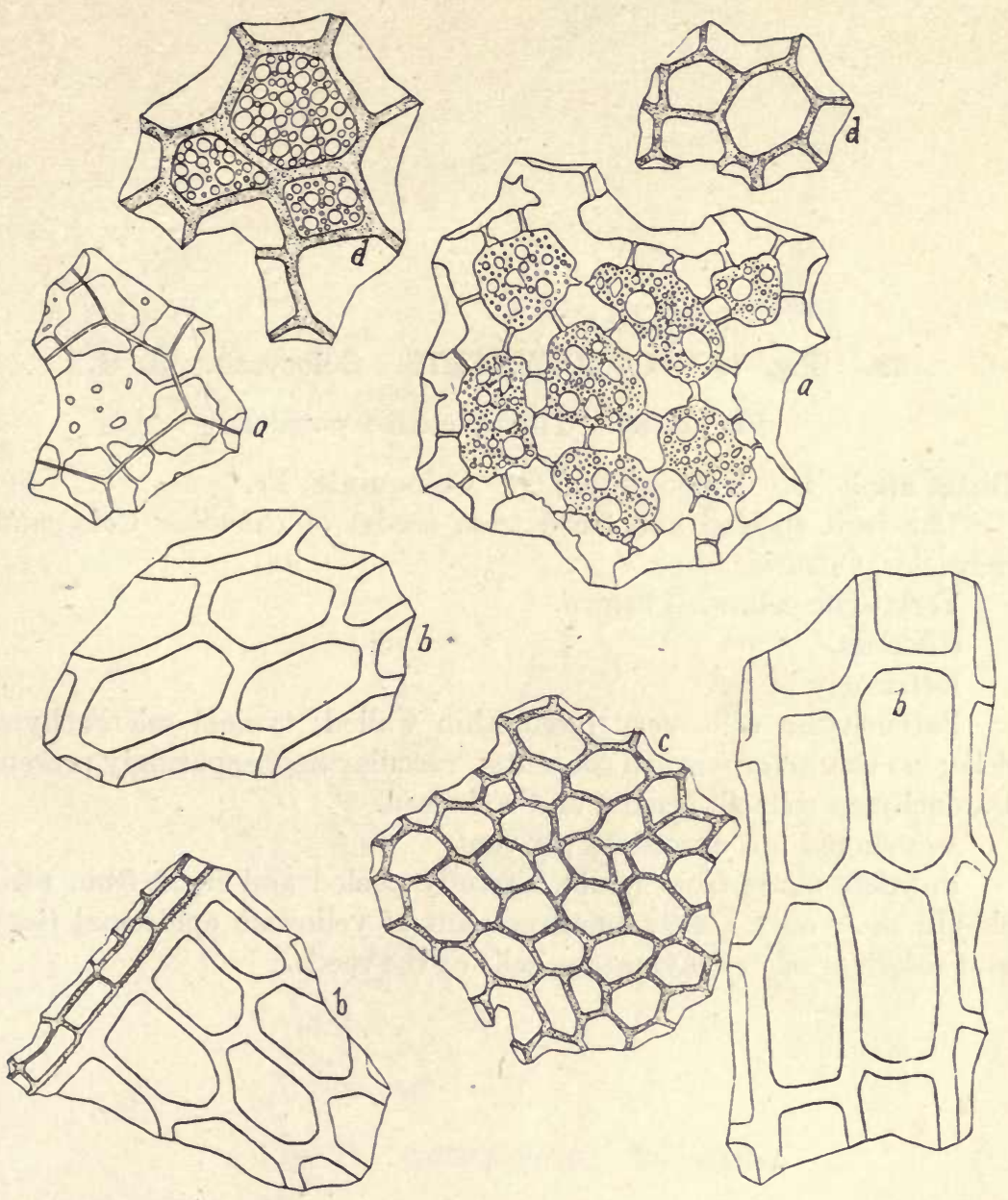

Fig. 78. COLCHICUM. Seed.

a. Endosperm cells with proteid granules and oil globules.

b. Endosperm, longitudinal view.

c. Brown epidermal cells.

d. Hypodermal cells. 


\section{9. (Fig. 79.) COLOCYNTHIS. Colocynth. U. S.}

Fl. ex. 30. Tinct., coarse powder.

Bitter apple, E. Koloquinten, G. Coloquinte, Fr.

The fruit (peeled and freed from seeds) of Citrullus Colocynthis Schrader, Cucurbitaceae.

Very light yellowish brown.

Odorless.

Extremely bitter.

Parenchyma cells very large, thin walled; typical sclerenchyma cells; no characteristic cell contents; vascular tissue sparingly present. Parenchyma cells all broken and collapsed.

Ash should not exceed 14 per cent.

Powders made from fruits carefully peeled and freed from seeds should show only a very small amount of yellowish epidermal tissue and colorless sclerenchymatous cells of the seeds. 

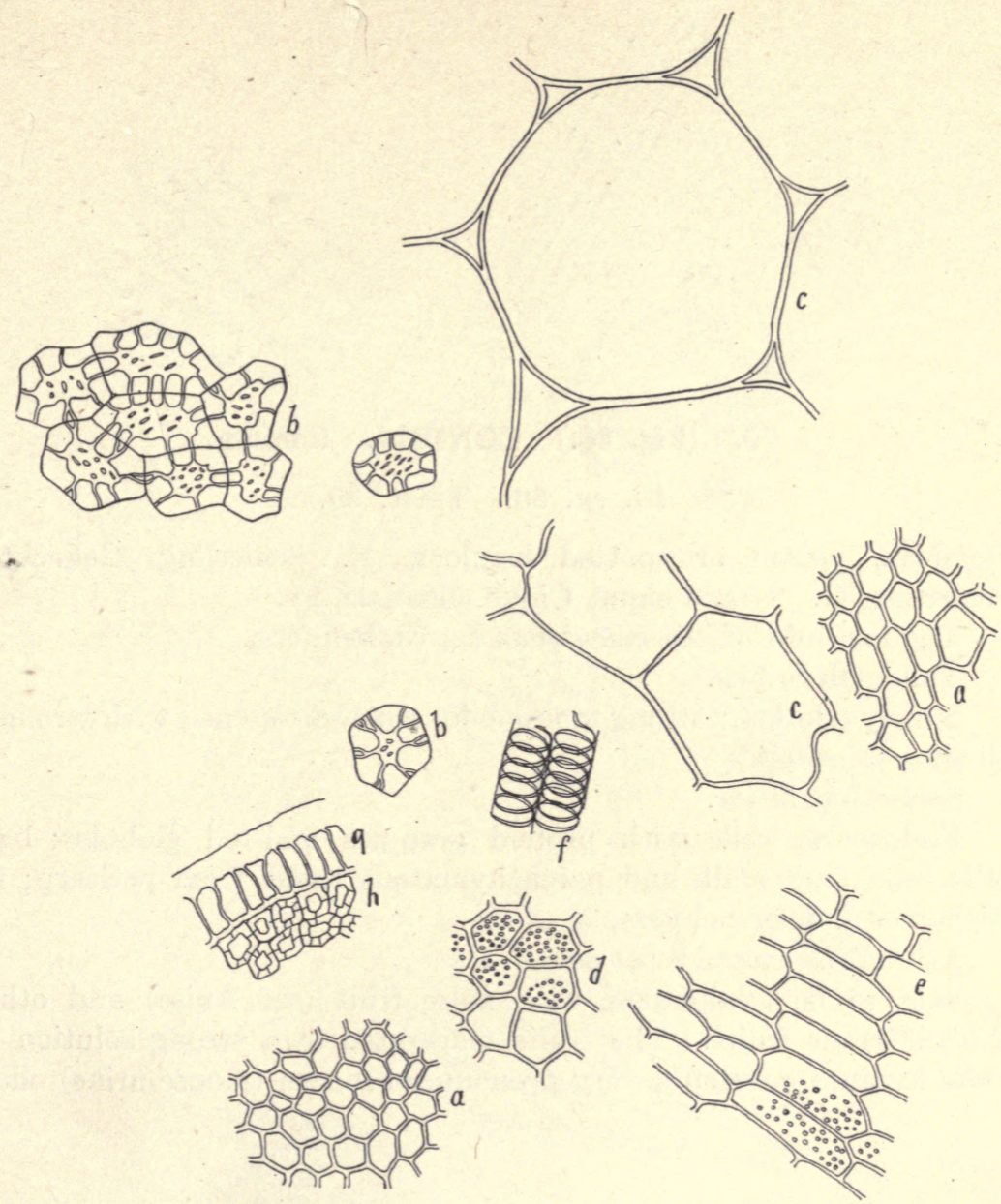

Fig. 79. COLOCYNTH. With seeds.

a. Epidermal cells.

$b$. Sclerenchyma cells.

c. Parenchyma.

d. Parenchyma.

e. Parenchyma.

f. Spiral ducts.

$g$. Epidermis of seed.

h. Small celled sclerenchyma. 


\section{0. (Fig. 80.) CONIUM. Conium.}

Fl. ex. 30. Tinct. 30 .

Hemlock, poison or spotted hemlock, E. Schierling, Gefleckter Schierling, G. Grand ciquë, Ciquë officinale, Fr.

The fruit of Conium maculatum L., Umbelliferæ.

Yellowish brown.

Nearly odorless; strong mouse odor when moistened with strongly alkaline solutions.

Somewhat bitter.

Endosperm cells with proteid granules and oil globules; bast cells from fruit stalk and parenchymatous tissue from pericarp; no trichomes or sclerenchyma.

Ash not to exceed 9 per cent.

Said to be adulterated with anise fruit (see Anise) and other Umbelliferous fruits. The fruits macerated in a strong solution of sodic hydrate develop a very pronounced mouse (mouse urine) odor. 


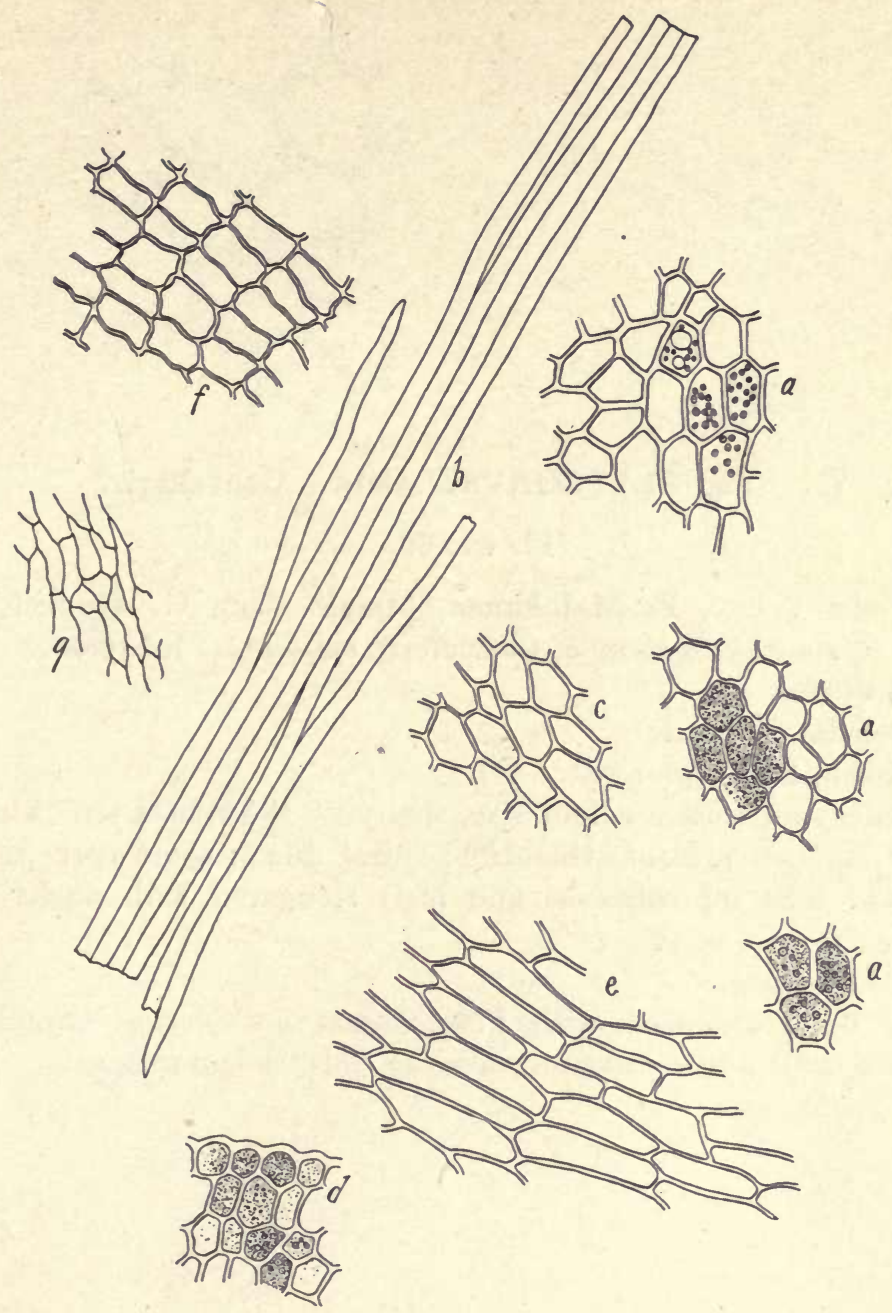

Fig. 80. CONIUM. Seed.

a. Endosperm cells with oil and proteid granules.

b. Bast fibers.

c. Parenchyma.

d. Endosperm tissue, lateral view.

e. Parenchyma of pericarp.

$f, g$. Parenchyma. 


\section{1. (Fig. 81.) CONVALLARIA. Convallaria.}

Fl. ex. 60 .

Lily of the Valley, E. Maiblumen, Maiglöcklein, G. Muguet, Fr. The rhizomes and roots of Convallaria majalis L., Liliaceae.

Dull brown.

Somewhat fragrant.

Sweetish, bitter, pungent.

Parenchyma cells medium size, many of the nuclei still visible; acicular crystals present; tracheids; spiral ducts; some cork tissue. Epidermal cells (of rhizomes and leaf) elongated with nuclei still visible.

Ash 9 per cent.

May be adulterated with Polygonatum multiflorum (European Solomon's seal) and Smilacina racemosa (false Solomon's seal). 


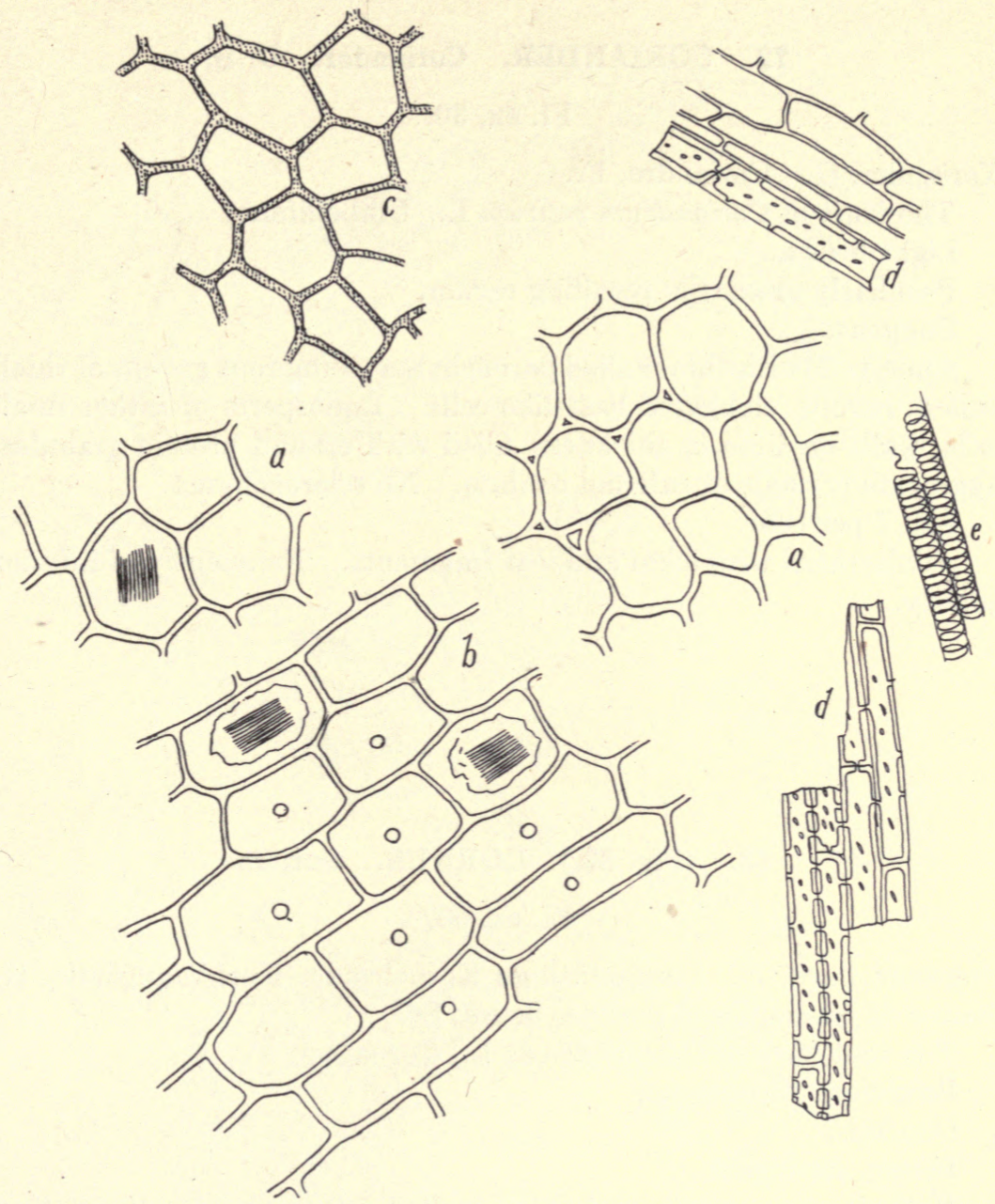

Fig. 81. CONVALLARIA.

$a, b$. Parenchyma with raphides and showing nuclei.

c. Cork tissue.

$d$. Tracheids.

e. Spiral ducts. 


\section{CORIANDER. Coriander. U. S.}

Fl. ex. 30.

Koriander, G. Coriandre, Fr.

The fruit of Coriandrum sativum L., Umbelliferæ.

Light brown.

Peculiarly aromatic; recalling carum.

Pungent.

Some yellowish thin-walled parenchyma; numerous groups of thick walled, porous, elongated bast-like cells. Endosperm of rather small cells; walls medium in thickness, filled with oil and proteid granules. Aggregate crystals of calcium oxalate. No sclerenchyma.

Ash 7 per cent.

Adulterated with stem and leaf fragments. Frequently of inferior quality.

73. (Fig. 82.) CORNUS. Cornus.

Fl. ex. 60 .

Dogwood bark, E. Grossblüthige Kornelrinde, Hornbaumrinde, G. Ecorce de carnouiller à grandes fleurs, Fr.

The root bark of Cornus florida L., Cornaceæ.

Bright pinkish brown.

Odorless.

Bitter, astringent.

Rather large porous and thick walled sclerenchyma alternating with smaller, less porous sclerenchyma containing a granular substance; parenchyma with prismatic and aggregate crystals of calcium oxalate. 


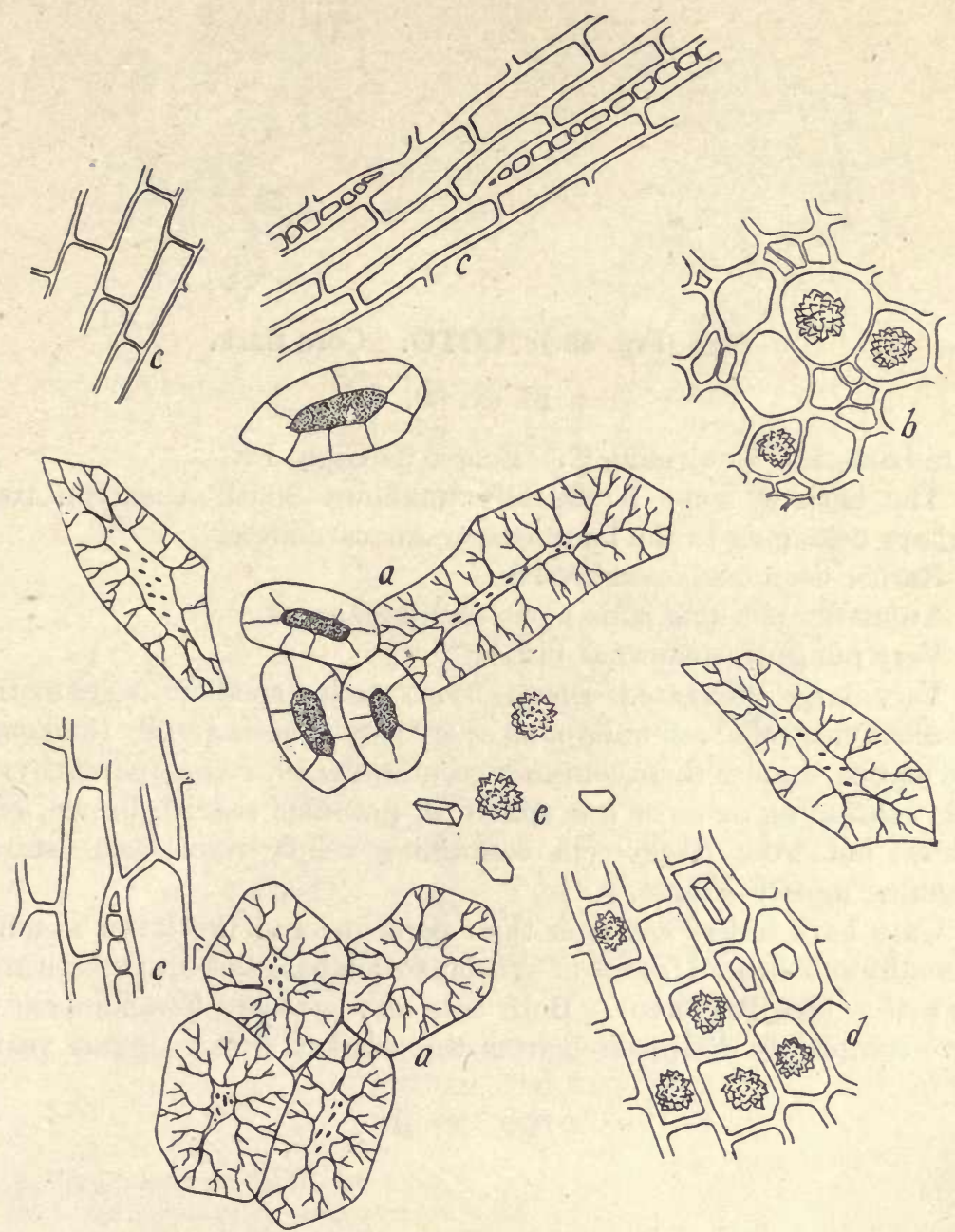

Fig. 82. CORNUS.

a. Sclerenchyma, some with granular contents.

$b$. Parenchyma, with crystals.

$c, d$. Parenchyma, longitudinal view.

$e$. Prismatic and aggregate crystals of calcium oxalate. 


\section{4. (Fig. 83.) COTO. Coto Bark.}

Fl. ex. 60 .

Para bark, E. Cotorinde, G. Ecorce de Coto, Fr.

The bark of some botanically unknown South American tree, perhaps belonging to the Lauraceæ or Anacardiaceæ.

Rather deep cinnamon brown.

Aromatic, recalling cinnamon; camphoraceous.

Very pungent, somewhat bitter.

Very large elongated sclerenchyma cells; smaller, isodiametric sclerenchyma cells; cell walls of all sclerenchyma cells greatly thickened and porous, some of them containing a granular substance; parenchyma cells containing more or less spherical, granular reddish brown, oily bodies; numerous larger cells containing yellow resin; some starch granules, mostly simple.

Coto bark is less common than paracoto and the latter is quite generally substituted for coto. Various other barks are also substituted for coto. (See Paracoto). Both coto and paracoto barks appear to have completely disappeared from the market within recent years. 


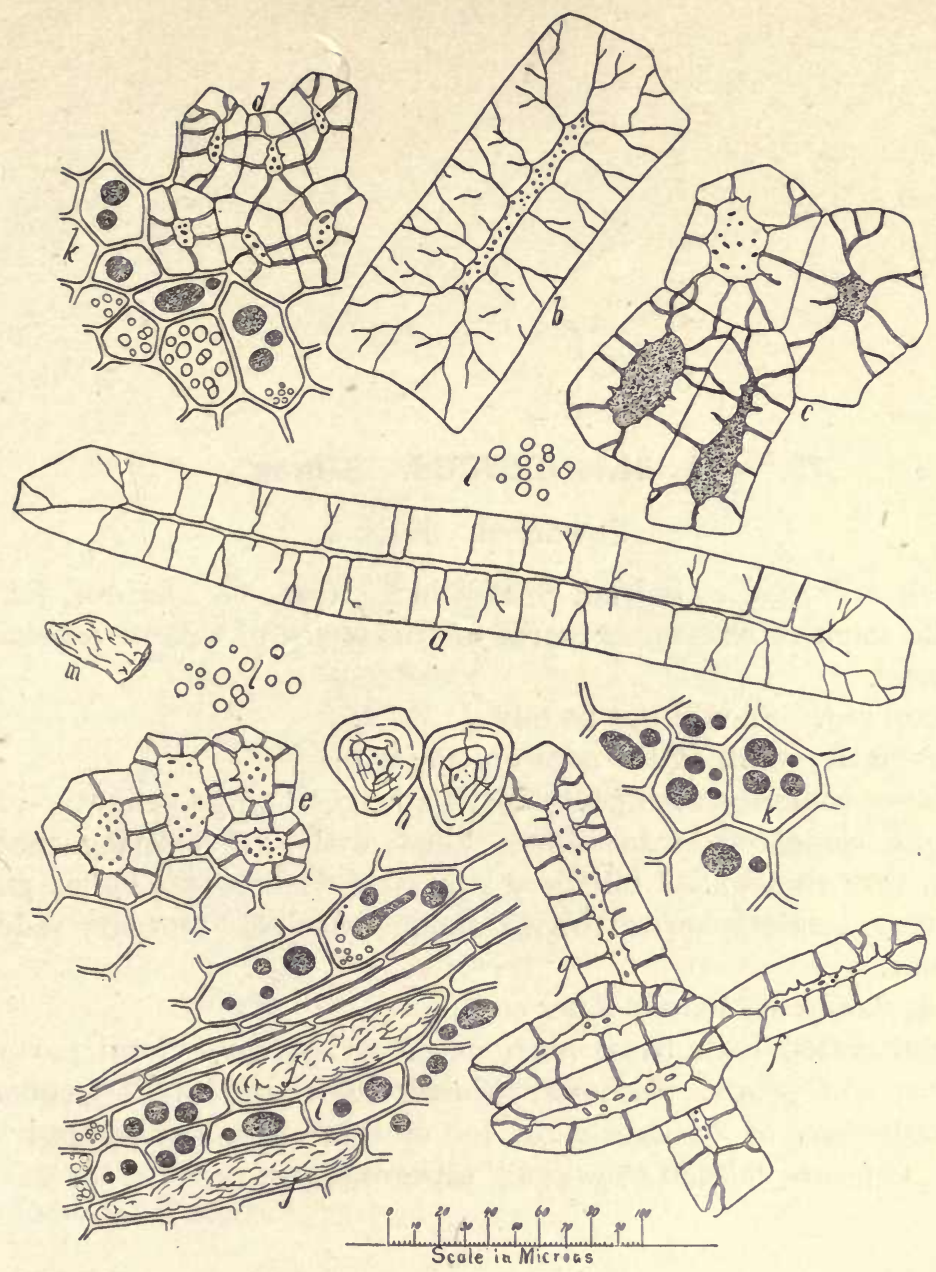

Fig. 83. COTO.

a. Large, long sclerenchyma cells.

b. Large rectangular sclerenchyma cells.

c. Sclerenchyma cells with granular contents.

- d. Medium sized sclerenchyma cells.

$e$. Thin walled sclerenchyma.

$f, g$. Elongated sclerenchyma.

$h$. Sclerenchyma with lamellar markings.

$i$. Dark reddish brown granular resinous matter.

j. Yellow resin.

k. Parenchyma.

l. Starch granules. 
75. (Fig. 84.) CROCUS. Saffron.

Powdered. Entire.

Spanish saffron, E. Safran, Spanischer Safran, G. Safran, Fr.

The stigmas and upper parts of the styles of Crocus sativus L. Iridaceae.

Deep red. Should not be oily.

Aromatic; recalling the odor of iodoform.

Bitter, somewhat pungent; saliva a bright orange yellow.

Cells elongated, thin-walled, filled with red coloring matter. Large, very thin-walled bladdery stigmatic trichomes. Pollen grains few, very large, spherical; exine thick, colorless; contents reddish, granular.

Ash should not exceed 5 per cent.

Adulterated with basal portions of styles, dyed floral parts, as stamens and petals. Safflower (Carthamus tinctorius) is frequently an adulterant of or substitute for crocus. Also adulterated with chalk, gypsum, colored emery, oil, glycerine, etc. 


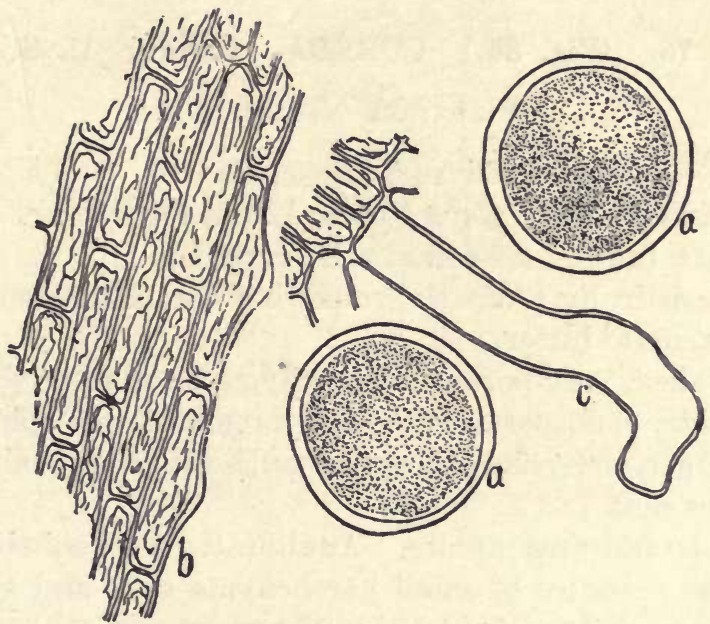

Fig. 84. CROCUS.

a. Pollen grains.

b. Tissue of style, cells with red coloring matter.

c. Trichome of stigma. 
76. (Fig. 85.) CUBEBA. Cubeb. U. S.

Fl. ex. 60 . Tinct. 30 .

Kubeben, G. Cubebe, poivre à queue, Fr.

The unripe fruit of Cubeba Cubeba L. fil., Piperaceae.

Deep dark brown; somewhat oily, granular.

Characteristically aromatic; somewhat camphoraceous.

Pungent, quite bitter.

Thick-walled, very porous sclerenchyma cells; some sclerenchymatous tracheids; endosperm cells with minute simple spherical starch granules; larger, somewhat elongated cells, containing oil.

Ash 7 per cent.

Powder deteriorates rapidly. Adulterated with cubeb stems (indicated by the presence of small parenchyma cells and abundance of vascular tissue and tracheids); black pepper and other fruits of the Piperaceae; Rhamnus Cathartica fruit, Juniper communis fruit, allspice; powdered nut shells, etc. 


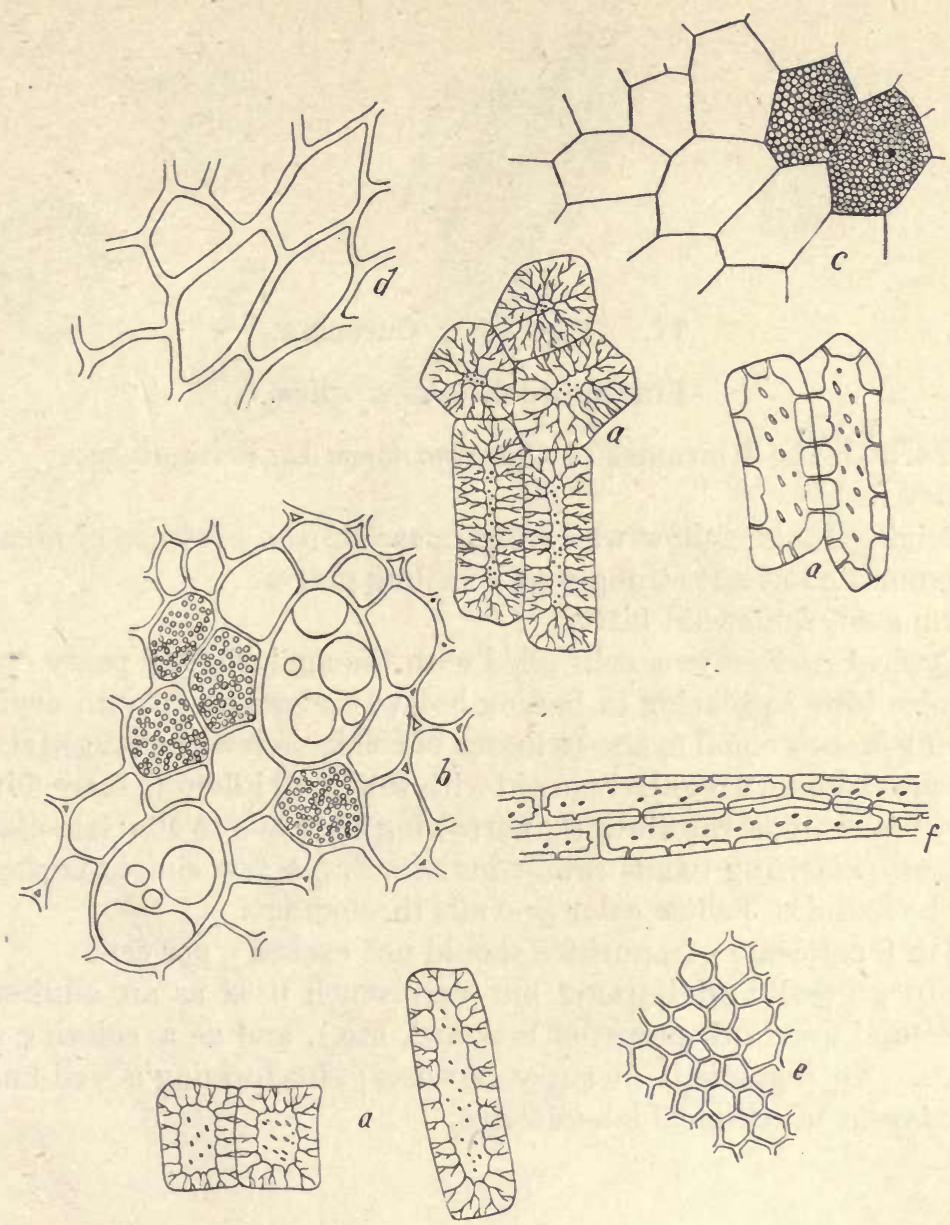

Fig. 85. CUBEBA.

a. Sclerenchyma.

b. Endosperm, with oil globules and proteid granules.

c. Cells of pericarp.

$d$. Parenchyma of stalk.

e. Epidermal cells, vertical view.

$f$. Tracheids. 


\section{7. (Fig. 86.) Curcuma.}

Fine powder. As a spice.

Turmeric. The Rhizomes of Curcuma longa L., Scitamineae.

Dry feel.

Bright orange yellow which disappears in the presence of alkalies.

Aromatic but not strongly so, recalling ginger.

Pungent, somewhat bitter.

Typical parenchyma cells filled with the agglurinated pasty starch granules (due to placing in boiling hot water preparatory to drying), forming masses equal in size to lumen of cells. A few unchanged starch granules; simple, irregularly ovoid with the small hilum (a mere dot) at the extreme tip of the abruptly narrowing end; $30 \mu$ to $40 \mu$; lamellation distinct, polarizing bands rathet indistinct. A few simple trichomes may be found. Yellow color prevails throughout.

Ash 8 per cent. Impurities should not exceed 5 per cent.

Not generally adulterated but very much used as an adulterant (in ground mustard,' prepared mustard, etc.), and as a coloring substance. An ingredient in curry powders; also forming a well-known test reagent in chemical laboratories. 


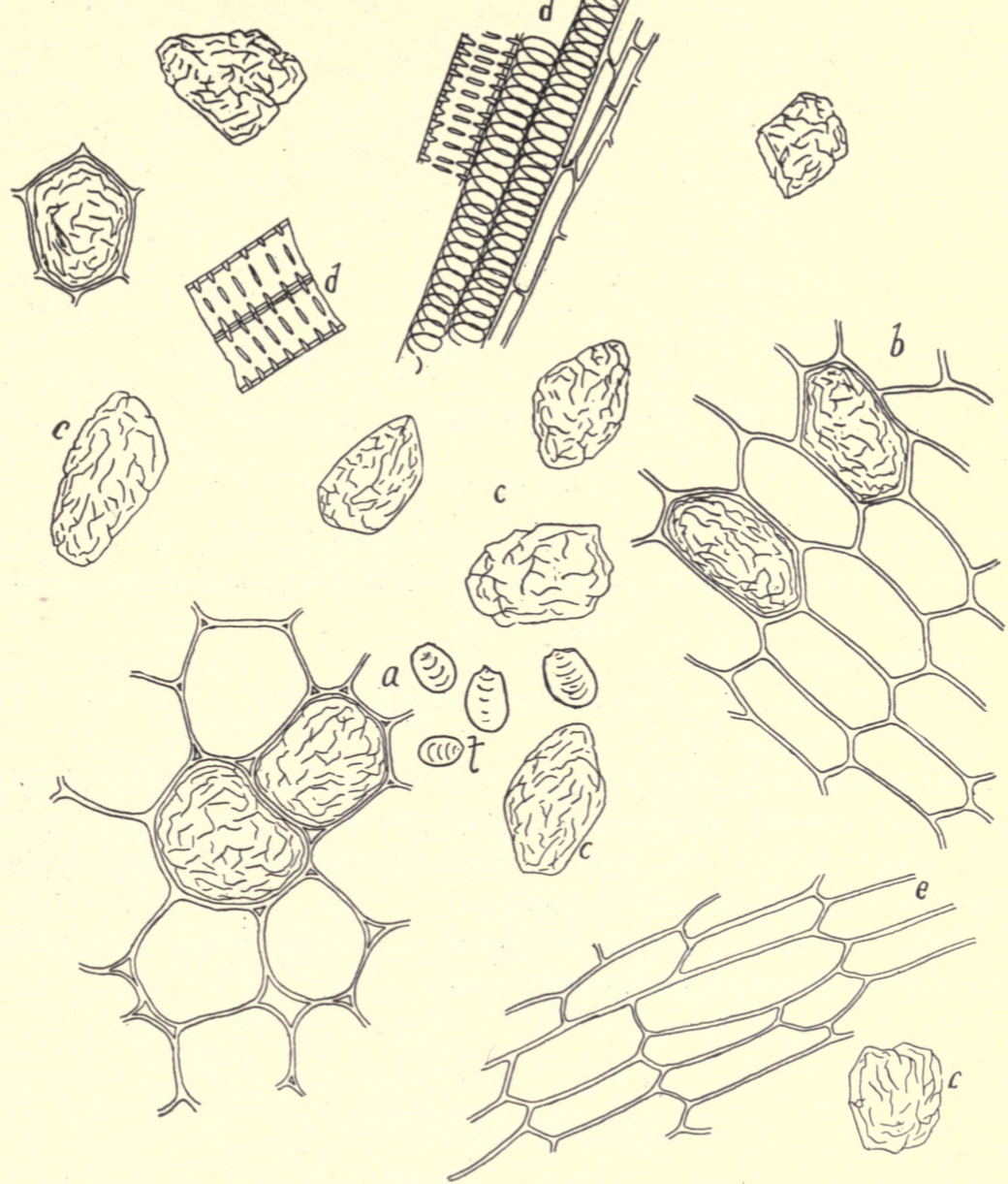

Fig. 86. CURCUMA.

a. Parenchyma with pasty starch.

b. Parenchyma, longitudinal view.

c. Masses of pasty starch.

d. Ducts.

e. Parenchyma.

$f$. Normal starch granules. 


\section{8. (Fig. 87.) CUSSO. Kousso.}

Fl. ex. 40.

Brayera, Kusso, E. Koso, Kusso, Cusso, G. Kousso, Fr.

The female (pistillate) flowering tops of Hagenia abyssinica Gmelin, Rosaceae.

Rather light brown.

Fragrant, recalling chamomile; somewhat heavy.

Bitter, pungent.

Epidermal cells with straight and wavy vertical walls; simple, somewhat twisted, single celled, trichomes; spherical pollen grains with three pores each; many celled glandular trichomes; typical aggregate crystals of calcium oxalate.

Numerous pollen grains and parts of anthers filled with pollen indicates adulteration with male flowers. 


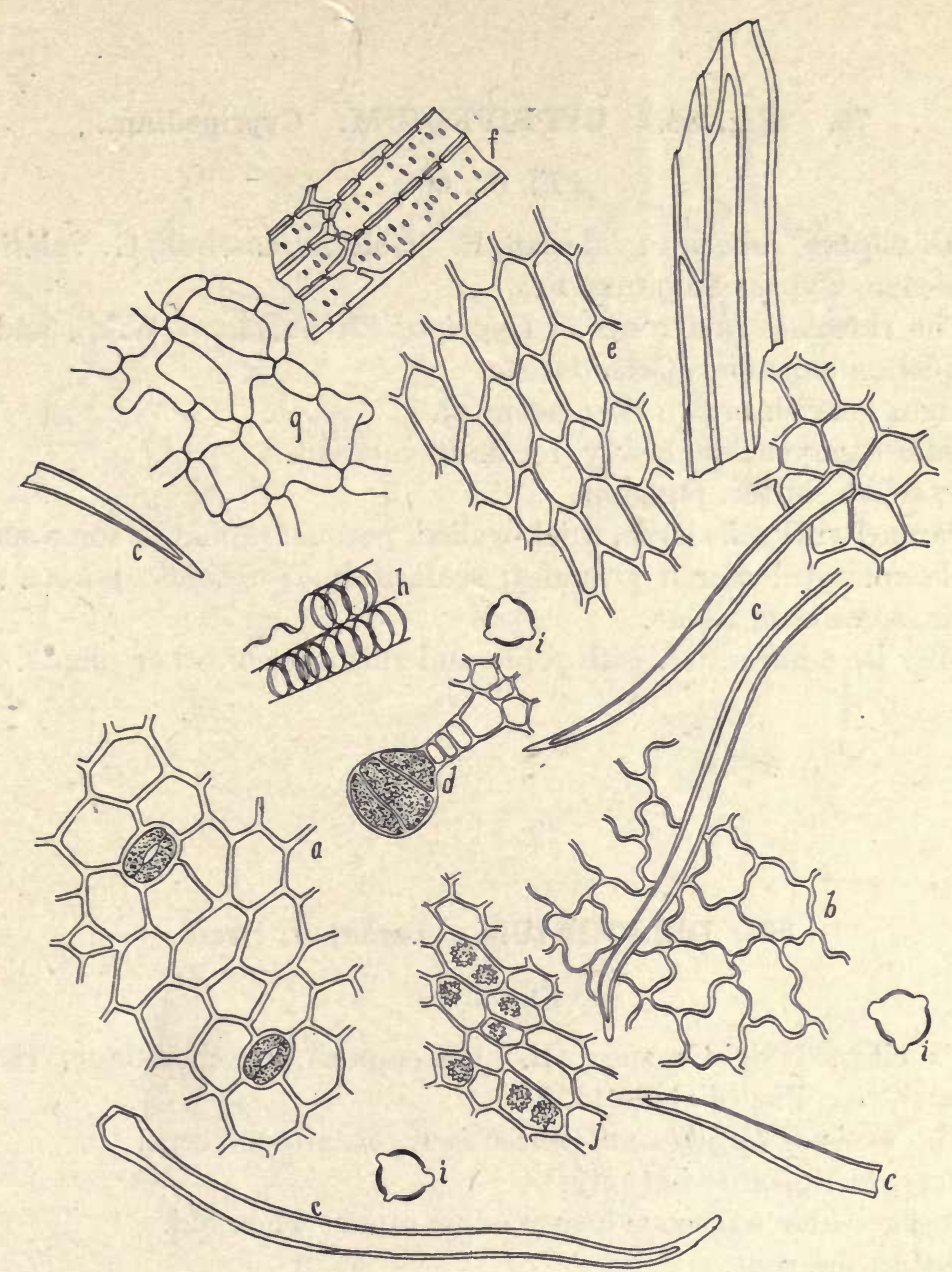

Fig. 87. CUSSO.

a. Lower epidermis.

b. Upper epidermis.

c. Trichomes.

d. Glandular trichome.

e. Parenchyma.

f. Tracheids.

$g$. Spongy tissue cells of leaf.

h. Spiral ducts.

$i$. Pollen grains. 


\section{9. (Fig. 88.) CYPRIPEDIUM. Cypripedium.}

Fl. ex. 60 .

Ladies' slipper, American valerian, E. Gelbfrauenschuh, G. Valêriane americane, Cypripede jaune, Fr.

The rhizomes and roots of Cypripedium pubescens Wild., and $C$. parviflorum Salisbury, Orchidaceae.

Light grayish brown (like aconite).

Odor disagreeable, heavy, recalling valerian.

Sweetish, bitter, pungent.

Parenchyma cells large, thick-walled, porous; raphides; some small, simple spherical starch granules; scalariform tracheids; porous tracheids; some cork tissue.

May be adulterated with roots and rhizomes of other plants.

\section{DELPHINIUM. Larkspur. Seed.}

Fl. ex. 40 .

Lark's claw, Knight's spur, E. Rittersporn, Lerchenklaue, Hornkümmel, G. Pied d'alouette, Fr.

The seeds of Delphinium consolida L., Ranunculaceae.

Very dark; somewhat oily.

Disagreeable nauseous heavy odor; rancid when old.

Bitter, pungent.

Outer cells of seed coat quite large; black, indistinct collapsed, thin-walled parenchyma. Endosperm cells large, thick-walled very porous and somewhat collenchymatous, filled with granular proteid matter and fat.

The seeds of related species are frequently substituted for the above. 


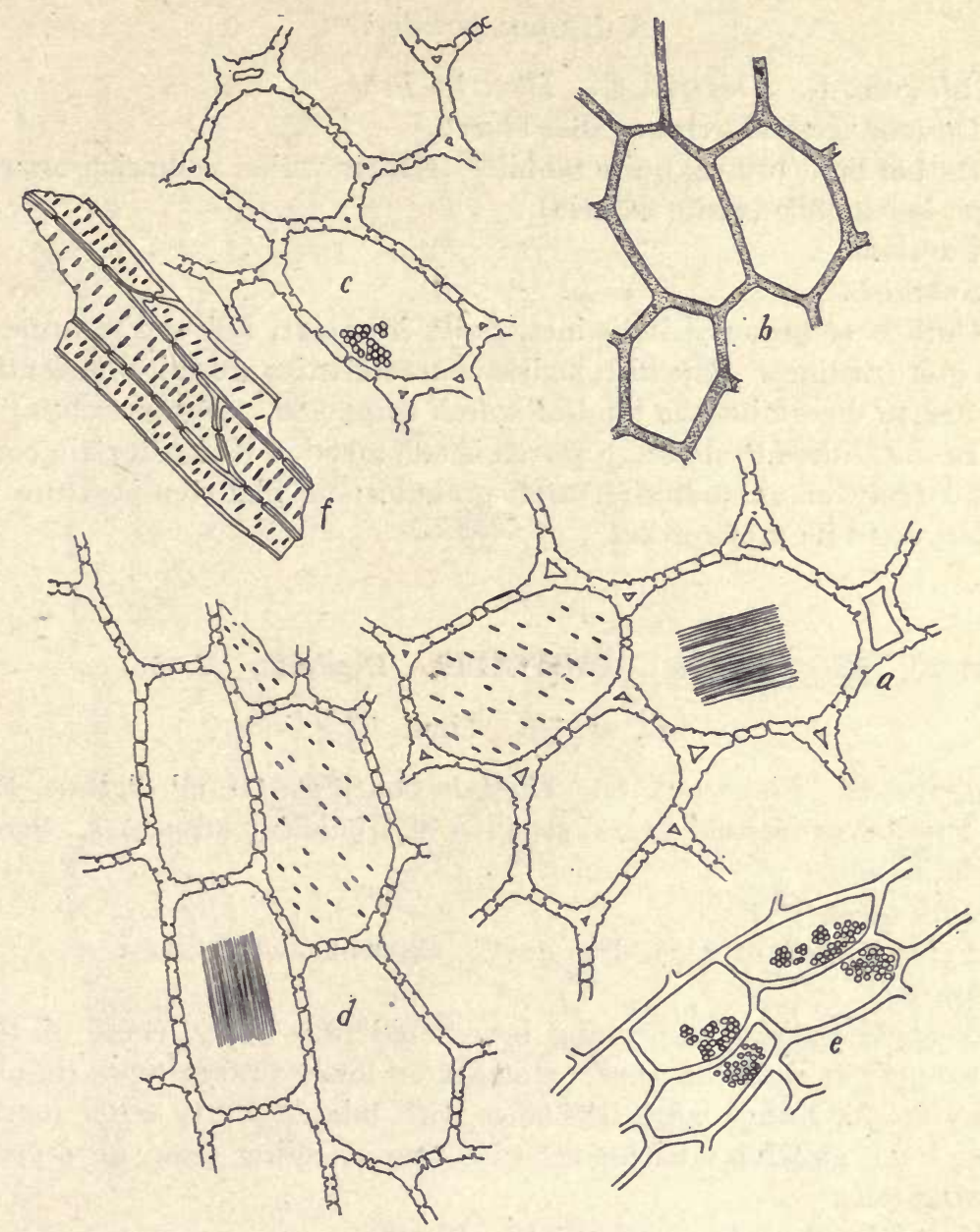

Fig. 88. CYPRIPEDIUM PUBESCENS.

$a, c, d$. Parenchyma cells and raphides.

b. Cork cells.

e. Parenchyma with starch granules.

f. Tracheids. 


\section{DEXTRINUM. Dextrin.}

A dry fine powder.

British gum, E. Dextrin, G. Dextrin, Fr.

Derived from starches. (See starch.)

Rather light brown, quite mobile. Nearly white, yellowish brown tinge, less mobile (white dextrin).

Odorless.

Sweetish.

Outline of granules indistinct, quite irregular, hili and stratification quite distinct. The histological characteristics are still sufficiently marked to determine the kind of starch employed. (See starches.)

In the United States corn starch is employed. White dextrin consists largely of unmodified starch granules; no high temperature is employed in its preparation.

\section{2. (Fig. 89.) DIGITALIS. Digitalis. U. S.}

Fl. ex. 60. Tinct. 60 .

Foxglove, E. Fingerhut, G. Digitale pourprée, Grand digitale, Fr.

The leaves (second years' growth) of Digitalis purpurea L., Scrophulariacex.

Dull green.

Faintly fragrant when dry; heavy, nauseous, when moist.

Bitter.

Vertical walls of upper and lower epidermis wavy, those of the lower more so than the upper; stomata on lower surface only; simple, many celled, rather large trichomes with minute warty outer markings; some glandular trichomes with two secreting cells; no crystal bearing cells.

Ash 8.5 per cent.

Adulterated with leaves of first year's growth; leaves of Verbascum Thapsis, (large, branched trichomes); Conyza squarrosa; Symphytum officinale; Inula Helenium; and common Comfrey. The histology of first and second year leaves requires further careful comparative study. The leaves of the first year plants contain fewer trichomes than the second year leaves and it is probable that a careful comparative trichome count will make it possible to detect admixtures. 


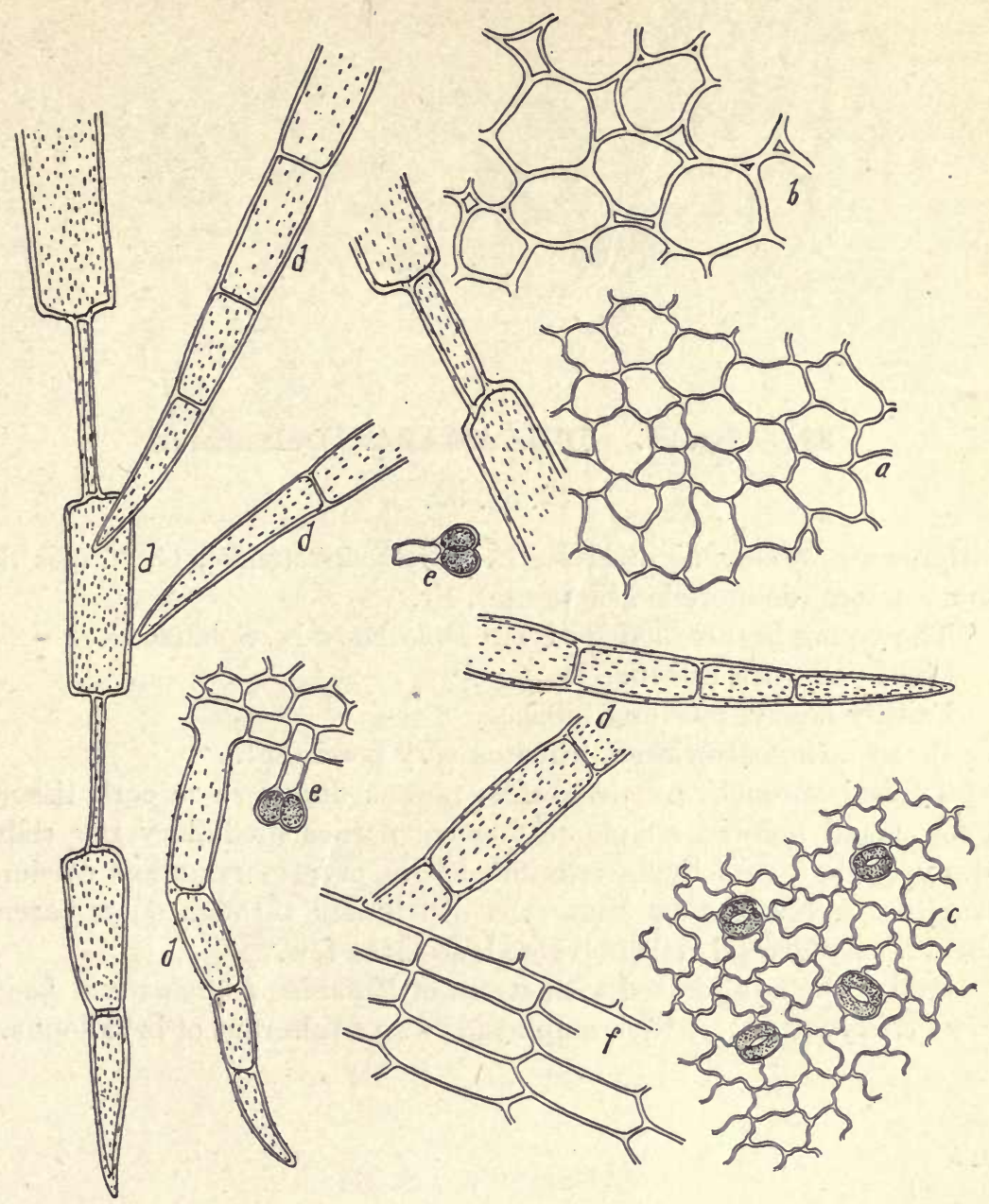

Fig. 89. DIGITALIS.

a. Upper epidermis.

b. Parenchyma.

c. Lower epidermis.

d. Trichomes.

e. Glandular trichomes.

f. Parenchyma, longitudinal view. 


\section{3. (Fig. 90.) DULCAMARA. Dulcamara.}

Fl. ex. 60 .

Bittersweet, woody nightshade, E. Bittersüssstengel, G. Tiges de douce-amere (de morelle grimpante), Fr.

The young branches of Solanum Dulcamara L., Solanaceæ.

Light yellowish brown.

Faintly heavy, recalling tobacco.

Bitter, afterwards sweet which is very persistent.

Typical parenchyma; tracheids; porous ducts; some cork tissue; a few small pointed simple trichomes; porous medullary ray cells. Many of the parenchyma cells filled with crypto-crystalline calcium oxalate. A few typical bast cells distributed through outer parenchyma. Epidermal cells polygonal; stomata few.

Said to be adulterated with stems of Humulus Lupulus and Lonicera Periclymenum. Much employed as an adulterant of belladonna. 


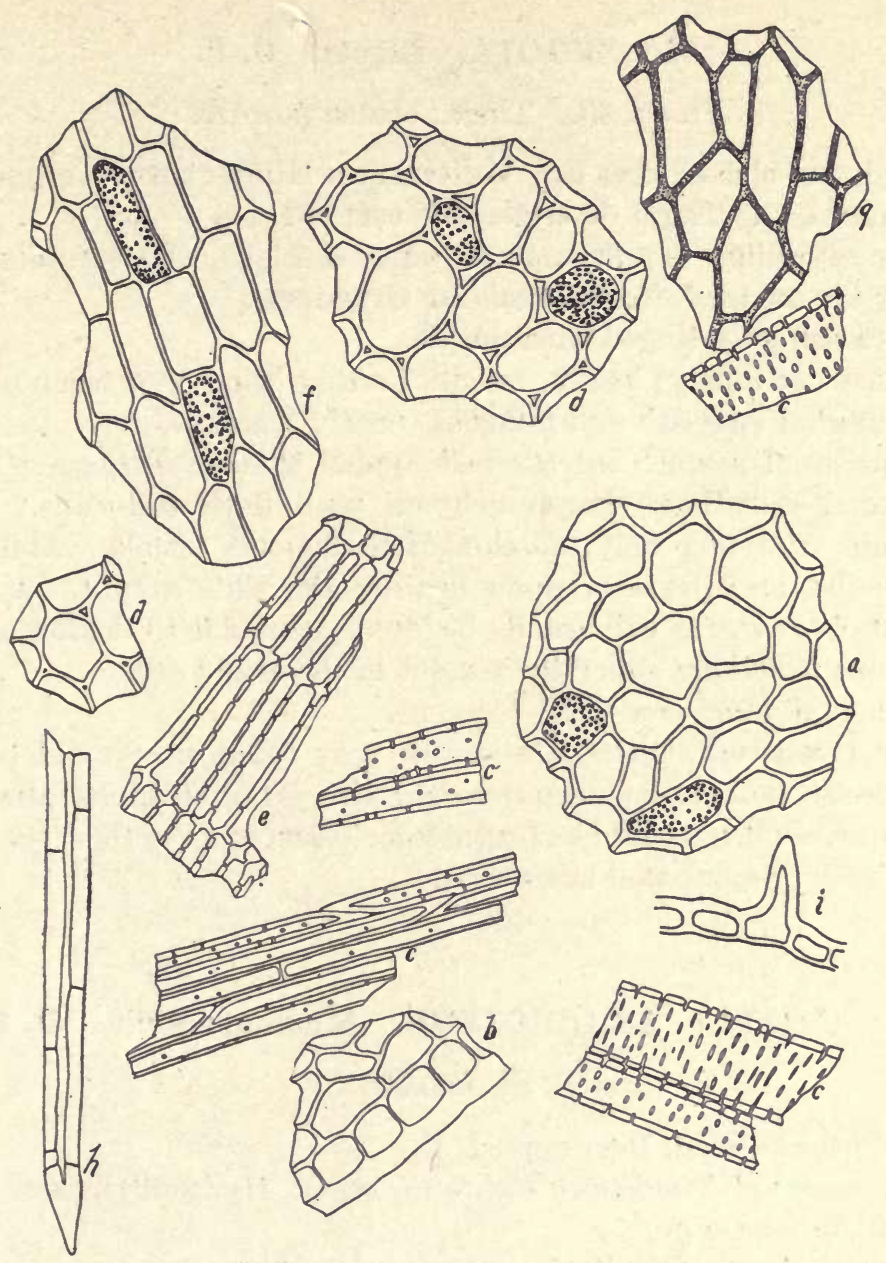

Fig. 90. DULCAMARA.

a. Epidermis.

b. Epidermis, lateral view.

c. Tracheids or wood fibers and porous ducts.

d. Parenchyma, with crypto-crystals.

e. Medullary ray.

f. Parenchyma, longitudinal view, with crystals.

g. Cork.

h. Typical bast.

i. Trichome. 


\section{ERGOTA. Ergota. U. S.}

Fl. ex. 60. Tinct., coarse powder.

Spurred rye, blasted rye, E. Mutterkorn, Hungerkorn, Kornmutter, Zapfenkorn, G. Ergot de seigle, Blé cornu, Fr.

The mycelium of Claviceps purpurea Tuslane, Hypocreaceæ, displacing the seeds of Secale cereale L., Gramineæ.

Dark ash gray tinged with purple.

Somewhat musty; heavy, rancid, herring brine odor when old.

Somewhat sweetish and pungent; nearly tasteless.

Consists of a much intertwined hyphal tissue. The outer layers of a small-celled pseudo-parenchyma with dark cell-walls. Small fragments of hyphæ only, no elongated elements visible. Abundant oil globules may be seen upon heating the slide mount. A small amount of rye starch will usually be found, traceable to the few normal rye grains which are generally present in the crude drug.

Ash should not exceed 4.5 per cent.

The powdered article deteriorates very rapidly. Should be free from foreign mold elements and yeast cells. May be adulterated with corn smut. There should be no vascular tissue or any other true vegetable tissue or epidermal structures.

\section{5. (Fig. 91.) ERIODICTYON. Mountain Balm. U. S.}

Fl. ex. 30 .

Consumptives' weed, Bear's weed, E.

The leaves of Eriodictyon Californicum G., Hydrophyllaceæ.

Light brownish green.

Somewhat aromatically fragrant; recalling tea or hay.

Sweetish, bitterish, sticky (resin).

Upper epidermal cells comparatively large, thick-walled with linear cuticular markings, vertical walls straight. Lower epidermal cells similar in form, but much smaller, and not readily seen because of the numerous trichomes. Numerous simple, single-celled, thickwalled, elongated, wavy trichomes. Some sessile glandular trichomes. Aggregate crystals of calcium oxalate.

Ash 7 per cent.

Mixed with Eriodictyon tomentosum which has short trichomes. 


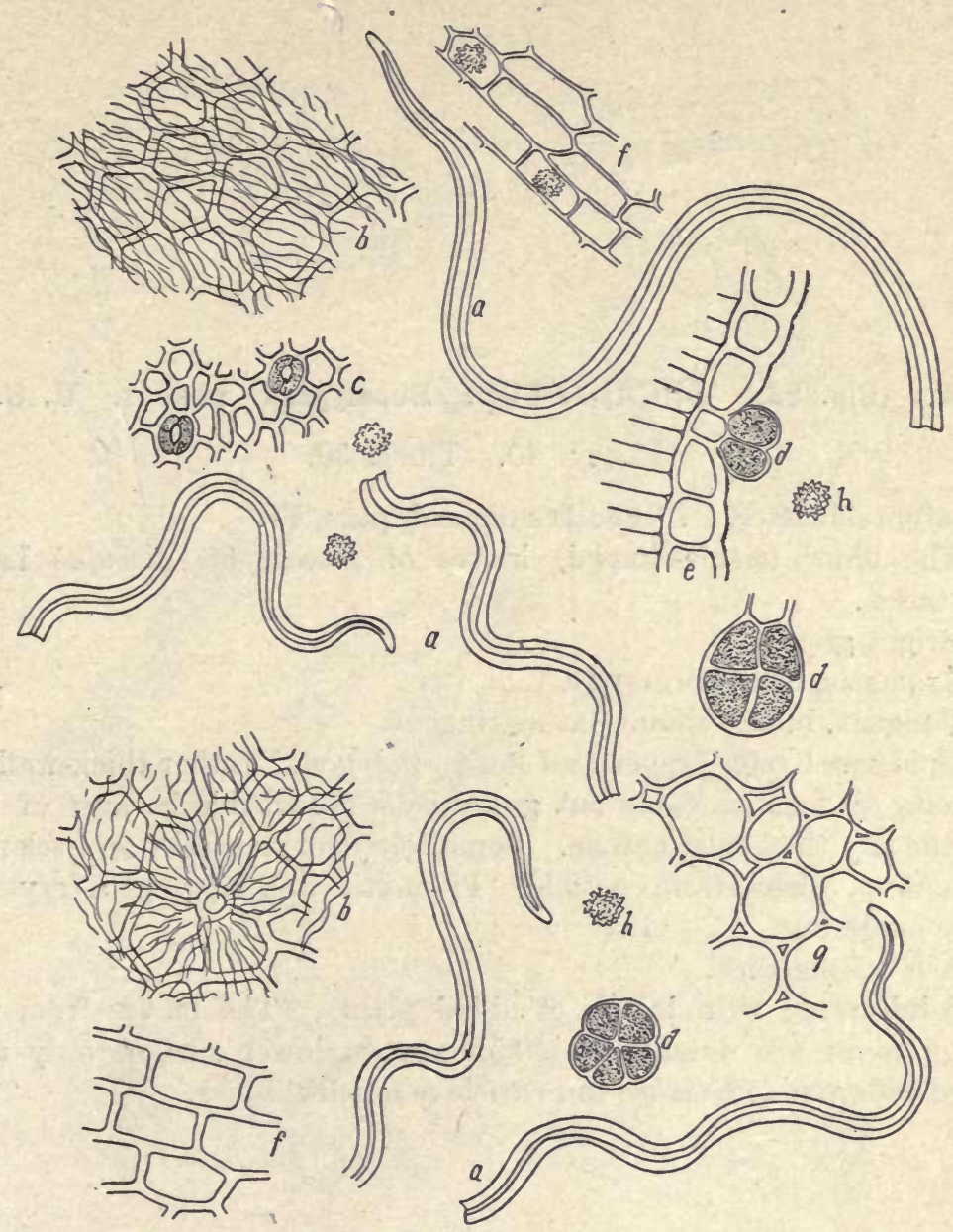

Fig. 91. ERIODICTYON.

a. Trichomes.

b. Upper epidermis.

c. Lower epidermis.

d. Glandular trichomes.

e. Upper epidermis, lateral view.

$f$. Parenchyma with crystals, longitudinal view.

g. Parenchyma.

h. Crystals. 
86. (Fig. 92.) EUCALYPTUS. Eucalyptus Leaves. U. S.

Fl. ex. 40. Tinct. 30.

Eukalyptusblätter, G. Feuilles d'eucalyptus, Fr.

The older (sickle-shaped) leaves of Eucalyptus globulus Lab., Myrtaceæ.

Bright green.

Aromatic, camphoraceous.

Pungent, bitter, somewhat astringent.

Epidermal cells (upper and lower) polygonal, rather thick-walled; stomata on both surfaces but guard cells not visible because of the enormously thickened cuticle. Some sclerenchyma cells and sclerenchymatous fibers from petiole. Prismatic and aggregate crystals quite numerous.

Ash 6.5 per cent.

Adulterated with leaves of allied plants. The leaves from the young plant are dorsiventral, stomata on lower surface only and guard cells visible because the cuticle is much thinner. 

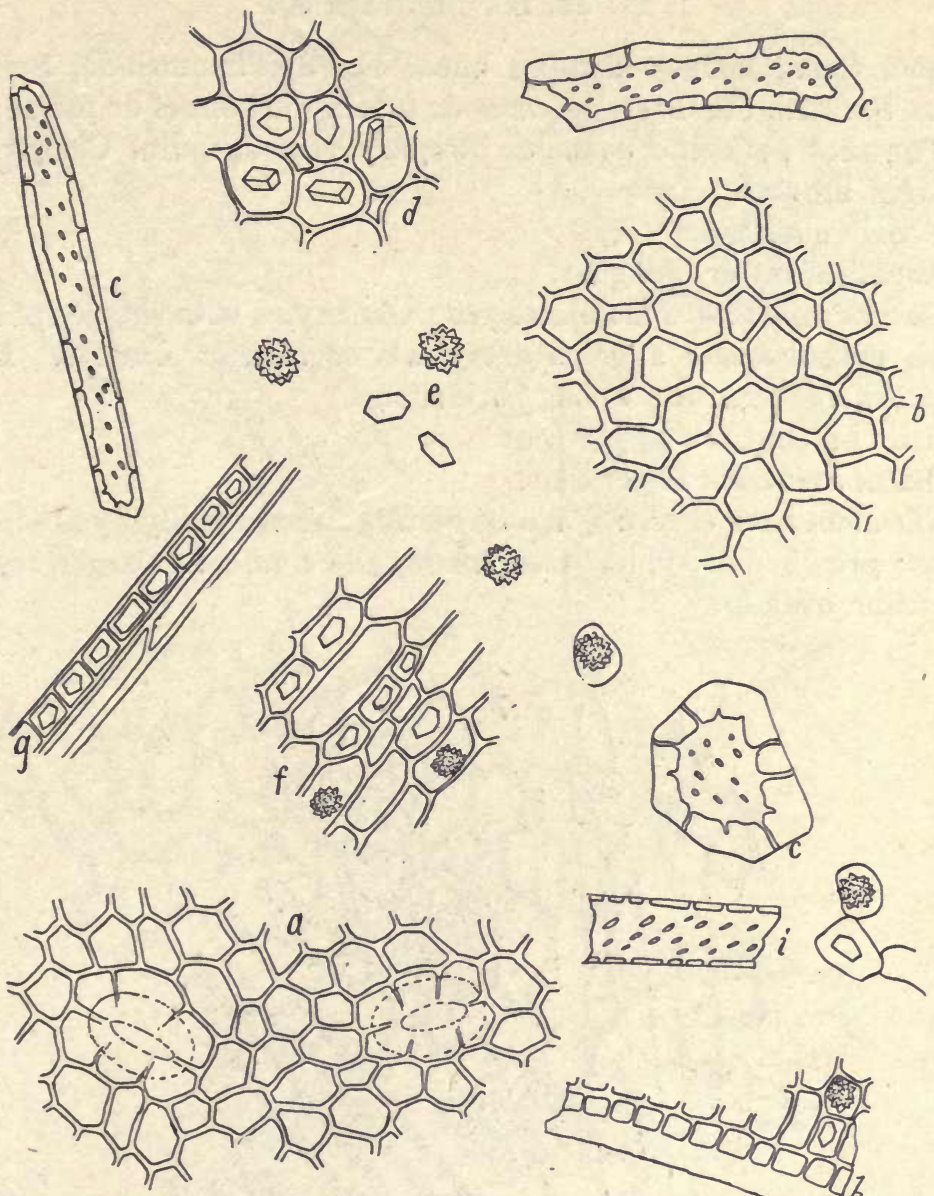

Fig. 92. EUCALYPTUS.

$a, b$. Epidermal tissues.

c. Sclerenchyma cells.

d. Parenchyma with crystals.

e. Prismatic and aggregate crystals.

f. Parenchyma, longitudinal view.

g. Crystal bearing fiber.

h. Epidermal cells. Profile view.

i. Tracheid.

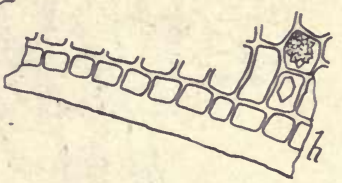


87. (Figs. 93 and 94.) EUONYMUS. Euonymus.

Fl. ex. 60. Extract 30.

Wahoo, Spindle tree, Burning bush, E. Spillbaumrinde, Spindelbaum, Pfaffenblüthen, G. Ecorce de fusain (de bonnet de prêtre), Fr.

The root bark of Euonymus atropurpureus Jacquin, Celastrineæ.

Light brown.

Nearly odorless.

Sweetish, bitter, pungent.

Rather thin-walled medium sized parenchyma with simple spherical starch granules and aggregate crystals of calcium oxalate. Ducts and tracheids from the wood; cork tissue.

Ash of stem bark 11 per cent.

Ash of root bark 12 per cent.

The stem bark (Fig. 93) can be distinguished readily by absence of starch; presence of typical bast fibers, and numerous larger crystals of calcium oxalate.

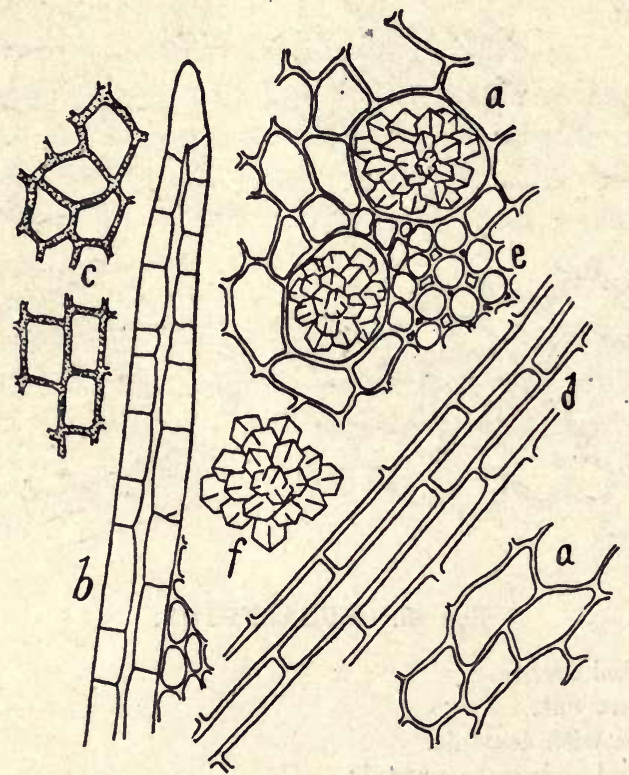

Fig. 93. EUONYMUS. Stem Bark.

a. Parenchyma with large aggregate crystals of calcium oxalate.

b. Typical thick-walled porous bast.

c. Cork.

d. Phlœm bast shown in transverse section (e).

$f$. Crystal. 


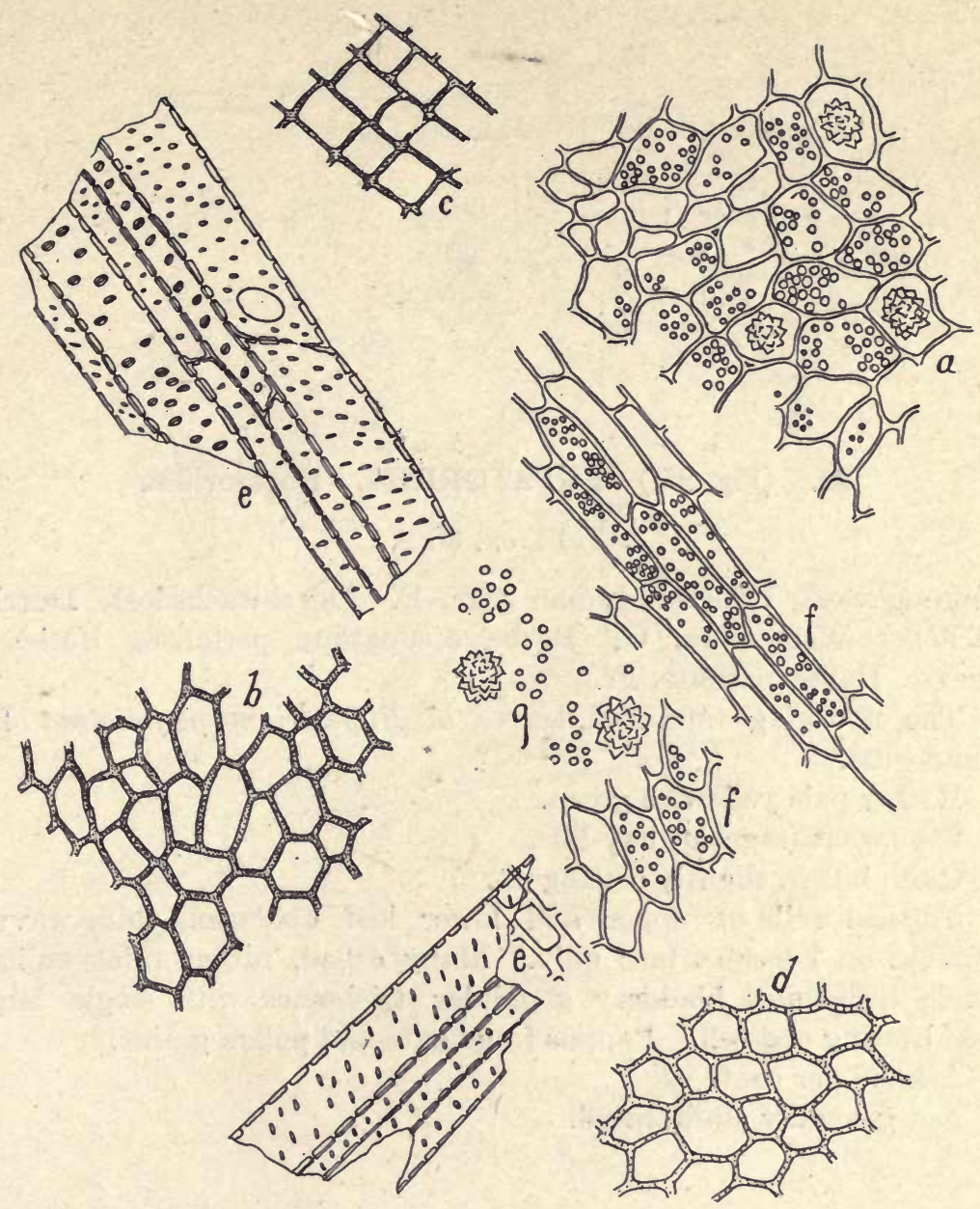

Fig. 94. EUONYMUS. Root Bark.

a. Parenchyma with starch granules and aggregate crystals of calcium oxalate. $b$, c. Cork tissue, top view and lateral view.

d. Cork.

e. Ducts and tracheids.

f. Parenchyma with starch, longitudinal view.

g. Starch and crystals. 


\section{8. (Fig. 95.) EUPATORIUM. Eupatorium.}

Fl. ex. 30 .

Thoroughwort, Boneset, Indian sage, E. Durchwachsdost, Durchwachener Wasserdost, G. Herbe d'eupatoire perfoliee, Herbe a á fievre, Herbe parfaite, Fr.

The flowering tops and leaves of Eupatorium perfoliatum L., Compositæ.

Rather pale yellowish green.

Somewhat fragrant, hay-like.

Quite bitter, slightly astringent.

Vertical walls of upper and lower leaf epidermis thin, wavy. Stomata on lower surface only. Many celled, rather thick-walled, simple trichomes; bladdery glandular trichomes with single large resin bearing end cell. Pappus fragments and pollen grains.

Ash 7.5 per cent.

Not generally adulterated. 

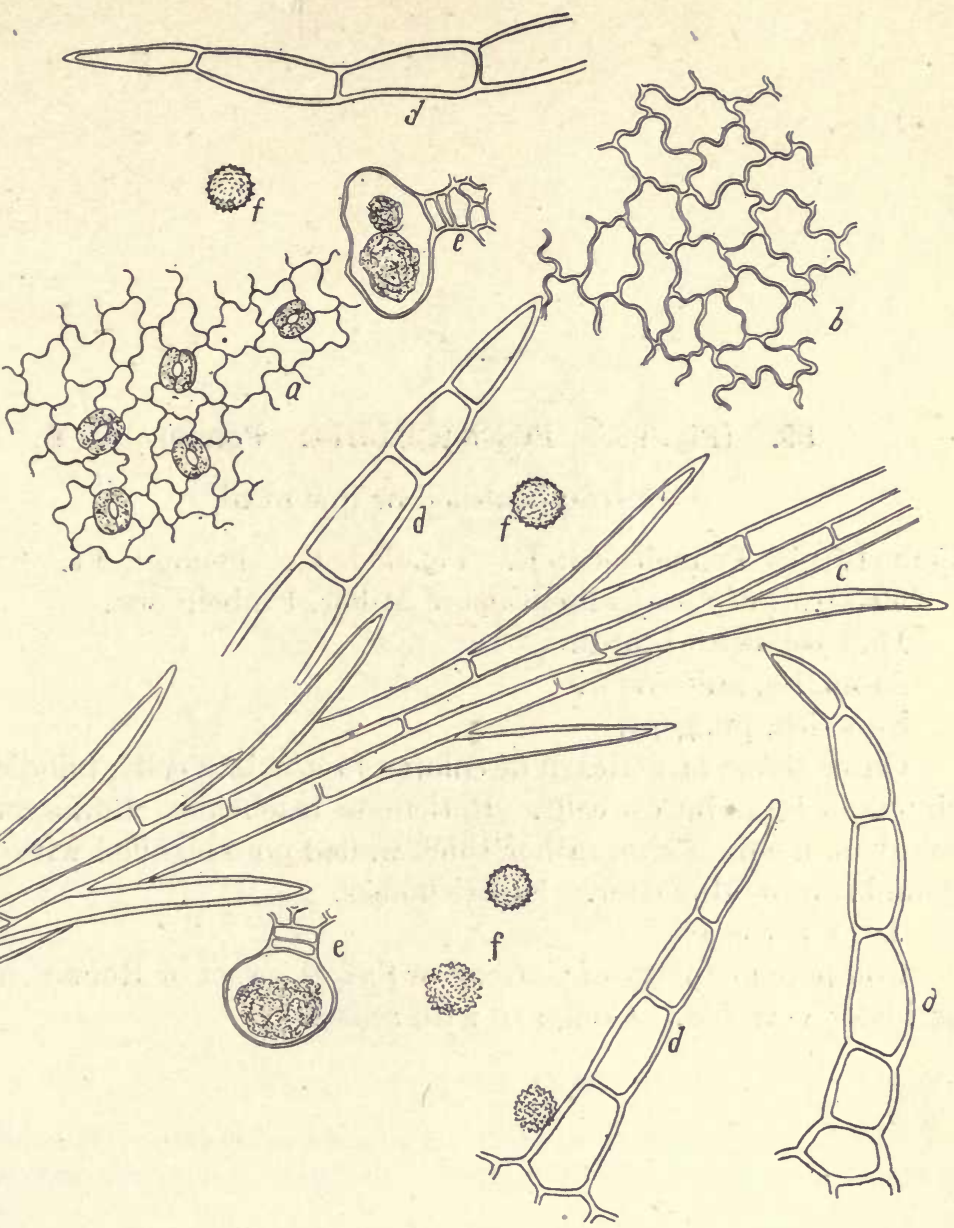

Fig. 95. EUPATORIUM.

a. Lower epidermis.

b. Upper epidermis.

c. Pappus.

d. Trichomes.

e. Glandular trichomes.

f. Pollen grains. 


\section{9. (Fig. 96.) FOENICULUM. Fennel. U. S.}

Entire; bruished or fine meal.

Fennel-fruit, Fennel-seed, E. Fenchel, G. Fenouil, Fr.

The fruit of Foeniculum vulgare Miller, Umbelliferæ.

Dull yellowish brown.

Aromatic, anise odor.

Sweetish, pungent.

Outer tissue of pericarp of colorless reticulate cells; middle parenchyma of large brown cells. Reticulate tracheids. Endosperm cells colorless, medium size, rather thick walled porous, filled with fat and granular proteid matter. No trichomes.

Ash 9 per cent.

Compare histology of German or Saxon, sweet or Roman, and wild or bitter varieties. Compare with anise. 


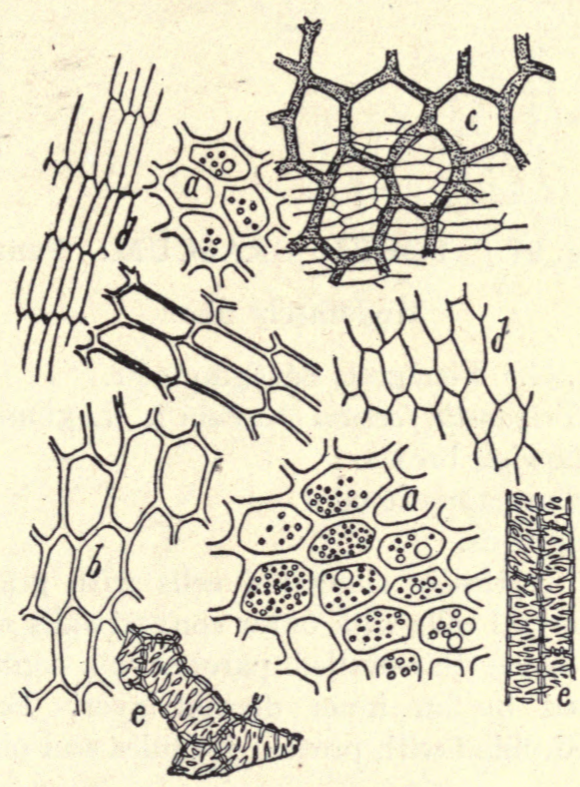

Fig. 96. FOENICULUM.

a. Endosperm cells bearing a few oil globules and crenate proteid granules.

b. Parenchyma cells of pericarp. Walls peculiarly pitted, not shown in drawing.

c. Deep reddish brown cells forming oil glands of pericarp.

$d$. Thin-walled cells.

e. Reticulate tissue. 
90. (Fig. 97.) FOEUM GRAECUM. Fenugreek.

Moderately fine.

Bockshornsamen, G. Fenugrec, Sénégrain, Fr.

The seeds of Trigonella foecum graecum L., Leguminosæ.

Very pale yellowish brown.

Very strong characteristic odor.

Bitter, mucilaginous.

Epidermis of vertically elongated cells with granular contents; semilunar hypodermal cells with outer convex walls much thicker, of yellowish color; some thin-walled parenchyma containing granular particles, followed by an inner dermal layer. Endosperm cells, rather thin-walled, filled with proteid granules and oil globules. 


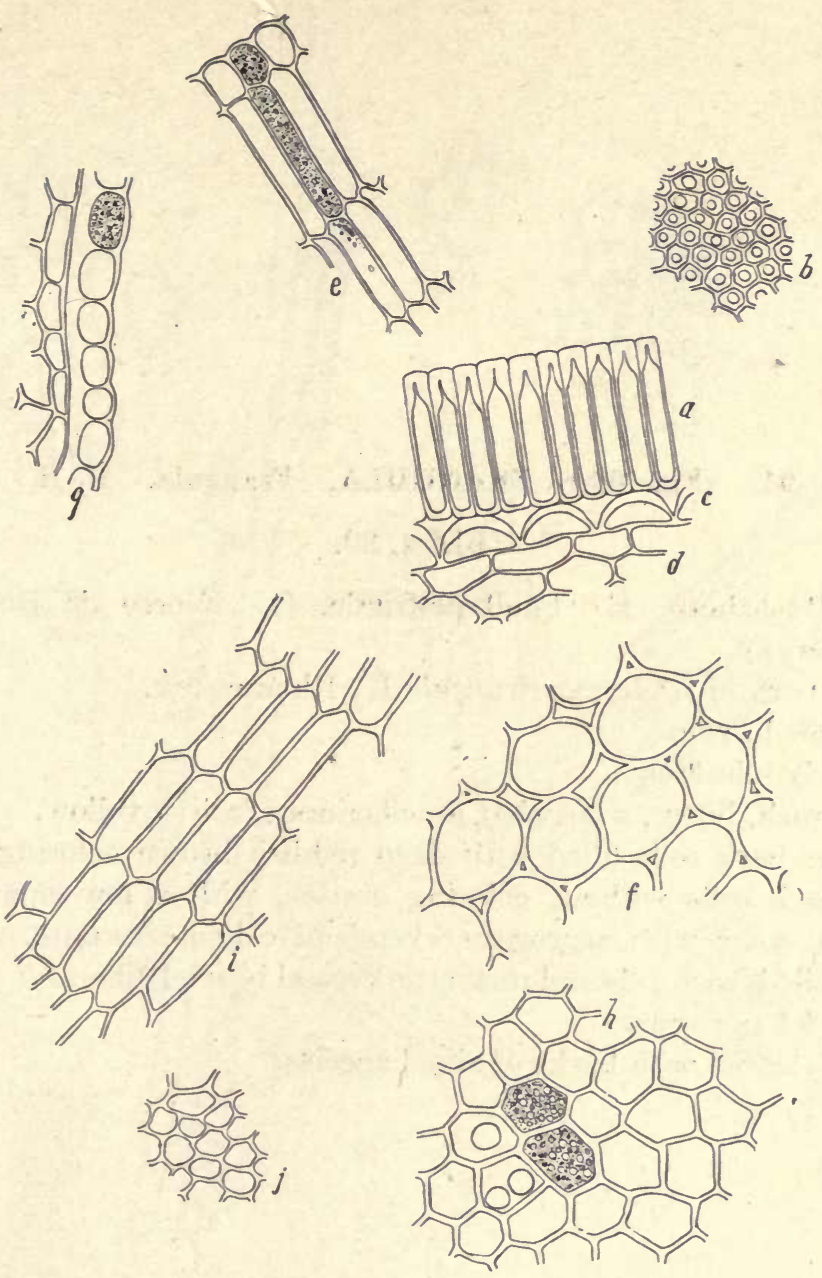

Fig. 97. FENUGREEK.

a. Epidermis, Iateral view.

b. Epidermis, vertical view.

c. Hypoderm.

d. Parenchyma.

e. Endosperm, outer.

f. Parenchyma.

g. Outer tissue.

$i, j$. Parenchyma. 
91. (Fig. 98.) FRANGULA. Frangula. U. S.

Fl. ex. 30.

Alder, Buckthorn, E. Faulbaumrinde, G. Ecorce de Bourdaine, Bourgène, Fr.

The bark of Rhamnus Frangula L., Rhamnaceæ.

Yellow brown.

Nearly odorless.

Sweetish, bitter, somewhat mucilaginous; saliva yellow.

Outer bark cells filled with deep reddish brown coloring matter. Inner bark cells without coloring matter, with a few small starch granules, some with aggregate crystals of calcium oxalate. Typical thick-walled bast cells and prismatic crystal bearing fibers.

Ash 4.5 per cent.

Adulterated with barks of allied species. 


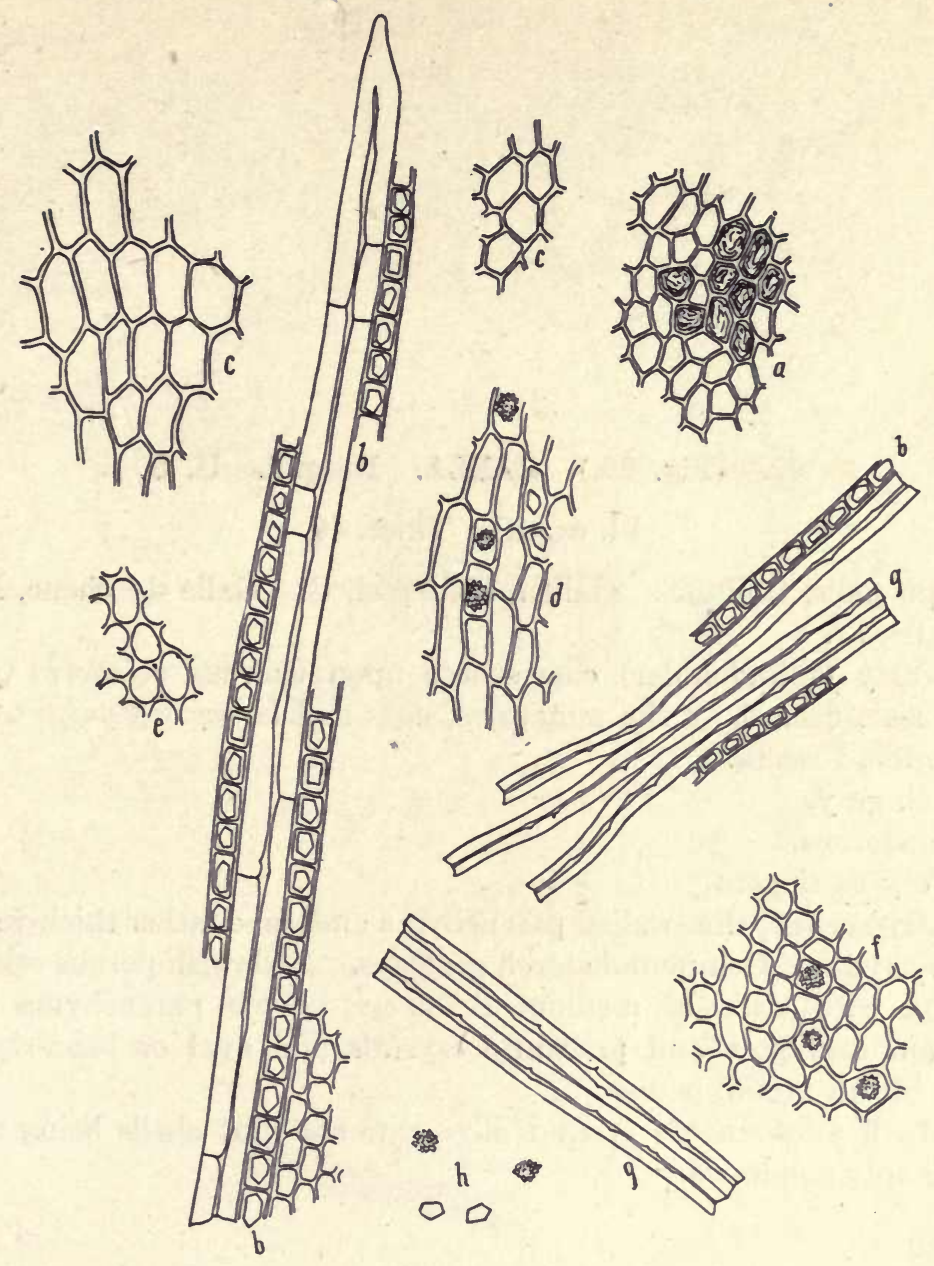

Fig. 98. FRANGULA.

a. Parenchyma with reddish brown contents.

b. Crystal bearing fibers.

c. Outer cork.

d. Parenchyma with crystals.

e. Parenchyma.

f. Parenchyma.

g. Bast. 


\section{2. (Fig. 99.) GALLA. Nutgall. U. S.}

Fl. ex. 40. Tinct. 40 .

Aleppo galls, Galls, E. Gallen, Galläpfel, G. Galle de chêne, Noix de galle, Fr.

Warty (sub-globular) excresences upon Quercus infectoria Oliv., Fagaceae, caused by the punctures, eggs and larvæ of Cynips Gallae tinctoriae, Insecta.

Ash gray.

Inodorous.

Very astringent.

Large celled, thin-walled parenchyma and some rather thick-walled parenchyma. Compound starch granules. Yellowish porous sclerenchyma with walls of medium thickness. Some parenchyma cells contain aggregate and prismatic crystals and oval or bean-shaped dark brown tannin bodies.

Much adulterated, ground olive pits and nut shells being most commonly employed. 


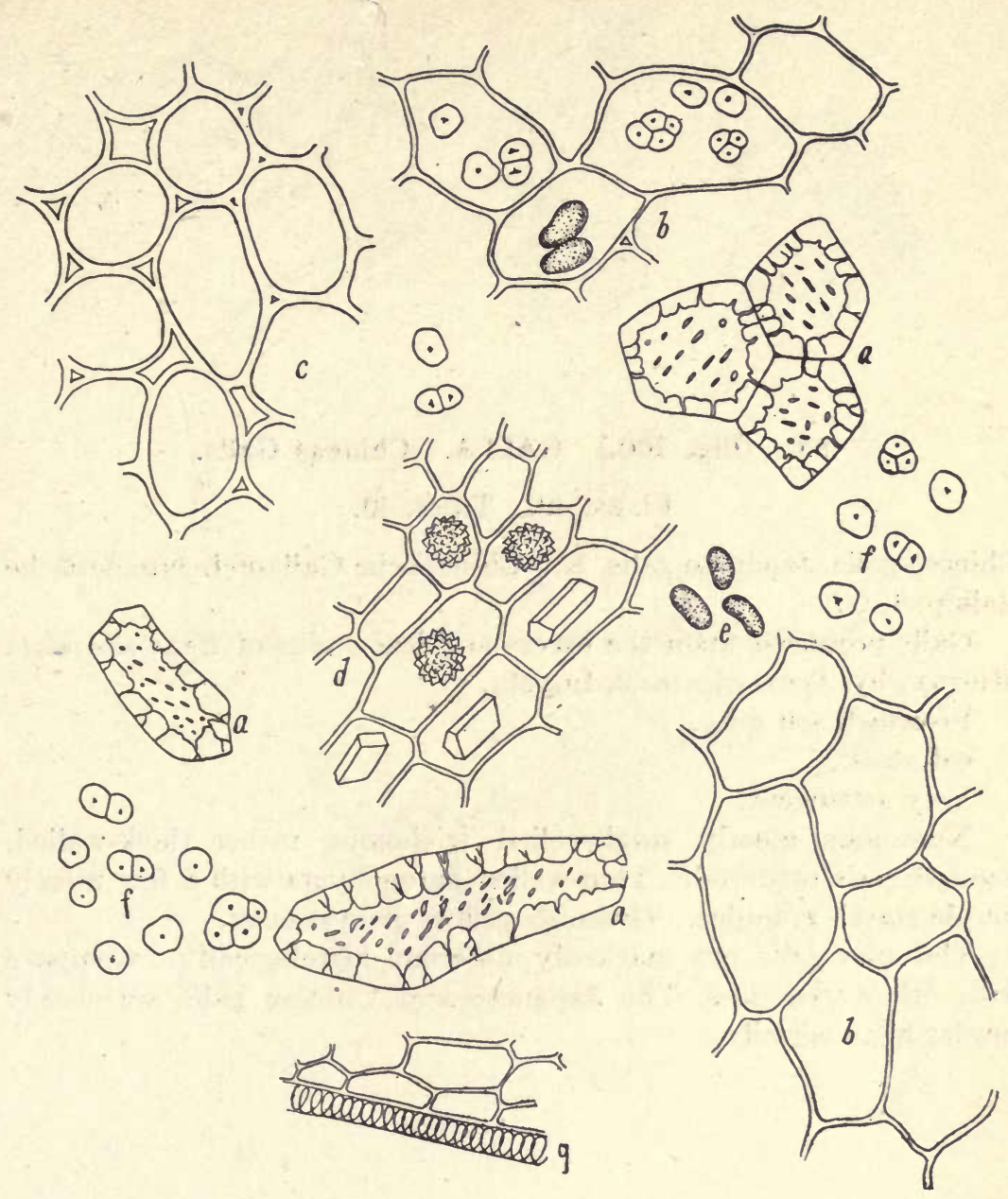

Fig. 99. GALLA. Aleppo.

a. Sclerenchyma.

b. Parenchyma with starch and tannin bodies.

c. Parenchyma.

d. Parenchyma with crystals.

e. Tannin bodies.

f. Starch granules.

g. Spiral duct. 


\section{3. (Fig. 100.) GALLA. Chinese Galls.}

Fl. ex. 40. Tinct. 40 .

Chinese galls, Japanese galls, E. Chinesische Galläpfel, Japanesische Galläpfel, G.

Galls produced upon the leaves and leaf stalks of Rhus semialata Murray, by Aphis chinensis, Insecta.

Brownish ash gray.

Odorless.

Very astringent.

Numerous mostly single-celled trichomes, rather thick-walled, pointed ends recurved. Thin-walled parenchyma with a few mostly simple starch granules. Greenish yellow resin masses.

The two galls are markedly different histologically. Compare with other varieties. The Japanese and Chinese galls are closely, similar histologically. 


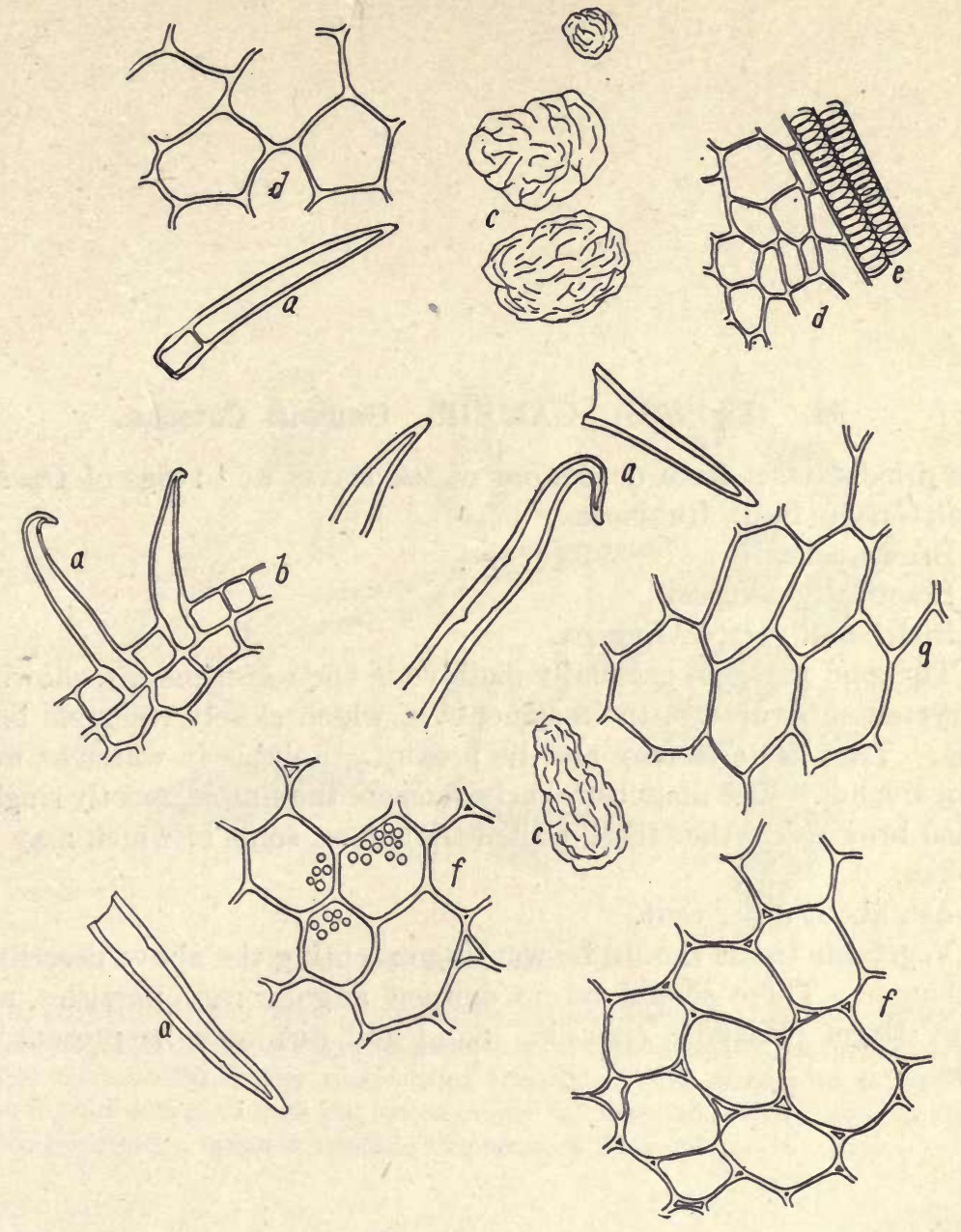

Fig. 100. GALLA. Chinese.

a. Trichomes.

b. Epidermis.

c. Yellow resin bodies.

d. Parenchyma.

e. Spiral ducts.

f. Parenchyma, witb starch. 


\section{4. (Fig. 101.) GAMBIR. Gambir. Catechu.}

The dried extract from decoctions of the leaves and twigs of Ourouparia Gambir Bail., Rubiaceæ.

Brown color.

Practically odorless.

Bitter and very astringent.

The gum particles gradually dissolve in the water mount, showing a crystalline structure, the fragments of which closely resemble bacteria. True bacteria may also be present. Soluble in water as well as in alcohol. The diagnostic inclusions are the simple, mostly singlecelled brownish rather thick-walled trichomes, some of which may be broken.

Ash about 5 per cent.

Vegetable tissue should be wanting excepting the above described trichomes. There should be no distinct angular resin particles, nor many larger prismatic crystals. Sand and dirt may be present in excess. 


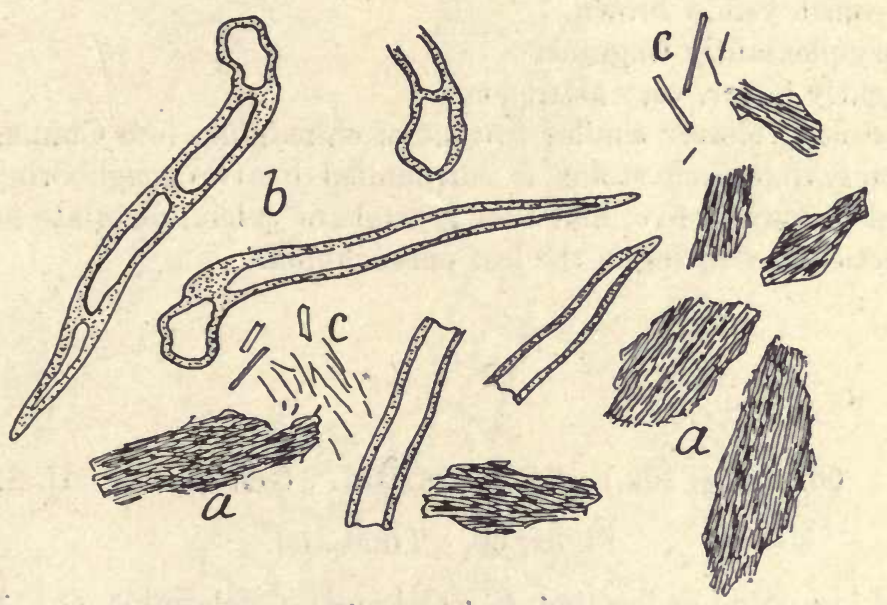

Fig. 101. GAMBIR.

$a$, particles of the gum mounted in water, showing the fine somewhat striate irregular needle-like crystalline structure; $l$, the diagnostic simple, brownish rather tbick-walled mostly single-celled trichomes. The thickening of the wall may extend entirely across the lumen giving the resemblance of a two- to threecelled trichome; $c$, larger crystalline fragments of the gambir. 


\section{GAULTHERIA. Gaultheria.}

Fl. ex. 40.

Wintergreen, Teaberry, Partridgeberry, Boxberry, Chickenberry, E. Canadischer Thee, Bergthee, G. Feuilles de gaulthérie, Thé du Canada, Thé de terre-neuve, Fr.

The leaves of Gaultheria procumbens L., Ericaceæ.

Greenish yellow brown.

Very pleasantly fragrant.

Slightly bitter, very astringent.

Histology closely similar to that of chimaphila (see Chimaphila), excepting that each stoma is surrounded by two neighboring cells instead of four to five, and that crystals or calcium oxalate are few or practically wanting in the leaf parenchyma.

\section{6. (Fig. 102.) GELSEMIUM. Gelsemium. U.S.}

Fl. ex. 60. Tinct., 60.

Yellow jessamine or jasmine, E. - Gelsemie, Giftjasmine, G. Jasmin sauvage, Fr.

The rhizomes and roots of Gelesemium sempervirens Aiton, Loganiacex.

Very pale brown.

Somewhat narcotic, heavy.

Very bitter.

Considerable cork tissue. Parenchyma cells rather small, with small spherical simple starch granules and prismatic crystals of calcium oxalate. Numerous tracheids and large porous ducts.

Ash 2.5 per cent.

Rarely adulterated. 

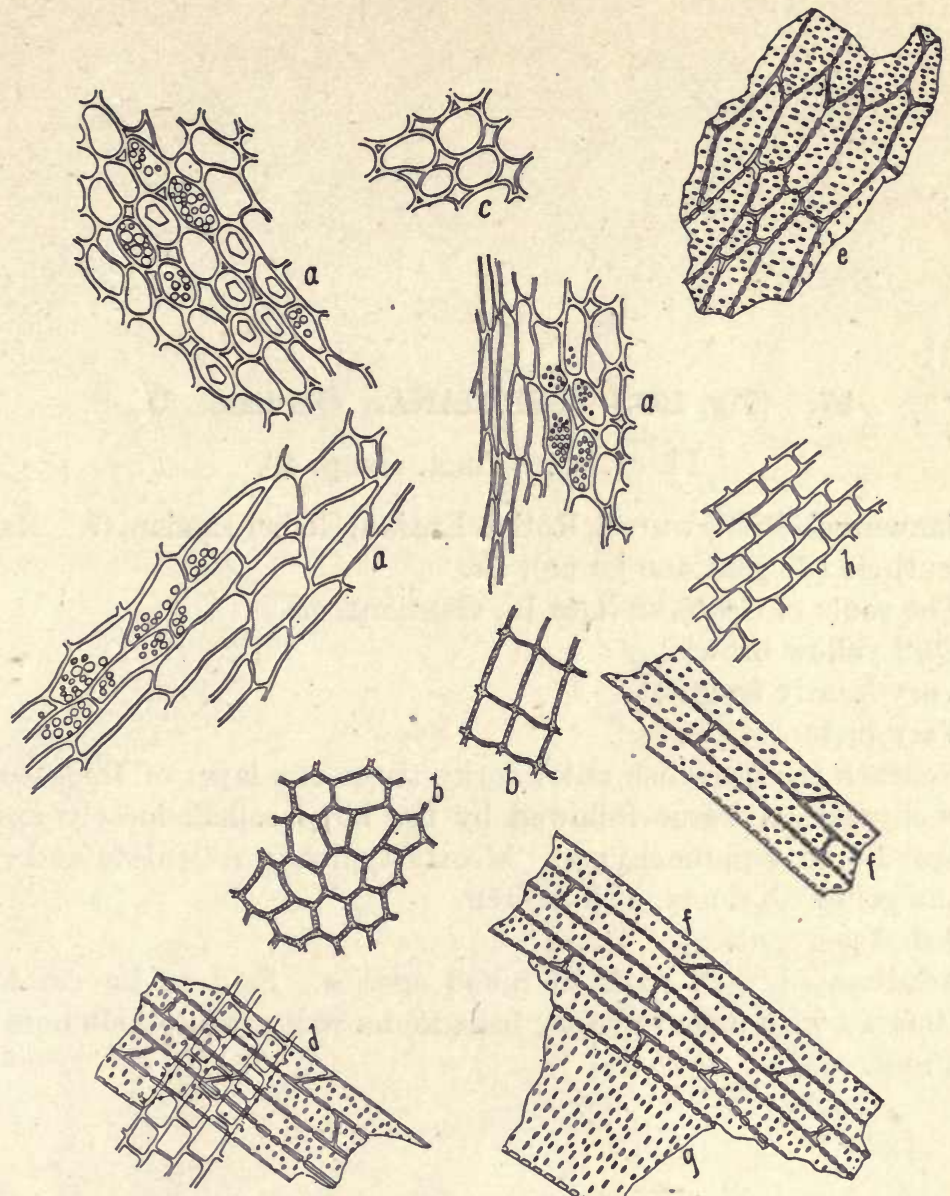

Fig. 102. GELSEMIUM.

a. Parenchyma with starch.

b. Epidermal tissue.

c. Parenchyma.

d. Tracheids and medullary ray.

$e, f$. Tracheids.

g. Porous duct.

h. Parenchyma. 


\section{7. (Fig. 103.) GENTIANA. Gentian. U. S.}

Fl. ex. 30. Tinct. comp. 40.

Enzianwurzel, Bitterwurzel, Rother Enzian, Gelber Enzian, G. Racine de gentiane (de gentiane jaune), Fr.

The roots of Gentiana lutea L., Gentianaceæ.

Dull yellow brown.

Very faintly fragrant.

Very bitter, sweetish.

Beneath the brownish outer corky tissue is a layer of thick-walled collenchymatous tissue followed by the large celled, loosely united, collapsed empty parenchyma. Mostly typically reticulate and some porous yellowish ducts. No starch.

Ash 3 per cent.

Adulterated with roots of allied species. Said to be carelessly adulterated with aconite roots, belladonna roots, white hellebore and orris root. 

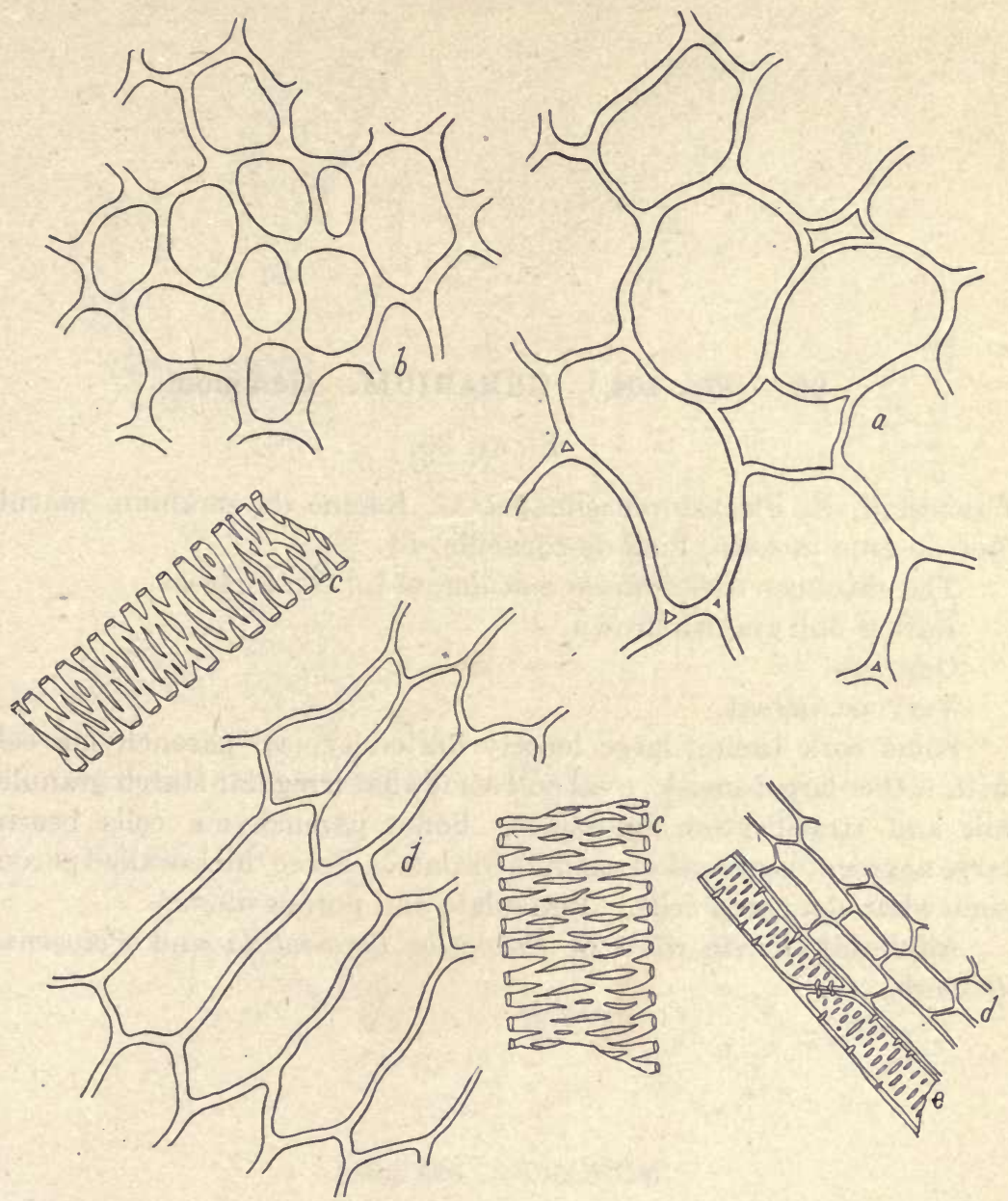

Fig. 103. GENTIAN.

a. Parenchyma.

b. Collenchymatous tissue.

c. Large reticulate ducts.

d. Parenchyma, longitudinal view.

e. Tracheids. 
98. (Fig. 104.) GERANIUM. Geranium.

Fl. ex. 30 .

Cranesbill, E. Fleckstorchschnabel, G. Racine de geranium macule, Bec-de-grue tacheté, Pied-de-corneille, Fr.

The rhizomes of Geranium maculatum L., Geraniaceæ.

Rather dull grayish brown.

Odorless.

Very astringent.

Some cork tissue; large loosely united typical parenchyma cells with rather large, simple, oval and somewhat irregular starch granules, hili and stratification indistinct. Some parenchyma cells bearing large aggregate crystals of calcium oxalate. Some thick-walled porous, somewhat elongated cells. Reticulate and porous ducts.

Adulterated with roots of Potentilla Tormentilla and Polygonum Bistorta. 


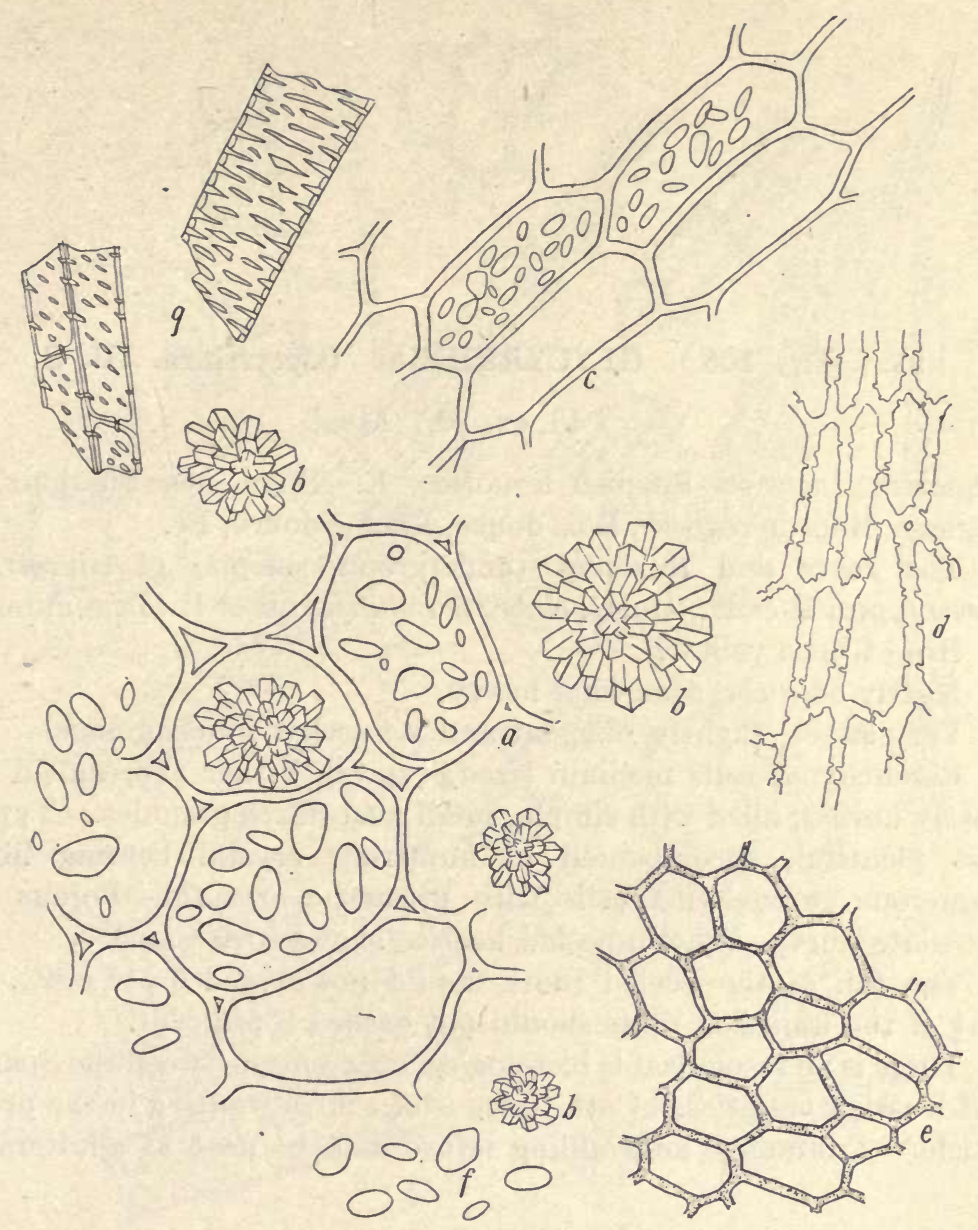

Fig. 104. GERANIUM.

a. Parenchyma with starch and crystals.

b. Aggregate crystals of calcium oxalate.

c. Parenchyma, longitudinal view.

d. Thick-walled porous parenchyma.

e. Cork.

f. Starch granules.

g. Ducts and tracheids. 
99. (Fig. 105.) GLYCYRRHIZA. Glycyrrhiza. U. S. Fl. ex. 30. Meal.

Liquorice, Licorice, Spanish liquorice, E. Spaniches Süssholz, G. Reglisse, Bois de réglisse, Bois douce, Racine douce, Fr.

The roots and rhizomes (underground stems) of Glycyrrhiza glabra typica $\mathrm{R}$ et $\mathrm{H}$., and $\mathrm{G}$. glabra glandulifera $\mathrm{R}$ et $\mathrm{H}$., Leguminosae.

Bright, pale yellow.

Nearly odorless, somewhat heavy.

Very sweet, slightly pungent and somewhat mucilaginous.

Parenchyma cells medium sized, typical, rather thin-walled and loosely united; filled with simple, small oval starch granules. Typical bast plentiful, accompanied by numerous crystal bearing fibers. Numerous parenchyma cells with prismatic crystals. Porous and reticulate ducts. The unpeeled licorice shows cork tissue.

The ash of the peeled roots should not exceed 6 per cent., and that of the unpeeled roots should not exceed 8 per cent.

There is no recognizable histological difference between the Spanish and Russian varieties. Cork tissue is of course wanting in the peeled article. Trimmings and milling refuse may be used as adulterants. 


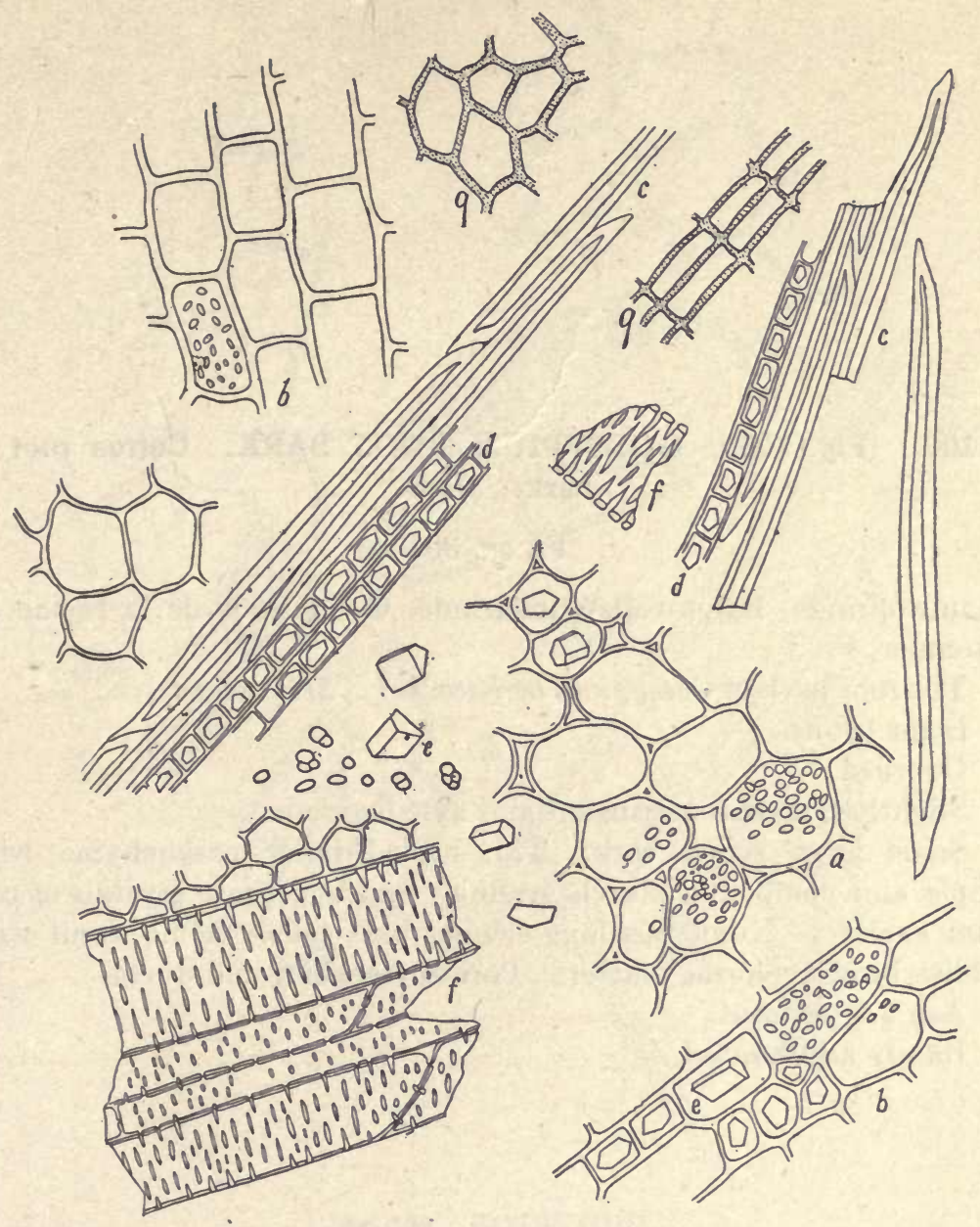

Fig. 105. GLYCYRRHIZA.

a. Parenchyma.

b. Parenchyma with crystals and starch.

c. Bast.

d. Crystal bearing fibers.

e. Crystals.

$f$. Ducts and tracheids.

g. Cork tissue. 
100. (Fig. 106.) GOSSYPIUM ROOT BARK. Cotton root bark. U. S.

Fl. ex. 30 .

Baumwollrinde, Baumwoll-Wurzelrinde, G. Ecorce de la racine de cotonnier, Fr.

The root bark of Gossypium herbaceum L., Malvaceæ.

Light brown.

Odorless.

Slightly pungent, astringent and mucilaginous.

Some large celled cork. Thin-walled inner parenchyma with simple and compound starch granules and aggregate crystals of calcium oxalate. Numerous long slender bast cells. Some tissue with reddish brown coloring matter. Porous tracheids and ducts.

Ash 5.5 per cent.

Rarely adulterated. 


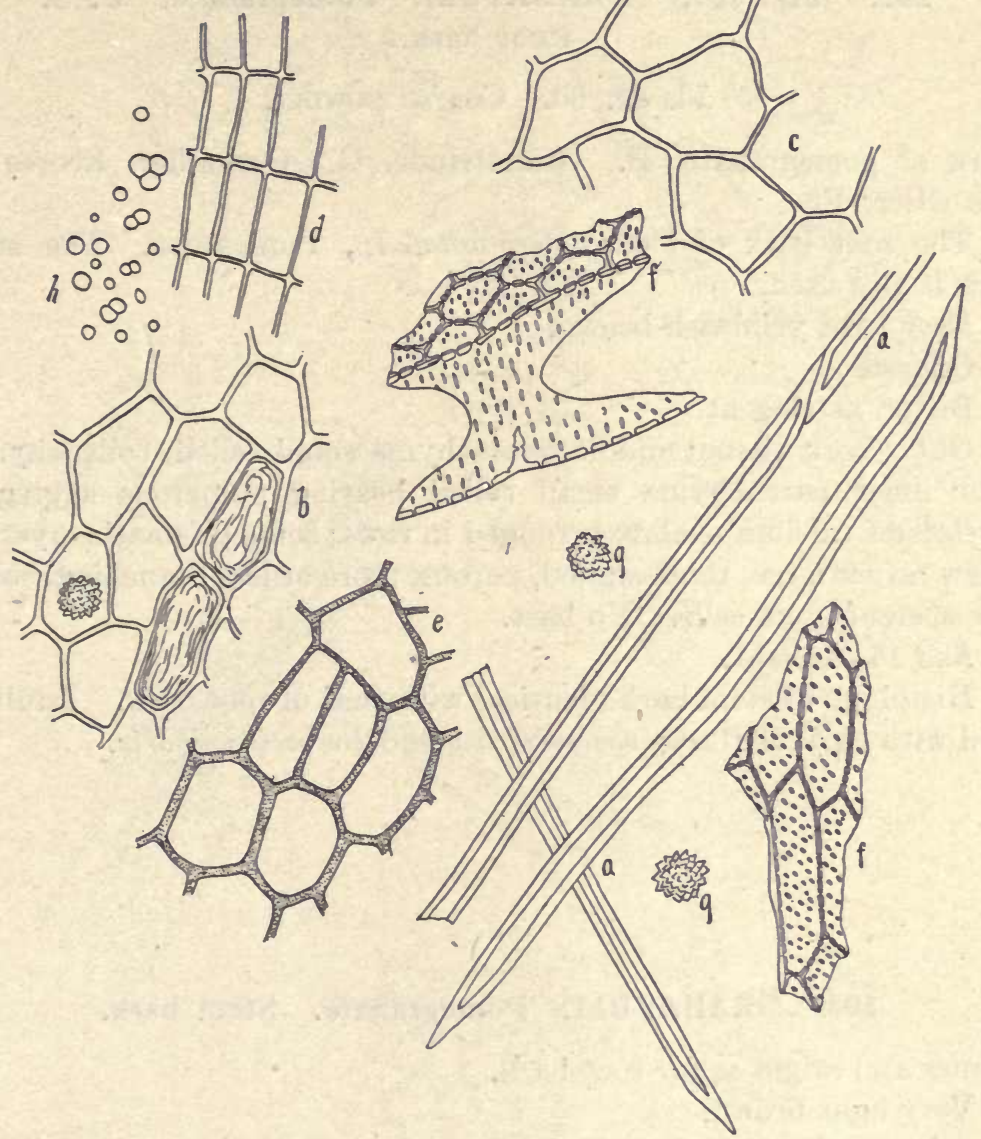

Fig. 106. GOSSYPIUM.

a. Bast.

$b$ Cells with reddish brown contents.

c. Parenchyma.

d. Cork, lateral view.

e. Cork, vertical view.

f. Tracheids and ducts.

g. Aggregate crystals of calcium oxalate.

h. Starch granules. 
101. (Fig. 107.) GRANATUM. Pomegranate. U. S. Root bark.

Fl. ex. 60. Coarse powder.

Bark of pomegranate, E. Granatrinde, G. Grenadier, Ecorce de balaustier, Fr.

The root bark of Punica Granatum L., Punicaceae. The stem bark is also used.

Very light yellowish brown.

Odorless.

Bitter, astringent.

Outer cork tissue; middle parenchyma small celled, collenchymatous; inner parenchyma small celled bearing numerous aggregate crystals of calcium oxalate arranged in rows; some prismatic crystals. A few rather large, thick-walled, porous, more or less branching, colorless sclerenchyma cells. No bast.

Ash 15 per cent.

Histology of stem bark identical with that of root bark. Adulterated with bark of Buxus sempervirens and Berberis vulgaris.

102. GRANATUM. Pomegranate. Stem bark.

Names and origin as for root bark.

Very light brown.

Odor and taste as for root bark.

Histology identical with that of root bark. The presence of spores (of fungi and lichens) and hyphal remnants would indicate the stem bark, as spot fungi and lichens do not grow on the root bark.

Ash 14 per cent.

May be intermixed with root bark. 


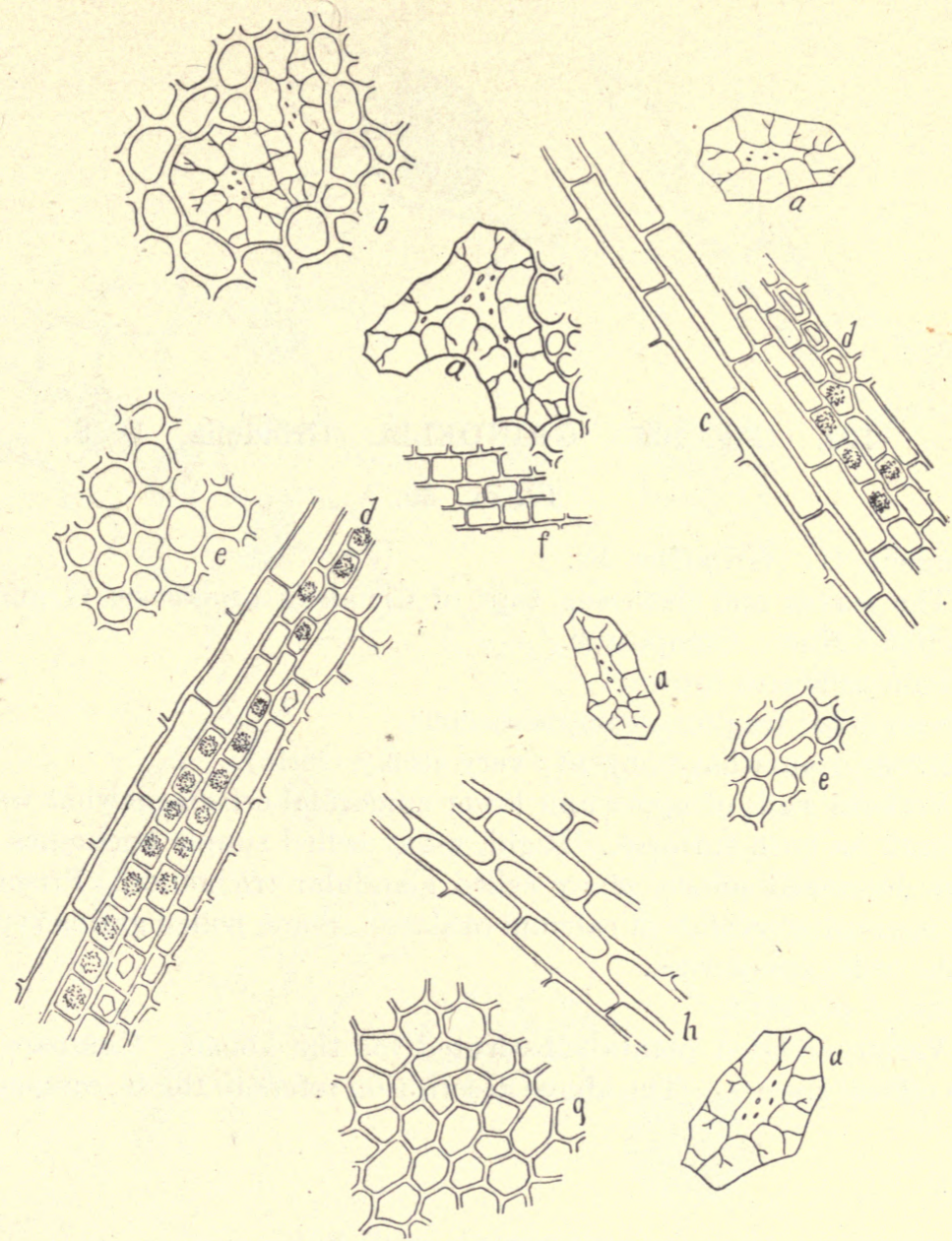

Fig. 107. GRANATUM. Root Bark.

a. Sclerenchyma cells.

b. Parenchyma and sclerenchyma.

$c, d$. Parenchyma, longitudinal view, with crystals.

e. Parenchyma.

f. Medullary ray.

g. Outer bark.

h. Parenchyma. 
103. (Fig. 108.) GRINDELIA. Grindelia. U. S. Fl. ex. 30 .

Grindelie, G. Grindélie, Fr.

The leaves and flowering tops of Grindelia camporum G. and $G$. cuneifolia Nutt., Compositæ.

Pale yellowish brown.

Somewhat fragrant, camphoraceous.

Bitter, somewhat pungent; very sticky (resin).

Vertical walls of upper and lower epidermal cells somewhat wavy; stomata on both surfaces. Rigid, many celled simple trichomes and some depressed sessile, many celled glandular trichomes. Prismatic and aggregate crystals of calcium oxalate. Some pollen grains typical of the order compositæ.

Ash 6 per cent.

Various related plants substituted for the above. Compare the two official species. The above description refers to the G. camporum. 


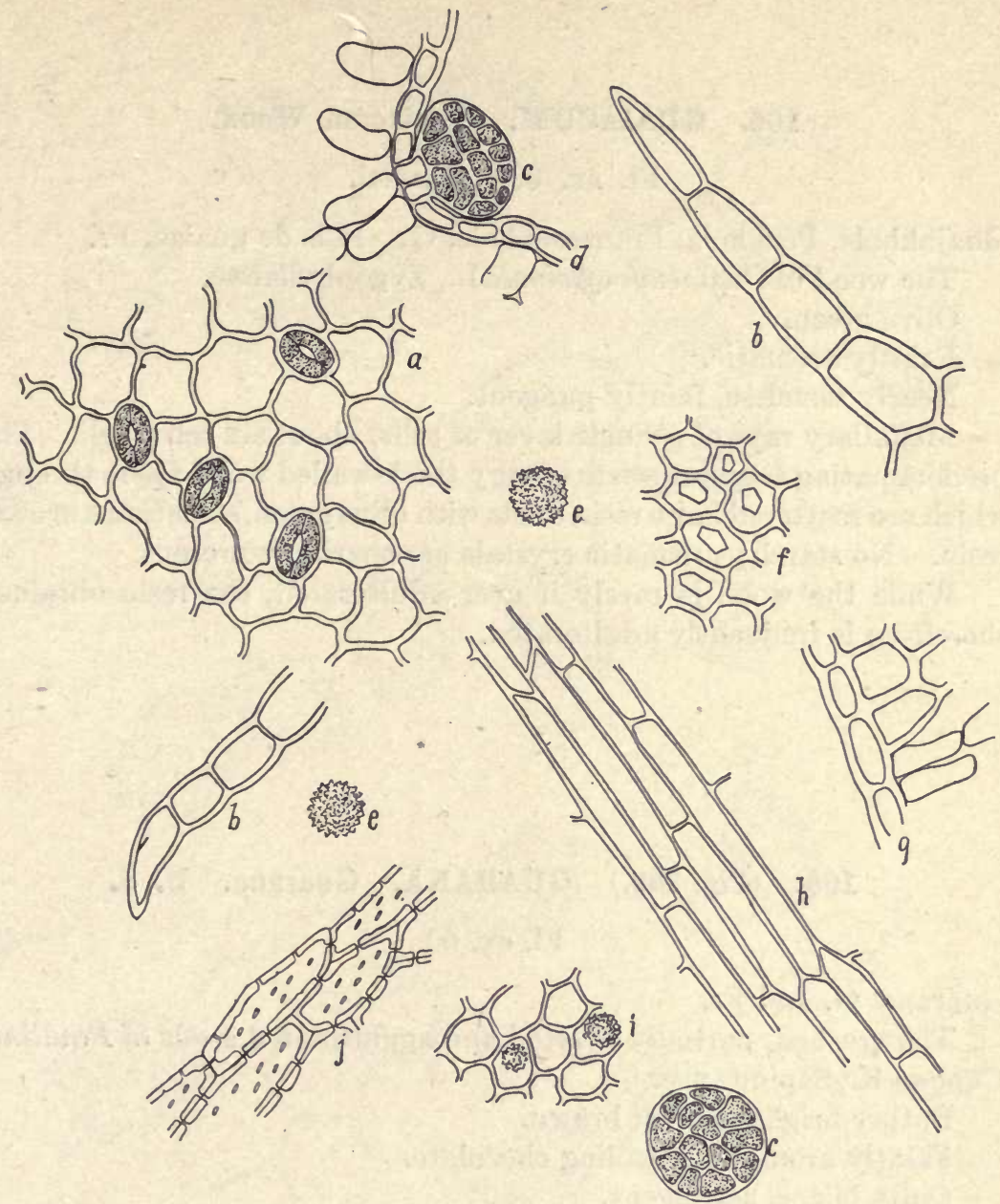

Fig. 108. GRINDELIA.

a. Epidermis.

b. Trichomes.

c. Glandular trichomes.

d. Epidermis, lateral view.

e. Pollen grains.

f. Parenchyma cells with crystals.

g. Epidermis, lateral view.

h. Parenchyma.

$i$. Parenchyma with aggregate crystals.

j. Tracheids. 


\title{
104. GUAIACUM. Guaiacum Wood.
}

\author{
Fl. ex. 60. Rasped.
}

Guajakholz, Pockholz, Franzosenholz, G. Bois de guaiac, Fr.

The wood of Guaiacum officinale L., Zygophyllaceæ.

Olive green.

Faintly aromatic.

Nearly tasteless, faintly pungent.

Medullary rays of a single layer of cells, about six cells high. The predominating tissue consists of very thick-walled wood fibers through which are scattered large resin ducts with olive green, sometimes brown, resin. No starch; prismatic crystals are sparingly present.

While the wood is rarely if ever adulterated, the resin obtained therefrom is frequently adulterated.

105. (Fig. 109.) GUARANA. Guarana. U. S.

Fl. ex. 60 .

- Guarana, G. and Fr.

The crushed, partially roasted and agglutinated seeds of Paullinia Cupana K., Sapindaceæ.

Rather bright reddish brown.

Faintly aromatic, recalling chocolate.

Quite bitter, astringent.

Medium sized to rather large typical, brown or brownish parenchyma cells filled with pasty starch. Some rather small, brown sclerenchyma cells. Numerous lumps of pasty starch of the dimensions of the cell lumen.

Ash 1.5 per cent.

Said to be adulterated with starch (cassava starch) and occasionally with cocoa seeds. 


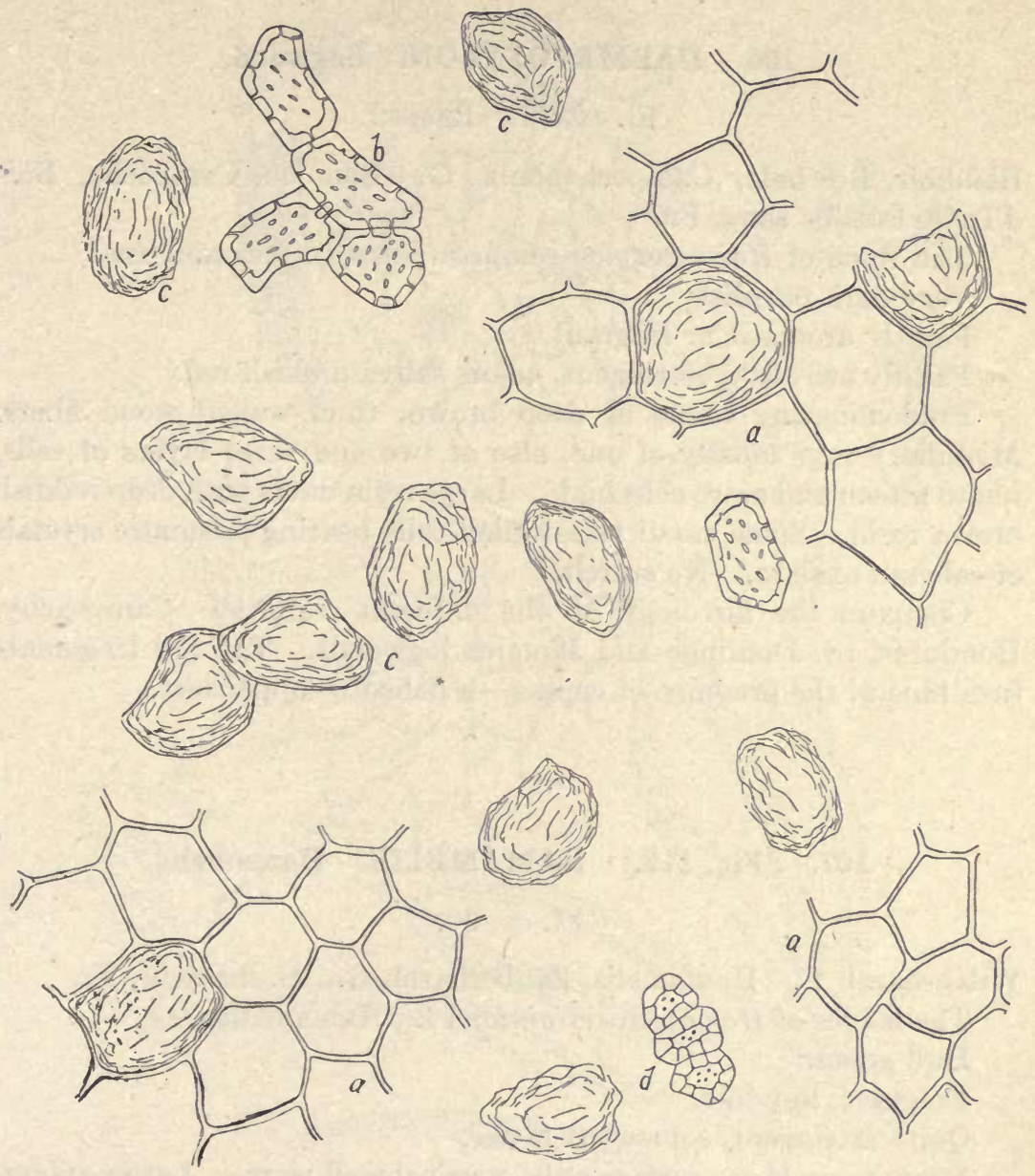

Fig. 109. GUARANA.

a. Parenchyma with pasty starch.

b. Sclerenchyma cells.

c. Masses of pasty starch.

d. Small sclerenchyma cells. 


\title{
106. HAEMATOXYLON. Logwood.
}

\author{
Fl. ex. 30. Rasped.
}

Blauholz, Blutholz, Campechenholz, G. Bois de Campêche, Bois d'Inde, Bois de sang, Fr.

The wood of Haematoxylon campechianum L., Leguminosæ.

Very dark purplish.

Faintly aromatic or fragrant.

Faintly sweetish, astringent, colors saliva pinkish red.

Predominating tissue of deep brown, thick-walled wood fibers. Medullary rays mostly of one, also of two and three layers of cells, ten to fifteen and more cells high. Large resin ducts with deep reddish brown resin. Some small thin-walled cells bearing prismatic crystals of calcium oxalate. No starch.

Compare the histology of the different varieties-Campeachy, Honduras, St. Domingo and Jamaica logwoods. The cell fragments turn blue in the presence of copper-a delicate copper test.

\section{7. (Fig. 110.) HAMAMELIS. Hamamelis.}

Fl. ex. 30.

Witch-hazel, E. Hamamelis, Zauberhazel, G. Hamamelis, Fr.

The leaves of Hamamelis virginiana L., Hamamelidaceæ.

Dull green.

Fragrant, hay-like.

Quite astringent, somewhat bitter.

Stomata on lower surface only, vertical wall wavy. Lower epidermal cells somewhat smaller than upper, Large aggregate (stellate clusters) trichomes of six to eight thick-walled cells. Scattered through the leaf parenchyma are found a few peculiar branching sclerenchyma cells like those of tea. Prismatic crystals plentiful. Palisade cells and spongy tissue cells resin bearing.

Ash 6 per cent.

Rather rarely adulterated. 


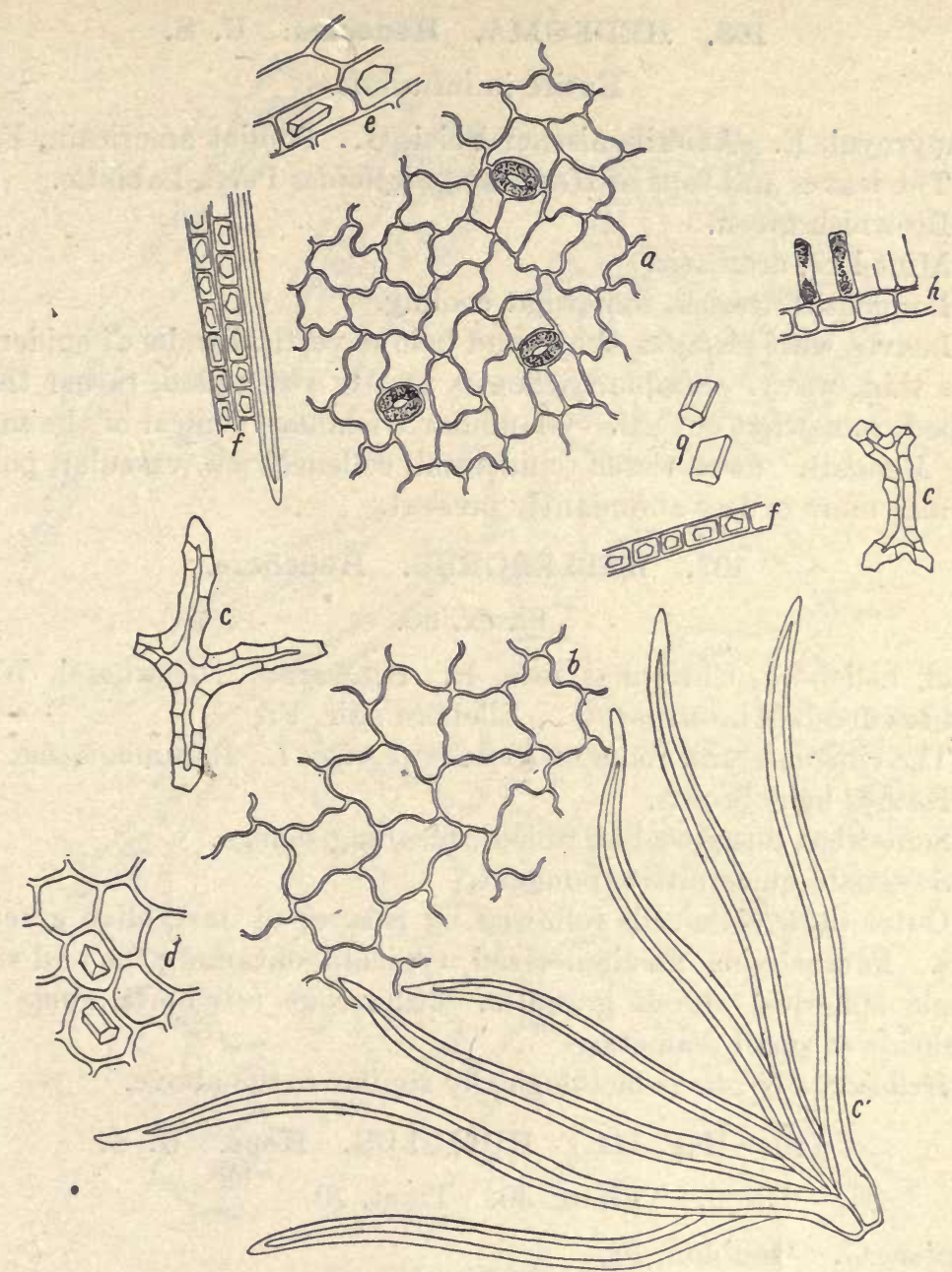

Fig. 110. HAMAMELIS.

a. Lower epidermis.

b. Upper epidermis.

c. Sclerenchyma cell from leaf blade.

c. Stellate trichome.

d. Parenchyma with crystals.

e. Parenchyma.

f. Crystal bearing fibers.

g. Prismatic crystals.

$h$. Epidermis of leaf, upper. 


\section{HEDEOMA. Hedeoma. U. S.}

Entire in infusions.

Pennyroyal, E. Amerikanischer Polei, G. . Pouliot americain, Fr.

The leaves and tops of Hedeoma pulegioides Pers., Labiatæ.

Brownish green.

Mint-like, aromatic.

Pungent, bitterish, somewhat cooling.

Leaves with stomata above and below, vertical walls of epidermal cells thin, wavy. Simple trichomes mostly two celled, rather thickwalled, somewhat curved. Glandular trichomes typical of the mints (see Mentha). Stem tissue (epidermal, collenchyma, vascular, parenchyma) more or less abundantly present.

\section{HELLEBORUS. Hellebore.}

Fl. ex. 60.

Black hellebore, Christmas rose, E. Schwarze Nieswurzel, Weihnachtswurzel, Winterrose, G. Ellebore noir, Fr.

The rhizomes and roots of Helleborus niger L., Ranunculaceæ.

Rather light brown.

Somewhat disagreeable, rancid, recalling senega.

Sweetish, quite bitter, pungent.

Outer dark cork cells followed by a layer of dark olive greenish cells. Parenchyma medium sized, typical, containing fat and small simple spherical starch granules. Numerous reticulate ducts and tracheids of small diameter.

Helleborus viridis is histologically similar to the above.

\section{0. (Fig. 111.) HUMULUS. Hops. U. S.}

Fl. ex. 30. Tinct. 20.

Hopfen, G. Houblon, Fr.

The fruit scales (strobiles) of Humulus Lupulus L., Moraceæ.

Light yellowish brown.

Peculiar, aromatic; valerian-like with age.

Bitter, somewhat astringent.

Vertical walls of the epidermal cells of strobile scales wavy; upper epidermal cells larger than lower; stomata on lower surface only. Scale parenchyma typically spongy, bearing small aggregate crystals of calcium oxalate. Single celled, simple trichomes. Large bright, yellow glands (lupulin). Insect (aphidæ) remnants are usually also found.

Ash 6 per cent.

Not generally adulterated. 


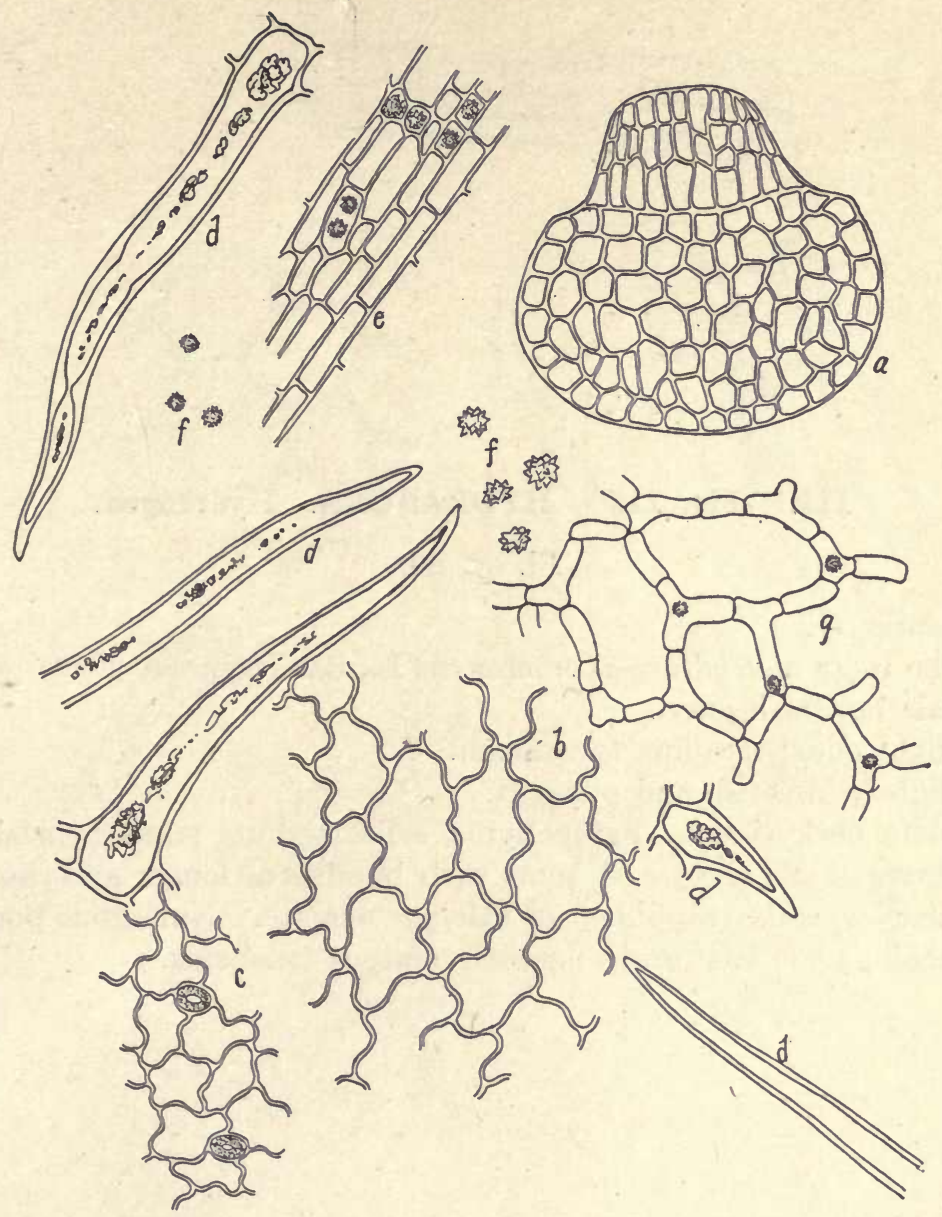

Fig. 111. HUMULUS.

a. Gland (lupulin).

b. Upper epidermal cells.

c. Epidermal tissue with stomata.

d. Trichomes.

e. Parenchyma with crystals.

f. Aggregate crystals of calcium oxalate.

g. Spongy tissue cells with crystals. 


\section{1. (Fig. 112.) HYDRANGEA. Hydrangea.} Fl. ex. 60 .

Hortensie, G.

The roots of Hydrangea arborescens L., Saxifragaceæ.

Pale brownish gray..

Slight odor; recalling taraxacum.

Slightly sweetish and pungent.

Some cork tissue. Parenchyma cells medium sized typical to rather small and elongated, some with bundles of longer and shorter acicular crystals (raphides) of calcium oxalate. Numerous porous tracheids; some bast and sclerenchymatous tracheids. 

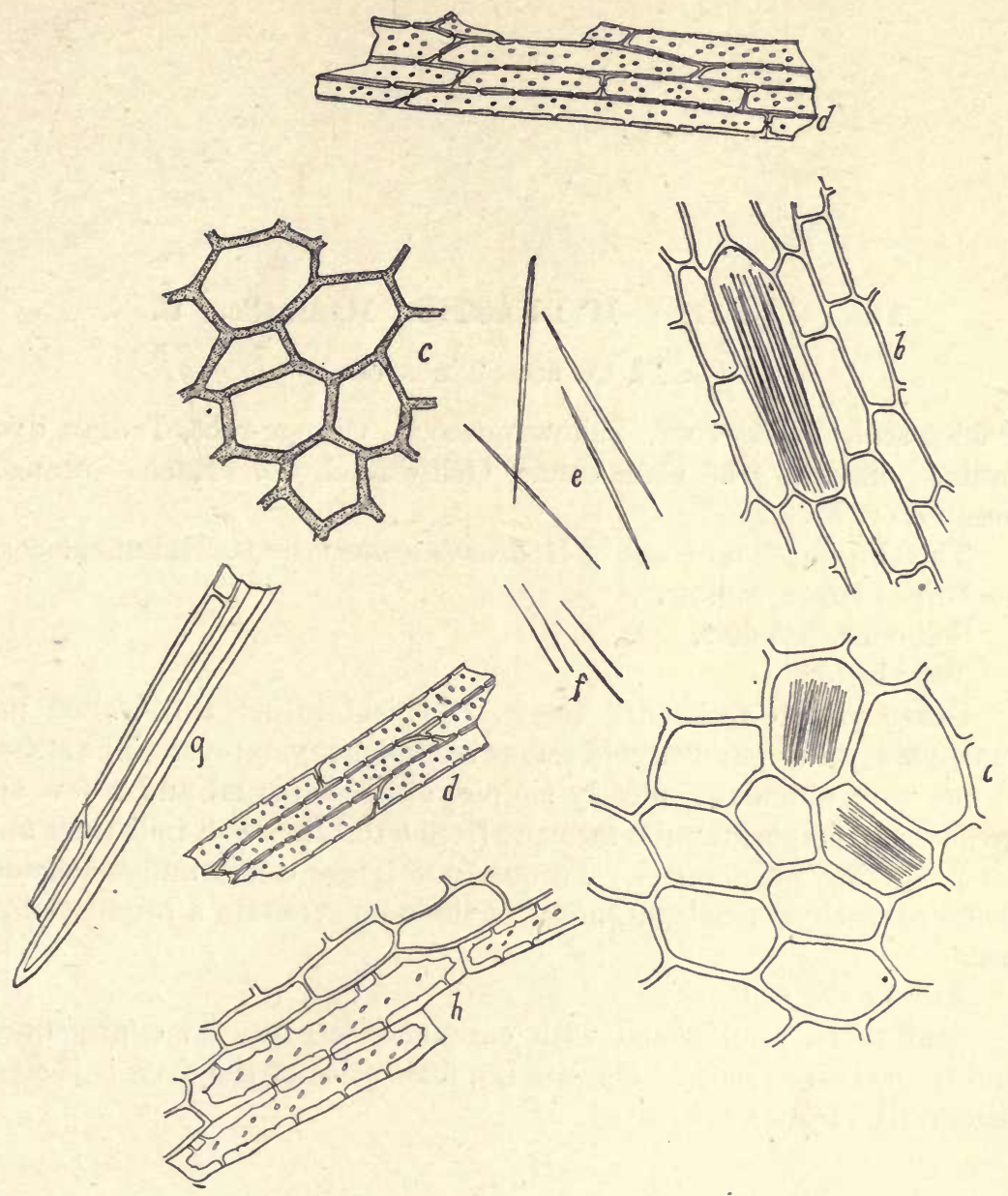

Fig. 112. HYDRANGEA.

a. Parenchyma with raphides.

b. Parenchyma with larger raphides.

c. Cork tissue.

$d$. Tracheids.

$e, f$. Acicular crystals.

g. Bast.

$h$. Sclerenchymatous tracheids. 


\section{2. (Fig. 113.) HYDRASTIS. Hydrastis. U. S.}

Fl. ex. 60. Tinct. 60 .

Golden-seal, Yellow-root, Yellow puccoon, Orange-root, Indian dye, Indian tumeric, E. Canadische Gelbwurzel, G. Racine orange, Sceau d'or, Fr.

The rhizomes and roots of Hydrastis canadensis L., Ranunculaceæ.

Bright lemon yellow.

Soil odor, peculiar.

Very bitter.

Outer rather dark cork tissue. Typical rather thin-walled parenchyma; outer parenchyma somewhat colenchymatous. The starch is not very abundant, mostly simple, also compound and a few aggregates. Simple granules measure from 5 to $11 \mu$. Hili indistinct and no polarizing phenomena. Porous, not large, ducts and tracheids. Some parenchyma cells and most of the ducts contain a bright yellow resin.

Ash 9.5 per cent.

Said to be adulterated with curcuma, serpentaria, cypripedium and several other roots. Despite the high price of the drug it is comparatively rarely adulterated. 


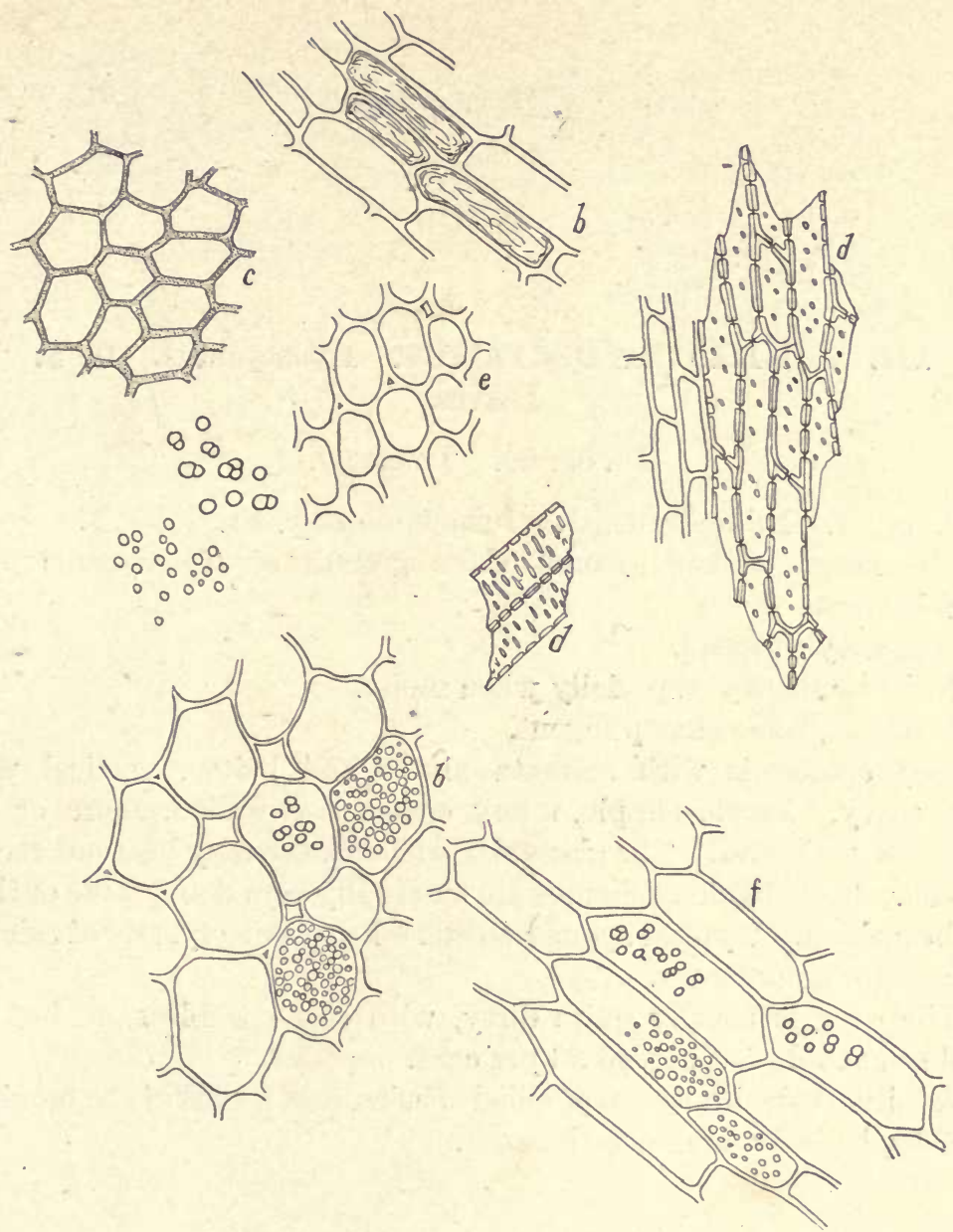

Fig. 113. HYDRASTIS.

a. Starch bearing parenchyma.

b. Parenchyma, longitudinal view.

c. Cork.

d. Tracheids.

e. Parenchyma.

f. Parenchyma, longitudinal view. 
113. (Fig. 114.) HYOSCYAMUS. Hyoscyamus. U. S. Leaves.

Fl. ex. 60. Tinct. 60 .

Henbane, E. Bilsenkraut, G. Jusquiame noir, Fr.

The leaves of the second year's growth of Hyoscyamus niger L., Solanaceæ.

Dull grayish green.

Narcotic, heavy, especially when moist.

Bitterish, somewhat pungent.

Leaf epidermis with stomata above and below; vertical walls thin, wavy. Large, simple, many celled, thin-walled, more or less collapsed trichomes. The glandular trichomes usually bear one secreting cell. The simple trichomes are externally pitted and some of them are branching. Typical spongy tissue. Prismatic crystals of calcium oxalate quite numerous.

The drug is usually quite dirty, with considerable sand but the total ash should not exceed 23 per cent.

Adulterated with leaves of allied species, and leaves of stramonium, digitalis, belladonna and verbascum. 


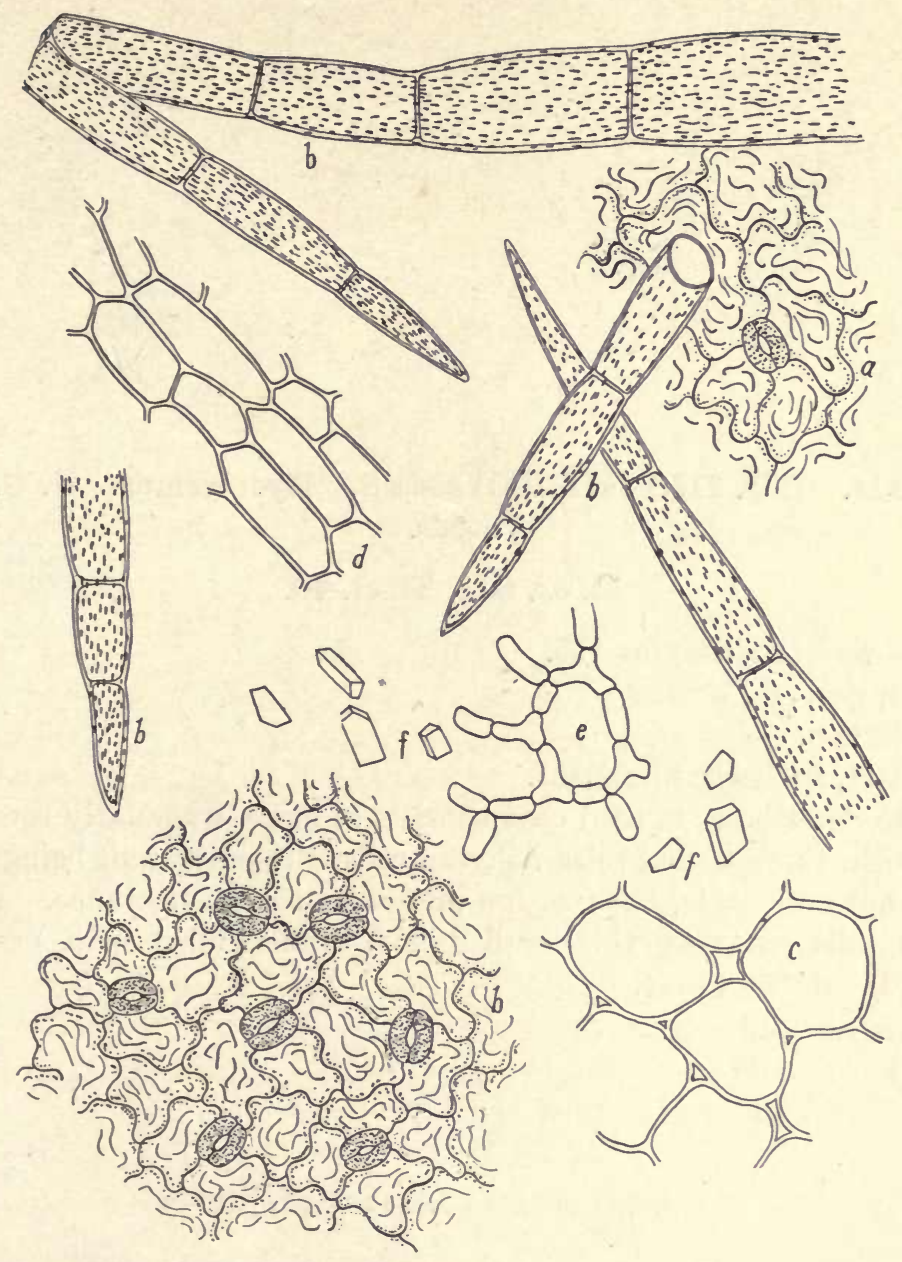

Fig. 114. HYOSCYAMUS. Leaf.

$a, b$. Epidermal tissues and trichomes.

$c, d$."Parenchyma.

e. Spongy tissue cells.

$f$. Prismatic crystals. 


\section{4. (Fig. 115.) HYOSCYAMUS. Hyoscyamus. U. S.}

\section{Seeds.}

Fl. ex. 60. Tinct. 40 .

Names and origin as for 113.

Ash gray.

Odorless.

Bitter, somewhat pungent.

The outer layer of seed coat consists of large, irregularly rounded, brownish, thick-walled sclerenchyma cells, the outer wall being thin, pores not noticeable, filled with a granular proteid substance. Endosperm cells not very thick-walled nor porous, filled with granular proteid matter and fat. 


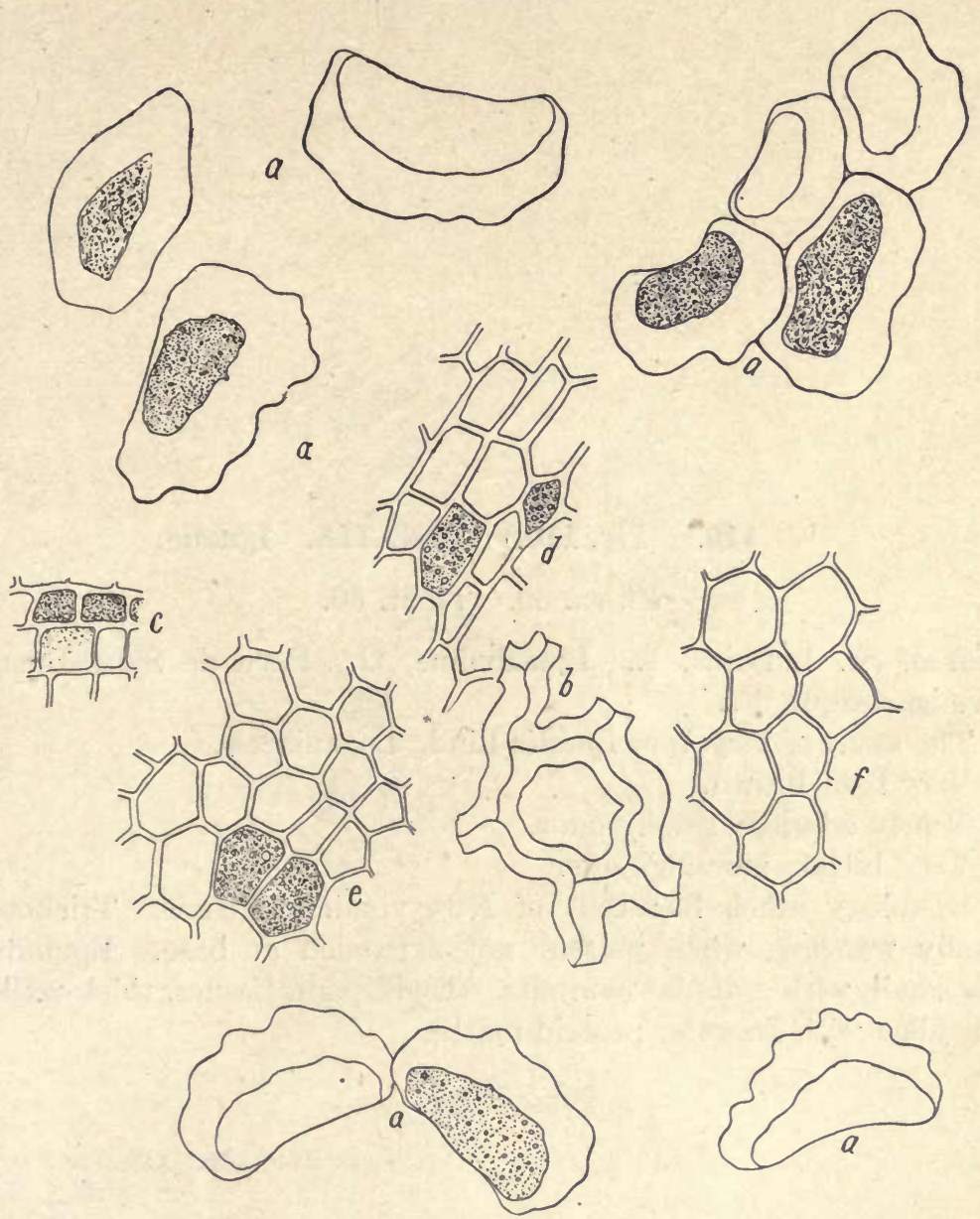

Fig. 115. HYOSCYAMUS. Seed.

a. Sclerenchyma cells of seed coat.

b. Sclerenchyma, vertical view.

c. Outer endosperm tissue.

d. Endosperm.

e. Endosperm tissue with proteid granules and oil.

f. Parenchyma. 


\section{5. (Fig. 116.) IGNATIA. Ignatia.}

Fl. ex. 60. Tinct. 60 .

Bean of St. Ignatius, E. Ignazbohne, G. Fève de Saint-Ignace, Fève igasurique, Fr.

The seeds of Strychnos Ignatia Lind., Loganiaceæ.

Very light brown.

Nearly odorless, smoky odor.

Very bitter, mucilaginous.

Histology much like that of Nux vomica buttons. Trichomes usually wanting, when present not expanded at base. Epidermal cells small, with granular contents. Endosperm tissues, thick-walled, cells filled with granular proteid matter. 


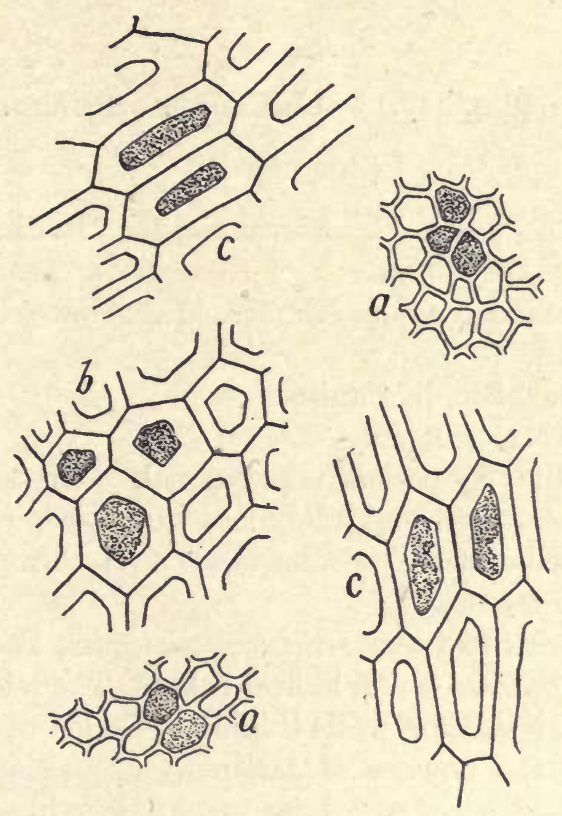

Fig. 116. IGNATIA.

a. Epidermal cells, vertical view.

b. Endosperm.

c. Endosperm. 


\section{6. (Fig. 117.) ILLICIUM. Illicium.}

Fine powder.

Star anise, Chinese anise, E. Sternanis, G. Badiane, Anise étoilé, Fr.

The fruit of Illicium verum Hooker, Magnoliaceæ.

Reddish brown.

Fragrantly aromatic, like anise.

Quite acid, sweet, pungent.

Epidermal cells of pericarp polygonal, with stomata. Brown tissue; parenchyma with oil globules; numerous elongated, thickwalled sclerenchyma cells. Endosperm cells thin-walled, with fat and proteid granules.

Adulterated with fruits of Illicium religiosum, known as Japanese star anise. The powder is of a lighter color. The sclerenchyma fibers of the endocarp are smaller, walls thinner. Boiled in dilute potassium hydrate solution the powder of Japanese star anise turns yellowish brown while the powder of true anise turns a deep blood red. Illicium floridanum differs histologically; compare epidermal sclerenchyma. 


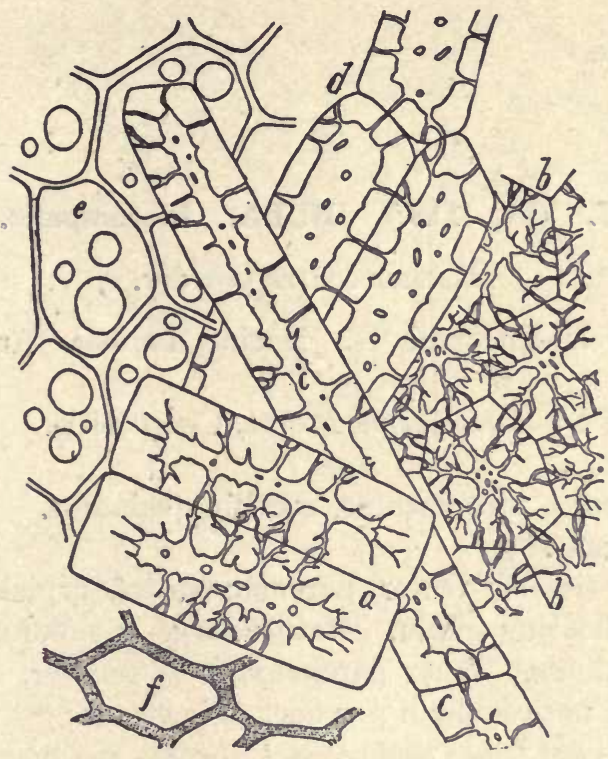

Fig. 117. ILLICIUM.

$a$. Two stone cells from testa of seeds.

$b$. End view of $a$.

c. Elongated sclerenchyma.

$d$. Sclerenchyma.

e. Oil bearing endosperm cells.

$f$. Deep reddish brown cells of pericarp. 


\section{7. (Fig. 118.) INULA. Elecampane.}

Rather coarse powder.

Alantwurzel, Helenenwurzal, G. Racine d'annee, Année commune (officinale), Fr.

The roots of Inula Helenium Merat, Compositæ.

Light brown.

Camphoraceous, terebinthine, recalling calamus.

Bitter, pungent.

Some cork tissue. Outer parenchyma of typical, thin-walled, collapsed cells bearing inulin. Rather large or medium sized porous and reticulate ducts. Inner parenchyma of smaller, elongated cells. Resin ducts not noticeable in powder. No starch.

Allied plants are Inula squarrosa, Pulicaria dysenterica and Carlina acaulis. 

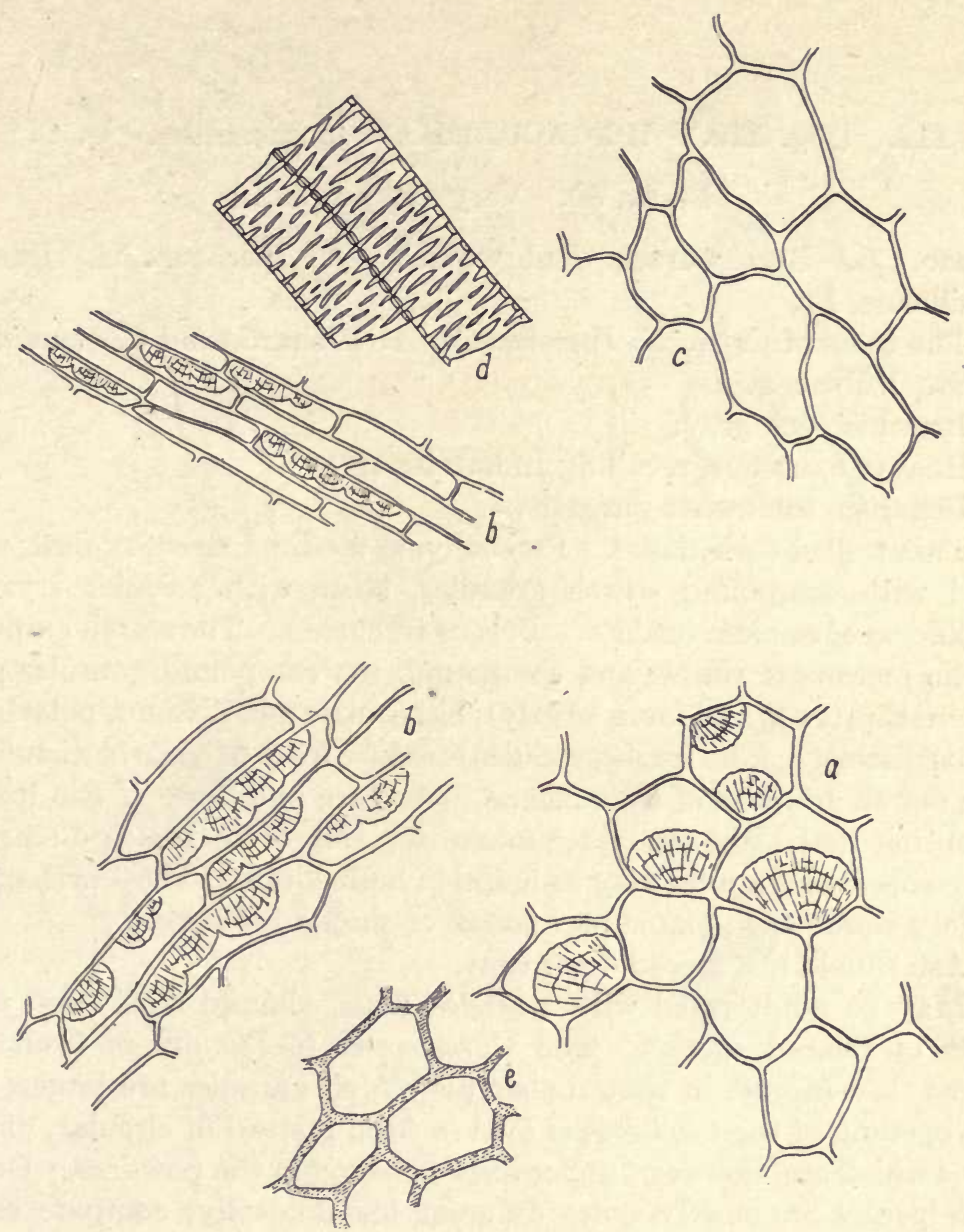

Fig. 118. INULA.

$a, b$. Parenchyma with inulin.

c. Parenchyma free from inulin.

d. Reticulate ducts.

e. Cork. 


\section{8. (Fig. 119.) IPECACUANHA. Ipecacuanha. U. S.}

Fl. ex. 80. Very fine powder.

Ipecac, E. Brechwurzel, Ruhrwurzel, G. Ipecacuanha, Racine brésilienne, Fr.

The roots of Cephaelis Ipecacuanha A. Richard, and C. acuminata Karst., Rubiaceæ.

Brownish ash gray.

Heavy, nauseous, recalling Indian hemp.

Bitterish, somewhat pungent.

Thin walled cork tissue. Parenchyma medium sized, typical; cells filled with compound starch granules, some with acicular crystals (raphides) of calcium oxalate. Porous tracheids. The starch granules of Rio ipecac are simple and compound, the compound granules predominating (twos and fours largely); hili centric and distinct, polarizing bands distinct. The single granules measure from 4 to $12 \mu$ in diameter. The starch granules of Carthagena ipecac are like those of Rio ipecac excepting that they are larger measuring from 4 to $17 \mu$ in diameter. Six-compound granules may be found in both kinds. The Carthagena variety shows the greater percentage of simple granules.

Ash should not exceed 4 per cent.

May be adulterated with starches, flour, almond meal; also with roots of related species. The Carthagena ipecac differs from the above (Rio ipecac) in that the simple starch granules are larger; the end opening of the tracheids is oval in form instead of circular, differences which are, however, not readily detected in the powders. Other false ipecacs are mostly quite different histologically; compare especially ducts, tracheids, crystals and starches. 


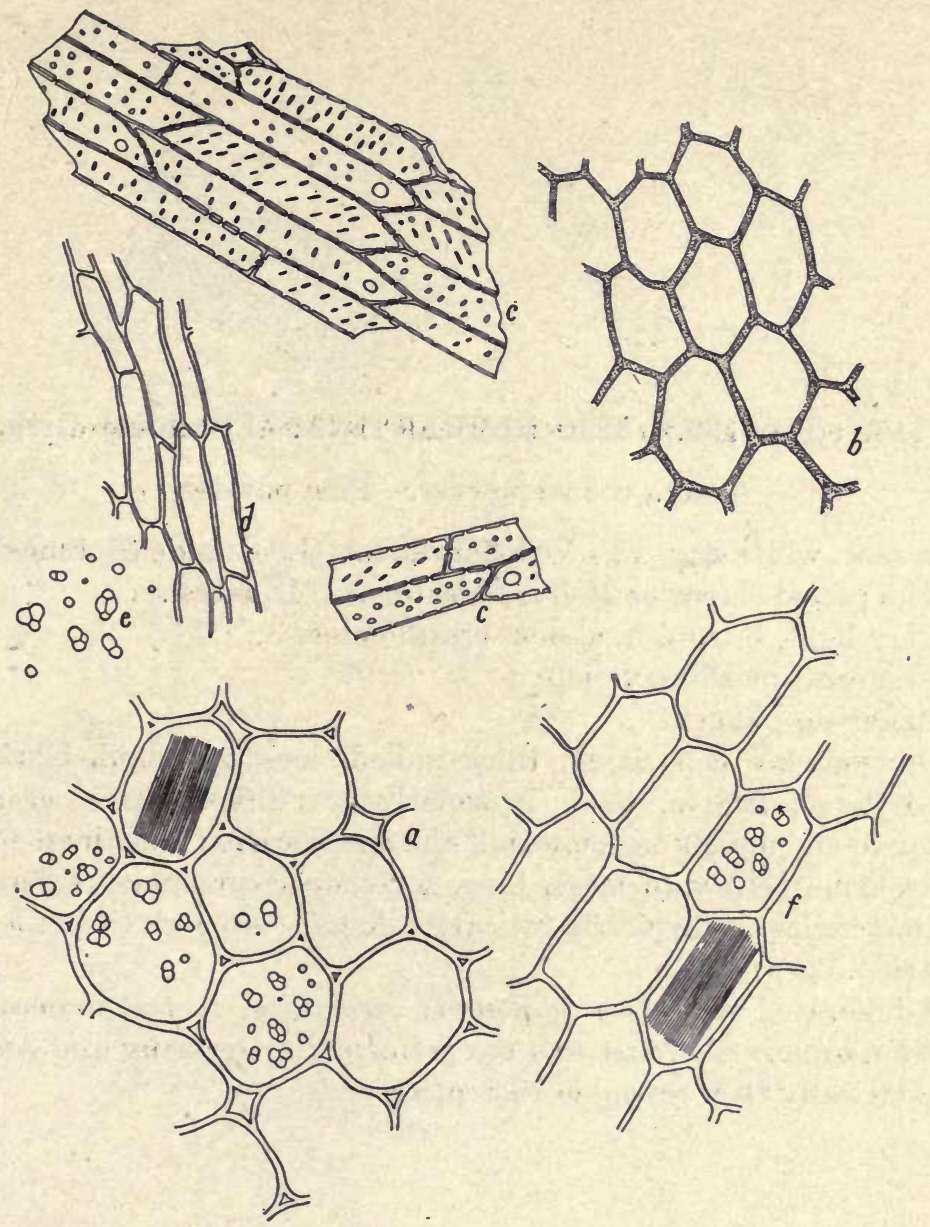

Fig: 119. IPECAC.

a. Parenchyma with raphides.

b. Cork.

c. Tracheids.

d. Phlœm parenchyma.

e. Starch granules.

f. Parenchyma, longitudinal view. 
119. (Fig. 120.) IRIS FLORENTINA. Florentine Orris.

Tinct., coarse powder. Fine powder.

Orris root, white flag, E. Veilchenwurzel, G. Iris de Florence, Fr.

The peeled rhizomes of Iris florentina L., Iridaceæ.

Very light, brownish, almost cream color.

Fragrant, recalling violets.

Bitterish, pungent.

Parenchyma cells large, thick-walled, loosely united, filled with rather large, simple, oval, irregularly pear-shaped starch granules, narrowed end mostly truncate, hili and stratification indistinct. Some parenchyma cells with large, long, rod-shaped prismatic crystals of calcium oxalate. Typically reticulate ducts. No cork tissue.

Ash 1.5 per cent.

Adulterated with Iris pallida, I. germanica, I. pseudacorus, and I. foetidissima. The first two are preferred in Germany and Austria. Histologically they resemble Florentine orris. 


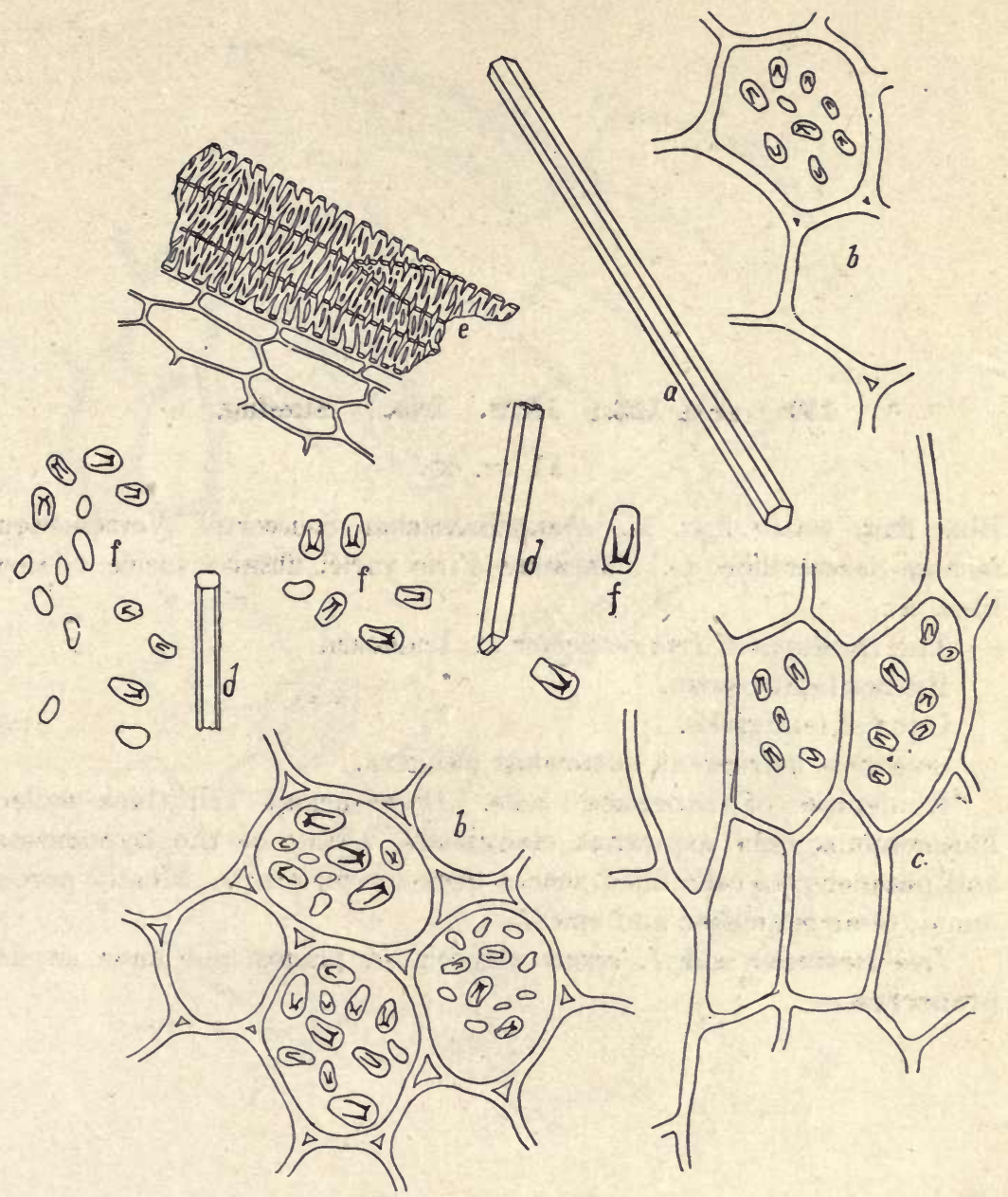

Fig. 120. IRIS FLORENTINA.

a. Large crystals.

b. Parenchyma with starch.

c. Parenchyma, longitudinal view.

$d$. Broken crystals.

$e$. Reticulate ducts.

$f$. Starch granules.

g. Starch granules showing characteristic U-shaped hilum. 
120. (Fig. 121.) IRIS. Iris. Blueflag.

Fl. ex. 60 .

Blue flag, water flag, E. Amerikanischer Schwertel, Verschiedenfarbige Schwertlilie, G. Rhizome d'iris varié, flambe variée, Glaieul bleu, Fr.

The rhizomes of Iris versicolor L., Iridaceæ.

Rather light brown.

Odor of fenugreek.

Sweetish, astringent, somewhat pungent.

Epidermis of suberized cells. Hypodermal cell thick-walled. Parenchyma cells somewhat elongated. Many of the hypodermal and parenchyma cells filled with a deep brown resin. Mostly porous ducts; some reticulate and spiral.

Iris virginica and $I$. verna are related plants and have similar properties. 


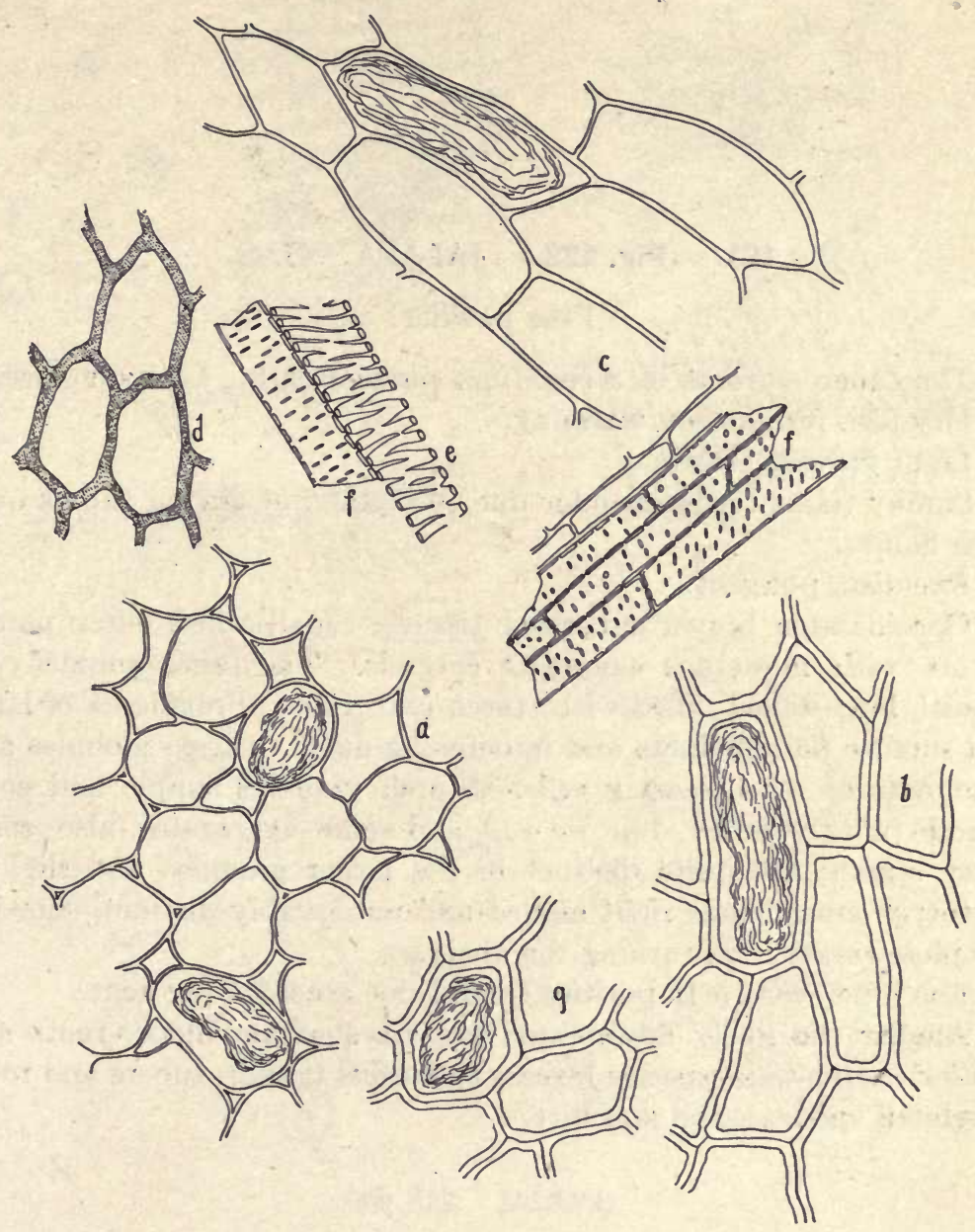

Fig. 121. IRIS VERSICOLOR.

a. Parenchyma, resin cell.

$b, g$. Hypodermal cells.

c. Parenchyma, longitudinal view.

$d$. Reddish brown cork cells.

e. Reticulate duct.

$f$. Porous duct.

g. Hypodermal cells. 


\section{1. (Fig. 122.) JALAPA. U. S.}

Fine powder.

The tuberous roots of Exogonium purga Benth., Convolvulaceae.

Dry feel, resinous on warming.

Light grayish brown.

Smoky (faint creosote) odor due to method of drying tubers over open flame.

Sweetish, pungent.

Considerable brown suberized tissue. Small-celled outer parenchyma with numerous aggregate crystals. The inner parenchyma typical, large-celled, filled with starch and resin. Fragments of large and smaller porous ducts and laticiferous ducts. Resin globules and fragments of resin bearing cells. Starch granules simple and compound (mostly twos), $14 \mu$ to $40 \mu$, and some aggregates, also some pasty starch; hili quite distinct in the larger granules and slightly excentric; cross bands right angled and remarkably distinct, showing complete rotation on turning the analyzer.

Ash 5 per cent. Impurities should not exceed 5 per cent.

Among the likely adulterants are starches and flour, roots and rootlets of the same species (excess of fibrous tissue); tubers and roots of related species; sand and dirt. 


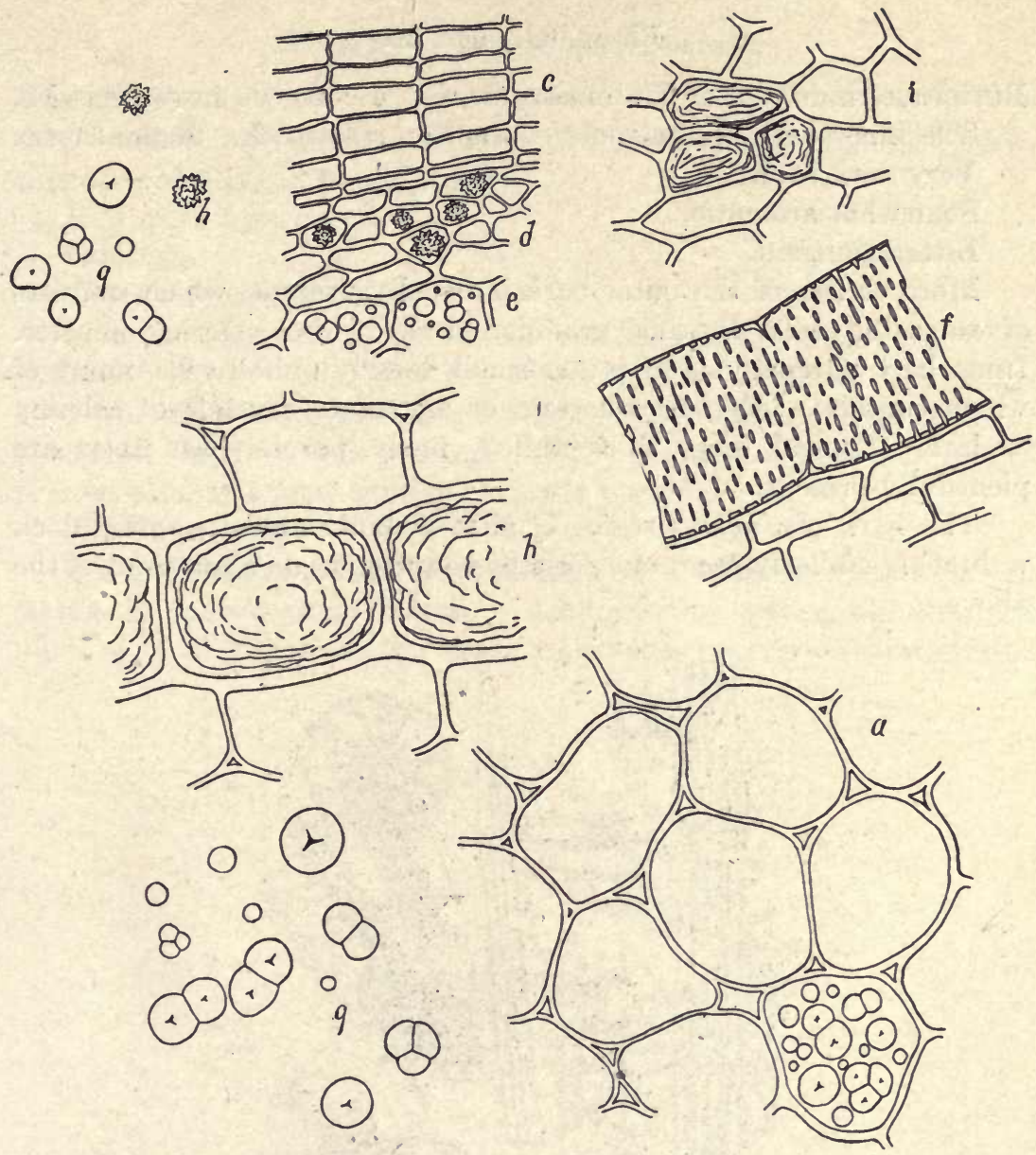

Fig. 122. JALAPA.

a. Parenchyma with starch.

b. Resin bearing cells.

c. Cork, lateral view.

$d$. Outer crystal bearing parenchyma.

e. Starch bearing parenchyma.

$f$. Large porous ducts.

g. Starch granules.

$h$. Aggregate crystals of calcium oxalate.

$i$. Outer cork tissue with reddish coloring matter. 


\section{2. (Fig. 123.) JUGLANS. Butternut-bark.}

Fl. ex. 60. Ex. 30 .

Butternussrinde, Graue Wallnussrinde, G. Ecorce de noyer gris, Fr.

The inner bark of the roots of Juglans cincerea L., Juglandacex.

Very dark brown.

Somewhat aromatic.

Bitter, pungent.

More or less of the outer bark is usually present, which consists of suberized cells bearing granular dark brown coloring matter. Inner bark parenchyma of rather small, loosely united cells, many of which contain a deep brown resin or aggregate crystals of calcium oxalate. Typical long, thick-walled, finely porous bast fibers are plentifully present.

The bark of Juglans regia (English walnut) and $J$. nigra (black walnut) is similarly used, but perhaps not often as an adulterant of the above.

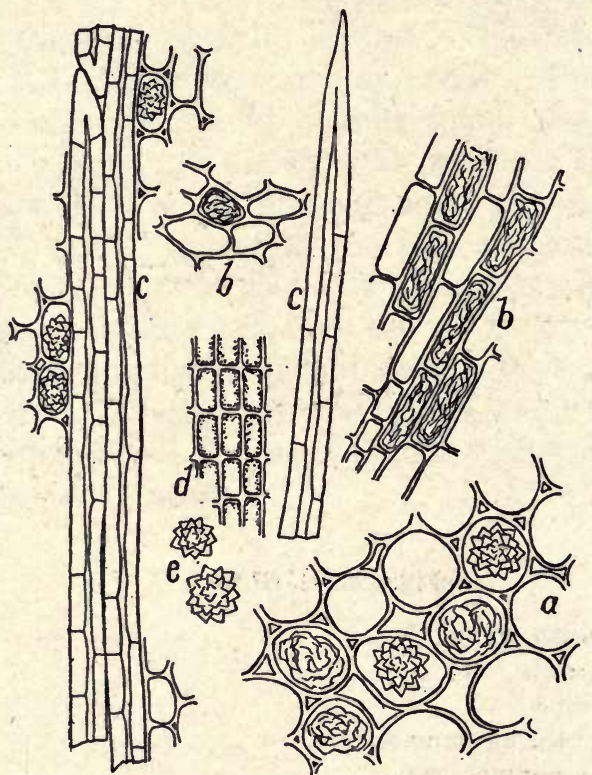

Fig. 123. JUGLANS.

a. Parenchyma cells with coloring matter and crystals.

b. Parenchyma, longitudinal view.

c. Bast fibers.

d. Cork, profile view.

e. Aggregate crystals of calcium oxalate. 


\section{3. (Fig. 124.) KAMALA. Kamala.}

Naturally a rather coarse powder.

Kamala, E., G., Fr.

The stellate trichomes and glandular trichomes of Mallotus philippinensis, Müller, Euphorbiaceæ.

Red, with brown.

Odorless.

Tasteless; sandy, gritty.

Kamala consists of glandular and aggregate trichomes. The glandular predominate; they are deep red, multicellular. The aggregate trichomes consist of single celled, rather thick-walled, more or less bent, light brownish hairs. Indistinct epidermal remnants are present also, and some sand is normally present.

Ash 6 per cent.

Quite generally adulterated; usually with a fine sand and colored starch (a maranta-like starch). Adulteration very easily detected micrcscopically because the kamala elements are very characteristic.

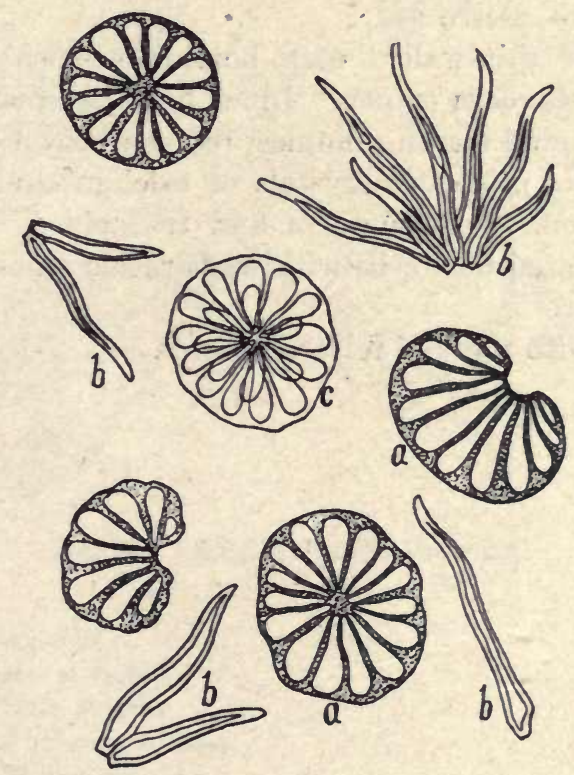

Fig. 124. RAMALA.

a. Deep reddish brown glandular trichomes.

b. Aggregate simple trichomes.

c. Gland decolorized with a weak solution of potassium hydrate. 


\section{4. (Fig. 125.) KRAMERIA. Peruvian Rhatany.}

Fl. ex. 30. Tinct. 40 .

Payta rhatany, E. Peruanische (Payta) Ratanhia, G. Ratanhia, Fr. The roots of Krameria triandra Ruiz et Pavon, Polygalaceæ.

Bright red brown.

Somewhat musty odor.

Very astringent, saliva red.

Outer bark of thin-walled cork bearing reddish brown coloring matter; some of the cells empty. Inner bark parenchyma cells with simple and compound starch granules, reddish brown coloring matter and small variable prismatic crystals of calcium oxalate, not unlike those of cinnamon. Porous ducts and tracheids. Typical, rather short, mostly isolated bast cells with walls rather thick.

Ash 4 per cent.

Adulterated with roots of related species. 


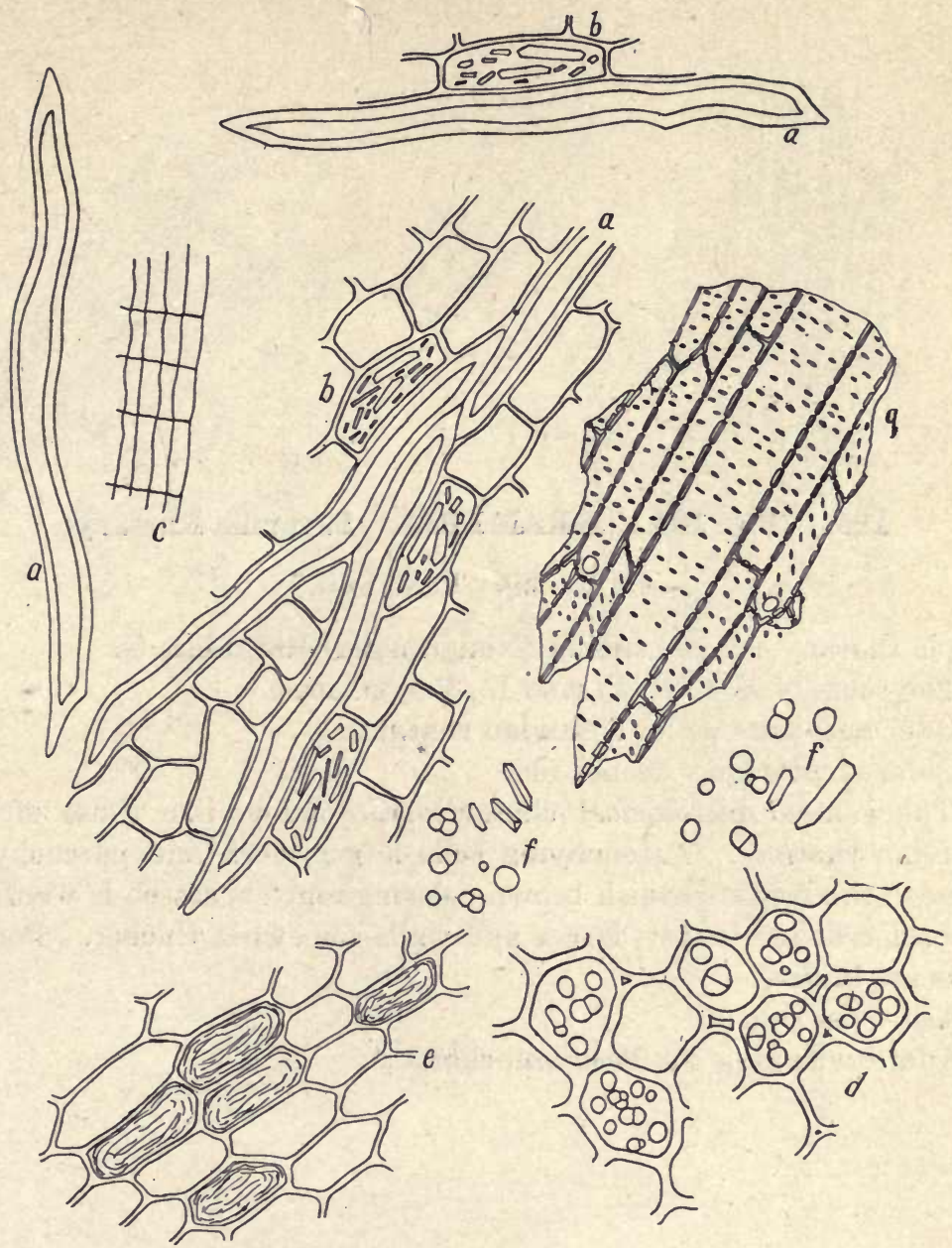

Fig. 125. KRAMERIA. Peruvian.

a. Bast.

b. Crystal bearing cells.

c. Outer cork, lateral view.

d. Parenchyma with starch.

e. Cells with red coloring matter.

$f$. Crystals and starch granules.

g. Tracheids and porous ducts. 
125. (Fig. 126.) KRAMERIA. Savanilla Rhatany.

Fl. ex. 30. Tinct. 40 .

Purple rhatany, E. Savanilla (Neugranada) Ratanhia, G.

The roots of Krameria Ixina L., Polygalaceæ.

Odor and taste as for Peruvian rhatany.

Color of powder a deeper red.

The general histological characteristics much like those of the Peruvian rhatany. Parenchyma cells larger; cork and parenchyma richer in the bright reddish brown coloring matter; starch is wanting; the bast cells are longer, larger and walls somewhat thicker. Porous ducts are larger.

Ash 4 per cent.

Adulterations as for Peruvian rhatany. 


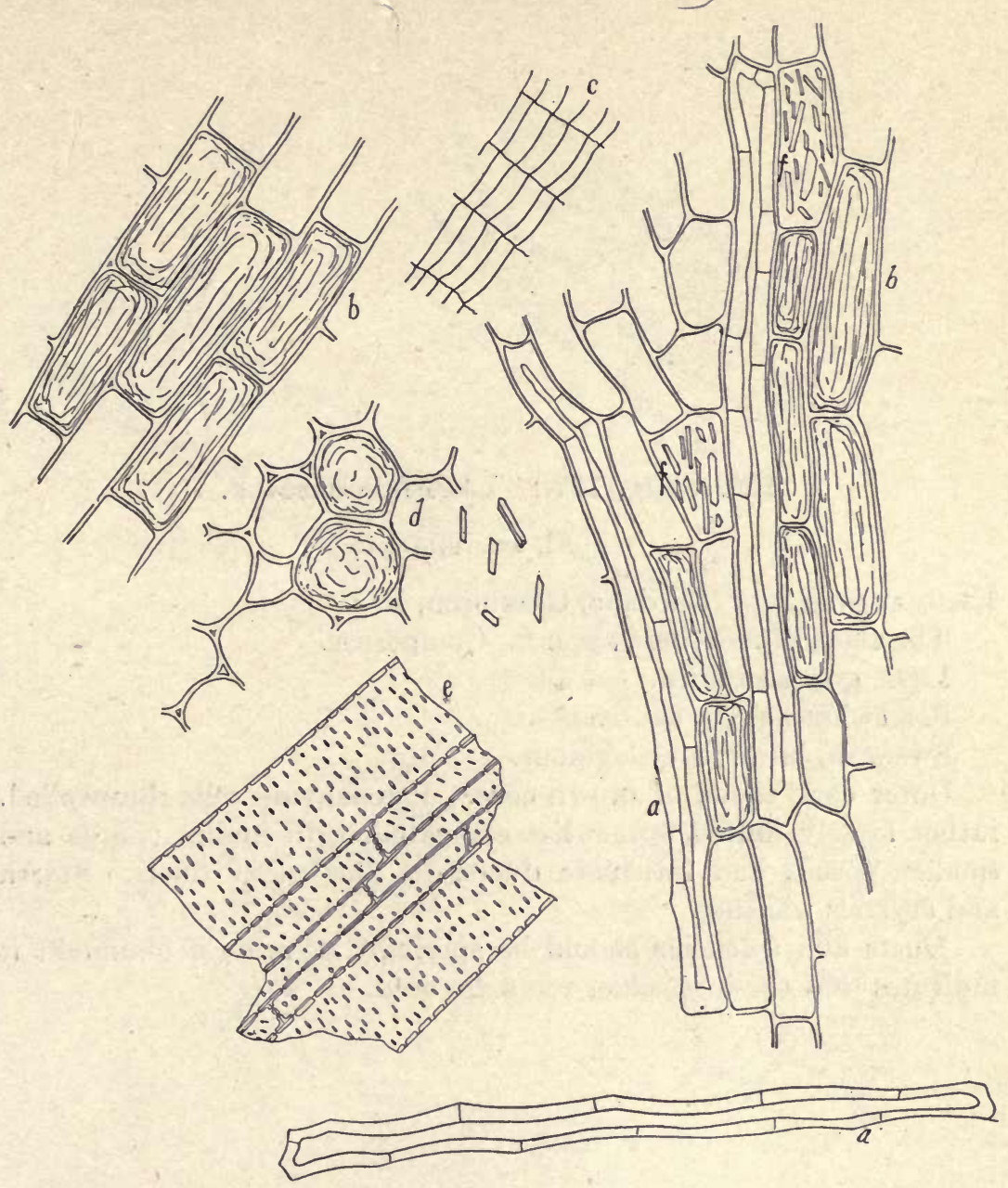

Fig. 126. KRAMERIA. Savanilla.

a. Bast.

b. Cells with red coloring matter.

c. Outer cork, lateral view.

d. Parenchyma with resin.

e. Porous ducts and tracheids.

$f$. Crystal bearing cells. 
126. (Fig. 127.) LAPPA. Burdock.

Fl. ex. 60.

Klettenwurzel, G. Bardane, Glouteron, Fr.

The roots of Arctium Lappa L., Compositæ.

Light grayish brown.

Somewhat heavy, nauseous.

Sweetish, bitter, mucilaginous.

Outer cork tissue of brown cells. Parenchyma cells thin-walled, rather loosely united, somewhat elongated, with inulin. Large and smaller porous and reticulate ducts. A few resin ducts. Starch and crystals wanting.

Ducts and tracheids should be sparingly present; if abundant it indicates that the inert older roots are used. 


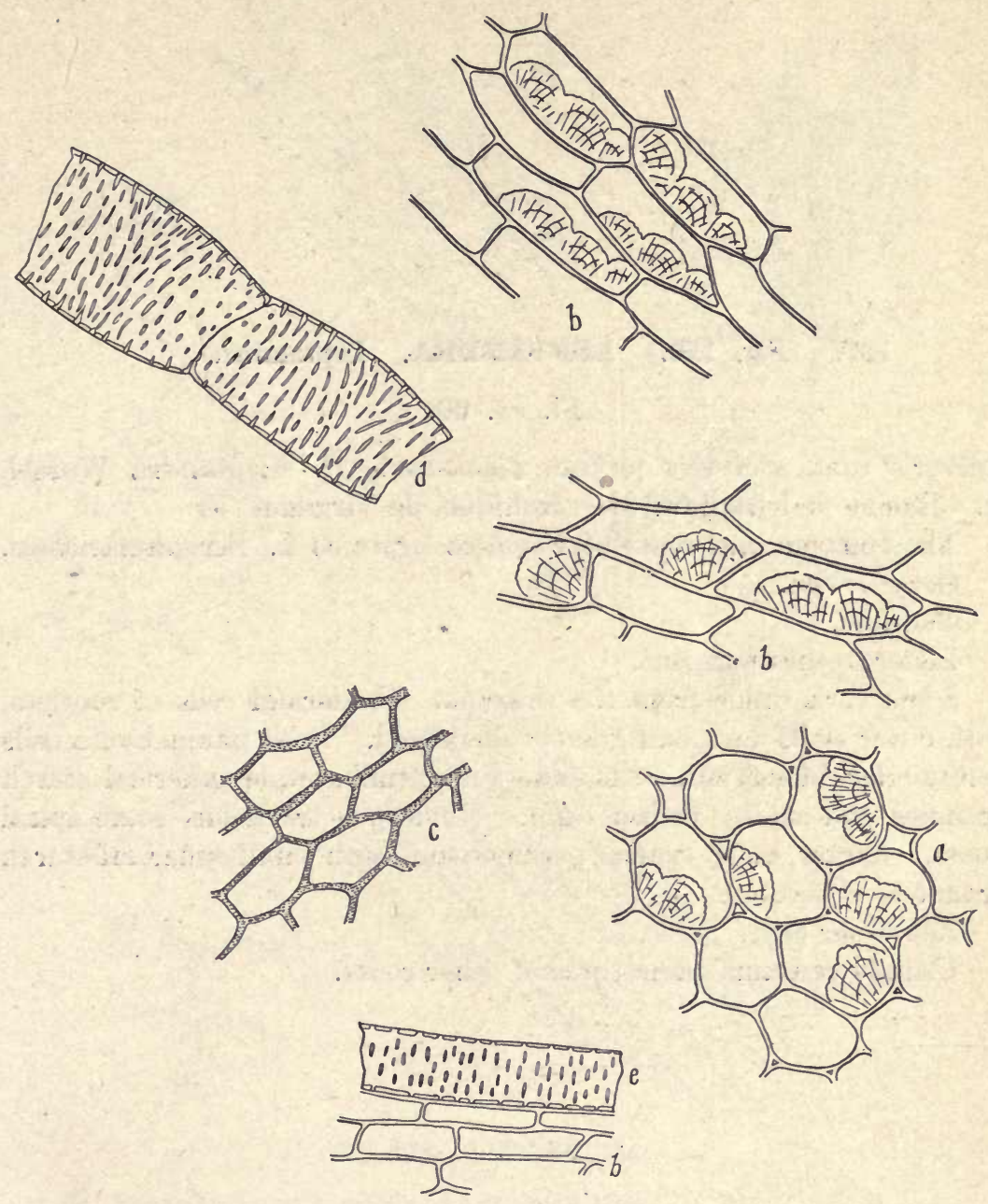

Fig. 127. LAPPA.

$a, b$. Parenchyma with inulin.

c. Cork.

d. Large porous duct.

e. Smaller porous duct. 
127. (Fig. 128.) LEPTANDRA. Leptandra.

Fl. ex. 60 .

Culver's root, Culver's physic, black-root, E. Leptandra Wurzel, G. Racine de leptandra (de véronique, de Virginie), Fr.

The rhizome and roots of Veronica virginica L., Scrophulariaceæ. Gray-brown.

Odorless.

Bitter, feebly pungent.

Some cork tissue from the rhizome. Epidermal cells of rootlets, with outer walls dark and greatly thickened. Root parenchyma cells rectangular, elongated, with some very small simple spherical starch granules and smoky brown resin. Numerous tracheids, some spiral ducts. Larger, more typical parenchyma, with small spherical starch granules, of rhizome.

Ash 6 per cent.

Usually contains admixtures of other roots. 


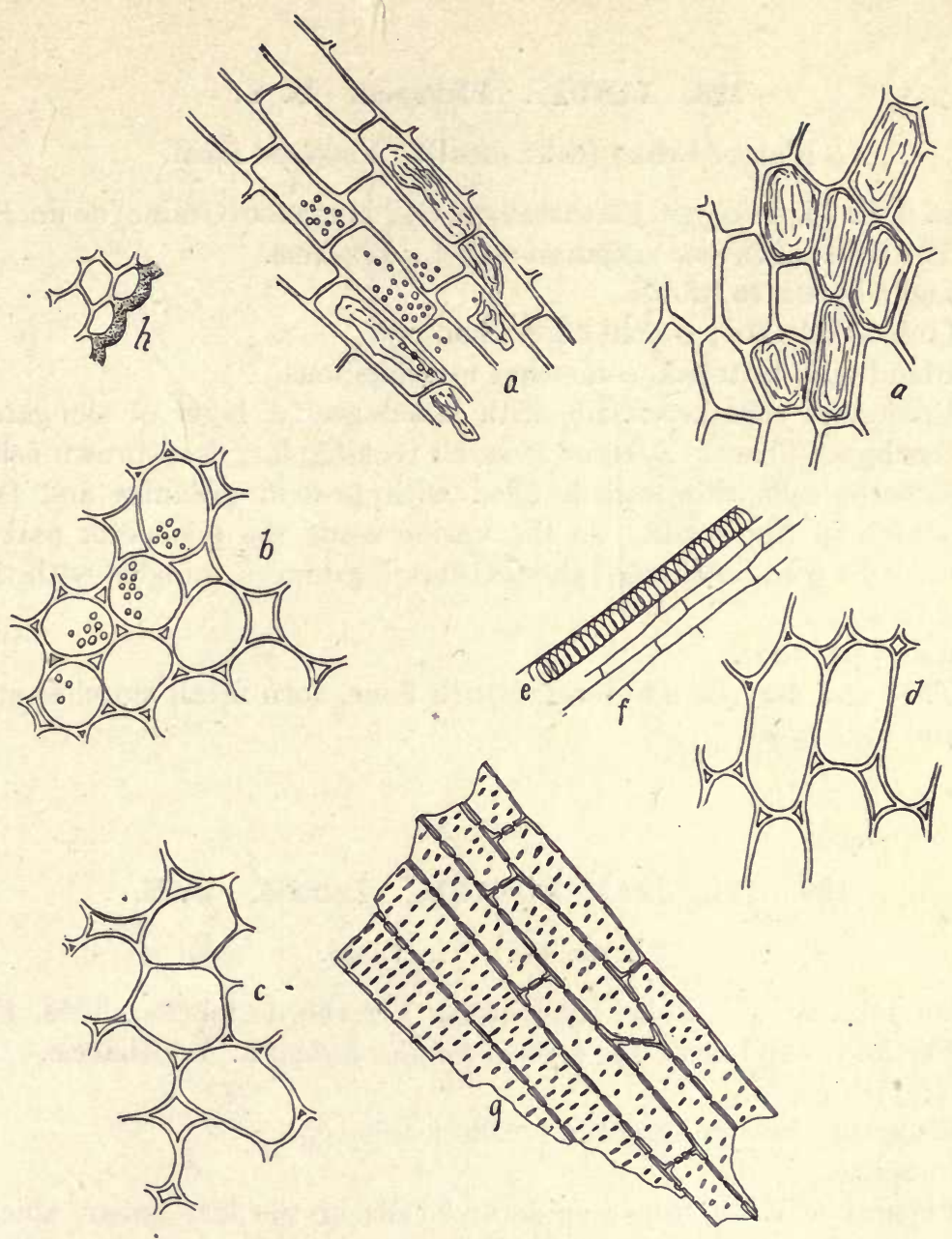

Fig. 128. LEPTANDRA.

$a, b$. Parenchyma with resin and coloring matter.

b. Parenchyma with starch.

c. Parenchyma.

d. Parenchyma, longitudinal view.

e. Spiral duct.

f. Phlœm tissue.

g. Tracheids.

$h$. Epidermal cells of rootlets. 


\section{LINUM. Flaxseed. U. S.}

Flaxseed cake (cake meal). Flaxseed meal.

Linseed, E. Leinsamen, Flachssamen, G. Semence (Graine) de lin, Fr. The seeds of Linum usitatissimum L., Linaceæ.

Light brown to brown.

Linseed oil odor; rancid odor when old.

Bland oily, bitterish, somewhat mucilaginous.

Epidermal cells prismatic, with mucilage. A layer of elongated sclerenchyma fibers. A layer of small rectangular, deep brown cells. Endosperm cells thin-walled, filled with proteid granules and fat. No starch in ripe seeds. In the unripe seeds the perisperm parenchyma cells contain simple spherical starch granules, mingled with the oil globules.

Ash 6 per cent.

The meal may be adulterated with flour, corn meal, starches and ground cake meal.

129. (Fig. 129.) LOBELIA. Lobelia. U. S. Fl. ex. 60. Tinct. 40.

Indian tobacco, E. Lobelienkraut, G. Herbe de lobélie enflée, Fr. The leaves and flowering tops of Lobelia inflata L., Lobeliaceæ.

Grayish green.

Fragrant; heavy, narcotic, recalling tobacco.

Pungent.

Vertical walls of upper epidermal cells of the leaf linear, thick, very porous; cuticle linearly marked. Lower epidermal tissue with stomata, vertical walls thin, wavy. Large, single celled, simple, rather thin-walled, conical trichomes, upper portion narrowed, with slight cuticular markings. Prismatic crystals of calcium oxalate.

Ash 10 per cent.

The most common adulterant is the basal stems and leaves, indicated by an excess of fibrous tissue. 


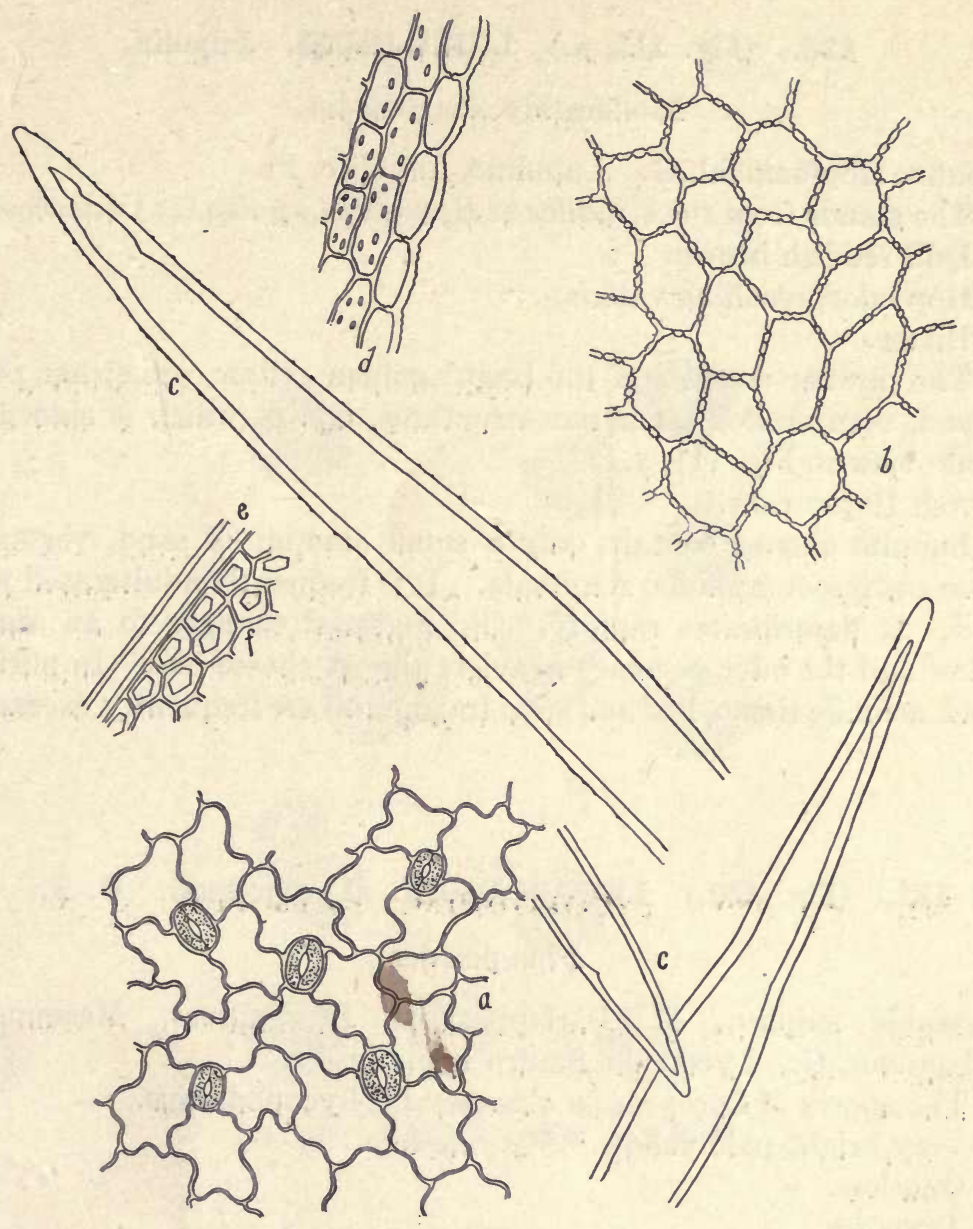

Fig. 129. LOBELIA.
a. Epidermal tissue, lower.
b. Upper epidermis.
c. Trichomes.
d. Epidermis, lateral view.
e. Bast fiber.
f. Crystal bearing cells. 
130. (Fig. 111, a.) LUPULINUM. Lupulin.

Moderately fine powder.

Lupulin, Hopfenmehl, G. Lupuline, Lupulite, Fr.

The glands from the strobiles of Humulus Lupulus L., Urticacex.

Dull reddish brown.

Hop odor, recalling valerian.

Bitter.

The powder consists of the bright golden yellow, somewhat pearshaped, many-celled glandular structures, one of which is shown in profile view in Fig. 111, a.

Ash 10 per cent.

Lupulin should contain only a small amount of sand, vegetable tissue and insect (aphidæ) remnants. It is frequently adulterated with sand. It deteriorates rapidly. Old material changes to an orange yellow and the odor becomes heavier, almost cheese-like. Impurities (sand, strobile tissue, leaf and stem fragments) are frequently excessive.

131. (Fig. 130.) LYCOPODIUM. Lycopodium. U. S.

Fine powder.

Vegetable sulphur, E. Bärlappsamen, Streupulver, Hexenmehl, Blitzpulver, G. Lycopode, Saufre végétale, Fr.

The spores of Lycopodium clavatum L., Lycopodiaceæ.

Very bright pale yellow. Very mobile.

Odorless.

Tasteless.

The powder consists almost wholly of the individual spores showing the facets of union with two other spores. Rarely two and three still united. Outer spore membrane delicately reticulate.

Ash 2 per cent.

Adulterated with spores of related species; talc, gypsum; starch, flour, dextrin; pollen grains of conifers; sulphur, turmeric. 

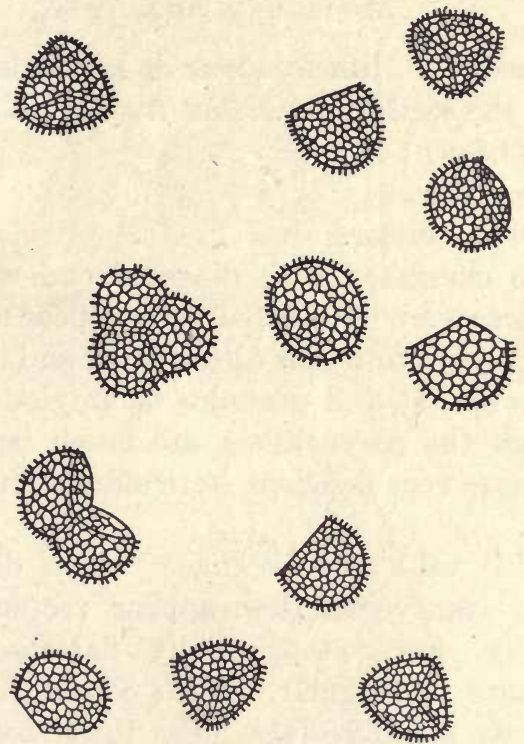

Fig. 130. LYCOPODIUM SPORES. 
132. (Figs. 131 and 132.) MACIS. Mace.

Moderately fine.

Muskatblüthe, Macis, G. Macis, Fleur de muscade, Fr.

The arillode of the seeds of Myristica fragrans L., Myristicaceæ.

Light yellowish brown; oily.

Delicate nutmeg odor.

Pungent, somewhat bitter.

Epidermal cells elongated with diagonal end walls, cuticle very thick. In transverse view epidermal cells appear somewhat tangentially flattened. Parenchyma cells rather small and thin walled, closely united and filled with fat and granules of amylodextrin, no starch. Distributed through the parenchyma are much larger resin-bearing cells. Vascular tissue very deficient (reticulate ducts.)

Ash 2 per cent.

Adulterated with wild or false mace, which differs in that the epidermal cells in transverse view appear rectangular, somewhat elongated vertically, never tangentially flattened. Amylodextrin granules larger, more rectangular. With concentrated sulfuric acid or potassium hydrate solution, false mace turns deep red, true mace yellowish. 


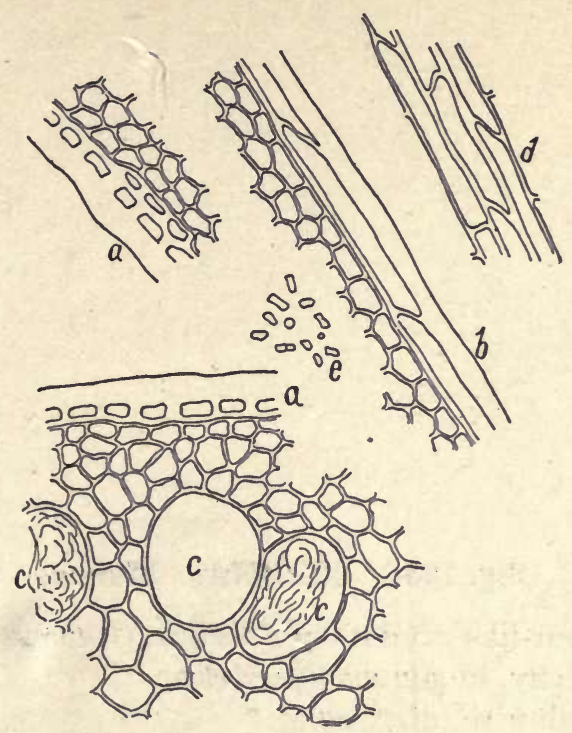

Fig. 131. MACE. True.

a. Transverse view of epidermis, parenchyma and resin cells (c). b. Longitudinal profile view of epidermal cells. $d$. Vertical view of epidermal cells. $e$. Amylodextrin granules.

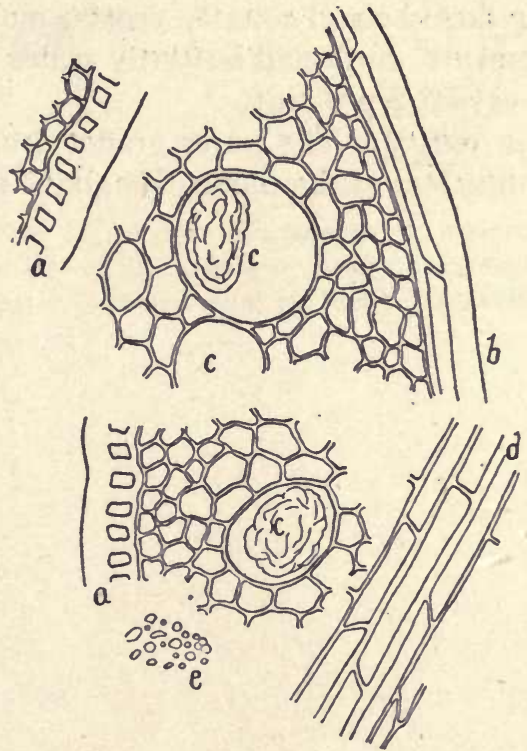

Fig. 132. MACE. False.

$a$. Transverse view of epidermal cells, parenchyma and resin cell. b. Longitudinal view of epidermis, parenchyma and resin cells. $d$. Vertical view of epidermal cells. e. Amylodextrin granules. 
133. (Fig. 133.) MANNA. Manna. U. S.

The dried sugar-like exudate of Fraxinus Ornus L., Oleaceæ.

Somewhat sticky, in gummed particles.

Somewhat yellowish, dirty color.

Faint odor.

Sweet taste.

Aggregates of prismatic crystals of mannose are present which gradually dissolve in water. Various impurities are quite generally present, among them bein gbacteria, yeasts, molds, mold spores, vegetable tissue elements, moth and butterfly scales, etc.

Ash should not exceed 2 per cent.

Varies greatly in purity. The purer grades are less hygroscopic and sticky and contain less of the impurities above mentioned. 

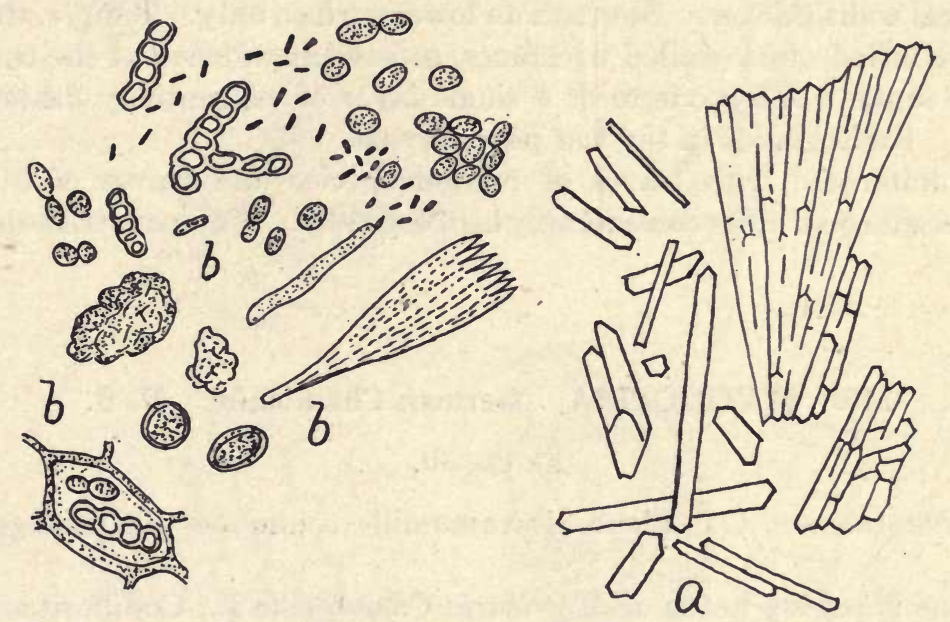

Fig. 133. MANNA. $a$, crystals of mannose; $b$, impurities which are usually present, more especially in the less pure grades, represented by bacteria, yeast cells, mold, mold spores, dirt and sand particles, vegetable tissue elements, moth and butterfly scales, etc. 


\section{4. (Fig. 134.) MATICO.}

Fl. ex. 30 .

Matico, E. G. Fr.

The leaves of Piper angustifolium L., Piperaceæ.

Brownish green.

Faintly aromatic, recalling chamomile.

Somewhat pungent and bitterish.

Epidermal cells above and below polygonal; upper much larger, vertical walls thicker. Stomata on lower surface only. Simple, three to five celled, thick-walled trichomes, somewhat widened at the transverse septæ. A hypoderm of a single layer of tangentially flattened cells. Resin glands in the leaf parenchyma.

Adulterated with leaves of related species and leaves of other plants which all differ considerably histologically. Compare trichomes.

\section{MATRICARIA. German Chamomile. U. S.}

Fl. ex. 30 .

Kamillenblumen, G. Fleurs de camomille commune (d'Allemagne), Fr.

The flowering heads of Matricaria Chamomilla L., Compositæ.

Greenish.

Fragrant, chamomile odor.

Bitter.

Epidermal cells with sinuate vertical walls; abundant collapsed parenchyma tissue; very porous tracheid-like cells. No starch. The pollen grains with prominent conical projections and three pores form the most marked microscopical characteristic of the powder. The glandular trichomes are usually so much collapsed as to be unrecognizable.

Ash 10 per cent.

Adulterated with flowers of Anthemis arvensis, Maruta cotula and other related plants. Compare with Roman chamomile. 

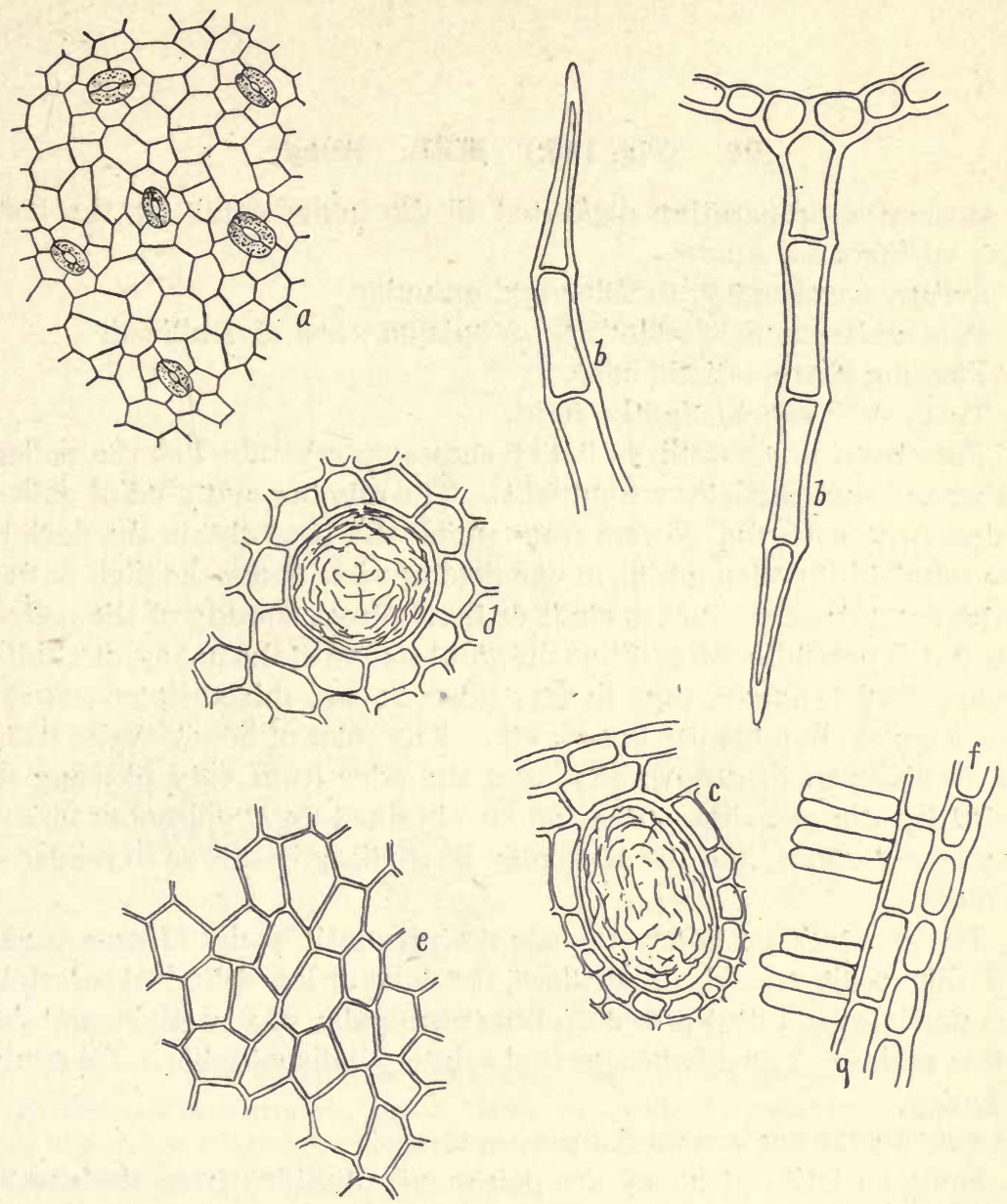

Fig. 134. MATICO.

a. Lower epidermis.

$b$. Trichomes.

c. Leaf gland with resin, lateral view.

d. Resin gland.

e. Upper epidermis.

f. Upper epidermis, lateral view.

g. Hypoderm. 


\section{6. (Fig. 135.) MEL. Honey.}

A saccharine preparation deposited in the honey-comb by the bee, Apis mellifera L., Apidæ.

Syrupy consistency, to thick and granular.

Pale amber to pale yellowish, to opaque when crystallized.

Pleasing characteristic odor.

Taste very sweet, slightly acrid.

The fresh, uncrystallized honey shows no crystals, but the pollen grains and wax particles are present. The number and kind of pollen grains vary with the flowers from which the bees obtain the nectar. The number of pollen grains in one field of view under the high power varies from less than one to eight or ten. From a study of the pollen grains it is possible to determine the floral source of the honey, as alfalfa honey, clover honey, sage honey, furze honey, mixed honey, sweet clover honey, bumble bee honey, etc. The color of honey varies from nearly colorless to deep brown, and the odor from very pleasing to decidedly disagreeable. The honey obtained from poisonous plants may be poisonous, and the taste may be so disagreeable as to render it inedible.

The crystallized honey reveals the prismatic scales of cane sugar and the needle crystals of lævulose, the more or less spherical colorless wax particles and brown to deep brown irregular wax particles and the pollen grains. The microscope is absolutely indispensable in the study of honey.

Ash should not exceed 0.3 per cent.

Some varieties of honey are poisonous, obtained from the nectar of the flowers of toxic plants. Imitation honey made from glucose, syrup, honey flavor and added pollen grains, is found upon the market. There may be partial substitution with glucose, etc. There may be false declaration of quality and grade and source. 


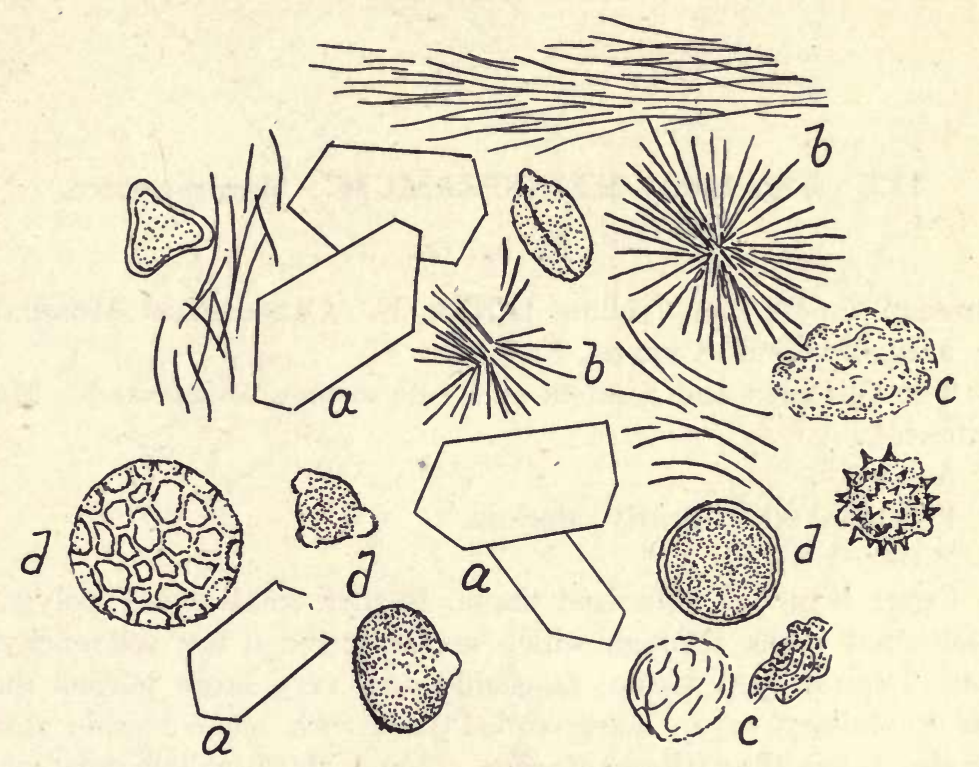

Fig. 135. MEL. HONEY.

The microscopic appearance of crystallized honey.

$a$, Crystals of cane sugar; $b$, crystal of lævulose; $c$, colored (usually brown) and colorless bits of wax which are constantly present in genuine honey; $d$, different kinds of pollen grains. 


\section{7. (Fig. 136.) MENISPERMUM. Menispermum.}

Fl. ex. 60 .

Canadian moon seed, yellow parilla, E. Canadisches Mondkorn, G. Ménisperme du Canada, Fr.

The rhizomes and rootlets of Menispermum canadense L., Menispermaceæ.

Ash gray.

Faint soil odor; nearly odorless.

Bitter.

Outer layer of suberized tissue. Rather small-celled polygonal hypodermal tissue through which are scattered a few sclerenchyma cells. Typical bast tissue; tracheids and very large porous ducts with medullary rays. Large-celled pith with some simple starch granules resembling those of corn. Some thick-walled very coarse parenchyma. 


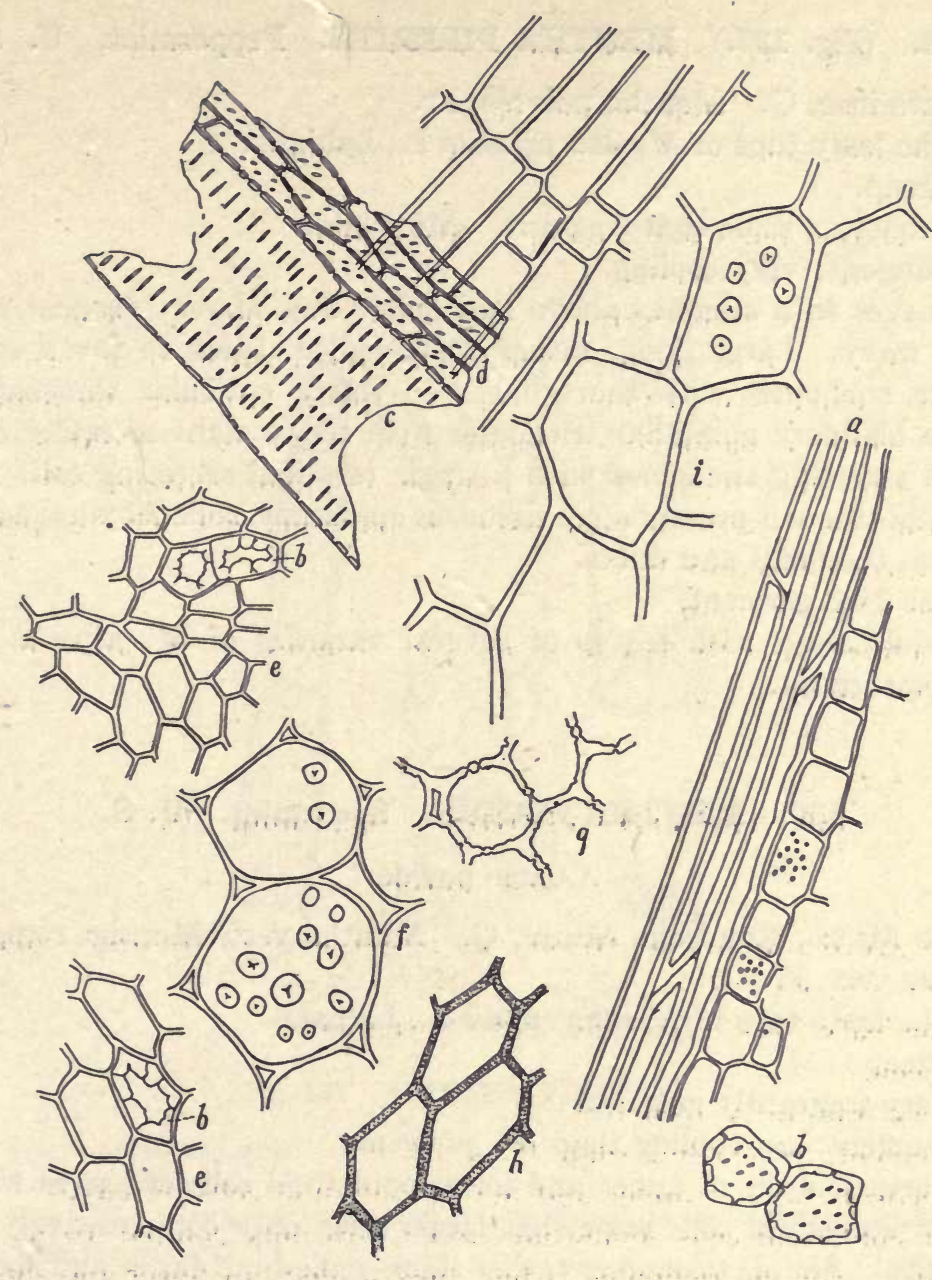

Fig. 136. MENISPERMUM.

a. Bast.

b. Sclerenchyma cells.

c. Large porous duct.

d. Tracheids and medullary rays.

e. Outer tissue with sclerenchyma cells $(b)$.

f. Parenchyma (pith) with starch.

g. Thick-walled porous cells.

h. Cork. 
138. (Fig. 137.) MENTHA PIPERITA. Peppermint. U. S.

Pfefferminze, G. Mentha poivrée, Fr.

The leafy tops of Mentha piperita L., Labiatæ.

Green.

Aromatic, somewhat fragrant. Mint odor.

Pungent; very cooling.

Leaves with stomata above and below, few above; vertical walls thin, wavy. Large, long, rather thick-walled, three to seven celled simple trichomes with short linear to warty cuticular thickenings. Large bladdery glandular trichomes with six to eight secreting cells. Small secreting trichomes with a single terminal secreting cell. Besides this there is present stem tissue, as epidermis, collenchyma, parenchyma, tracheids and ducts.

Ash 12.5 per cent.

Adulterated with leaves of several varieties of $M$. piperita and with spearmint.

139. MENTHA VIRIDIS. Spearmint. U. S.

Coarse powder.

Grüne Minze, Römische Minze, G. Menthe vert, Mentha romaine, Baume vert, Fr.

The leafy tops of Mentha viridis L., Labiatæ.

Green.

Very fragrantly aromatic.

Pungent, less cooling than $M$. piperita.

Vertical walls of upper and lower epidermal cells of leaves wavy. Upper epidermal cells somewhat larger with only comparatively few stomata. Simple trichomes rather thick-walled but fewer and shorter than in peppermint; cuticular markings. less prominent and less decidedly linear, more warty. Glandular trichomes are similar to those of peppermint.

Ash 12.5 per cent.

According to several authorities the glandular trichomes of peppermint are distinguished at once by the menthol crystals, a characteristic which does not seem to be marked. May be admixed and adulterated with various species and varieties of mint. 


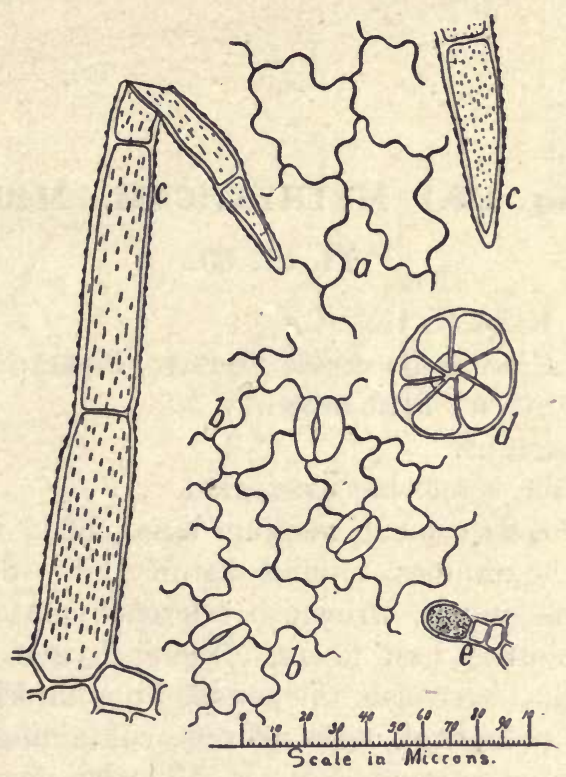

Fig. 137. MENTHA PIPERITA.

a. Upper epidermal cells.

b. Lower epidermis.

c. Trichomes, simple, showing cuticular markings (a medium sized trichome).

d. Gland, top view.

e. Small glandular trichome. 
140. (Fig. 138.) METHYSTICUM. Methysticum.

Fl. ex. 60 .

Ava, ava Kava, Kava Kava.

The roots of Piper methysticum Fœrster, Piperaceæ.

Light brown to very light brown.

Somewhat fragrant.

Pungent, bitter, somewhat astringent.

Parenchyma cells typical, medium sized, filled with rather large compound starch granules, having distinct hili. Scalariform, reticulate and porous ducts. Brownish sclerenchymatous, porous, bast fibers; nearly colorless bast fibers. Sclerenchymatous, very porous, tracheids. Typical brownish, thick-walled porous sclerenchyma fibers Epidermal cells polygonal, walls porous, containing crystalline substances. Elongated parenchymatous cells with deep brown resinous matter. 


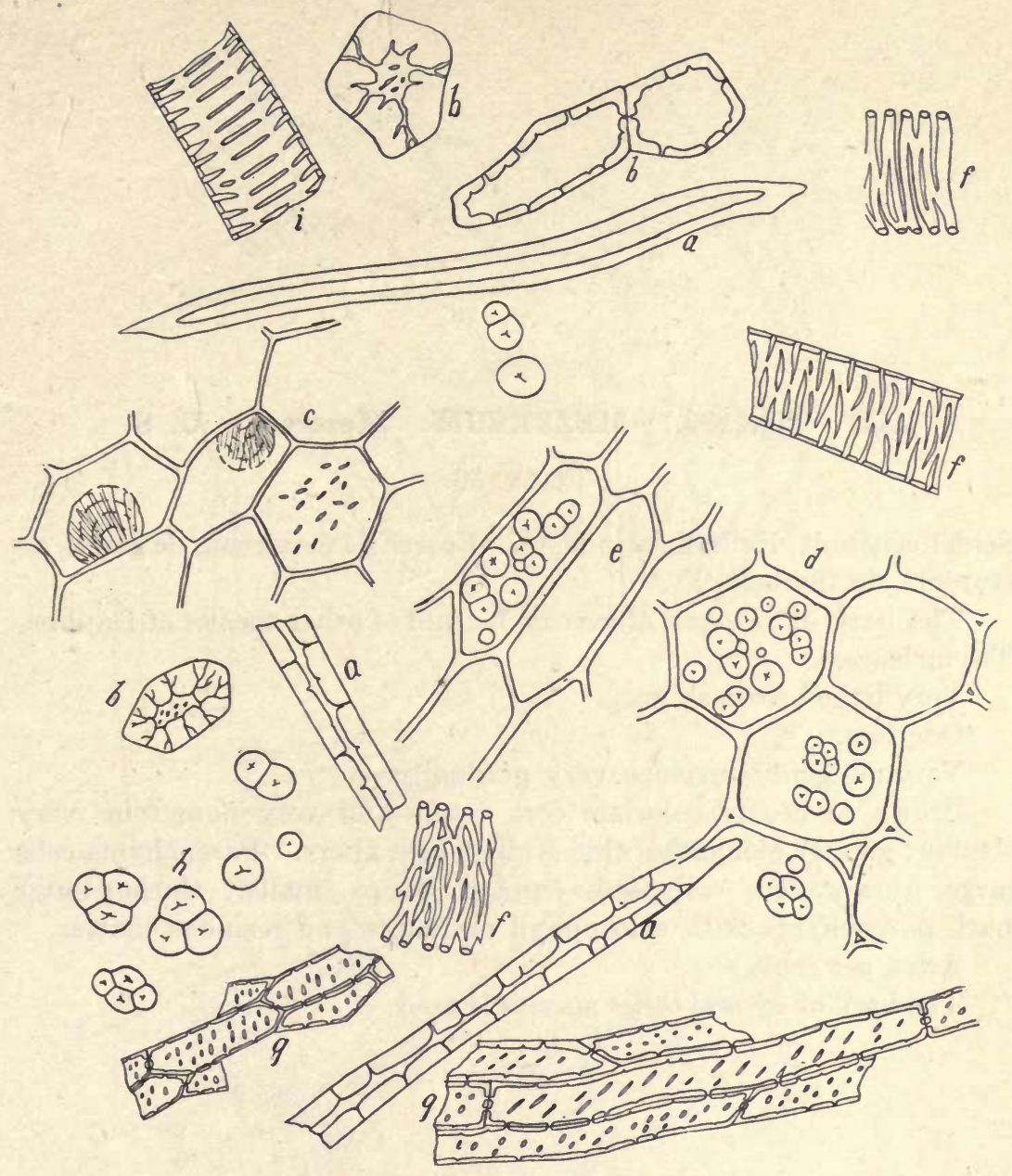

Fig. 138. METHYSTICUM.

a. Bast cell.

b. Sclerenchyma.

c. Parenchyma with crystals.

d. Parenchyma with starch.

e. Parenchyma, longitudinal view.

$f$. Reticulate ducts.

g. Tracheids.

h. Starch granules.

$i$. Scalariform duct. 


\section{1. (Fig. 139.) MEZEREUM. Mezereon. U. S.} Fl. ex. 30 .

Seidelbastrinde, Kellerhalsrinde, G. Ecorce de mézéréon, de garou, de lauréole, de thymele, Fr.

The bark of Daphne Mezereum L., and of other species of Daphne, Thymeleaceæ.

Very light brownish gray.

Odorless.

Very pungent, develops very gradually.

Brown to nearly colorless cork tissue and very numerous, very slender, greatly elongated, thin-walled, bast fibers. Parenchyma cells large, thin-walled, collapsed, empty. Some smaller, thicker outer bark parenchyma with chlorophyll remnants and resinous matter.

Ash 4 per cent.

The bark of several other species is used. 


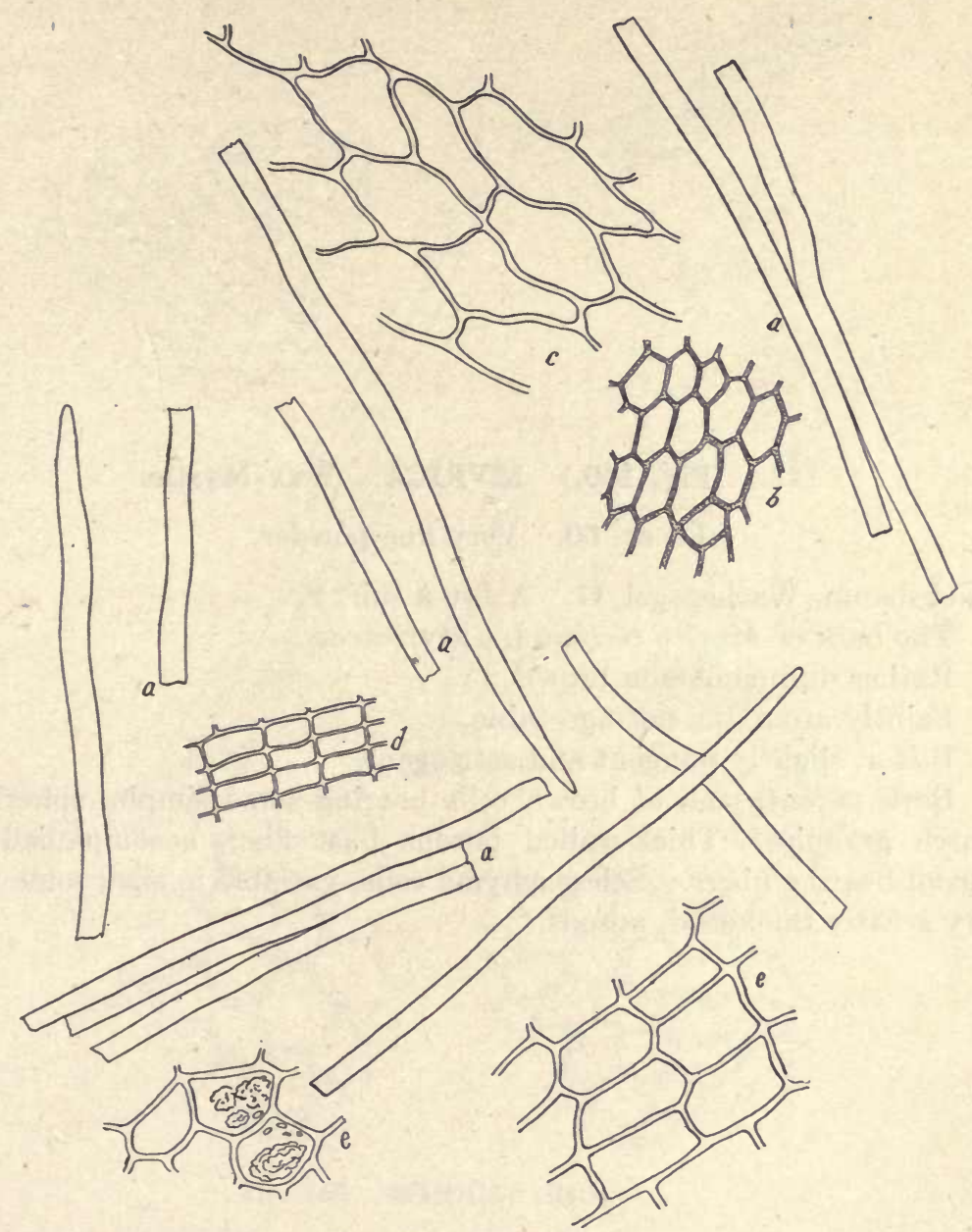

Fig. 139. MEZEREUM.
a. Bast.
b. Cork, vertical view.
c. Parenchyma.
d. Cork, lateral view.
e. Parenchyma. 
142. (Fig. 140.) MYRICA. Wax-Myrtle.

Fl. ex. 60. Very fine powder.

Wachsbaum, Wachsgagel, G. Arbre à suif, Fr.

The bark of Myrica cerifera L., Myricaceæ.

Rather dull cinnamon brown.

Faintly aromatic, not agreeable.

Bitter, slightly pungent and astringent.

Bark parenchyma of brown cells bearing some simple, spherical starch granules. Thick-walled porous bast fibers accompanied by crystal-bearing fibers. Sclerenchyma cells, variable in size; some not very greatly thickened, porous. 


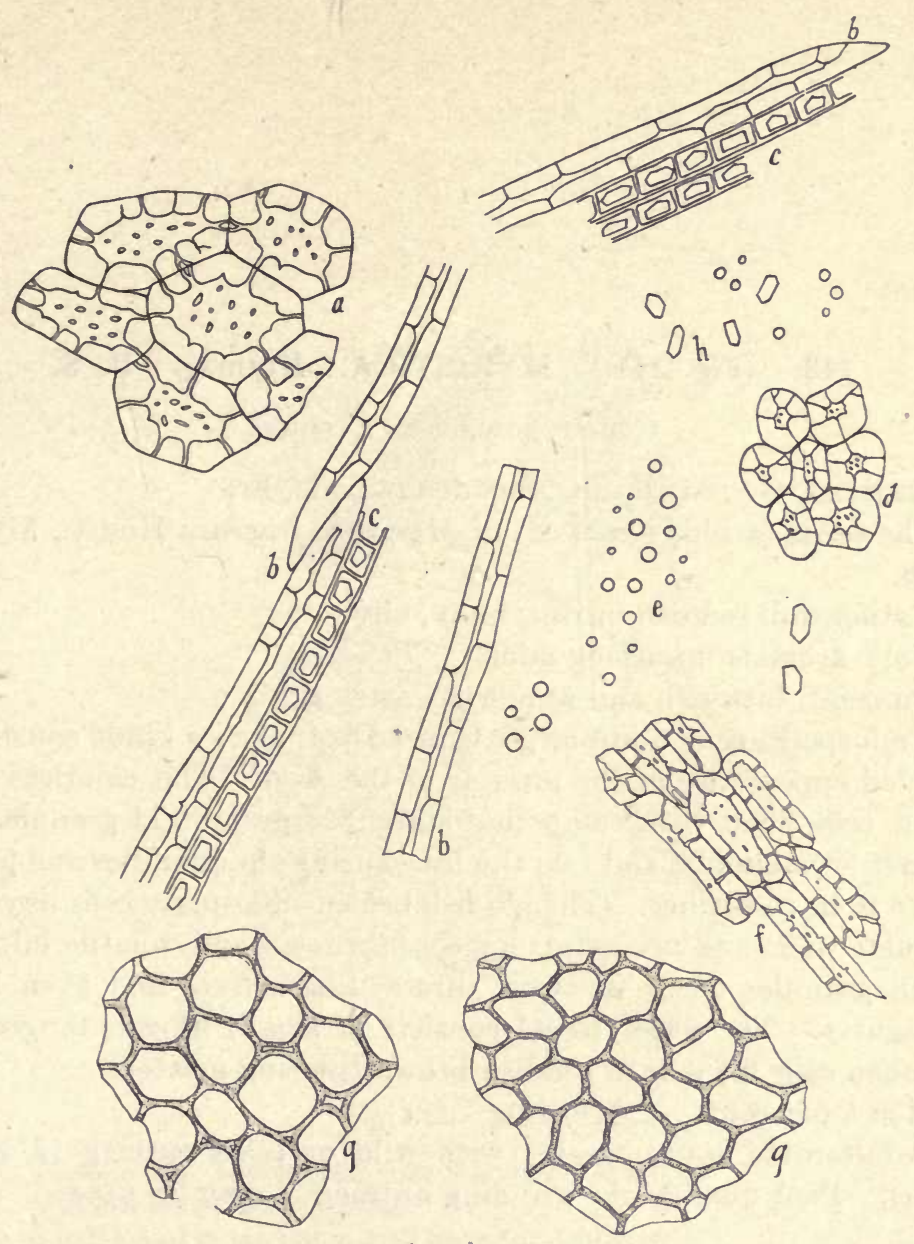

Fig. 140. MYRICA. Bark.

a. Larger sclerenchyma.

b. Bast.

c. Crystal-bearing fibers.

d. Smaller sclerenchyma.

e. Starch granules.

f. Elongated sclerenchyma.

g. Bark parenchyma.

$h$. Prismatic crystals and starch granules. 
143. (Fig. 141.) MYRISTICA. Nutmeg. U. S.

Coarse powder as a spice.

Muskatnuss, G. Muscade, Noix de muscade, Fr.

The seeds (arillus removed) of Myristica fragrans Houtt., Myristicaceæ.

Rather dull reddish brown; fatty, oily.

Very aromatic; nutmeg odor.

Pungent, bitterish and somewhat astringent.

Endosperm cells quite large, thin-walled, of two kinds causing the marbled appearance of the interior of the seed. The colorless endosperm cells filled with compound starch, large proteid granules with distinct crystalloids, and fat; the fat causing the granules and proteid bodies to be indistinct. The reddish brown endosperm cells have very irregular walls and are empty or contain resin and volatile oil. The starch granules occur in twos, threes, fours, fives and even higher aggregates. The outer tissue consists of small, brown, tangentially flattened cells filled with reddish brown coloring matter.

Ash 3 per cent.

Adulterated (only rarely) with wild or false nutmeg (Myristica fatua). Poor quality of "grinding nutmegs". may be used. 


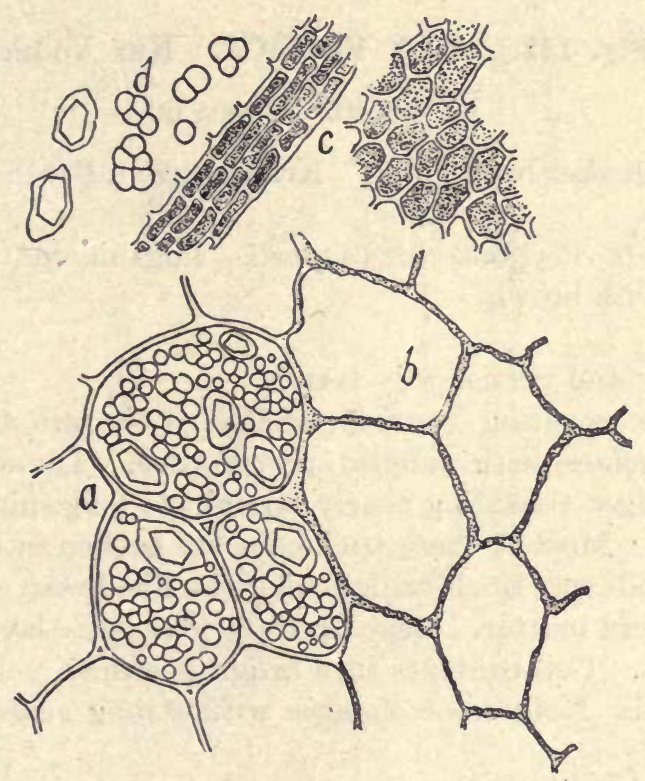

Fig. 141. MYRISTICA.

a. Parenchyma (endosperm) with starch and crystals.

b. Reddish brown parenchyma.

c. Small-celled outer tissue with granular contents.

d. Starch and crystals. 


\section{4. (Fig. 142.) NUX VOMICA. Nux Vomica. U. S.} Fl. ex. 40. Tinct. 60 .

Poison-nut, Quaker buttons, E. Krähenaugen, Brechnuss, G. Noix vomiques, Fr.

The seeds of Strychnos nux vomica L., Loganiaceæ.

Light grayish brown.

\section{Odorless.}

Extremely and persistently bitter.

The outer covering consists wholly of elongated, thick-walled, colorless trichomes, with widened, porous base. The wall is unevenly thickened, ridges extending nearly straight to long spirally from base to near apex. Most of these trichomes are broken in the powdering. Endosperm cells very thick-walled, colorless, filled with oil globules and granular proteid matter. Beneath the trichomatic layer is a tissue of flattened cells. Cell-contents turn bright brownish yellow with tincture of iodine. Note color changes with strong acids (mineral) and alkalies.

Ash should not exceed 2.5 per cent.

Not generally adulterated. Ignatia beans may be substituted which are similar in structure and show similar reactions with acids, alkalies and with tincture of iodine. 


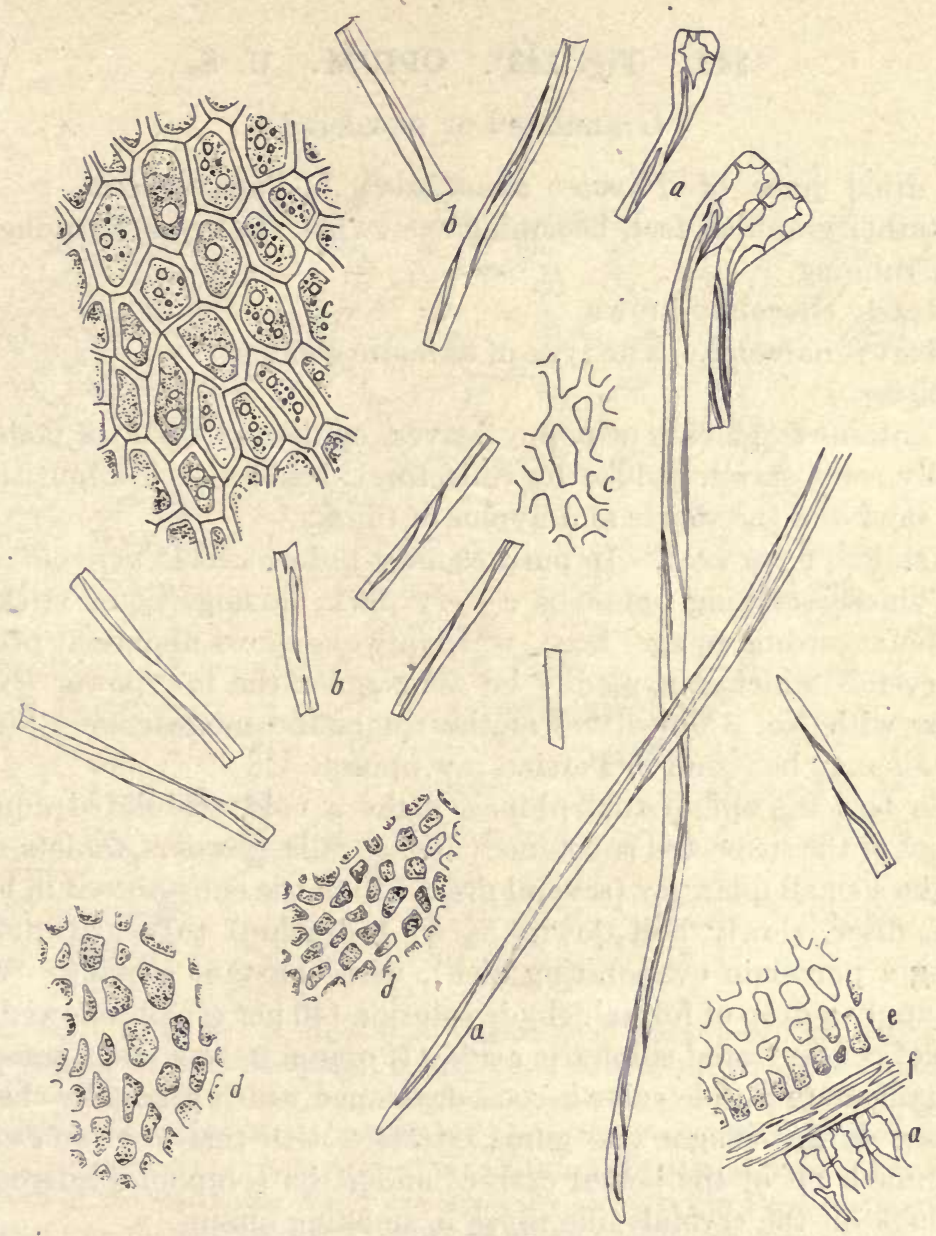

Fig. 142. NUX VOMICA.
a. Trichomes.
b. Trichomatic fragments.
c. d. Endosperm tissue.
e. Outer endosperm, lateral view.
f. Hypodermal tissue. 


\section{5. (Fig. 143), OPIUM. U. S.}

Granulated or powdered.

The dried juice of Papaver somniferum L, Papaveraceæ.

Rather granular feel, becoming somewhat sticky on warming and brisk rubbing.

Nearly chocolate brown.

Heavy, narcotic. The type of narcotic odors.

Bitter.

Contains fragments of poppy leaves, epidermal tissue of pods and usually some starch (added by collectors); besides such impurities as dirt, sand and the spores and hyphæ of fungi.

Ash 5 to 6 per cent. Impurities must not exceed 15 per cent:

Chinese smoking opium is a very dark, homogeneous, sticky to brittle (according to age) mass, which always shows abundant prismatic crystals which can readily be seen under the low power (No. 2 ocular with No. 3 objective) of the compound microscope. Similar crystals may be found in Persian raw opium.

To test for opium (morphine), make a cold acidulated aqueous extract of the suspected substance (such as pills, powders, tablets, etc.), or take a small quantity (several drachms) of the substance if in liquid form, filter, slowly boil down ( $1 / 2$ to 1 drachm) to nearly dryness (using a porcelain evaporating dish), with constant stirring. When cool apply a drop of formaldehyde solution (40 per cent.) followed by a drop of concentrated sulphuric acid. If opium (morphine) is present a permanganate purple color is soon developed which gradually changes to very dark. (Sugar and gums interfere with this test somewhat.) Examine a bit of the boiled extract under the compound microscope and look for the crystals like those in smoking opium.

Among the possible adulterants of raw opium are excess of poppy leaves and pods, excess of starch, sand and dirt. Mold and other fungi are frequently present. (A standard of moisture percentage for gum opium should be adopted.) 

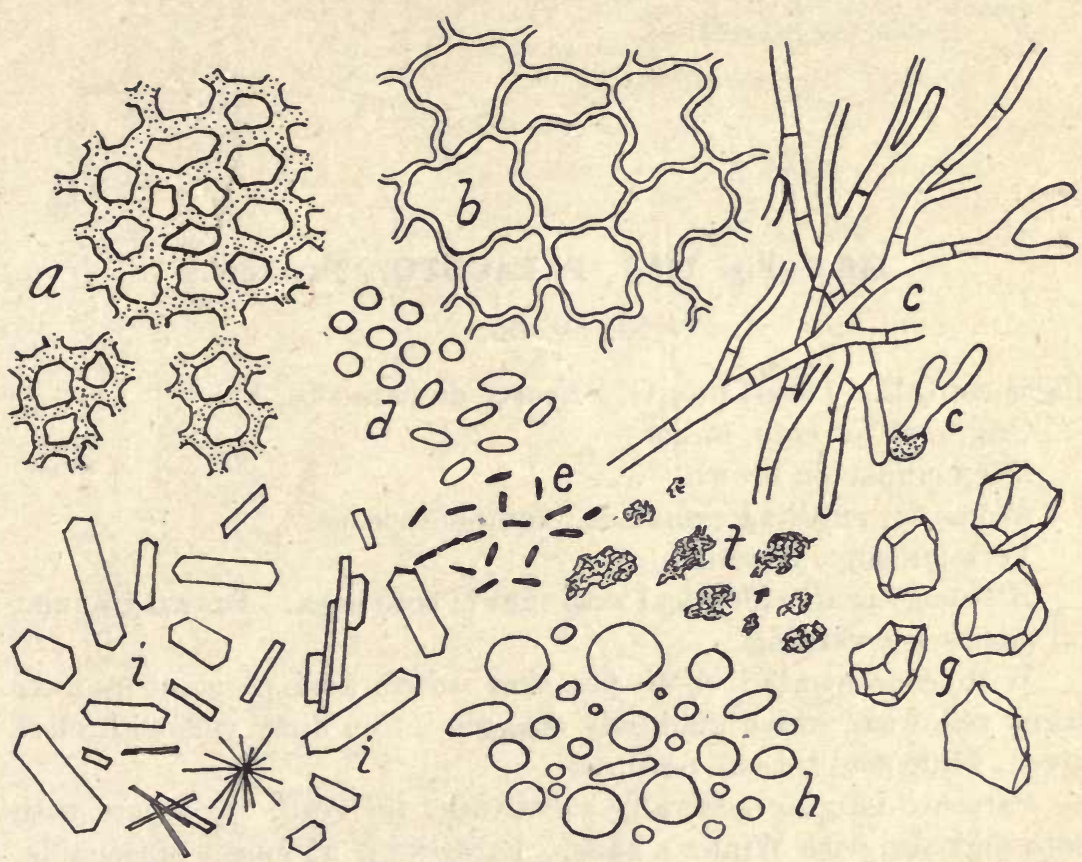

Fig. 143. OPIUM. $a$, Epidermal fragments of the pericarp are very abundantly present in Turkish opium; $b$, epidermal cells of the poppy leaf which are likewise abundantly present in gum opium; $c$, mold hyphæ are usually abundant as are also mold spores $(d)$; $e$, bacteria are abundant; $f$, dirt particles and $g$, sand particlcs are present; $h$, cereal (wheat) starch is usually present in small amounts; $i$, crystals of the meconate: which are especially abundant in Persian gum opium and constitute the characteristic inclusions of the Chinese smoking opium. It is possible to determine the alkaloidal strength of the Chinese smoking opium by the numerical crystal count. 


\section{6. (Fig. 144.) PARACOTO. Paracoto.}

Fl. ex. 60 .

False coto, E. Para-Coto, G. Ecorce de paracoto, Fr.

Origin, as for coto, unknown.

Deep cinnamon brown.

Aromatic, recalling cinnamon; camphoraceous.

Very pungent, bitterish.

Histology nearly identical with that of coto bark. Brown granular oil bodies are wanting.

With concentrated or 40 per cent. nitric acid paracoto powder turns yellowish, which gradually changes into a dirty yellowish olive green, while coto turns a deep red.

Paracoto is quite generally substituted for coto. Compare with coto and also with Winter's bark. Paracoto is no longer obtainable. 


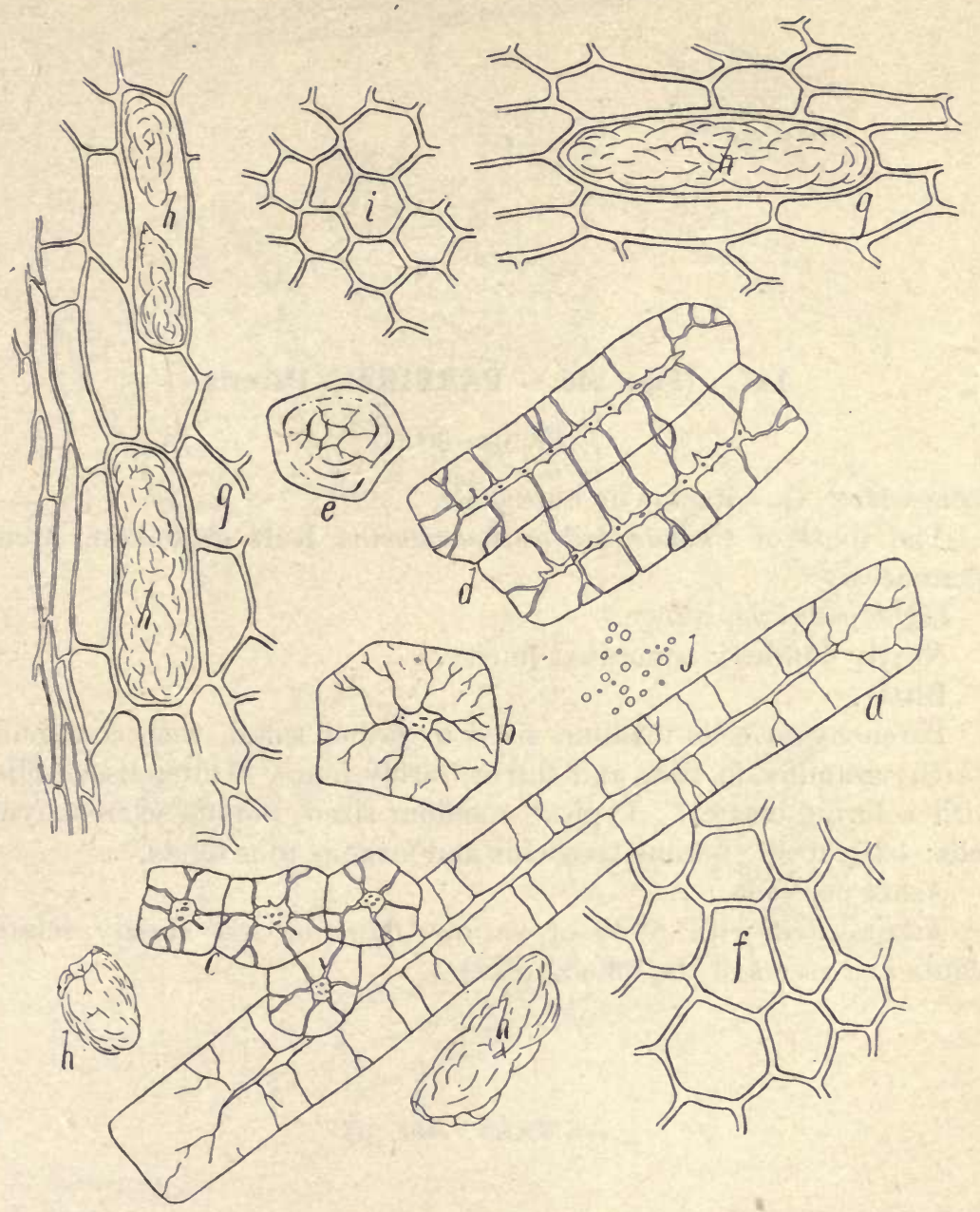

Fig. 144. PARACOTO.

$a, b, c, d, e$. Sclerenchyma cells.

f. Parenchyma.

g. Parenchyma with resin cells $(h)$.

h. Resin masses.

$i$. Outer cork cells.

j. Starch. 


\title{
147. (Fig. 145.) PAREIRA. Pareria.
}

\author{
Fl. ex. 30 .
}

Grieswurzel, G. Racine de butua, Fr.

The roots of Chondodendron tomentosum Ruiz et Pavon, Menispermaceæ.

Light yellowish brown.

Nearly odorless; somewhat musty.

Bitter.

Parenchyma cells medium sized to rather small, with compound starch; granules in twos and threes, rarely fours. Outer tissue filled with coloring matter. Typical, medium sized, porous sclerenchyma cells; bast fibers; porous tracheids and large porous ducts.

Ash 4 per cent.

Adulterated with roots of various more or less closely related plants and stems of the official plant. 


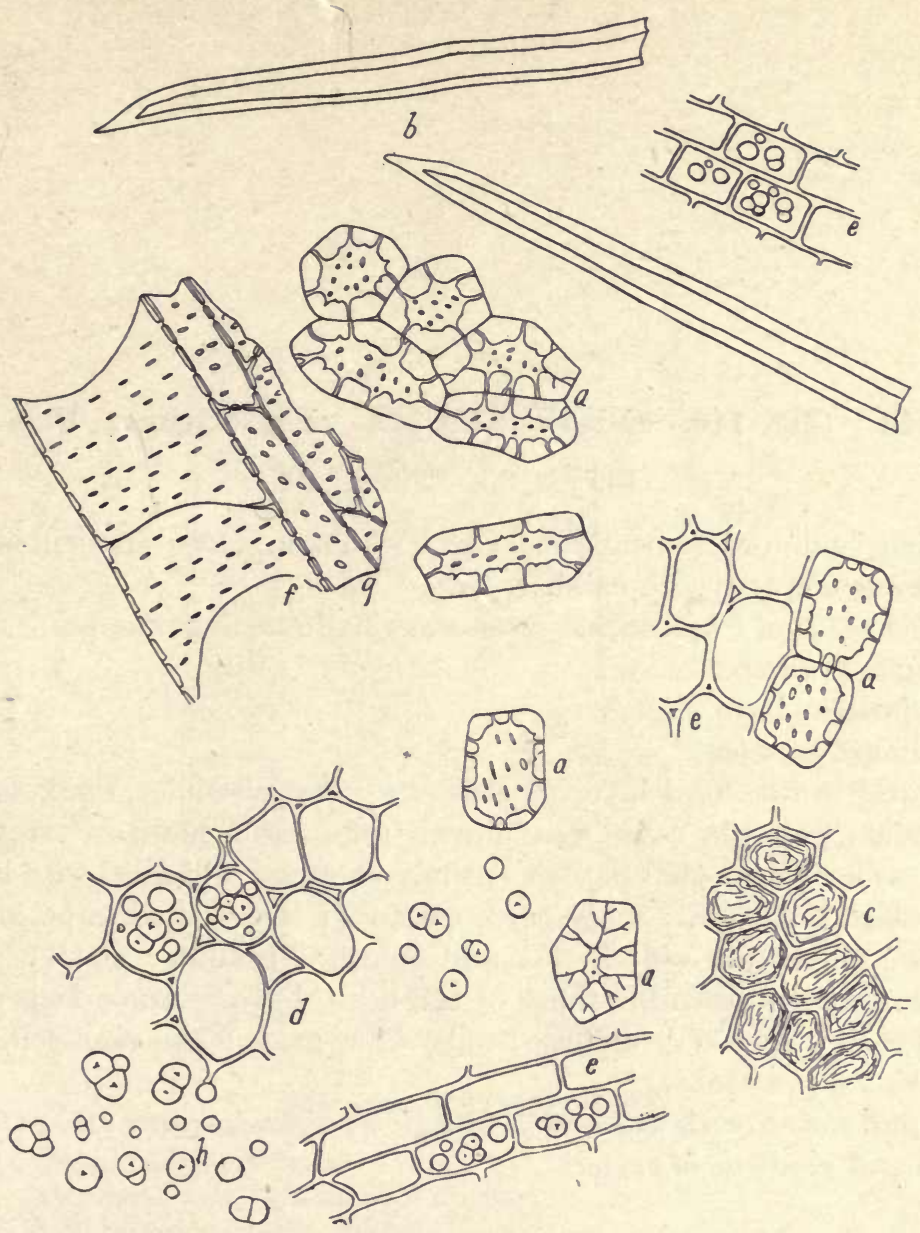

Fig. 145. PAREIRA.

a. Sclerenchyma.

b. Bast.

c. Cells with coloring matter.

d. Parenchyma with starch.

e. Parenchyma, longitudinal view.

f. Large porous duct.

g. Tracheids.

h. Starch granules. 
148. (Fig. 146.) PHYSOSTIGMA. Physostigma. U. S.

Fl. ex. 30. Tinct. 40.

Calabar bean, ordeal bean, E. Calabarbohnen, Gottesurtheilbohnen, G. Fève d'épreuve du calabar, Fr.

The seeds of Physostigma venenosum Balfour, Leguminosæ.

Light brown; oily.

Odorless; bean odor.

Almost tasteless.

Outer brown hard layer consists of verylong, slender, thick-walled, brownish, palisade cells, with brown granular contents. Irregular, thick-walled, somewhat porous, entirely colorless cells filled with bright red coloring matter. Endosperm cells very thin-walled, large, loosely united, filled with starch, fat and colorless granular matter. The starch granules resemble those of the bean, but are much larger, hili and stratification very distinct; only a few granules in each cell.

Ash 2.5 per cent.

Adulterated with seeds of Physostigma cylindrospermum, palm oil seeds and seeds of Mucuna. 

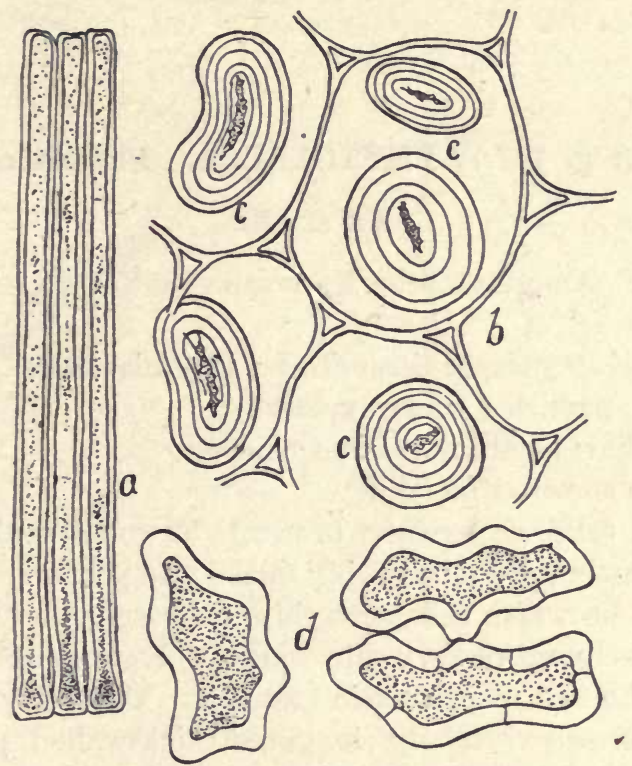

Fig. 146. PHYSOSTIGMA.

a. Epidermal palisade cells.

b. Endosperm cells with starch granules (c).

d. Hypodermal cells with red coloring matter. 


\section{9. (Fig. 147.) PHYTOLACCA. Phytolacca-Berry.}

Fl. ex. 20.

Pokeberry, E. Amerikanische Kermesbeere, G. Raisin d'Amerique, Fr.

The fruit of Phytolacca decandra L., Phytolaccaceæ.

Very dark; particles adhering, sticky.

Odor peculiar; recalling roasted chicory.

Sweetish, somewhat pungent.

Epidermal cells of pericarp brown, polygonal, walls thin, transversely very finely porous; showing nuclei and proteid matter. Below this a layer of brownish cells with thin, delicately wavy vertical walls. Pericarp parenchyma of very thin-walled polygonal cells entirely filled with small spherical to prismatic granules. Outer layer of seed coat deep reddish brown vertically elongated thick-walled, porous, sclerenchyma cells. Endosperm cells rather small, containing oil globules and small spherical granules. 


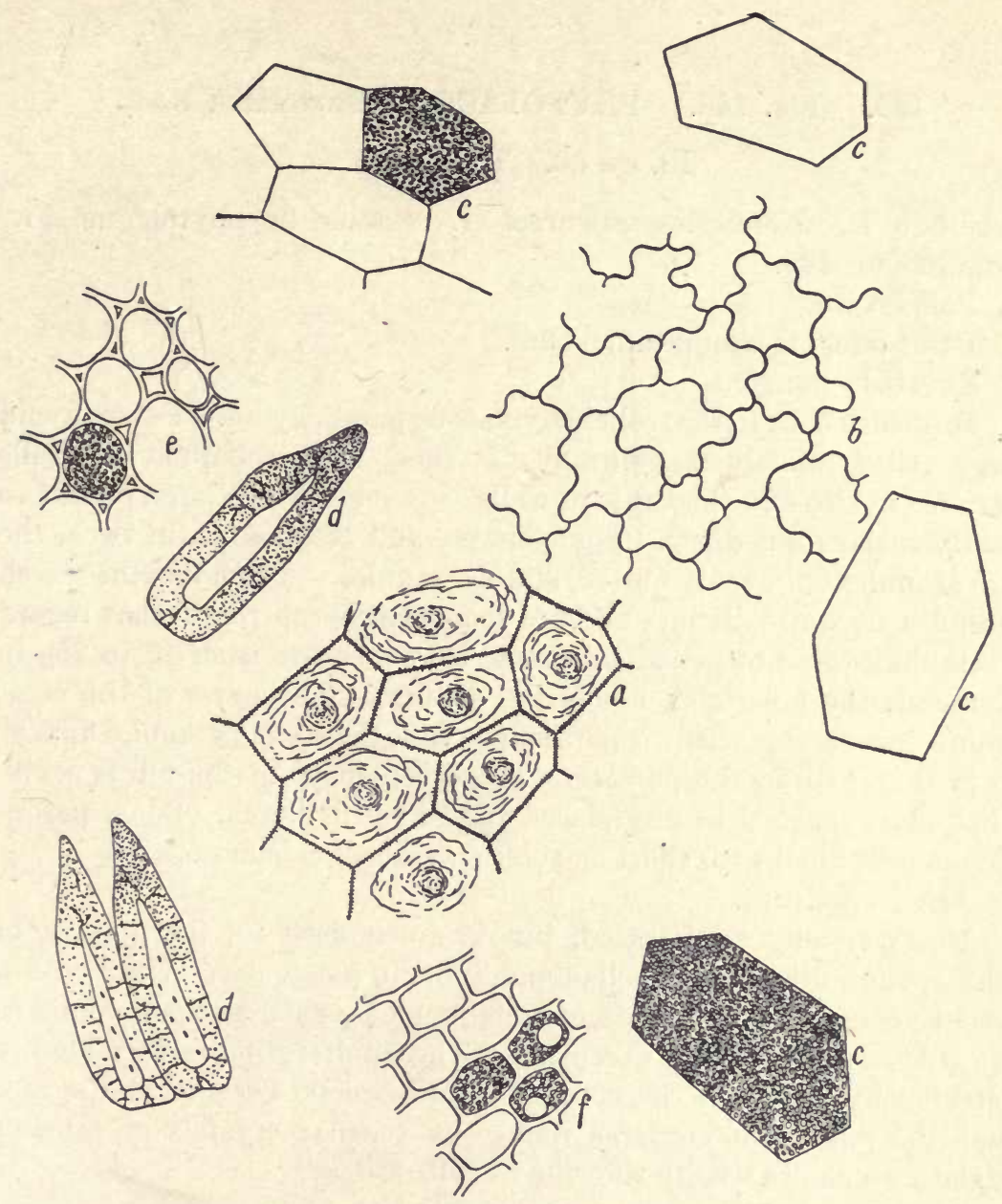

Fig. 147. PHYTOLACCA. Fruit.

a. Epidermis of pericarp.

$b$. Cells of pericarp.

c. Parenchyma of pericarp with small granules.

$d$. Radially elongated epidermal cells of seed.

$e, f$. Endosperm cells. 


\section{0. (Fig. 148.) PHYTOLACCA. Phytolacca Root.}

Fl. ex. 60. Tinct. 50 .

Pokeroot, E. Kermesbeerenwurzel G. Racine de phytolaque, Fr. Origin as for 149 .

Pale brown.

Faint odor; recalling taraxacum.

Sweetish, pungent.

Brownish cork tissue; collenchymatous parenchyma. Parenchyma large celled, mostly tangentially flattened, walls collapsed and cells variable in size and thickness of walls. Tracheids and large porous to nearly scalariform ducts. Some simple and compound (in twos, the two granules not evenly united) starch granules. The hili of the starch granules are quite distinct and are somewhat excentric, in that regard resembling those of belladonna root, they measure from 10 to $25 \mu$. in diameter, the polarizing bands are distinct. The parts of the compound granules are easily separated, so that the simple granules appear to predominate in the powder. The eccentricity of the hili is somewhat more marked in phytolacca than in belladonna. Some parenchyma cells filled with short acicular crystals of calcium oxalate.

Ash 14 per cent.

Not generally adulterated, but is much used for the purpose of adulterating other roots, belladonna roots in particular. Until within recent years the adulteration of belladonna by means of pokeroot was the rule rather than the exception. The adulteration is very readily detected by means of the compound microscope because of the fact that the poke root contains numerous acicular crystals of calcium oxalate which are wholly wanting in belladonna. 


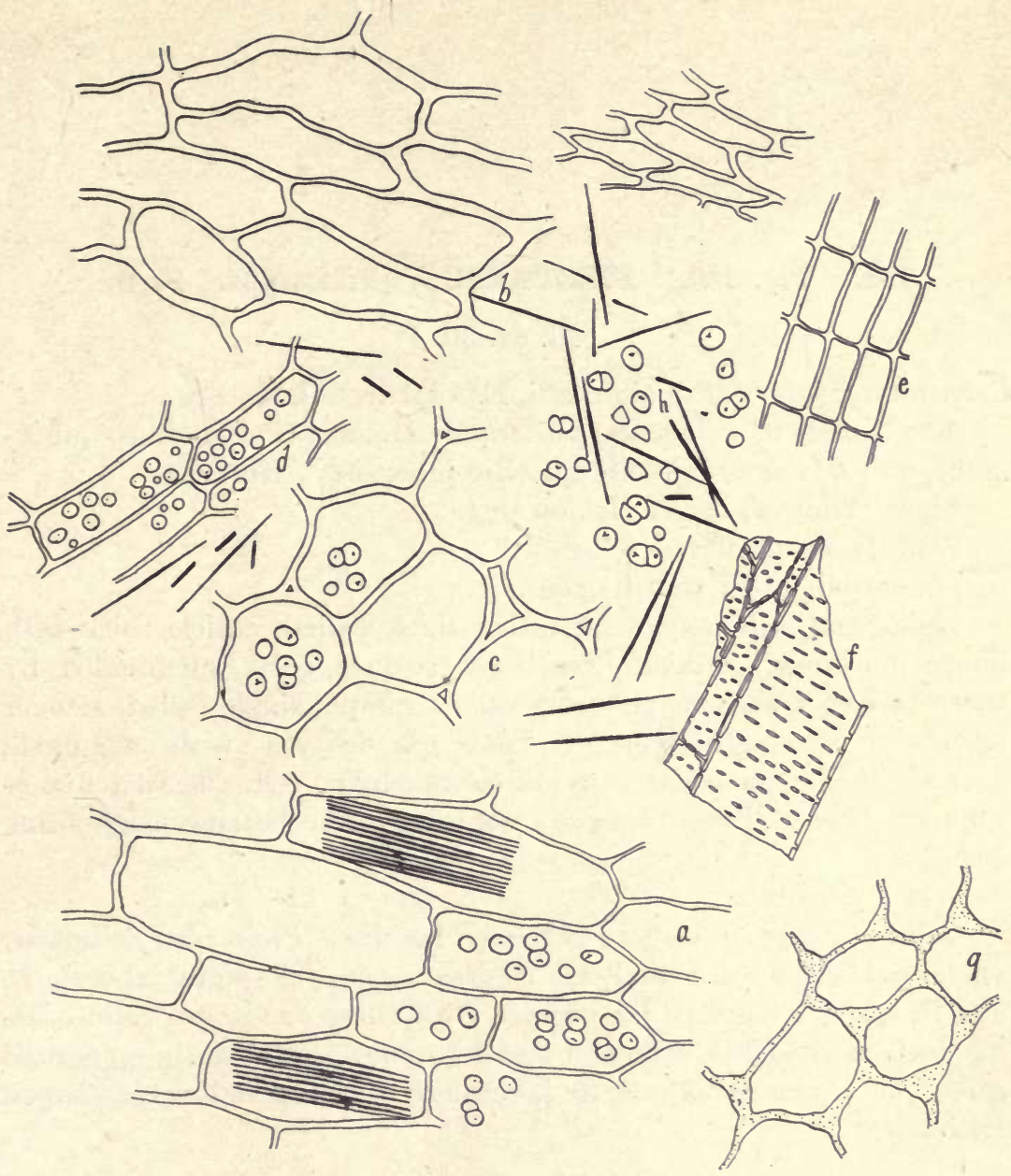

Fig. 148. PHYTOLACCA. Root.

a. Parenchyma with crystal bearing oell.

b. Outer parenchyma.

c. Parenchyma.

d. Parenchyma with starch.

e. Cork, lateral view.

f. Porous duct and tracheids.

g. Collenchyma.

h. Starch and crystals. 


\section{1. (Fig. 149.) PILOCARPUS. Pilocarpus. U. S.}

Fl. ex. 30.

Pernambuco jaborandi, jaborandi, E. Jaborandi, G., Fr.

The leaflets of Pilocarpus Jaborandi Holmes (Pernambuco jaborandi), and $P$. microphyllus Stapf (Rio jaborandi), Rutaceæ.

Light yellowish brown; lemon tinge.

Slightly aromatic and fragrant.

Somewhat bitter and pungent.

Epidermal cells polygonal, rather thick-walled, cuticle thick with linear markings. Stomata on lower surface only, surrounded by three to five arched neighboring cells. Simple single celled, slender trichomes sparingly present. Leaf parenchyma with aggregate crystals of calcium oxalate. Some sclerenchyma cells and sclerchymatous tracheids. P. microphyllus contains resin bearing neighboring cells.

Ash 6 per cent.

Adulterated with leaflets of related species. Pilocarpus Selloanus; epidermal cells a third smaller. P. pennatifolius (Paraguy jaborandi), and $P$. spicatus (Aracati jaborandi), with numerous brown resin bearing leaf parenchyma cells and small granules and resin in epidermal cells. P. trachylophus (Ceara jaborandi) with curved sickle shaped trichomes. 


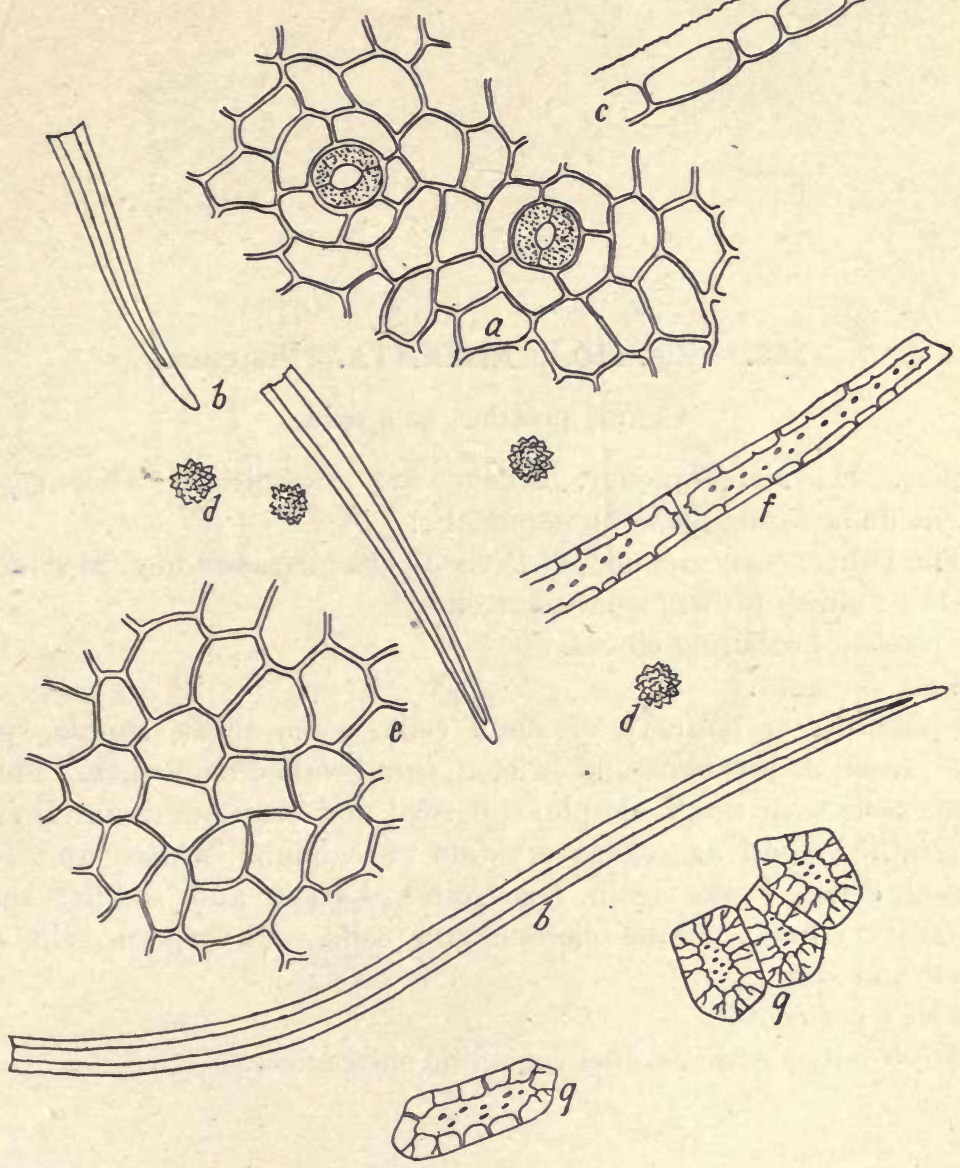

Fig. 149. PILOCARPUS.

a. Lower epidermis.

b. Trichomes.

c. Upper epidermis, lateral view.

d. Aggregate crystals of calcium oxalate.

e. Upper epidermis.

f. Tracheids.

g. Sclerenchyma. 


\section{2. (Fig. 150.) PIMENTA. Pimenta.}

Coarse powder, as a spice.

Allspice, E. Nelkenpfeffer, Neugewürz. Englisches Gewürz, G. Piment de la Jamaique, Touteepice, Fr.

The fruit, nearly ripened, of Pimenta officinalis Lindley, Myrtaceæ.

Dull reddish brown, somewhat oily.

Aromatic; recalling cloves.

Very pungent.

Epidermis of pericarp of small cells; some short, simple, single celled, more or less bent and twisted, thick-walled trichomes. Parenchyma cells with small, simple, spherical and compound starch granules, rather small aggregate crystals of calcium oxalate and resin bearing cells. Large resin reservoirs. Larger and smaller thickwalled, very finely porous sclerenchyma cells. Endosperm cells with starch and resin.

Ash 4 per cent.

Adulterated with various vegetable substances. 

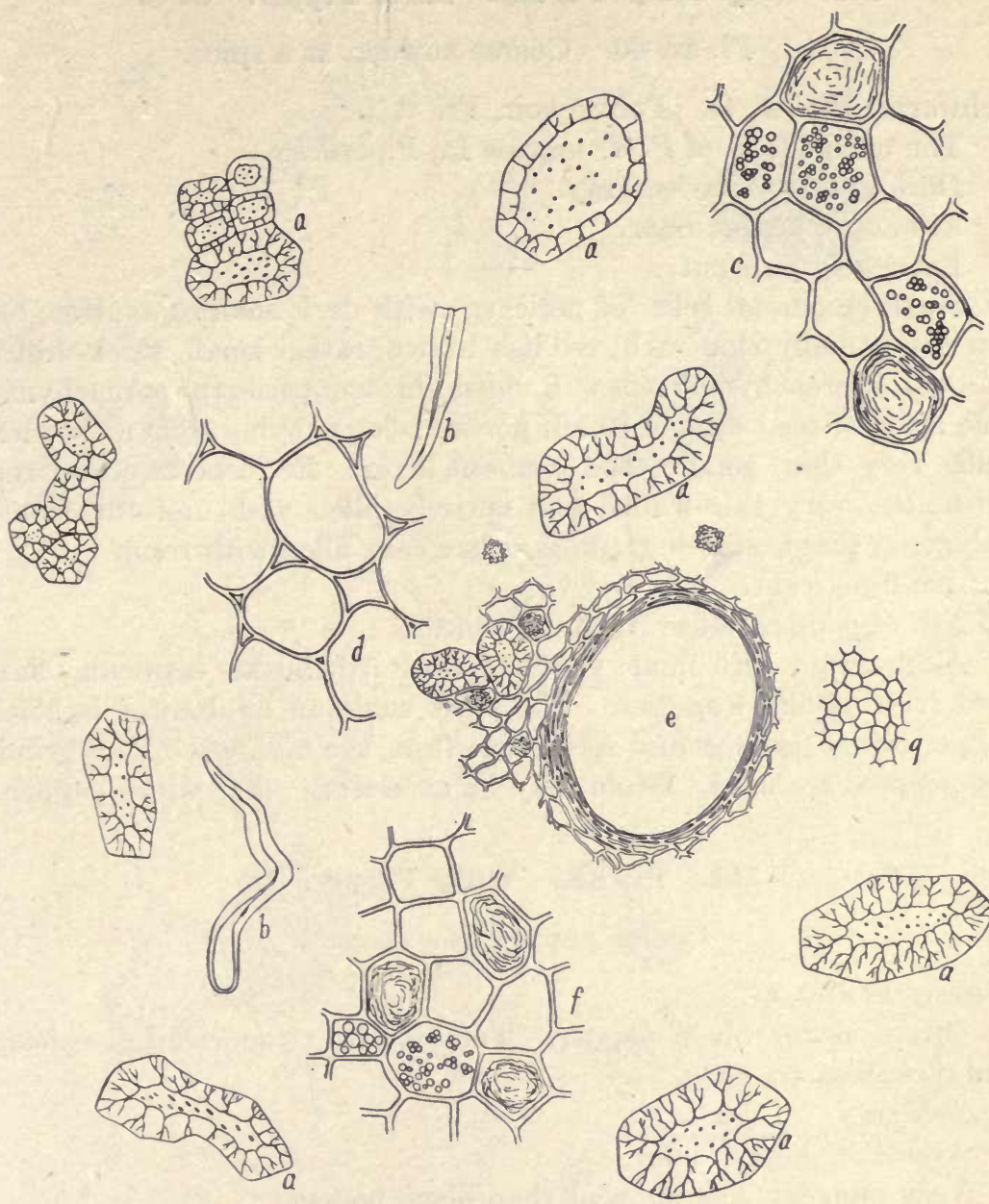

Fig. 150. PIMENTA.

a. Sclerenchyma.

b. Trichomes.

c. Parenchyma with starch and resin.

d. Parenchyma.

e. Gland, sclerenchyma and crystal bearing cell.

$f$. Endosperm cells with starch and resin.

g. Epidermal cells. 


\section{3. (Fig. 151.) PIPER. Black Pepper. U. S.}

Fl. ex. 60. Coarse powder, as a spice.

Schwarzer Pfeffer, G. Poivre noir, Fr.

The unripe fruit of Piper nigrum L., Piperaceæ.

Dark gray to mottled gray.

Aromatic; pepper odor.

Extremely pungent.

Small epidermal cells (of pericarp) with dark coloring matter; below this radially elongated, reddish brown, rather small, thick-walled porous, sclerenchyma cells. Reddish brown pericarp parenchyma. One layer of seed coat of small, porous sclerenchyma cells with outer walls very thin; small celled pigment layer. Endosperm cells large, prismatic, very thin-walled and entirely filled with uniform, small, polygonal simple starch granules; some cells filled with resin.

Ash 6 per cent.

Ash of pepper refuse 10.25 per cent.

Adulterated with flour, starches, mustard, husks, capsicum, flaxseed fruit of allied species. The most common adulterant is black pepper refuse (tailings and screenings from the milling). Poor grinding peppers are used. Mold may be excessive. (See white pepper.)

\section{PIPER. White Pepper.}

Coarse powder as a spice.

Weisser Pfeffer, G.

Origin as for black pepper. The ripe fruits deprived of epicarp and mesocarp are used.

Ash gray.

Aromatic; pepper odor.

Very pungent; less pungent than black pepper.

Histology as for black pepper, excepting that the epidermis, outer sclerenchyma cells and most of the pericarp parenchyma cells are wanting.

Ash 2 per cent.

Adulterations as for black pepper. Long pepper (Piper longum) has no resin bearing cells in endosperm and cells are smaller. The majority of adulterants differ very markedly histologically and are readily detected microscopically. Nut shells are also very extensively used as an adulterant of pepper. Further, winnowings and refuse, stems, date, olive and other seed shells and hulls. 


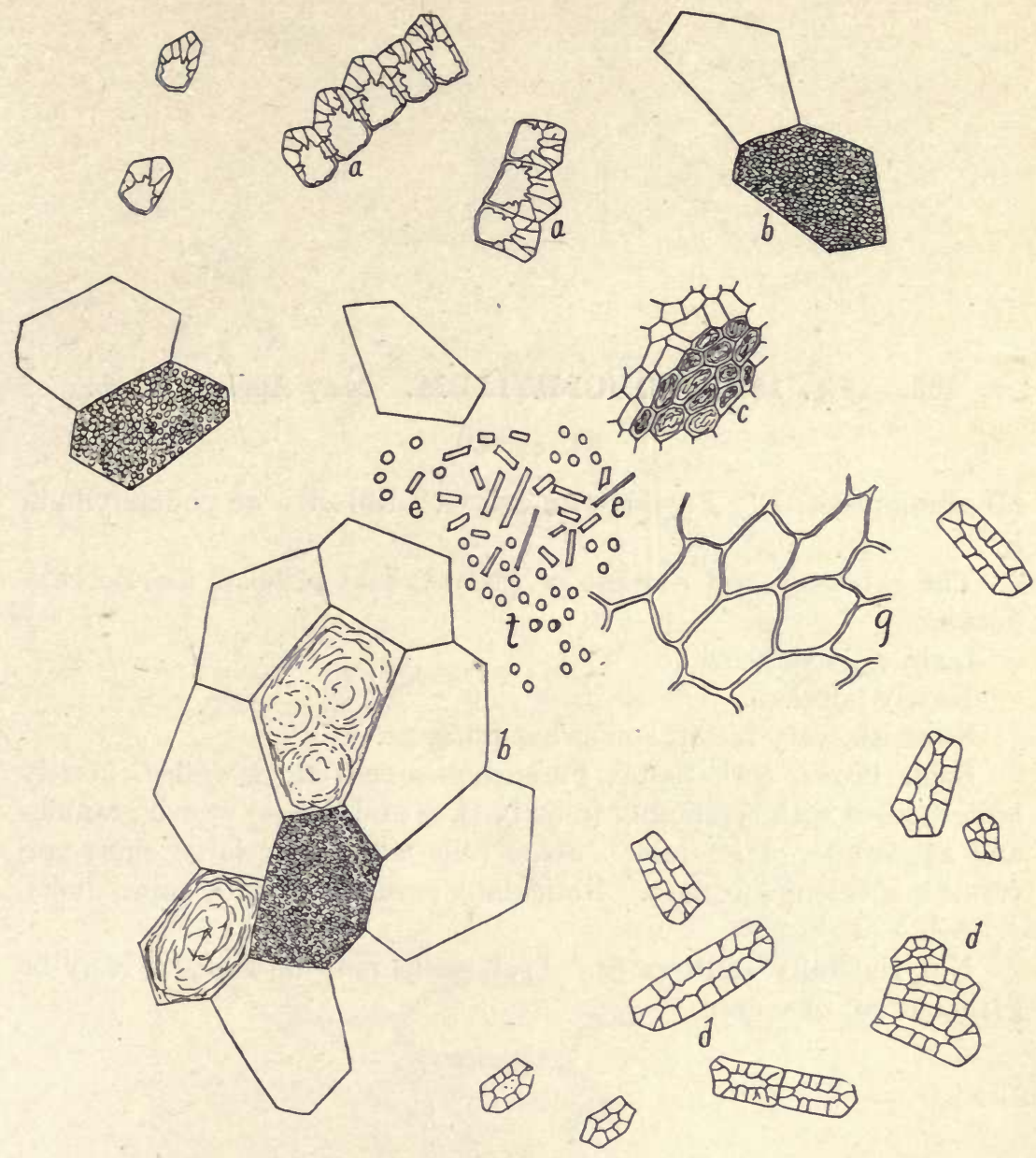

Fig. 151. PIPER. Black.

a. Sclerenchyma with unequally thickened walls.

b. Endosperm tissue with starch and resin.

c. Epidermal cells.

d. Typical sclerenchyma.

$e$. Crystals of piperin.

f. Starch granules.

g. Pericarp parenchyma. 
155. (Fig. 152.) PODOPHYLLUM. May Apple. U. S.

Fl. ex. 60 .

Mandrake root, E. Fussblattwurzel, G. Rhizome de podophyllum, Fr.

The rhizomes and rootlets of Podophyllum peltatum L., Berberidaceæ.

Light grayish brown.

- Nearly odorless.

Sweetish, very bitter, somewhat pungent.

Some brown cork tissue, Parenchyma cells thick-walled, loosely united, filled with compound (mostly twos and threes) starch granules and aggregates of granules. Some cells with quite large aggregate crystals of calcium oxalate. Reticulate, porous, and a few spiral ducts.

Ash 4 per cent.

Not generally adulterated. Leaf stalks may be added. May be gathered out of season. 


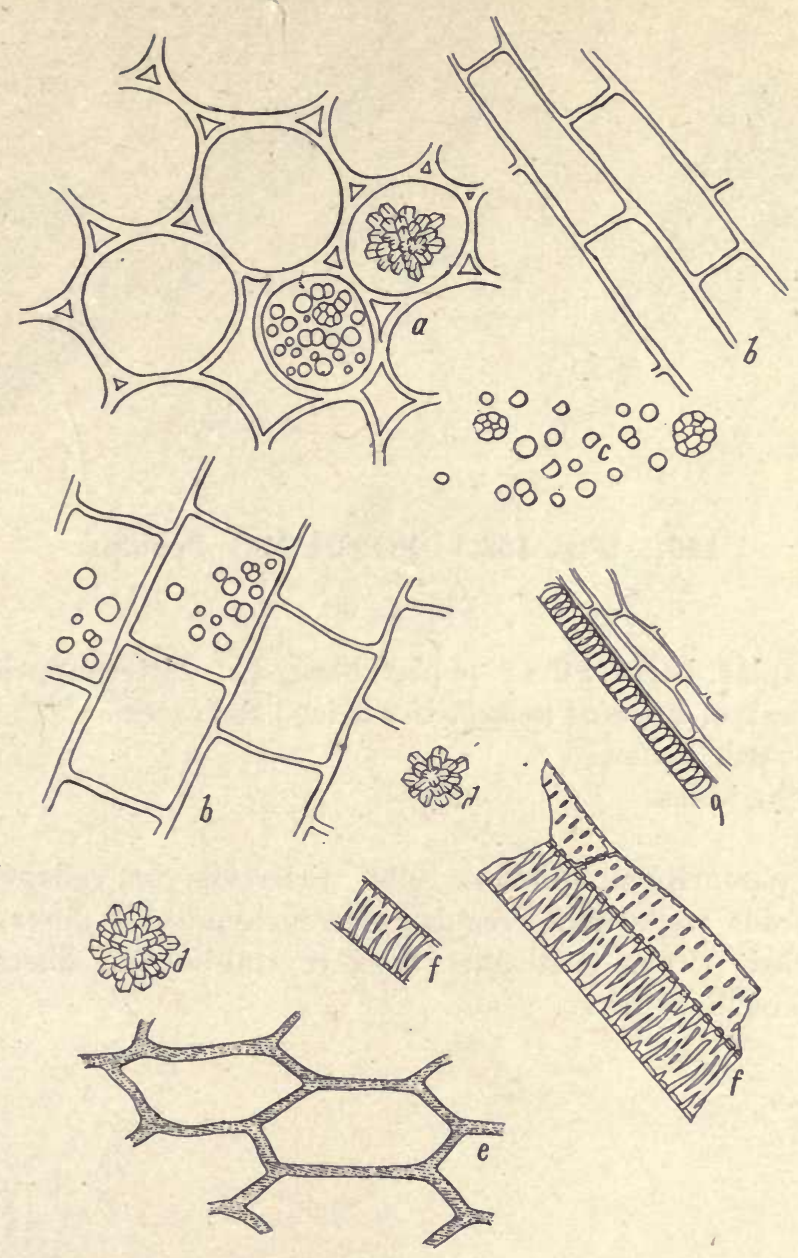

Fig. 152. PODOPHYLLUM.

a. Parenchyma with starch and crystals.

b. Parenchyma, longitudinal view.

c. Starch, simple, compound and aggregate.

d. Aggregate crystals of calcium oxalate.

e. Cork.

f. Reticulate ducts and tracheids.

g. Spiral duct. 
156. (Fig. 153.) POPULUS. Populus.

Fl. ex. 60.

White poplar bark, Silver poplar bark, E. Zitterpappelrinde, G. The bark of Populus tremelloides Mich., Salicaceæ.

Bright pale yellow.

Nearly odorless.

Bitter.

Some parenchyma and cork cells. Sclerenchyma cells with thick, finely porous walls and irregular sclerenchymatous fibers. Rather thick-walled, porous bast fibers and crystal-bearing fibers. Many layered medullary rays. 


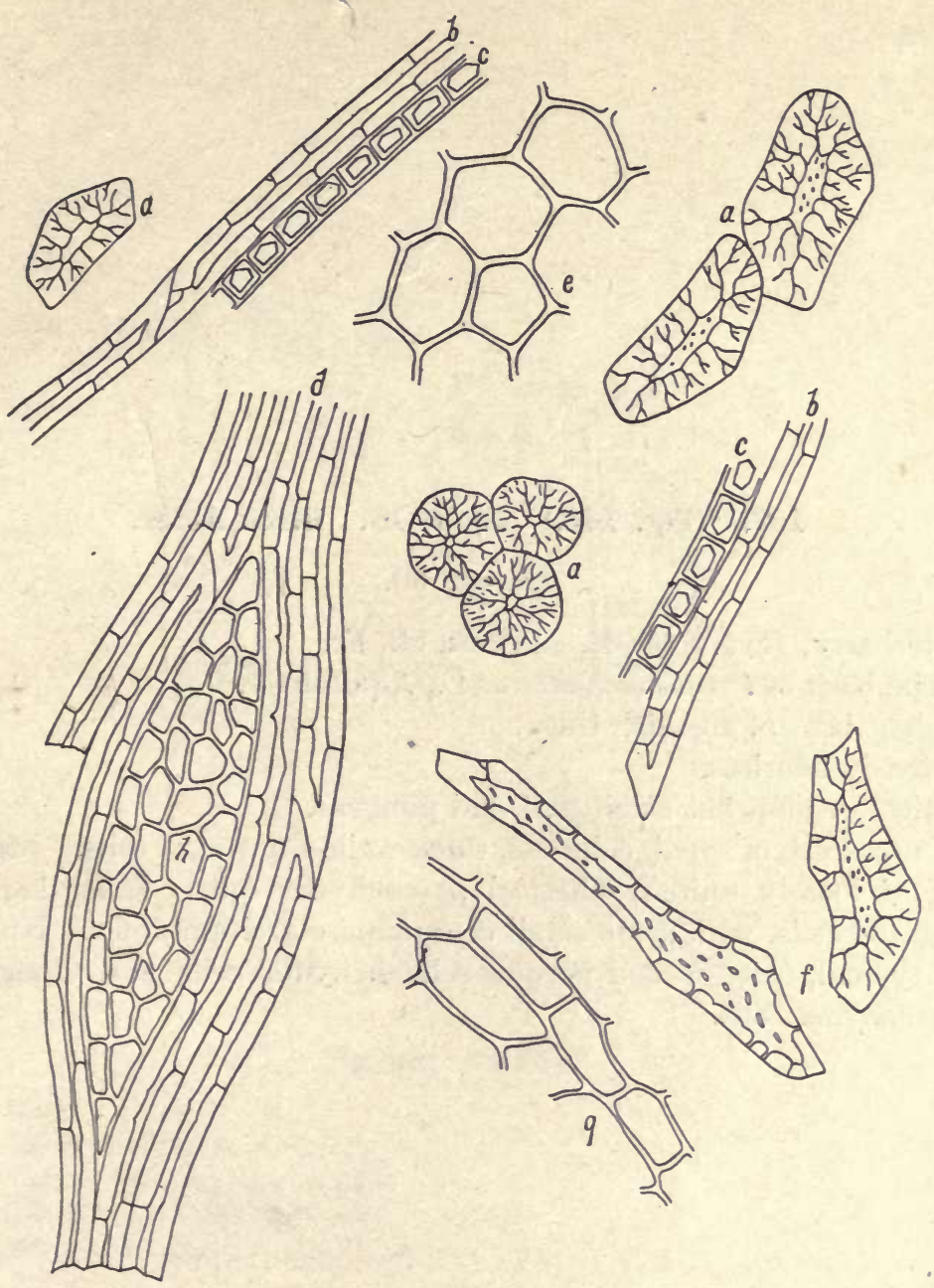

Fig. 153. POPULUS.

a. Sclerenchyma.

b. Bast.

c. Crystal bearing fiber.

d. Bast and medullary ray $(h)$ (tangential view).

$e$. Parenchyma.

$f$. Sclerenchymatous bast.

g. Parenchyma. 


\section{7. (Fig. 154.) PRINOS. Black Alder.}

Fl. ex. 60 .

Winterberry, feverbush, E. Prinos, G., Fr.

The bark of Prinos verticillatus L., Aquifoliaceæ.

Light brown, greenish tinge.

Nearly odorless.

Bitter, somewhat astringent and pungent.

Outer bark of small, colorless, thick-walled, flattened cells. Middle bark of loosely united spherical parenchyma cells. Inner bark of elongated cells, with some small compound starch granules. Numerous typical, thick-walled porous sclerenchyma cells and elongated sclerenchyma cells. 


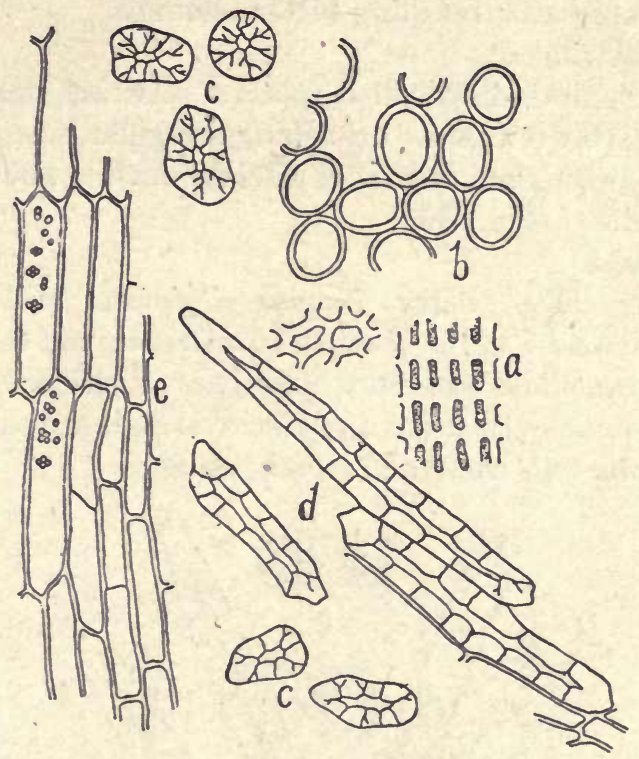

Fig. 154. PRINOS.

a. Outer bark cells.

t. Middle bark cells.

c. Spheroidal sclerenchyma cells.

d. Elongated sclerenchyma cells.

e. Inner bark cells with small compound starch granules 
158. (Figs. 155 and 156.) PRUNUS SEROTINA. Wildcherry Bark. U. S.

Fl. ex. 20. Inf. 40.

Wildekirschenrinde, G. Ecorce de cérisier, Fr.

The bark of Prunus serotina Ehrhart, Rosaceæ.

Bright reddish brown.

Somewhat aromatic, recalling bitter almonds.

Bitter and astringent.

Numerous typical thickwalled, porous sclerenchyma cells. Bast fibers comparatively few; some branching, irregular, sclerenchymatous. Aggregate and prismatic crystals of calcium oxalate abundant in bark parenchyma cells. (Fig. 156.)

Ash 4 per cent.

The bark of choke cherry (Prunus virginiana Miller) (Fig. 155) differs from the above in the absence of sclerenchyma cells; bast fibers normal and branching, are very abundant; aggregate crystals very numerous and some quite large; prismatic crystals are wanting; middle bark parenchyma cells small and loosely united.

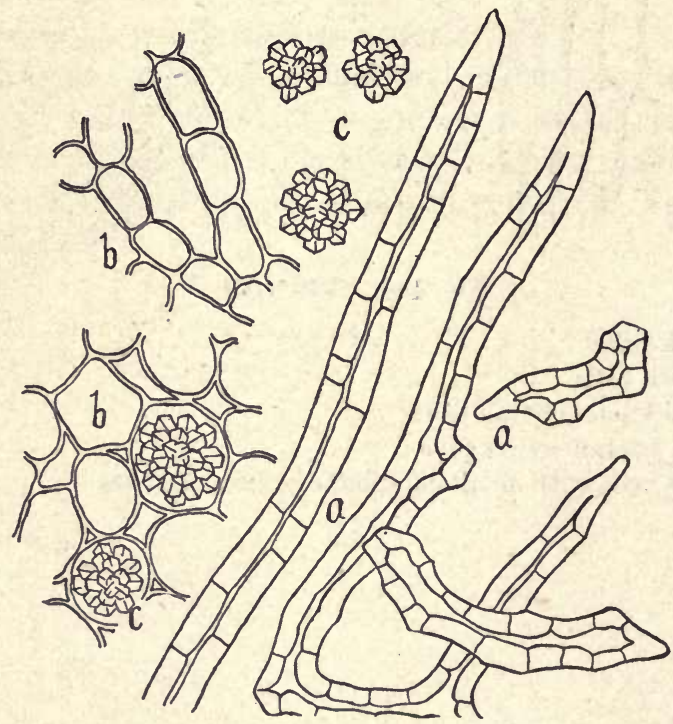

Fig. 155. PRUNUS VIRGINIANA. (Choke Cherry.)

a. Bast, simple and branching.

b. Parenchyma cells.

c. Aggregate crystals. 

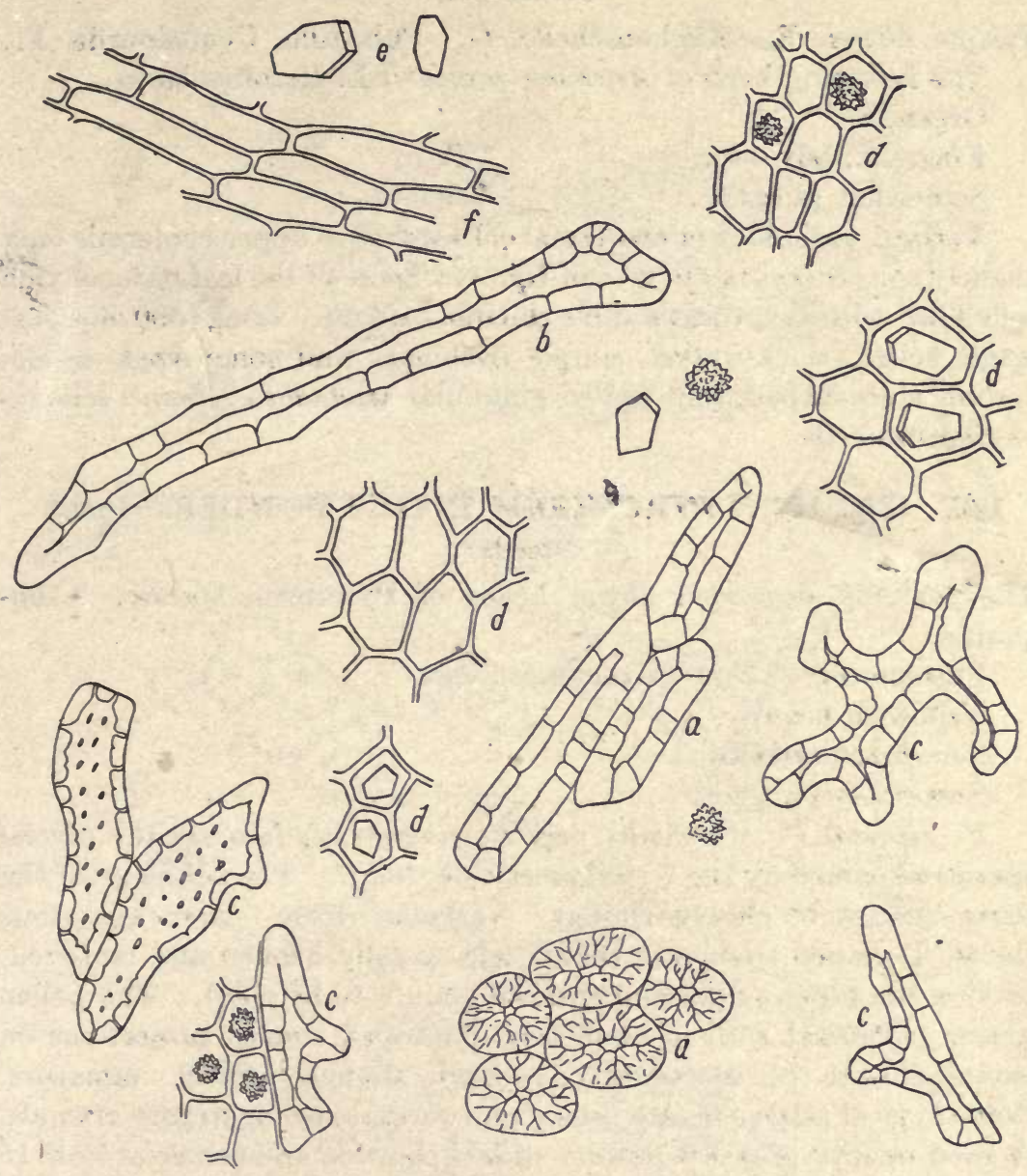

Fig. 156. PRUNUS SEROTINA.

a. Sclerenchyma.

b. Bast.

c. Branching bast.

d. Parenchyma with crystals.

e. Prismatic crystals.

f. Parenchyma, longitudinal view. 


\section{PULSATILLA. Pulsatilla.}

Fl. ex. 30.

Pasque flower, E. Küchenschelle, G. PuIsatille, Coquelourde, Fr. The flowering herb of Anemone pratensis L. Ranunculaceæ.

Greenish.

Fragrant; hay odor.

Somewhat pungent.

Vertical wall of lower epidermal cells wavy, of upper epidermis only slightly so. Stomata above and below. Some of the leaf parenchyma cells filled with cryptocrystalline calcium oxalate. Long (500 microns) single celled, thick-walled, simple trichomes and some single celled. Indian club-shaped, thin-walled glandular trichomes. Some sclerenchymatous cells.

\section{0. (Fig. 157). PYRETHRUM INSECT POWDER. Insect Powder.}

The partially expanded flower heads of Pyrethrum species. Compositæ.

Fine powder. Non-characteristic feel.

Yellowish brown.

Somewhat aromatic.

Somewhat pungent.

$P$. roseum, $P$. Marshallii and $P$. cinerariaefolium are the official species as named by the U. S. Insecticide Board. The histology of the three species is closely similar. Vascular tissue, parenchymatous tissue, T-shaped trichomes (basal cells usually broken and removed, leaving the tapering pointed end cell plainly to be seen). The pollen grains (spherical with incompletely developed conical projections on exine) should be abundantly present, though mostly immature. Some typical sclerenchyma cells (from torus); also aggregate crystals. A good quality of insect powder should show on an average at least 15 immature pollen grains in the field of the compound microscope (high power-No. 2 oc. and No. 7 obj.).

Ash 6 to 7 per cent. Impurities (inclusive of pyrethrum stems) should not exceed 15 per cent.

Very commonly adulterated. Most common adulterants are pyrethrum stems (excess of fibrous tissue and pollen grains few or none) also suspect old flower heads (few mature pollen grains, abundant seed tissue, sclerenchyma cells excessive); flower heads of related species, of calendula, of chamomile, etc.; sawdust, curcuma, mustard hulls, flour, corn meal, etc. A standard based upon the number of pollen grains present should be adopted. An insect powder showing less than an average of 3 to 5 immature pollen grains to the field (high power) of the compound miscroscope should be rejected. 


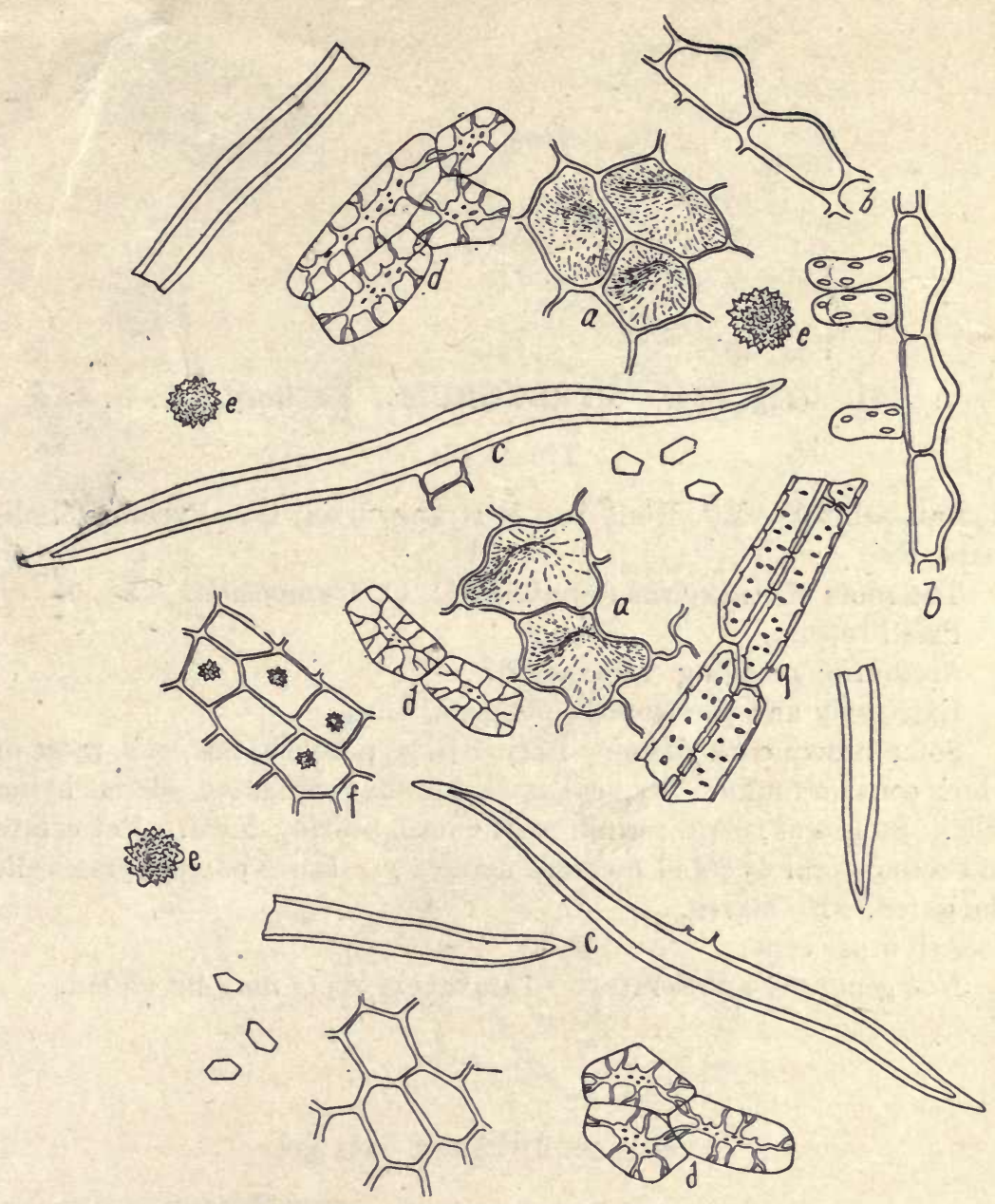

Fig. 157. PYRETHRUM. Flowers.

a. Epidermal cells.

b. Epidermis, lateral view.

c. Trichomes.

d. Sclerenchyma.

e. Pollen grains.

f. Parenchyma with crystals.

g. Tracheids. 
161. (Fig. 158.) PYRETHRUM. Pellitory. U. S.

Tinct. 40.

Roman pellitory, E. Römische Bertramwurzel, G. Pyrèthre, Salivaire, Fr.

The roots of Anacyclus Pyrethrum D. C., Compositæ.

Pale brown.

Aromatic; recalling taraxacum.

Extremely and persistently pungent.

Some brown cork tissue. Rather large parenchyma cells, most of which contain inulin. Typical and somewhat elongated sclerenchyma cells. Lumps of yellow resin from the resin bearing ducts. Reticulate and some spiral ducts of medium diameter. Inner parenchyma cells elongated. No starch.

Ash 5 per cent.

Not generally adulterated. Taraxacum roots may be added. 

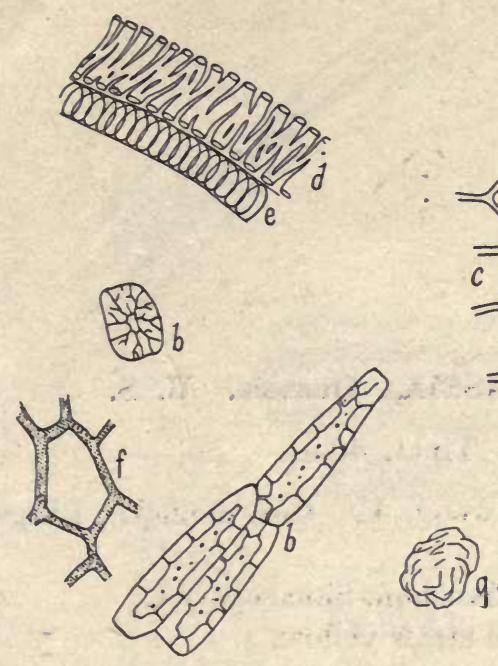

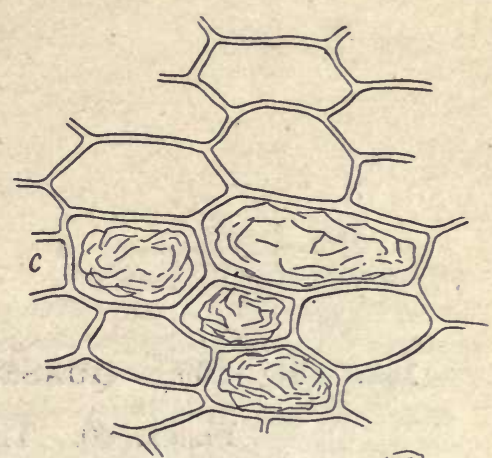

(1)
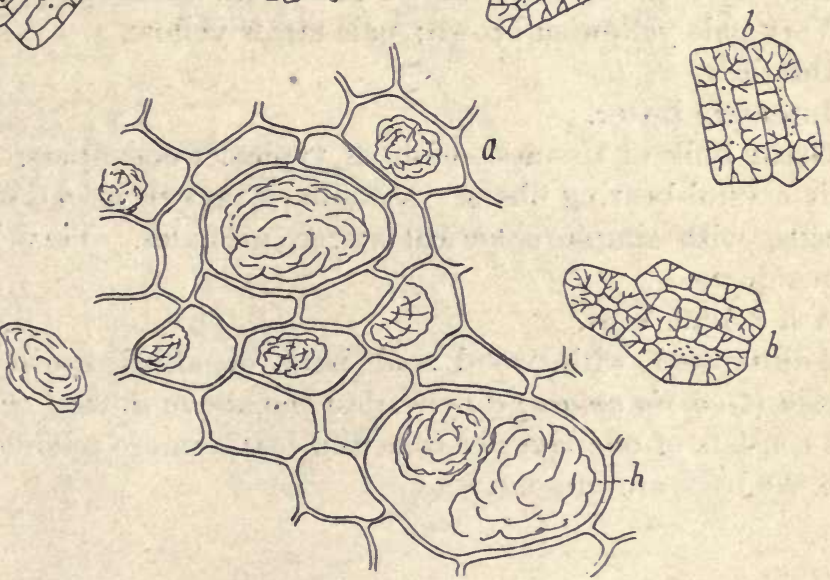

Fig. 158. PYRETHRUM. Root.

a. Parenchyma with resin.

b. Sclerenchyma.

c. Parenchyma, longitudinal view.

d. Reticulate duct.

$e$. Spiral duct.

f. Cork.

g. Resin mass.

h. Resin mass. 
162. (Fig. 159.) QUASSIA. Quassia. U. S.

F1. ex. 60. Tinct. 40 .

Bitter ash, Quassia wood, Bitter wood, E. Quassienholz, Fliegenholz, G. Quassie, Bois amere, Fr.

The wood of Picrasma excelsa Planchon, Simarubaceæ.

Very pale yellowish brown; pale straw yellow.

Odorless.

Intensely bitter.

Great bulk of tissue consists of typical wood fibers. Short prismatic crystal-bearing fibers. Medullary rays from one to four layers of cells, with simple spherical starch granules. Very large, finely porous ducts.

Ash 2.5 per cent.

Adulterated with wood and bark of allied species. Surinam quassia (Quassia amara) differs from the above in that the medullary rays consists of one layer of cells and furthermore sclerenchyma cells from the bark are present. 


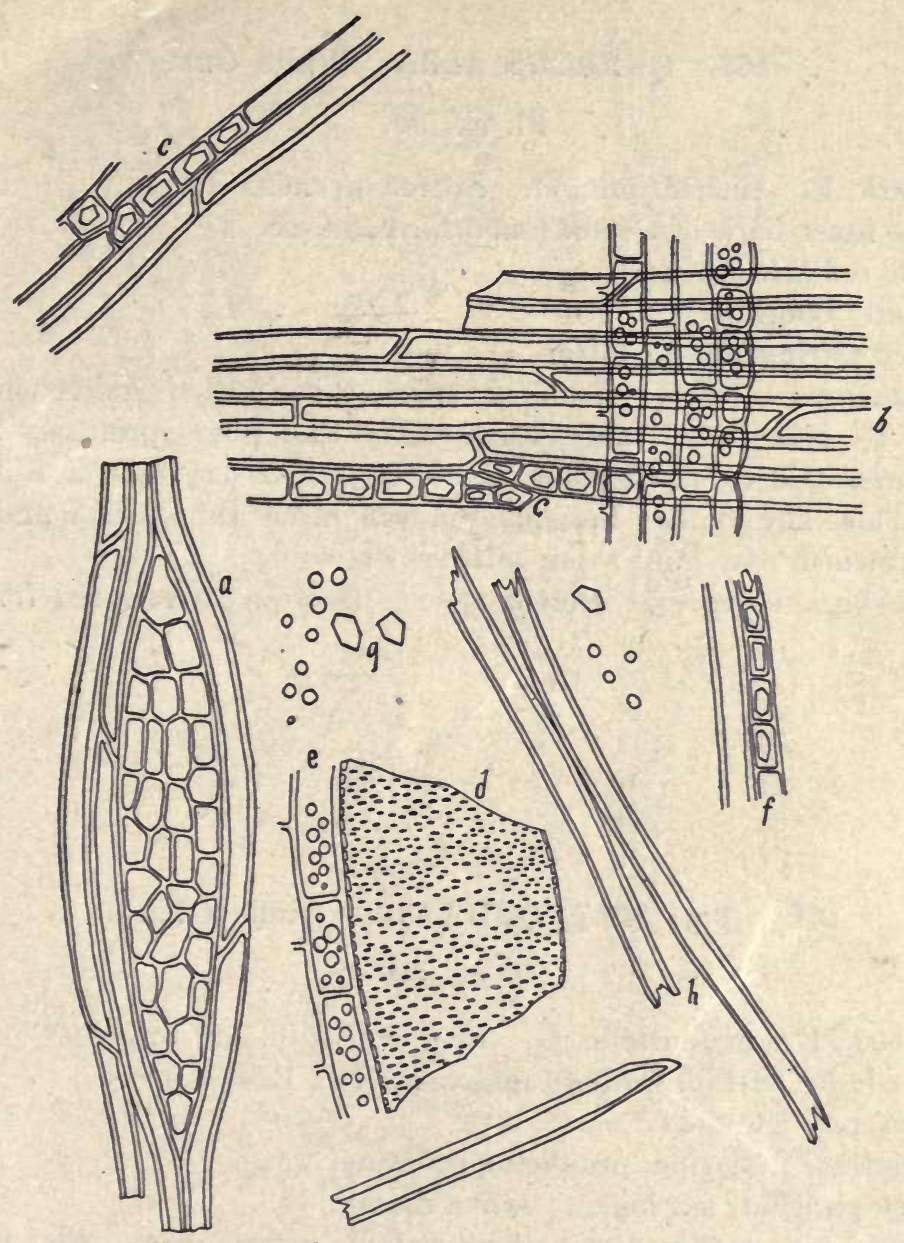

Fig. 159. QUASSIA.

a. Wood fibers and medullary ray, tang. view.

b. Wood fibers and med. ray, radial view.

$c, f$. Crystal bearing cells.

d. Large porous duct.

ve. Medullary ray with starch.

g. Crystals and starch granules.

h. Wood fibers. 


\section{QUERCUS ALBA. White Oak.}

Fl. ex. 30 .

Oak bark, E. Eichenrinde, G. Ecorce de chêne, Fr.

The inner bark of Quercus alba L., Fagaceæ.

Pale reddish brown.

Nearly odorless.

Very astringent and bitter.

Numerous typical, medium sized, thick-walled sclerenchyma cells. Typical, rather large, thick-walled bast fibers, profusely lined with prismatic crystal-bearing fibers; aggregate crystals of calcium oxalate also abundant. Parenchyma cells rather thin-walled, and of a pale brownish rosy hue; some with brown resin.

The bark of various related species is often substituted for the above.

\section{4. (Fig. 160.) QUILLAJA. Quillaja bark.}

Fl. ex. 30 .

Soap-bark, E. Seifenrinde, G. Ecorce de quillaya, Fr.

The inner bark of Quillaja Saponaria Fr., Rosaceæ.

Very pale ash gray.

Odorless; irritating, producing sneezing.

Very pungent, astringent; saliva foamy.

Numerous, rather large, thick-walled, porous bast cells; many of them irregular, nodular, bent and branching; some short and sclerenchymatous. Remnants of the outer brown cork tissue may be found. Inner bark parenchyma cells entirely colorless, elongated; most cells with single large elongated prisms of calcium oxalate.

Not generally adulterated. 


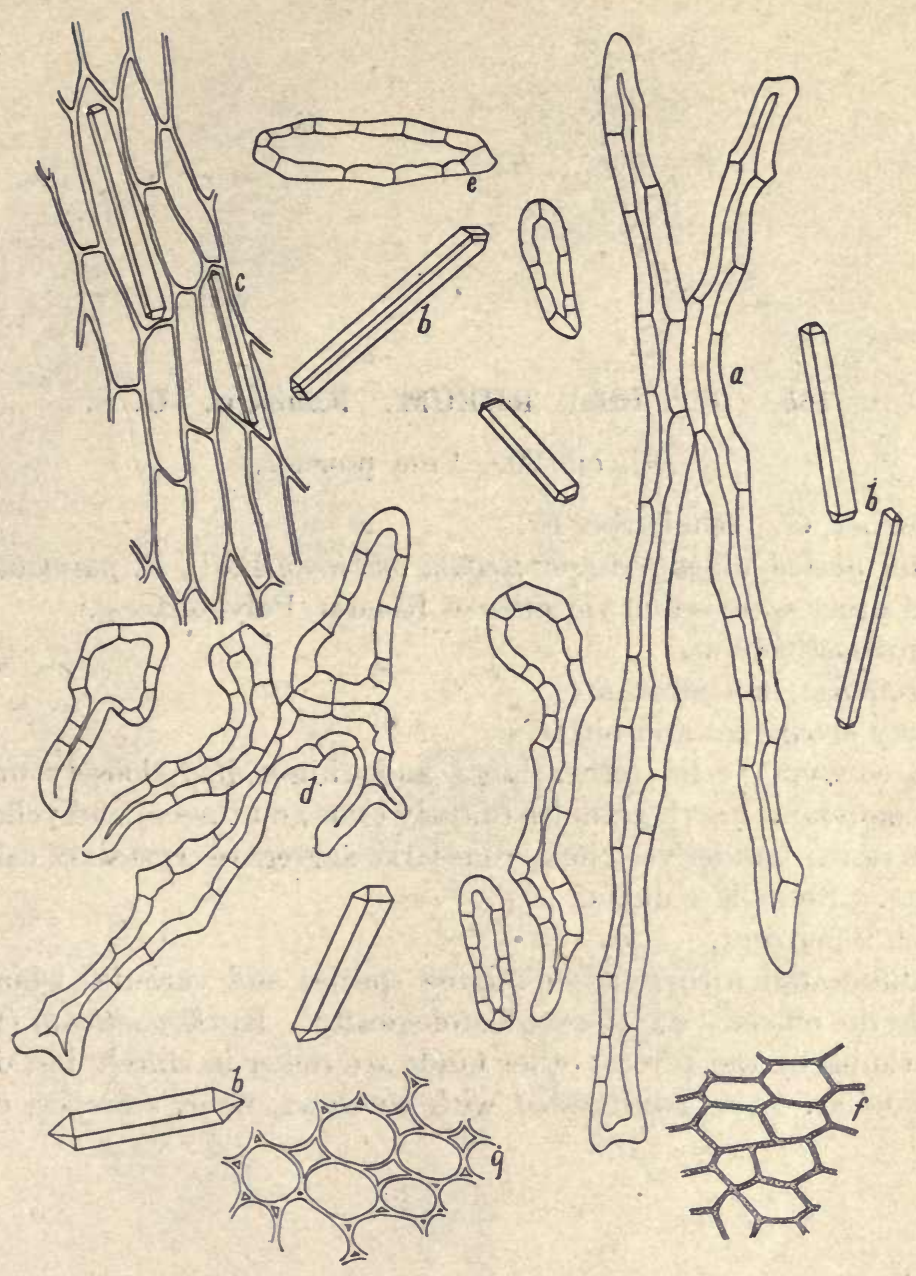

Fig. 160. QUILLAJA.
a. Bast.
b. Crystals.
c. Parenchyma with crystals.
d. Branching bast cells.
e. Sclerenchyma.
f. Outer bark.
g. Parenchyma. 
165. (Fig. 161.) RHEUM. Rhubarb. U. S.

Fl. ex. 30. Fine powder.

Rhabarber, G. Rhubarbe, Fr.

The peeled older roots of Rheum officinale Bail., R. palmatum $L$. and of other species and varieties of Rheum, Polygonaceæ.

Brownish yellow.

Aromatic; not pleasant.

Very astringent and bitter.

Parenchyma cells rather large and thin-walled, loosely united, with compound starch granules (mostly twos and threes) and yellowish brown resin; besides very numerous large aggregate crystals of calcium oxalate. Reticulate ducts.

Ash 9 per cent.

Adulterated with roots of related species and varieties which resemble the official very closely histologically. R. rhaponticum (European rhubarb) and several other kinds are richer in starch, but otherwise similar. Also adulterated with curcuma, flour, starches, etc. 

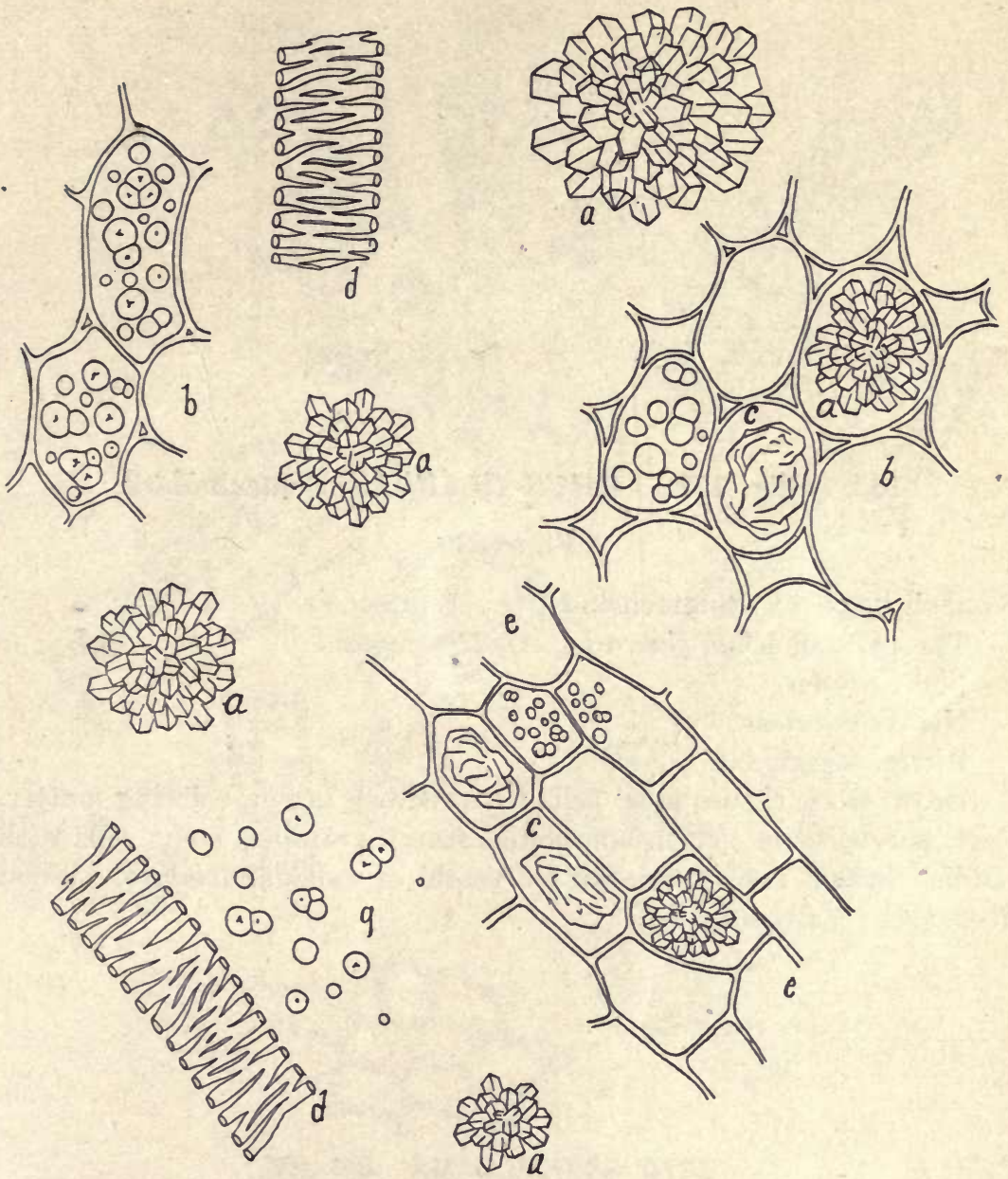

Fig. 161. RHEUM.

a. Crystals of calcium oxalate.

b. Parenchyma with starch, resin and crystals.

c. Resin.

d. Reticulate ducts.

e. Parenchyma, longitudinal view.

g. Starch. 
166. (Fig. 162.) RHUS GLABRA. Sumach Bark.

Fl. ex. 30 .

Sumach bark, E. Sumachrinde, G. Sumac, Fr.

The bark of Rhus glabra L., Anacardiaceæ.

inght brown.

Nearly odorless.

Bitter, astringent.

Brown cork tissue; most cells with reddish brown coloring matter. Bark parenchyma rich in compound starch granules; some cells with reddish brown resin; aggregate crystals of calcium oxalate. Wood fibers; sclerenchyma cells. 


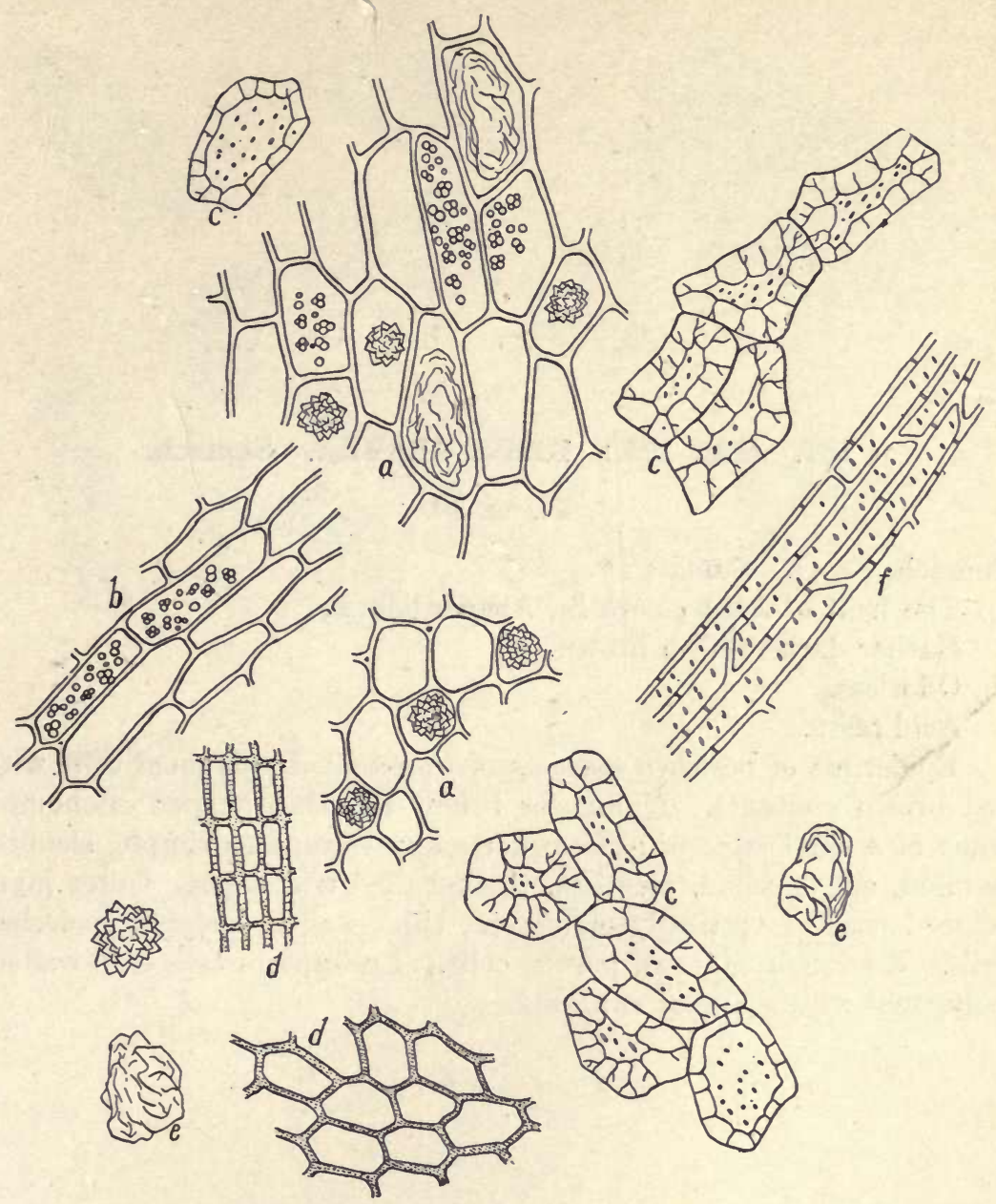

Fig. 162. RHUS GLABRA BARK.

a. Bark parenchyma with compound starch, crystals and yellowish brown resin.

b. Parenchyma, longitudinal view.

c. Sclerenchyma cells.

d. Cork, vertical and lateral views.

e. Resin.

f. Wood fibers, porous. 


\section{7. (Fig. 163.) RHUS GLABRA. Sumach.}

Fl. ex. 30 .

Sumach, E., G. Sumac, Fr.

The fruit of Rhus glabra L., Anacardiaceæ.

Rather dark reddish brown.

Odorless.

Acid taste.

Epidermis of pericarp consists of thin-walled polygonal cells with red brown contents. Numerous bright red club shaped trichomes, some of a single row of cells, other many rows; also simple, slender, pointed, single-celled, colorless, thick-walled trichomes. Outer layer of seed coat of vertically elongated, thick-walled, irregular, colorless cells. Sclerenchymatous, porous cells. Endosperm cells thin-walled, polygonal with granular contents. 

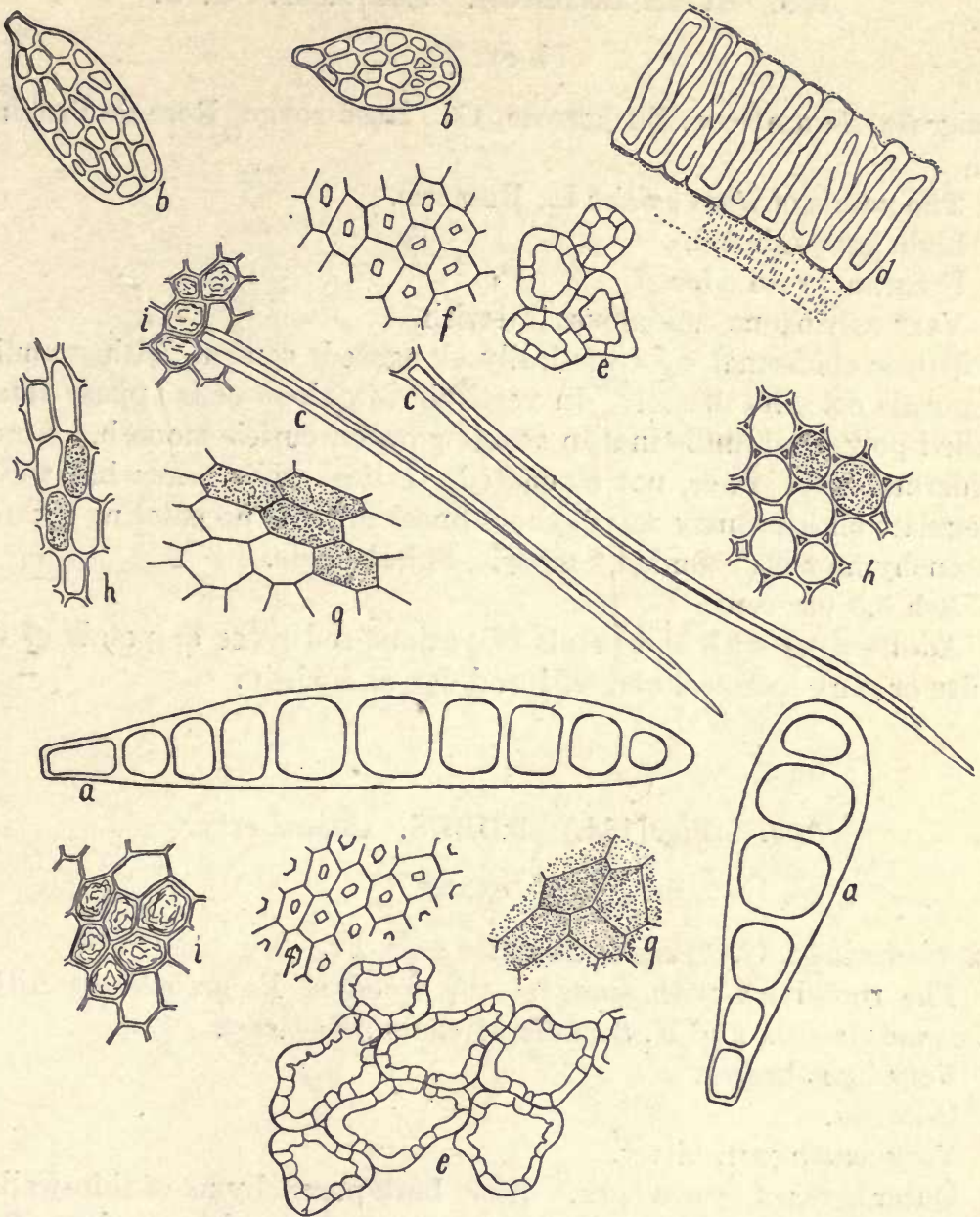

Fig. 163. RHUS GLABRA FRUIT.

$a, b$. Deep red many celled trichomes.

c. Colorless trichomes.

d. Outer layer of seed coat, lateral view.

$e$. Thick-walled porous cells of testa.

$f$. Colorless crystal bearing layer of testa.

g. Endosperm cells.

h. Parenchyma of pericarp.

$i$. Epidermal cells of pericarp. 


\section{ROSA GALLICA. Red Rose. U. S.}

Fl. ex. 30.

Essigrose, Sammtrose, Zuckerrose, G. Rose rouge, Rose de Provins, Fr.

The petals of Rosa gallica L., Rosaceæ. .

Light purplish red.

Fragrant; rose odor.

Very astringent, acidulous, bitterish.

Upper epidermal cells vertically elongated, conical, with granules of purple coloring matter. In vertical view these cells appear thickwalled polygonal, indistinct in coarse powder, cuticle smooth. Lower epidermal cells larger, not elongated, vertical walls somewhat wavy, irregular; cuticle finely wavy, short linear striate; no coloring matter. Parenchyma cells rounded, empty. Spiral ducts.

Ash 3.5 per cent.

Adulterated with the petals of various red roses or petals of the white or pink roses colored with red dye as fuchsin.

\section{Fig. (164.) RUBUS. Blackberry.}

Fl. ex. 60 .

Brombeerrinde, G. Ecorce de rouce noir, Fr.

The root bark with some of the wood of Rubus villosus Aiton, $R$. canadensis L., and R. trivialis Michaux, Rosaceæ.

Very light brown.

Odorless.

Very astringent, bitter.

Outer layer of brown cork. Inner bark parenchyma of thin-walled, closely united cells bearing simple spherical starch granules. Bast fibers with walls of medium thickness, porous, containing some starch; outer walls of bast appear shreddy. A few short sclerenchymatous tracheids accompany bast fibers. Numerous tracheids and porous ducts from wood remnants of roots.

Compare the histology of the three official roots. May be adulterated with roots and rhizomes of other plants. 


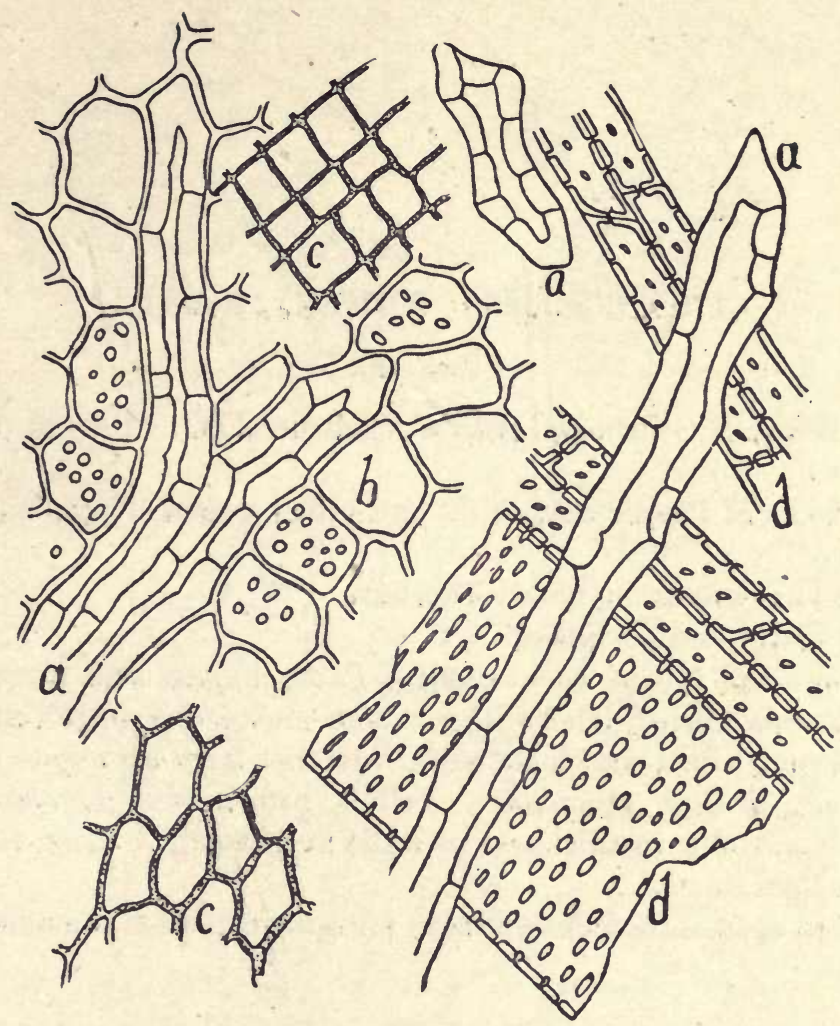

Fig. 164. RUBUS VILLOSUS.

a. Bast fibers, some starch and a few sclerenchymatous fibers.

b. Parenchyma with starch.

c. Cork.

d. Ducts and tracheids. 
170. (Fig. 165.) RUMEX. Rumex.

Fl. ex. 30.

Yellow Dock, E. Grindwurzel, Mengelwurzel, G. Racine patience frisée, Fr.

The roots of Rumex crispus L., and other species, Polygonaceæ.

Brown.

Somewhat aromatic; nearly odorless.

Very bitter and astringent.

Thin-walled brown cork tissue. Parenchyma cells large; thinwalled, loosely united, filled with granular matter and simple, elliptical, oval and egg shaped starch granules. Rather large aggregate crystals of calcium oxalate abundant. Yellow brown sclerenchyma cells, somewhat variable in thickness of walls and in form. Bast, tracheids and reticulate ducts.

Related species of dock (Rumex) are subtituted for the above. 


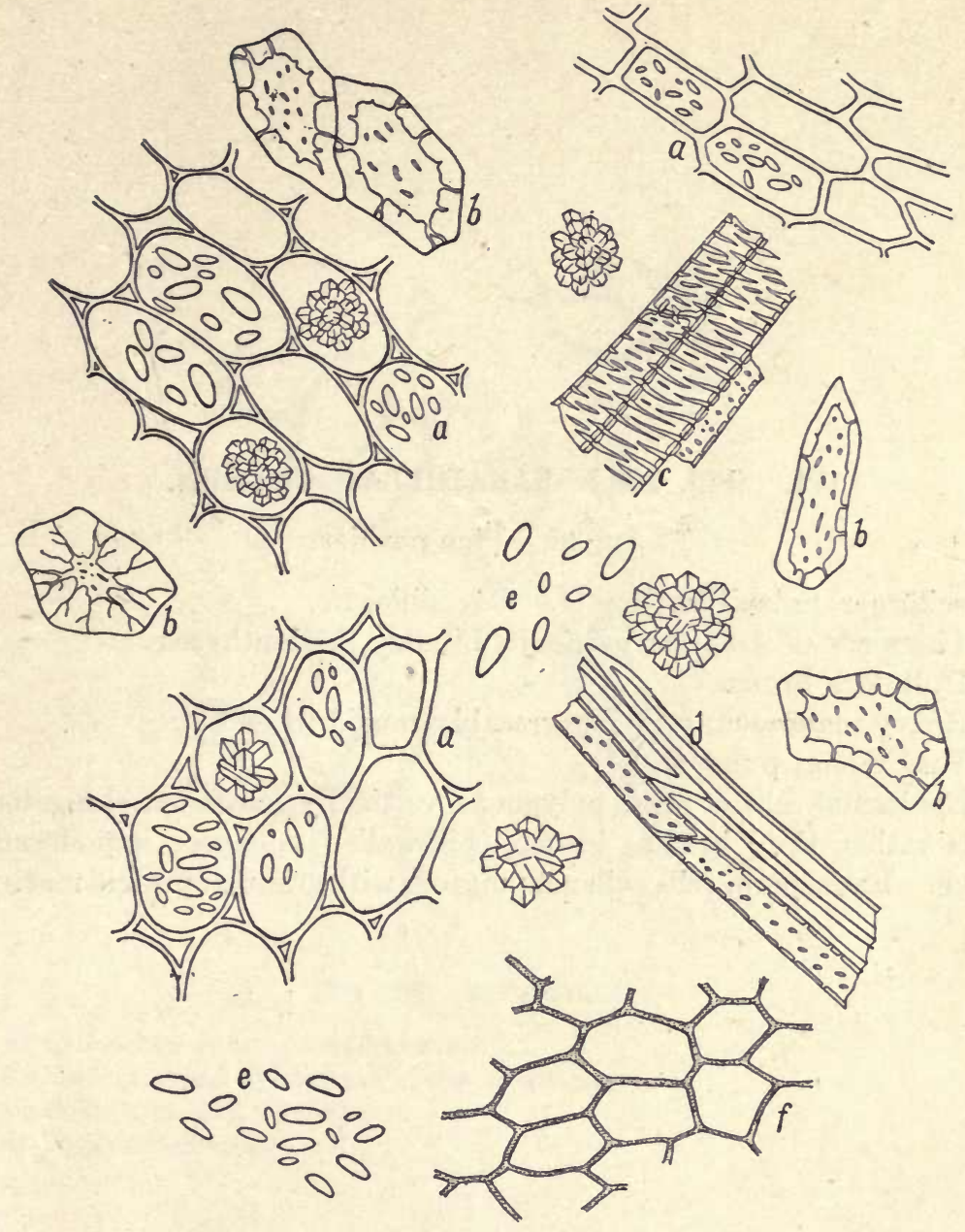

Fig. 165. RUMEX.

a. Parenchyma with starch granules and crystals.

$b$. Sclerenchyma cells.

c. Ducts and tracheids.

d. Bast.

e. Starch granules and crystals.

f. Cork cells. 


\section{1. (Fig. 166.) SABADILLA. Cevadilla.}

Fl. ex. 30. Fine powder.

Läusekörner, Sabadillsamen, G. Cévadille, Fr.

The seeds of Asagraea officinalis Lindley, Melanthaceæ.

Dull dark brown.

Heavy, nauseous; very disagreeably rancid when old.

Very bitter, pungent.

Epidermal cells of seeds polygonal, vertically somewhat elongated, walls rather thin, brown; brown, thin-walled, collapsed hypodermal tissue. Endosperm cells collenchymatous with granular proteid matter. 


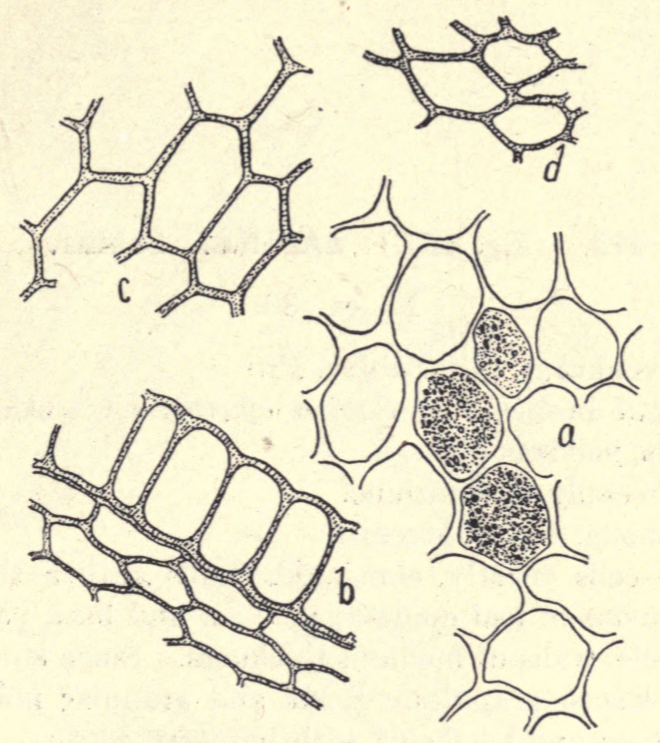

Fig. 166. SABADILLA.

a. Collenchymatous endosperm tissue.

b. Epidermal and hypodermal tissue, profile view.

c. Epidermal cells, vertical view.

d. Hypodermal cells. 
172. (Fig. 167.) SABINA. Sabina.

Fl. ex. 30 .

Sadebaum, Sevenkraut, G. Sabine, Fr.

The terminal branches of Sabina officinalis Garcke, Coniferæ.

Rather light yellowish brown.

Very disagreeably terebinthine.

Bitter, resinous; Saliva greenish.

Epidermal cells mostly elongated, walls rather thick, porous. Numerous stomata of leaf epidermis. Leaf and bark parenchyma of rather large cells, walls of medium thickness. Some simple spherical and irregular starch granules. Resin and granular matter in most cells. Bast fibers and tracheids with bordered pits. 


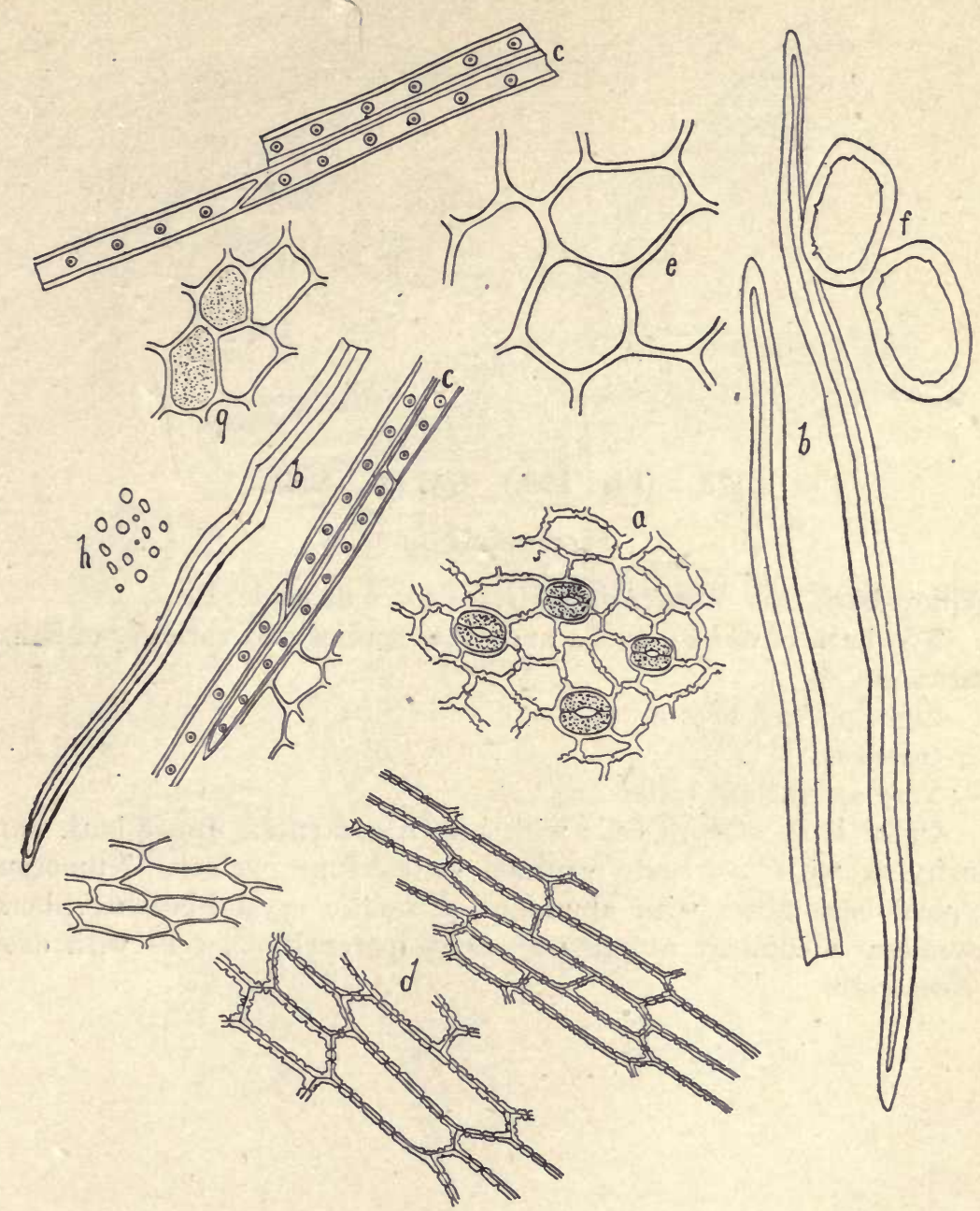

Fig. 167. SABINA.

a. Epidermis with stomata.

b. Bast fibers.

c. Tracheids with bordered pits.

d. Epidermal tissue.

e. Large parenchyma cells.

f. Sclerenchymatous cells.

g. Bark parenchyma cells.

h. Starch granules. 
173. (Fig. 168.) SALIX. Salix.

Moderately fine.

Willow-bark, E. Weidenrinde, G. Ecorce de saule, Fr.

The bark of Salix alba L., and other species and varieties of Salix, Salicaceæ.

Light pinkish brown.

Odorless.

Very astringent, bitter.

Outer bark of cork cells with brown contents. Inner bark parenchyma with aggregate crystals of calcium oxalate. Numerous typical bast fibers with abundant prismatic crystal-bearing fibers; abundant medullary ray tissue. Some parenchyma cells with deep brown resin. 


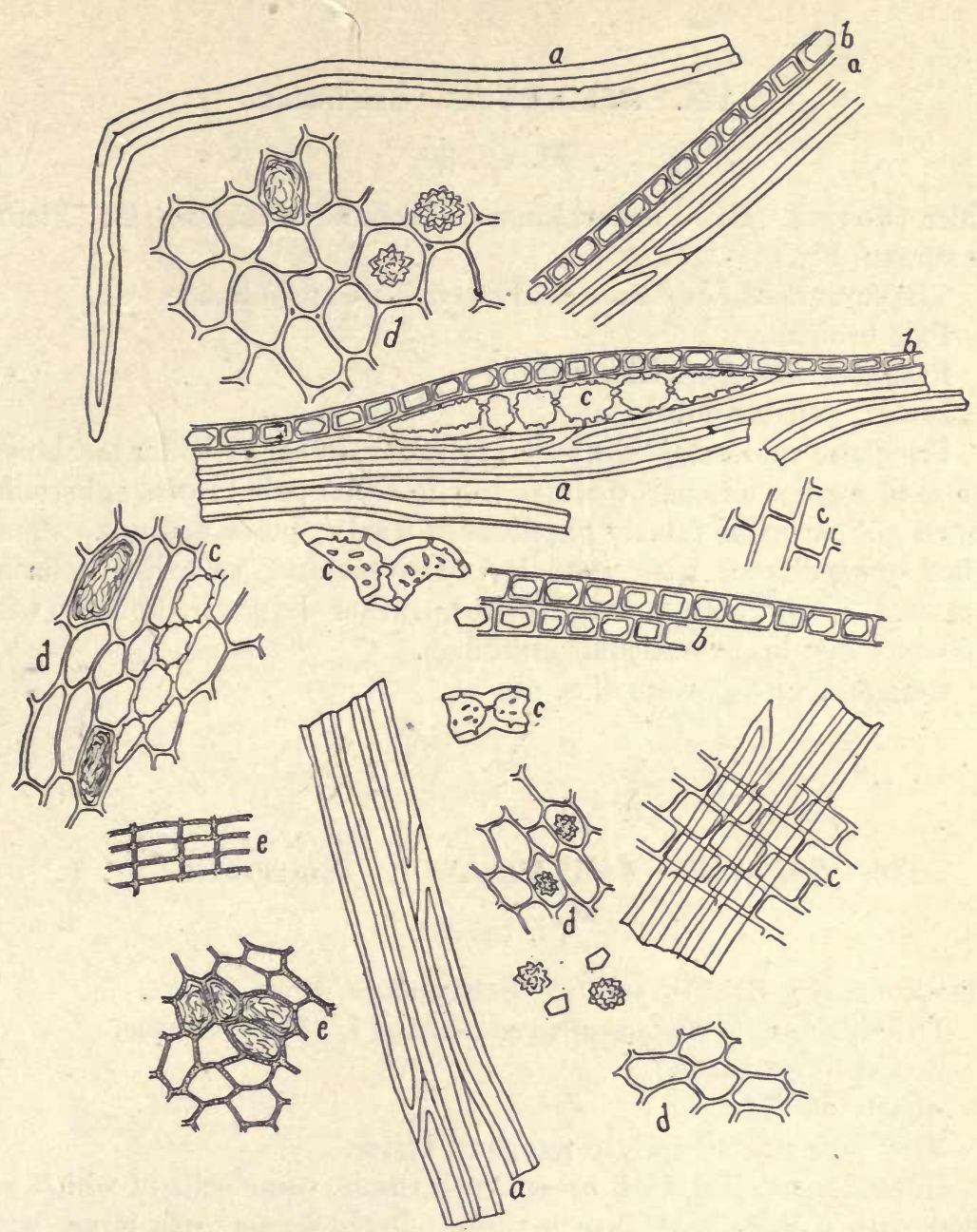

Fig. 168. SALIX.

a. Bast fibers.

b. Crystal bearing fibers.

c. Medullary rays and fragments.

d. Inner bark parenchyma with crystals and deep reddish brown resin.

e. Cork tissue with deep brown coloring matter. 


\section{SAMBUCUS. Sambucus.}

F1. ex. 30.

Elder flowers, E. Fliederblumen, Hollunderblumen, G. Fleurs de sureau, Fr.

The flowers of Sambucus canadensis L., Caprifoliaceæ.

Pale brown.

Fragrant: recalling chamomille.

Bitter, mucilaginous.

Prismatic epidermal cells with irregularly linear euticular markings. Stomata nearly circular, distinct. Numerous pale brown, spheroidal pollen grains; exine faintly papillose or warty; pores distinct. Small celled parenchyma with granular particles and yellowish coloring matter. A few simple single-celled, rather large trichomes, with distinct wavy linear cuticular markings.

Compare with flowers of S. nigra.

175. (Fig. 169.) SANGUINARIA. Sanguinaria. U. S.

Fl. ex. 60 .

Bloodroot, E. Blutwurzel, G. Sanguinaire, Fr.

The rhizomes of Sanguinaria canadensis L., Papaveraceæ.

Bright brownish red.

Nearly odorless.

Very persistently acridly pungent, bitter.

Outer large-celled dark brown cork tissue, some cells of which are filled with a very dark brown resin. Parenchyma cells large, with thin reddish brown walls, some resin-bearing parenchyma cells. Starch granules mostly single, nearly spherical, hili centric and quite distinct, 3 to $18 \mu$ in diameter, polarizing bands distinct. Laticiferous ducts with brown contents. Ducts mostly reticulate.

Ash 5.5 per cent.

Not generally adulterated. 


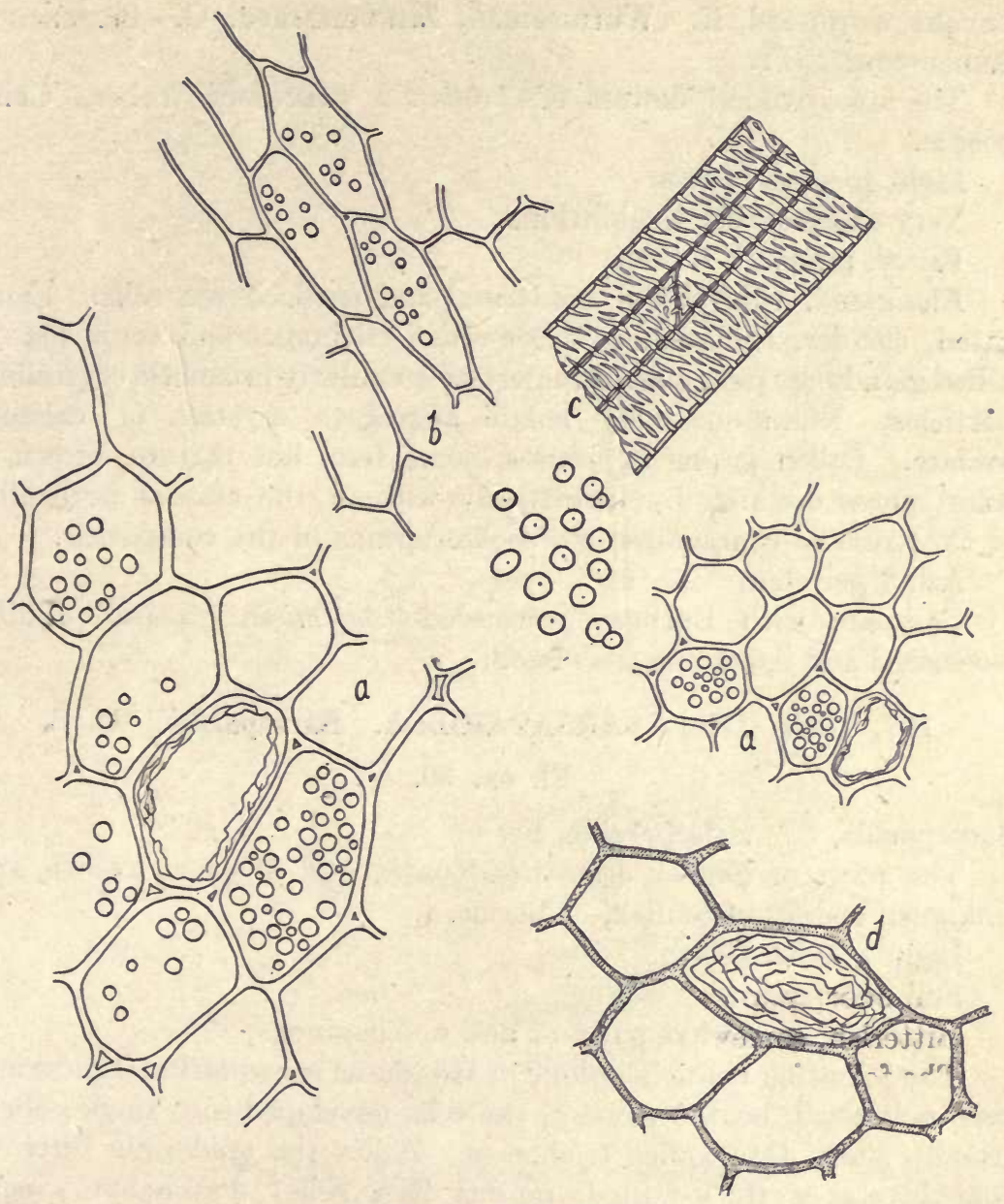

Fig. 169. SANGUINARIA.

a. Parenchyma cells, transverse view, with starch and resin.

b. Parenchyma, longitudinal view.

c. Reticulate ducts.

d. Cork cells, one with resin. 


\section{SANTONICA. Santonica.}

Fl. ex. 30 .

Levant wormseed, E. Wurmsamen, Zittwersamen, G. Semencine, Semen-contra, Fr.

The unexpanded flowers of Artemisia pauciflora Weber., Compositæ.

Light greensh brown.

Very disagreeably terebinthine.

Bitter, pungent, cooling.

Elongated, thin-walled epidermal and parenchyma cells. Elongated, slender, thin-walled, single-celled trichomes and some manycelled glandular trichomes. Numerous irregularly prismatic crystalline pårticles. Numerous very small aggregate crystals of calcium oxalate. Pollen grains in masses, some free, not mature, brown in color, pores distinct, but practically without the conical projection of the exine so characteristic of pollen grains of the compositæ.

Ash 8 per cent.

Compare with Barbary wormseed (Artemisia ramosa), Indian wormseed and American wormseed.

\section{7. (Fig. 170.) SARSAPARILLA. Sarsaparilla. U. S.}

\section{Fl. ex. 30 .}

Sassaparilla, G. Salsepareille, Fr.

The roots of Smilax officinalis Kunth, and of other known and unknown species of Smilax, Liliaceæ.

Light grayish brown.

Soil odor; musty.

Bitterish, somewhat pungent and mucilaginous.

The following is the histology of Honduras sarsaparilla: Epidermal cells polygonal, brown, some of the cells developed into single-celled, usually short, thin-walled trichomes. Below the epidermis three to four layers of thick-walled, porous bast cells. Parenchyma cells elongated, cylindrical, filled with compound starch granules; some cells with raphides of calcium oxalate. Endoderm cells of uniform thickness, elongated, a very light brown color, porous. Woody tissue consists of tracheids and very large scalariform ducts.

Ash 10 per cent.

The histological differences of the different sarsaparillas, as seen in carefully prepared sections, is quite marked, but these differences are not so evident in the powders. Compare histology of the more important commercial varieties. 


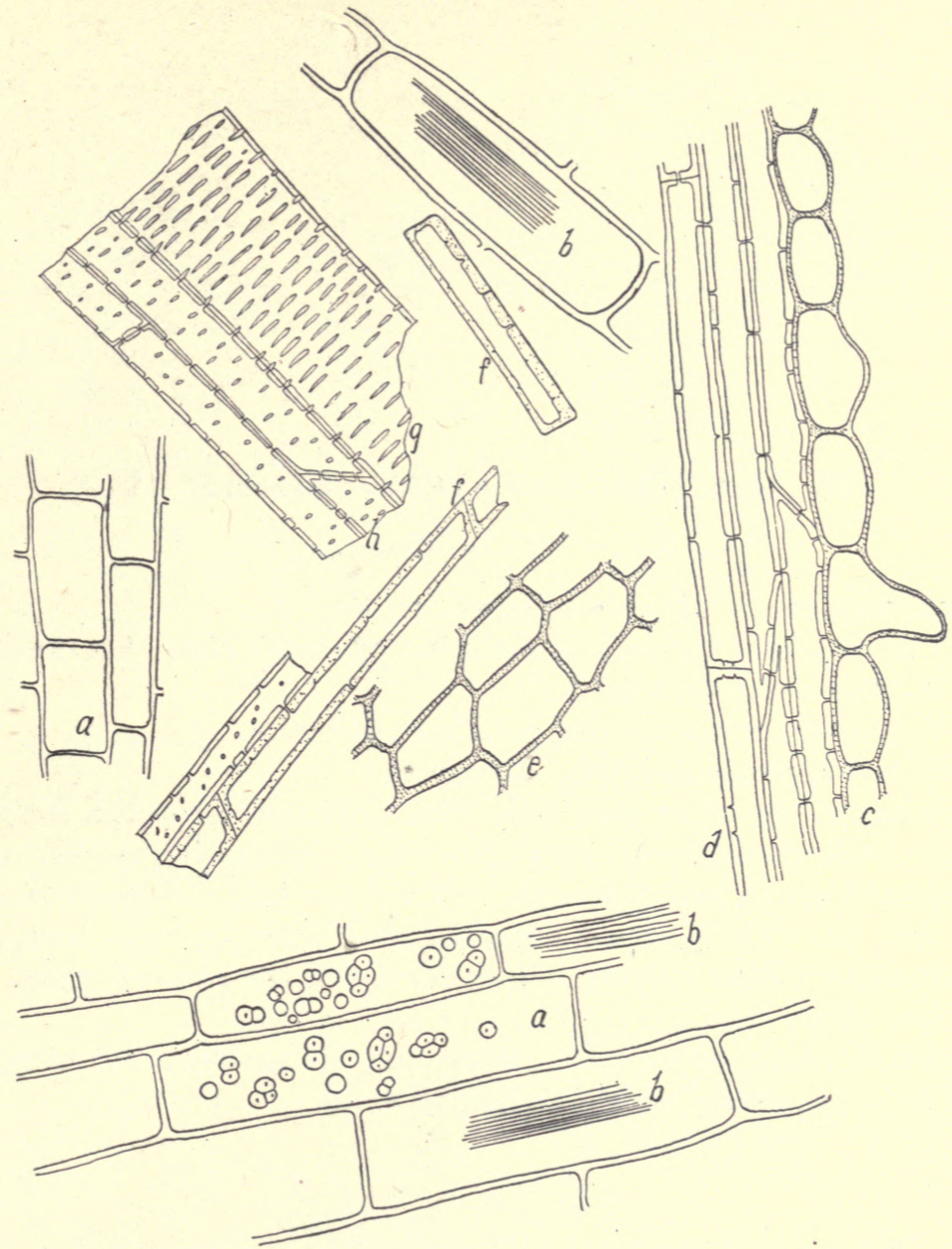

Fig. 170. SARSAPARILLA. Honduras.

a. Parenchyma cells, longitudinal view, filled with starch, also showing raphides.

b. Raphides.

c. Epidermis, lateral view.

d. Hypodermal bast or woody tissue.

$e$. Epidermal cells, vertical view.

$f$. Endoderm cells, longitudinal view.

g. Scalariform duct.

$h$. Tracheids. 
178. (Fig. 171.) SASSAFRAS. Sassafras. U. S.

Fl. ex. 60 .

Sassafrasrinde, G. Ecorce de sassafras, Fr.

The root bark (peeled) or Sassafras officinalis Nees, Lauraceæ.

Bright reddish brown.

Very fragrantly aromatic; recalling star anise.

Sweetish, pungent, bitter, astringent.

Some of the outer cork cells with bright red brownish contents. Inner bark parenchyma cells thin-walled, containing rather small compound starch granules, with very distinct hili, and many of them fat and oil. Thick-walled, comparatively short, porous bast cells. Sclerenchyma cells varying in size, form and thickness of walls.

Ash 10 per cent.

Adulteration infrequent. Bark may be gathered out of season and may contain an excess of adhering wood. 


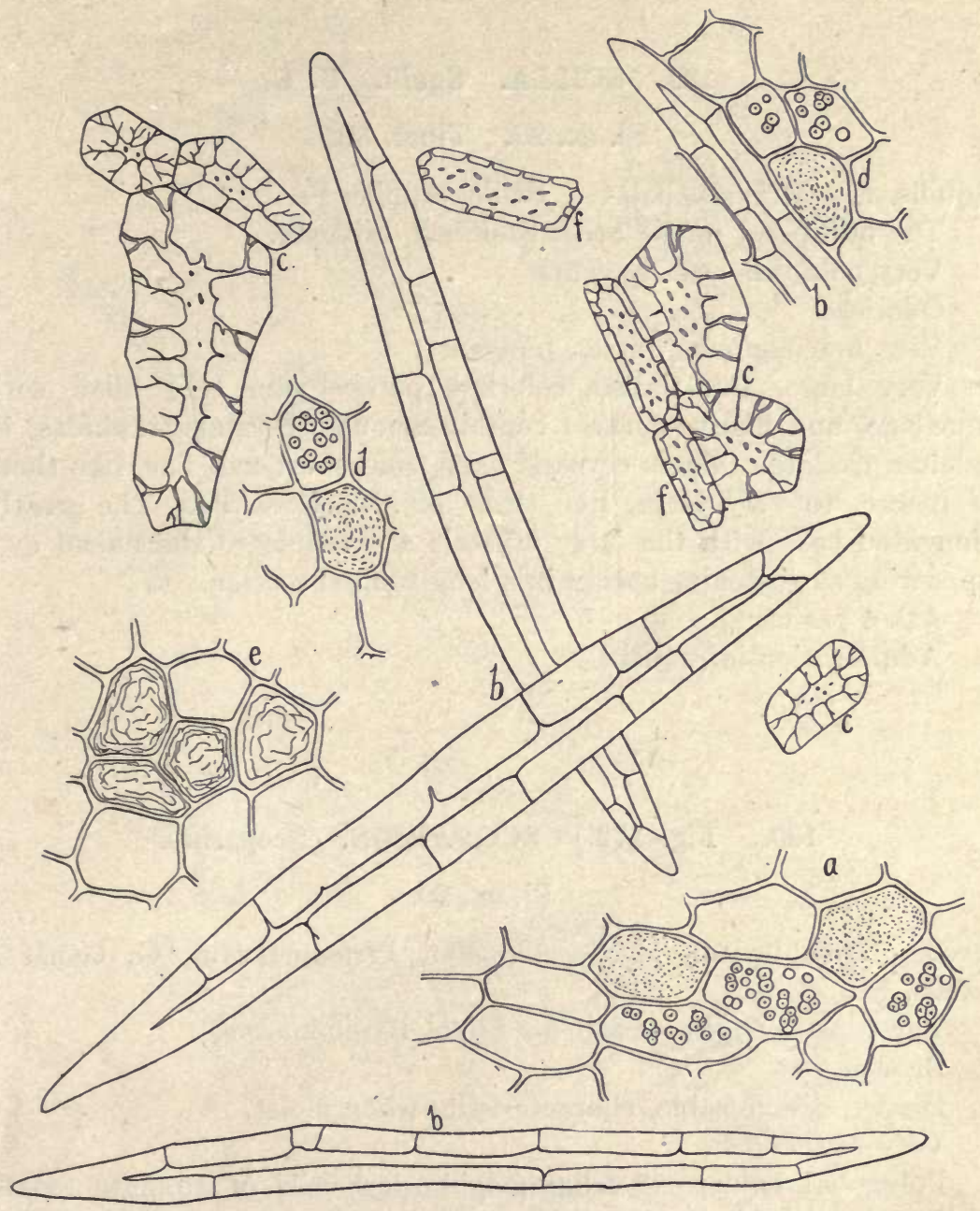

Fig. 171. SASSAFRAS.

a. Inner bark parenchyma cells with starch and oily contents, transverse view.

b. Bast fibers.

c. Thick-walled sclerenchyma cells.

d. Parenchyma cells, longitudinal view.

e. Outer cork cells with bright red contents.

f. Thin-walled sclerenchyma cells. 


\section{SCILLA. Squill. U. S.}

Fl. ex. 20. Tinct. 30 .

Squills, E. Meerzwiebel, G. Scille, Squille, Fr.

The bulbs of Urginea Scilla Steinheil, Liliaceæ.

Very pale yellowish brown.

Odorless.

Very mucilaginous, bitter, pungent.

Very large, thin-walled, colorless parenchyma cells filled with mucilage, and many of them contain acicular crystals (raphides) of calcium oxalate. These crystals vary from short and fine, like those of ipecac, to very. large, like those of Iris florentina. The greatly elongated cells with the large crystals are visible to the naked eye, appearing as glistening specks in a longitudinal section.

Ash 4 per cent.

Adulteration infrequent.

\section{Fig. 172.) SCOPARIUS. Scoparius.}

Fl. ex. 20.

Broom, Irish broom, E. Besenginster, Pfriemenkraut, G. Genêt á balais, Fr.

The tops of Cytisus scoparius Link., Papilionaceæ.

Brown.

Heavy, disagreeable, characteristic; when moist.

Very bitter.

Polygonal epidermal cells; neighboring cells of stomata small. Yellowish, simple, single-celled, thick-walled trichomes, with a few small warty markings on cuticle; basal ends broken off diagonally. Some bast and crystal-bearing fibers. Numerous small spiral ducts with delicate spiral thickenings; some annular and reticulate ducts and tracheids. Oval brownish pollen grains resembling a foot-ball in form. Some parenchymatous tissue and rectangular (in longitudinal view) hypodermal tissue. 


$$
\underbrace{\frac{5}{x-5 x} x}
$$

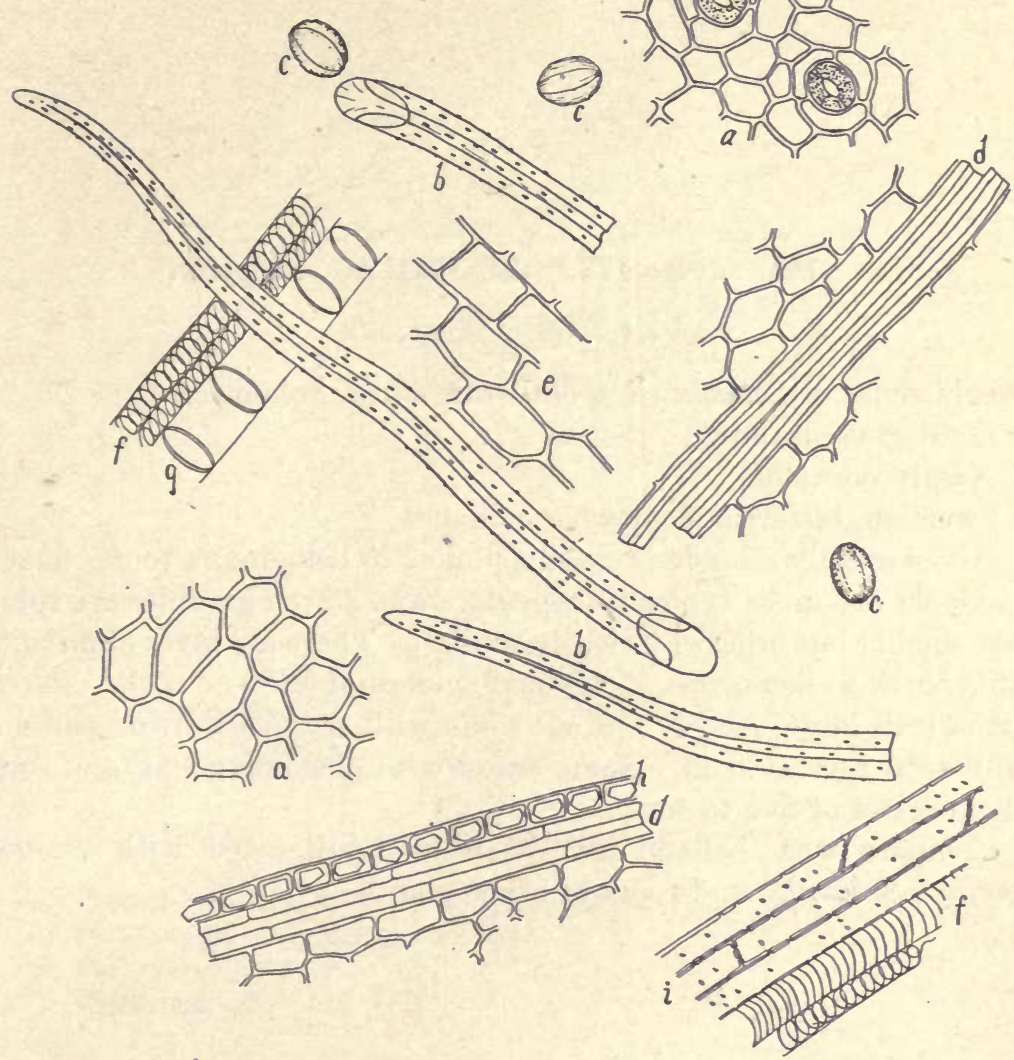

Fig. 172. SCOPARIUS.

a. Epidermal tissue with stomata.

b. Trichomes.

c. Pollen grains.

d. Bast fibers.

e. Hypodermal tissue.

f. Spiral ducts.

g. Annular duct.

$h$. Prismatic crystal bearing fiber. 
181. (Fig. 173.) SCOPOLA. Scopolia.

Fl. ex. 60. Tinct. 60 .

The rhizomes of Scopola (Scopolia) carniolica, Solanaceæ.

Light grayish brown.

Nearly odorless.

Sweetish, bitterish, somewhat pungent.

Histologically scopola is closely similar to belladonna root. Ducts of scopola are more typically reticulate and starch granules are somewhat smaller but otherwise closely similar. There is a layer of distinct, rather thick-walled brown, polygonal epidermal cells; no cork. Parenchyma cells large, loosely united; some with reddish brown resin and many with crystal sand. Some starch granules polygonal, and some in aggregates of five to seven.

Compare with belladonna. May be adulterated with Scopola japonica, S. lurida, and roots of other plants. 


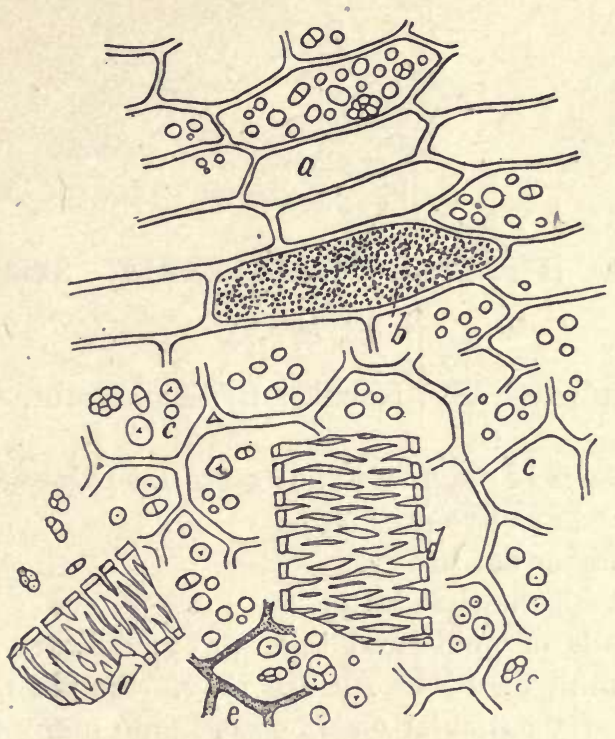

Fig. 173. SCOPOLA.

a. Parenchyma with stareh and cryptocrystals $(b)$.

c. Parenchyma cells, transverse view.

d. Reticulate ducts.

e. Epidermal cell. 


\section{2. (Fig. 174.) SCUTELLARIA. Skullcap.}

Fl. ex. 30 .

Hoodwort, Madweed, E. Helmkraut, Schildkraut, G. Scutellaire, Fr.

The leafy parts of Scutellaria lateriflora L., Labiatæ.

Deep, somewhat olive green.

Fragrant; somewhat heavy.

Sweetish and somewhat bitter.

Vertical walls of epidermal cells wavy; delicate wavy cuticular markings; stomata on lower surface only. Simple many celled trichomes with warty cuticular markings. Large many celled glandular trichomes and smaller glands with two secreting cells. Some oval pollen grains. 

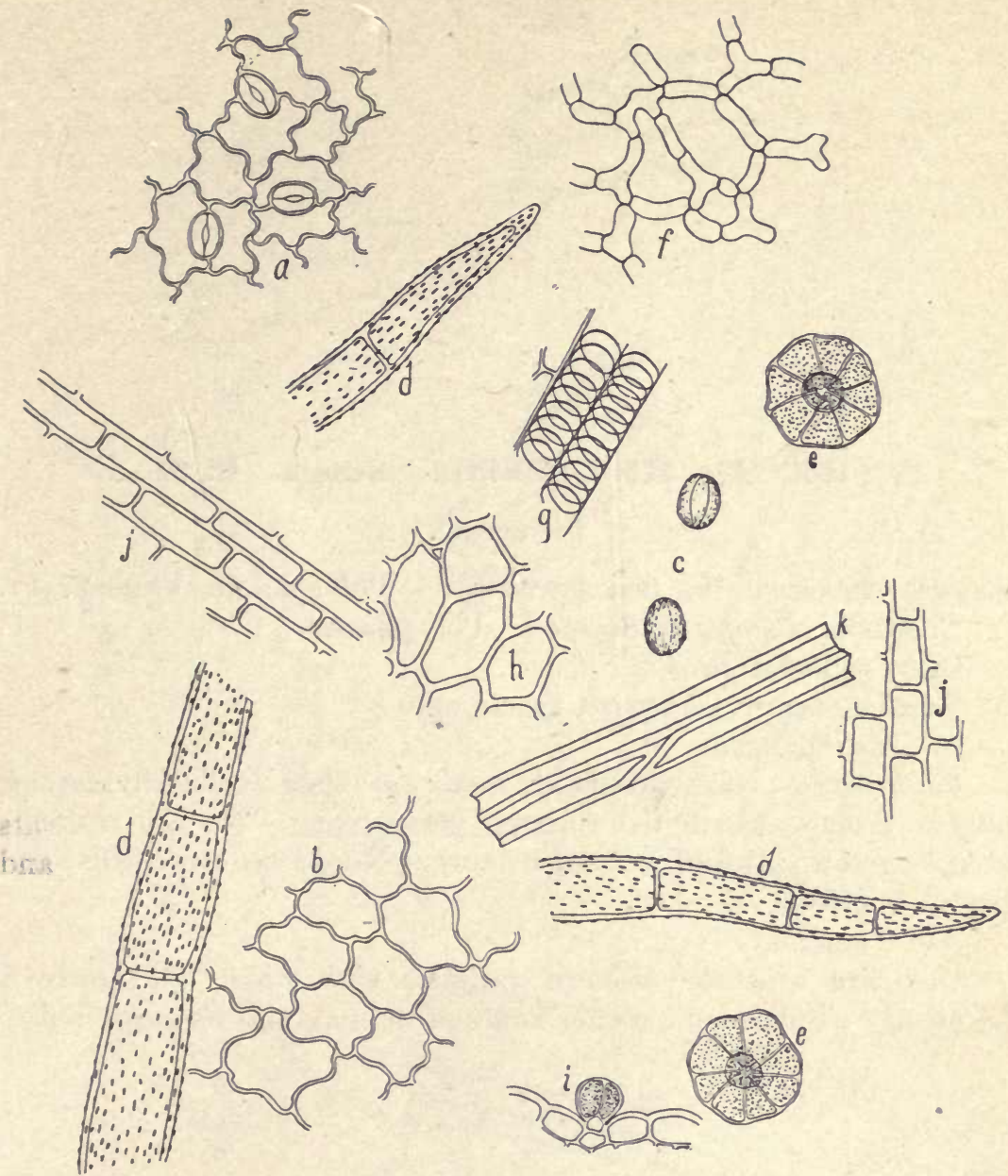

Fig. 174. SCUTELLARIA.

a. Lower epidermis.

b. Upper epidermis.

c. Pollen grains.

d. Trichomes.

e. Glands, top view.

f. Spongy tissue of leaves.

g. Spiral ducts.

h. Parenchyma.

i. Small gland and epidermal cells, profile view.

j. Parenchyma. 


\section{3. (Fig. 175.) SENEGA. Senega. U. S.}

Fl. ex. 30.

Senega, snakeroot, E. Senegawurzel, G. Polygale de Virginie, Fr. The roots of Polygala Senega L., Polygalaceæ.

Light yellowish brown.

Peculiar, heavy, somewhat rancid odor.

Sweetish, pungent.

Parenchyma cells elongated; many of them collenchymatous; phlœm groups distributed through parenchyma. No cell contents excepting fat. Outer yellowish cork. Numerous tracheids and porous ducts.

Ash 5 per cent.

Compare with the western varieties with which the above is frequently adulterated. Other adulterants may also be suspected. 

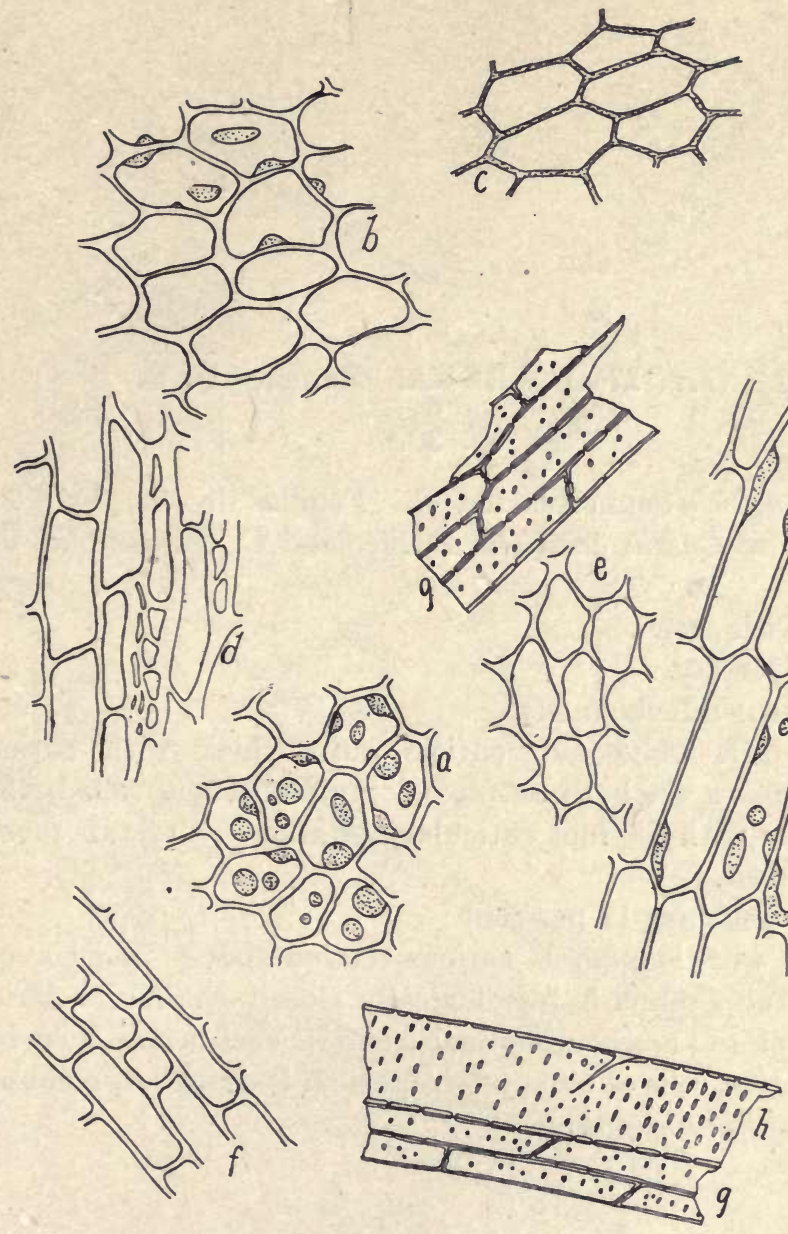

Fig. 175. SENEGA.

a. Parenchyma with fat.

$b, e$. Collenchymatous tissue.

c. Cork.

d. Collenchyma and phlœm group, longitudinal view.

$f$. Parenchyma, longitudinal view.

g. Tracheids.

h. Porous duct. 


\section{4. (Fig. 176.) SENNA. Senna. U. S.}

Fl. ex. 30.

Alexandriasenna, E. Sennesblätter, G. Feuilles de séne, Fr.

The leaflets of Cassia acutifolia Delile, and C. augustifolia Vohl, Leguminosæ.

Light yellowish green.

Somewhat fragrant.

Slightly bitter; mucilaginous.

Epidermal cells polygonal, cuticle quite thick with cuticular markings. Stomata on both surfaces. Simple, single celled, thickwalled trichomes with distinct cuticular markings. Crystals present. Ash 10 per cent.

Ash of senna siftings 17 per cent.

Adulterated with leaflets of various related species and leaves of other plants. India senna is histologically closely similar to African. Trichomes longer and more numerous; as a rule each stoma is enclosed by two neighboring cells of unequal size, which is much less commonly the case in Alexandria senna. 


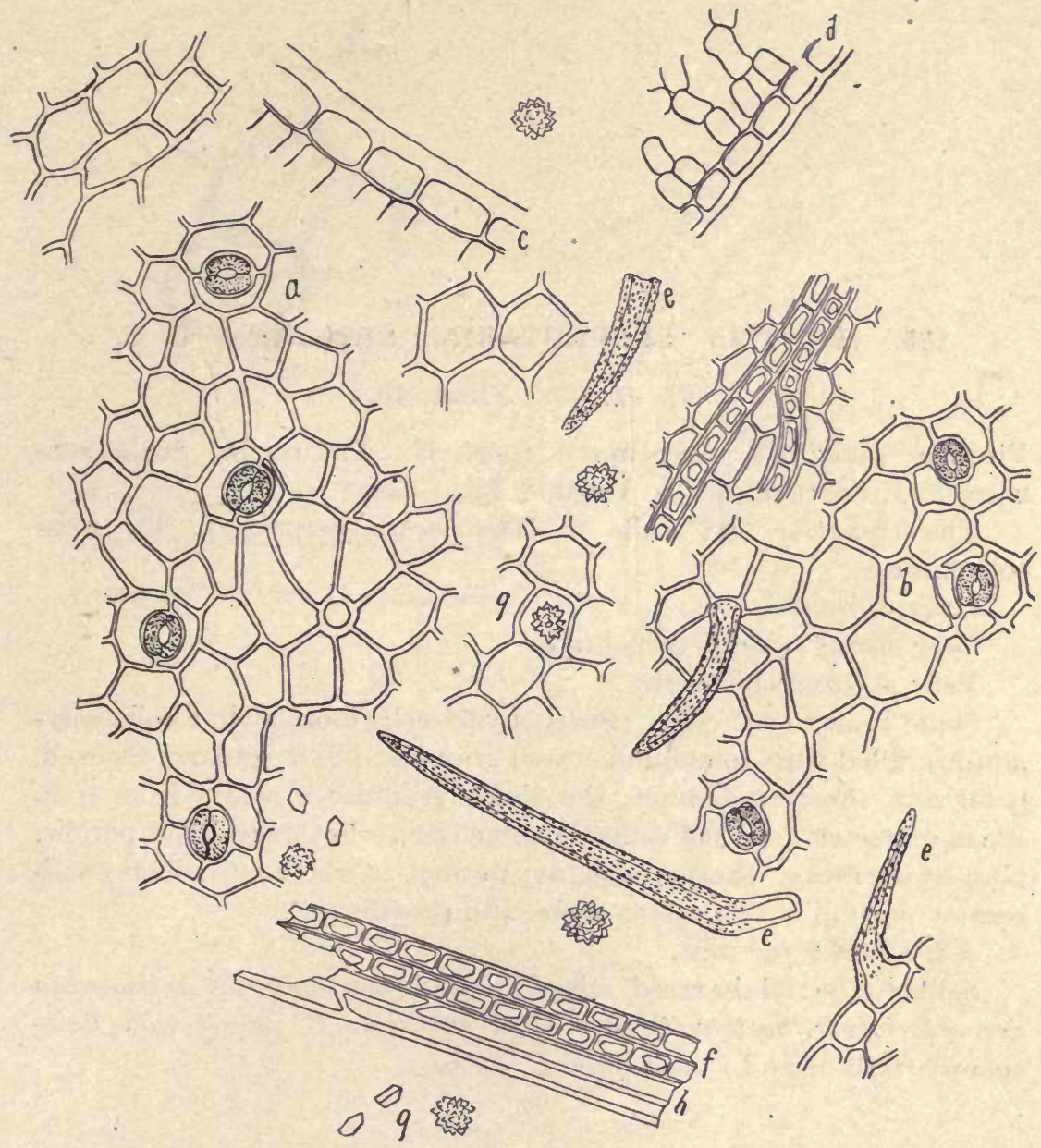

Fig. 176. ALEXANDRIA AND INDIA SENNAS.

a. Lowcr epidermis of India senna.

b. Epidermis of Alexandria senna.

$c, d$. Epidermis, lateral view.

e. Trichomes.

f. Crystal bearing fibers from vascular tissue.

g. Crystals.

$h$. Bast of vascular bundles. 
185. (Fig. 177.) SERPENTARIA. Serpentaria. U. S. Fl. ex. 60. Tinct. 40 .

Virginia snakeroot, Serpentary root, E. Virginische Schlangenwurzel, G. Serpentaire de Virginie, Fr.

The rhizomes and roots of Aristolochia Serpentaria L., Aristolochiaceæ.

Grayish brown.

Very strong odor of turpentine.

Very pungent, bitterish.

Some brown cork cells. Parenchyma cells more or less collenchymatous, filled with compound starch granules, hili irregularly fissured, polarizing effects indistinct, the single granules measure from 6 to $10 \mu$ in diameter. Pith or central parenchyma cells thick-walled, porous. Numerous rather short tracheids; porous to reticulate ducts with greater portion of transverse septæ still present.

Ash about 9 per cent.

Said to be adulterated with Spigelia marilandica, Aristolochia Serpentaria var. hastata, Cypripedium pubescens, C. parviflorum, Palemonium reptans and Panax quinquefolium. 

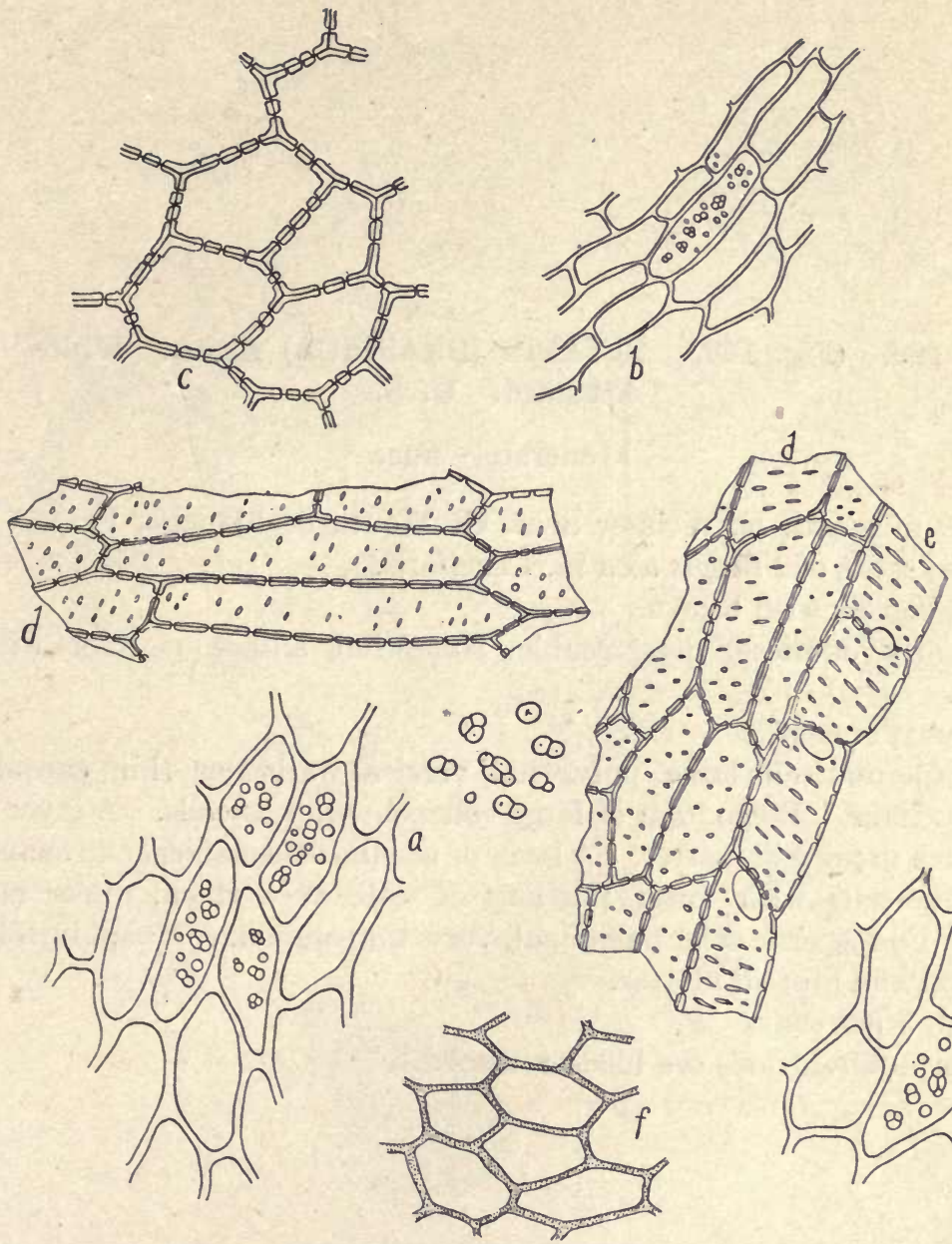

Fig. 177. SERPENTARIA.

$a, b$. Parenchyma cells with starch.

c. Pith or central parenchyma.

d. Tracheids.

c. Porous duct.

f. Cork cells. 
186. (Fig. 178.) SINAPIS (BRASSICA) ALBA. White Mustard. U. S.

Moderately fine.

Yellow mustard, E. Weisser Senf, G. Moutarde blanche, Fr.

The seeds of Sinapis alba L., Cruciferæ.

Light yellowish brown.

Nearly odorless; disagreeable, somewhat alliaceous odor when moist.

Very pungent.

Epidermal cells large, polygonal, vertical walls very thin, containing mucilage. Hypoderm of large collenchymatous cells. A layer of cells rich in proteid matter. A layer of peculiar mechanical cup shaped palisade cells with lower portions of walls very thick, upper part thin. Endosperm cells polygonal, very thin-walled, completely filled with fat and proteid matter.

Ash 5 per cent.

For adulterations see black mustard. 


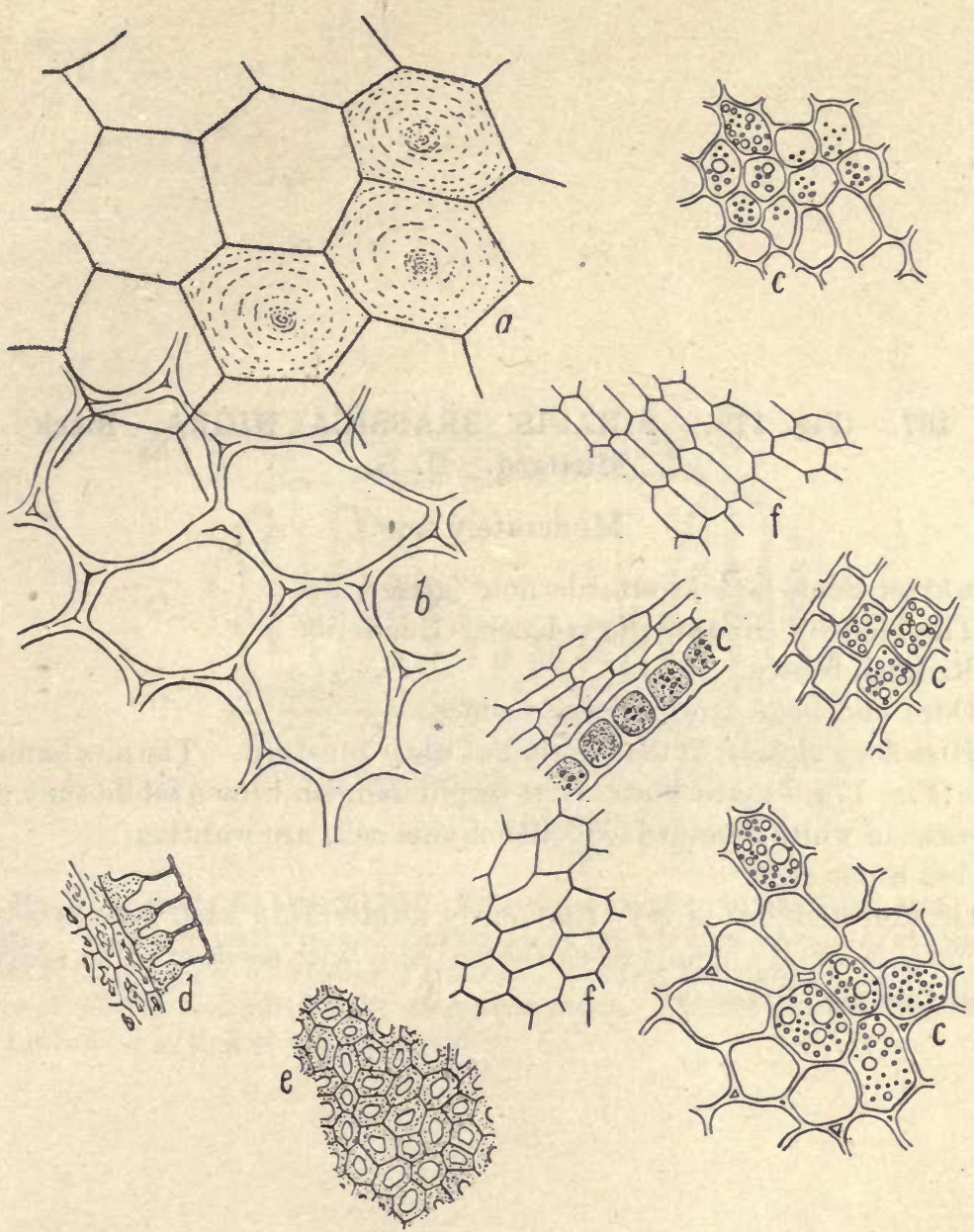

Fig. 178. SINAPIS ALBA.

a. Epidermal cells with mucilage, vertical view.

b. Collenchymatous hypoderm.

c. Proteid and oil bearing parenchyma.

d. Mechanical cells, profile view.

e. Mechanical cells, vertical view.

f. Endosperm cells, entirely filled with fat and proteid matter. 
187. (Fig. 179.) SINAPIS (BRASSICA) NIGRA. Black Mustard. U. S.

Moderately fine.

Schwarzer Senf, G. Moutarde noir (grise), Fr.

The seeds of Sinapis nigra Koch, Cruciferæ.

Reddish brown.

Odor and taste as for white mustard.

Histology closely similar to that of white mustard. The mechanical cells (Fig. 179, b), are however a bright reddish brown while they are colorless in white mustard. Collenchyma cells are wanting.

Ash 6 per cent.

Ground mustard is very frequently adulterated with flour, starch, curcuma, a small amount of capsicum; also with seeds of other species of Sinapis and Brassica. 


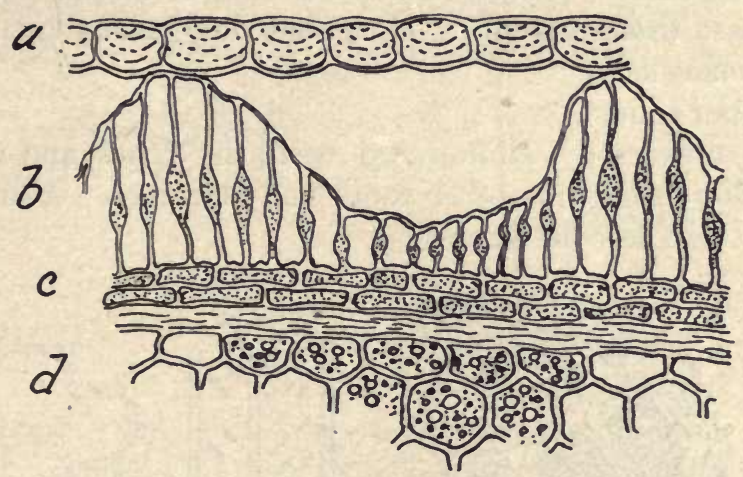

Fig. 179. BLACK MUSTARD. Transverse section through the seed coat (testa). Compare with the seed coat tissues of the white mustard. a, epidermal layer; $b$, hypodermal palisade cells (note the variation in length); $c$, dark colored layer of cells; $d$; beginning of the endosperm tissue. The seed coat tissue of rape seed is similar to that of black mustard. 
188. (Figs. 180 and 181.) SPIGELIA. Spigelia. U. S. Fl. ex. 60 .

Pinkroot, E. Maryländische Spigelie, G. Spigelie du Maryland, Fr.

The rhizomes and roots of Spigelic marilandica L., Loganiaceæ.

Light brown.

Somewhat aromatic.

Bitter.

Outer suberized tissue containing dark coloring matter; parenchyma cells elongated containing some simple mostly spherical small starch granules; abundant porous tracheids and occasional spiral ducts. No true bast tissue excepting elongated non-porous tracheids. No sclerenchyma cells.

Ash 10 per cent:

Almost universally adulterated with the roots and rhizomes of Ruellia ciliosa; also with other roots and rhizomes. Adulteration is the rule rather than the exception.
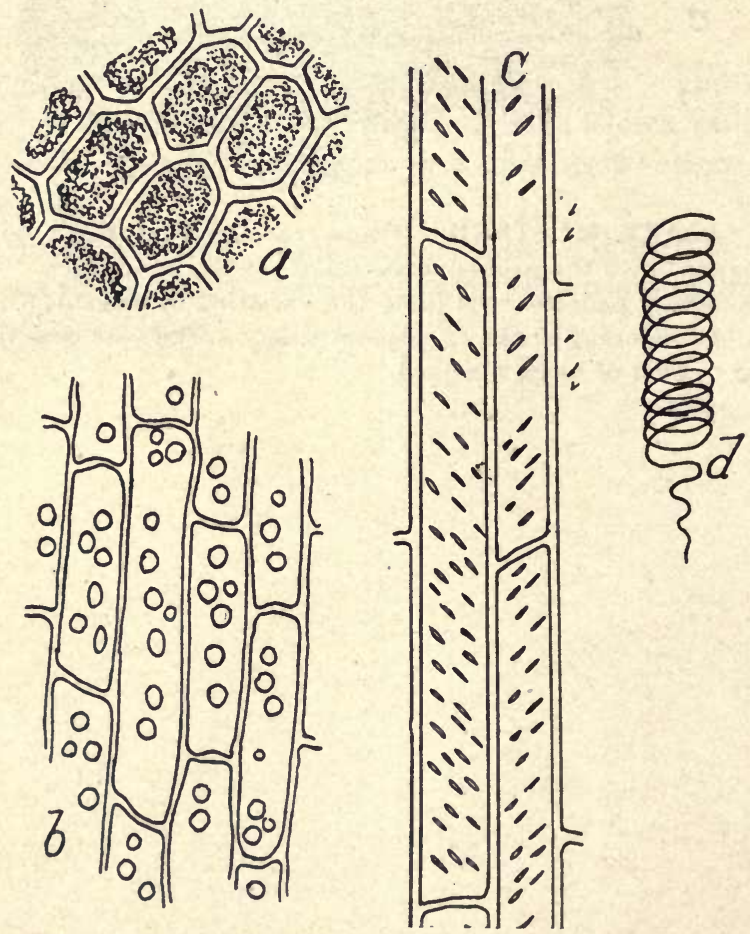

Fig. 180. SPIGELIA MARILANDICA. $a$, outer cork parenchyma containing coroling substances; $b$, elongated parenchyma cells bearing some starch; $c$, the porous tracheids are very abundant; $d$, spiral and reticulate ducts are sparingly present. 


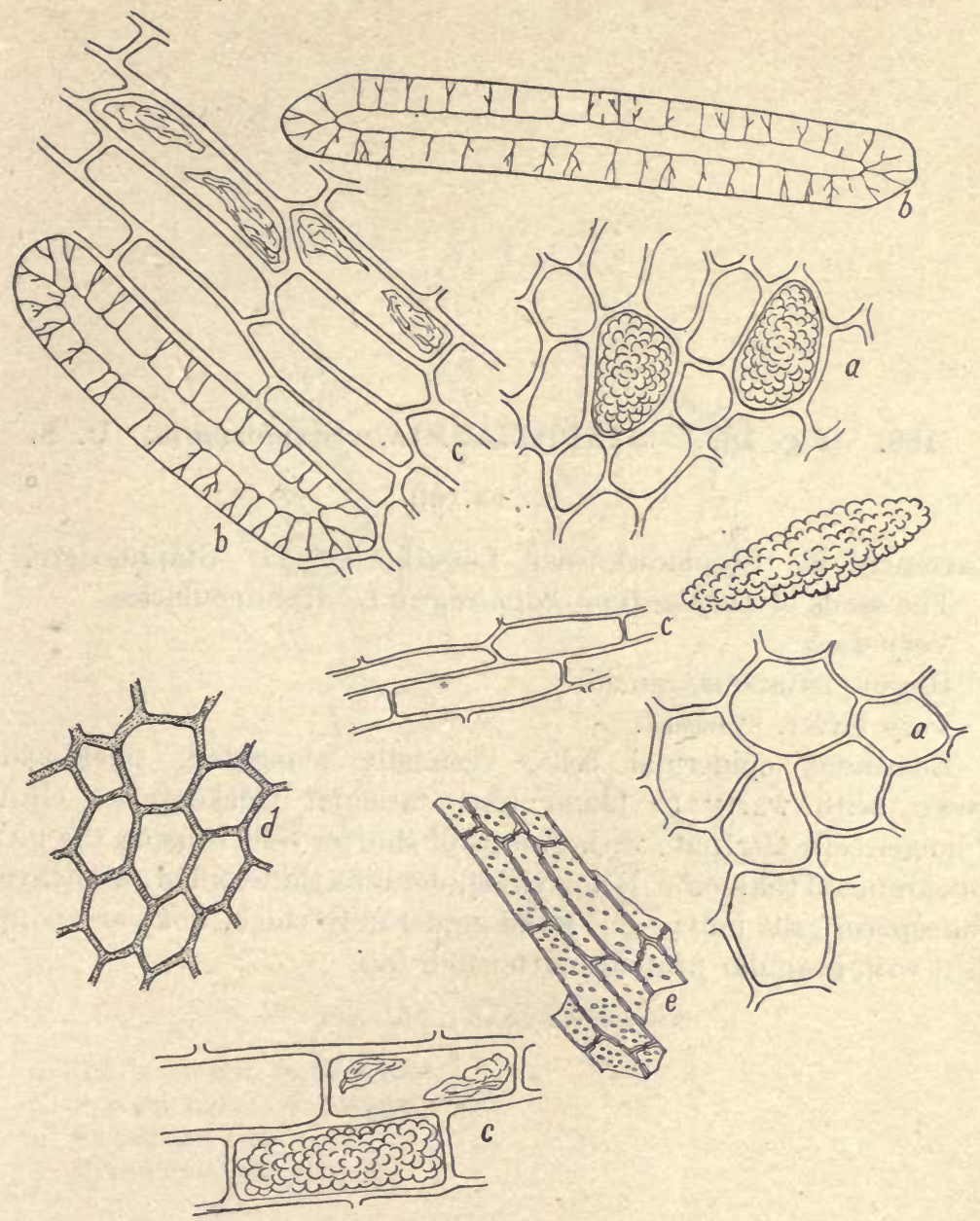

Fig. 181. Ruellia ciliosa roots and rhizomes. This constitutes the most common adulterant of Spigelia marilandica.

a. Outer parenchyma, two cells with cystoliths.

b. Sclerenchyma cells.

c. Parenchyma cells, longitudinal view.

d. Cork tissue.

e. Tracheids. 
189. (Fig. 182.) STAPHISAGRIA. Staphisagria. U. S. Fl. ex. 60.

Stavesacre, E. Stephanskörner, Läusekörner, G. Staphisaigre, Fr. The seeds of Delphinium Staphisagria L., Ranunculaceæ.

Very dark.

Heavy, nauseous, rancid.

Very bitter, pungent.

Enormous epidermal cells, vertically elongated, thick-walled, brown, with warty to filamentous cuticular thickenings. Groups of longer cells alternate with groups of shorter cells causing the pitted appearance of the seed. Below the epidermis a thin-walled parenchyma. Endosperm cells polygonal, walls moderately thick, not very porous, filled with granular proteid matter and fat: 


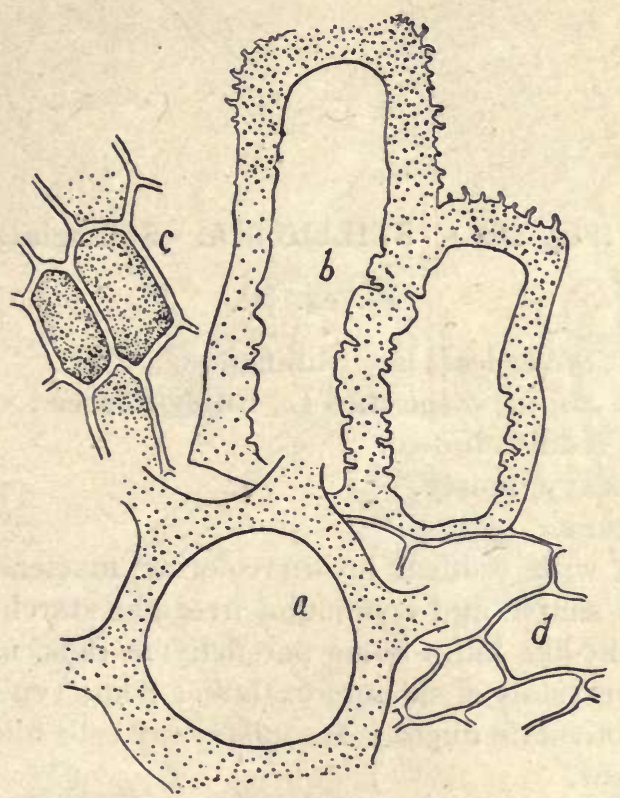

Fig. 182. STAPHISAGRIA.

a. Epidermal cell, vertical view.

b. Two epidermal cells, lateral view.

c. Endosperm cells.

d. Hypodermal parenchyma. 
190. (Fig. 183.) STILLINGIA. Stillingia. U. S.

Fl. ex. 30 .

Queen's delight, Silver leaf, E. Stillingie, G., Fr.

The roots of Stillingia sylvatica L., Euphorbiaceæ.

Rather pale reddish brown.

Somewhat heavy, musty.

Bitter, pungent.

Cork tissue with reddish brown coloring matter. Parenchyma cells filled with simple and compound irregular starch granules with quite distinct slit-like hili. Some parenchyma cells, usually smaller, with aggregate crystals of calcium oxalate. Some typical bast fibers; tracheids and reticulate ducts. Medullary ray cells filled with starch.

Ash 5 per cent.

Rarely adulterated. 


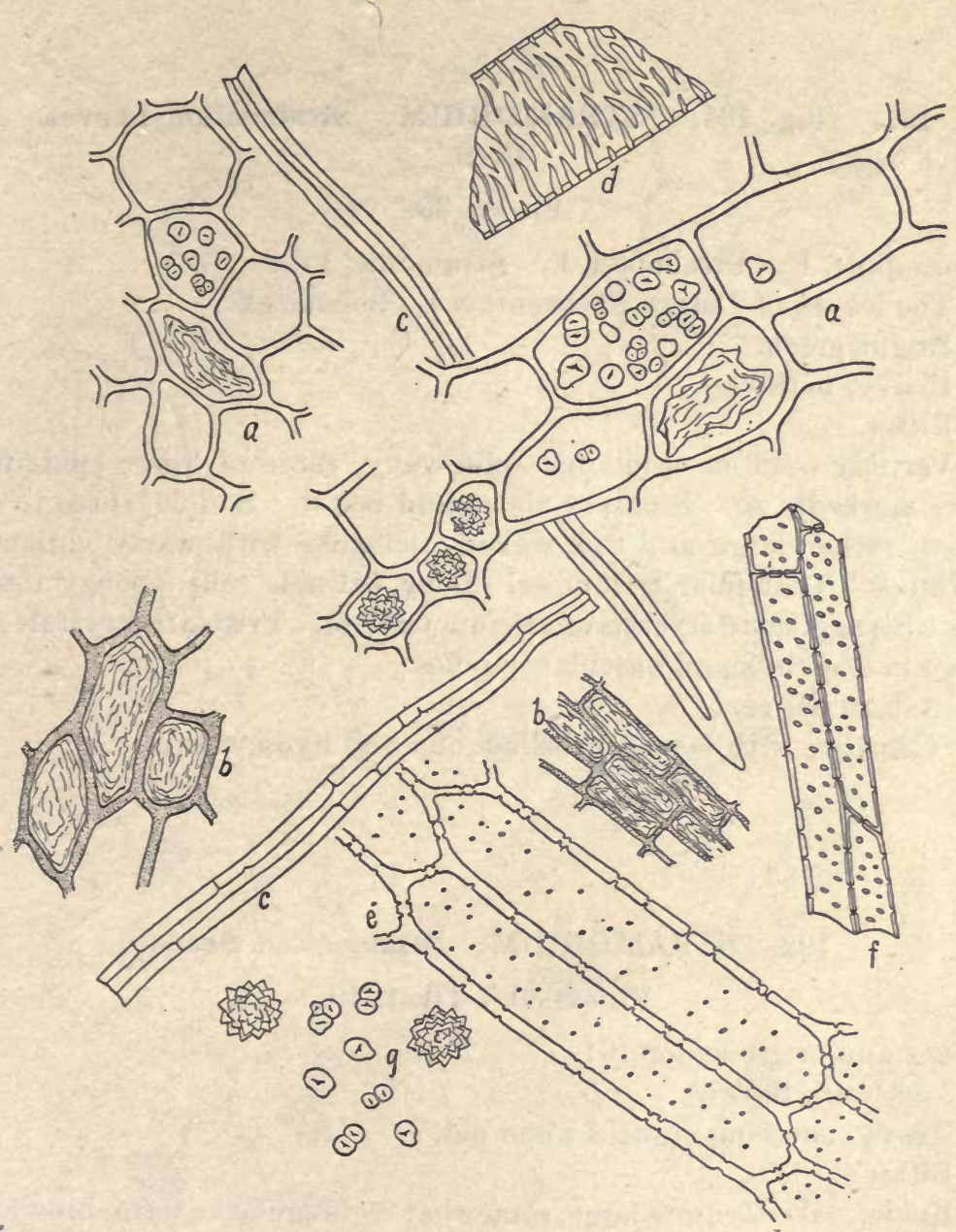

Fig. 183. STILLINGIA.

a. Parenchyma with starch, crystals and some brown resin.

$b$. Cork with reddish brown coloring matter.

c. Bast fibers.

d. Reticulate duct.

e. Porous parenchyma, longitudinal view.

f. Tracheids.

g. Starch and aggregate crystals of calcium oxalate. 
191. (Fig. 184.) STRAMONIUM. Stramonium Leaves. U. S.

Fl. ex. 30 .

Thornapple, E. Stechapfel, F. Stramoine, Fr.

The leaves of Datura Stramonium L., Solanaceæ.

Bright green.

Heavy, nauseous.

Bitter.

Vertical walls of epidermal cells wavy, those of lower epidermis more markedly so. Stomata above and below. Simple, three to six celled, rather large and thin-walled trichomes with warty cuticular markings Glandular trichomes. Long palisade cells, spongy tissue cells with aggregate crystals of calcium oxalate. Prismatic crystals are found in leaf stalk and vascular bundles.

Ash 20 pèr cent.

Compare with leaves of belladonna and hyoscyamus.

\section{STRAMONIUM. Stramonium Seeds.}

Fl. ex. 30. Tinct. 40 .

Names and origin as for 191.

Very dark brown.

Heavy, nauseous; rancid when old.

Bitter.

Epidermal cells quite large, somewhat rectangular in form, brownish in color, walls greatly thickened with numerous branching pores; outer walls wavy, producing warts and ridges as seen in lateral views. Endosperm cells polygonal, thick-walled, but not distinctly porous, bearing crenate aleuron grains and fat. Concentrated sulfuric acid colors the powder deep red. 


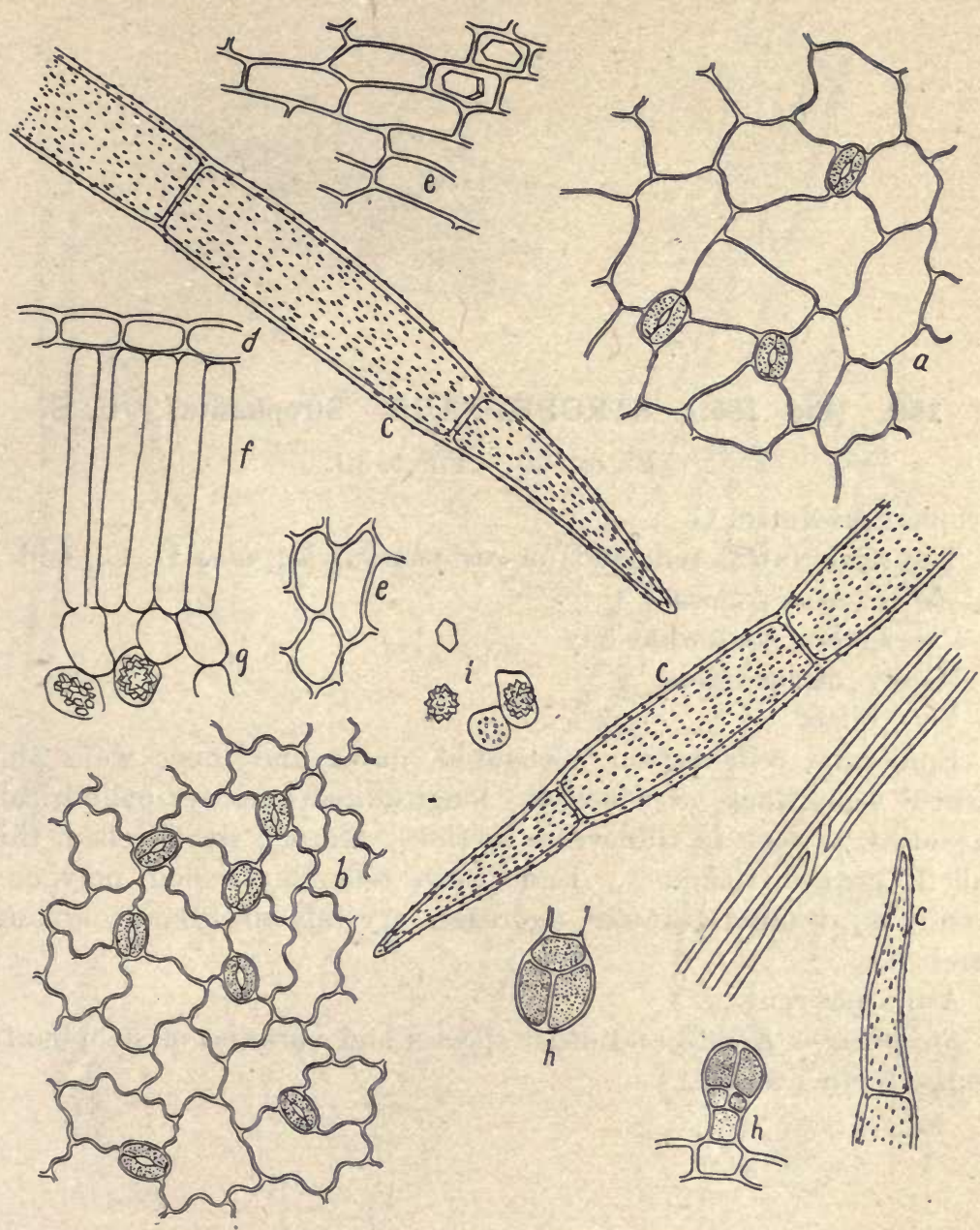

Fig. 184. STRAMONIUM LEAVES.

a. Upper epidermis.

b. Lower epidermis.

c. Trichomes.

e. Parenchyma cells of petiole.

$d, f, g$. Epidermis, palisade cells and spongy tissue cells.

h. Glandular trichomes.

i. Crystals. 
193. (Fig. 185.) STROPHANTUS. Strophantus. U. S. Fl. ex. 30 . Tinct. 30 .

Strophantussamen, G.

The seeds (awns removed) or Strophantus hispidus D. C., and S. Kombe O., Apocynaceæ.

Pale brown, somewhat oily.

Heavy, disagreeable.

Very bitter.

Epidermal cells brown, elongated, outer and inner walls thin, vertical walls thick, of which the longitudinal ones are cylindrically thickened, as seen in transverse section. Simple, single-celled, thinwalled, brown trichomes. Endosperm cells thin-walled, polygonal, bearing oil, proteid granules, aggregate crystals and some compound starch.

Ash 5 per cent.

Strophantus Kombe and other species and varieties of strophantus require further study. 


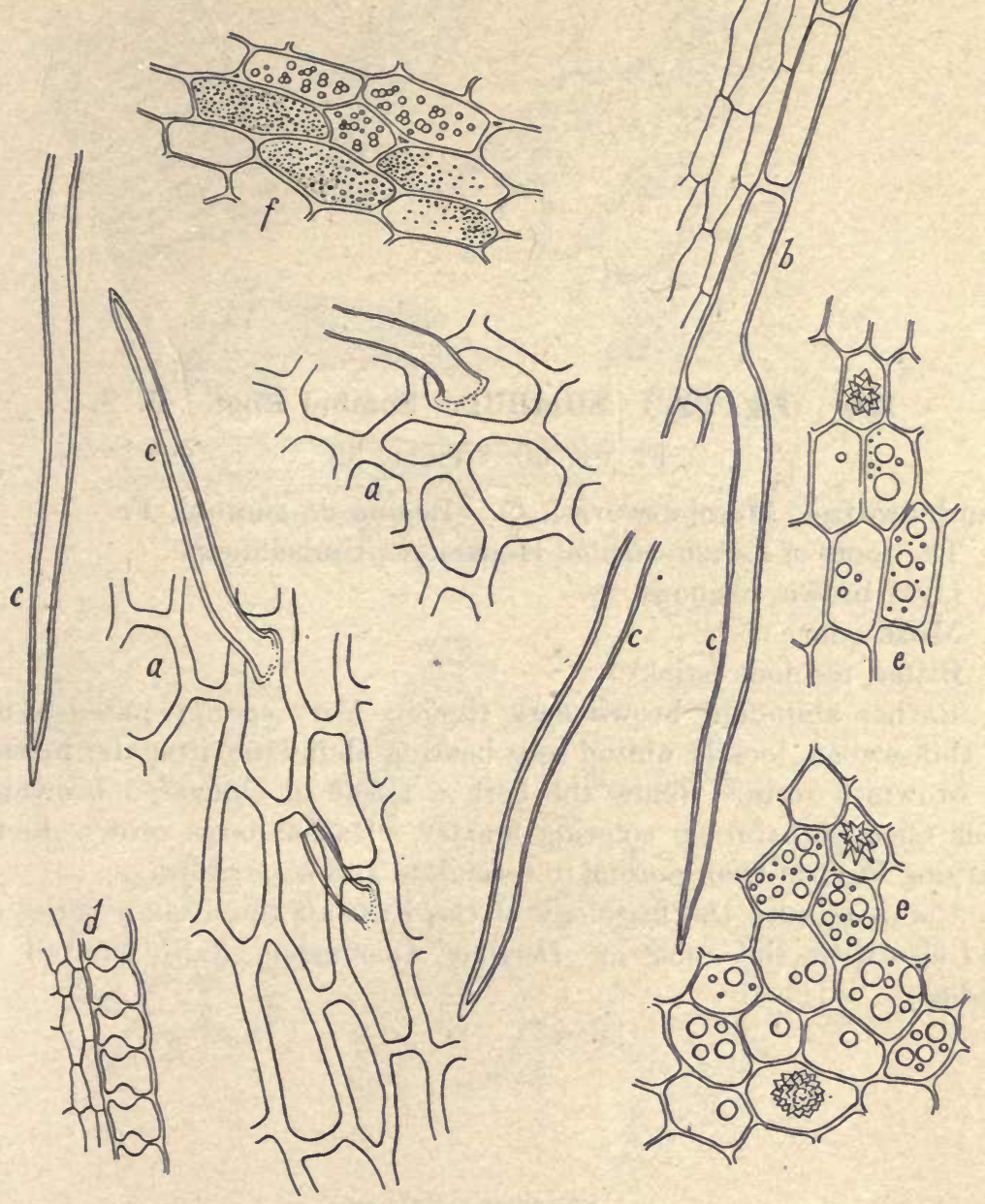

Fig. 185. STROPHANTUS.

a. Epidermis, vertical view.

b. Epidermis and trichome, lateral or side view.

c. Trichomes.

d. Epidermis, transverse view.

e. Endosperm tissue, showing oil and crystals.

$f$. Outer tissue with granular proteid matter and starch. 
194. (Fig. 186.) SUMBUL. Sumbul Root. U. S.

Fl. ex. 60. Tinct. 30 .

Sumbulwurzel, Moschuswurzel, G. Racine de sumbul, Fr.

The roots of Ferula Sumbul Hooker jr., Umbelliferæ.

Light brown, resinous.

Musk odor.

Bitter, resinous (sticky).

Rather abundant brown cork tissue. Very spongy parenchyma of thin-walled, loosely united cells bearing abundant, irregular masses of brownish resin. Below the cork a tissue of elongated brownish cells filled with brown coloring matter. Rather large brown ducts, varying in form from porous to reticulate and scalariform.

Compare with the histology of the Russian and Indian varieties, and also with the roots of Dorema Amoniacum (false sumbul of India). 


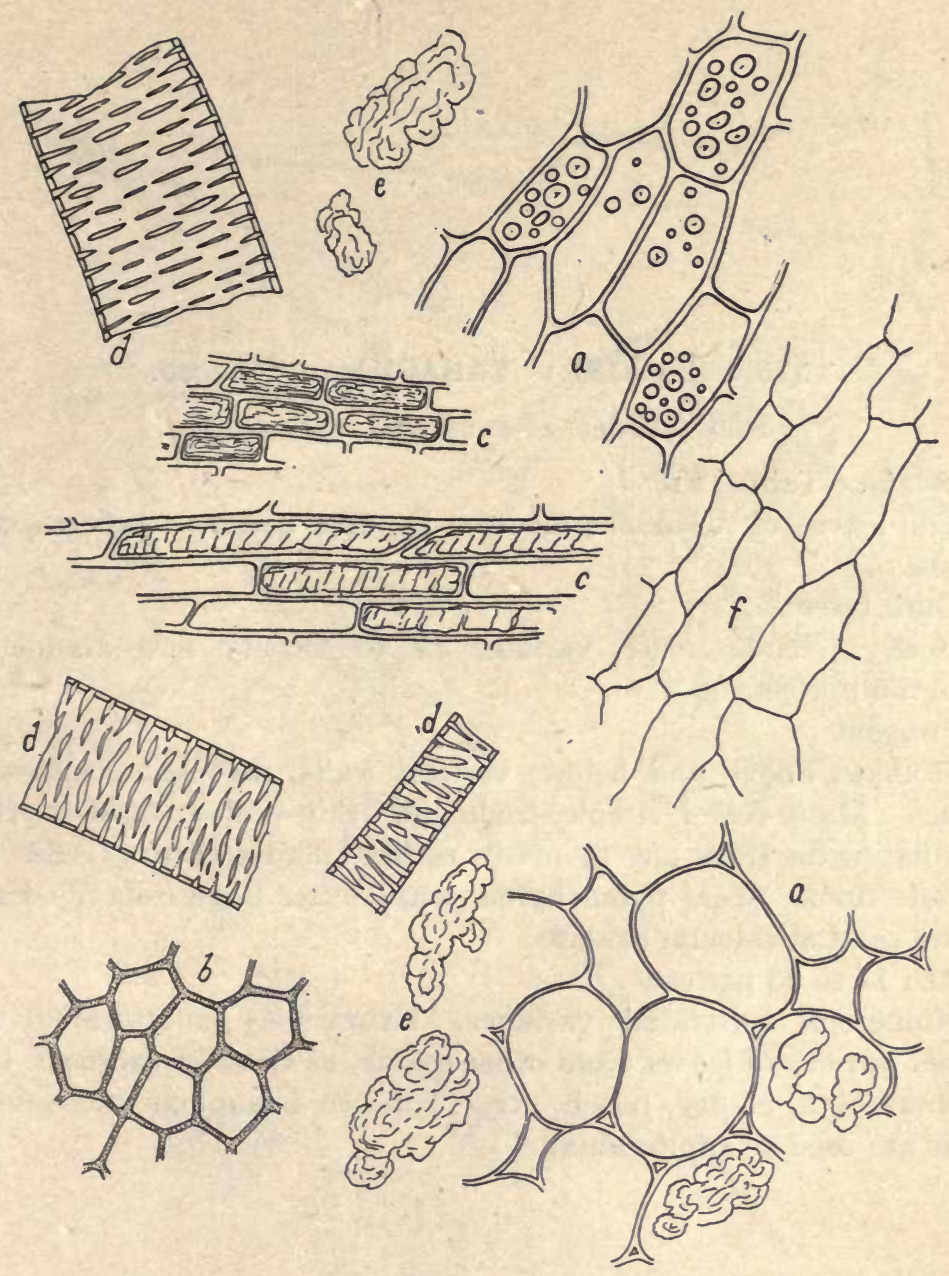

Fig. 186. SUMBUL.

a. Parenchyma.

b. Cork.

c. Tissue below the cork, bearing reddish brown coloring matter.

$d$. Reticulate ducts.

e. Resin masses.

f. Very thin-walled, collapsed parenchyma. 


\section{5. (Fig. 187.) TABACUM. Tobacco.}

Fine powder, as snuff and insecticide.

Tabak, G. Tabac, Fr.

The leaves of Nicotiana tabacum L., and cultural varieties, Solanaceæ.

Dark brown.

Heavy, characteristic; variable as to variety and manner of curing and preparing.

Pungent,

Stomata above and below; vertical walls, wavy and somewhat porous. Many-celled simple trichomes, thin-walled; most of them terminating in from one to many rather small secreting cells. No palisade tissue. Leaf parenchyma, with rather large cells filled with crystal sand of calcium oxalate.

Ash 14 to 25 per cent.

Numerous cultivated varieties. Extensively adulterated with a great variety of leaves from other plants, as those of cabbage, beet, chestnut, rose, cherry, peach, etc. Tobacco trimmings and tobacco stems are used as adulterants. 


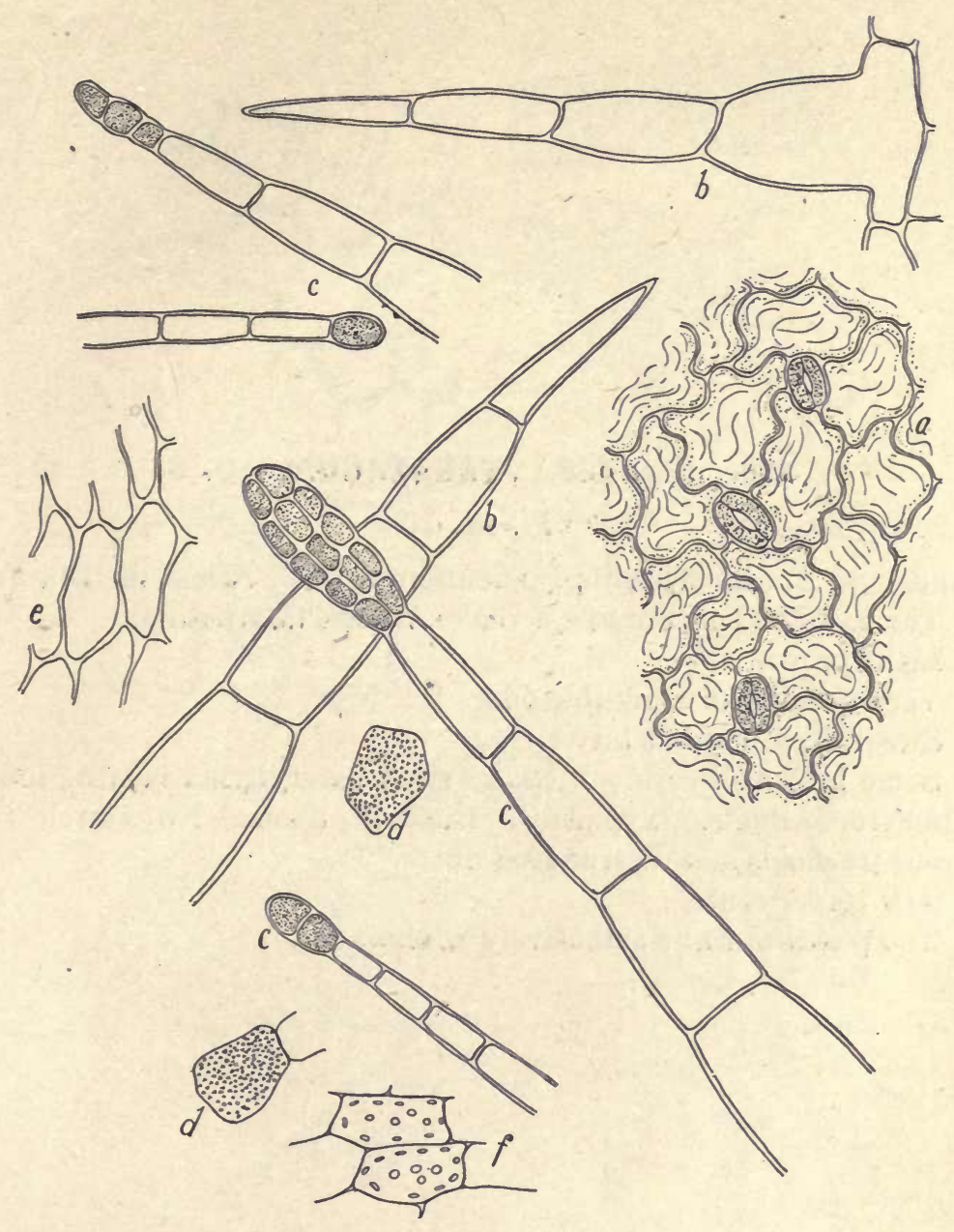

Fig. 187. TABACUM.

a. Upper epidermis.

b. Non-glandular trichomes.

c. Glandular trichomes.

d. Cells with crystals.

$e$. Parenchyma (collenchymatous) from midrib.

$f$. Leaf parenchyma with chlorophyll. 
196. (Fig. 188.) TARAXACUM. U. S.

Fl. ex. 30.

Dandelion, E. Löwenzahn, Pfaffenröhrchen, G. Dent de lion, Fr.

The roots of Taraxacum officinale Weber, Compositæ.

Light brown.

Very peculiar disagreeable odor.

Sweetish, somewhat bitter.

Some brownish cork. Medium sized parenchyma bearing inulin. Laticiferous ducts. Typically reticulate ducts. No starch. No porous tracheids and no true bast fibers.

Ash 10 per cent.

Too plentiful to be extensively adulterated. 


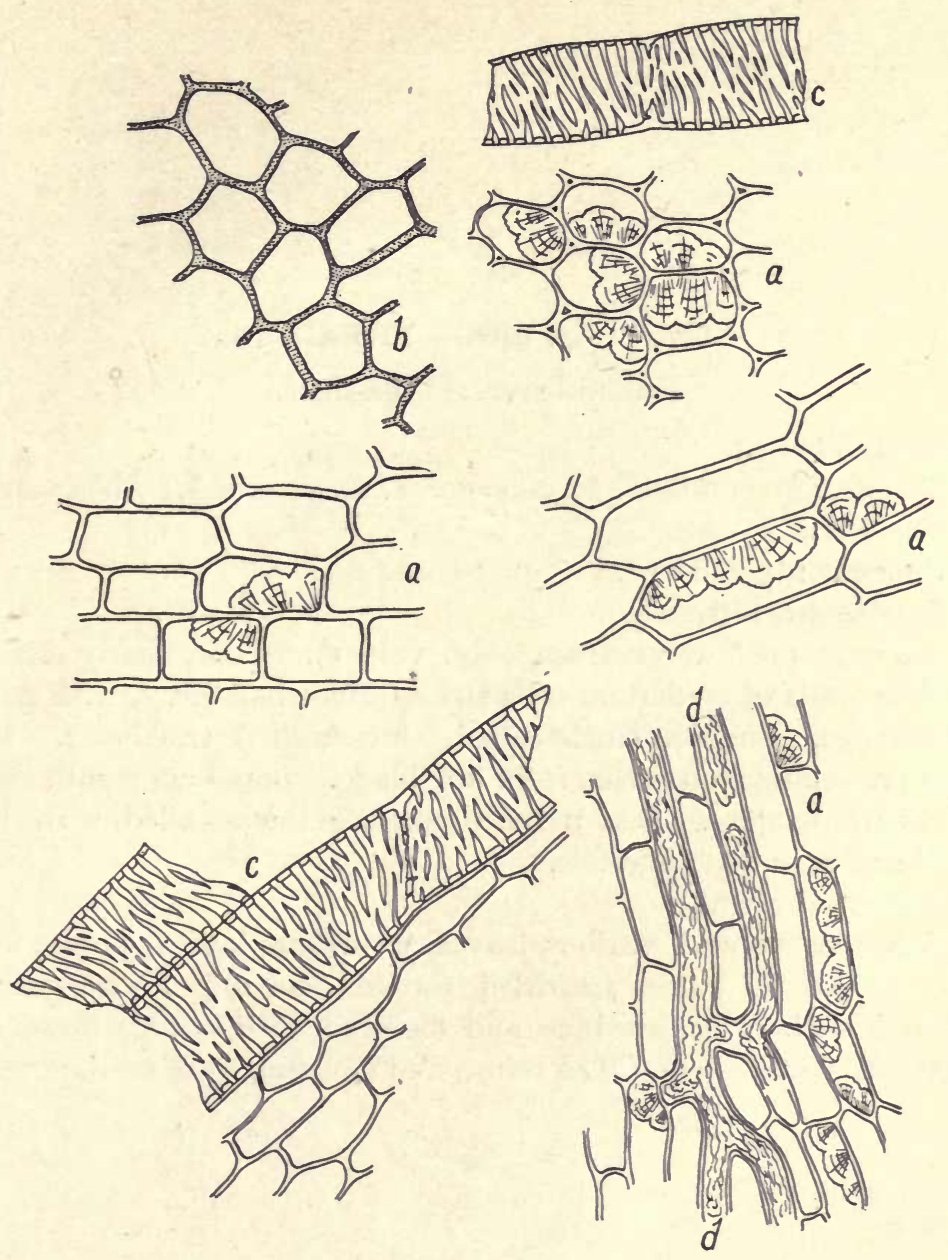

Fig. 188. TARAXACUM.

a. Parenchyma with inulin.

b. Cork.

c. Reticulate ducts.

$d$. Laticiferous ducts. 
197. (Fig. 189.) THEA. Tea.

Rolled leaves. Tea-dust.

Thee, G. Thé, Fr.

The leaves (younger and older) of Thea sinensis L., Theaceæ.

Very dark green.

Fragrant; tea-odor.

Astringent, bitterish.

Stomata on lower surface only, very numerous, nearly orbicular. Vertical walls of epidermal cells thick, somewhat wavy, with nodular thickenings. Simple, single-celled, thick-walled trichomes. A few large branching stone-cells, from leaf blade. Small aggregate crystals of calcium oxalate. Leaf parenchyma cells thick-walled, with chlorophyll and aggregate crystals.

Ash 5.5 per cent.

Adulterated with various leaves, as willow leaves, poplar leaves, etc. Exhausted leaves are dried, rerolled and mixed with good tea. Colored with Prussian blue and flavored with orange flowers and other fragrant flowers. Tea refuse and sweepings are used. 


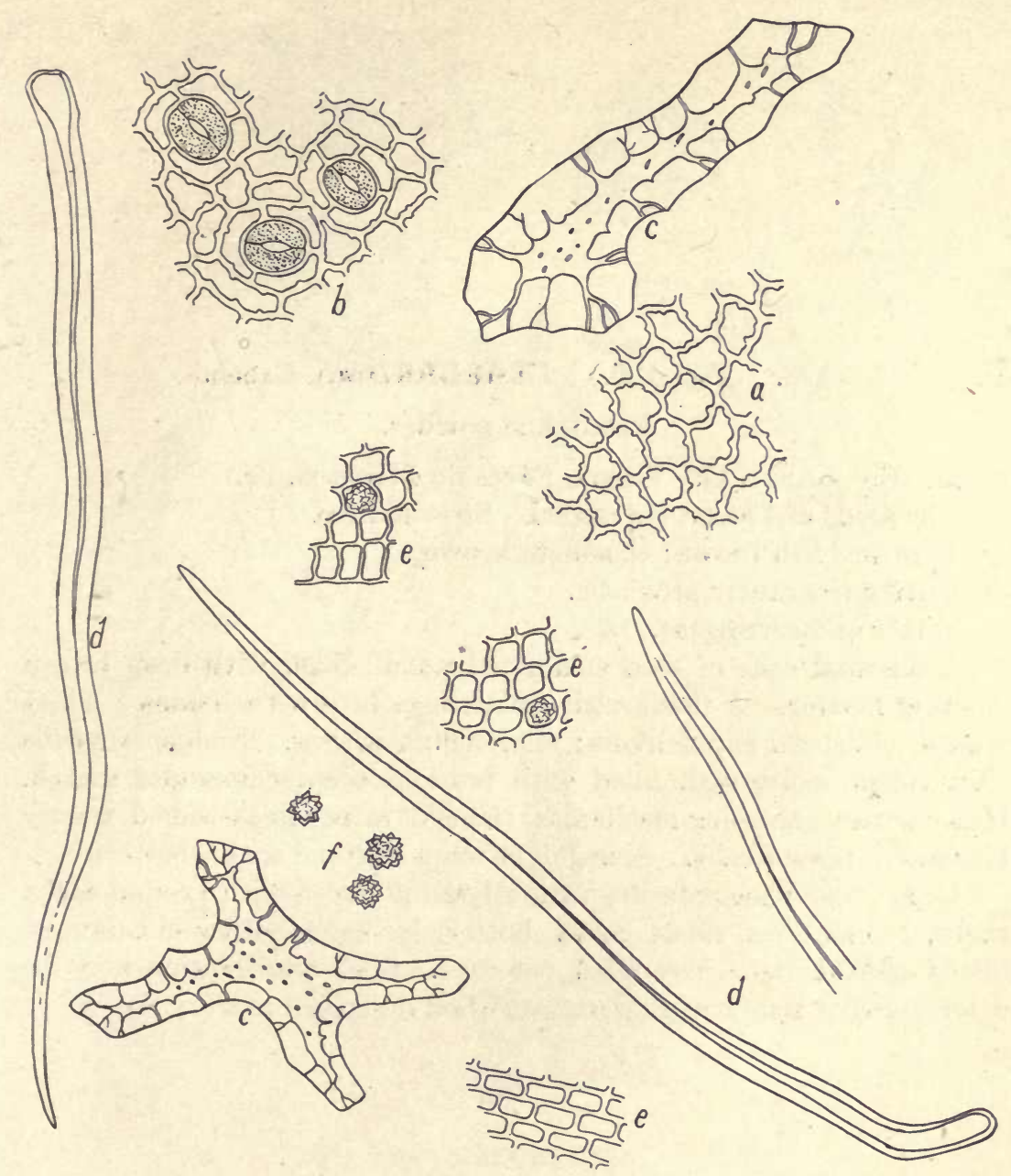

Fig. 189. THEA.

a. Upper epidermis.

b. Lower epidermis.

c. Sclerenchyma cells.

d. Trichomes.

e. Leaf parenchyma.

$f$. Crystals. 
198. (Fig. 190.) THEOBROMA. Cacao.

Paste, fine powder.

Cocoa, E. Kakao, G. Cacoa, Féves du Mexique, Fr.

The seeds of Theobroma cacao L., Sterculiaceæ.

Deep reddish brown; chocolate brown.

Mildly fragrantly aromatic.

Bitter and astringent.

Epidermal cells of seed small, polygonal, filled with deep brown coloring matter. A few multicellular deep brown trichomes. Thinwalled, collapsed parenchyma; selerenchyma layer. Endosperm cells thin-walled, polygonal, filled with fat and some compound starch. Hull remnants showing mechanical tissue of rather thick-walled, mostly elongated, porous cells. Spiral duct remnants and some crystals.

Cocoa and chocolate are variously adulterated with ground cocoa shells, starch, rice, flour, cocoa butter, lard, and other substances. Shells should not exceed 3.5 per cent. Shell adulteration may be determined quantitatively by the method described in Part I. 

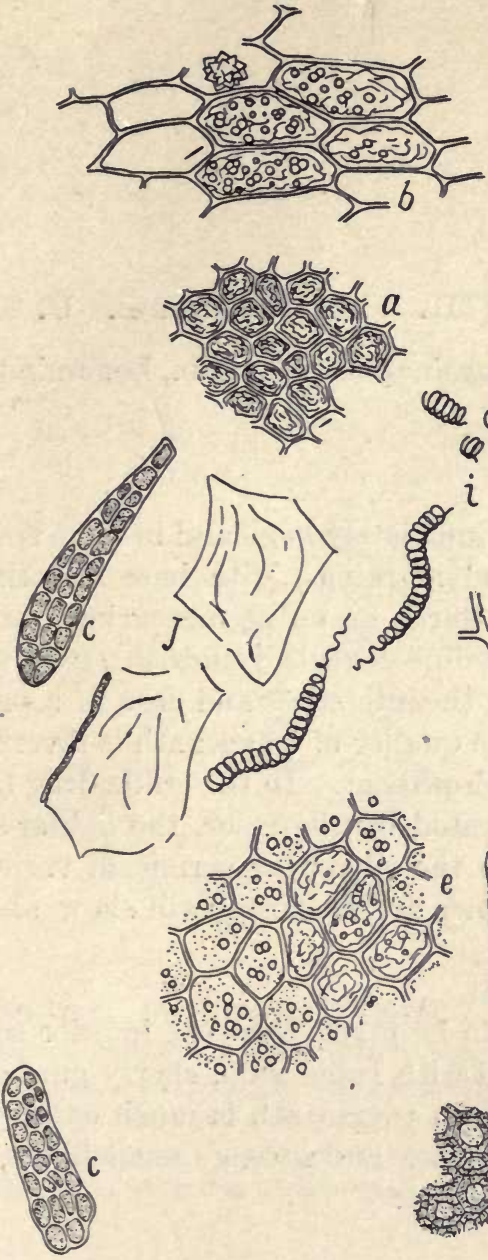
a
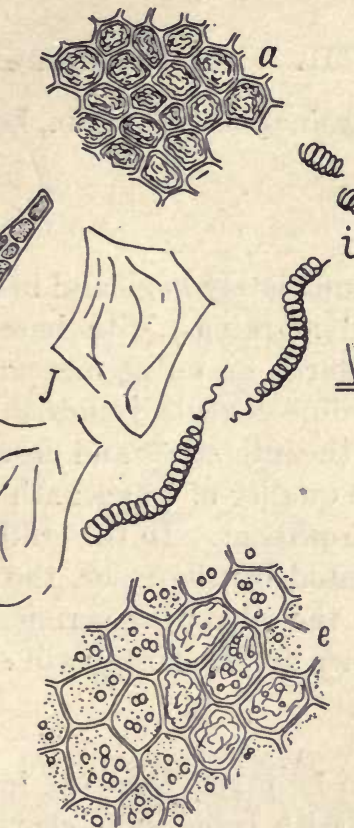
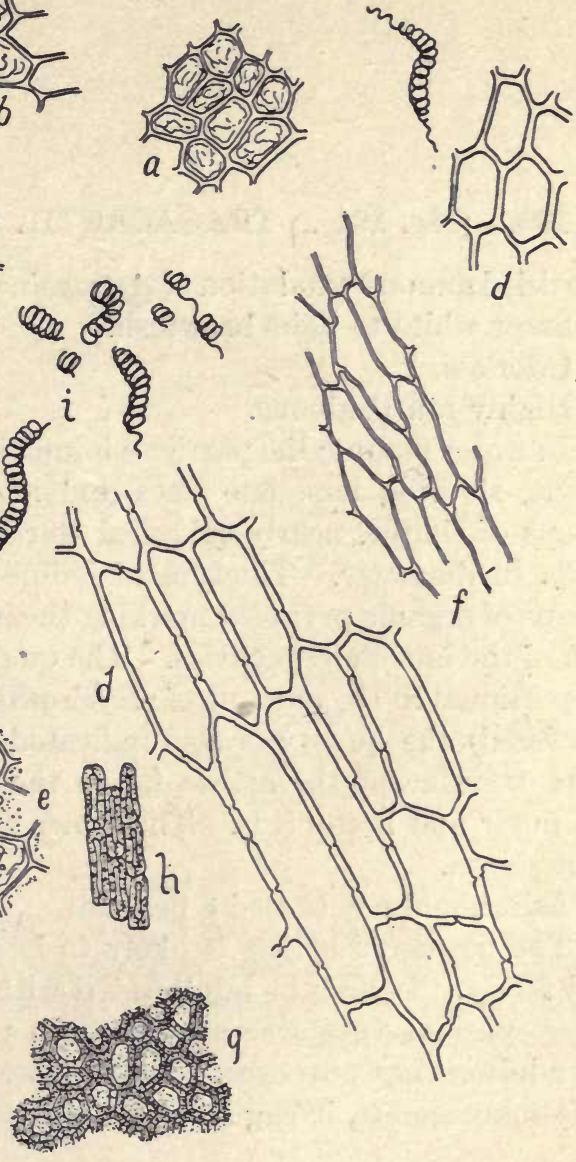

Fig. 190. THEOBROMA.

a. Epidermal cells of seed.

$b$. Endosperm cells with fat and starch, longitudinal view.

c. Trichomes.

d. Mechanical cells of hull.

e. Endosperm cells.

f. Parenchyma.

g. Sclerenchyma, top view.

$h$. Sclerenchyma cells, profile view.

$i$. Spiral ducts which are abundant in the shell tissue.

j. Mucilaginous substance characteristic of shell tissue. 
199. (Fig. 191). TRAGACANTH. Gum Tragacanth. U.S.

The dried gummy exudation of Astragalus gummifer Lab., Leguminosæ.

Snow white to light brownish.

Odorless.

Highly mucilaginous.

In water mounts the particles immediately swell and become translucent, showing lamellate lines and markings, with here and there groups of simple, nearly spherical starch granules, measuring from 4 to $8 \mu$ in diameter. Tincture of iodine reveals yellowish striæ and groups of organic particles marking the interstices and lines of separation of the lamellate particles. The quality of tragacanth is inversely proportional to the amount of starch present. In the crude drug (not powdered) the quality is also indicated by the color, the lighter and more translucent the article (as in the ribbon or vermicelli variety) the purer and better it is. The brown article (sorts) will show abundant starch.

Ash should not exceed 3 per cent.

The powdered article is likely to be made from the inferior sorts and refuse. It may be adulterated with India gum, cherry gum and other spurious vegetable gums. Gum tragacanth is much employed for adulterating purposes; as ice cream and sausage meat fillers, as thickening agents, in egg substitutes, etc. 


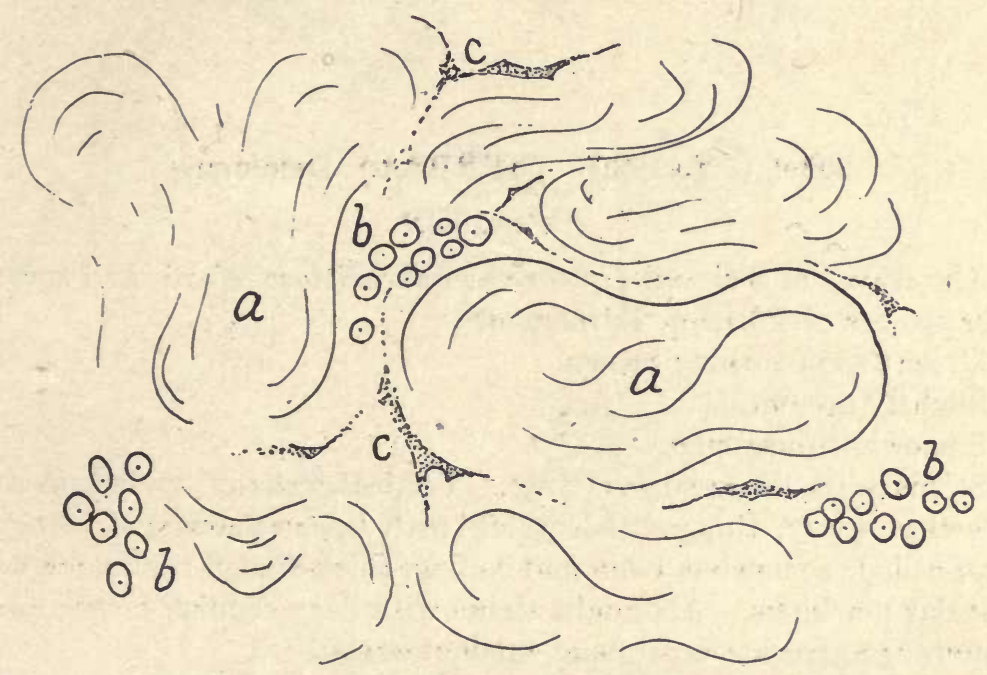

Fig. 191. GUM TRAGACANTH. A bit of the gum mounted in water and examined under a medium power. $a$, the gum presents a somewhat striated appearance, interrupted by organic matter which takes on a bright yellow coloration with tincture of iodine $(c) ; b$, groups of simple starch granules are distributed through the gum. The better the quality of tragacanth the fewer the starch granules, but even the highest grade contains some starch. 


\section{0. (Fig. 192.) TURNERA. Damiana.}

Fl. ex. 30.

The leaves of Turnera diffusa var aphrodisiaca Ward, and several other species of Turnera, Turneraceæ.

Green; soon turning brown.

Slightly aromatic.

Somewhat pungent.

Stomata on lower surface only. Vertical walls of epidermal cells somewhat wavy, thin; cuticle thick with linear markings. Simple, single-celled, somewhat bent and coiling, thick-walled trichomes with cuticular markings. Abundant tissue with deep reddish brown resin. Numerous aggregate crystals of calcium oxalate.

Compare with T. diffusa, T. microphylla, and Aplopappus discoidea (false damiana). 


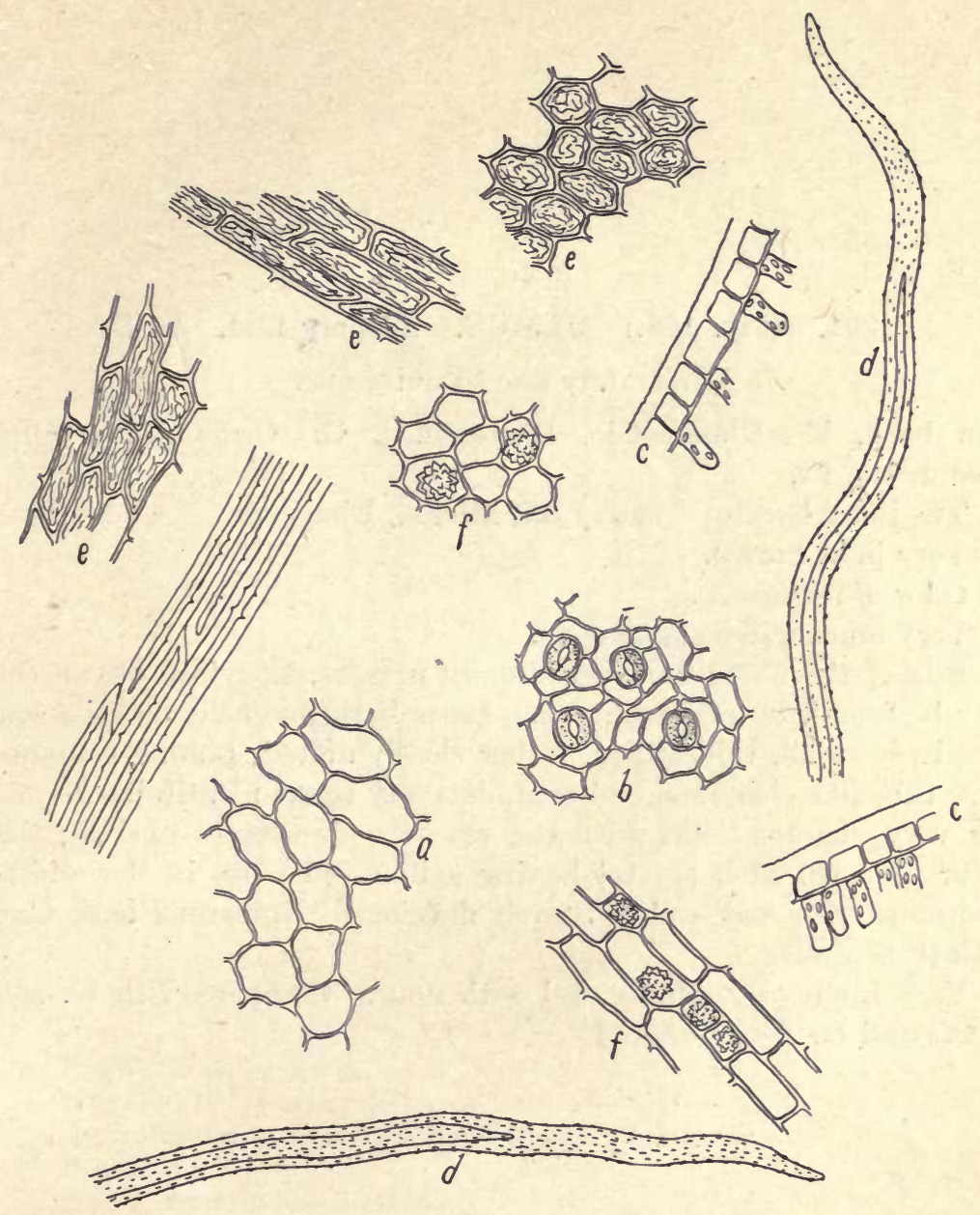

Fig. 192. TURNERA.

a. Upper epidermis.

b. Lower epidermis.

c. Epidermis, lateral view.

d. Trichomes.

$e$. Resin bearing tissue of leaf and petiole.

$f$. Crystal bearing parenchyma. 


\section{1. (Fig. 193.) ULMUS. Slippery Elm. U. S.}

Moderately fine to quite fine.

Elm bark, E. Ulmenrinde, Rüsterrinde, G. Orme fauve, Orme Champêtre, Fr.

The inner bark of Ulmus fulva Michx., Ulmaceæ.

Very light brown.

Odor of fenugreek.

Very mucilaginous; tasteless.

Bits of the outer bark are usually present, therefore brown cells may be found, no sclerenchyma. Inner bark parenchyma cells comparatively small, thin-walled, rather closely united; porous, elongated sieve tube like elements, and medullary ray tissue plentiful. Numerous very characteristic prismatic crystals of calcium oxalate; they occur in twos, each crystal having a hilum-like dot in the middle. Enormous mucilage cells. Starch deficient. Numerous bast fibers with thick walls.

Very frequently adulterated with flour. Compare with $U$. campestris and U. Americana. 


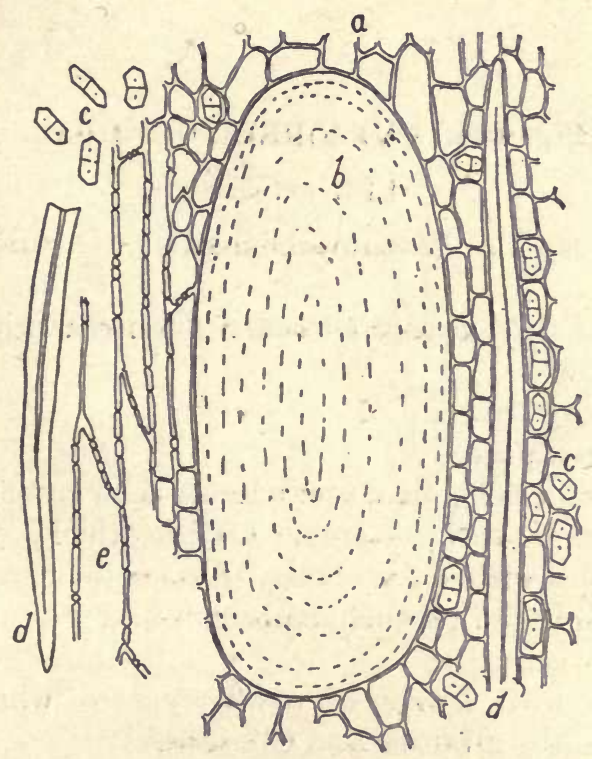

Fig. 193. ULMUS.

a. Inner bark parenchyma.

b. Medium sized mucilage cell.

c. Characteristic erystals (twin crystals) of calcium oxalate.

$d$. Bast fibers.

e. Porous, tracheid-like elements. 
202. (Fig. 194.) UVA URSI. Uva Ursi. U. S. Fl. ex. 30 .

Bearberry leaves, E. Bärentraubenblàtter, G. Busserole, Raisin d'ours, Fr.

The leaves of Arctostaphylos Uvaursi Sprengel, Ericaceæ.

Greenish brown.

Somewhat fragrant.

Very astringent, bitter.

Epidermal cells, polygonal, upper larger than lower; large orbicular stomata on lower surface only. Cuticle thick, yellowish. Leaf parenchyma cells with oil globules. Prismatic crystals of calcium oxalate. Thick-walled parenchymatous tissue.

Ash 3.25 per cent.

Adulterated with leaves of cowberry, red whortleberry, sand myrtle, box, trailing arbutus, and Chimaphila. 

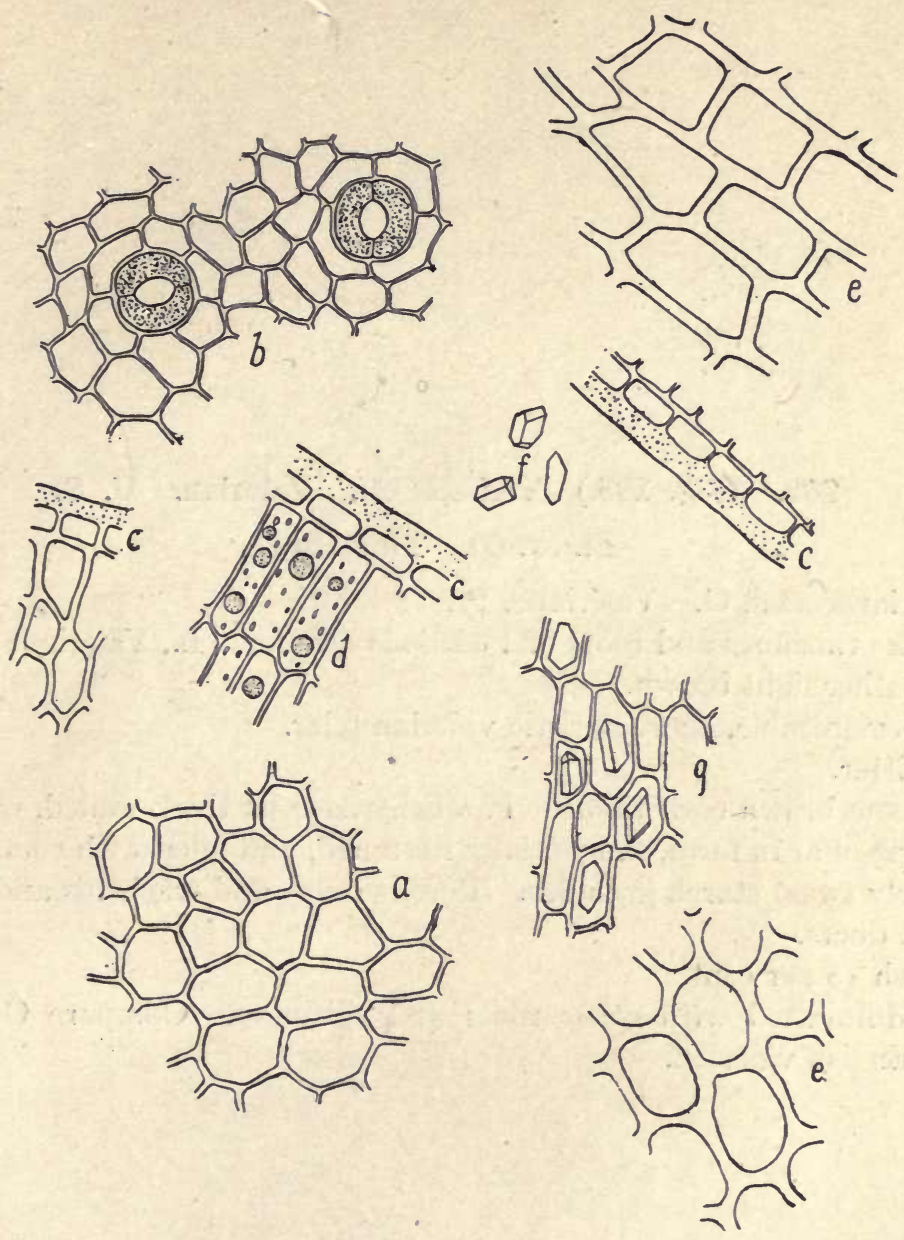

Fig. 194. UVA URSI.

a. Upper epidermis.

b. Lower epidermis.

c. Parenchyma of leaf blade.

d. Palisade tissue cells with oil globules and chlorophyll grains.

e. Parenchyma from leaf blade.

f. Crystals.

g. Parenchyma with crystals. 
203. (Fig. 195.) VALERIAN. Valerian. U. S. Fl. ex. 60. Tinct. 60 ,

Baldrianwurzel, G. Valériane, Fr.

The rhizomes and roots of Valeriana officinalis L., Valerianaceæ. Rather light brown.

Disagreeable, characteristic valerian odor.

Bitter.

Some brown cork tissue. Parenchyma cells thick-walled, more or less irregular in form, tangentially flattened, and filled with compound (mostly twos) starch granules. Porous ducts and tracheids and some spiral ducts.

Ash 15 per cent.

Adulterated with other roots and rhizomes. Compare German and Engish valerian. 


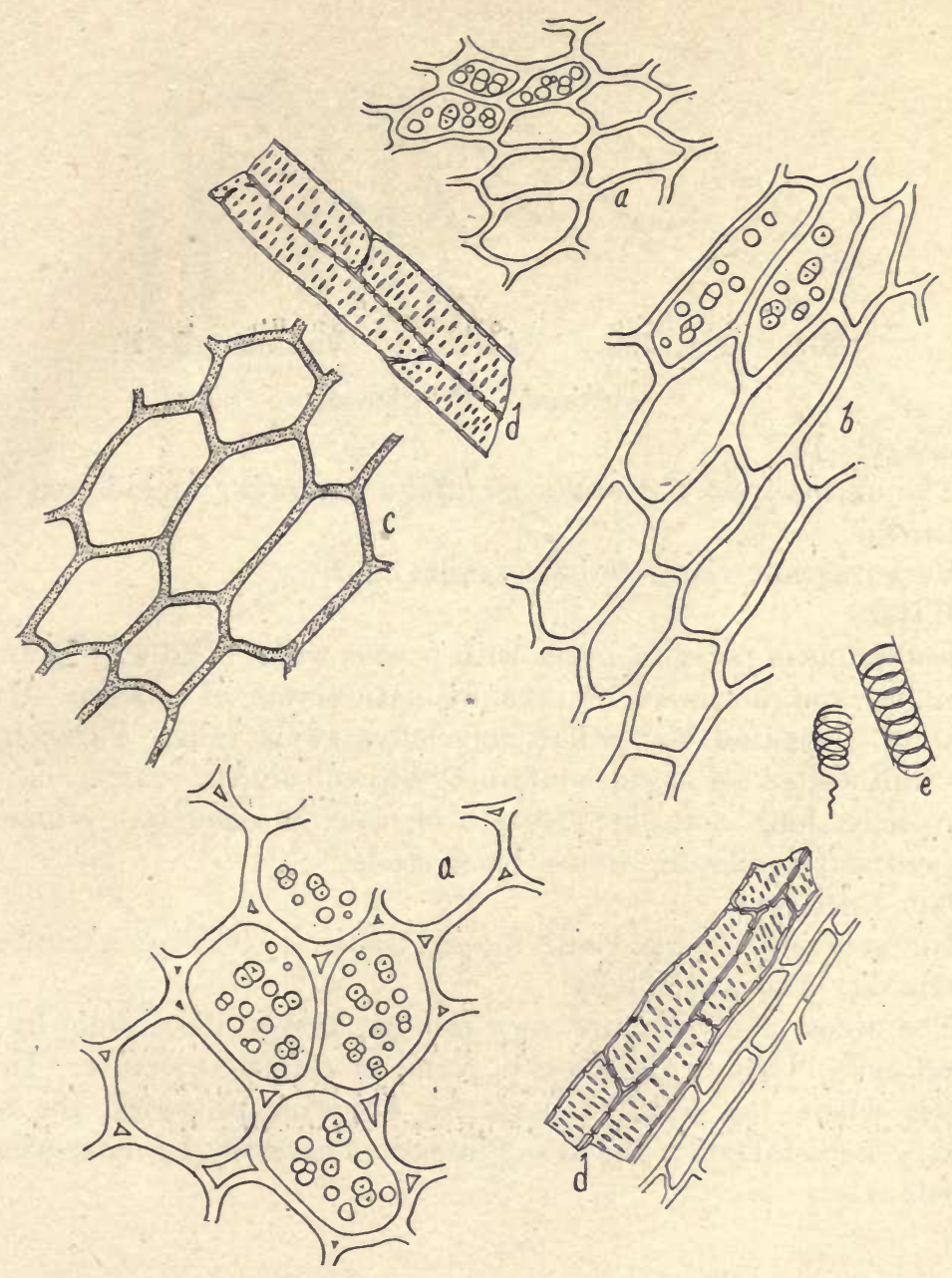

Fig. 195. VALERIAN.

a. Parenchyma with starch, transverse view.

b. Parenchyma, longitudinal view.

c. Cork.

d. Tracheids.

e. Spiral duct. 


\section{4. (Fig. 196.) VANILLA. Vanilla. U. S.}

Bruised. Powdered.

Vanille, G., Fr.

The unripe fruit of Vanilla planifolia Andrews, Orchidaceæ.

Brown.

Very fragrant, characteristic vanilla odor.

Bitter.

Epidermis of polygonal cells with porous walls, filled with granular substance, and each cell contains a prismatic crystal of vanillin. Hypoderm of elongated somewhat collenchymatous cells. Parenchyma cells thin-walled collapsed, containing brown coloring matter, oil, and some cells, long acicular crystals of calcium oxalate. Numerous tracheids. (Numerous minute black seeds.)

Ash 3 per cent.

Not generally admixed with foreign tissue. There are a number of commercial grades of vanilla.

The seeds of vanilla are very minute, barely discernible by the naked eye. They are globose in form, of simple structure. In the tropics where the pods are used for flavoring purposes, the seeds have been mistaken for the ova of intestinal parasites by inexperienced clinicians. 


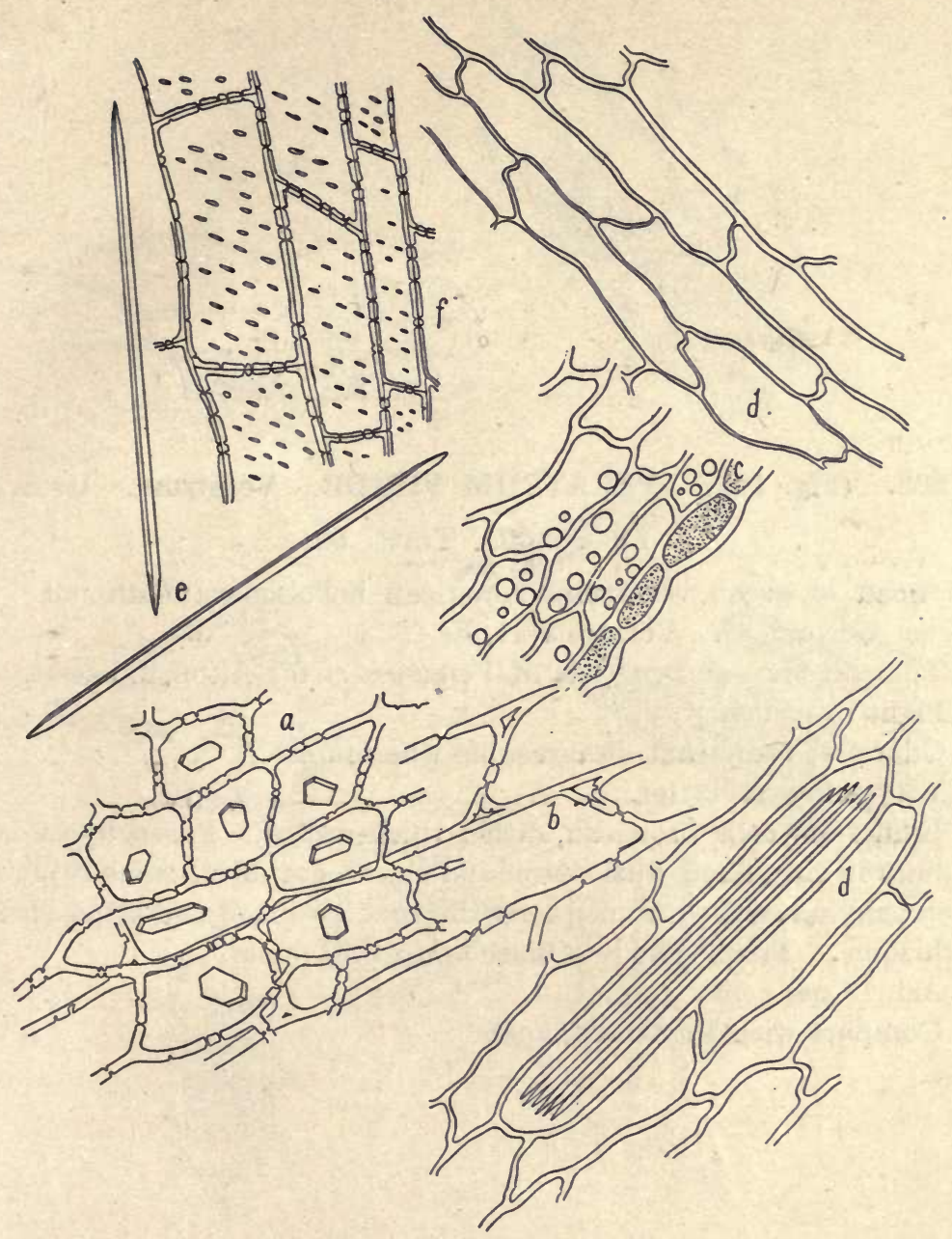

Fig. 196. VANILLA.

a. Epidermal cells, vertical view, showing crystals of vanillin.

b. Hypodermal cells.

c. Epidermis, transverse view.

$d$ Parenchyma cells with crystals of calcium oxalate, longitudinal view.

e. Crystals of calcium oxalate.

f. Tracheids. 
205. (Fig. 197.) VERATRUM VIRIDE. Veratrum. U. S. Fl. ex. 60. Tinct. 60 .

American or green veratrum, American hellebore, Indian poke, E. Grüner Germer, G. Vératre vert, Fr.

The rhizomes and rootlets of Veratrum viride Aiton, Liliaceæ.

Light brownish gray.

Odorless; somewhat disagreeable when moist.

Very pungent, bitter.

Epidermal cells brownish, rather thick-walled. Parenchyma cells medium in size, filled with compound starch granules; some raphides. Sclerenchyma cells with unequally thickened walls of endoderm sheath of rhizome. Tracheids; reticulate and spiral ducts.

Ash 13 per cent.

Compare with Veratrum album. 

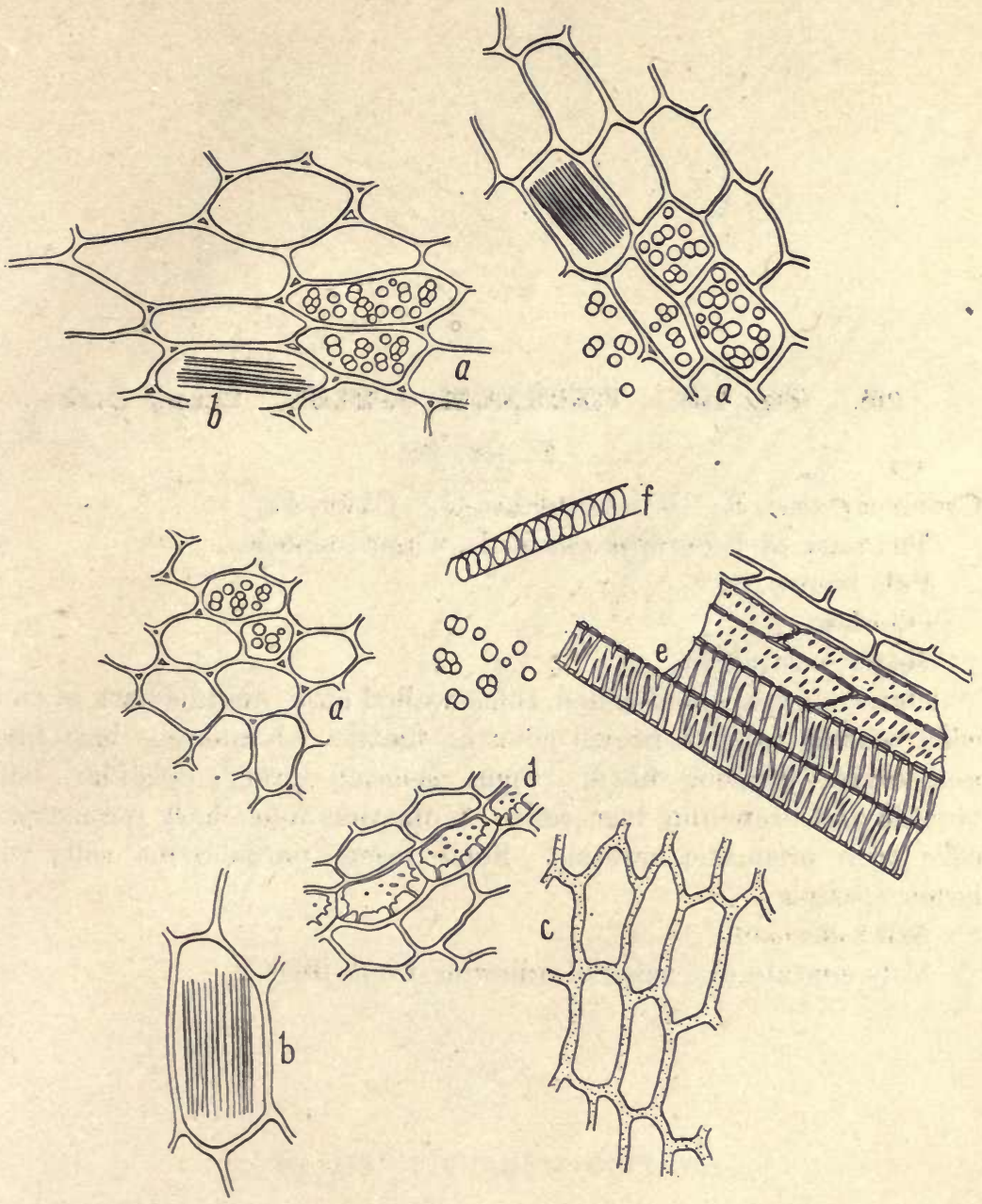

Fig. 197. VERATRUM VIRIDE.

a. Parenchyma cells with starch.

b. Raphides.

c. Epidermal cells vertical view.

d. Sclerenchyma cells of endoderm, transverse view.

$e$. Ducts and tracheids.

f. Spiral duct. 


\section{6. (Fig. 198.) VIBURNUM OPULUS. Cramp Bark.}

Fl. ex. 60.

Cranberry tree, E. Wasserholder, G. Obier, Fr.

The bark of Viburnum opulus L., Caprifoliaceæ.

Pale brown.

Odorless.

Bitter, astringent.

Outer bark of small-celled, thick-walled cork; middle bark of small cells bearing reddish brown coloring matter. Numerous bast fibers and crystal bearing fibers. Some isolated larger; irregular, bent, twisted and branching bast cells. Numerous inner bark parenchyma cells with prismatic crystals. Some larger parenchyma cells with larger crystals.

Ash 5 per cent.

May contain an excess of adhering wood fiber. 


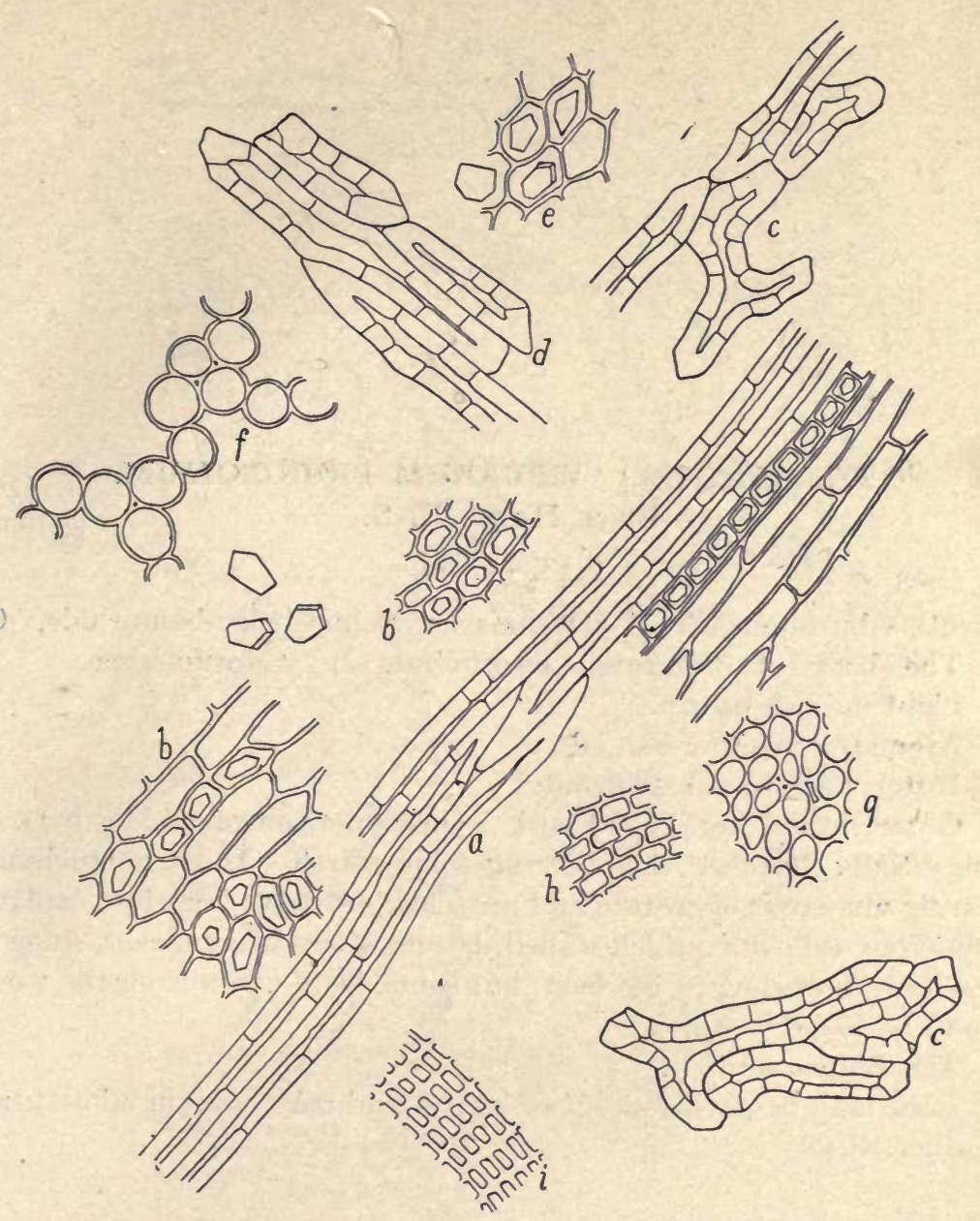

Fig. 198. VIBURNUM OPULUS.

a. Normal bast fibers.

b. Inner bark parenchyma with crystals.

c. Branching bast cells.

d. Short bast cells.

e. Parenchyma with larger crystals.

$f$. Loose parenchyma of spheroidal cells.

$g, h$. Outer parenchyma.

i. Outer cork. 


\section{7. (Fig. 199.) VIBURNUM PRUNIFOLIUM.}

\section{Black Haw. U. S.}

Fl. ex. 60 .

Sweet viburnum, E. Amerikanische Schneeballenbaumrinde, G.

The bark of Viburnum prunifolium L., Caprifoliaceæ.

Light reddish brown.

Aromatic, valerian-like odor.

Bitter, somewhat astringent.

Outer rather large-celled cork. Outer portion of middle bark of tangentially flattened cells bearing some starch. Inner parenchyma bearing numerous aggregate and prismatic crystals of calcium oxalate. Numerous yellowish, thick-walled, porous sclerenchyma cells, some of which are branching. No bast, but some wood fibers from the wood are to be found.

Ash 7.5 per cent.

Bark may be gathered out of season and may contain admixtures of other barks. 


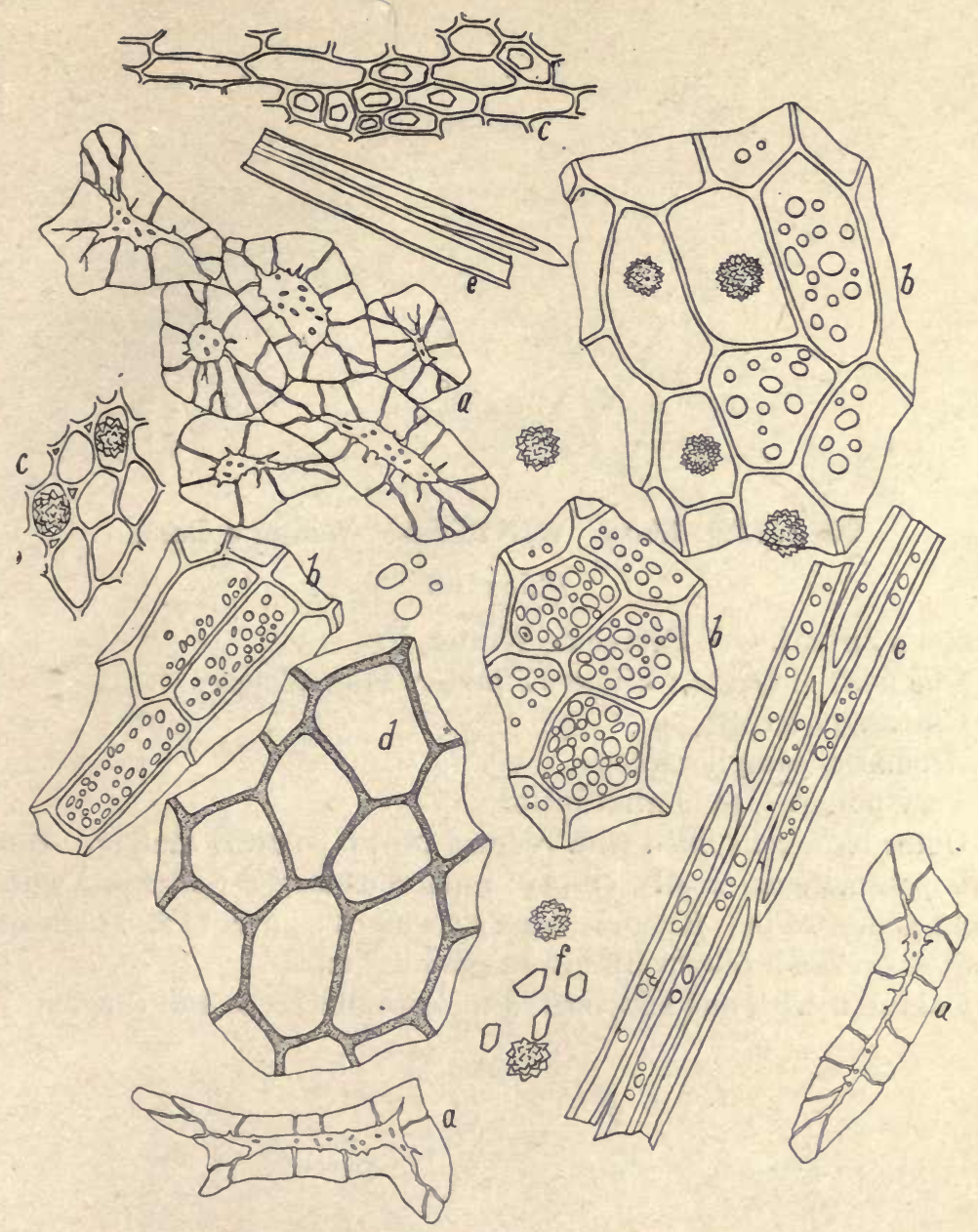

Fig. 199. VIBURNUM PRUNIFOLIUM.

a. Sclerenchyma.

b. Outer bark parenchyma, vertical view.

c. Inner, smaller celled, parenchyma with crystals.

d. Cork.

e. Wood fibers.

f. Crystals. 


\section{8. (Fig. 200.) WINTERA. Winter's Bark.}

Fl. ex. 60.

Winter's Zimmt, G. Ecorce de Winter, Fr.

The bark of Drimys Winteri Fœrster, Magnoliaceæ.

Cinnamon brown.

Áromatic, camphoraceous.

Very pungent, somewhat bitter.

Outer bark cells filled with reddish brown coloring matter. Inner bark parenchyma mostly empty; numerous larger cells filled with a bright yellow resin. Sclerenchyma cells much as in coto and paracoto, pores large, some filled with brown granular matter.

Confused with and substituted for coto, paracoto and canella. 


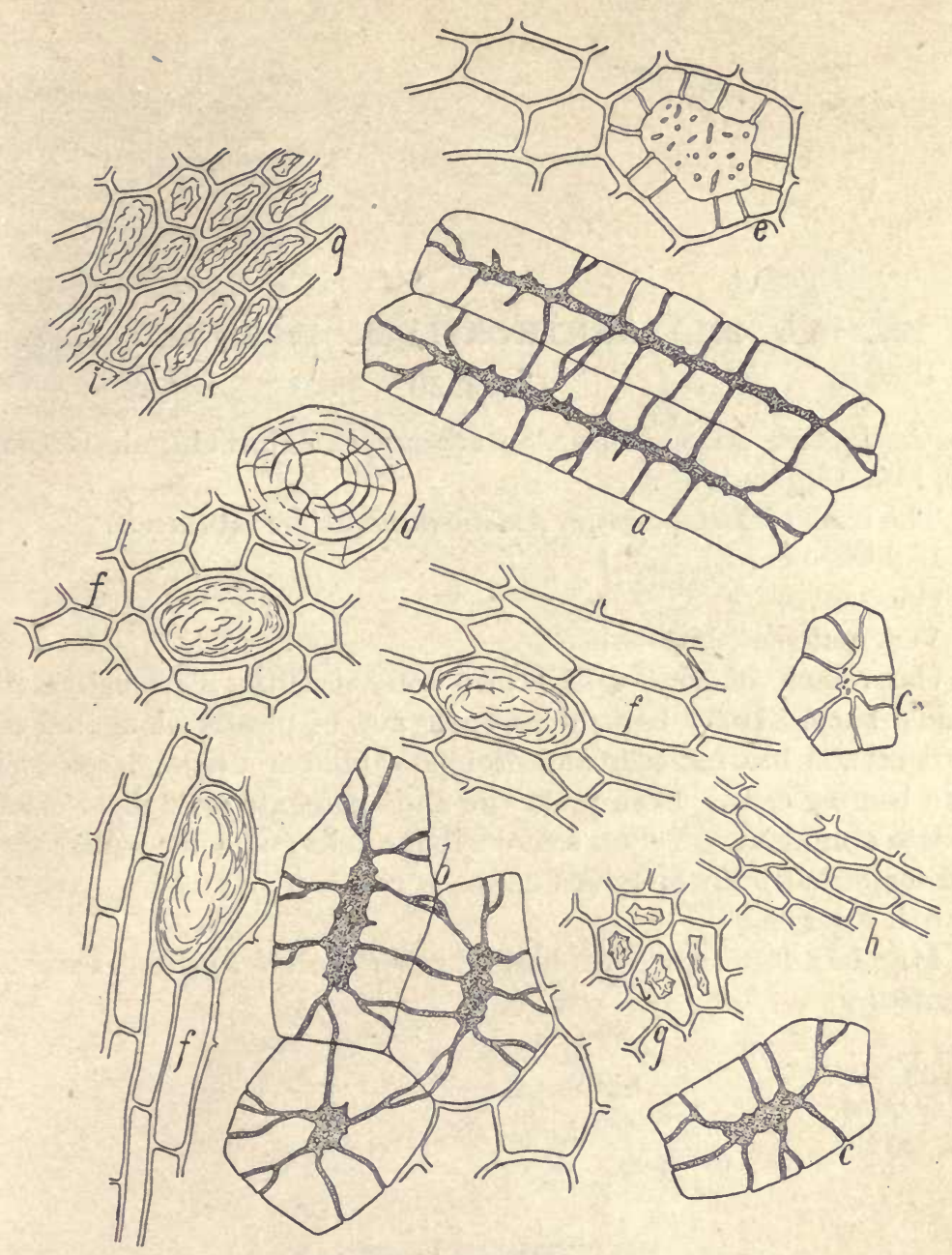

Fig. 200. WINTERA.

$a, b, c, d, e$. Sclerenchyma cells.

$f, h$. Parenchyma cells with resin.

g. Outer bark cells with reddish brown coloring matter. 
209. (Fig. 201.) XANTHOXYLUM. Prickly Ash. U. S. Fl. ex. 30 .

Toothache tree, Angelica tree, Suterberry, E. Zahnwehrinde, G. Clavalier, Frêne épineux, Fr.

The bark of Xanthoxylum Americanum Miller, Rutaceæ.

Light brown.

Odorless.

Very pungent, bitterish.

Outer bark of cork with brown cell-contents. Collenchymatous middle bark. Inner bark of parenchyma, of mostly elongated cells, short crystal bearing cells and groups of phlœm tissue; large yellow resin bearing cells. Both prismatic and aggregate crystals of calcium oxalate abundant. Yellow sclerenchyma cells and some bent, twisted and somewhat branching bast cells.

Ash 5 per cent.

May be adulterated with bark of other species, Angustura and false Angustura. 

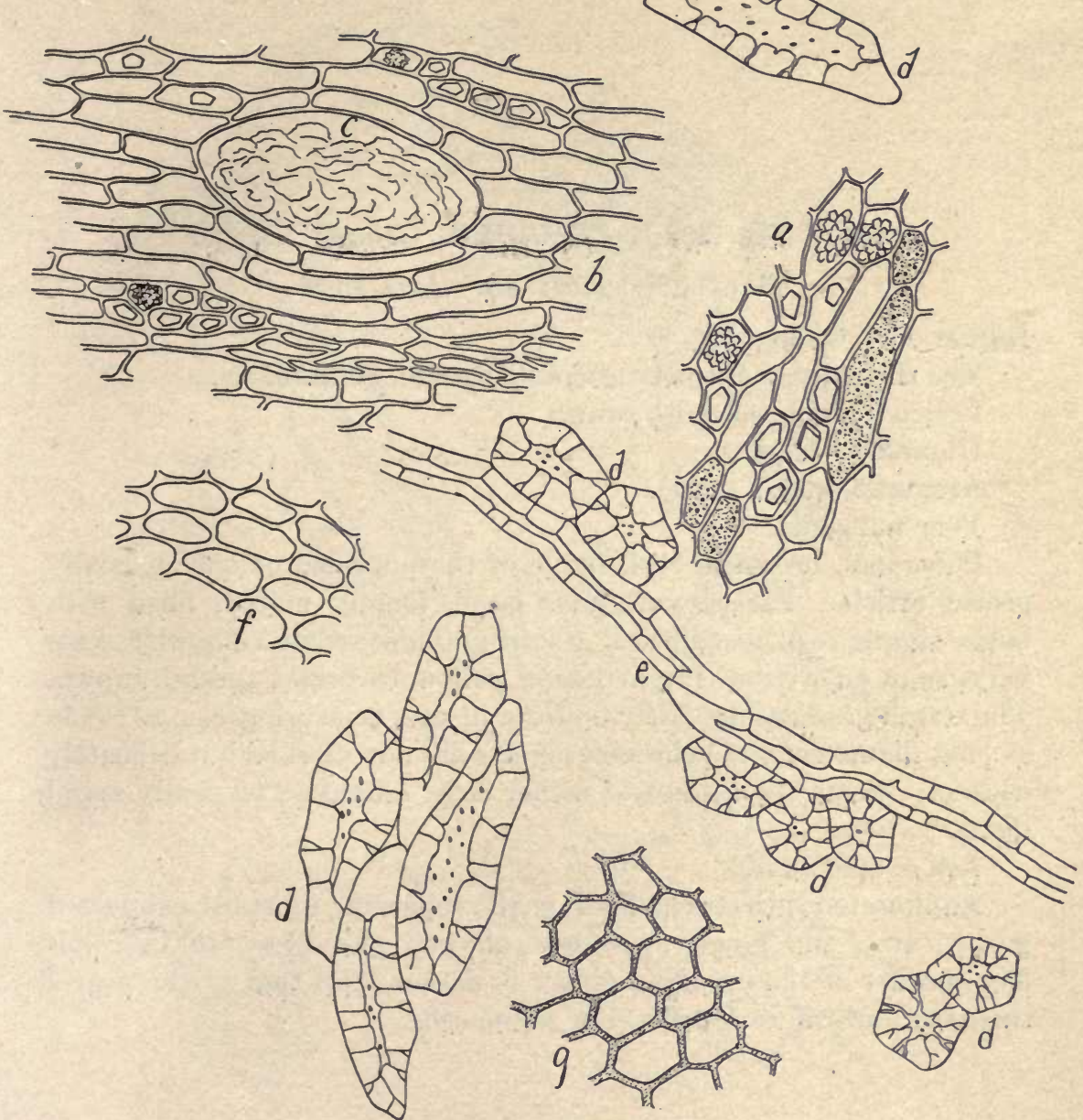

Fig. 201. XANTHOXYLUM.

a. Parenchyma with crystals and granular contents.

b. Parenchyma and resin cells (c).

$d$. Sclerenchyma.

e. Bast.

f. Collenchymatous tissue.

g. Outer bark parenchyma. 


\section{0. (Fig. 202.) ZINGIBER. Ginger. U. S.}

Fl. ex. 30. Tinct. 40. As a spice.

Ingwer, G. Gingembre, Fr.

The rhizomes of Zingiber officinate Roscce, Scitamineæ.

Peeled-Light yellowish brown.

Unpeeled-Darker.

Aromatic; ginger odor.

Very pungent.

Polygonal, brownish cork tissue of the unpeeled or only partially peeled article. Parenchyma cells large, loosely united, filled with large, simple oval to elliptical starch granules; some cells with resin varying in color from bright lemon yellow to bright reddish brown. The starch granules are fairly uniform in size, measuring from 30 to $45 \mu$ in long diameter; the polarizing effects are not marked but delicately distinct. Some tracheids and rather large reticulate to nearly spiral ducts.

Ash 4.5 per cent.

Adulterated with starch, flour, chalk, capsicum, mustard, exhausted ginger, etc. Old ginger becomes yellowed and brownish in color. The powder of the unpeeled ginger is darker than that of the peeled rhizomes and will reveal the cork tissue cells. 


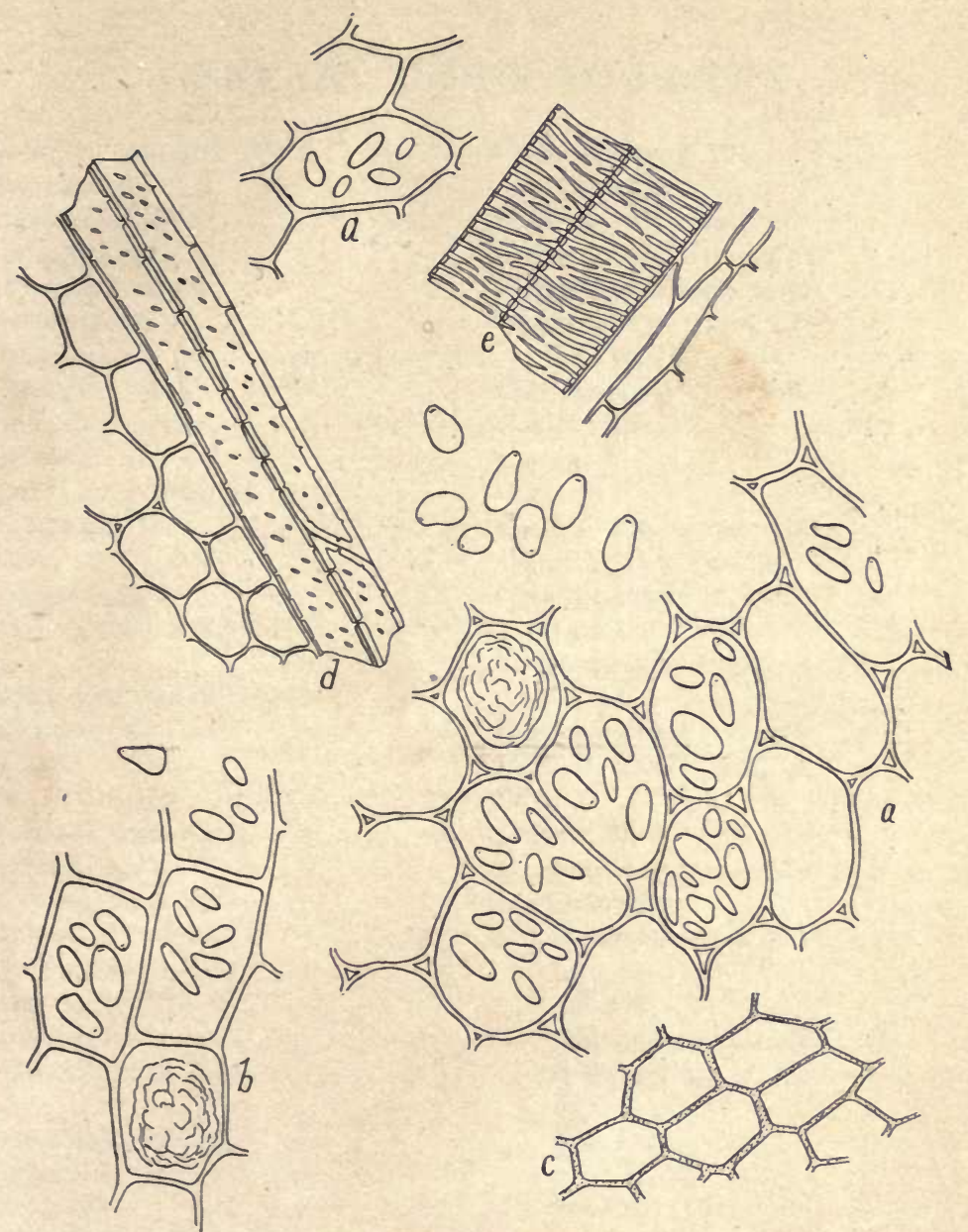

Fig. 202. ZINGIBER.

a. Parenchyma with starch and one cell with resin, transverse view.

b. Parenchyma, longitudinal view.

c. Cork, vertical view.

d. Tracheids.

e. Ducts. 



\section{GENERAL INDEX TO PART I}

Adulterants, common, 67

Adulteration, 61 accidental, 61 criminal, 62 detection of, 69 of drugs, 60 harmful, 42 harmless, 41 intentional, 62 manner of, 63 substances used, 64

Agar, test for, 152

Amylum, 198

Apparatus, 141

Ash determination, 43, 73

Bacteria, counting of, 142

Banda mace, 73

Barks, 84

Bastin, 5

Beaker sand test, 73

Benzoate of soda, 34

Benzoic acid test, 73

Bisulphide of carbon, 52

Black pepper test, 169

Bombay mace, 73

Breithaupt, 6

Broca's stain, 142

Carbon disulphide, 52

Cell contents, 102

Chamot, 154

Characteristic tissues, 172

Chloroform, 52

Chlorphenol, 13

Cinchona test, 73, 166

Cinnamon, test for, 161

Claims, false, 30

Clay, 67

Cloves, test for, 162

Cocoa, shells, 162 test for, 162

Coffee adulteration, 28
Color, of drugs, 10 standards, 10

Coloring substances, 68

Common adulterants, 67

Compound licorice powder; 170

Compound powders, 132 key to, 133

Condition powders, 163

Conium test, 73

Cooley, 6

Cork, 91

Council of pharmacy, 36

Counting chamber, 157

Crystals, study of, 139 types of, 139

Curcuma thread test, 74

Decomposition test, 144

Digitalis leaves, test, 168

Dirt, 67

Dohme, 6

Drug action compensation, 42

Drugs act, 28

Drugs, adulteration of, 60 ash, 43

color of, 10

commonly adulterated, 68

deterioration of, 38

exhausted, 65

fineness of, 42

inferior, 65

keys to, 115

moldy, 38

non-pharmacopoeial, 41

odorless, 18

old, 39

parasites in, $39,46,50,52$

for percolation, 42

powdering of, 53

purity of, 27

quality of, 27

store room for, 38

substandard, 36 
Drugs, tastes of, 22, 24, 25 variations in quality, 45

Eggs, imitation, 28

Ether, 52

Exhausted drugs, 65

Extract of malt, 200

Fineness of powders, 55

Flea glass, 2

Flowers, 76

Formaldehyde test, 74

Fruits, 87

Fungi, 47

Glucose, 200

Glycyrrhiza test, 169

Grahe's cinchona test, 73

Grinding drugs, 54

Guarantees, 37, 39

Hanausek, 154

Hand gluten test, 74

Hemacytometer, 142

Hoffmann, 5

Hooke, 3

Hypoderm, 85

Illustrations of tissues, 103

Inferior drugs, 65

Insect powder, 146 test for, 162, 168

Insecticide board, 33

Inspectors, 31

Iodine reaction, 74

Japanese tea, 28

Kaolin, 56

Karo syrup, 200

Key, to compound powders, 132 macroanalytical, 115 microanalytical, 123 simple powders, 115 to starches, 201

König, 154

Kraemer, 9

Laboratories, of Bureau, 33 equipment, 70
Lead, 69

Leaves, structure of, 83

Leeuwenhoek, 2

Lenses, 1

Lenticels, 89

Lichens, 49

Licorice powder, 170

Licorice test, 169

Lime, 67

Loeffler's stain, 142

Lloyd's reagent, 56

Mace test, 73

Macroanalytical key, 115

Maisch, 9

Malt extract, 200

Maltose, 200

Malt syrup, 200

Mansfield, 9

Mercaptan, 13

Meyer, 154

Microanalysis, 70 of crystals, 136 of flours, 147 . percentage determinations, $\mathbf{7 7}$ problems, 164 quantitative, 141, 154 report blanks, 76 of starches, 147

Microchemical reactions, 72

Microchemical reagents, 71

Micro-gluten test, 75

Micrometry, 142

Microscopes, 2

compound, 1, 7

Cuff's, 3

history of, 1

Hooke's, 3,5

Jansen's, 3

Leeuwenhoek's, 2

in pharmacy, 1

simple, 2

Wilson's, 2, 3

Microscopical characteristics, 171

Microscopic examination, 71

Microscopic laboratory, 70

Misbranding, 30

Misstatements, 30

Mustard, 170 
N. F. powders, 132

N. F. standards, 40

Neighboring cells, 85

New remedies, 36

Non-pharmacopoeial drugs, 41

Notices of judgment, 27

Numerical counts, 142

Nutmegs, wooden, 28

Odor, 12

Odors, attraction for, 14 classification, 16 modification of, 19 persistence of, 14 standards of, 12

Olfactory nerves, 12

Opium, smoking, 151

Organoleptic tests, 75

Palisade tissues, 85

Pappus, 87

Parasites, 46 animal, 50

vegetable, 46

Pepper, 69 test for, 169

Pharmacognosist,s 31, 35

Phloroglucin, 73

Powdered drugs, 54 colors of, 58 examination of, 70

fineness of, 54

grouping of, 58

keys to, 115

mixing of, 55

percentage determinations, 77 preservation of, 57

Powdering drugs, 54

Preservation of powders, 57

Pure drugs act, 29

Purity rubric, 1

Pyrethrum powders, 146

Quantitative, estimation, 77 microanalysis, 141, 154

Reactions, microchemical, 72

Referee Board, 33

Refuse, 28, 65

Report blanks, 75
Rhamnus, test for, 167

Rhizomes, 90

Roots, 90

Rubric, purity, 1

Rusby, 6

Samples, taking of, 31

Sand, 66 beaker test, 73

Sayre, 6

Schlotterbeck, 6

Seeds, 87

Senna test, 167

Sieves, meshes of, 56

Sifting drugs, 54

Smell, sensation of, 13

Smoking opium, 151

Sodium benzoate, 34

Sophistication of drugs, 60

Spices, adulteration of, 68

Spore counts, 142

Stains, 142

Standards, 40 definition of, 40

Starches, 198

count, 148

key to, 210

morphology of, 202

percentage tables, 149

polarization of, 202

Stems, 92

Stomata, 85

Substitution, 63

Sulphur, 169

Sweepings, 28

Tactile sensations, 11

Taste, 20 aromatic, 21

classification of, 22

mixed, 21

standards of, 20

Tea, commission, 33 Japanese, 28

Tests, for agar, 152 beaker sand test, 73

benzoic acid, 73

boric acid, 74

butter fat, 152

cinchona, 73 
Tests, cinnamon, 161 cloves, 162 conium, 73 curcuma, 74 decomposition, 144 gluten, 74

Grahe's, 73 insect powder, 162 lignin, 73 mace, 73 organoleptic, 75 salicylic acid, 74 senna, 167 starch, 74 sublimation, 73 sulphurous acid, 74

Tissues, characteristics, 172 descriptions of, 101 distribution of, 83 epidermal, 84 identification of, 78 illustrations of, 78, 103 naming of, 78
Tissues, tabulation of; 79, 93 terminology of, 78

Torre, 2

Touch, 11

Trimmings, 28

Turmeric, 74

U. S. P., labels, 41 powders, 132 standards, 40

Vegetable powders, 58

Vogel, 154

Wall, 9

Weinzierl, 154

Winnowings, 65

Wood, 93

Yeast count, 142

Ziehl's carbol fuchsin, 142 Zwaluwenberg, 6 



\section{THIS BOOK IS DUH ON TI
STAMPED BELOW}

AN INITIAL FINE OF 25 CENTS WILL BE ASSESSED FOR FAILURE TO RETURN THIS BOOK ON THE DATE DUE. THE PENALTY WILL INCREASE TO 50 CENTS ON THE FOURTH DAY AND TO \$1.00 ON THE SEVENTH DAY OVERDUE.

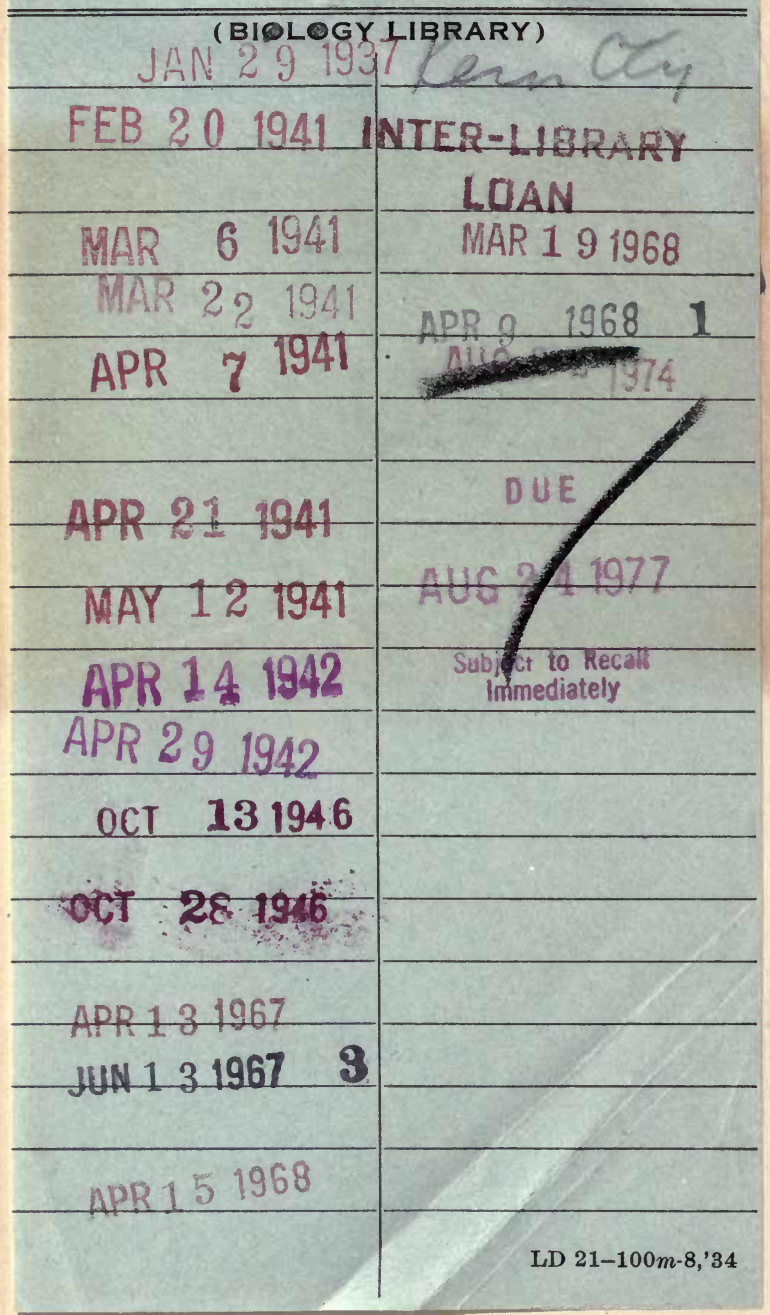




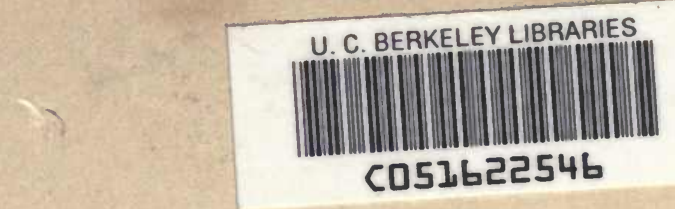

sot.
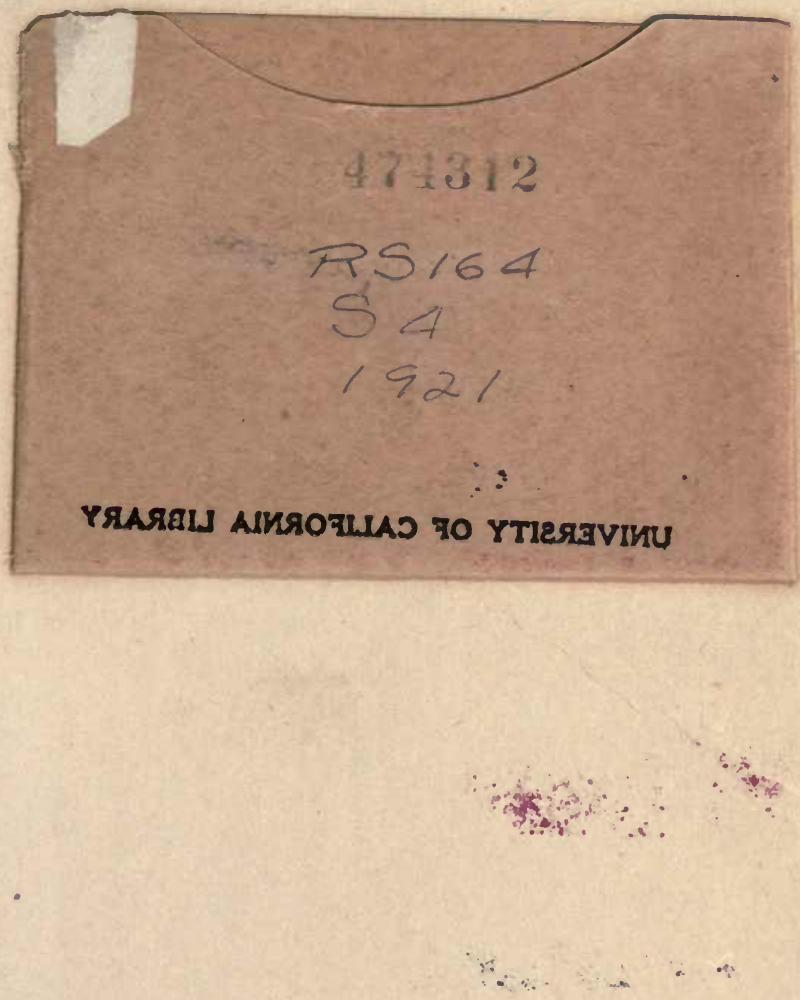
